\title{
ESTUDIO DE LA CAPACIDAD \\ DE LOS MICROORGANISMOS DEL KEFIR, PARA INHIBIR EL DESARROLLO FÚNGICO Y PARA SECUESTRAR MICOTOXINAS
}

\section{TESIS DOCTORAL}

ÁNGELA MARÍA LEÓN PELAEZ

DIRECTORA: DOCTORA GRACIELA LILIANA DE ANTONI

CODIRECTORA: DOCTORA LEDA GIANNUZZI

\section{3}

FACULTAD DE CIENCIAS EXACTAS -UNLP

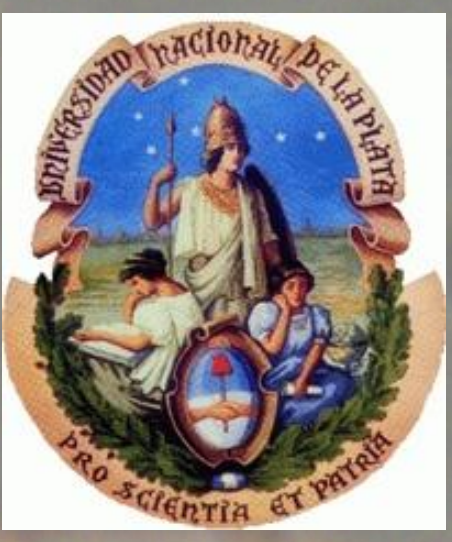




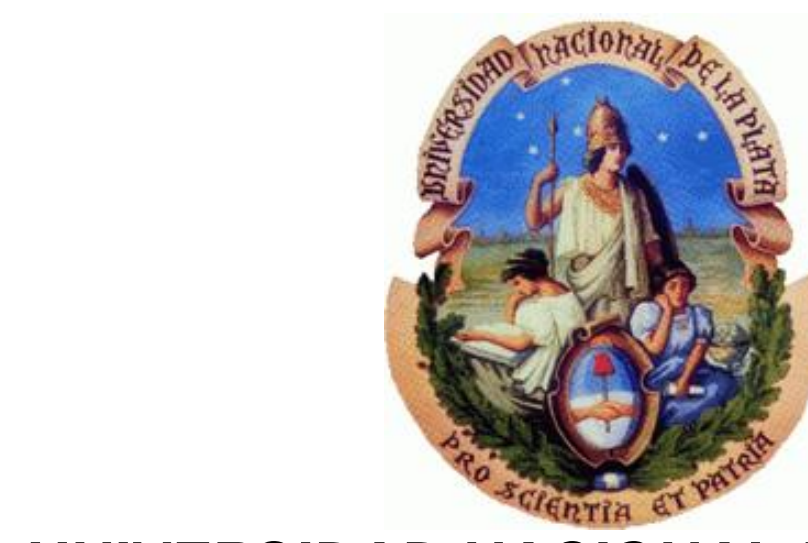

\title{
UNIVERSIDAD NACIONAL DE LA PLATA
}

FACULTAD DE CIENCIAS EXACTAS

DEPARTAMENTO DE CIENCIAS BIOLÓGICAS

Trabajo de Tesis Doctoral

ESTUDIO DE LA CAPACIDAD DE LOS MICROORGANISMOS

DEL KEFIR, PARA INHIBIR EL DESARROLLO FÚNGICO Y

PARA SECUESTRAR MICOTOXINAS

\author{
ÁNGELA MARÍA LEÓN PELAEZ \\ DIRECTORA: DOCTORA GRACIELA LILIANA DE ANTONI \\ CODIRECTORA: DOCTORA LEDA GIANNUZZI
}


Factores que controlan el crecimiento fúngico y la producción de micotoxinas

Acción toxica de las micotoxinas

Aflatoxinas

Legislación

Ocurrencia de aflatoxinas en alimentos

Prevención y control de micotoxinas 14

Buenas prácticas agrícolas

Ingeniería genética

Sustancias antifúngicas

Detoxificación de los alimentos contaminados con

micotoxinas

Métodos físicos

Métodos químicos

Métodos biológicos

El kefir

Preparación del inóculo de hongos filamentosos 29

Microorganismos aislados de gránulos de Kefir (MK)

Obtención del producto fermentado con gránulos de kefir y con microorganismos aislados del gránulo de kefir (MK)

Obtención del SLC a partir de los productos fermentados con gránulos de kefir y con microorganismos aislados del gránulo de kefir

4.8 Análisis por HPLC de los ácidos láctico y acético en los SLC y en los alimentos adicionados de productos fermentados

Preparación de los SLC acidificados artificialmente con ácidos orgánicos puros y con $\mathrm{HCl}$

Determinación de las pendientes de crecimiento $K_{D}$ $(\mathrm{mm} / \mathrm{h})$ y del tiempo de duración de la fase $\mathrm{Lag}(\mathrm{h})$

4.10.1.2 Determinación del Índice de Inhibición de $\mathrm{K}_{\mathrm{D}}(\mathrm{IIK} \mathrm{K} \%)$ y del Índice de Incremento de la fase Lag (IILag \%)

Cálculo de la concentración de ácidos orgánicos no disociados

4.13. Determinación de la estabilidad del alimento adicionado de leche o permeado de suero fermentado con gránulos de kefir CIDCA AGK1. 
fermentada con gránulos de kefir o del PSFG adicionado al alimento

4.13.2 Determinación de $\mathrm{pH}$ y de la concentración de ácidos orgánicos

4.13.3 Determinación de la presencia de aflatoxinas en el alimento

4.13.4 Estudio de la Resistencia del alimento adicionado a la contaminación natural

4.13.5 Estudio de la resistencia del alimento adicionado a la contaminación artificial

Resultados y Discusión

Inhibición del crecimiento fúngico con ácidos puros y

5.1

aplicación de los ácidos en la preservación de la arepa

41

Introducción

41

Objetivos 46

5.2 .1

Objetivo General

46

Objetivos Específicos 46

5.2 .2

5.3

5.3 .1

Materiales y Métodos

46
47

Hongos filamentosos $\quad 47$

5.3 .2

Medios de cultivo de los hongos filamentosos 47

5.3 .3

Obtención de las soluciones de conidios

47
47

Ensayos de Inhibición del crecimiento fúngico 47

5.3.5 Cálculo de la concentración de ácidos orgánicos no disociados

5.3.6 Determinación de la CIM (concentración inhibitoria mínima) y CIC (concentración inhibitoria fraccionaria)

Fabricación de la Arepa y determinación de la estabilidad del alimento adicionado de ácidos orgánicos puros (láctico y acético)

Determinación de la estabilidad de la arepa adicionada de ácidos orgánicos láctico y acético

5.3.7.2.1 Estudio de la resistencia de la arepa adicionada de ácidos láctico y acético a la contaminación natural.

5.3.7.2.2 Estudio de la resistencia de la arepa adicionada de ácidos láctico y acético a la contaminación artificial.

5.3.7.3 Evaluación sensorial de arepas adicionadas con ácidos láctico y acético y mezclas de ambos.

5.4.2 Efecto de la concentración de ácido no disociado sobre el crecimiento de diferentes cepas de A. flavus.

Determinación de la concentración inhibitoria fraccionaria (CIF)

5.4.4 Resistencia a la contaminación natural y artificial por arepas adicionadas de ácidos orgánicos láctico y acético

5.4.5 Evaluación sensorial de arepas adicionadas con ácidos

6.1 Inhibición del crecimiento fúngico con leche fermentada 
Obtención de los Sobrenadantes Libres de Células

Medios de cultivo para los ensayos de inhibición fúngica.

Ensayos de Inhibición del crecimiento fúngico.

6.1.3.8.1.1 Determinación de la tasa de crecimiento $K_{D}(\mathrm{~mm} / \mathrm{h})$ y del tiempo de duración de la fase Lag (h).

6.1.3.8.1.2 Determinación del Índice de Inhibición de $\mathrm{K}_{\mathrm{D}}\left(\mathrm{IIK} \mathrm{K}_{\mathrm{D}} \%\right)$ y del Índice de Incremento de la fase Lag (IILag \%).

Fabricación de la arepa y determinación de la estabilidad del alimento adicionado de leche fermentada con gránulo CIDCA AGK1.

Estabilidad de la arepa adicionada de leche fermentada

6.1.3.9.2.1 Determinación de $\mathrm{pH}$ y de la concentración de ácidos orgánicos en la arepa.

6.1.3.9.2.2 Supervivencia de las BAL y LEV provenientes de leche fermentada con kefir y estudio de la resistencia de la arepa adicionada de kefir a la contaminación natural.

6.1.3.9.2.3 Estudio de la resistencia de la arepa adicionada de leche fermentada con kefir a la contaminación artificial.

Prueba de perfil sensorial de sabor de las arepas con

Análisis Estadístico.

Resultados y Discusión.

Cinética de acidificación a $30^{\circ} \mathrm{C}$ y a $37^{\circ} \mathrm{C}$, de la leche inoculada con gránulo CIDCA AGK1 obtenidos de leches fermentadas con gránulos de kefir CIDCA AGK1 y AGK2.

6.1.4.2.1 Efecto antifúngico sobre A. flavus AFUNL5, de los SLC de leches fermentadas a $20{ }^{\circ} \mathrm{C}$ con gránulos de kefir CIDCA AGK1 y CIDCA AGK2.

6.1.4.2.1.1 Efecto antifúngico de sobrenadantes libres de células (SLC) de leche fermentada con gránulo CIDCA AGK2 a $20^{\circ} \mathrm{C}$ sobre $A$. flavus AFUNL5.

6.1.4.2.1.2 Efecto antifúngico de SLC de leche fermentada con gránulo CIDCA AGK1 a $20^{\circ} \mathrm{C}$ sobre A. flavus AFUNL5.

6.1.4.2.2 Efecto antifúngico sobre A. flavus AFUNL5, de los SLC de leches fermentadas a $30{ }^{\circ} \mathrm{C}$ con gránulos de kefir CIDCA AGK1 y CIDCA AGK2.

6.1.4.2.2.1 Efecto antifúngico sobre $A$. flavus AFUNL5 con SLC de leche fermentada con gránulo CIDCA AGK1 a $30^{\circ} \mathrm{C}$.

6.1.4.2.2.2 Efecto antifúngico sobre $A$. flavus AFUNL5 con SLC de leche fermentada con gránulo CIDCA AGK2 a $30^{\circ} \mathrm{C}$. 
6.1.4.2.3.1 Efecto antifúngico sobre $A$. flavus AFUNL5 con SLC de leche fermentada con gránulo CIDCA AGK1 a $37^{\circ} \mathrm{C}$.

6.1.4.2.3.2 Efecto antifúngico sobre $A$. flavus AFUNL5 con SLC de leche fermentada con gránulo CIDCA AGK2 a $37^{\circ} \mathrm{C}$.

Determinación del Índice de Inhibición de la tasa de crecimiento IIK $\mathrm{K}_{\mathrm{D}}(\%)$ y del Índice de Incremento de la fase de latencia IILag (\%) de los tratamientos con SLC de leche fermentada con gránulos CIDCA AGK1 y AGK2.

6.1.6 Efecto de soluciones mezcla de ácidos orgánicos preparadas en agua destilada, sobre el crecimiento de A. flavus AFUNL5 en medio sólido

Efecto de soluciones de ácidos orgánicos preparadas en leche, sobre el crecimiento de $A$. flavus AFUNL5 en medio sólido.

6.1.7.1 Efecto de mezcla de ácidos orgánicos preparados en leche en las mismas concentraciones del SLC obtenido con gránulo CIDCA AGK1, sobre el crecimiento de $A$. flavus AFUNL5 en medio sólido.

6.1.7.2 Efecto de la mezcla de ácidos orgánicos preparados en leche en las mismas concentraciones del SLC obtenido con gránulo CIDCA AGK2, sobre el crecimiento de $A$. flavus AFUNL5 en medio sólido.

Efecto de sobrenadantes de leche acidificada con ácidos fuertes sobre el crecimiento de $A$. flavus AFUNL5.

Efecto de la adición de leche fermentada con gránulo CIDCA AGK1 en la estabilidad de la Arepa.

6.1.9.1 Determinación de $\mathrm{pH}$ y de la concentración de ácidos orgánicos en la Arepa.

6.1.9.2 Supervivencia de las BAL y LEV en las arepas adicionadas con kefir y resistencia de las mismas a la contaminación natural.

6.1.9.3 Estudio de la resistencia de la arepa adicionada de leche fermentada con kefir a la contaminación artificial.

Perfil sensorial de sabor de arepas de maíz con kefir. con gránulos de kefir (PSFG) y con microorganismos aislados de gránulos de kefir (PSFM)

Materiales y Métodos. 126

Alimento para pollos.

Aislamiento y Clasificación de hongos filamentosos del alimento para pollos.

Obtención de ADN e identificación molecular de los hongos aislados.

Obtención del micelio y Ruptura celular.

Purificación del ADN. 
6.2.3.8 Obtención del permeado de suero fermentado con gránulo CIDCA AGK1 (PSFG) y con microorganismos aislados del kefir (PSFM).

6.2.3.9 Obtención del SLC a partir del permeado de suero fermentado con gránulo CIDCA AGK1 (PSFG) y PS fermentado con microorganismos del kefir (PSFM).

6.2.3.10 Determinación de la composición del permeado de suero sin fermentar (PS), del permeado de suero fermentado con gránulos de kefir (PSFG) y del permeado de suero fermentado con microorganismos del kefir (PSFM).

Determinación de Lactosa.

Determinación de Nitrógeno total.

Análisis por HPLC de los ácidos láctico y acético en los SLC.

6.2.3.12 Preparación del permeado de suero (PS) acidificado artificialmente con ácidos orgánicos puros y con $\mathrm{HCl}$.

6.2.3.15 Adición al alimento para pollos del PS fermentado con gránulos de kefir CIDCA AGK1 (PSFG), y del PS acidificado artificialmente con ácidos puros y con $\mathrm{HCl}$.

Determinación de la estabilidad del alimento para pollos adicionado con permeado de suero fermentado con gránulos de kefir CIDCA AGK1 (PSFG).

6.2.3.16.1 Supervivencia de las BAL y LEV provenientes del PSFG adicionado al alimento.

6.2.3.16.3 Determinación de $\mathrm{pH}$ y de la concentración de ácidos orgánicos.

Determinación de la presencia de aflatoxinas en el alimento. contaminación natural.

Estudio de la resistencia del alimento adicionado a la contaminación artificial.

Aplicación de la Clave taxonómica según Pitt \& Hocking, 1999.

Caracterización de cada hongo según las claves gránulos de kefir CIDCA AGK1 (PSFG) y con microorganismos aislados del kefir (PSFM). fermentado con gránulos de kefir CIDCA AGK1 (PSFG) y con microorganismos del kefir (PSFM). 
6.2.4.5 Adición del PS fermentado con gránulo de kefir CIDCA AGK1 (PSFG) al alimento para pollos.

6.2.4.6 Secado del alimento de Pollo adicionado con permeado de suero fermentado con gránulo de kefir CIDCA AGK1 (PSFG).

6.2.4.7 Determinación de la estabilidad del alimento para pollos adicionado con permeado de suero fermentado con gránulos de kefir CIDCA AGK1 (PSFG).

6.2.4.7.1 Resistencia de los microorganismos del kefir al secado en el alimento adicionado de PSFG.

6.2.4.7.2 Determinación de la actividad acuosa $\left(\mathrm{a}_{\mathrm{w}}\right), \mathrm{pH}$, concentración de ácidos orgánicos, aflatoxinas y resistencia a la contaminación natural por el alimento adicionado con PSFG.

6.2.4.7.3 Estudio de la resistencia del alimento adicionado con Permeado de Suero Fermentado con Gránulos (PSFG) a la contaminación artificial con hongos filamentosos.

7 Estudio de la capacidad de decontaminación de aflatoxina AFB1 por microorganismos del kefir 181

Objetivos específicos. 185

Materiales y Métodos. $\quad 186$

Microorganismos empleados. 186

Medios de cultivo y de diluciones. $\quad 187$

7.3.2.2 Soluciones y medios de cultivo para recuento de

Preparación de la solución madre y la solución de trabajo de aflatoxina.

Preparación de los microorganismos para los experimentos de secuestro de aflatoxina AFB1 190

7.3.5 Desafío de captura de aflatoxina AFB1 por microorganismos aislados del kefir y microorganismos totales del gránulo CIDCA AGK1.

7.3.6 Recuento de los microorganismos empleados en los estudios de captura de aflatoxina AFB1

7.3.7 Determinación de la concentración de aflatoxina AFB1 en el sobrenadante (SN) del desafío, mediante HPLC

Determinación de la estabilidad del complejo toxinalevadura. 
del gránulo de kefir CIDCA AGK1.

Desafío en presencia de microorganismos viables y no viables.

Determinación de la hidrofobicidad de los microorganismos.

Análisis estadístico

captura de aflatoxina AFB1 por el conjunto de microorganismos del gránulo de Kefir CIDCA AGK1 cultivados en PS.

Determinación de la capacidad de captura de aflatoxina AFB1 por microorganismos aislados del gránulo de kefir.

Estudio de la influencia del porcentaje de hidrofobicidad superficial en la captura de aflatoxina AFB1

Cinética de captura durante 48 horas de aflatoxina AFB1 por microorganismos totales del gránulo de kefir CIDCA AGK1, Lactobacillus plantarum 83114 y Kluyveromyces marxianus 8154 cultivados en Permeado de suero (PS).

7.4.4.1 Captura de Aflatoxina AFB1 en función del tiempo de co-incubación con microorganismos totales del gránulo de kefir CIDCA AGK1 cultivado en permeado de suero PS 5\%.

7.4.4.2 Captura de Aflatoxina AFB1 en función del tiempo de co-incubación con L. plantarum 83114 cultivado en Permeado de suero PS 5\%.

7.4.4.3 Captura de Aflatoxina AFB1 en función del tiempo de co-incubación con K. marxianus 8154 cultivada en Permeado de Suero al 5\%.

Determinación de la estabilidad del complejo toxinamicroorganismo.

7.4.5.1 Estabilidad del complejo K. marxianus 8154 - aflatoxina AFB1.

7.4.5.2 Estabilidad del complejo L. plantarum 83114 - aflatoxina AFB1

7.4.6 Determinación de la capacidad de captura de aflatoxina AFB1 por microorganismos totales del gránulo de kefir CIDCA AGK1, L. plantarum 83114 y K. marxianus 8154 en solución salina a diferentes $\mathrm{pH}$.

Captura de aflatoxina AFB1 en presencia de microorganismos viables y no viables.

7.4.8 Capacidad de captura de aflatoxina AFB1 con diferentes concentraciones de L. plantarum 83114 y $K$. marxianus 8154.

Anexo 2 Aplicación de la clave taxonómica según Pitt \& Hocking, 1999

Anexo 3 Secuencias ITS1-5,8Sr DNA y gráficos de calidad de hongos aislados de alimento para pollos 


\section{ÍNDICE DE TABLAS}

\begin{tabular}{|c|c|c|}
\hline Tabla № & Descripción & Página \\
\hline 4.1 & $\begin{array}{l}\text { Soluciones de ácidos en agua según las concentraciones } \\
\text { determinadas en sobrenadantes obtenidos con gránulos CIDCA AGK1 } \\
\text { y AGK2. }\end{array}$ & 32 \\
\hline 4.2 & $\begin{array}{l}\text { Soluciones de ácidos en leche según las concentraciones } \\
\text { determinadas en sobrenadantes obtenidos con gránulos CIDCA AGK1 } \\
\text { y AGK2. }\end{array}$ & 33 \\
\hline 5.1 & Composición de la arepa según la FAO. & 43 \\
\hline 5.2 & $\begin{array}{l}\text { Requisitos fisicoquímicos para masas utilizadas en la preparación de } \\
\text { arepas de maíz refrigeradas. }\end{array}$ & 44 \\
\hline 5.3 & Requisitos fisicoquímicos para arepas de maíz refrigeradas. & 44 \\
\hline 5.4 & $\begin{array}{l}\text { Parámetros cinéticos de A.flavus AFUNQ6 cultivado en presencia de } \\
\text { ácido acético y láctico. }\end{array}$ & 54 \\
\hline 5.5 & $\begin{array}{l}\text { Crecimiento de } A \text {. flavus AFUNL1, AFUNL2 y AFUNL3 con ácidos } \\
\text { orgánicos }\end{array}$ & 57 \\
\hline 5.6 & $\begin{array}{l}\text { Crecimiento de } A \text {. flavus }(\mathrm{C}) \text { o no crecimiento }(\mathrm{NC}) \text { bajo la acción de } \\
\text { diferentes mezclas de ácido acético y láctico en el medio luego de } 30 \\
\text { días de incubación a } 30^{\circ} \mathrm{C} \text {. }\end{array}$ & 65 \\
\hline 5.7 & $\begin{array}{l}\text { Vida útil (días) de arepas Antioqueña elaboradas con diferentes tipos } \\
\text { de ácidos: acético, láctico y mezcla láctico: acético y almacenadas a } \\
10 \text { y } 20^{\circ} \mathrm{C} \text {. }\end{array}$ & 67 \\
\hline 6.1 .1 & $\begin{array}{l}\text { Velocidad de crecimiento y fase Lag de } A \text {. flavus AFUNL5 en } \\
\text { presencia de SLC de leche fermentada con gránulos de kefir CIDCA } \\
\text { AGK1 y AGK2 incubados a } 20^{\circ} \mathrm{C} \text {. }\end{array}$ & 84 \\
\hline 6.1 .2 & $\begin{array}{l}\text { Velocidad de crecimiento y fase Lag de } A \text {. flavus AFUNL5 en } \\
\text { presencia de SLC de gránulos de kefir CIDCA AGK1 y AGK2 } \\
\text { incubados a } 30^{\circ} \mathrm{C} \text {. }\end{array}$ & 88 \\
\hline 6.1 .3 & $\begin{array}{l}\text { Velocidad de crecimiento y fase Lag de } A \text {. flavus AFUNL5 en } \\
\text { presencia de SLC de gránulos de kefir CIDCA AGK1 y CIDCA AGK2 } \\
\text { incubados a } 37^{\circ} \mathrm{C} \text {. }\end{array}$ & 91 \\
\hline 6.1 .4 & $\begin{array}{l}\text { IILag (\%) e IIK } \mathrm{D}_{\mathrm{D}}(\%) \text { de } A \text {. flavus AFUNL5 en presencia de SLC } \\
\text { obtenidos con leche fermentada a } 20,30 \text { y } 37^{\circ} \mathrm{C} \text {, con gránulos de } \\
\text { kefir CIDCA AGK1 y AGK2. }\end{array}$ & 93 \\
\hline 6.1 .5 & $\begin{array}{l}\text { Parámetros de crecimiento } \mathrm{K}_{\mathrm{D}}(\mathrm{mm} / \mathrm{h}) \text { y Lag e índices } I I \mathrm{~K}_{\mathrm{D}} \text { y Lag }(\%) \\
\text { de } A \text {. flavus AFUNL5 en presencia de mezclas de ácidos orgánicos } \\
\text { preparadas en agua destilada (láctico y acético). }\end{array}$ & 100 \\
\hline 6.1 .6 & $\begin{array}{l}\text { Parámetros de crecimiento } \mathrm{K}_{\mathrm{D}}(\mathrm{mm} / \mathrm{h}) \text { y Lag e índices } \mathrm{IIK}_{\mathrm{D}} \text { y Lag (\%) } \\
\text { de } A \text {. flavus AFUNL5 en presencia de sobrenadantes de leche } \\
\text { acidificada con mezclas de ácidos orgánicos (láctico y acético). }\end{array}$ & 106 \\
\hline 6.1 .7 & $\begin{array}{l}\text { Parámetros de crecimiento } \mathrm{K}_{\mathrm{D}}(\mathrm{mm} / \mathrm{h}) \text { y Lag }(\mathrm{h}) \text { e índices IIK } \mathrm{K} \text { y Lag } \\
(\%) \text { de } A \text {. flavus AFUNL5 en presencia de sobrenadantes de leche } \\
\text { acidificada con ácido fuerte }(\mathrm{HCl} 3 \mathrm{M}) \text {. }\end{array}$ & 109 \\
\hline 6.1 .8 & pH y concentración de ácidos orgánicos en la arepa antioqueña & 113 \\
\hline 6.1 .9 & $\begin{array}{l}\text { Recuentos de Bacterias Ácido Lácticas (BAL), Levaduras (LEV) y } \\
\text { Hongos Filamentosos (HF) en la Arepa. }\end{array}$ & 113 \\
\hline 6.1 .10 & $\begin{array}{l}\text { Días transcurridos para la aparición visible del hongo adicionado a las } \\
\text { arepas. }\end{array}$ & 115 \\
\hline 6.1 .11 & $\begin{array}{l}\text { Sabores detectados por los jueces del Panel sensorial, en las arepas } \\
\text { fabricadas con y sin kefir. }\end{array}$ & 117 \\
\hline 6.2 .1 & $\begin{array}{l}\text { Nomenclatura inicial y características de los hongos aislados del } \\
\text { alimento para pollos. }\end{array}$ & 137 \\
\hline 6.2 .2 & $\begin{array}{l}\text { Diámetro de crecimiento }(\mathrm{mm}) \text { de los hongos a las } 24,48,72 \text { horas y } \\
7 \text { días, (a) } 5^{\circ} \mathrm{C} \text {; (b) } 25^{\circ} \mathrm{C} \text { y }(\mathrm{c}) 37^{\circ} \mathrm{C} \text {. }\end{array}$ & 138 \\
\hline 6.2 .3 & Diámetro de las colonias para Aspergillus. & 148 \\
\hline 6.2 .4 & Clasificación molecular de los hongos aislados del alimento de pollo. & 152 \\
\hline 6.2 .5 & $\begin{array}{l}\text { Comparación de la clasificación del hongo P. sumatrense según } \\
\text { diferentes autores (Houbraken, Frisvad \& } \square \text { Samson, 2011). }\end{array}$ & 153 \\
\hline
\end{tabular}




\begin{tabular}{|c|c|c|}
\hline 6.2 .6 & $\begin{array}{l}\text { Composición del PS y del PS fermentado durante } 33 \text { horas a } 30^{\circ} \mathrm{C} \\
\text { con gránulo de kefir CIDCA AGK1 y con L. plantarum aislados de } \\
\text { gránulo de kefir. }\end{array}$ & 160 \\
\hline 6.2 .7 & $\begin{array}{l}\text { Porcentajes de reducción de la germinación de hongos filamentosos } \\
\text { con PS fermentado con MK. }\end{array}$ & 164 \\
\hline 6.2 .8 & $\begin{array}{l}\text { Niveles estimados de bacterias acido lácticas (BAL) y levaduras } \\
\text { consumidas por día en el alimento balanceado por pollos de } \\
\text { diferentes días de vida. }\end{array}$ & 167 \\
\hline 6.2 .9 & $\begin{array}{l}\text { Recuentos de BAL y LEV (UFC/g) en el alimento de pollo adicionado } \\
\text { con PSFG y secado, durante el almacenamiento. }\end{array}$ & 170 \\
\hline 6.2 .10 & $\begin{array}{l}\text { Consumo esperado de BAL y LEV del alimento de pollo adicionado de } \\
\text { PSFG (1:1) a los } 15 \text { y } 30 \text { días de almacenamiento, según los días de } \\
\text { vida del pollo. }\end{array}$ & 171 \\
\hline 6.2 .11 & $\begin{array}{l}\mathrm{a}_{\mathrm{w}}, \mathrm{pH} \text { y ácidos orgánicos en el alimento adicionado con PSFG } \\
\text { durante el almacenamiento } \mathrm{a} 20^{\circ} \mathrm{C} \text {. }\end{array}$ & 175 \\
\hline 6.2 .12 & $\begin{array}{l}\text { Vida útil del alimento para pollos adicionado con permeado de suero } \\
\text { fermentado con gránulos (PSFG), adicionado de ácidos orgánicos } \\
\text { (AO) y acidificado con ácidos fuertes ( } \mathrm{HCl} 3 \mathrm{M}) \text {, contaminado con } \\
\text { hongos filamentosos. }\end{array}$ & 178 \\
\hline 7.1 & $\begin{array}{l}\text { Microorganismos evaluados en la capacidad de secuestrar aflatoxina } \\
\text { AFB1. }\end{array}$ & 186 \\
\hline 7.2 & Absorbancia y $\varepsilon$ obtenidos para las tres concentraciones de $\mathrm{K}_{2} \mathrm{Cr}_{2} \mathrm{O}_{7}$. & 188 \\
\hline 7.3 & $\begin{array}{l}\text { Concentraciones teóricas de AFB1 y área obtenida en la corrida de } \\
\text { HPLC. }\end{array}$ & 189 \\
\hline 7.4 & $\begin{array}{l}\text { Porcentaje de captura de los microorganismos totales del kefir } \\
\text { cultivados en PS al } 5 \% \text {. }\end{array}$ & 197 \\
\hline 7.5 & $\begin{array}{l}\text { Porcentajes de captura de aflatoxina AFB1, } 150(\mathrm{ppb}) \text { por lactobacilos } \\
\text { aislados de gránulos de kefir. }\end{array}$ & 199 \\
\hline 7.6 & $\begin{array}{l}\text { Porcentajes de captura de aflatoxina AFB1 }(150 \mathrm{ppm}) \text { por levaduras } \\
\text { aisladas del kefir y de otros productos lácteos fermentados }{ }^{1} \text {. }\end{array}$ & 201 \\
\hline 7.7 & $\begin{array}{l}\text { Porcentaje de captura de aflatoxina AFB1 y porcentaje de } \\
\text { Hidrofobicidad de lactobacilos aislados del kefir. }\end{array}$ & 204 \\
\hline 7.8 & $\begin{array}{l}\text { Porcentaje de captura de aflatoxina AFB1 y porcentaje de } \\
\text { Hidrofobicidad de levaduras aisladas del kefir. }\end{array}$ & 207 \\
\hline 7.9 & $\begin{array}{l}\text { Recuentos de los microorganismos después del desafío con aflatoxina } \\
\text { AFB1 a diferentes valores de } \mathrm{pH} \text {. }\end{array}$ & 221 \\
\hline
\end{tabular}




\section{ÍNDICE DE FIGURAS}

\begin{tabular}{|c|c|c|}
\hline Figura № & Descripción & Página \\
\hline 1.1 & $\begin{array}{l}\text { Estructuras químicas de las principales aflatoxinas encontradas en } \\
\text { los alimentos llamadas aflatoxina B1, G1 y M1 con un doble } \\
\text { enlace en la posición 8-9 y aflatoxinas B2, G2 y M2 sin doble enlace } \\
\text { en la posición 8-9. }\end{array}$ & 8 \\
\hline 5.1 & $\begin{array}{l}\text { Crecimiento de } A \text {. flavus en medios sólidos en presencia de } \\
\text { diferentes concentraciones de ácido láctico y acético. }\end{array}$ & 52 \\
\hline 5.2 & $\begin{array}{l}\text { Efecto de la concentración de acido acético sin disociar [HAc] y de } \\
\text { ácido láctico sin disociar [LA] sobre la velocidad de crecimiento } \\
\text { fúngico } \mathrm{K}_{\mathrm{D}}(\mathrm{mm} / \mathrm{h}) \text { y fase de latencia }(\mathrm{h}) \text { de diferentes cepas de } A \text {. } \\
\text { flavus. }\end{array}$ & 61 \\
\hline 5.3 & $\begin{array}{l}\mathrm{I}_{\mathrm{KD}} \% \text { y relación LagT/LagC para } A \text { flavus AFUNQ6 en función de la } \\
\text { concentración de ácido láctico sin disociar }(\mathrm{HL}) \text { y ácido acético } \\
(\mathrm{HAC}) \text {. }\end{array}$ & 63 \\
\hline 5.4 & Recuentos fúngicos en arepas. & 66 \\
\hline 5.5 & $\begin{array}{l}\text { Evaluación sensorial realizado por el panel no entrenado de Arepa } \\
\text { Antioqueña elaborada con ácidos orgánicos. }\end{array}$ & 68 \\
\hline 6.1 .1 & $\begin{array}{l}\text { Cinética de acidificación de leche con gránulo CIDCA AGK1 al } 10 \% \\
\text { y a } 30^{\circ} \mathrm{C} \text {. }\end{array}$ & 79 \\
\hline 6.1 .2 & $\begin{array}{l}\text { Cinética de acidificación de leche con gránulo CIDCA AGK1 al 10\% } \\
\text { y a } 37^{\circ} \mathrm{C} \text {. }\end{array}$ & 80 \\
\hline 6.1 .3 & Curva de crecimiento $A$. flavus AFUNL5 a $30^{\circ} \mathrm{C}$ y Regresión lineal. & 81 \\
\hline 6.1 .4 & $\begin{array}{l}\text { Curva de crecimiento y regresión lineal de la curva de crecimiento } \\
\text { de } A \text {. flavus AFUNL5 tratado con SLC de gránulo de kefir CIDCA } \\
\text { AGK2 fermentado a } 20 \circ \mathrm{O} \text {, a pH } 3,53,3 \text { y } 3,05 \text {, con el SLC en } \\
\text { concentración del } 50 \%, 10 \%, 1 \% \text {. }\end{array}$ & 83 \\
\hline 6.1 .5 & $\begin{array}{l}\text { Curva de crecimiento y regresión lineal de la curva de crecimiento } \\
\text { de } A \text {. flavus AFUNL5 cultivado con SLC de gránulo de kefir CIDCA } \\
\text { AGK1 fermentado a } 20{ }^{\circ} \mathrm{C} \text {, a pH } 3,1 \text {, con el SLC en concentración } \\
\text { del } 50 \% \text {. }\end{array}$ & 83 \\
\hline 6.1 .6 & 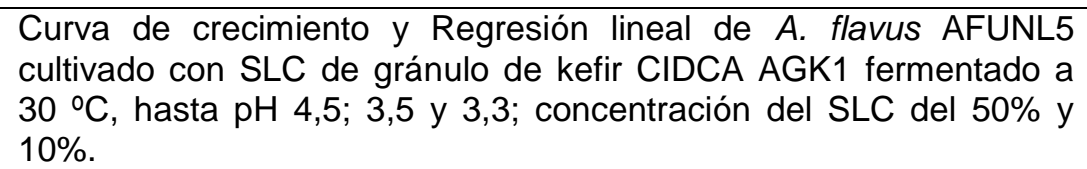 & 85 \\
\hline 6.1 .7 & $\begin{array}{l}\text { Curva de crecimiento y Regresión lineal de A. flavus AFUNL5 } \\
\text { cultivado con SLC de gránulo de kefir CIDCA AGK2 fermentado a } \\
30 \text { 드, hasta pH 4,5; } 3,5 \text { y } 3,3 \text {; en concentración del } 50 \% \text { y } 10 \% \text {. }\end{array}$ & 86 \\
\hline 6.1 .8 & $\begin{array}{l}\text { Curva de crecimiento y Regresión lineal de la curva de crecimiento } \\
\text { de } A \text {. flavus AFUNL5 cultivado con SLC de gránulo de kefir CIDCA } \\
\text { AGK1 fermentado a } 37^{\circ} \mathrm{C} \text {, a pH } 3,3 \text {, con el SLC en concentración } \\
\text { del } 50 \% \text {. }\end{array}$ & 90 \\
\hline 6.1 .9 & $\begin{array}{l}\text { Curva de crecimiento y Regresión lineal de la curva de crecimiento } \\
\text { de } A \text {. flavus AFUNL5 cultivado con SLC de gránulo de kefir CIDCA } \\
\text { AGK2 fermentado a } 37^{\circ} \mathrm{C} \text {, a pH } 3,3 \text {. }\end{array}$ & 90 \\
\hline 6.1 .10 & $\begin{array}{l}\text { Curva de de crecimiento de } A \text {. flavus AFUNL5 y Regresión lineal en } \\
\text { medio MEA sin adición de SLC. }\end{array}$ & 98 \\
\hline 6.1 .11 & $\begin{array}{l}\text { Curva de crecimiento y Regresión lineal de la curva de crecimiento } \\
\text { de } A \text {. flavus AFUNL5 cultivado con mezcla de ácidos orgánicos } \\
\text { preparada en agua destilada a pH } 3,5 \text { (símil SLC obtenidos con } \\
\text { gránulo de kefir CIDCA AGK1). }\end{array}$ & 98 \\
\hline 6.1 .12 & $\begin{array}{l}\text { Curva de crecimiento y Regresión lineal de la curva de crecimiento } \\
\text { de } A \text {. flavus AFUNL5 cultivado con mezcla de ácidos orgánicos } \\
\text { preparada en agua destilada a pH 3,3 (símil SLC obtenidos con } \\
\text { gránulo de kefir CIDCA AGK1). }\end{array}$ & 98 \\
\hline 6.1 .13 & $\begin{array}{l}\text { Comparación de los Índices } \| \mathrm{K}_{\mathrm{D}} \text { e IILag de } A \text {. flavus AFUNL5 } \\
\text { cultivado con mezclas de ácidos orgánicos preparados en agua } \\
\text { destilada. }\end{array}$ & 101 \\
\hline
\end{tabular}




\begin{tabular}{|c|c|c|}
\hline 6.1 .14 & $\begin{array}{l}\text { Curva de crecimiento y Regresión lineal de la curva de crecimiento } \\
\text { de A. flavus AFUNL5 cultivado con sobrenadantes de leche } \\
\text { acidificada con ácidos orgánicos símil SLC obtenido con gránulo } \\
\text { CIDCA AGK1, a pH } 3,5 \text { concentraciones } 50 \% \text { y } 10 \% \text { en el medio. }\end{array}$ & 102 \\
\hline 6.1 .15 & $\begin{array}{l}\text { Curva de crecimiento y Regresión lineal de la curva de crecimiento } \\
\text { de A. flavus AFUNL5 cultivado con sobrenadantes de leche } \\
\text { acidificada con ácidos orgánicos símil SLC obtenido con gránulo } \\
\text { CIDCA AGK1, a pH } 3,0 \text { concentración } 50 \% \text { en el medio. }\end{array}$ & 103 \\
\hline 6.1 .16 & $\begin{array}{l}\text { Curva de crecimiento y Regresión lineal de la curva de crecimiento } \\
\text { de } A \text {. flavus AFUNL5 cultivado con sobrenadantes de leche } \\
\text { acidificada con ácidos orgánicos símil SLC obtenidos con gránulo } \\
\text { CIDCA AGK2, a pH 3,3, concentraciones } 50 \text { y } 10 \% \text { en el medio. }\end{array}$ & 104 \\
\hline 6.1 .17 & $\begin{array}{l}\text { Curva de crecimiento y Regresión lineal de la curva de crecimiento } \\
\text { de } A \text {. flavus AFUNL5 cultivado con SLC de leche acidificada con } \\
\text { ácidos orgánicos símil gránulo CIDCA AGK2, a pH } 3,0 \\
\text { concentraciones } 50 \% \text { y } 10 \% \text { en el medio. }\end{array}$ & 105 \\
\hline 6.1 .18 & $\begin{array}{l}\text { Comparación de los İndices IIK } \mathrm{K}_{\mathrm{D}} \text { e IILag de } A \text {. flavus AFUNL5 } \\
\text { cultivado con sobrenadantes de leche acidificada con mezclas de } \\
\text { ácidos orgánicos. }\end{array}$ & 107 \\
\hline 6.1 .19 & $\begin{array}{l}\text { Curva de crecimiento y Regresión lineal de la curva de crecimiento } \\
\text { de } A \text {. flavus AFUNL5 cultivado con sobrenadantes de leche } \\
\text { acidificada con } \mathrm{HCl} 3 \mathrm{M} \text {, a pH } 3,5 \text { concentración } 50 \% \text { y } 10 \% \text { en el } \\
\text { medio. }\end{array}$ & 109 \\
\hline 6.1 .20 & $\begin{array}{l}\text { Curva de crecimiento y Regresión lineal de la curva de crecimiento } \\
\text { de } A \text {. flavus AFUNL5 cultivado con sobrenadantes de leche } \\
\text { acidificada con } \mathrm{HCl} 3 \mathrm{M} \text {, a pH } 3,0 \text { concentración } 50 \% \text { y } 10 \% \text { en el } \\
\text { medio. }\end{array}$ & 110 \\
\hline 6.1 .21 & Arepas contaminadas con conidios de $A$. flavus AFUNL5. & 115 \\
\hline 6.1 .22 & Arepas comerciales en Colombia. & 116 \\
\hline 6.1 .23 & Perfil de sabor de Arepa control y Arepa con kefir en masa al $10 \%$. & 117 \\
\hline 6.2 .1 & $\begin{array}{l}\text { Gen que codifica para el ARN ribosomal RNA18SrDNA - } 5,8 \text { SrADN } \\
-28 \text { y y } 5 \text { S RNA. }\end{array}$ & 123 \\
\hline 6.2 .2 & $\begin{array}{l}\text { Crecimiento en } 7 \text { días de incubación del hongo marrón tipo } \\
\text { Aspergillus (4) en diferentes medios de cultivo. }\end{array}$ & 139 \\
\hline 6.2 .3 & $\begin{array}{l}\text { (a) Célula reproductiva y (b) Estipe, Vesícula y conidios del hongo } \\
\text { Marrón tipo Aspergillus (4). }\end{array}$ & 140 \\
\hline 6.2 .4 & Hongo Azul tipo Aspergillus (3) en medio CYA. & 141 \\
\hline 6.2 .5 & Cabeza aspergilar de hongo azul tipo Aspergillus (3). & 142 \\
\hline 6.2 .6 & $\begin{array}{l}\text { Crecimiento en } 7 \text { días de incubación del hongo gris tipo Penicillium } \\
\text { (5), en medio de cultivo G25N. }\end{array}$ & 142 \\
\hline 6.2 .7 & $\begin{array}{l}\text { Hifa fértil y conidios del hongo gris tipo Penicillium (5), cultivado en } \\
\text { medio Malta. }\end{array}$ & 142 \\
\hline 6.2 .8 & $\begin{array}{l}\text { Crecimiento en } 7 \text { días de incubación del hongo azul tipo Penicillium } \\
\text { (6) en diferentes medios de cultivo. G25N. }\end{array}$ & 143 \\
\hline 6.2 .9 & $\begin{array}{l}\text { Hifa fértil y conidios del hongo azul tipo Penicillium (6), cultivado en } \\
\text { medio Malta. }\end{array}$ & 144 \\
\hline 6.2 .10 & $\begin{array}{l}\text { Colonias de Hongo verde (2) a } 25^{\circ} \mathrm{C} \text { en medios G25N, CYA, Malta y } \\
\text { DRBC. }\end{array}$ & 145 \\
\hline 6.2 .11 & Hifas y conidios de Hongo verde (2). & 146 \\
\hline 6.2 .12 & $\begin{array}{l}\text { Crecimiento en } 7 \text { días de incubación del hongo algodonoso gris tipo } \\
\text { Rhizopus (1) en diferentes medios de cultivo. }\end{array}$ & 146 \\
\hline 6.2 .13 & $\begin{array}{l}\text { Hifa fértil de del hongo algodonoso gris tipo Rhizopus (1) en medio } \\
\text { de cultivo Malta. }\end{array}$ & 147 \\
\hline 6.2 .14 & $\begin{array}{l}\text { Productos de la PCR de la región ITS1 }-5,8 S{ }_{R} \mathrm{DNA}-\mathrm{ITS} 2 \text {, de } \\
\text { algunos hongos aislados. }\end{array}$ & 150 \\
\hline 6.2 .15 & $\begin{array}{l}\text { Cinética de acidificación del PS adicionado de gránulo de kefir } \\
\text { CIDCA AGK1 al } 10 \% \text { o de microorganismos aislados del kefir } \\
\text { (concentración inicial } 2 \times 10^{7} \mathrm{UFC} / \mathrm{ml} \text { ). }\end{array}$ & 158 \\
\hline 6.2 .16 & Porcentaje de reducción de la germinación de hongos filamentosos & 163 \\
\hline
\end{tabular}




\begin{tabular}{|c|c|c|}
\hline & $\begin{array}{l}\text { con permeado de suero fermentado con gránulo CIDCA AGK1 } \\
\text { (PSFG), permeado de suero PS acidificado con ácidos orgánicos y } \\
\text { PS acidificado con } \mathrm{HCl} 3 \mathrm{M} \text {. }\end{array}$ & \\
\hline 6.2 .17 & $\begin{array}{l}\text { Porcentajes de reducción de la germinación de hongos filamentosos } \\
\text { con permeado de suero fermentado con } L \text {. plantarum y } K \text {. } \\
\text { marxianus. }\end{array}$ & 165 \\
\hline 6.2 .18 & $\begin{array}{l}\text { Proceso de Secado de la mezcla PSFG y alimento de pollo en } \\
\text { proporción } 1: 2 \text { y } 1: 1 \mathrm{vol} / \mathrm{p} \text {. }\end{array}$ & 169 \\
\hline 6.2 .19 & $\begin{array}{l}\text { Evolución de los microorganismos del kefir y de los hongos } \\
\text { filamentosos naturales del alimento para pollos adicionado con } \\
\text { PSFG (1:1) durante } 30 \text { días de almacenamiento a } 20^{\circ} \mathrm{C} \text {. }\end{array}$ & 176 \\
\hline 6.2 .20 & $\begin{array}{l}\text { Estado de desarrollo del alimento para pollos, contaminado con } A \text {. } \\
\text { parasiticus NRRL } 2999 \text { a los } 30 \text { días de almacenamiento. }\end{array}$ & 179 \\
\hline 7.1 & Regresión lineal de las áreas y concentraciones de aflatoxina AFB1 & 189 \\
\hline 7.2 & Etapas de los experimentos de captura de aflatoxina AFB1. & 192 \\
\hline 7.3 & $\begin{array}{l}\text { Porcentaje de captura de aflatoxina AFB1 por lactobacilos en } \\
\text { función del medio de cultivo. }\end{array}$ & 200 \\
\hline 7.4 & $\begin{array}{l}\text { Porcentaje de captura de aflatoxina AFB1 por levaduras aisladas de } \\
\text { gránulos de kefir y de colección. }\end{array}$ & 202 \\
\hline 7.5 & $\begin{array}{l}\text { Relación entre el \% de captura de Aflatoxina AFB1 y el \% de } \\
\text { Hidrofobicidad de los lactobacilos evaluados. }\end{array}$ & 206 \\
\hline 7.6 & $\begin{array}{l}\text { Relación entre el \% de captura de Aflatoxina AFB1 y el \% de } \\
\text { Hidrofobicidad de las levaduras evaluadas. }\end{array}$ & 207 \\
\hline 7.7 & $\begin{array}{l}\text { Porcentaje de captura de aflatoxina AFB1 del total de } \\
\text { microorganismos del kefir durante } 48 \text { horas. }\end{array}$ & 209 \\
\hline 7.8 & $\begin{array}{l}\text { Porcentaje de captura de aflatoxina AFB1 en función del tiempo de } \\
\text { co-incubación con } L \text {. plantarum } 83114 \text { cultivado previamente en PS }\end{array}$ & 210 \\
\hline 7.9 & $\begin{array}{l}\text { Porcentaje de captura de aflatoxina AFB1 en función del tiempo de } \\
\text { coincubación con Kluyveromyces marxianus } 8154 \text { cultivada } \\
\text { previamente en caldo MRS. }\end{array}$ & 211 \\
\hline 7.10 & $\begin{array}{l}\text { Porcentaje de retención de aflatoxina AFB1 por } K \text {. marxianus } \\
\text { CIDCA } 8154 \text { después del primer lavado del pellet obtenido durante } \\
\text { los distintos tiempos de coincubación. }\end{array}$ & 214 \\
\hline 7.11 & $\begin{array}{l}\text { Porcentaje de retención de aflatoxina AFB1 por L. plantarum CIDCA } \\
83114 \text { en los lavados de pellets obtenidos durante } 48 \text { horas de co- } \\
\text { incubación. }\end{array}$ & 215 \\
\hline 7.12 & $\begin{array}{l}\text { Porcentaje de captura de AFB1 por microorganismos totales del } \\
\text { gránulo CIDCA AGK1, L. plantarum } 83114 \text { y K. marxianus } 8154 \text {, a } \\
\text { diferentes valores de } \mathrm{pH} \text {. }\end{array}$ & 219 \\
\hline 7.13 & $\begin{array}{l}\text { Porcentaje de captura de aflatoxina AFB1 por L. plantarum } 83114 \text { y } \\
\text { K. marxianus } 8154 \text { viables y no viables por pasteurización. }\end{array}$ & 224 \\
\hline 7.14 & $\begin{array}{l}\text { Porcentaje de retención de aflatoxina AFB1 }(150 \text { ppb) por } L \text {. } \\
\text { plantarum CIDCA } 83114 \text { y } K \text {. marxianus CIDCA } 8154 \text { en diferentes } \\
\text { concentraciones de microorganismo. }\end{array}$ & 226 \\
\hline
\end{tabular}




\section{PRESENTACIÓN GENERAL}

A continuación se presenta el desarrollo de la tesis titulada ESTUDIO DE LA CAPACIDAD DE LOS MICROORGANISMOS DEL KEFIR, PARA INHIBIR EL DESARROLLO FÚNGICO Y PARA SECUESTRAR MICOTOXINAS.

En la primera parte del texto se presentan la introducción, los objetivos, las hipótesis y los materiales y métodos generales.

En la segunda parte del texto se desarrollan los resultados obtenidos. Estos se distribuyen en cuatro capítulos que a su vez tienen su propia introducción, objetivos y los materiales y métodos que sean específicos del capítulo. Al terminar esta parte se presentan las conclusiones, las referencias bibliográficas y los anexos del texto. 


\section{AGRADECIMIENTOS}

A Dios por haber guiado este camino.

A la Dra Graciela De Antoni por recibirme en su grupo, por su acompañamiento y amistad invaluable durante estos años.

A la Dra Leda Giannuzzi por su asesoría y sincera amistad.

A la Facultad de Ciencias Exactas de la UNLP.

A la Universidad de Antioquia, Msc Olga Martínez y Msc. Andrés Caro y los laboratorios de análisis Físicoquímicos y de Análisis Sensorial de la Facultad de Química Farmacéutica y de la Facultad de Nutrición y Dietética.

Al CIDCA (Centro de Estudios en Criotecnología y Preservación de Alimentos).

A la cátedra de Toxicología y los Drs Darío Andrinolo y Daniela Sedán por su apoyo en las determinaciones por HPLC.

A la Dra Silvana Vero por su apoyo en los experimentos de identificación fúngica, realizados en la Universidad de la República, Uruguay.

A los compañeros de la Cátedra de Microbiología de la FCE.

A los compañeros del CIDCA.

A los compañeros de la Cátedra Libre en Salud y Derechos Humanos.

A los compañeros del proyecto Kefir un Alimento Probiótico a costo cero.

A Fernanda Hamet por su cariño y amistad.

A Raúl Gamba por su amistad, apoyo, fidelidad y paciencia durante los largos ratos de experimentación, discusión y pensamiento sobre esta tesis.

A Gabriela Diosma por su apoyo y ternura en el camino.

A Patricio De Urraza, Pablo Pérez, Inés Iglesias y Andrea Ghizzonne.

A Candela Moure, Mariángeles Carrá, Anita Moretti, Carolina Valiente,Mariana Correa, Carolina Ni Coló, que me han acompañado en la experimentación y pensamiento de esta tesis.

A Roberto Zapata, por su mano extendida siempre llena de amor y fortaleza inacabables.

A Ofelia Peláez, Juan Diego León, Silvia León, Celina Urrego, Inés Peláez, Margarita Peláez, Rita Peláez, Mercedes Peláez, Melba León y Eleazar León quienes desde la distancia siempre me acompañan.

A Walter León quien me inició desde chica en el amor por el estudio y que sigue acompañándome desde el cielo.

A Lucrecia y Demetrio por acompañarme con su ternura en las horas interminables.

A Federica, Susana, Chuflix y Salchicha que me acompañan en el cielo de Moguer. 
ESTUDIO DE LA CAPACIDAD DE LOS MICROORGANISMOS DEL KEFIR, PARA INHIBIR EL DESARROLLO FÙNGICO Y PARA SECUESTRAR MICOTOXINAS 


\section{INDICE}

PRESENTACION GENERAL

1 INTRODUCCIÓN

2 OBJETIVOS

2.1 Objetivos Generales

2.2 Objetivos Específicos

3 HIPÓTESIS

\section{MATERIALES Y MÉTODOS GENERALES}

4.1 Hongos filamentosos.

4.2 Preparación del inóculo de hongos filamentosos.

4.3 Gránulos de kefir.

4.4 Microorganismos aislados de gránulos de Kefir (MK).

4.5 Curvas de acidificación.

4.6 Obtención del producto fermentado con gránulos de kefir y con microorganismos aislados del gránulo de kefir (MK).

4.7 Obtención del SLC a partir de los productos fermentados con gránulos de kefir y con microorganismos aislados del gránulo de kefir.

4.8 Análisis por HPLC de los ácidos láctico y acético en los SLC y en los alimentos adicionados de productos fermentados.

4.9 Preparación de los SLC acidificados artificialmente con ácidos orgánicos puros y con $\mathrm{HCl}$.

4.10 Determinación del porcentaje de reducción de la germinación de conidios (\%RG).

4.11 Determinación de la estabilidad del alimento adicionado de leche o permeado de suero fermentado con gránulos de kefir CIDCA AGK1.

- Supervivencia de las BAL y LEV provenientes de leche o PSFG adicionado al alimento.

- Determinación de pH y de la concentración de ácidos orgánicos.

- Estudio de la Resistencia del alimento adicionado a la contaminación natural.

- Estudio de la resistencia del alimento adicionado a la contaminación artificial.

4.12 Determinación del aumento de biomasa de los gránulos de kefir CIDCA cultivados en leche. 


\section{RESULTADOS Y DISCUSIÓN}

5. INHIBICIÓN DEL CRECIMIENTO FÚNGICO CON ÁCIDOS PUROS Y APLICACIÓN DE LOS ÁCIDOS EN FABRICACIÓN DE AREPA.

5.1 Introducción

5.2 Objetivos

5.2.1 Objetivo General

5.2.2 Objetivos Específicos

5.3 Materiales y Métodos

5.3.1 Hongos filamentosos

5.3.2 Medios de cultivo de los hongos filamentosos

5.3.3 Obtención de las soluciones de conidios

5.3.4 Ensayos de Inhibición del crecimiento fúngico

5.3.5 Cálculo de la concentración de ácidos orgánicos no disociados

5.3.6 Determinación de la CIM (concentración inhibitoria mínima) y CIC (concentración inhibitoria fraccionaria)

5.3.7 Fabricación de la arepa y determinación de la estabilidad del alimento adicionado de ácidos orgánicos puros (láctico y acético)

5.3.7.1. Fabricación de la arepa

5.3.7.2 Determinación de la estabilidad de la arepa adicionada de ácidos orgánicos láctico y acético.

-Estudio de la resistencia de la arepa adicionada de ácidos láctico y acético a la contaminación natural.

-Estudio de la resistencia de la arepa adicionada de ácidos láctico y acético a la contaminación artificial.

5.3.7.3 Evaluación sensorial de arepas adicionadas con ácidos láctico y acético y mezclas de ambos.

\subsubsection{Análisis estadístico}

5.4 Resultados y Discusión

5.4.1 Efecto del ácido láctico y ácido acético sobre el crecimiento de diferentes cepas de $A$. flavus en medio sólido.

5.4.2 Efecto de la concentración de ácido no disociado sobre el crecimiento de diferentes cepas de $A$. flavus.

5.4.3. Determinación de la concentración inhibitoria fraccionaria (CIF) 
5.4.4 Resistencia a la contaminación natural y artificial por arepas adicionadas de ácidos orgánicos láctico y acético.

5.4.5 Evaluación sensorial de arepas adicionadas con ácidos láctico y acético y mezclas de ambos.

5.5 Conclusiones

6. INHIBICIÓN DEL CRECIMIENTO FÚNGICO CON KEFIR

6.1 INHIBICIÓN DEL CRECIMIENTO FÚNGICO CON LECHE FERMENTADA CON GRÁNULOS DE KEFIR.

6.1.1 Introducción.

6.1.2 Objetivos.

- Objetivo General.

- Objetivos específicos.

6.1.3 Materiales y Métodos

6.1.3.1 Gránulos de Kefir.

6.1.3.2 Hongos filamentosos.

6.1.3.4 Medios de cultivo de los hongos filamentosos.

6.1.3.5 Obtención de los Sobrenadantes Libres de Células (SLC).

6.1.3.6 Obtención de las soluciones de conidios.

6.1.3.7 Medios de cultivo para los ensayos de inhibición fúngica.

6.1.3.8 Ensayos de Inhibición del crecimiento fúngico.

6.1.3.8.1 Método de difusión en agar.

- Determinación de la tasa de crecimiento $K_{D}(\mathrm{~mm} / \mathrm{h})$ y del tiempo de duración de la fase Lag $(\mathrm{h})$.

- Determinación del Índice de Inhibición de $\mathrm{K}_{\mathrm{D}}(\mathrm{IIK} \mathrm{K} \%$ ) y del Índice de Incremento de la fase Lag (IILag \%).

6.1.3.9 Fabricación de la arepa y determinación de la estabilidad del alimento adicionado de leche fermentada con gránulo CIDCA AGK1.

6.1.3.9.1 Fabricación de la arepa.

6.1.3.9.2 Estabilidad de la arepa adicionada de leche fermentada con gránulo CIDCA AGK1.

- Determinación de pH y de la concentración de ácidos orgánicos en la arepa. 
- Supervivencia de las BAL y LEV provenientes de leche fermentada con kefir y estudio de la resistencia de la arepa adicionada de kefir a la contaminación natural.

- Estudio de la resistencia de la arepa adicionada de leche fermentada con kefir a la contaminación artificial.

6.1.3.10 Prueba de perfil sensorial de sabor de las arepas con kefir.

6.1.3.11 Análisis Estadístico.

6.1.4 Resultados y Discusión.

6.1.4.1 Cinética de acidificación a $30^{\circ} \mathrm{C}$ y a $37^{\circ} \mathrm{C}$, de la leche inoculada con gránulo CIDCA AGK1.

6.1.4.2 Estudios de Inhibición de A. flavus AFUNL5 con SLC obtenidos de leches fermentadas con gránulos de kefir CIDCA AGK1 y AGK2.

6.1.4.2.1 Efecto antifúngico sobre A. flavus AFUNL5, de los sobrenadantes libres de células (SLC) de leches fermentadas a $20{ }^{\circ} \mathrm{C}$ con gránulos de kefir CIDCA AGK1 y CIDCA AGK2.

- Efecto antifúngico de SLC de leche fermentada con gránulo CIDCA AGK2 a $20^{\circ} \mathrm{C}$ sobre A. flavus AFUNL5.

- Efecto antifúngico de SLC de leche fermentada con gránulo CIDCA AGK1 a $20^{\circ} \mathrm{C}$ sobre A. flavus AFUNL5.

6.1.4.2.2 Efecto antifúngico sobre A. flavus AFUNL5, de los sobrenadantes libres de células (SLC) de leches fermentadas a $30{ }^{\circ} \mathrm{C}$ con gránulos de kefir CIDCA AGK1 y CIDCA AGK2.

- Efecto antifúngico sobre $A$. flavus AFUNL5 con SLC de leche fermentada con gránulo CIDCA AGK1 a $30^{\circ} \mathrm{C}$.

- Efecto antifúngico sobre $A$. flavus AFUNL5 con SLC de leche fermentada con gránulo CIDCA AGK2 a $30^{\circ} \mathrm{C}$.

6.1.4.2.3 Efecto antifúngico sobre A. flavus AFUNL5, de los sobrenadantes libres de células (SLC) de leches fermentadas a $37^{\circ} \mathrm{C}$ con gránulos de kefir CIDCA AGK1 y CIDCA AGK2.

- Efecto antifúngico sobre $A$. flavus AFUNL5 con SLC de leche fermentada con gránulo CIDCA AGK1 a $37^{\circ} \mathrm{C}$.

- Efecto antifúngico sobre $A$. flavus AFUNL5 con SLC de leche fermentada con gránulo CIDCA AGK2 a $37^{\circ} \mathrm{C}$. 
6.1.5 Determinación del Índice de Inhibición de la tasa de crecimiento IIK $\mathrm{K}_{\mathrm{D}}(\%)$ y del Índice de Incremento de la fase de latencia IILag (\%) de los tratamientos con SLC de leche fermentada con gránulos CIDCA AGK1 y AGK2.

6.1.6 Efecto de soluciones mezcla de ácidos orgánicos preparadas en agua destilada, sobre el crecimiento de $A$. flavus AFUNL5 en medio sólido.

6.1.7 Efecto de soluciones de ácidos orgánicos preparadas en leche, sobre el crecimiento de $A$. flavus AFUNL5 en medio sólido.

6.1.7.1 Efecto de mezcla de ácidos orgánicos preparados en leche en las mismas concentraciones del SLC obtenido con gránulo CIDCA AGK1, sobre el crecimiento de $A$. flavus AFUNL5 en medio sólido.

6.1.7.2 Efecto de la mezcla de ácidos orgánicos preparados en leche en las mismas concentraciones del SLC obtenido con gránulo CIDCA AGK2, sobre el crecimiento de $A$. flavus AFUNL5 en medio sólido.

6.1.8 Efecto de sobrenadantes de leche acidificada con ácidos fuertes sobre el crecimiento de $A$. flavus AFUNL5.

6.1.9 Efecto de la adición de leche fermentada con gránulo CIDCA AGK1 en la estabilidad de la Arepa.

- Determinación de pH y de la concentración de ácidos orgánicos en la Arepa.

- Supervivencia de las BAL y LEV en las arepas adicionadas con kefir y resistencia de las mismas a la contaminación natural.

- Estudio de la resistencia de la arepa adicionada de leche fermentada con kefir a la contaminación artificial.

- Estudio de la resistencia de la arepa adicionada de leche fermentada con kefir a la contaminación artificial.

6.1.10 Perfil sensorial de sabor de arepas de maíz con kefir.

6.1.11 Conclusiones

6.2 EFECTO ANTIFÚNGICO DEL PERMEADO DE SUERO FERMENTADO CON GRÁNULOS DE KEFIR (PSFG) Y CON MICROORGANISMOS AISLADOS DE GRÁNULOS DE KEFIR (PSFM)

6.2.1 Introducción

6.2.2 Objetivos

6.2.2.1 Objetivo General 


\subsubsection{Objetivos Específicos}

\subsubsection{Materiales y Métodos.}

6.2.3.1 Alimento para pollos.

6.2.3.2 Hongos filamentosos.

6.2.3.3 Aislamiento y Clasificación de hongos filamentosos del alimento para pollos.

6.2.3.4 Obtención de ADN e identificación molecular de los hongos aislados.

- Obtención del micelio y Ruptura celular.

- Purificación del ADN.

-Amplificación del ADN por PCR.

- Electroforesis en Gel de Agarosa.

6.2.3.5 Gránulos de Kefir

6.2.3.6 Microorganismos aislados de gránulos de Kefir (MK)

6.2.3.7 Curvas de acidificación del permeado de suero fermentado con gránulos de kefir (PSFG) y con microorganismos aislados del kefir (PSFM).

6.2.3.8 Obtención del permeado de suero fermentado con gránulo CIDCA AGK1 (PSFG) y con microorganismos aislados del kefir (PSFM)

6.2.3.9 Obtención del SLC a partir del permeado de suero fermentado con gránulo CIDCA AGK1 (PSFG) y PS fermentado con microorganismos del kefir (PSFM).

6.2.3.10 Determinación de la composición del permeado de suero sin fermentar (PS), del permeado de suero fermentado con gránulos de kefir (PSFG) y del permeado de suero fermentado con microorganismos del kefir (PSFM).

- Determinación de Lactosa.

- Determinación de sólidos solubles totales.

- Determinación de Nitrógeno total.

- Cenizas totales.

6.2.3.11 Análisis por HPLC de los ácidos láctico y acético en los SLC.

6.2.3.12 Preparación del permeado de suero (PS) acidificado artificialmente con ácidos orgánicos puros y con $\mathrm{HCl}$.

6.2.3.13 Preparación del inóculo de hongos filamentosos

6.2.3.14 Determinación del porcentaje de reducción de la germinación de conidios (\%RG) 
6.2.3.15 Adición al alimento para pollos del PS fermentado con gránulos de kefir CIDCA AGK1 (PSFG), y del PS acidificado artificialmente con ácidos puros y con $\mathrm{HCl}$.

6.2.3.16 Determinación de la estabilidad del alimento para pollos adicionado con permeado de suero fermentado con gránulos de kefir CIDCA AGK1 (PSFG).

- Supervivencia de las BAL y LEV provenientes del PSFG adicionado al alimento.

- Determinación de la actividad acuosa $\left(a_{w}\right)$.

- Determinación de pH y de la concentración de ácidos orgánicos.

- Determinación de la presencia de aflatoxinas en el alimento.

- Estudio de la Resistencia del alimento adicionado a la contaminación natural.

- Estudio de la resistencia del alimento adicionado a la contaminación artificial.

\subsubsection{Resultados y Discusión}

6.2.4.1 Hongos filamentosos aislados del alimento para pollos.

A Clasificación a nivel morfológico.

- Aplicación de la Clave taxonómica según Pitt \& Hocking, 1999.

- Análisis de cada hongo según el capítulo al que dirige la clave taxonómica general según se indica en el anexo 1.

- Capítulo 8: Aspergillus:

- Otras características del género Aspergillus.

- Clasificación de los Aspergillus en sub-géneros y secciones

- Clave taxonómica de los dos hongos tipo Aspergillus sp. en los medios de cultivo.

- Clasificación Morfológica de los dos hongos Penicillium sp.

- Clave taxonómica para subgéneros de Penicillium (Pitt \& Hocking, 1999)

- Clasificación morfológica del hongo verde (2).

- Clave taxonómica para hongos misceláneos (Pitt \& Hocking, 1999):

- Clasificación morfológica del hongo algodonoso gris tipo Rhizopus (1).

- Clave taxonómica para Mucorales. 
B Clasificación a nivel Molecular.

6.2.4.2 Cinética de acidificación del PS fermentado con gránulos de kefir CIDCA AGK1 (PSFG) y con microorganismos aislados del kefir (PSFM).

6.2.4.3 Determinación de la composición del PS, el PS fermentado con gránulos de kefir CIDCA AGK1 (PSFG) y con microorganismos del kefir (PSFM).

6.2.4.4 Porcentaje de reducción de la germinación de los hongos filamentosos (\%RG) con permeado de suero fermentado con gránulos de kefir CIDCA AGK1 (PSFG), PS acidificado artificialmente con $\mathrm{HCl}$ y ácidos orgánicos y PS fermentado con microorganismos del kefir (PSFMK).

6.2.4.5 Adición del PS fermentado con gránulo de kefir CIDCA AGK1 (PSFG) al alimento para pollos.

6.2.4.6 Secado del alimento de Pollo adicionado con permeado de suero fermentado con gránulo de kefir CIDCA AGK1 (PSFG).

6.2.4.7 Determinación de la estabilidad del alimento para pollos adicionado con permeado de suero fermentado con gránulos de kefir CIDCA AGK1 (PSFG).

- Resistencia de los microorganismos del kefir al secado en el alimento adicionado de PSFG.

- Determinación de la actividad acuosa $\left(\mathrm{a}_{\mathrm{w}}\right), \mathrm{pH}$, concentración de ácidos orgánicos, aflatoxinas y resistencia a la contaminación natural por el alimento adicionado con PSFG.

- Estudio de la resistencia del alimento adicionado con Permeado de Suero Fermentado con Gránulos (PSFG) a la contaminación artificial con hongos filamentosos.

6.2.5 Conclusiones

7 ESTUDIO DE LA CAPACIDAD DE DECONTAMINACIÓN DE AFLATOXINA AFB1 POR MICROORGANISMOS DEL KEFIR

7.1 Introducción

7.2 Objetivos.

7.2.1 Objetivo general.

7.2.2 Objetivos específicos.

7.3 Materiales y Métodos.

7.3.1 Microorganismos empleados. 
7.3.2 Medios de cultivo y de diluciones.

- Cultivo de microorganismos.

- Soluciones y medios de cultivo para recuento de microorganismos.

- Solución de Bilis de Buey.

- Proteasas.

7.3.3 Preparación de la solución de aflatoxina AFB1.

- Preparación de la solución madre y la solución de trabajo de aflatoxina.

- Determinación de la concentración de aflatoxinas.

- Solución de aflatoxina AFB1 a diferentes $\mathrm{pH}$.

7.3.4 Preparación de los microorganismos para los experimentos de secuestro de aflatoxina AFB1.

- Microorganismos Aislados.

- Conjunto de microorganismos provenientes del gránulo de kefir.

7.3.5 Desafío de captura de aflatoxina AFB1 por microorganismos aislados del kefir y microorganismos totales del gránulo CIDCA AGK1.

7.3.6 Recuento de los microorganismos empleados en los estudios de captura de aflatoxina AFB1.

7.3.7 Determinación de la concentración de aflatoxina AFB1 en el sobrenadante (SN) del desafío, mediante HPLC.

7.3.8 Desafío de 48 horas con aflatoxina AFB1.

-Coincubación con aflatoxina AFB1.

- Determinación de la estabilidad del complejo toxina-levadura.

7.3.9 Curva dosis - respuesta de secuestro de aflatoxina AFB1 con diferentes concentraciones de L. plantarum 83114, K. marxianus 8154 y de microorganismos totales del gránulo de kefir CIDCA AGK1.

7.3.10 Desafío en presencia de microorganismos viables y no viables.

7.3.11 Desafío a diferentes valores de $\mathrm{pH}$.

7.3.12 Desafío en presencia de bilis.

7.3.13 Determinación de la hidrofobicidad de los microorganismos evaluados.

7.3.14 Análisis estadístico

7.4 Resultados y Discusión 
7.4.1 Determinación de la capacidad de captura de aflatoxina AFB1 por el conjunto de microorganismos del gránulo de Kefir CIDCA AGK1 cultivados en PS.

7.4.2 Determinación de la capacidad de captura de aflatoxina AFB1 por microorganismos aislados del gránulo de kefir.

7.4.2.1 Captura de aflatoxina AFB1 por lactobacilos.

7.4.2.2 Captura de AFB1 por parte de levaduras

7.4.3 Estudio de la influencia del porcentaje de hidrofobicidad superficial en la captura de aflatoxina AFB1.

7.4.4 Cinética de captura durante 48 horas de aflatoxina AFB1 por microorganismos totales del gránulo de kefir CIDCA AGK1, Lactobacillus plantarum 83114 y Kluyveromyces marxianus 8154 cultivados en Permeado de suero (PS).

7.4.4.1 Captura de Aflatoxina AFB1 en función del tiempo de co-incubación con microorganismos totales del gránulo de kefir CIDCA AGK1 cultivado en permeado de suero PS $5 \%$.

7.4.4.2 Captura de Aflatoxina AFB1 en función del tiempo de co-incubación con L. plantarum 83114 cultivado en Permeado de suero PS 5\%.

7.4.4.3 Captura de Aflatoxina AFB1 en función del tiempo de co-incubación con K. marxianus 8154 cultivada en Permeado de Suero al $5 \%$.

7.4.5 Determinación de la estabilidad del complejo toxina-microorganismo.

7.4.5.1 Estabilidad del complejo K. marxianus 8154 - aflatoxina AFB1.

7.4.5.2 Estabilidad del complejo L. plantarum 83114 - aflatoxina AFB1.

7.4.6 Determinación de la capacidad de captura de aflatoxina AFB1 por microorganismos totales del gránulo de kefir CIDCA AGK1, L. plantarum 83114 y K. marxianus 8154 en solución salina a diferentes $\mathrm{pH}$.

7.4.7 Captura de aflatoxina AFB1 en presencia de microorganismos viables y no viables.

7.4.8 Capacidad de captura de aflatoxina AFB1 con diferentes concentraciones de L. plantarum 83114 y K. marxianus 8154 .

7.4.9 Captura de Aflatoxina AFB1 en presencia de bilis.

7.5 Conclusiones 
8 CONCLUSIONES GENERALES Y PERSPECTIVAS

9 REFERENCIAS BIBLIOGRÁFICAS

ANEXO 1

ANEXO 2 


$$
\begin{aligned}
& \text { CAPÍTULO 1: } \\
& \text { INTRODUCCIÓN } \\
& \text { GENERAL }
\end{aligned}
$$




\section{INTRODUCCIÓN GENERAL}

\subsection{Los hongos filamentosos y las micotoxinas.}

La contaminación de alimentos por hongos filamentosos y levaduras es causa de grandes pérdidas económicas en todo el mundo. Muchos hongos son reconocidos agentes de deterioro y pueden alterar las características organolépticas de los alimentos. Desde el punto de vista sanitario, algunos de ellos producen esporas que generan reacciones alérgicas en el hombre y animales. Otros presentan la capacidad de producir una gran variedad de metabolitos secundarios denominados micotoxinas. Los hongos productores de micotoxinas se encuentran muy difundidos en el ambiente y resultan ser contaminantes frecuentes de los alimentos (Pitt \& Hocking, 1999).

Los hongos filamentosos presentan una gama óptima de temperatura de crecimiento que se encuentra entre 28 y $37^{\circ} \mathrm{C}$ y pueden crecer en un amplio rango, el cual se extiende entre 12 y $48^{\circ} \mathrm{C}$. Se presentan en la naturaleza bajo la forma de micelio o esporas sexuales o asexuales llamadas conidios. Bajo condiciones adversas tales como desecación o escasez de nutrientes, forman estructuras de resistencia. De este modo permanecen latentes hasta que las condiciones ambientales cambian y se hacen favorables; es entonces cuando los esporos germinan dando nuevo micelio (Cotty, 1988; Yu, Cleveland, Nierman, \& Bennett, 2005).

Las micotoxinas son metabolitos secundarios que se generan cuando la fase de crecimiento del hongo llega a su etapa final y durante la fase estacionaria, siendo a menudo asociado con la diferenciación y la esporulación. Son moléculas relativamente pequeñas $(\mathrm{PM}<700 \mathrm{Da})$. La mayor parte de estos metabolitos secundarios se originan en la ruta policetónica. Existen otras rutas biosintéticas pero son más complejas y esa complejidad se relaciona con un menor número de especies fúngicas capaces de sintetizar las micotoxinas (Moss, 1991). Las micotoxinas constituyen un problema a nivel mundial por su alta incidencia y niveles de ocurrencia en alimentos para humanos y animales. Antes de la 
cosecha, el riesgo para el desarrollo de aflatoxinas es mayor durante los períodos de sequía, dado que cuando la humedad está debajo del valor normal y la temperatura es alta, el número de esporas fúngicas en el aire aumenta y éstas infectan las cosechas a través los insectos y se favorece la producción de aflatoxinas (Christensen, 1987). Durante la fase de post-cosecha, la proliferación de hongos y producción de aflatoxinas puede aumentarse en sitios de almacenamiento calientes y húmedos (Díaz, 2006).

Las especies toxicogénicas de mayor importancia pertenecen a tres géneros de hongos, Aspergillus, Penicillium y Fusarium. También producen micotoxinas ciertas especies de Alternaria, Claviceps, Stachybotrys, Pithomyces, Phoma, Diploidia, Trichothecium, Rhizoctonia y Myrothecium. Estos hongos son capaces de crecer sobre una gran variedad de sustratos bajo diversas condiciones ambientales.

La mayoría de los productos agrícolas son susceptibles de contaminación por hongos durante algunas de las etapas de producción, procesamiento, transporte o almacenamiento. (Vaamonde, 1996). Aspergillus y Penicillium se encuentran generalmente como contaminantes en alimentos durante el secado y almacenamiento, mientras que las especies de Fusarium pueden producir micotoxinas antes o después de la cosecha (CAST, 2003). Sin embargo, la presencia de esporos de estos mohos en un alimento no implica necesariamente la presencia de micotoxinas, sino que indica un riesgo potencial de contaminación. Asimismo, se debe tener en cuenta que las diferentes cepas de una especie difieren en su capacidad de producir micotoxinas y es común encontrar cierta proporción de aislamientos no toxigénicos. Se encotró que de 3460 aislamientos de Aspergillus flavus, el 74,4\% de éstos resultaron ser cepas toxicogénicas. Por otra parte, de 29 aislamientos de Fusarium graminearum el $93,1 \%$ de estos resultan ser cepas toxicogénicas (Vaamonde, 1996). Por otra parte, la ausencia de hongos toxicogénicos no garantiza que el alimento esté libre de micotoxinas, pues las toxinas pueden persistir aun cuando el hongo haya perdido su viabilidad. 
Dentro de las familias más importantes de micotoxinas se encuentran las aflatoxinas, los tricotecenos, la ocratoxina $A$, las fumonisinas y la zearalenona. Las condiciones de colonización de los sustratos por los hongos micotoxigénicos, así como su posterior contaminación con micotoxinas juegan un papel fundamental en las estrategias de vigilancia y control de la industria alimentaria. Se resumen a continuación algunas características de dos géneros toxicogénicos con los que se trabajó en esta tesis.

Los mohos del género Aspergillus causan el deterioro de muchos productos alimenticios. Los productos metabólicos de su desarrollo suelen ser muy tóxicos, tanto para el hombre como para otros animales. También inhiben la germinación del grano y causan cambios de color, aumento de la temperatura, enmohecimiento, apelmazado y finalmente podredumbre de las semillas. Algunas especies como $A$. niger o $A$. oryzae, son de interés industrial y se emplean en la fermentación de alimentos (Kozakiewicz 1989).

La identificación fúngica se hace con base en las características macro y micromorfológicas en diversos medios de cultivo incubados a distintas temperaturas (Pitt \& Hocking, 1999) y mediante técnicas moleculares como la secuenciación de los genes que codifican para la región ITS1 5,8S- ITS2, para la calmodulina y para la $\beta$ - tubulina, principalmente (Vero, 2011). La ubicuidad del género Aspergillus es debida a su capacidad de crecer a diferentes temperaturas sobre substratos con diverso contenido de humedad. La colonización de los granos por Aspergillus y otros hongos durante el almacenamiento, se produce de forma explosiva cuando la humedad relativa del ambiente intergranular se eleva por sobre el 70\%, sin que se desencadene aún el fenómeno de brotación (Eguiazú, 1984). El rango de temperatura para el crecimiento varía desde $0-5^{\circ} \mathrm{C}$ para $A$. glaucus hasta $50-55^{\circ} \mathrm{C}$ para $A$. fumigatus, estando el óptimo entre 30 y $33^{\circ} \mathrm{C}$ para la mayoría de las especies. Se ha determinado que granos almacenados por debajo de 5 a $10^{\circ} \mathrm{C}$ y con un porcentaje de humedad del 15\%, no fueron afectados por Aspergillus durante un año (Kozakiewicz, 1989). Son varios los metabolitos secundarios de Aspergillus que son considerados micotoxinas: aflatoxinas, esterigmatocistina y otros, 
algunos de los cuales también son producidos por especies de Penicillium, como el ácido ciclopiazónico y la ocratoxina (Smith \& Ross, 1991).

Las especies del género Penicillium se desarrollan sobre diversos substratos como granos, paja, cueros y frutas, entre otros. Su identificación con base en las características morfológicas fue optimizada cuando Pitt (1980) normalizó las condiciones de cultivo y Frisvad (1981) consideró la formación de los metabolitos secundarios en la descripción de las especies. (Pitt \& Leistner 1991).

El género Penicilium crece sobre los alimentos preparados o sus materias primas, de origen vegetal 0 animal, en presencia de actividad acuosa y nutrientes adecuados. La baja temperatura de almacenamiento disminuye la velocidad del deterioro de las frutas infectadas por $P$. expansum, pero no lo previene. Los granos de cereales pueden contener $P$. aurantiogriseum aún antes de la cosecha, especialmente en las épocas húmedas, pero la mayor contaminación ocurre en los depósitos donde se mantienen las esporas desde una cosecha anterior (Lacey, 1989). La esporulación a una baja actividad del agua permite a los hongos completar su ciclo de vida sobreviviendo a las condiciones adversas, para ser luego diseminados por insectos y ácaros (Magan \& Lacey, 1988).

\subsection{Factores que controlan el crecimiento fúngico y la producción de micotoxinas}

El crecimiento fúngico y la formación de micotoxinas dependen de una serie de factores como humedad, temperatura, presencia de oxígeno, tiempo para el crecimiento fúngico, composición del sustrato, lesiones en la integridad del grano causadas por insectos, daño mecánico/térmico, cantidad de inóculo del hongo e interacción y/o competencia entre diversas cepas fúngicas. Esta gama de factores demuestra que el control de los mismos, en el sentido de la prevención, se vuelve muy difícil en condiciones tropicales. 
Aun cuando una cepa de hongo tenga el potencial genético para biosintetizar una micotoxina, su producción estará determinada por la disponibilidad de nutrientes en el sustrato y por diversos factores ambientales.

La gran diversidad de sustratos naturales que son regularmente colonizados por numerosas especies de hongos indican que estos microorganismos toleran amplias variaciones en la concentración de nutrientes esenciales y pueden utilizar tanto el carbono como el nitrógeno combinados de muy diversas formas. La presencia de algunos oligoelementos como el $\mathrm{Zn}$, es esencial para la producción de ciertas micotoxinas,.

Los sustratos naturales difieren en su capacidad para estimular la biosíntesis de micotoxinas. La producción de aflatoxinas, por ejemplo, es mayor en maíz, arroz, o semillas de algodón que en sorgo y soja. Se ha sugerido que uno de los factores responsables de la baja incidencia de contaminación en soja, podría ser el contenido elevado de ácido fítico que formaría complejos con el $\mathrm{Zn}$, mineral esencial para la síntesis de la aflatoxina (Palgrem \& Hayes, 1987).

Entre los factores ambientales que influyen sobre el crecimiento de los hongos y la producción de micotoxinas los más importantes son la temperatura y la actividad acuosa. Los hongos toxicogénicos presentan diferentes requerimientos en lo que respecta a la temperatura óptima y temperaturas extremas de crecimiento así como para valores de actividad acuosa que resultan limitantes para su desarrollo y para la biosíntesis de las toxinas. En muchos casos la producción de la toxina ocurre en un rango de actividad acuosa considerablemente más alta que las requeridas para el crecimiento del hongo y en un rango de temperatura más estrecho (Magan \& Lacey, 1984).

La producción de micotoxinas se ha observado que es muy baja a casi nula a actividad acuosa menor a 0,95 mientras que el desarrollo de hongos toxicogénicos puede detectarse a una actividad acuosa entre 0,70 y 0,80 . Los datos referidos a valores óptimos y limitantes de temperatura y actividad acuosa no han sido evaluados para todas las micotoxinas de importancia en alimentos. Es difícil comparar los resultados obtenidos en diferentes laboratorios porque estos valores dependen de la cepa y del sustrato empleado, de las condiciones 
de cultivo (luz, $\mathrm{O}_{2}, \mathrm{pH}$, etc.) y de los procedimientos analíticos. Se ha determinado que Aspergillus flavus tiene una temperatura óptima de crecimiento aproximadamente de $37^{\circ} \mathrm{C}$; pero la máxima acumulación de aflatoxinas ocurre en el rango de 25 a $30{ }^{\circ} \mathrm{C}$ (Diener \& Davis, 1977). Para Aspergillus ochraceus la temperatura óptima de crecimiento es aproximadamente de $30 \stackrel{\circ}{\circ}$ mientras que la máxima acumulación de ocratoxina ocurre a $31{ }^{\circ} \mathrm{C}$ (Northolt, Van Egmond \& Paulsch, 1978).

En condiciones naturales, otros factores además de los considerados interactúan sobre el crecimiento y el metabolismo de los hongos. Entre éstos, la interacción con otros microorganismos, la presencia de agentes antimicrobianos, la acción de otros entes biológicos tales como insectos y roedores. También el genoma de la planta influye sobre la cantidad de micotoxinas que puede producir un hongo que ha colonizado exitosamente el sustrato en la etapa de pre- o post cosecha. La búsqueda de variedades resistentes así como las derivadas de la ingeniería genética buscan controlar la formación de toxinas en cultivos como el maíz, maní y soja (Vaamonde, 1996).

\subsection{Acción tóxica de las micotoxinas}

La enfermedad resultante de la exposición a las micotoxinas se denomina micotoxicosis (CAST, 2003). Entre las micotoxinas involucradas en las micotoxicosis se encuentra el alcaloide del ergot que produce ergotismo cuyo hongo productor es Claviceps purpurea. Las aflatoxinas producen aflatoxicosis siendo producidas por $A$. flavus, $A$. parasiticus y $A$. nomius. La ocratoxina $\mathrm{A}$ es una micotoxina que genera la ocratoxicosis producida por $A$. ochraceus y $P$. verrucosum. La Zearalenona produce hiperestrogenismo y es producida por Fusarium graminearum y $F$. culmorum. Los tricotecenos producen fusariotoxicosis y son producidos por $F$. graminearum, $F$. sporotrichioides, $F$. tricinctum y $F$. poae. La toxina T-2 produce una enfermedad denominada leucopenia tóxica alimentaria y es generada por $F$. sporotrichioides y $F$. poae. (Abarca, Bragulat, Castellá, Accensi \& Cabañes, 2000).

Los efectos tóxicos de las micotoxinas son muy variados de la misma forma que lo son sus estructuras químicas. Para cada toxina existe un órgano 
primariamente afectado. Así, el órgano blanco de las aflatoxinas es el hígado, para la ocratoxina y la citrinina es el riñón, para la toxina T-2 es el sistema inmunológico y las mucosas, para el deoxinivalenol es la mucosa intestinal y para la zearalenona es el tracto urogenital (Godoy, 1985).

Una de las principales características de las micotoxinas es que son tóxicas a bajas concentraciones (hipotóxicas) y su acción es acumulativa, con efectos retardados en el tiempo, propio de las toxinas mutagénicas. Las de mayor relevancia a nivel mundial, por su efecto sobre la salud pública y la productividad de los animales son: aflatoxinas, fumonisinas, ocratoxina $A$, tricotecenos (toxina T-2), deoxinivalenol y zearalenonas (FAO, 2003; Godoy, 2006; Romagnoli, 2008).

En general, los principales factores que influyen en la toxicidad de las micotoxinas sobre los animales son:

a) La especie animal (diferencia en sensibilidad).

b) La concentración de la toxina y el tiempo de exposición.

c) Nutrición y estado sanitario de los animales.

d) La edad y sexo de los animales.

e) Presencia de varias toxinas, que pueden actuar sinérgicamente (Devegowda, 2005).

Entre las problemáticas más comúnmente asociadas a la contaminación por micotoxinas y su incidencia sobre la producción animal se encuentran la alteración y reducción de la calidad física y nutritiva del cereal empleado en los alimentos; la mala absorción y/o la no utilización de los nutrientes; el rechazo del alimento por parte de los animales, lo que se traduce en disminución de la ingesta y consecuente reducción de la productividad; el incremento de la susceptibilidad a las enfermedades infecciosas y el efecto sinérgico con otras toxinas (Mallman, 1998; Presello \& Botta, 2004; Quiroga, 2004). En cerdos se encuentran particularmente alteraciones del tracto gastrointestinal tales como vómito y hemorragias, asociados a deoxinivalenol; edema pulmonar asociado a 
fumonisina $\mathrm{B} 1$; nefropatía porcina y efectos carcinogénicos asociados a ocratoxina $A$; hiperestrogenismo, vulvovaginitis $y$ otros trastornos de la reproducción tanto en hembras como en machos, asociados con la zearalenona (Mallman \& Dilkin, 2011; Chulze, 2012).

\subsection{Aflatoxinas}

La contaminación de alimentos con A. flavus fue descubierta por primera vez como consecuencia de un brote que produjo una muerte súbita de cientos de pavos en el año 1960 y fue denominada enfermedad $X$ de los pavos o "Turkey $X$ Disease" (Blount, 1961). Este hallazgo produjo el aislamiento de un compuesto fluorescente referido como aflatoxina debido a la abreviatura de toxina de "Aspergillus flavus toxin" (Nesbitt, O’kelly, Regeant \& Sheridan, 1962). Las estructuras químicas de las 6 toxinas más predominantes en la dieta se presentan en la figura 1.1 .

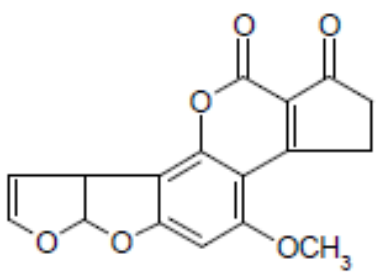

$\mathrm{AFB}_{1}$

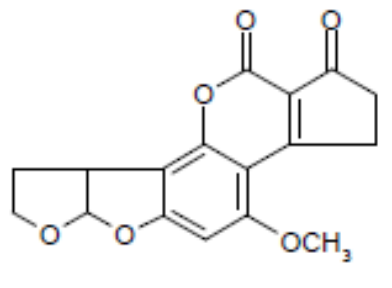

$\mathrm{AFB}_{2}$<smiles>COc1cc2c(c3oc(=O)c4c(c13)CCOC4=O)C1C=COC1O2</smiles>

$A F G_{1}$

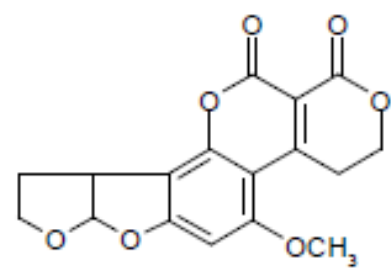

$\mathrm{AFG}_{2}$

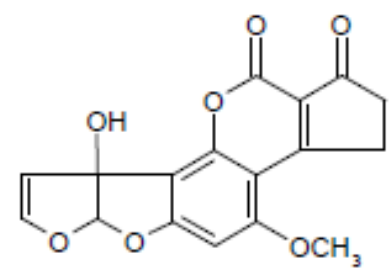

$\mathrm{AFM}_{1}$

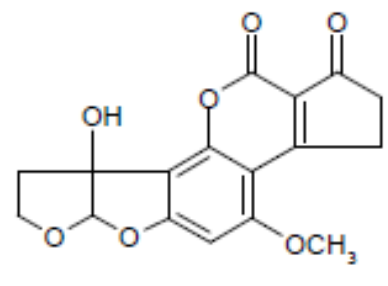

$\mathrm{AFM}_{2}$

Figura 1.1 Estructuras químicas de las principales aflatoxinas encontradas en los alimentos llamadas aflatoxina B1, G1 y M1 con un doble enlace en la posición 8-9 y aflatoxinas B2, G2 y M2 sin doble enlace en la posición 8-9.

Químicamente, las aflatoxinas corresponden a derivados del grupo de difuranocumarina que muestran fluorescencia bajo la luz ultravioleta. De acuerdo 
al color de la fluorescencia las aflatoxinas son agrupadas en aflatoxina B1 y B2 (AFB1, AFB2) por su color azul y G1 y G2 (AFG1, AFG2) por su fluorescencia verde al de ser corridas en una placa cromatográfica. Las aflatoxinas M1 y M2 (AFM1, AFM2) son metabolitos derivados de AFB1 y AFB2 (Carnaghan, Hartley \& O'Kelly, 1963). La aflatoxina AFB1 es las mas tóxica y presenta mayor prevalencia, seguida por G1, B2 y G2 con un incremento de la toxicidad en ese orden (Busby, 1984). AFM1 se detecta en leche y productos lácteos y su toxicidad es comparable a AFB1 (Busby, 1984). Las aflatoxinas pueden ser producidas por cuatro especies de Aspergillus como son A. flavus, A. parasiticus, A. nomius y A. pseudotamarii (Pitt, 2000; CAST, 2003).

La contaminación de los alimentos con estos hongos y aflatoxinas ha sido detectada más frecuentemente en África y sur este de Asia. Los alimentos más frecuentemente contaminados con aflatoxinas son maíz y productos del maíz, maní, frutas secas y productos lácteos (éstos con AFM1) (IARC, 1993). En el caso de las aflatoxinas, a sus efectos hepatotóxicos y hepatocancerígenos se añaden el efecto inmunodepresor, aumentando la susceptibilidad a enfermedades de origen viral y bacteriano (Richard, Payne, Desjardin, Maragos, Norred, Pestka, Phillips, Van Egmond, Vardon, Whitaker \& Wood, 2003; Presello \& Botta, 2004).

La exposición diaria humana a aflatoxinas varia entre los diversos países y ha sido estimada entre 3,5-14,8 ng/kg/día en Kenia, 11,4 -158,6 ng/kg/día en Swazilandia, 38,6 -183,7 ng/kg/día en Mozambique, 16,5 ng/kg/día en Transkei (Sudáfrica), 4-115 ng/kg/día en Gambia y 6.5-53 ng/kg/día en Tailandia, mientras que la exposición en Estado Unidos es de $2,7 \mathrm{ng} / \mathrm{kg} / \mathrm{día}$ (Hall \& Wild, 1994; Williams, Phillips, Jolly, Stiles, Jolly \& Aggarwal, 2004).

Existe evidencia epidemiológica que indica que las aflatoxinas son productoras de enfermedad humana en diversas regiones del mundo. Al respecto, los estudios epidemiológicos en África y Asia Oriental han demostrado una correlación positiva entre el logaritmo de ingestión de alimentos contaminados con aflatoxina B1 y la ocurrencia de cáncer primario de hígado en humanos 
(Álvarez, Carvajal, Ruisánchez \& Rojo, 2000). En América Latina se registra el cáncer de hígado en el cuarto lugar de muerte por cáncer, sin estar asociado a altas tasas de hepatitis $B$, cirrosis $u$ otras enfermedades hepáticas, lo cual deja entre las causas posibles el efecto de las aflatoxinas. A pesar de que más del 60 \% se registra como cáncer de hígado no especificado como primario ni como secundario, con frecuencia el cáncer secundario por metástasis se diagnostica y luego se registra como primario, cuando en realidad se trata de lesiones malignas producto de una lesión de origen no determinado o de diagnóstico tardío (Gallardo \& Rodríguez, 1999). El Instituto Nacional de Cancerología en Colombia, en el año 2003 diagnosticó 19 casos nuevos de cáncer de hígado y vías biliares intrahepáticas (INC, 2004) y actualmente se desarrollan estudios de cuantificación de biomarcadores de exposición a aflatoxinas con el fin de establecer el riesgo de carcinoma hepatocelular en la población colombiana (Urrego \& Díaz, 2006).

Existe evidencia indicando que la exposición crónica a aflatoxinas induce la producción de células cancerígenas, convirtiéndolo en un problema de salud pública, especialmente cuando se asegura que del 20 al $50 \%$ de todos los cánceres están relacionados con factores de la dieta (Montesano, 1997; Groopman, Jiaqui \& Donahue, 1992). La aflatoxina AFB1, junto al virus de la hepatitis $B$, son considerados como los factores de riesgo de cáncer hepatocelular en China y África del Norte, estimándose en 250.000 muertes anualmente (Eaton \& Groopman, 1994). En la exposición crónica el efecto más drástico ocurre en el ADN y su efecto se puede subdividir en carcinogénico, mutagénico y teratogénico. Bioquímicamente, se considera que las aflatoxinas, en especial la AFB1, pueden pasar en el hígado por dos fases. La fase I por acción del complejo citocromo p-450 mono-oxigenasa que produce en el organismo una variedad de derivados reducidos y oxidados que supuestamente no presentan actividad carcinogénica, como los productos AFQ1 y AFM1. Pero también puede producir productos como la aflatoxina AFB1, 8, 9 epóxido (AFBO), que es un producto inestable y que forma aductos con el ADN, el cual puede llevar a mutaciones en proto-oncogen y genes supresores de tumores (Montesano, 1997). El compuesto AFBO puede llegar a conjugarse con 
proteínas o sufrir hidroxilación o conjugarse con el glutatión (GSH) en el hígado y ser excretado en la orina o en las heces como ácido mercaptúrico, o combinarse con proteínas de diferentes tejidos, provocando diferentes clases de intoxicaciones. Además de los efectos carcinogénicos, la aflatoxinas y sus metabolitos pueden afectar cualquier órgano, causando hígado graso, necrosis moderada y extensiva, hemorragia, alargamiento de la vesícula, daño en el sistema inmune, nervioso o reproductivo (Dvorackova, 1990; Llewellyn, 1988).

\subsection{Legislación}

Varios países han establecido reglamentaciones acerca de los límites a la concentración de aflatoxinas en diversos alimentos. En el caso de las aflatoxinas, al ser reconocidas como carcinógenas, se entiende que sería deseable evitar por completo su presencia en los alimentos. Sin embargo, las aflatoxinas no son sustancias agregadas intencionalmente como sucede con algunos aditivos o pesticidas. Tampoco son sustancias naturales de los alimentos como es el caso de otras sustancias tóxicas. Por el momento se acepta que las micotoxinas no pueden ser simplemente eliminadas corrigiendo ciertos aspectos de las prácticas agrícolas y de manufactura, porque su presencia es el resultado de un conjunto de condiciones que no son totalmente predecibles y controlables por el hombre, como las condiciones climáticas.

Por otra parte, aún no se ha establecido con certeza cual es el nivel por debajo del cual se puede asegurar que no haya efectos adversos. Los límites de tolerancia se establecen sobre la base de soluciones de compromiso. Uno de los argumentos a favor de tolerar cierto nivel de contaminación es que al aplicar límites muy estrictos existe el peligro de tener que desechar alimentos muy necesarios para evitar el hambre en poblaciones carenciadas. La situación es crítica cuando se debe evitar el riesgo de cáncer sin llegar a la pérdida de alimentos indispensables.

Debido a la toxicidad de estas sustancias, organismos como la USDA (United States Department of Agriculture) y la Comisión Europea (CE) han propuesto regulaciones que establecen límites para la comercialización. El reglamento de la 
Comision Europea establece los siguientes límites máximos reglamentarios para las aflatoxinas. En maíz sin procesar, el limite máximo es de $5 \mu \mathrm{g} / \mathrm{kg}$ para AFB1 y $10 \mu \mathrm{g} / \mathrm{kg}$ para el total de AF (suma de B1, B2, G1 y G2) (EC, 2010).

\subsection{Ocurrencia de aflatoxinas en alimentos}

La ocurrencia de aflatoxinas en alimentos en diversos países indica que el maní y el maíz son los cultivos de mayor riesgo de contaminación y que los granos pequeños (sorgo, cebada, avena, trigo, centeno, arroz) en general son menos susceptibles. Sin embargo, pueden contaminarse a causa de un manejo inadecuado de pre y postcosecha y/o por condiciones climáticas adversas.

La presencia natural de micotoxinas en la Argentina ha sido investigada en granos de maíz (Broggi, Pacin, Gasparovic, Sacchi, Rothermel, Gallay \& Resnik, 2007; Chulze, Bertinetti, Dalcero, Etcheverry, Farnochi, Torres, Rizzo \& Varsavsky, 1989; González, Martínez, Pacin, Resnik \& Sydenham, 1999; Pacin, Broggi, Resnik \& González, 2001; Resnik, Neira, Pacin, Martinez, Apro \& Latreite, 1996), así como en otros productos (Solovey, Somozat, Cano, Pacin \& Resnik, 1999).

Se estudió la presencia natural de aflatoxinas y zearalenona entre los años 1983 y 1994 en muestras de maíz de las provincias de Buenos Aires y Santa Fe, Argentina. Los resultados obtenidos indicaron que de 2.271 muestras analizadas, $1.214(53,5 \%)$ estaban contaminadas con micotoxinas. La aflatoxina B1 se identificó en el 19,6\% de las muestras analizadas, la aflatoxina B2 en 4,1\% y la zearalenona en $29,8 \%$. Ninguna de las muestras contenía cantidades detectables de aflatoxina G2. La contaminación por aflatoxinas no se detectó en las cosechas 1988, 1993 y 1994 y, en los otros años, con la excepción de 1989, los niveles de contaminación fueron bajos (Resnik, Neira, Pacin, Martinez, Apro \& Latreite, 1996).

Más recientemente, en Argentina se ha estudiado la ocurrencia de micotoxinas en maíz entre los años 1999- 2010. Un total de 3246 muestras de maíz, recién 
cosechado (1655) y de almacenamiento (1591) se obtuvieron de diferentes regiones. En todos los años estudiados los niveles de aflatoxinas fueron bajos excepto para muestras provenientes de la cosecha del año 2003 y para muestras almacenadas del año 2007. Los valores promedio de la aflatoxina B1 para muestras recién cosechadas variaron entre 0,38 y $2,54 \mu \mathrm{g} / \mathrm{kg}$ y para muestras almacenadas entre 0,22 y 4,5 $\mu \mathrm{g} / \mathrm{kg}$ (Garrido, Hernández, Pezzani \& Pacin, 2012).

Los estudios llevados a cabo en Colombia demuestran claramente que las micotoxinas constituyen un problema real y que aún falta mucho por investigar en este campo de la toxicología alimentaria, particularmente en lo que respecta a la incidencia de otras micotoxinas como son los tricotecenos. La posibilidad de contaminación con micotoxinas en alimentos de consumo humano y animal representa un riesgo toxicológico real para la salud pública y la salud animal.

La relevancia del continuo monitoreo de aflatoxinas en los granos susceptibles a contaminación quedó demostrada a finales del año 2001 cuando prácticamente la totalidad de la cosecha de maíz del municipio de Cereté, Departamento de Córdoba, resultó contaminada con aflatoxinas. Los niveles de contaminación oscilaron entre $15,2 \mu \mathrm{g} / \mathrm{kg}$ y $282,6 \mu \mathrm{g} / \mathrm{kg}$ de aflatoxina B1. Este hecho inusual (una incidencia del 100\% y niveles muy altos de aflatoxina B1), se atribuyó a la conjunción de varios factores dentro de los cuales se encontraron condiciones ambientales, características fenotípicas de los híbridos utilizados y la presencia endémica de plagas como el "cogollero del maíz" (Spodoptera frugiperda), las cuales generan condiciones favorables para el establecimiento del hongo (Acuña \& Diaz, 2005).

Es importante resaltar que la base de la alimentación en Colombia es el maíz y que la contaminación por hongos y aflatoxinas en los granos de maíz pasa a los alimentos que de consumo popular en alimentación cotidiana como son la arepa, la empanada, el bollo de maíz, el tamal y otros. 


\section{7 Prevención y control de micotoxinas}

La prevención de la contaminación sería el método más racional y seguro para la salud pública en el control de la contaminación por micotoxinas de los productos alimenticios. Sin embargo, en muchos casos eso no es posible ya sea por razones climáticas o económicas (Samarajeewa, Sen, Choen \& Wei, 1990). De ser posible su aplicación, existen diferentes estrategias para reducir el riesgo de contaminación fúngica. La implementación de Buenas Prácticas agrícolas, de planes de Buenas prácticas de Manufactura y un sistema de Análisis de Riesgos y Control de Puntos Críticos (HACCP) permite garantizar la inocuidad desde la producción de las materias primas hasta el producto terminado. Por otra parte, la adición de sustancias antifúngicas también contribuye a la prevención del crecimiento fúngico y de producción de las micotoxinas.

\subsubsection{Buenas prácticas agrícolas}

Resulta importante mejorar las prácticas agrícolas evitando el ataque de hongos toxicogénicos pudiendo esto iniciarse en el campo. Una de las medidas más efectivas del control fúngico es el uso de semillas de buena calidad y libres de hongos, conjuntamente con un control del ataque de los insectos y las enfermedades de las plantas evitando lesionar el cereal, lo que produce una rápida invasión de hongos.

Durante el almacenamiento de las cosechas, la humedad y la temperatura ambiente, así como la presencia de microorganismos competidores influyen decisivamente en el metabolismo fúngico y en la capacidad de producción de sus toxinas. Para una conservación a corto plazo se recomiendan como valores máximos de humedad del grano del $8 \%$, humedad relativa del ambiente de $70 \%$ y temperatura ambiente de $20^{\circ} \mathrm{C}$. Asimismo, para una conservación a mediano plazo, los valores máximos recomendados son humedad del grano del $8 \%$, humedad relativa del ambiente $60 \%$ y temperatura ambiente de $5^{\circ} \mathrm{C}$. 
En algunos países como Ghana, donde se producen alimentos autóctonos de maíz fermentados (Kenkel o masa de maíz fermentada) a nivel industrial, se han implementado Programas de Buenas Prácticas de Manufactura y HACCP obteniendo resultados positivos en la disminución de los riesgos de contaminación por patógenos y hongos toxicogénicos. La aplicación de estos programas ha permitido disminuir las aflatoxinas totales desde niveles que variaban entre 64,1 y $196 \mu \mathrm{g} / \mathrm{kg}$ antes de la implementación de los planes de BPM, hasta 17,2 y $14,5 \mu \mathrm{g} / \mathrm{kg}$ una vez estos fueron puestos en funcionamiento (Amoa-Awua, Ngunjiri, Anlobe, Kpodo, Halm, Ewurafua, Hayford \& Jakobsen, 2007).

Las buenas prácticas de cultivo y el empleo de variedades de semillas producidas para resistir al ataque de insectos y consecuente infestación fúngica de las semillas, así como el uso de plaguicidas adecuados y aprobados, representan medidas preventivas razonables para luchar contra la contaminación en el campo. Sin embargo, la aplicación de esas prácticas, las condiciones creadas por el medio ambiente $y / o$ las prácticas agrícolas tradicionales pueden dificultar las medidas preventivas.

\subsubsection{Ingeniería genética}

Las modificaciones genéticas realizadas a las plantas (transgénesis) logran la sobre-expresión de proteínas y metabolitos antifúgicos, que aumentan el sistema de defensa de la planta. A través de la ingeniería genética se desarrollan nuevas variedades, capaces de resistir el ataque de los hongos o inhibir la producción de toxinas. El genoma de la planta puede influir en la expresión de la biosíntesis de la micotoxinas. Los esfuerzos iniciales fueron identificar variedades de cultivos resistentes a la naturaleza, pero sólo se ha observado una resistencia parcial a la contaminación por aflatoxinas. No obstante, estos estudios han ayudado a comprender tanto los factores que hacen a la planta resistente a la infección así como la ruta biosintética de las aflatoxinas, proporcionando así una base para interferir potencialmente con estos procesos mediante la ingeniería genética de plantas resistentes (Wild \& Hall, 2000). 
Algunas plantas, por ejemplo, el maní, producen compuestos antifúngicos tales como fitoalexinas que pueden proporcionar protección contra los hongos invasores (Keenan \& Savage, 1994). En la semilla de maíz, las proteínas que contribuyen a la resistencia a la producción de aflatoxina tienen capacidad ya sea para inhibir el crecimiento de hongos, o la formación de toxinas (Chen, Brown, Lax, Guo, Cleveland \& Russin, 1998; Guo, Brown, Lax, Cleveland, Russin \& Widstrom, 1998). Estos estudios han permitido la identificación de los genes implicados en la resistencia y la posibilidad de insertarlos en otras variedades, obteniendo genotipos resistentes.

\subsubsection{Sustancias antifúngicas}

Otras alternativas incluyen la inhibición del crecimiento del hongo y de la producción de micotoxinas empleando sustancias antifúngicas. La contaminación de las cosechas puede ser prevenida o disminuida usando ácidos como el benzoico, sórbico, propiónico, fórmico y acético. El pH del alimento debe estar alrededor del pKa del ácido para garantizar que gran parte de este ácido se encuentre sin disociar y así garantizar el efecto antifúngico (León, Serna, Quintero, Gamba, De Antoni \& Giannuzzi, 2012). Por otra parte, la cantidad de ácido adicionada al producto almacenado debe estar relacionada con la cantidad de agua del mismo y debe estar distribuido de una manera uniforme en todo el volumen a tratar. Por el contrario, la utilización de estos ácidos en bajas concentraciones puede llevar al riesgo de que se produzca un incremento en la capacidad toxigénica de determinados hongos.

Desde hace tiempo se ha demostrado que los ácidos débiles tienen una actividad antimicrobiana mayor a $\mathrm{pH}$ ácido que a $\mathrm{pH}$ cercano a la neutralidad (Simon \& Blackman, 1949) y que el ácido acético presenta una mayor capacidad inhibitoria contra hongos, levaduras y bacterias (Blom \& Mörtvedt, 1991). 


\subsection{Detoxificación de los alimentos contaminados con micotoxinas}

El mejor método para controlar la contaminación de los alimentos por micotoxinas es la prevención. Pero cuando el producto ya está contaminado y será usado como alimento, es necesario eliminar o disminuir esta contaminación o su absorción en el organismo. La decontaminación de micotoxinas se refiere al tratamiento para remover, destruir o reducir el efecto tóxico de las toxinas en el alimento.

La FAO estableció una serie de criterios para determinar si el proceso de decontaminación es apropiado o no, debiendo considerarse lo siguiente.

- Destruir, inactivar o eliminar la toxina.

- No producir residuos tóxicos o carcinogénicos en los productos finales o en alimentos obtenidos a partir de animales que se alimentaron de una dieta detoxificada.

- Mantener el valor nutritivo y la aceptabilidad del producto.

- No alterar las propiedades tecnológicas importantes de forma significativa.

- Destruir todas las esporas y micelios fúngicos para que no puedan, en condiciones favorables, proliferar y producir nuevas micotoxinas.

Las estrategias para prevenir la presencia de aflatoxinas y eliminar, inactivar o reducir su biodisponibilidad en alimentos contaminados incluyen métodos físicos, químicos y biológicos (Bueno, Salvano, Silva, González \& Oliver, 2001; CAST, 2003; Kabak, Alan \& Var, 2006). La aplicación de estos métodos presenta sin embargo limitaciones que se refieren a la pérdida de calidad nutricional así como de las propiedades sensoriales de los alimentos. Por otra parte, en ocasiones, el costo del equipamiento necesario para la aplicación de estas técnicas así como la imposibilidad de garantizar los resultados deseados, hacen que los alimentos para alimentación humana y animal conserven la contaminación con aflatoxinas. Por ejemplo, en la industria avícola, la aflatoxina B1 (AFB1) representa un contaminante no deseado y aparece en los alimentos para aves en niveles de 0200 ng/g (Dalcero, Magnoli, Chiacchiera, Palacios \& Reynoso, 1997). A continuación se presenta una reseña de los principales métodos de decontaminación. 


\subsubsection{Métodos físicos}

Los métodos físicos y electrónicos de separación y control de hongos contaminantes a menudo han sido usados por industrias para reducir los niveles de aflatoxinas, ya que estos granos están destinados al consumo humano. Entre los métodos físicos se incluyen, la separación mecánica, la flotación, separación por color o remoción de los granos quebrados y lavado con soluciones después de la recolección de los granos.

Probablemente, el método físico más empleado en una industria sea la separación de granos quebrados, lo cual permite reducir la contaminación por micotoxinas. Sin embargo, con frecuencia no se hace, debido a un concepto equivocado de utilizar al máximo los granos, sin pensar en los riesgos productivos (Pitt \& Hocking, 2006).

Las radiaciones como los rayos $\mathrm{X}$, son capaces de producir una emisión elevada de energía, la cual produce la ruptura de estructuras moleculares estables. Se ha establecido que las aflatoxinas B1 y G1 son más sensibles a los rayos $\mathrm{X}$.

El calor utilizado como método físico para la destrucción de micotoxinas resulta poco eficaz ya que las temperaturas que se alcanzan durante el proceso de detoxificación afectan a las vitaminas y proteínas del alimento (Zakhia-Rozis, 2007).

\subsubsection{Métodos químicos}

La detoxificación de productos contaminados por inactivación a través de reacciones químicas, alta presión o extracción, usando un solvente orgánico o una combinación de éstos, ha sido utilizada para el control de las aflatoxinas desde 1960.

La utilización de amoníaco para la decontaminación de productos agrícolas contaminados por aflatoxinas ha demostrado ser muy eficiente. Sin embargo, su 
posterior utilización como alimento humano o animal es inadecuada debido a las alteraciones físico-químicas generadas.

Otro método a ser considerado para la detoxificación es el uso de solventes. Una de las características físico-químicas más destacadas de las micotoxinas es su capacidad de ser solubles en solventes orgánicos. Así, combinaciones de solventes tales como hexano/acetona-agua o isopropanol-agua entre otros, han demostrado arrastrar las micotoxinas.

Por otra parte, el empleo de agentes químicos reactivos incluye sustancias químicas capaces de reaccionar con la estructura de las micotoxinas. Así se dispone de ácidos tales como el ácido clorhídrico, sulfúrico y derivados. Estos ácidos son capaces de reaccionar con los grupos lactona de las aflatoxinas B1, G1, patulina, zearalenona y con dobles enlaces no aromáticos presentes en aflatoxinas, patulina, zearalenona y tricotecenos. Toxicológicamente, la reacción de adición de los ácidos con los dobles enlaces parece ser la más eficaz en cuanto a detoxificación se refiere, ya que los productos de reacción son sustancias polares, eliminables por la orina.

Los álcalis tales como monoetil y metilamina, hidróxido y cloruro cálcico, hidróxido y carbonato sódico y amónico son reactivos con los grupos lactona de las aflatoxinas, ocratoxina, patulina y zearalenona.

Los agentes oxidantes como el ozono, peróxidos y permanganatos en solución alcalina son reactivos con los dobles enlaces no conjugados de aflatoxinas y patulina. El ozono ha sido usado por décadas para esterilizar y preservar alimentos. El Departamento Administrativo de Alimentos y Drogas de los Estados Unidos (FDA) ha establecido que el empleo de ozono es una metodología segura, GRAS (Generally Recognized As Safe). Para ello, se dispone de una cámara donde se coloca el producto a tratar, el cual está provisto de un distribuidor vertical del gas ozono, de tal manera que se asegure una distribución homogénea sobre el producto. La reacción denominada ozonólisis genera nuevas moléculas más pequeñas, aunque algunos de los productos obtenidos pueden ser tóxicos (Prudente \& King, 2002). 
La reacción de glicolización produce dos grupos hidroxilo que posteriormente pueden formar puentes de hidrógeno. Pero aun siendo este mecanismo eficaz para la detoxificación, debería utilizarse en combinación con polímeros o silicatos capaces de adsorber físicamente la aflatoxina (Mc Kenzi, Sarr, Mayura, Bailey, Millar, Rogers, Corred, Voss, Plattner, Kubena \& Phillips,1997).

Los agentes reductores como el formol resultan ser reactivos con los grupos carbonilo de aflatoxina B1, B2, sterigmatocistina, zearalenona, nivalenol y deoxinivalenol, dando lugar a grupos hidroxilo que posteriormente podrán formar puentes de hidrógeno (Samarajeewa, Sen, Cohen \& Wei, 1990).

No obstante, estos tratamientos están siendo rechazados por las nuevas legislaciones europeas, debido a los efectos secundarios que pueden producir en los consumidores (Lingk, 1991; Sanchis, Marin \& Ramos, 2000; Unnikrishnan \& Nath, 2002; García \& Heredia, 2006; Magan, 2006).

El empleo de agentes químicos inertes como sustancias capaces de adsorber las moléculas de micotoxinas en su estructura también ha sido estudiado. Se destacan 3 grupos: el carbón activado, los polímeros de polivinilpirrolidona y las arcillas, silicatos sintéticos. El carbón activado corresponde a una estructura de carbono con una gran superficie externa, tanto fuera como en el interior de las moléculas, muy empleado en la fijación de toxinas entéricas. Los polímeros de pirrolidona forman puentes de hidrógeno y nitrógeno en su estructura. Los silicatos alumínicos pertenecen al grupo de las arcillas, que poseen una estructura tridimensional básica formada por la unión de tetraedros de $\mathrm{SiO}_{4}$, entre los cuales se intercalan otros iones como el aluminio. A diferencia de los silicatos alumínicos naturales, se desarrollaron los silicatos sódico alumínico cálcico hidratados -HSCAS-, que poseen mayor capacidad de adsorción al ser productos refinados. El empleo de HSCAS en la alimentación animal resultó esencial para mejorar los parámetros sanitarios y económicos de aquellos animales con problemas por contaminación con micotoxinas en el pienso (Borrell \& Gimeno, 2002; Lara, Muñoz, Rivera, Bringas \& Pérez, 1998) 
En busca de nuevas alternativas de control con sustancias que sean inofensivas tanto para el hombre como para el ambiente, se están empleando compuestos de origen natural que tengan propiedades antifúngicas, como son los aceites esenciales. Estos se componen de mezclas complejas de hidrocarburos, compuestos oxigenados y residuos no volátiles, contenidos en glándulas 0 vesículas secretoras inmersas en los tejidos de las hojas, flores, corteza (pericarpio) y semillas de los frutos de algunas plantas. Entre los géneros que han sido utilizados para extracción de aceites esenciales están: Thymus, Origanum, Syzygium, Mentha y Eucalyptus, los cuales han presentado efectos antifúngicos y antibacteriales (Serrano, Martínez-Romero, Guillén, Valverde, Zapata, Castillo \& Valero, 2008).

\subsubsection{Métodos biológicos}

Pitt \& Hocking (2006) han desarrollado técnicas que permiten disminuir la producción de aflatoxinas en alimentos, usando la exclusión competitiva o inhibición competitiva. Para ello se contaminar el suelo o los granos con hongos como A. flavus o A. parasiticus no toxigénicos. El proceso de inhibición se logra porque los microorganismos no toxigénicos inoculados se desarrollan mejor sobre el sustrato, reduciendo el desarrollo de los hongos micotoxigénicos.

Otra forma de decontaminación ocurre durante el proceso fermentativo. En la producción de pan empleando granos de trigo contaminados con deoxinivalenol, se observó una reducción de los niveles de toxinas atribuida a la fermentación y al proceso térmico al cual fue sometido el producto. Esta decontaminación ocurre debido a que la levadura puede adsorber las toxinas presentes, reduciendo la contaminación (Shetty \& Jespersen, 2006).

Así mismo, se han usado bacterias endofíticas, como Bacillus subtilis; cuyo sistema enzimático reduce la acumulación de micotoxinas, ya que esta bacteria ocupa un lugar ecológico dentro de la planta de maíz y compite con hongos como $F$. moniliforme, cuya estrategia funciona como un principio competitivo de exclusión (Bacon, Yates, Hinton \& Meredith, 2001). 
Algunos experimentos de fermentación alcohólica con Saccharomyces cerevisiae con mosto contaminado con deoxinivalenol (DON) y zearalenona (ZEA), demostraron que después de 7 a 9 días de fermentación, DON fue estable al proceso. Sin embargo, ZEA fue convertida a $\beta$-zearalenol ( $\beta$-ZEL) en un $69 \%$, y a a-zearalenol en un 8,1\%. La mayor parte de la transformación de la zearalenona ocurrió durante los días 1 y 2 de fermentación, demostrando la inestabilidad de la toxina frente a este proceso (Mallmann, Hummes \& Giacomini, 2002). Otras investigaciones demostraron buenos resultados de inhibición parte de Bacillus spp sobre el crecimiento y producción de aflatoxinas por A. flavus, A. parasiticus y Trichoderma spp (Kimura \& Hiram, 1988).

En los estudios sobre aflatoxinas, la investigación se ha enfocado intensamente en la disminución de la absorción intestinal a nivel del tracto gastrointestinal de animales y humanos (El-Nezami, Mykkanen, Kankaanpaa, Suomalainen, Salminen \& Ahokas, 2000; Phillips, 1999). Para ello se ha buscado en la utilización de Bacterias Ácido Lácticas (BAL) que tengan capacidad de disminuir la adherencia de patógenos y toxinas bacterianas a líneas celulares (Schnurer \& Magnuson, 2005).

Se ha demostrado que diferentes bacterias probióticas, en especial lactobacilos (Peltonen, El-Nezami, Haskard, Ahokas \& Salminen, 2001, El-Nezami, Kankaanpaa, Salminen \& Ahokas 1998a; Haskard, El-Nezami, Kankaanpaa, Salminen \& Ahokas, 2001; Lee, El-Nezami, Haskard, Gratz, Puong, Salminen \& Mykkanen, 2003) y diferentes levaduras tienen la capacidad de unirse eficientemente a AFB1 in vitro (Armando, Dogi, Pizzolitto, Escobar, Peirano, Salvano, Sabini, Combina, Dalcero \& Cavaglieri, 2011; Pizzolito, Salvano \& Dalcero, 2012). Se ha estudiado la capacidad de captura de lactobacilos como Lactobacillus rhamnosus GG (El-Nezami, Kankaanpaa, Salminen, Ahokas \& ElNezami 1998b, Haskard, El-Nezami, Kankaanpaa, Salminen \& Ahokas, 2001), la capacidad de captura e inhibición de producción de aflatoxinas por $L$. casei (Hernández-Mendoza, Garcia \& Steele, 2009; Chang \& Kim, 2007) y la capacidad de captura también de levaduras como Saccharomyces cerevisiae 
(Bueno, Casale, Pizzolitto, Salvano \& Oliver, 2007; Pizzolitto, Bueno, Armando, Cavaglieri, Dalcero \& Salvano, 2011) aunque los resultados in vivo son controvertidos (El-Nezami, Mykkanen, Kankaanpaa, Salminen \& Ahokas, 2000a). Las toxinas pueden ser secuestradas mediante una unión fuerte de éstas con microorganismos, evitándose la absorción a nivel del tracto gastrointestinal. El secuestro depende de las propiedades superficiales de las bacterias involucradas las cuales a su vez están determinadas por las características fisicoquímicas y la naturaleza química de las moléculas de la superficie bacteriana (Peltonen, El-Nezami, Salminen \& Ahokas, 2000; Haskard, Binnion \& Ahokas, 2000). En general las moléculas superficiales involucradas en la adhesión se denominan adhesinas y entre ellas se pueden citar las lectinas (proteínas superficiales que se unen a carbohidratos) e hidrofobinas (proteínas hidrofóbicas superficiales). Las adhesinas se encuentran localizadas sobre la superficie de la pared celular, formando la capa-S o sobre apéndices celulares proteicos como las fimbrias y fibrillas (Ofek \& Doyle, 1994).

\subsection{El kefir}

Los microorganismos capaces de secuestrar aflatoxinas pueden considerarse probióticos y las bacterias más importantes desde el punto de vista probiótico pertenecen a los géneros Bifidobacterium y Lactobacillus. Un sistema microbiano complejo con características probióticas es el gránulo de kefir, una matriz de exopolisacárido y proteínas donde conviven en actividad simbiótica bacterias ácido lácticas, bacterias acido acéticas y levaduras (Garrote, 1999).

El gránulo de kefir puede fermentar la leche, obteniéndose el kefir el cual está descripto en el Código Alimentario Argentino como "El producto cuya fermentación se realiza con cultivos ácido lácticos elaborados con granos de kefir, Lactobacillus kefir, especies de los géneros Leuconostoc, Lactococcus y Acetobacter, con producción de ácido láctico, etanol y dióxido de carbono. Los granos de kefir están constituidos por levaduras fermentadoras de la lactosa (Kluyveromyces marxianus) y levaduras no fermentadoras de la lactosa (Saccharomyces omnisporus, Saccharomyces cereviciae y Saccharomyces 
exiguus), Lactobacillus casei, Bifidobacterium spp y Streptococcus salivarius subsp.termophilus) (CAA, 2006).

El kefir es una leche fermentada originada hace cientos de años en las montañas caucásicas. Su consumo se ha hecho popular principalmente en países del este de Europa como Rusia, Polonia, República Checa, Alemania, Rumania y Eslovaquia, entro otros. Lo mismo ocurre en Asia. En estos lugares la producción de kefir es industrial mientras que en Argentina es artesanal. El kefir se obtiene por la actividad fermentativa producida por los microorganismos contenidos en gránulos de kefir cuando se inoculan en la leche. Los microorganismos se crecen y se multiplican, pasando a la leche. Sus gránulos son masas gelatinosas, irregulares de color blanco o ligeramente amarillento de consistencia elástica e insolubles en agua (Garrote, 1999).

Desde hace un tiempo se ha descripto que en los gránulos de kefir se encuentra una asociación simbiótica de bacterias y levaduras (y también el hongo filamentoso Geotrichum candidum) (Zourari \& Anifantakis, 1988; Kosikowski, 1982), responsables de la doble fermentación, ácido láctica y alcohólica, a consecuencia de la cual se obtiene una bebida con características organolépticas definidas. La microflora del kefir consiste en bacterias lácticas homofermentativas y heterofermentativas, levaduras fermentadoras y no fermentadoras de la lactosa y bacterias ácido acéticas. Algunos de los microorganismos presentes en los gránulos de kefir y que se transfieren a la leche son: Lactobacillus, Lactococcus, Leuconostoc, Acetobacter, Saccharomyces y Kluyveromyces entre otros (Garrote, 1999).

La leche fermentada contiene acido láctico, acido acético, etanol, dióxido de carbono, vitaminas del complejo B y compuestos aromáticos como diacetilo y acetaldehído. También está presente el kefirán, un polisacárido bacteriano constituido por D-glucosa y D-galactosa en proporción 1:1, soluble en agua que constituye un $25 \%$ del peso seco de los gránulos (La Riviére, Kooiman \& Schmidt, 1967; Abraham \& De Antoni, 1999). Otros autores demostraron el poder inhibitorio de los gránulos de kefir liofilizados con glicerol y reconstituidos, 
sobre Staphylococcus aureus, Klebsiella pneumoneae y Escherichia coli, pero no sobre Saccharomyces cerevisiae ni Candida albicans (Brialy, Rivalland, Coiffard \& De Roeck Houltzhauer, 1995). Se han estudiado los efectos protectores en animales y se ha reportado que la administración de kefir previene la colonización con Salmonella kedougou en pollos, adjudicando este efecto no solo a la complejidad de la microbiota del kefir, sino también a su integridad. Zacconi, Parisi, Sarra, Dallavalle \& Bottazzi, 1995).

En investigaciones donde se fermentó leche o suero de quesería con con el gránulo entero de kefir, se estableció que el producto fermentado tenía actividad antimicrobiana frente a diversas bacterias patógenas como E. coli, Salmonella spp., Bacillus cereus y Klebsiella, y contra parásitos como Giardia intestinales (Garrote, 1999; Kakisu, 2006; Londero, 2012; Correa, 2012). Sin embargo, la capacidad para inhibir el desarrollo de hongos toxicogénicos y la producción de toxinas apenas comienza a ser estudiado. Por ello, el estudio de la actividad antagonista del Kefir como inhibidor del desarrollo de hongos y/o de la liberación de las micotoxinas al medio podría aportar un conocimiento básico para su futura aplicación en alimentos generando un efecto benéfico en la salud pública.

Dado que el kefir es una bebida láctea fermentada con microorganismos probióticos (Garrote, 1999), la capacidad de inhibir el crecimiento fúngico y de secuestrar aflatoxina AFB1 por parte de microorganismos aislados del gránulo de kefir cultivados en diferentes medios de cultivo y coincubados con hongos 0 aflatoxinas podría ser una estrategia promisoria en la captura de aflatoxinas.

Se ha estudiado la capacidad de diferentes tipos de BAL para inhibir el crecimiento fúngico (Onilude, Fagade, Bello \& Fadahunsi, 2005; Lavermicocca, Valerio \& Visconti, 2003; Gerez, Torino, Rollán \& Font de Valdez, 2009; Magnusson \& Schnürer, 2001, Chang \& Kim, 2007) y recientemente se ha publicado sobre esta capacidad en los microorganismos del kefir y en los gránulos de kefir (Ismaiel, 2011). El estudio de la inhibición fúngica y de la captura de aflatoxinas con los microorganismos del kefir sería de importancia fundamental dado que el consumo de las leches fermentadas con kefir está 
ampliamente distribuido en comunidades del este europeo y de inmigrantes en Argentina. En nuestro país, su consumo se ha venido expandiendo gradualmente durante el siglo pasado y el actual. Además, a partir del año 2004, se inició la divulgación sistemática de su consumo en comedores comunitarios e instituciones educativas de la ciudad de La Plata y alrededores, mediante el proyecto de extensión "Kefir un Alimento Probiótico a costo cero", de la Facultad de Ciencias Exactas de la UNLP. Dado que el kefir es un alimento descripto en el Código Alimentario Argentino, podría pensarse en la adición de dicho producto a otras matrices alimentarias tanto de consumo humano como animal. Por estas razones, en esta tesis doctoral se propone el estudio del efecto del kefir sobre el desarrollo de hongos toxigénicos, tanto en lo referente a la inhibición de su crecimiento como a la captura de sus micotoxinas.

\subsection{Justificación del estudio.}

El principal objetivo de esta tesis fue profundizar el conocimiento sobre el kefir especialmente en su acción contra el crecimiento fúngico y el secuestro de micotoxinas. Sr destaca que estos aspectos del kefir han sido poco estudiados. También se buscó dilucidar si la acción frente a hongos y micotoxinas estaría asociada a la presencia del conjunto de todos los microorganismos presentes en el kefir o si podría atribuirse a alguno de sus microorganismos en particular. Dado que el kefir es un alimento natural, en el caso de poseer efecto antifungico y secuestrante de micotoxinas, se podría utilizar para disminuir la presencia de hongos y micotoxinas en alimentos. Por otra parte, se podrían utilizar para los mismos fines, concentrados de microorganismos aislados del kefir. $\mathrm{Si}$ se observara un efecto contra hongos y micotoxinas por parte del kefir entero, sería importante desde el punto de vista social, ya que es un producto artesanal de costo cero, que podría aportar a la prevención de micotoxicosis en humanos y animales, siendo aplicable en pequeños emprendimientos de producción de animales para consumo. Tanto el kefir entero como los microorganismos aislados del kefir, se podrían utilizar para el desarrollo de un nuevo producto con capacidad antifúngica y decontaminante de micotoxinas que además poseería actividad probiótica. 


\section{CAPÍTULO 2:}

\section{OBJETIVOS}




\section{OBJETIVOS}

\subsection{OBJETIVO GENERAL}

Estudiar la potencialidad de los microorganismos del gránulo de kefir y sus metabolitos para inhibir el desarrollo de hongos filamentosos, toxicogénicos y no toxicogénicos y para secuestrar micotoxinas.

\subsection{OBJETIVOS ESPECÍFICOS}

2.2.1 Estudiar el efecto antifúngico de bacterias, levaduras y productos fermentados con kefir sobre los hongos toxicogénicos y no toxicogénicos.

2.2.2 Analizar el efecto que ejercen los ácidos orgánicos puros y en mezclas en concentraciones similares a las presentes en los productos fermentados con kefir, en la inhibición del crecimiento de hongos filamentosos toxicogénicos y no toxicogénicos.

2.2.3 Determinar la capacidad de los microorganismos totales del kefir y de los lactobacilos y las levaduras aislados del gránulo de kefir para capturar aflatoxina AFB1 bajo diferentes condiciones de cultivo.

2.2.4 Evaluar la aplicación de diferentes microorganismos del kefir en la extensión de la vida útil y en las propiedades sensoriales de arepas de maíz y alimento para pollos. 


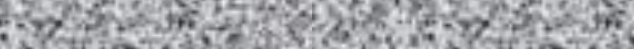

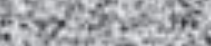




\section{HIPÓTESIS}

3.1 Las BAL y las levaduras del kefir tienen la capacidad de inhibir el crecimiento de hongos filamentosos.

3.2 Los sobrenadantes del kefir, de los productos fermentados con BAL y con levaduras del kefir tienen la capacidad de reducir el crecimiento de hongos filamentosos in vitro.

3.3 La adición a los alimentos de productos fermentados con kefir aumenta la vida útil del producto a nivel microbiológico y su resistencia a la contaminación fúngica.

3.4 Las BAL y las levaduras del kefir tienen la propiedad de secuestrar micotoxinas in vitro.

3.5 La capacidad secuestrante de aflatoxina AFB1 por parte de BAL y levaduras del kefir es determinada por el tipo de microorganismo, por su hidrofobicidad superficial, por el medio en el cual son cultivadas, por la concentración de microorganismo, por el tiempo de coincubación con la aflatoxina, por la viabilidad del microorganismo y por el $\mathrm{pH}$ del medio de desafío. 


\section{CAPÍTULO 4:}

MATERIALES $Y$

MÉTODOS

GENERALES 


\section{MATERIALES Y MÉTODOS GENERALES}

\subsection{Hongos filamentosos.}

Los estudios de inhibición fúngica se realizaron con hongos de la colección de la Cátedra de Microbiología-FCE-UNLP: Cepas de A.flavus aisladas de alimentos AFUNL1, AFUNL2, AFUNL3, AFUNL5 y AFUNQ6. Las cuatro primeras provienen de la Universidad Nacional del Litoral y AFUNQ6 fue facilitada por la Universidad Nacional de Quilmes. Se emplearon también cepas de A.parasiticus: APUNL1, APUNL2, APUNL3, A. parasiticus NRRL 2999 у APUNQ5. Las tres primeras fueron facilitadas por la Universidad Nacional del Litoral, mientras que A. flavus NRRL 2999 y APUNQ5 fueron cedidas por la Universidad Nacional de Quilmes.

También se emplearon hongos filamentosos aislados y clasificados en esta tesis, a partir de alimento balanceado para pollos Nutrisur ${ }^{\circledR}$ : Trichoderma longibrachiatum CMUNLP5, Aspergillus fumigatus CMUNLP2, Rhizopus macrosporus var. rhizopodiformis, Penicillium sumatrense CMUNLP3, Penicillium crustosum CMUNLP4 y Aspergillus terreus CMUNLP1. Las cepas fúngicas se mantuvieron a $4^{\circ} \mathrm{C}$ en agar agua (agar $0,2 \% \mathrm{p} / \mathrm{v}$ ).

\subsection{Preparación del inóculo de hongos filamentosos.}

Los hongos filamentosos se cultivaron en tubos con agar papa en pico de flauta (Merck $^{\circledR}$, Darmstadt, Alemania) a $30^{\circ} \mathrm{C}$ hasta su esporulación. El inóculo de esporas se preparó por lavado de la superficie del agar con una solución estéril de lauril sulfato de sodio (Merck ${ }^{\circledR}$, Darmstadt, Alemania) al 0,01\% (m/v) en solución de glucosa al 1\% (m/v) (Carlo Erba ${ }^{\circledR}$, Milán, Italia). Se adicionaron diez mililitros de esta solución sobre la superficie del tubo de agar inclinado y se aflojaron los conidios mediante raspado suave con ansa (Molina y Giannuzzi, 1999). El número de conidios se determinó por recuento en cámara de Neubauer y se prepararon soluciones de $1 \times 10^{4}$ conidios $/ \mathrm{ml}$. 


\subsection{Gránulos de kefir.}

Se emplearon los gránulos CIDCA AGK1 y AGK2, caracterizados en el CIDCA (Centro de Investigación y Desarrollo en Criotecnología de Alimentos), Universidad Nacional de La Plata (UNLP), Argentina (Garrote, 1999). Estos se conservaron congelados en leche a $-20^{\circ} \mathrm{C}$ y se reactivaron mediante dos pasajes consecutivos de fermentación a $30^{\circ} \mathrm{C}$ en leche UHT $\left(\right.$ Sancor ${ }^{\circledR}$, Argentina). Una vez reactivados se efectuaron las fermentaciones a diferentes concentraciones de gránulo y Temperatura para los estudios de inhibición. Las fermentaciones fueron realizadas en leche (capítulo 6.1) o en Permeado de Suero (capítulo 6.2).

\subsection{Microorganismos aislados de gránulos de Kefir (MK).}

Se emplearon microorganismos aislados de gránulos de kefir y caracterizadas en el CIDCA (Centro de Investigación y Desarrollo en Criotecnología de Alimentos) de la U.N.L.P: Lactobacillus kefir CIDCA 8348, 83111, 8325 Y L. kefir JCM5818; L. plantarum 83114, 8327, 8318 y 8316; Saccharomyces cerevisiae 81103 y 8116, Kluyveromyces marxianus 8154, S. lipolytica 8112 , Saccharomyces boulardii, K. lactis y el hongo filamentoso Geotrichum candidum (Garrote, 1999). Las cepas se conservan en leche y caldo MRS a $20^{\circ} \mathrm{C}$ y para efectuar los experimentos se reactivaron mediante dos pasajes consecutivos cultivándolas por 24 horas a $30^{\circ} \mathrm{C}$ en caldo MRS (DIFCO ${ }^{\circledR}$, Beauvais, Francia), antes de cultivarlas en Permeado de suero (PS).

\subsection{Curvas de acidificación.}

Para realizar la curva de acidificación de leche o PS el sustrato se inoculó con gránulo CIDCA AGK1 o AGK2 al 10\% y se incubó a diferentes temperaturas $\left(20^{\circ} \mathrm{C}, 30^{\circ} \mathrm{C}\right.$ y $\left.37^{\circ} \mathrm{C}\right)$. Se tomaron lecturas periódicas del $\mathrm{pH}$ del producto durante la fermentación con un pHmetro ALTRONIX TPX-III (Altronix ${ }^{\circledR}$, Taiwan) 
hasta alcanzar pH final de 3,0 (leche) o de 3,7 (permeado de suero). Para realizar la curva de acidificación del PS fermentado con microorganismos aislados del kefir, éstos se activaron saliendo de $-20^{\circ} \mathrm{C}$, cultivándolos mediante dos pasajes consecutivos en caldo MRS (DIFCO ${ }^{\circledR}$, Beauvais, Francia). Se inocularon $100 \mu \mathrm{l} / 5 \mathrm{ml}$ de PS estéril; se incubaron a $30^{\circ} \mathrm{C}$ y se tomaron medidas de $\mathrm{pH}$ hasta alcanzar el $\mathrm{pH}$ final de 3,7. Las curvas de acidificación se construyeron graficando $\mathrm{pH}$ vs. Tiempo.

\subsection{Obtención del producto fermentado con gránulos de kefir y con microorganismos aislados del gránulo de kefir (MK).}

Los productos fermentados se prepararon como se describió en el apartado anterior. Para los productos fermentados con gránulo de kefir, al finalizar la fermentación, los gránulos se separaron del producto fermentado empleando un colador de malla de $1 \mathrm{~mm}^{2}$. Los microorganismos presentes en los productos fermentados se precipitaron en ultracentrífuga Eppendorf 5415D (Eppendorf ${ }^{\circledR}$, Alemania), 15 minutos a 13000 rpm, descartando el pellet y congelando el sobrenadante para su posterior filtración.

4.7 Obtención del sobrenadante libre de células (SLC) a partir de los productos fermentados con gránulos de kefir y con microorganismos aislados del gránulo de kefir.

El sobrenadante se esterilizó en filtros de 0,22 $\mu \mathrm{m}$ de poro (Sigma-Aldrich ${ }^{\circledR}$, USA) y el SLC obtenido se almacenó a $-20^{\circ} \mathrm{C}$ hasta la realización de los ensayos de actividad antifúngica.

\subsection{Análisis por HPLC de los ácidos láctico y acético en los SLC y en los alimentos adicionados de productos fermentados.}

La concentración de ácido láctico y ácido acético se determinó en el SLC del producto fermentado. Para determinar los ácidos de los alimentos adicionados 
de producto fermentado, se diluyó $1 / 10$ el alimento en agua bidestilada, se homogenizó en stomacher (Laboratory Blender Stomacher $400^{\circledR}$, Inglaterra) y se filtró con filtros de 0,22 $\mu \mathrm{m}$ (Sigma-Aldrich ${ }^{\circledR}$, USA). Los SLC se analizaron por HPLC (Agilent Technologies ${ }^{\circledR}$ series 1200, Santa Clara CA, USA), columna de intercambio iónico Aminex HPX-87H (Bio-Rad ${ }^{\circledR}$, Hercules, USA). Se empleó fase móvil $\mathrm{H}_{2} \mathrm{SO}_{4}$ 0,009N (Merck ${ }^{\circledR}$, Darmstadt, Alemania) a un caudal de 0,6 $\mathrm{ml} / \mathrm{min}$, con detector ultravioleta a longitud de onda de $214 \mathrm{~nm}$ (Garrote, 1999). Se hicieron curvas patrón de ácido acético (Merck ${ }^{\circledR}$, Darmstadt, Alemania) de 25, 50, 100, 200, 700 y 1500 ppm y de ácido láctico (Carlo Erba ${ }^{\circledR}$, Milán, Italia) de $500,1000,4000,8000,10.000$ y 14.000 ppm.

\subsection{Preparación de los SLC acidificados artificialmente con ácidos orgánicos puros y con $\mathrm{HCl}$.}

Para acidificar artificialmente la leche, los ácidos orgánicos se prepararon en dos solventes: agua destilada estéril y leche UHT (Sancor ${ }^{\circledR}$, Argentina), con base en las concentraciones determinadas en esta tesis en leche fermentada con gránulos CIDCA AGK1 y AGK2. Las soluciones de ácidos en agua se prepararon con las siguientes concentraciones determinadas a diferentes valores de $\mathrm{pH}$.

\begin{tabular}{|c|c|c|}
\hline pH mezcla & Ácido Láctico (AGK1) (\%) & Ácido Acético (AGK1) (\%) \\
\hline 4,5 & 0,407 & 0,03 \\
\hline 3,5 & 1,947 & 0,044 \\
\hline 3,3 & 1,076 & 0,065 \\
\hline
\end{tabular}

Tabla 4.1 Soluciones de ácidos en agua según las concentraciones determinadas en sobrenadantes obtenidos con gránulos CIDCA AGK1 y AGK2.

Las soluciones de ácidos orgánicos se hicieron agregando a la leche los ácidos en las concentraciones determinadas en leche fermentada con gránulos de kefir CIDCA AGK1 y AGK2 y se obtuvieron los SLC con las concentraciones indicadas en la tabla siguiente. 


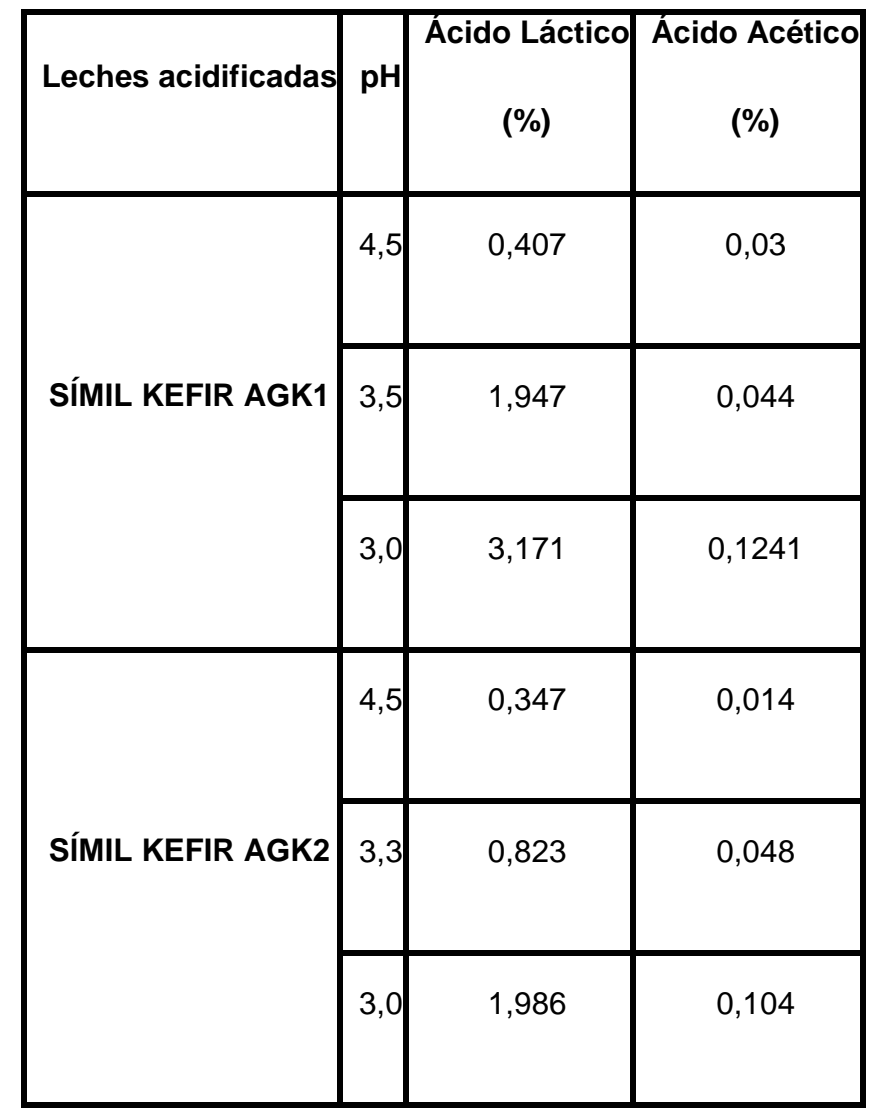

Tabla 4.2 Soluciones de ácidos orgánicos preparados en leche según las concentraciones determinadas en sobrenadantes obtenidos con gránulos CIDCA AGK1 y AGK2.

La acidificación con ácidos fuertes se hizo con HCl 3 M (Merck $^{\circledR}$, Darmstadt, Alemania) y se acidificó leche UHT (Sancor ${ }^{\circledR}$, Argentina) hasta valores de $\mathrm{pH}$ de $4,5,3,5,3,3$ y 3,0 .

Se acidificó el permeado de suero (PS) (ILOLAY ${ }^{\circledR}$, Santa Fé, Argentina) con ácido láctico y acético, según las concentraciones determinadas en esta tesis por HPLC en permeado de suero fermentado con gránulo CIDCA AGK1 (PSFG). Se adicionó $0,74 \%$ v/v de acido láctico (Carlo Erba ${ }^{\circledR}$, Milán, Italia) y $0,29 \%$ v/v de ácido acético (Merck ${ }^{\circledR}$, Darmstadt, Alemania) y se ajustó el pH a 3,7 con $\mathrm{HCl} 3 \mathrm{M}$ (Merck ${ }^{\circledR}$, Darmstadt, Alemania). La acidificación con ácido fuerte se hizo con $\mathrm{HCl} 3 \mathrm{M}$ (Merck ${ }^{\circledR}$, Darmstadt, Alemania) hasta pH 3,7. El PS adicionado con ácidos orgánicos y con $\mathrm{HCl}$ se centrifugó y esterilizó por filtración. Todos los SLC estériles obtenidos se almacenaron a $-20 \stackrel{\circ}{C}$ hasta su posterior empleo para determinar su potencial antifúngico. 


\subsection{Ensayos de inhibición de Crecimiento Fúngico.}

\subsubsection{Método de difusión en agar.}

Los ensayos se realizaron en placas de Petri conteniendo el medio de cultivo Malta (Anexo 1), el cual se autoclavó a $121^{\circ} \mathrm{C}$ durante $15 \mathrm{~min}$, se enfró a $45^{\circ} \mathrm{C}$ y se mezcló con la sustancia a evaluar como inhibidor del crecimiento fúngico (ácidos orgánicos puros o SLC obtenidos con leche o PSFG) en diferentes concentraciones. La mezcla medio-sustancia antifúngica se sirvió en placas de Petri (80 mm de diámetro) y se dejó solidificar. El pH final del medio se determinó con un microprocesador Hannah pH 211 pHmetro. Se consideró como medio control al medio malta sin ácidos agregados.

Un recuento de $10^{3}$ conidios totales se inoculó en el centro de cada placa. Dado que los hongos filamentosos crecen en medios sólidos en forma de colonias circulares alrededor de la zona inicial de inoculación, se realizaron mediciones de los diámetros de colonias en forma diaria. Estas se realizaron colocando las placas de Petri sobre una escala milimétrica iluminada desde abajo por una luz. Se hicieron cuatro medidas de diámetro y los resultados se expresaron como el valor medio del diámetro de las colonias (Horner \& Anagnostopoulos, 1973). Se graficó el diámetro de las colonias en función del tiempo de incubación del hongo.

\subsubsection{Determinación de las pendientes de crecimiento $K_{D}(\mathrm{~mm} / \mathrm{h})$} y del tiempo de duración de la fase Lag (h).

A partir de las mediciones realizadas, se obtuvieron las curvas de crecimiento de diámetro vs. tiempo. La tasa de crecimiento $\mathrm{K}_{\mathrm{D}}(\mathrm{mm} / \mathrm{h})$, se calculó a partir de la pendiente de la regresión lineal correspondiente al crecimiento de las colonias utilizando el programa Sigma Plot 9.0. 
La fase de latencia corresponde al tiempo en horas necesario para que la colonia crezca más allá del la zona del inóculo inicial (normalmente entre 5 y 7 mm) (Catadores, Oomes \& Brulm, 1997; Molina \& Giannuzzi, 1999). El tiempo de duración de la fase de latencia Lag (h) se calculó con la ecuación 4.1.

$\operatorname{Lag}(\mathrm{h})=\left(\Phi-Y_{0}\right) / \mathrm{K}_{\mathrm{D}}$

Ecuación 4.1

Donde:

$\Phi=$ Diámetro de inóculo inicial

$Y_{0}=$ Punto de corte de la recta de la regresión lineal en el eje $Y$

$\mathrm{K}_{\mathrm{D}}=$ pendiente de la recta de la regresión lineal del crecimiento fúngico (tasa de crecimiento) (Molina \& Giannuzzi, 1999).

\subsubsection{Determinación del Índice de Inhibición de $\mathrm{K}_{\mathrm{D}}\left(\mathrm{II} \mathrm{K}_{\mathrm{D}} \%\right)$ y del} Índice de Incremento de la fase Lag (IILag \%).

Los índices de inhibición de la tasa de crecimiento $\mathrm{IIK}_{\mathrm{D}}(\%)$ y de incremento de la fase de latencia, IILag (\%) se calcularon relacionando el valor obtenido con el tratamiento con aquel correspondiente al control, según las ecuaciones 4.2 y 4.3 (Molina \& Giannuzzi, 1999).

IIK $\mathrm{K}_{\mathrm{D}}=\left\{\left(\mathrm{K}_{\text {Dcontrol }}-\mathrm{K}_{\mathrm{DT \text {ratamiento }}}\right) / \mathrm{K}_{\text {Dcontrol }}\right\} \times 100$

Ecuación 4.2

Donde:

$\mathrm{K}_{\text {Dcontrol }}=$ Tasa de crecimiento del control

$\mathrm{K}_{\mathrm{DT} \text { ratamiento }}=$ Tasa de crecimiento de cada tratamiento

IILag $=\left\{\left(\operatorname{Lag}_{\text {Tratamiento }}-\operatorname{Lag}_{\text {control }}\right) / \operatorname{Lag}_{\text {control }}\right\} \times 100$

Ecuación 4.3

Donde:

Lag $_{\text {control }}=$ Tiempo de la fase lag del control

$\operatorname{Lag}_{\text {Tratamiento }}=$ Tiempo de la fase Lag de cada tratamiento 


\subsection{Determinación del porcentaje de reducción de la germinación de conidios (\%RG).}

Se estudió la capacidad para reducir la germinación de los conidios, por los sobrenadantes libres de células (SLC) de PS fermentado con gránulos o con microorganismos aislados del gránulo de kefir, según la técnica de reducción de la germinación de los conidios en placas estériles de microdilución (96 fosas) (Brand ${ }^{\circledR}$, Wertheim, Alemania) (Gerez, Rollán, Torino \& Font de Valdéz, 2009; Lavermicocca, Valerio, Evidente, Lazaroni, Corsetti \& Gobbetti, 2000). Se agregaron $10 \mu \mathrm{l}$ de una suspensión con $10^{4}$ conidios $/ \mathrm{ml}$ de cada hongo a fosas con $190 \mu \mathrm{l}$ del SLC del producto fermentado a evaluar. El control positivo consistió en SLC de PS sin fermentar que fue centrifugado y esterilizado por microfiltración al igual que los SLC provenientes de las fermentaciones.

Una vez inoculado cada tratamiento, se incubaron las placas a $30^{\circ} \mathrm{C}$ por $48 \mathrm{~h}$. Se leyó la DO de los tratamientos en un lector de microplacas RT-2100C (Pioway, Nanjing, China) a una longitud de onda de $580 \mathrm{~nm}$. La actividad antifúngica de los SLC fue expresada como el porcentaje de reducción de la germinación (\%RG) medido a una $\mathrm{DO}_{580}$ comparado con el control, mediante la fórmula:

$\% R G=\left[\left(\mathrm{DO}_{\mathrm{cp}}-\mathrm{DO}_{\mathrm{tto}}\right) / \mathrm{DO}_{\mathrm{cp}}\right] \times 100$

Ecuación 4.4

Donde:

$\mathrm{DO}_{\mathrm{cp}}$ : Densidad óptica del control positivo

$\mathrm{DO}_{\mathrm{tto}}$ : Densidad óptica del tratamiento

Una reducción de la germinación de los conidios mayor al $20 \%$ se consideró positiva, la reducción fue baja entre 20 y $40 \%$, media entre el $40 \%$ y $70 \%$ y fuerte por encima al 70\% (Gerez, Rollán, Torino \& Font de Valdés, 2009). Los ensayos fueron realizados por cuadruplicado, y se hicieron tres repeticiones de cada experimento. 


\subsection{Cálculo de la concentración de ácidos orgánicos no disociados.}

La concentración de los ácidos no disociados se hizo con la siguiente ecuación. $\left.H A=\frac{a \underline{\overline{\times}} H^{+}}{H^{+}+K_{a}}\right\}$ Ecuación 4.5

[HA]: concentración total de ácido no disociado (mM)

[Ca]: concentración total de ácido en el medio de cultivo (mM)

$\left[\mathrm{H}^{+}\right]$: concentración protones

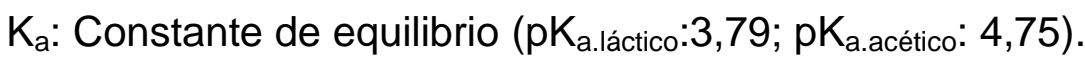

\subsection{Determinación de la estabilidad del alimento adicionado de leche o permeado de suero fermentado con gránulos de kefir CIDCA AGK1 (PSFG).}

La arepa (capítulos 5 y 6.1) se hizo cocinando maíz durante dos horas en agua abundante. A continuación se molió en un molino de cizalla manual y se obtuvo una masa. La masa se adicionó de ácidos láctico y acéticos puros (capítulo 5) 0 de leche fermentada con gránulos de kefir CIDCA AGK1 (capítulo 6.1). Las arepas se armaron como discos de aproximadamente $8 \mathrm{~cm}$ de diámetro y 8 $\mathrm{mm}$ de espesor y se asaron en horno de gas, (Segesa ${ }^{\circledR}$, Argentina), 15 minutos por cada lado, a $140 \stackrel{\circ}{\circ}$. Éstas se enfriaron a temperatura ambiente por 90 minutos, se empacaron en bolsas de polietileno selladas y se almacenaron a 14ํㅡ. El pH final de las arepas se midió en un pHmetro Hannah pH 211 Microprocessor.

El alimento de pollo (capítulo 6.2) se adicionó con permeado de suero fermentado con gránulo CIDCA AGK1 (PSFG). Con el fin de conocer la estabilidad del alimento adicionado del producto fermentado con gránulos de kefir, se hicieron las siguientes determinaciones durante el almacenamiento para las arepas y para el alimento de pollos. 
4.13.1 Supervivencia de las BAL y LEV provenientes de leche fermentada con gránulos de kefir o del PSFG adicionado al alimento.

Se realizaron recuentos de la leche fermentada y del PSFG antes de ser adicionados al alimento y del alimento una vez elaborado. Se homogenizaron en un stomacher, $10 \mathrm{ml}$ del producto fermentado o $10 \mathrm{~g}$ del alimento (con kefir de leche o PSFG) en $90 \mathrm{ml}$ de agua de peptona al 0,1\% (mas glicerol al 20\% en el alimento de pollos) y se hicieron diluciones seriadas 1/10. Se sembraron tres diluciones sucesivas por duplicado, inoculando $100 \mu \mathrm{L}$ de la dilución correspondiente en la superficie del agar, distribuyéndolos con perlas de vidrio estériles. Para el recuento de BAL se empleó medio MRS (Difco ${ }^{\circledR}$, Beauvais, Francia) e YGC, Extracto de levadura, glucosa, cloramfenicol, (Merck ${ }^{\circledR}$,

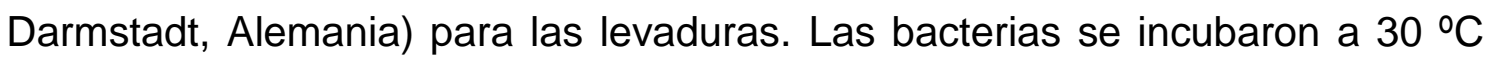
durante $48 \mathrm{~h}$ y las levaduras por 5 días. Se cuantificaron las unidades formadoras de colonia (UFC/ml o UFC/g) (Magalhães, Pereira, Dias \& Schwan, 2010). Los experimentos se realizaron por triplicado.

4.13.2 Determinación de $\mathrm{pH}$ y de la concentración de ácidos orgánicos.

De los productos fermentados se tomaron $5 \mathrm{ml}$ y se midió el $\mathrm{pH}$. Se homogenizaron $5 \mathrm{~g}$ del alimento en $45 \mathrm{ml}$ de agua destilada estéril, se ultracentrifugaron y filtraron con filtros de 0,22 $\mu \mathrm{m}$. Se midió el $\mathrm{pH}$ en un pHmetro ALTRONIX TPX-III. Los ácidos presentes en los SLC se determinaron mediante HPLC según la técnica descripta en 4.8 .

\subsubsection{Determinación de la presencia de aflatoxinas en el alimento.}

$25 \mathrm{gr}$ de muestra se diluyeron en $250 \mathrm{ml}$ de una solución metanol:agua destilada 70\%:30\%, agitando con perlas en vortex por 5 minutos y a $120 \mathrm{rpm}$ por 30 minutos. Se filtró en papel de filtro Whatman y en filtro estéril de 0,22 $\mu \mathrm{m}$. La concentración de aflatoxinas se determinó mediante cromatografía 
líquida de alta definición usando columna aminex C-18, en un equipo JENCK S.A Instrumental, CBM-20A, SPD-M20A, LC20AT, DGUD60-20As. Se empleó un rango constante de escaneo 190-800 nm, longitud de onda de $360 \mathrm{~nm}$ y flujo de corrida de $1 \mathrm{ml} / \mathrm{min}$ de la mezcla agua:acetonitrilo:metanol (60\%:30\%:10\%). El tiempo de corrida y de retención de AFB1 fueron 7 y 4,33 minutos. El volumen de inyección fueron $20 \mu \mathrm{l}$. Se empleó un patrón de aflatoxina AFB1 de 2,08 ppm (BIOPURE ${ }^{\circledR}$ ). El límite de cuantificación fue de 25 ppb y el límite de detección de 10 ppb.

\subsubsection{Estudio de la resistencia del alimento adicionado a la} contaminación natural.

Los alimentos se homogenizaron y se hicieron diluciones seriadas $1 / 10$ como se describió en 4.13.1, sembrando en medio Diclorán Rosa de Bengala, Cloramfenicol (DRBC) $\left(\right.$ BIOKAR $^{\circledR}$, Oise, Francia). Las placas se incubaron a $20^{\circ} \mathrm{C}$ por 5 días y los recuentos se expresaron como UFC/g de alimento.

\subsubsection{Estudio de la resistencia del alimento adicionado a la contaminación artificial.}

Los alimentos (pollos y arepas) adicionados ya fuera con ácidos orgánicos puros, kefir de leche o PSFG, se contaminaron pulverizando cada 100 gramos con $1 \mathrm{ml}$ de solución de $1 \times 10^{4}$ conidios $/ \mathrm{ml}$. El control se hizo adicionando agua destilada estéril en la misma proporción. En el caso de las arepas, una vez contaminadas, se dejaron secar y se almacenaron en bolsas de polietileno selladas a $14^{\circ} \mathrm{C}$ (y a $20^{\circ} \mathrm{C}$ en el caso de las adicionadas de ácidos orgánicos puros). El alimento para pollos contaminado se almacenó en cajas de Petri a $20^{\circ} \mathrm{C}$.

Las bolsas de arepas y las cajas de alimento para pollos se observaron diariamente y se compararon los días necesarios para que se diera la aparición visible del hongo en los diversos tratamientos y en el control. 


\section{RESULTADOS Y DISCUSIÓN}

Los resultados de esta investigación se presentan en varios capítulos. En los primeros se desarrollan todos los experimentos de inhibición del crecimiento fúngico. Estos fueron realizados con ácidos puros, con leche fermentada con kefir (gránulos CIDCA AGK1 y AGK2), ambos aplicados en la vida útil de la arepa de maíz. Otro capítulo se realizó con permeado de suero fermentado con kefir (gránulos y microorganismos aislados) aplicado para adicionar al alimento para pollos. En el último capítulo se estudió la capacidad de secuestrar aflatoxina AFB1 por parte del conjunto de microorganismos del gránulo de kefir y por los microorganismos aislados. 


$$
\begin{aligned}
& \text { CAPÍTULO 5: } \\
& \text { INHIBICIÓN DEL } \\
& \text { CRECIMIENTO } \\
& \text { FÚNGICO CON ÁCIDOS } \\
& \text { PUROS Y ÁPLICACIÓN } \\
& \text { DE LOS ÁCIDOS EN LA } \\
& \text { PRESERVACIÓN DE LA } \\
& \text { AREPA }
\end{aligned}
$$




\section{INHIBICIÓN DEL CRECIMIENTO FÚNGICO CON ÁCIDOS PUROS Y APLICACIÓN DE LOS ÁCIDOS EN LA PRESERVACIÓN DE LA AREPA.}

\subsection{Introducción}

La contaminación fúngica de alimentos por Aspergillus flavus y A. parasiticus causa enormes pérdidas de alimentos, especialmente en cereales y en las zonas tropicales, donde la temperatura y la humedad favorecen su desarrollo (Klich \& Pitt, 1988; Pitt \& Hocking, 1997). Asimismo, los problemas de contaminación son frecuentes en las plantas de procesamiento de alimentos, donde las esporas de hongos presentes en la materia prima de los alimentos son difíciles de erradicar del medio ambiente. A pesar de que los hongos pueden ser destruidos durante el proceso de cocción, la contaminación surge de las esporas de mohos provenientes de la atmósfera y de las superficies, durante los procesos de enfriamiento, acabado y envasado (Seiler, 1988). La temperatura y la humedad en el entorno del ambiente donde se lleva a cabo el procesamiento de los alimentos pueden causar la prevalencia de hongos y su contaminación.

Además de las pérdidas económicas derivadas de la presencia de hongos filamentosos, otro motivo de preocupación es la posible producción de micotoxinas como las aflatoxinas AFB1, AFG1 y AFM1 las cuales son reconocidas como carcinógenos humanos y se clasifican dentro del Grupo 1. Adicionalmente, las aflatoxinas M1 y B2 pertenecen al Grupo 2B denominados así por ser probables carcinógenos humanos 2B (IARC, 1993).

Con frecuencia, debido al clima cálido y la humedad relativa del ambiente, muchos cereales de consumo masivo pueden ser atacados por hongos filamentosos, principalmente de los géneros Fusarium, Aspergillus y Penicilium, los cuales sintetizan micotoxinas, siendo de relevancia toxicológica la aflatoxina AFB1, producida por A. flavus. Entre los cereales el maíz resulta de importancia por su alto consumo en el mundo. 

APLICACIÓN DE LOS ÁCIDOS EN LA PRESERVACIÓN DE LA AREPA.

En Colombia, los cultivos de maíz son atacados con frecuencia por hongos oportunistas, debido a factores como el fenotipo de los híbridos, los cuales tienen hojas que no los cubren completamente, dejando un espacio para que polillas como el "cogollero del maíz", muerdan el grano y abran una vía de entrada a las esporas de hongos presentes en el ambiente que terminan invadiendo el fruto (Mendivelso, 2006). El maíz contaminado se comercializa en la industria de alimentos y de concentrados de suministro animal, pasando así las aflatoxinas como la B1 al hombre y aves, cerdos y vacas. Adicionalmente, se ha determinado la presencia de aflatoxinas en el $100 \%$ de muestras evaluadas de productos derivados del maíz en el Departamento de Antioquia - Colombia (Martínez \& Arcila, 2006). También se ha demostrado la prevalencia de aflatoxinas en arroz y derivados, semillas de leguminosas y "snacks" (Díaz, Perilla \& Rojas, 2001). Los cereales y leguminosas constituyen la materia prima de alimentos que son consumidos acompañando casi todas las comidas como es la arepa de maíz.

Según la Norma Técnica Colombiana NTC 5372 de 2005, la arepa se define como un producto para consumo obtenido a partir de la masa de maíz blanca, amarilla o mezcla de ambas previamente cocida, mezclada con otros ingredientes como sal, queso, entre otros, la cual debe ser almacenada en refrigeración de $4{ }^{\circ} \mathrm{C}$ a $10{ }^{\circ} \mathrm{C}$. En Colombia se clasifica según la forma de cocción y de acuerdo con su composición. Las arepas hechas con base en maíz deben ser fabricadas con masa de maíz y libres de contaminación física, química y biológica. En Antioquia, el consumo de arepa de maíz forma parte de los hábitos alimentarios, es utilizada en comidas principales y algunas secundarias. Debido a diferentes aspectos socioeconómicos y culturales, han aumentado las empresas productoras de arepas de diferente complejidad tecnológica y volumen de producción (Martínez \& Arcila, 2006). Este producto elaborado con maíz cocido, molido, amasado, moldeado y asado, de forma redonda, acompaña casi todos los alimentos siendo considerado componente fundamental de la dieta diaria y es un marcador de los hábitos alimentarios de los hogares de las zonas rurales y urbanas del Departamento de Antioquia (De Peña, 2000; Pereirą \& Bernal, 2001; Vasco \& Giraldo, 1995). 
Se han estudiado las tendencias de consumo de la arepa de maíz por la población de Medellín. En 335 hogares de la ciudad el perfil alimentario y nutricional arrojó que el 90,1\% de los encuestados incluían la arepa de maíz en la alimentación diaria y que el consumo per cápita familia/día era de 75 a 80 gramos de arepa (Álvarez, Benjumea, Roldan, Martínez, Maya \& Montoya, 2004). Se investigó el consumo de alimentos y su frecuencia entre 167 alumnos de dos colegios de la misma ciudad, demostrando que la arepa se consume al desayuno, al almuerzo y la comida en un $47 \%, 5,4 \%$ y $32,3 \%$ respectivamente. El 7,2\% del grupo entrevistado consumía la arepa también en la merienda (Restrepo, 2004). También están en las comidas principales, el arroz, el café, la leche y los derivados lácteos, lo cual permite afirmar que existe una exposición continua a las aflatoxinas, factor de riesgo asociado al cáncer hepático.

La descripción de la arepa según la FAO, se relaciona en la tabla 5.1

Tabla 5.1. Composición de la arepa según la FAO

\begin{tabular}{|c|c|}
\hline \multicolumn{2}{|c|}{ Descripción de alimento código: $\mathbf{A 0 2 7}$} \\
\hline País de origen: & Colombia \\
\hline Genérico: & Arepa \\
\hline Tipo: & de maíz blanco trillado \\
\hline Cepa: & plana delgada \\
\hline Género: & Zea \\
\hline
\end{tabular}

La norma técnica del Instituto Colombiano de Normas Técnicas y Certificación ICONTEC estableció un máximo recuento de $10^{3} \mathrm{UFC} / \mathrm{ml}$ de hongos y levaduras en arepas (ICONTEC, 2007), el cual se busca reducir y mantener durante mayor tiempo en las arepas que se adicionarán con ácidos puros. También se establecieron requisitos fisicoquímicos tanto para masas como arepas cocidas y almacenadas en refrigeración, tal como se indica en las tablas 5.2 y 5.3 . 
Tabla 5.2 Requisitos fisicoquímicos para masas utilizadas en la preparación de arepas de maíz refrigeradas.

\begin{tabular}{|l|c|c|}
\hline \multicolumn{1}{|c|}{ Requisito } & \multicolumn{2}{|c|}{ Valores } \\
\hline & Mínimo & Máximo \\
\hline $\begin{array}{l}\text { Humedad en fracción de masa en base seca, en } \\
\text { porcentaje }\end{array}$ & 62 & 73 \\
\hline $\mathrm{pH}$. & 5 & 6,5 \\
\hline Aflatoxinas $(\mu \mathrm{g} / \mathrm{kg})$ & - & 10 \\
\hline
\end{tabular}

Tabla 5.3 Requisitos fisicoquímicos para arepas de maíz refrigeradas.

\begin{tabular}{|l|c|c|c|c|c|c|}
\hline Requisito & \multicolumn{2}{|c|}{$\begin{array}{c}\text { Arepas sencillas } \\
\text { (blancas, amarillas o } \\
\text { mezcla de ambas tipo } \\
\text { antioqueñas e } \\
\text { integrales) }\end{array}$} & $\begin{array}{c}\text { Arepas con queso en } \\
\text { la masa (con } \\
\text { margarina y/o } \\
\text { mantequilla) }\end{array}$ & $\begin{array}{c}\text { Arepas rellenas } \\
\text { de queso (con } \\
\text { margarina y/o } \\
\text { mantequilla) }\end{array}$ \\
\hline & Mínimo & Máximo & Mínimo & Máximo & Mínimo & Máximo \\
\hline $\begin{array}{l}\text { Proteína en fracción de masa } \\
\text { en base seca, en porcentaje }\end{array}$ & 3,2 & - & 5 & - & 8 & - \\
\hline $\begin{array}{l}\text { Humedad en fracción de masa } \\
\text { en base seca, en porcentaje }\end{array}$ & 55 & 68 & 42 & 65 & 55 & 65 \\
\hline Aflatoxinas $(\mu \mathrm{\mu g} / \mathrm{kg}$ ) & - & 10 & - & 10 & - & 10 \\
\hline * El factor de conversión para determinar el porcentaje de proteína es de 6,25 para cualquier tipo \\
de arepa.
\end{tabular}

La presencia de aflatoxinas se ha detectado en arepas elaboradas tanto a nivel artesanal como por la industria (Martínez, Arcila \& Laverde, 2006). La humedad relativa y la temperatura en la planta de procesamiento son los principales factores que favorecen el desarrollo de hongos en el procesamiento y envasado de la Arepa (Martínez \& Arcila, 2006). Este producto presenta un requisito microbiológico máximo de $10^{3}$ UFC/g de mohos y levaduras (ICONTEC, 2005). La humedad máxima del grano durante el almacenamiento debe ser de 15,5\%, lo cual reduce el crecimiento de hongos y detiene el metabolismo de grano. Esto permite una reducción de la temperatura y la concentración de $\mathrm{CO}_{2}$ en el silo de almacenamiento de maíz (Charley, 1991; Malagut, 2006).

El concepto de obstáculo o métodos combinados de conservación se ha empleado para evitar la contaminación fúngica (Gould, 1995). Bajo este concepto se incluyen factores tales como el calor, el frío, la actividad acuosa, $\mathrm{pH}$, el potencial oxido-reducción y la adición de conservantes que dificultan el desarrollo natural de los microorganismos. Estas técnicas de conservación permiten aumentar la estabilidad de los alimentos, manteniendo sus 
5 INHIBICIÓN DEL CRECIMIENTO FÚNGICO CON ÁCIDOS PUROS Y APLICACIÓN DE LOS ÁCIDOS EN LA PRESERVACIÓN DE LA AREPA.

características de calidad muy parecidas al alimento original. Entre éstas, los ácidos orgánicos que se encuentran naturalmente en los alimentos constituyen métodos seguros de preservación de alimentos. Los ácidos más utilizados son el acético, ascórbico, láctico y propiónico, entre otros (Davidson, 2005). En este sentido, Molina \& Giannuzzi (1999) demostraron que la adición de un ácido débil como el ácido propiónico en el medio de cultivo permite modificar de forma significativa los parámetros cinéticos de $A$. parasiticus.

Es reconocido que la actividad antifúngica óptima se produce a un $\mathrm{pH}$ cercano al $\mathrm{pK}_{\mathrm{a}}$ del ácido ya que favorece la forma no disociada, la cual atraviesa libremente a través de la membrana plasmática de los microorganismos en general y de los hongos en particular (Bogaert \& Naidu, 2000; Cramer \& prestegard, 1977). En el interior celular se disocia debido a que el $\mathrm{pH}$ interno es mayor y en esas condiciones ejerce su acción conservante debido a la acumulación de aniones y protones dentro de la célula (Brul \& Coote, 1999; Jay, 2000). Los protones liberados desestabilizan el $\mathrm{pH}$ intracelular neutro y rompen el gradiente de la membrana celular (Salmond, Kroll \& Booth, 1984). Debido al gasto de energía durante el bombeo de los protones al exterior de la membrana, se genera una disminución de la concentración de ATP necesario para el crecimiento celular y se detiene el crecimiento del hongo (Hunter \& Segel, 1973).

Adicionalmente, el efecto antifúngico puede incrementar si dos ácidos débiles se aplican en conjunto, logrando un efecto sinérgico. Sin embargo, si se producen efectos antagónicos, la eficacia de los antimicrobianos puede reducirse enormemente (Davidson \& Parish, 1989; López-Malo, Palou, Parish \& Davidson, 2005). Los ácidos láctico y acético han sido utilizados individualmente como inhibidores de hongos filamentosos, ambos son reconocidos como seguros GRAS (Generally Recognized As Safety) y su concentración máxima está limitada por los parámetros sensoriales. Estos ácidos se encuentran presentes en los alimentos fermentados y también son fáciles de obtener comercialmente. Su efecto inhibitorio se basa en la "teoría de la preservación de los ácidos débiles" que se ha descrito anteriormente (Freese, Sheu \& Galliers, 1973; Salmond, Kroll \& Booth, 1984; Stratford, Plumridge, Nebe-von-Caron \& Archer, 

APLICACIÓN DE LOS ÁCIDOS EN LA PRESERVACIÓN DE LA AREPA.

2009). Otros trabajos científicos dan cuenta sobre los efectos sinérgicos antimicrobianos entre el ácido acético y láctico (Adams \& Hall, 1988; Dickson \& Maynard, 1992; Rubin, 1978). La aplicación de estos ácidos para inhibir hongos filamentosos en un producto elaborado con base en maíz como es la arepa antioqueña, aún no ha sido estudiado. Habría que contemplar la posibilidad de que el agregado de los mismos podría conducir a cambios sensoriales en el producto.

En este capítulo se estudió la inhibición fúngica de $A$. flavus con ácidos láctico y acético puros. Se determinó la CIM de cada ácido puro y la Concentración Fraccionaria Mínima de la mezcla de ambos contra $A$. flavus. Una vez establecidos estos valores, se evaluó el efecto de su adición en la arepa antioqueña, tanto sobre su vida útil como sus propiedades sensoriales.

\subsection{Objetivos}

\subsubsection{Objetivo General}

5.2.1.1 Evaluar el efecto del ácido láctico y acético individualmente y en mezclas binarias en la inhibición de $A$. flavus mediante estudios in vitro y en un alimento a base de maíz.

\subsubsection{Objetivos específicos}

5.2.2.1 Evaluar los parámetros cinéticos (Velocidad de crecimiento y fase de latencia) de A. flavus, afectados por diferentes concentraciones de ácido acético y ácido láctico aplicados en forma individual en medios de cultivo sólidos.

5.2.2.2 Determinar la Concentración Inhibitoria Mínima (CIM) del ácido acético y del ácido láctico sobre $A$. flavus.

5.2.2.3 Relacionar las concentraciones no disociadas de ácido acético y láctico con los parámetros cinéticos (Velocidad de crecimiento y fase de latencia) de $A$. flavus. 
5.2.2.4 Evaluar la acción sinérgica, aditiva o antagónica de diversas mezclas de ácido acético y láctico sobre $A$. flavus.

5.2.2.5 Evaluar la aplicación de los ácidos en la extensión de la vida útil y en las propiedades sensoriales de la arepa antioqueña.

\subsection{Materiales y métodos.}

\subsubsection{Hongos Filamentosos.}

En este capítulo se emplearon los hongos $A$. flavus AFUNQ6, cedido por la Universidad Nacional de Quilmes (UNQUI, Argentina) y A. flavus AFUNL1, AFUNL2 y AFUNL3, cedidos por la Universidad Nacional del Litoral (UNL, Argentina). Los hongos se conservaron y activaron como se describió en materiales y métodos generales.

\subsubsection{Medios de cultivo de los hongos filamentosos.}

Los hongos se conservaron en Agar Agua $(0,2 \%)$ a $4{ }^{\circ} \mathrm{C}$, se cultivaron en Agar PDA-papa dextrosa $\left(\right.$ Merck $^{\circledR}$, Darmstadt, Alemania) y se prepararon las soluciones de conidios de acuerdo a los materiales y métodos generales.

\subsubsection{Obtención de las soluciones de conidios.}

Las soluciones de conidios empleadas en este capítulo se prepararon según materiales y métodos generales.

\subsubsection{Ensayos de Inhibición del crecimiento fúngico.}

La inhibición del crecimiento fúngico se estudió mediante el método de difusión en agar en medio malta (Anexo 1) como se describió en materiales y métodos generales. El medio de cultivo estéril se mezcló con ácido láctico (Carlo Erba ${ }^{\circledR}$, Italia) en el rango de 11,9-357,7 mM o ácido acético (Merck ${ }^{\circledR}$, Darmstadt, 
Alemania) en el rango de 13,0-41,6 mM o con mezclas de ambos ácidos. Las concentraciones de ácidos examinadas correspondieron al máximo permitido por Código Alimentario Argentino (CAA, 2006) para la cerveza de 3\% de ácido láctico y $0,5 \%$ de ácido acético. También se consideraron los niveles indicados por Davidson (2001) de ácido láctico entre 0,2 y 2,5\% para inhibir hongos filamentosos.

Los hongos filamentosos se cultivaron, diluyeron e inocularon según materiales y métodos generales. Para el control se consideró el medio de cultivo malta sin adición de ácidos. Las curvas de crecimiento, regresiones lineales y el cálculo de los parámetros cinéticos tasa de crecimiento $K_{D}(\mathrm{~mm} / \mathrm{h})$, duración de la fase de latencia Lag (h) y los índices de inhibición de la tasa de crecimiento IIK $\mathrm{K}_{\mathrm{D}}(\%)$ y de incremento de la fase de latencia, IILag (\%) se calcularon según materiales y métodos generales. En este capítulo, dado que se encontraron los mayores incrementos de fase Lag, también se determinó la siguiente relación: LagT/LagC, donde LagT y LagC corresponden a las fases de latencia obtenidas en los experimentos de crecimiento fúngico tratados con los ácidos y el control respectivamente. $I I K_{D}$ adquiere valores de $100 \%$ cuando $K_{D}$ del tratamiento es igual a 0 y el hongo permanece en la fase de latencia durante todo el tiempo de incubación. IIK $\mathrm{K}$ es 0 cuando la tasa de crecimiento de los hongos tratados y los correspondientes controles muestran el mismo ritmo de crecimiento $\left(K_{D C}=K_{D T}\right)$. IIK $K_{D}$ varía de 0 a 100\% debido a la acción conservante de los ácidos orgánicos.

\subsubsection{Cálculo de la concentración de ácidos orgánicos no disociados.}

El cálculo de la concentración de ácidos láctico y acético se realizó como se describió en Materiales y Métodos generales.

\subsubsection{Determinación de la CIM (concentración inhibitoria mínima) y CIC (concentración inhibitoria fraccionaria)}

La concentración inhibitoria mínima (CIM) de los ácidos láctico y acético aplicados en forma individual y en mezclas binarias se definió como la concentración mínima probada que inhibió el crecimiento de $A$. flavus durante 20 

APLICACIÓN DE LOS ÁCIDOS EN LA PRESERVACIÓN DE LA AREPA.

días. Las diferentes CIM halladas se transformaron en concentración inhibitoria fraccionaria (CIF), según Davidson \& Parish (1989) y López-Malo, BarretoValdivieso, Palou, \& San Martín, 2007), según las siguientes fórmulas.

$\mathrm{CIF}_{\text {láctico }}=(\mathrm{CIM}$ ácido láctico en presencia de ácido acético $) /(\mathrm{CIM}$ láctico solo $) \quad$ Ecuación 5.2

$\mathrm{CIF}_{\text {acético }}=(\mathrm{CIM}$ ácido acético en presencia de ácido láctico $) /(\mathrm{CIM}$ acético solo $)$ Ecuación 5.3

La sinergia generada por la mezcla de ácidos puede ser expresada en forma matemática por medio de la concentración inhibitoria fraccionaria CIF, que se calcula a partir de valores de CIM para cada uno de los ácidos orgánicos como sigue:

$\mathrm{CIF}_{\text {índice }=} \mathrm{ClF}_{\text {láctico }}+\mathrm{CIF}_{\text {acético }}$

Ecuación 5.4

Esta relación puede ser interpretada de la siguiente manera:

- Si la relación entre el ácido láctico y acético es aditivo, la suma de los valores de CIF en la ecuación 5.4 es 1.

- Asimismo, si la interacción entre el ácido láctico y acético es sinérgica la suma esperada de los CIF es inferior a 1.

- La relación es antagónica si la suma de las fracciones es mayor a 1 (Adams \& Hall, 1988; Dickson \& Maynard, 1992; Rubin, 1978; Berenbaum, 1977).

\subsubsection{Fabricación de la Arepa y determinación de la estabilidad del alimento adicionado de ácidos orgánicos puros (láctico y acético)}

Para determinar el efecto de los ácidos orgánicos en la vida útil de la arepa, se adicionaron las concentraciones de MIC y CIF establecidas para láctico y acético a la masa y se evaluó el tiempo de conservación.

\subsubsection{Fabricación de la Arepa}

Las arepas se fabricaron tal como se describió en Materiales y Métodos generales. Los tratamientos fueron: 

APLICACIÓN DE LOS ÁCIDOS EN LA PRESERVACIÓN DE LA AREPA.

- Adición de ácido láctico en concentración final de 357,67 mM.

- Adición de ácido acético en concentración final de 41,57 mM

- Adición de mezcla de ácido láctico 56 mM con 30 mM de ácido acético.

- Arepas control sin ácidos.

Una vez cocidas, las arepas se enfriaron a temperatura ambiente por $90 \mathrm{~min}$, se empacaron y sellaron en bolsas de polietileno y se almacenaron a $10 \stackrel{\circ}{\circ}$ y $20 \stackrel{\circ}{ } \mathrm{C}$.

Durante el almacenamiento se realizaron los recuentos fúngicos para determinar la vida útil.

\subsubsection{Determinación de la estabilidad de la arepa adicionada de ácidos orgánicos láctico y acético.}

Se hicieron las siguientes determinaciones para las arepas.

\subsection{Estudio de la resistencia de la arepa adicionada de ácidos} láctico y acético a la contaminación natural.

El estudio de los recuentos de hongos filamentosos en la arepa se hizo tal como se describió en materiales y métodos generales. Este ensayo se realizó durante con el fin de evaluar el tiempo para que el producto para obtener el nivel máximo de $10^{3}$ UFC / g permitido por la Norma Técnica Colombiana NTC 5372 (ICONTEC, 2007). La vida útil se definió como el tiempo en días en que el recuento fúngico alcanza valores de $10^{3} \mathrm{UFC} / \mathrm{g}$.

\subsection{Estudio de la resistencia de la arepa adicionada de ácidos} láctico y acético a la contaminación artificial.

Con el fin de determinar la resistencia fúngica que daban los ácidos agregados a las arepas, las arepas hechas con las soluciones de ácidos fueron contaminadas superficialmente con $A$. flavus AFUNL1, según lo descrito en materiales y métodos generales. Los tratamientos fueron los mismos descritos para la resistencia a la contaminación natural y se hizo además un grupo de arepas no contaminado con conidios. Las arepas se empacaron y sellaron en bolsas de 

APLICACIÓN DE LOS ÁCIDOS EN LA PRESERVACIÓN DE LA AREPA.

polietileno, se almacenaron a $10^{\circ} \mathrm{C}$ y $20^{\circ} \mathrm{C}$ y se observaron diariamente para determinar la aparición visible de los hongos. La resistencia a los hongos dada por los conservantes ácidos se definió como el tiempo (en días) necesarios para hacer visibles los hongos (Gerez, Torino, Rollán \& Font de Valdez, 2009).

\subsubsection{Evaluación sensorial de arepas adicionadas con ácidos láctico y acético y mezclas de ambos.}

Las arepas fabricadas con ácido acético $41,57 \mathrm{mM}$, ácido láctico $357,67 \mathrm{mM}$ y la mezcla $56 \mathrm{mM}$ láctico: acético $30 \mathrm{mM}$ fueron evaluados por 22 panelistas no entrenados en el CIDCA. Se presentaron a los evaluadores las arepas en porciones idénticas $(10 \mathrm{~g})$ numeradas mediante números de tres dígitos aleatorios. Los panelistas evaluaron apariencia, consistencia, sabor y aceptabilidad global utilizando la siguiente escala: con los puntos (0) "No me gustó nada", (5) "Tampoco me gusta o me disgusta", y (10) "Me gusta mucho "(valores de aceptación). (Auerswald, Schwarz, Kornelson, Krumbein \& Bruckner, 1999).

\subsubsection{Análisis estadístico.}

Todos los parámetros de crecimiento se analizaron con el programa SIGMAPLOT ${ }^{\circledR}$ 9.0. Los resultados de tres ensayos independientes se presentan como los valores medios y sus correspondientes desviaciones estándar (SD). Se analizaron diferencias significativas en la cinética de crecimiento mediante el análisis de varianza (ANOVA) empleando un nivel de significación $p<0,05$. Ello se realizó utilizando el programa STATGRAPHICS Plus 5,1. Todos los experimentos se realizaron por triplicado. 


\subsection{Resultados y Discusión.}

\subsubsection{Efecto del ácido láctico y ácido acético sobre el crecimiento de diferentes cepas de A. flavus en medio sólido.}

La figura 5.1 muestra algunas de las concentraciones de ácido acético y láctico ensayadas sobre el crecimiento de la cepa no toxicogénica A. flavus AFUNQ6 (a, b) y de la cepa toxicogénica $A$. flavus AFUNL2 (c y d) en función del tiempo. Debe aclararse que se estudió previamente un rango amplio de concentraciones de ácidos utilizando la cepa no toxicogénica (Tabla 5.4) con el fin de evaluar la inhibición del hongo reduciendo el riesgo de manipulación y así determinar el valor de CIM para luego evaluarlo sobre otras cepas de $A$. flavus toxicogénicas.
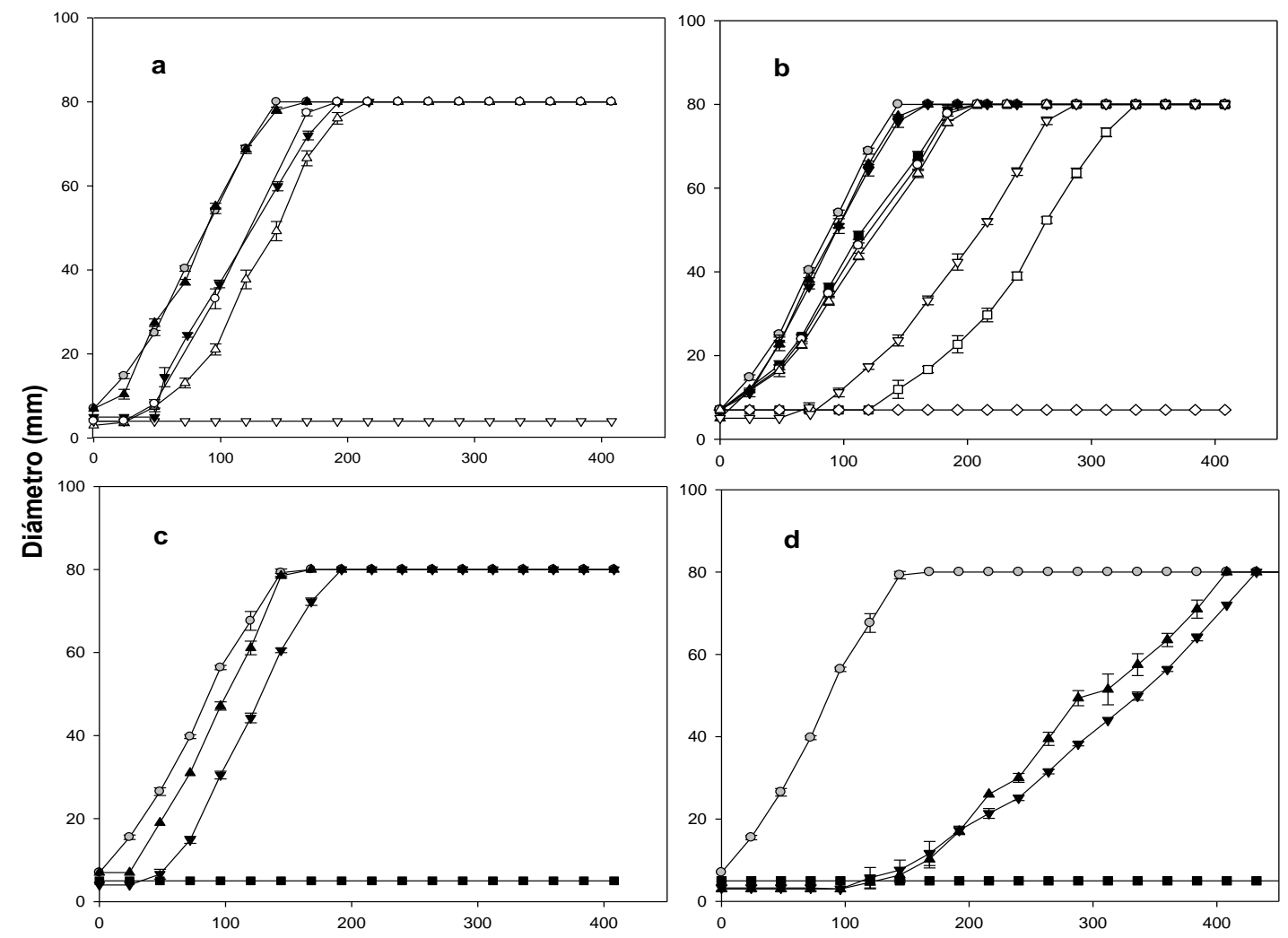

Tiempo $(h)$

Figura 5.1 Crecimiento de $A$. flavus en medios sólidos en presencia de diferentes concentraciones de ácido láctico y acético. A. flavus AFUNQ6 (a, b), A. flavus AFUNL2 (c, d): (a) Ácido acético: - control, $\Delta 13,0 \mathrm{mM}, \boldsymbol{\nabla} 31,2 \mathrm{mM}, \bigcirc 34,6 \mathrm{mM}, \triangle 38,1 \mathrm{mM}, \nabla 41,6 \mathrm{mM}$. (b) Ácido láctico: - control, $\Delta 11,9 \mathrm{mM}, \boldsymbol{\nabla} 17,9 \mathrm{mM}, \boldsymbol{\square} 47,7 \mathrm{mM}, \bigcirc 71,5 \mathrm{mM}, \triangle 95,4 \mathrm{mM}, \nabla 274,2$ $\mathrm{mM}, \square 333,8 \mathrm{mM}, \diamond 357,7 \mathrm{mM}$. (c) Ácido acético: $\bullet$ control, $\boldsymbol{\Delta} 20,8 \mathrm{mM}, \boldsymbol{\nabla} 34,6 \mathrm{mM}, \boldsymbol{\square} 38,1$ mM. (d) Ácido láctico: Control, $\triangle 238,5 \mathrm{mM}, \boldsymbol{\nabla} 262,3 \mathrm{mM}, \boldsymbol{2 7 4 , 2} \mathrm{mM}$. 

APLICACIÓN DE LOS ÁCIDOS EN LA PRESERVACIÓN DE LA AREPA.

En la curvas de crecimiento se observó inicialmente un período de latencia donde el hongo no podía superar el diámetro de inóculo inicial. Una vez superada la fase Lag, las mediciones del diámetro permitieron observar una línea recta correspondiente a la fase de crecimiento (tasa de crecimiento $K_{D}$, $\mathrm{mm} / \mathrm{h}$, que se calculará después como la pendiente de la regresión de esta línea). Pudo observarse que a medida que aumentaba la concentración del ácido, la fase de latencia aumentaba y la velocidad de crecimiento disminuía con respecto al control hasta que a cierta concentración se lograba la inhibición total del crecimiento fúngico.

El descenso progresivo en la velocidad de crecimiento y el incremento en la fase de latencia coinciden con los resultados obtenidos por Molina \& Giannuzzi (1999) donde se demostró que el aumento de la concentración de un ácido orgánico débil como el ácido propiónico en medio de cultivo, generaba diferencias significativas en el descenso de $\mathrm{K}_{D}$ y en el aumento de la fase Lag de un hongo alterador de los cereales como A. parasiticus.

En la Tabla 5.4 se presenta en detalle el efecto que ejerce el incremento en la concentración de los ácidos láctico y acético (de su concentración no disociada y del $\mathrm{pH}$ final) sobre los parámetros cinéticos $\mathrm{K}_{\mathrm{D}}(\mathrm{mm} / \mathrm{h})$ y Lag $(\mathrm{h})$. También puede visualizarse el índice de inhibición de $\mathrm{K}_{\mathrm{D}}(\%)$ y la relación Lag $_{\text {tratamiento }} / \mathrm{Lag}_{\text {control }}$ que se calcularon con los parámetros cinéticos en relación con los parámetros del control de A. flavus AFUNQ6. 
5 INHIBICIÓN DEL CRECIMIENTO FÚNGICO CON ÁCIDOS PUROS Y APLICACIÓN DE LOS ÁCIDOS EN LA PRESERVACIÓN DE LA AREPA.

verificándose el aumento de la inhibición gracias al aumento del porcentaje de ácido no disociado. En el caso del ácido acético, el 50\% de ácido no disociado se estableció en concentración 17,32 mM a pH 4,77, a la cual, al igual que con el ácido láctico, se duplicó por primera vez la fase Lag con respecto al control.

La CIM corresponde a la menor concentración de ácido a la cual el hongo no puede crecer y corresponde a una línea que no supera el diámetro de inóculo en el gráfico de crecimiento. Los valores de CIM establecidos para el ácido láctico fueron de $357,67 \mathrm{mM}$, a un $\mathrm{pH}$ de 2,74, donde casi todas las moléculas de ácido láctico existen en la forma no disociada $(91,83 \%, 328,4 \mathrm{mM})$ demostrando que es necesario un alto porcentaje de ácido no disociado y un $\mathrm{pH}$ muy ácido para inhibir $A$. flavus, lo cual puede ser desfavorable para las propiedades sensoriales de los alimentos. Por el contrario, la CIM del ácido acético se estableció en 41,57 $\mathrm{mM}$ a pH de 4,62 con sólo un $57,43 \%$ de moléculas no disociadas (23,87 mM).

La CIM del ácido acético fue casi 9 veces inferior a la concentración de ácido láctico, ya que su $\mathrm{pK}_{\mathrm{a}}(4,75)$ favorece una mayor concentración de ácido no disociado que en el ácido láctico al mismo valor de $\mathrm{pH}$. La inhibición fúngica se obtuvo con menor concentración de ácido acético, a un pH poco ácido, lo cual favoreció una mayor aceptación del producto cuando se aplicó como preservante.

La CIM de ácido láctico fue inferior al máximo permitido por el Código Alimentario Argentino (555,5 mM, 5\%) para bebidas fermentadas y cerveza (CAA, 2006); fue 1,2 veces superior a la concentración máxima de 2,5\% para inhibir hongos y bacterias determinada por Davidson (2001) y 3,3 veces superior al valor máximo de acido láctico para yogurt recomendado por el Ministerio de Salud de Colombia (Ministerio Salud de Colombia, 1989). También fue 2,23 veces superior a la concentración necesaria de $160 \mathrm{mM}$ a pH 4 para inhibir $A$. fumigatus y $A$. nidulans que son otras especies relevantes en la alteración de los alimentos (Lind, Jonsson \& Schnürer, 2005). 

APLICACIÓN DE LOS ÁCIDOS EN LA PRESERVACIÓN DE LA AREPA.

La CIM obtenida para el ácido acético fue casi la mitad del máximo de 83,3 mM $(0,5 \% \mathrm{p} / \mathrm{p})$ permitido para acido acético en bebidas fermentadas (CAA, 2006) y 3,54 veces inferior a la concentración de $120 \mathrm{mM}$ de acido acético a $\mathrm{pH} 5$ necesaria para inhibir A. fumigatus y A.nidulans (Lind, Jonsson \& Schnürer, 2005).

Una vez se establecieron los valores de la CIM de ambos ácidos para $A$. flavus AFUNQ6, se procedió a evaluar para las cepas toxicogénicas de A. flavus (AFUNL1, AFUNL2 y AFUNL3) la actividad inhibidora de los ácidos en concentraciones por encima y por debajo de la CIM de A. flavus AFUNQ6. En la tabla 5.5 se presenta el efecto de los ácidos láctico y acético sobre los parámetros cinéticos $K_{D}(\mathrm{~mm} / \mathrm{h})$ y Lag $(\mathrm{h})$ sobre las cepas toxigénicas y los índices IIK $K_{D}(\%)$ y LagT/LagC. 
Tabla 5.5 Crecimiento de A. flavus AFUNL1, AFUNL2 y AFUNL3 con ácidos orgánicos

\begin{tabular}{|c|c|c|c|c|c|c|c|c|c|c|c|c|c|c|}
\hline \multirow{2}{*}{$\begin{array}{c}\text { Ácido } \\
\text { acético } \\
\text { [mM] }\end{array}$} & \multirow{2}{*}{\begin{tabular}{|c|}
$\mathrm{pH}$ \\
del \\
medio
\end{tabular}} & \multirow{2}{*}{$\begin{array}{c}\mathrm{Uac} \\
{[\mathrm{Mm}]^{1}}\end{array}$} & \multicolumn{4}{|c|}{ A. flavus AFUNL1 } & \multicolumn{4}{|c|}{ A. flavus AFUNL2 } & \multicolumn{4}{|c|}{ A. flavus AFUNL3 } \\
\hline & & & $\begin{array}{c}\mathrm{K}_{\mathrm{D}} \\
(\mathrm{mm} / \mathrm{h})^{2} \\
\end{array}$ & $\begin{array}{l}I I K_{D} \\
(\%)^{2} \\
\end{array}$ & $\begin{array}{l}\text { Lag } \\
(\mathrm{h})^{2}\end{array}$ & $\operatorname{Lag}_{\mathrm{T}} / \mathrm{LagC}^{2}$ & $\begin{array}{c}\mathrm{K}_{\mathrm{D}} \\
(\mathrm{mm} / \mathrm{h})^{2} \\
\end{array}$ & $\begin{array}{l}I K_{D} \\
(\%)^{2} \\
\end{array}$ & $\begin{array}{l}\text { Lag } \\
(h)^{2}\end{array}$ & $\operatorname{Lag}_{\mathrm{T}} / \operatorname{LagC}^{2}$ & $\begin{array}{c}\mathrm{K}_{\mathrm{D}} \\
(\mathrm{mm} / \mathrm{h})^{2} \\
\end{array}$ & $\begin{array}{l}I K_{D} \\
(\%)^{2} \\
\end{array}$ & $\begin{array}{l}\text { Lag } \\
(\mathrm{h})^{2}\end{array}$ & $\operatorname{Lag}_{\mathrm{T}} / \mathrm{LagC}^{2}$ \\
\hline 0 & 6,34 & 0 & $0,57 \pm 0,0036$ & - & $10,30 \pm 2,29$ & - & $0,55 \pm 0,0061$ & - & $9,84 \pm 1,00$ & - & $0,59 \pm 0,0101$ & - & $20,26 \pm 1,65$ & - \\
\hline 20,78 & 4,77 & 10,16 & $0,53 \pm 0,0069$ & 7,02 & $21,34 \pm 1,49$ & 1,95 & $0,53 \pm 0,0096$ & 3,64 & $24,35 \pm 2,09$ & 2,47 & $0,58 \pm 0,0210$ & 1,69 & $32,15 \pm 2,22$ & 1,59 \\
\hline 27,71 & 4,73 & 13,86 & $0,52 \pm 0,0057$ & 8,77 & $31,62 \pm 1,24$ & 2,89 & $0,52 \pm 0,0099$ & 5,45 & $28,08 \pm 3,32$ & 2,85 & $0,57 \pm 0,0110$ & 3,38 & $45,10 \pm 3,11$ & 2,23 \\
\hline 34,64 & 4,70 & 18,32 & $0,50 \pm 0,0083$ & 12,28 & $42,72 \pm 2,15$ & 3,90 & $0,52 \pm 0,0071$ & 5,45 & $46,08 \pm 2,19$ & 4,68 & $0,51 \pm 0,0230$ & 13,56 & $54,95 \pm 4,34$ & 2,71 \\
\hline 38,10 & 4,69 & 20,37 & 0 & 100,00 & $>400,00$ & - & 0 & 100,00 & $>400,00$ & - & 0 & 100,00 & $>400,00$ & - \\
\hline \multirow{2}{*}{$\begin{array}{c}\text { Ácido } \\
\text { láctico } \\
{[\mathrm{mM}]}\end{array}$} & \multirow[t]{2}{*}{$\begin{array}{c}\mathrm{pH} \\
\text { del } \\
\text { medio }\end{array}$} & \multirow[t]{2}{*}{$\begin{array}{c}\text { Uac } \\
{[\mathrm{Mm}]^{1}}\end{array}$} & \multicolumn{4}{|c|}{ A. flavus AFUNL1 } & \multicolumn{4}{|c|}{ A. flavus AFUNL2 } & \multicolumn{4}{|c|}{ A. flavus AFUNL3 } \\
\hline & & & $\begin{array}{c}\mathrm{K}_{\mathrm{D}} \\
(\mathrm{mm} / \mathrm{h})^{2}\end{array}$ & $\begin{array}{l}I I K_{D} \\
(\%)^{2} \\
\end{array}$ & $\begin{array}{l}\text { Lag } \\
(\mathrm{h})^{2}\end{array}$ & $\operatorname{Lag}_{\mathrm{T}} / \mathrm{LagC}^{2}$ & $\begin{array}{c}\mathrm{K}_{\mathrm{D}} \\
(\mathrm{mm} / \mathrm{h})^{2} \\
\end{array}$ & $\begin{array}{l}1 \mathrm{IK} \mathrm{K}_{\mathrm{D}} \\
(\%)^{2} \\
\end{array}$ & $\begin{array}{l}\text { Lag } \\
\text { (h) }\end{array}$ & $\operatorname{Lag}_{\mathrm{T}} / \operatorname{LagC}^{2}$ & $\begin{array}{c}\mathrm{K}_{\mathrm{D}} \\
(\mathrm{mm} / \mathrm{h})^{2}\end{array}$ & $\begin{array}{l}1 \mathrm{IK} \mathrm{K}_{\mathrm{D}} \\
(\%)^{2} \\
\end{array}$ & $\begin{array}{l}\text { Lag } \\
\text { (h) }\end{array}$ & $\operatorname{Lag}_{\mathrm{T}} / \operatorname{LagC}^{2}$ \\
\hline 0 & 6,34 & & $0,57 \pm 0,0036$ & - & $10,93 \pm 2,29$ & - & $0.55 \pm 0.0061$ & - & $9.84 \pm 1.00$ & - & $0.59 \pm 0.010$ & - & $20.26 \pm 1.65$ & - \\
\hline 214,60 & 3,60 & 121,40 & $0,41 \pm 0,0062$ & 28,07 & $53,66 \pm 2,93$ & 4,90 & $0.38 \pm 0.0052$ & 30.91 & $100.32 \pm 5.34$ & 10.20 & $0.45 \pm 0.0051$ & 23.73 & $30.15 \pm 4.16$ & 1.49 \\
\hline 238,45 & 3,12 & 196,45 & $0,36 \pm 0,0057$ & 36,84 & $53,14 \pm 2,25$ & 4,86 & $0.28 \pm 0.0041$ & 49.09 & $136.89 \pm 6.41$ & 13.91 & $0.40 \pm 0.0046$ & 32.20 & $38 \pm 5.54$ & 1.88 \\
\hline 262,29 & 3,00 & 225,69 & $0,34 \pm 0,0077$ & 40,35 & $55,92 \pm 3,12$ & 5,12 & $0.23 \pm 0.0029$ & 58.18 & $179.49 \pm 6.2$ & 18.24 & $0.38 \pm 0.0050$ & 35.59 & $62.17 \pm 2.96$ & 3.07 \\
\hline 274,21 & 2,95 & 239,58 & $0,32 \pm 0,0141$ & 43,86 & $71,93 \pm 4,97$ & 6,58 & 0 & 100.00 & $>400.00^{3}$ & - & \begin{tabular}{|l|}
$0.35 \pm 0.0027$ \\
\end{tabular} & 40.68 & $67.72 \pm 1.69$ & 3.34 \\
\hline 309,98 & 2,80 & 281,20 & $0,31 \pm 0,0073$ & 45,61 & $66,96 \pm 4,81$ & 6,13 & - & - & - & - & $0.34 \pm 0.0051$ & 42.37 & $91.35 \pm 4.3$ & 4.51 \\
\hline 357,67 & 2,74 & 328,40 & $0,21 \pm 0,0061$ & 63,16 & $93,80 \pm 7,82$ & 8,58 & - & - & - & - & $0.25 \pm 0.0036$ & 57.63 & $118.13 \pm 5.53$ & 5.83 \\
\hline 381,51 & 2,69 & 353,44 & $0,19 \pm 0,0079$ & 66,67 & $140,10 \pm 7,99$ & 12,82 & - & - & - & - & $0.23 \pm 0.0030$ & 61.02 & $127.22 \pm 5.19$ & 6.28 \\
\hline 393,43 & 2,59 & 370,08 & $0,17 \pm 0,0041$ & 70,18 & $157,11 \pm 4,87$ & 14,37 & - & - & - & - & 0 & 100.00 & $>400.00^{3}$ & - \\
\hline 405,36 & 2,58 & 381,81 & 0 & 100,00 & $>400,00^{3}$ & - & - & - & - & - & - & - & - & - \\
\hline
\end{tabular}

concentración de ácidos no disociados $(\mathrm{mM})$.

${ }^{2}$ Los parámetros cinéticos son: KD (mm/h), fase Lag (h), índice de inhibición de KD: IIKD(\%) e índice Lagtratamiento/Lagcontrol: LagT/LagC.

${ }^{3}$ Máximo tiempo hasta el cual se revisaron las cajas de Petri.

${ }^{4}$ En negrita se resalta la CIM determinada para cada cepa. 

APLICACIÓN DE LOS ÁCIDOS EN LA PRESERVACIÓN DE LA AREPA.

Al igual que con $A$. flavus AFUNQ6, la inhibición del crecimiento aumentó con el incremento en la concentración de ácidos. Con casi todas las concentraciones de ácidos la fase de latencia duplicó a la correspondiente al control, hasta un máximo de 4,68 y 18,24 veces con ácido acético y láctico respectivamente.

Los valores de CIM establecidos para las cepas toxicogénicas fueron cercanos a los de la cepa no toxicogénica. Los resultados demostraron que la sensibilidad fue cepa dependiente (Stratford, Plumridge, Nebe-von-Caron \& Archer, 2009). Aún cuando la CIM del ácido acético fue igual para las tres cepas toxcogénicas (38,1 mM a pH de 4,69), los valores de CIM de ácido láctico fueron diferentes. Estos fueron 405,36 mM (pH 2,58), 274,21 mM (pH 2,95) y 393,43 mM (pH 2,59) para $A$. flavus AFUNL1, AFUNL2 y AFUNL3 respectivamente. De acuerdo a estos resultados, todas las cepas tuvieron una resistencia similar al ácido acético y la cepa más resistente al ácido láctico fue $A$. flavus AFUNL1.

También se determinó que los valores de CIM del ácido láctico resultaron ser casi diez veces superiores a los valores de CIM del ácido acético.

Respecto a la forma de acción de los ácidos orgánicos, se ha demostrado que el efecto antimicrobiano del ácido láctico se debe básicamente a dos principales mecanismos. El primero es la capacidad del ácido láctico para reducir el pH del medio y el comportamiento lipofílico de la forma protonizada (no disociada) que facilita su penetración a través de la pared de la célula (Freese, Sheu \& Galliers, 1973; Hunter, 1973; Salmond, 1984); el segundo es el efecto de los lactatos (principalmente lactato de sodio) que ejercen acción sobre la actividad de agua en alimentos con humedad intermedia (Debevere, 1989; Loncin, 1975). En esta tesis se ha considerado el primer mecanismo, dado el uso del ácido láctico y no de sus sales.

La mayoría de los microorganismos son susceptibles a los efectos antimicrobianos en presencia de ácidos orgánicos y tal inhibición aumenta por la reducción del pH del medio de cultivo (Conner, Scott \& Bernard, 1990; Farber, Sanders, Dunfield \& Prescott, 1989; Ita \& Hutkins, 1991). Este fenómeno es 

APLICACIÓN DE LOS ÁCIDOS EN LA PRESERVACIÓN DE LA AREPA.

debido a la propiedad hidrofóbica de los ácidos orgánicos, lo que permite la difusión libre de la forma protonizada a través de la membrana celular. Este proceso de difusión se lleva a cabo espontáneamente debido a los gradientes de $\mathrm{pH}$ y osmolaridad que existen entre los lados interior y exterior de la célula. Generalmente, el pH intracelular es mayor que el extracelular, y el ácido experimenta disociación tan pronto como entra en el citoplasma celular y luego disminuye el pH intracelular mediante la liberación del protón. Para contrarrestar la disminución del pH citoplásmico celular, dando como resultado la ionización del ácido introducido, la célula invierte la principal parte de su contenido de energía para eliminar estos protones recién formados lo que resulta en la cinética de crecimiento más lento (Cassio, Leao \& Van Uden, 1987; Ten Brink \& Konings, 1980; Ten Brink, Otto, Hansen \& Konings, 1985).

La ionización de un ácido orgánico en el citoplasma ocurre de forma inmediata y es sistemáticamente equilibrada por la exportación de un protón bajo el impulso de la fuerza promotora la cual se establece a nivel de la membrana celular. Cuando este sistema es continuamente activado, el sistema de regeneración de ATP se ve afectado como en el transporte activo de nutrientes en la célula (Sheu, Salomon, Simmons, Sreevalsan \& Freese, 1975).

Otras funciones celulares, además del metabolismo de la energía, también se ven afectadas. Se demostró que la ocurrencia de perturbaciones en el transporte transmembrana de aminoácidos y que algunos cambios estructurales de las proteínas, ácidos nucleicos, fosfolípidos y las perturbaciones en el sistema enzimático también pueden deberse al bombeo de protones contragradiente que ocurre en la célula fúngica (Freese, Sheu \& Galliers, 1973; Eklund, 1980; Hunter, 1973).

Considerando que el efecto antimicrobiano se debe fundamentalmente a la fracción no disociada, el análisis de la efectividad de los ácidos se realizó considerando el efecto de la concentración sin disociar sobre el desarrollo fúngico, situación que se ha presentado en este apartado y se desarrollará gráficamente a continuación. 
5 INHIBICIÓN DEL CRECIMIENTO FÚNGICO CON ÁCIDOS PUROS Y APLICACIÓN DE LOS ÁCIDOS EN LA PRESERVACIÓN DE LA AREPA.

\subsubsection{Efecto de la concentración de ácido no disociado sobre el crecimiento de diferentes cepas de $A$. flavus.}

El efecto antimicrobiano de los ácidos orgánicos es causado principalmente por la acción de la fracción no disociada del ácido en lugar de los iones hidrógeno. Esto es debido al aumento de la parte no disociada del ácido débil que al estar presente en forma no cargada presenta una mayor capacidad de penetrar las células que los productos de disociación (Giannuzzi, Contreras \& Zaritzky, 1999). La concentración de los ácidos débiles no disociados tales como el ácido láctico o acético (monopróticos), se calcularon mediante la ecuación 4.5, descripta en materiales y métodos generales.

Respecto a los resultados encontrados en el punto anterior, el valor de CIM del ácido láctico para la cepa no toxicogénica fue $357,70 \mathrm{mM}$. Al pH 2,74, correspondiente a la CIM del acido láctico, casi todas las moléculas del ácido existen en la forma no disociada $(91,8 \%)$, siendo la concentración de láctico sin disociar de 328,4 (mM). Esto implica que se necesita una gran proporción de ácido láctico no disociado y un valor de $\mathrm{pH}$ muy ácido para inhibir $A$. flavus, lo cual puede ser desfavorable para su aplicación en alimentos alimenticios debido a las alteraciones que pueden generarse en las propiedades sensoriales.

Por el contrario, el valor de CIM del ácido acético hallado de $41,57 \mathrm{mM}$ a un $\mathrm{pH}$ 4,62 , con sólo el $57,43 \%$ de las moléculas en forma no disociada, siendo la concentración de acético sin disociar de 23,87 mM.

El valor de CIM del ácido acético resultó ser casi 9 veces más bajo que el valor de CIM del ácido láctico, debido al pKa 4,75 que permite una mayor concentración de moléculas no disociadas que las de ácido láctico al mismo valor de $\mathrm{pH}$.

Por otra parte, resulta de interés evaluar cual es el efecto de la concentración de ácido sin disociar sobre los parámetros de crecimiento fúngicos velocidad específica de crecimiento (KD) y sobre la duración de la fase de latencia (lag). 
La Figura 5.2 muestra una relación entre los parámetros cinéticos ( $K_{D}$ y duración de la fase Lag) y la concentración de ácido no disociado para diferentes cepas de Aspergillus flavus.
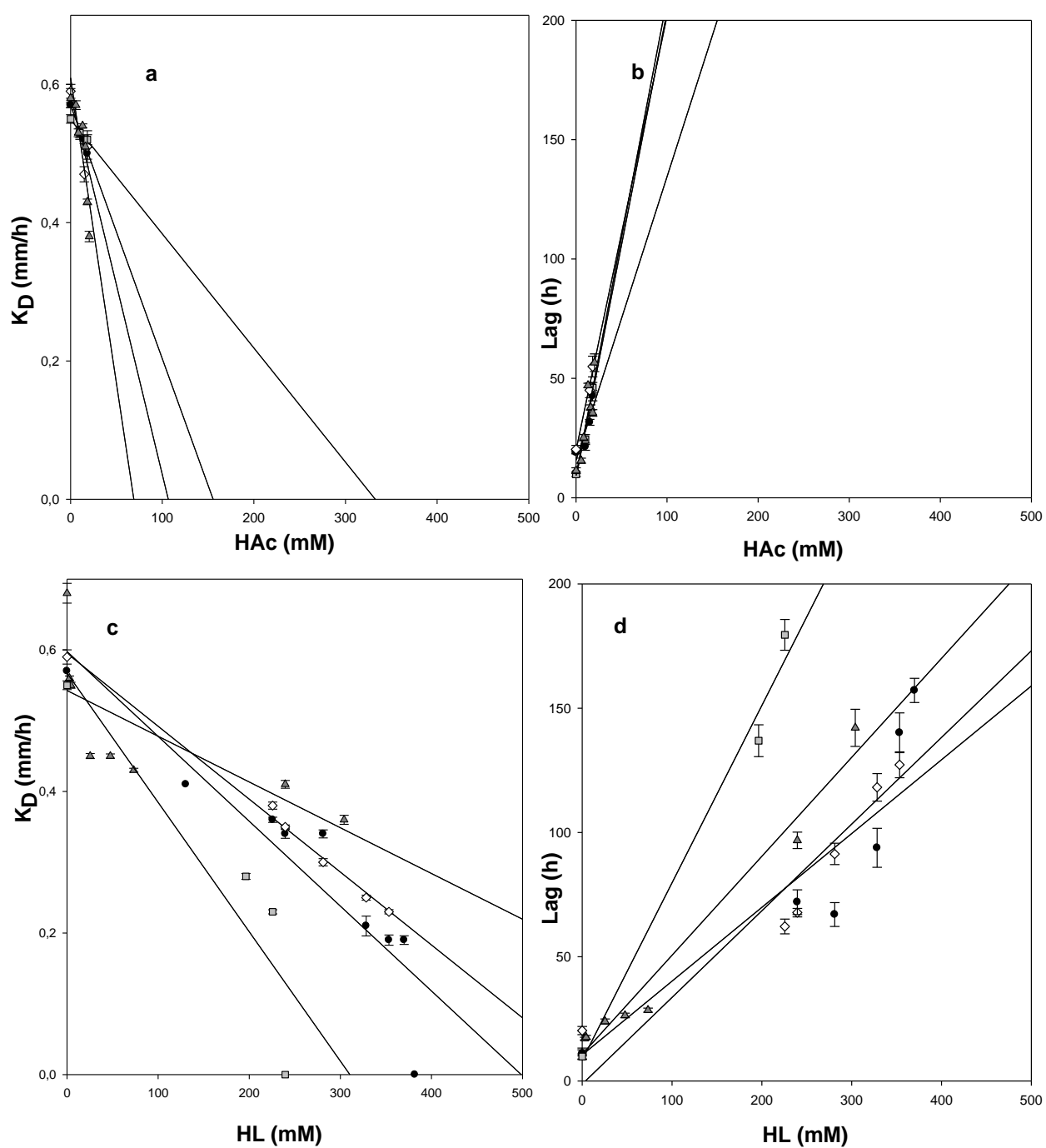

Figura 5.2 Efecto de la concentración de acido acético sin disociar [HAc] y de ácido láctico sin disociar [HL] sobre la velocidad de crecimiento fúngico $K_{D}(\mathrm{~mm} / \mathrm{h})$ y fase de latencia $(\mathrm{h})$ de diferentes cepas de A. flavus. $\mathbf{\Delta}$ : AFUNQ6, ๑: AFUNL1, $\mathbf{\square}$ : AFUNL2, $\diamond:$ AFUNL3.

HAc:Concentración de ácido acético no disociado.

HL: Concentración de ácido láctico no disociado.

En todos los casos estudiados, al aumentar la concentración de ácido no disociado se produjo una disminución en valores de $K_{D}$ y un aumento en la duración de la fase de latencia. Para las cepas AFUNQ6, AFUNL1, AFUNL2 y AFUNL3, el coeficiente de relación $\left(R^{2}\right)$ entre la concentración de ácido acético 
5 INHIBICIÓN DEL CRECIMIENTO FÚNGICO CON ÁCIDOS PUROS Y APLICACIÓN DE LOS ÁCIDOS EN LA PRESERVACIÓN DE LA AREPA. no disociado y fase de latencia se encontró en el rango de 0,76 a 0,99 y $R^{2}$ entre dicha concentración y la tasa de crecimiento estuvo entre 0,76 y 0,98 .

El coeficiente $R^{2}$ entre la concentración de ácido láctico no disociado y la fase de latencia estuvo en el rango 0,81 a 0,98 y el $R^{2}$ entre la concentración del ácido láctico no disociado y el valor de $K_{D}$ se encontró entre 0,54 y 0,99.

Las pendientes de la regresión lineal entre la fase de latencia vs. la concentración de ácido acético no disociado fueron: 2,0, 1,2, 2,0 y 1,8 h/[HAc] (mM) para A. flavus AFUNQ6, AFUNL1, AFUNL2 y AFUNL3 respectivamente.

Las pendientes de la regresión lineal entre la fase de latencia vs. la concentración de ácido láctico no disociado fueron $0,39,0,35,0,71$ y $0,23 \mathrm{~h} /[\mathrm{HL}]$ (mM) para A. flavus AFUNQ6, AFUNL1,AFUNL2 y AFUNL3 respectivamente.

Las pendientes de regresión lineal entre la concentración de acido acético no disociada vs $\mathrm{K}_{\mathrm{D}}$ fueron de $8,82,3,67,1,85$ y $5,48 \mathrm{~mm}^{-1} /[\mathrm{HAc}](\mathrm{mM})$ para $A$. flavus AFUNQ6, AFUNL1, AFUNL2 y AFUNL3 respectivamente.

Las pendientes de regresión lineal entre la concentración de ácido láctico no disociada vs. $\mathrm{K}_{\mathrm{D}}$ fueron $6,46,1,19,1,63$ y $1,03 \mathrm{~mm}^{-1} /[\mathrm{HL}](\mathrm{mM})$ para $A$. flavus AFUNQ6, AFUNL1, AFUNL2 y AFUNL3 respectivamente.

Para cada cepa, las pendientes de la regresión lineal entre la concentración de ácido acético sin disociar fueron mayores que las correspondientes a las halladas empleando ácido láctico no disociado lo que indica un mayor efecto antimicrobiano del ácido acético sobre los parámetros cinéticos Lag (h) y $K_{D}$ $(\mathrm{mm} / \mathrm{h})$.

La Figura 5.3 muestra los valores del Índice de inhibición IIK $(\%)$ y la relación Lag tratamiento/Lag control (LagT/LagC) de A. flavus AFUNQ6 en función de diferentes concentraciones de ácidos láctico y acético no disociados. 


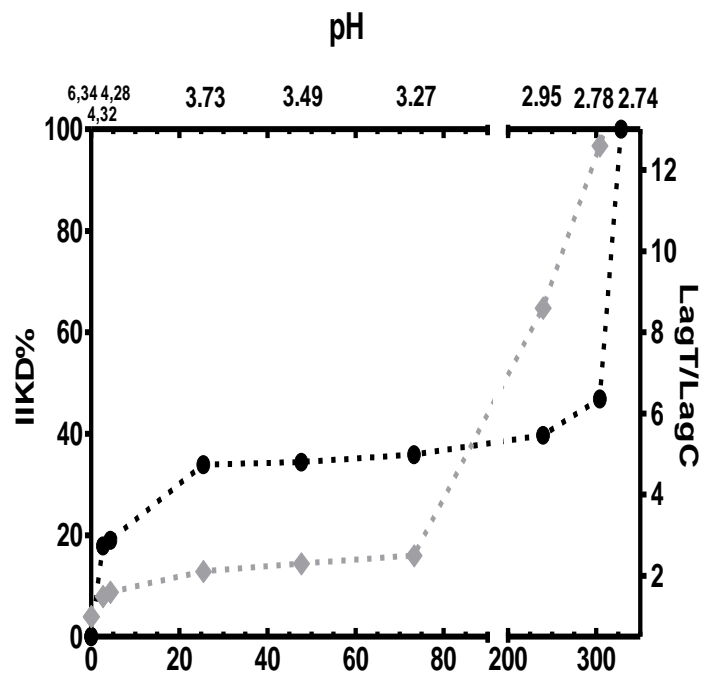

$\mathrm{HL}[\mathrm{mM}]$

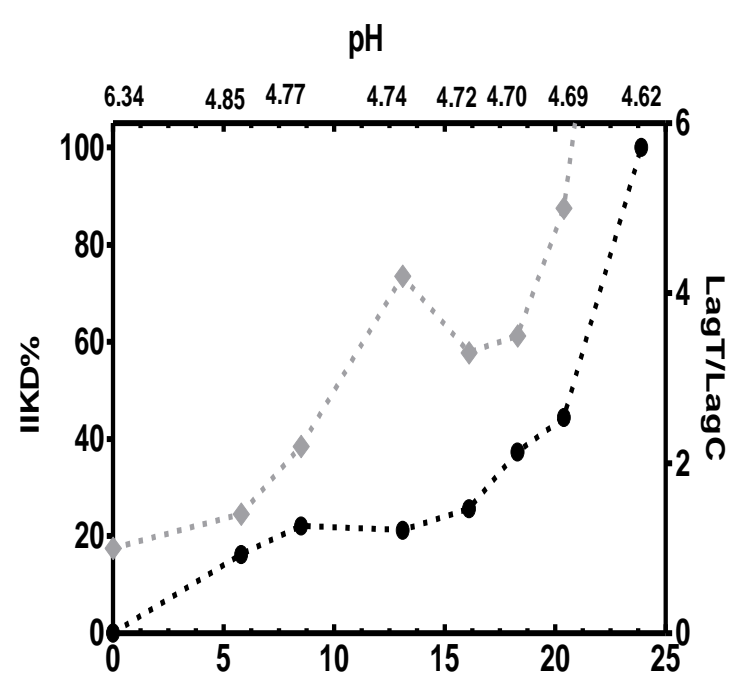

$\mathrm{HAc}[\mathrm{mM}]$

Figura 5.3 IIK $\mathrm{K}_{D} \%$ y relación LagT/LagC para $A$ flavus AFUNQ6 en función de la concentración de ácido láctico $(\mathrm{HL})$ y ácido acético $\left(H \mathrm{H}_{C}\right)$ sin disociar. $\bullet$ : IIK $\mathrm{K}_{\mathrm{D}} \%$ Índice de inhibición del crecimiento fúngico, $\diamond$ LagT/LagC: fase de latencia del hongo tratado con ácidos/ fase de latencia del hongo sin tratar.

Puede observarse que el índice de inhibición de $\mathrm{K}_{\mathrm{D}}\left(\% \mathrm{II} \mathrm{K}_{\mathrm{D}}\right.$ ) aumentó con el aumento del contenido de ácido acético y láctico no disociado indicando su acción antifúngica. Sin embargo, el efecto fue más notorio para el ácido acético,

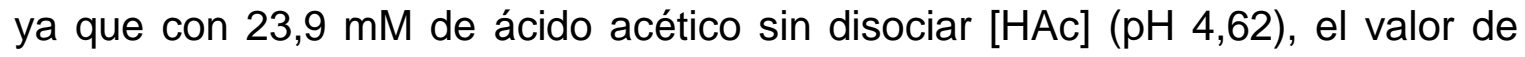
$\| K_{\mathrm{D}}$ fue de 100\% mientras que para obtener la misma inhibición resultó necesario 328,4 mM de ácido láctico sin disociar [HL] $(\mathrm{pH} 2,74)$.

La relación $\mathrm{LagT} / \mathrm{LagC}$ demostró la relación entre la fase de latencia del hongo tratado con diferentes concentraciones de ácidos sin disociar con su fase de latencia creciendo en el medio control (medio sin ácido). El efecto de la concentración de los ácidos sin disociar respecto a la relación LagT/LagC resultó ser mayor para el ácido acético que para el ácido láctico. Pudo determinarse por ejemplo, que a $24 \mathrm{mM}$ de ácido acético no disociado el valor de LagT/LagC fue 5 , mientras que a esa misma concentración $24 \mathrm{mM}$ de ácido láctico no disociado LagT/LagC fue 2. 


\subsubsection{Determinación de la concentración inhibitoria fraccionaria (CIF)}

Algunas investigaciones previas han informado que existen efectos sinérgicos antimicrobianos entre los ácidos orgánicos como son los ácidos acético y láctico (Adams \& Hall, 1988; Dickson \& Maynard, 1992; Rubin, 1978). Se ha demostrado sinergia entre mezclas de ácido láctico, ácido cítrico y sorbato de potasio ya sea retardando el crecimiento de Salmonella, Yersinia enterocolitica, Pseudomonas fluorescens, dos cepas de Lactobacillus (Restaino, Komatsu \& Syracuse, 1981) y cuatro cepas de levaduras osmofílicas (Restaino, Lenvich \& Bills, 1982) o por la inhibición total de su crecimiento.

Dado el sinergismo entre el ácido acético y láctico descripto por otros autores (Adams \& Hall, 1988; Dickson \& Maynard, 1992; Rubin, 1978), se decidió estudiar el efecto conjunto de varias mezclas de ambos ácidos sobre el crecimiento de $A$. flavus. En este trabajo, se evaluaron mezclas de ácidos láctico y acético en concentraciones por debajo de la CIM para la cepa no toxigénica de A. flavus AFUNQ6, con el fin de reducir la concentración necesaria de cada ácido en la mezcla de inhibición fúngica en comparación con los valores CIM individuales. Para ello, se estudió el efecto de diferentes mezclas de ácidos acético y láctico sobre el crecimiento de $A$. flavus AFUNQ6 durante 30 días de incubación a $30^{\circ} \mathrm{C}$.

Los ensayos se realizaron con las tres concentraciones más bajas de ácido acético evaluados individualmente (17,3 mM, $26 \mathrm{mM}$ y 31,2 mM) para $A$. flavus AFUNQ6 y concentraciones de ácido láctico entre 12,0 mM (Concentración mínima evaluada en las concentraciones individuales) y 95,4 $\mathrm{mM}$ con el fin de determinar el crecimiento de hongos (C) o no crecimiento (NC). Los resultados obtenidos se presentan en la tabla 5.6.

La mezcla binaria más baja que inhibió el crecimiento de hongos fue láctico 78,0 mM: acético 31,2 mM a pH 3,38, donde las concentraciones fueron 4,6 y 1,3 veces inferiores a sus valores de $\mathrm{CIM}$ individuales. $\mathrm{A}$ este $\mathrm{pH}$, ambos ácidos se encontraban por debajo de sus valores de $\mathrm{pK}_{\mathrm{a}}$ y las concentraciones de ácidos 

APLICACIÓN DE LOS ÁCIDOS EN LA PRESERVACIÓN DE LA AREPA.

no disociados fueron [HAc] $30 \mathrm{mM}$ : [HL] $56 \mathrm{mM}$. Con estos resultados se pudo detectar que al pH 3,38 el ácido acético se encontraba en un 96\% en estado no disociado, mientras que sólo el $72 \%$ del ácido láctico estaba sin disociar.

Las mezclas de ácido acético 17,3 mM y 26,0 mM con la mayor concentración de ácido láctico $(95,4 \mathrm{mM})$ no produjeron la inhibición de los hongos. Puede afirmarse entonces que en estas condiciones, el principal efecto antifúngico se debió a la concentración del ácido acético; el efecto sinérgico en el efecto antifúngico de la mezcla se basó fundamentalmente en la concentración de ácido acético (debido a su pKa más alto), que se vio favorecido por la capacidad acidificante del ácido láctico.

Tabla 5.6 Crecimiento de A. flavus (C) o no crecimiento (NC) bajo la acción de diferentes mezclas de ácido acético y láctico en el medio luego de 30 días de incubación a $30^{\circ} \mathrm{C}$.

\begin{tabular}{|c|c|c|c|c|c|c|c|c|c|}
\hline \multirow{2}{*}{ Acido acético $(\mathbf{m M})$} & \multicolumn{8}{|c|}{ Ácido láctico (mM) } \\
\cline { 2 - 12 } & 12,0 & 22,0 & 33,0 & 44,0 & 56,0 & 67,0 & 78,0 & 89,0 & 95,4 \\
\hline 17,3 & C & C & C & C & C & C & C & C & C \\
\hline 26,0 & C & C & C & C & C & C & C & C & C \\
\hline 31,2 & C & C & C & C & C & C & NC & NC & NC \\
\hline Valor CIF & - & - & - & - & - & - & 0,63 & 0,66 & 0,68 \\
\hline
\end{tabular}

La mezcla también mostró un efecto antifúngico en las cepas toxigénicas de $A$. flavus AFUNL1, AFUNL2 y AFUNL3 (datos no mostrados). Resultó notable el hallazgo que $A$. flavus AFUNL3 fue sensible incluso a una concentración más baja de la mezcla de ácido láctico $35,8 \mathrm{~mm}$ : ácido acético 27,8 mM. Sin embargo, la mezcla láctico $78,00 \mathrm{mM}$ :acético $31,20 \mathrm{mM}$ se recomienda para asegurar la inhibición de todas las cepas. La sinergia generada por la mezcla de ambos ácidos permite demostrar que es posible utilizar menores concentraciones de ácidos con el fin de inhibir el crecimiento de hongos.

Los resultados encontrados en los sistemas in vitro permitieron analizar si estos ácidos, podrían ser usados en forma individual o combinada para extender la vida útil de un producto cereal reconocido como portador de hongos y toxinas. Este producto es la arepa de maíz, en el cual, la adición de ácido acético, láctico 
o mezcla de ambos podría ser efectivo para inhibir el desarrollo fúngico y la posterior producción de toxinas. Sin embargo, como resultado de la adición de estos ácidos, podrían generarse sabores desagradables para el consumidor, por lo cual se hizo además una prueba de aceptación de la arepa adicionada de ácidos orgánicos puros.

A tal efecto se elaboraron arepas empleando en su formulación ácido acético y láctico y mezclas de ambos a efectos de evaluar el desarrollo fúngico en las arepas durante el almacenamiento y las propiedades sensoriales que darían los ácidos adicionados.

\subsubsection{Resistencia a la contaminación natural y artificial por arepas adicionadas de ácidos orgánicos láctico y acético}

La Figura 5.4 presenta los resultados de los recuentos fúngicos hallados durante el almacenamiento a 10 y $20^{\circ} \mathrm{C}$ en las arepas control y las elaboradas con ácidos acético, láctico y mezcla de estos.
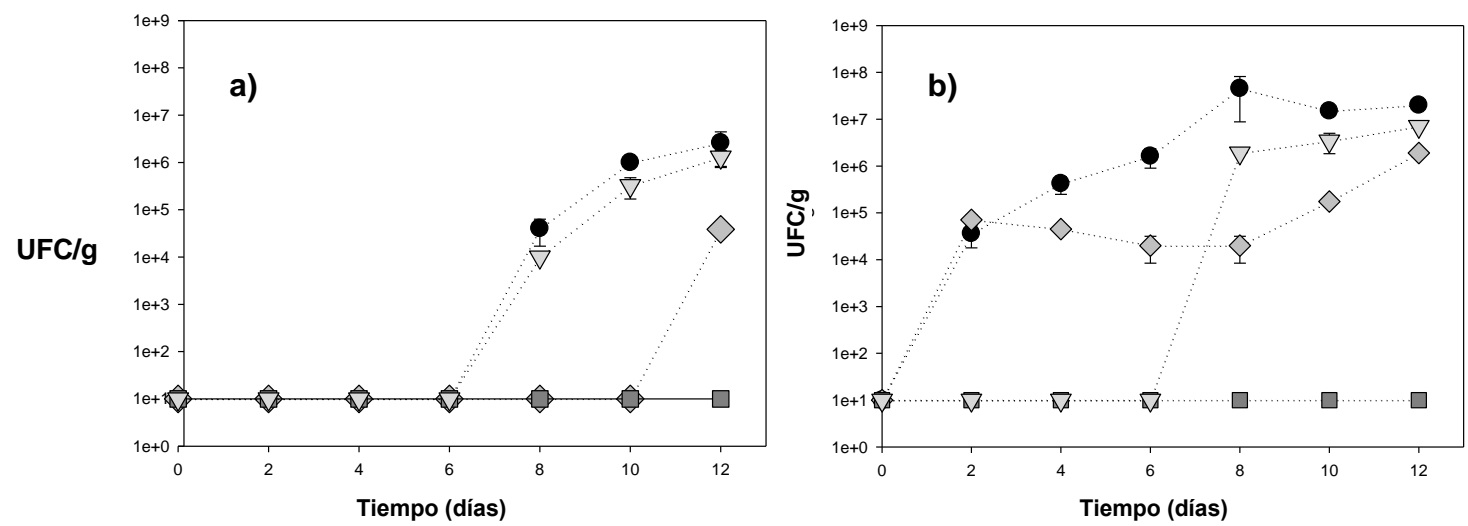

Figura 5.4 Recuentos fúngicos en arepas: - control y elaboradas con $\bullet$ ácido acético 41,57 $\mathrm{mM}$, : ácido láctico $357,67 \mathrm{mM}$ y $\nabla$ : mezcla ácido láctico $78,00 \mathrm{mM}$ : ácido acético $31,20 \mathrm{mM}$. a) almacenadas a $10^{\circ} \mathrm{C}$ y b) almacenadas a $20^{\circ} \mathrm{C}$.

A $10^{\circ} \mathrm{C}$, los ácidos láctico y acético prolongaron la vida útil de las arepas de manera significativa $(p<0.05)$ con respecto al control; mientras que la mezcla no presentó diferencia estadísticamente significativa $(p<0.05)$ con respecto al control. 

APLICACIÓN DE LOS ÁCIDOS EN LA PRESERVACIÓN DE LA AREPA.

A $20^{\circ} \mathrm{C}$, hasta el día seis se observó mayor efecto preservante por la mezcla que por el ácido acético. Pero, a partir de este día se observó un comportamiento similar al obtenido a $10^{\circ} \mathrm{C}$. La prueba LSD de Fischer demostró que los tres tratamientos produjeron un aumento significativo $(p<0.05)$ de la vida útil de las arepas con respecto al control pero que no hubo diferencia estadísticamente significativa entre ellos.

Se definió como vida útil de las arepas al tiempo al cual los recuentos fúngicos alcanzan valores máximos de $10^{3} \mathrm{UFC} / \mathrm{g}$ (ICONTEC, 2007), de acuerdo a ello, los valores de vida útil de cada tipo de producto elaborado en su formulación con ácido acético, láctico o mezcla de ambos, se presentan en la Tabla 5.7.

Tabla 5.7 Vida útil (días) de arepas elaboradas con diferentes tipos de ácidos: acético, láctico y mezcla láctico: acético y almacenadas a 10 y $20^{\circ} \mathrm{C}$

\begin{tabular}{|c|c|c|}
\hline Tratamiento & $\mathbf{1 0} \mathbf{C}$ & $\mathbf{2 0} \mathbf{C}$ \\
\hline Control & 7 días & 1,5 días \\
\hline Ácido láctico $357,67 \mathrm{mM}$ & Más de 12 días & Más de 12 días \\
\hline Ácido acético $41,57 \mathrm{mM}$ & 11 días & 1,5 días \\
\hline Láctico78,00 mM:acético $31,20 \mathrm{mM}$ & 7,2 días & 6,5 días \\
\hline
\end{tabular}

Los resultados de la Tabla 5.7 indican que el ácido láctico permitió lograr más de 12 días de vida útil sin alcanzar recuentos mayores a $10^{3} \mathrm{UFC} / \mathrm{g}$ por lo que podría ser elegido para adicionar como preservante en la formulación de estos productos.

También el empleo de ácido acético permitió extender la vida del producto a 11 días almacenado a $10^{\circ} \mathrm{C}$, extendiendo en 3 días respecto del control a esa temperatura.

Por otra parte, la mezcla de láctico: acético logró una vida útil de 7,2 y 6,5 días en almacenamiento a 10 y $20^{\circ} \mathrm{C}$ respectivamente. Los resultados anteriores deben ser completados con los correspondientes análisis sensoriales de estos productos y así evaluar en forma integral la vida útil del producto. 


\subsubsection{Evaluación sensorial de arepas adicionadas con ácidos láctico y acético y mezclas de ambos.}

La Figura 5.5 presenta los resultados de la prueba de aceptación del consumidor realizado a las arepas elaboradas con ácido acético 41,57 mM, ácido láctico 357,67 mM y mezcla ácido láctico 78,00 mM: ácido acético 31,20 mM.

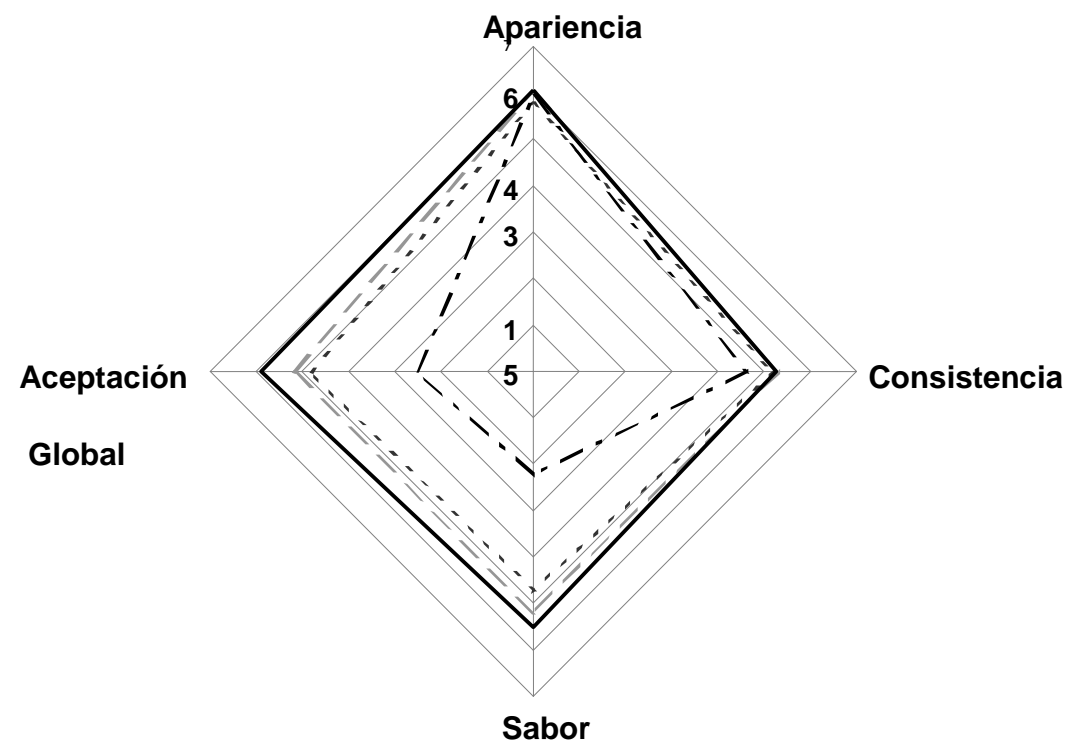

Figura 5.5 Evaluación sensorial realizado por el panel no entrenado de arepa elaborada con ácidos orgánicos: —- :Control;-- - - - ácido láctico 78,00 mM:ácido acético 31,20 mM; -----:ácido acético 41,54 mM, - - - - :ácido láctico 357,67 mM

El sabor presentó diferencia estadísticamente significativa entre las arepas elaboradas con ácido láctico y los demás tratamientos. Las arepas elaboradas con ácido láctico obtuvieron una calificación de sabor muy baja $(2,23)$ a diferencia de los demás tratamientos, los cuales obtuvieron una calificación media $(5,00)$.

Por otra parte los tres tratamientos no presentaron diferencias significativas $(p<0.05)$ con el control en la apariencia y consistencia, mientras que la aceptabilidad global presento diferencia estadísticamente significativa $(p>0.05)$ para la muestra elaborada con ácido láctico, por lo que esta muestra fue rechazada desde el punto de vista organoléptico, pese a su capacidad inhibitoria. 

APLICACIÓN DE LOS ÁCIDOS EN LA PRESERVACIÓN DE LA AREPA.

A partir de estos resultados, se consideró el ácido acético como el conservante más adecuado a $10^{\circ} \mathrm{C}$, y éste y la mezcla láctico: acético, como los preservantes mas indicados a $20^{\circ} \mathrm{C}$, dado el efecto inhibitorio sobre el crecimiento fúngico y la aceptación sensorial de ambos por los consumidores.

Como se discutió anteriormente, el valor de $\mathrm{pK}_{\mathrm{a}}$ de ácido acético permitió un mayor porcentaje de moléculas de ácido sin disociar a un $\mathrm{pH}$ superior que el del ácido láctico sólo. El ácido acético presentó mayor capacidad antifúngica y menor efecto sobre las propiedades sensoriales del producto como lo presenta el ácido láctico.

Al aplicar la mezcla de ácidos, la reducción en la concentración de ácido láctico necesaria para la inhibición fúngica permitió alcanzar un valor de $\mathrm{pH}$ inferior a 4,50, similar al pH final alcanzado en el valor de MIC de acido acético individual pero mucho mayor al valor de $\mathrm{pH}$ final correspondiente al valor de MIC del ácido láctico. Esto generó un efecto positivo en las propiedades sensoriales del producto como se mostró en la figura 5.5. El empleo de la mezcla de ácidos disminuyó la cantidad de ácido requerido para la inhibición fúngica así como los efectos indeseables sobre el sabor en los estudios sensoriales, dado que este pH es similar al valor del pH correspondiente a MIC del ácido acético: 4,62.

La inhibición fúngica se obtiene con una menor concentración de ácido acético a un valor de $\mathrm{pH}$ poco ácido, lo que permite esperar mejores propiedades sensoriales de sabor en los productos alimenticios en los que se lo utilice como conservante. Será de interés desarrollar investigaciones de mezclas binarias en sistemas reales de alimentos para su aplicación potencial en la conservación de alimentos.

\subsection{Conclusiones}

La CIM para el ácido acético determinada para todos los hongos estudiados fue de 38,1 mM. La CIM del ácido láctico fue diferente para las cuatro cepas: 357,67 mM, 405,36 mM, 274,21 mM y 393,43 mM para A. flavus AFUNQ6, AFUNL1, AFUNL2 y AFUNL3 respectivamente. 
5 INHIBICIÓN DEL CRECIMIENTO FÚNGICO CON ÁCIDOS PUROS Y APLICACIÓN DE LOS ÁCIDOS EN LA PRESERVACIÓN DE LA AREPA.

Los valores de CIM para el ácido láctico resultaron ser aproximadamente diez veces mayores que los valores de CIM del ácido acético para $A$. flavus. A partir de los resultados anteriores se concluye que la CIM de acido acético fue casi 9 veces menor que la CIM del ácido láctico, en virtud de que el pK de 4,75 del ácido acético favoreció la mayor concentración de moléculas no disociadas que de láctico al mismo pH. La inhibición fúngica se logró con menor concentración de acético a un valor de $\mathrm{pH}$ no muy ácido, lo que permite esperar mejores propiedades sensoriales de sabor en el producto que se aplique como preservante.

Todas las cepas tuvieron la misma resistencia al ácido acético mientras que la más resistente al ácido láctico fue $A$. flavus AFUNL1.

Las mezclas de ácidos láctico y acético mostraron un efecto sinérgico indicando que puede realizarse una reducción de la concentración necesaria de cada ácido en la mezcla para la inhibición de hongos en comparación con los valores de CIM aplicados en forma individual.

La mezcla inhibidora determinada para todas las cepas fue láctico $78,0 \mathrm{mM}$ : acético $31,2 \mathrm{mM}$, con un valor de $\mathrm{pH}$ de 3,38 que presenta concentraciones inferiores a los valores de CIM individuales.

Mediante estudios de recuentos fúngicos se determinó la vida útil del producto de 11 días para las elaboradas con 41,54 mM de ácido acético y almacenadas a $10^{\circ} \mathrm{C}$. Las arepas almacenadas a $20^{\circ} \mathrm{C}$ presentaron una vida útil de 6,5 días siendo estas reparadas con una mezcla de ácido láctico $56 \mathrm{mM}$ : ácido acético $30 \mathrm{mM}$.

Las arepas fabricadas con 357,67 mM de ácido láctico fueron rechazadas por el panel sensorial por presentar sabor ácido a pesar de presentar bajos recuentos fúngicos. 


\section{INHIBICIÓN DEL CRECIMIENTO FÚNGICO CON KEFIR}

\subsection{INHIBICIÓN DEL CRECIMIENTO FÚNGICO CON LECHE FERMENTADA CON GRÁNULOS DE KEFIR.}

\subsubsection{Introducción.}

El gránulo de kefir, su composición y propiedades ya fueron descriptas en la Introducción general. La adición del gránulo de kefir a la leche constituye el momento inicial de la fermentación. Los aspectos relacionados con la fermentación se han estudiado como la cinética de crecimiento de los microorganimos en la leche y de producción de ácidos, $\mathrm{CO}_{2}$, viscosidad y consumo de lactosa (Garrote, 1999). Al agregar los gránulos a la leche, las levaduras (LEV), lactococos (LC), lactobacilos (bacterias ácido lácticas: BAL) y bacterias ácido acéticas (BAA) pasan inmediatamente a la leche, indicando que parte de los microorganismos adheridos al gránulo de kefir se desprenden y pasan a la fase líquida donde, junto a los microorganismos adheridos al gránulo, comienzan la fermentación. En dicha fermentación, realizada a $20{ }^{\circ} \mathrm{C}$, las LEV alcanzaron la fase estacionaria a las 24 horas mientras que las BAL y LC a las 48 horas (Garrote, 1999). Al adicionar el gránulo de kefir al 10\%, la leche desciende aproximadamente de un $\mathrm{pH}$ 6,6 a 6,3 y al final de la fermentación puede alcanzar un $\mathrm{pH}$ tan bajo como de 3,00 (datos de esta tesis). Comienza un descenso del pH gradual que se ha reportado a un valor entre 4,2 y 4,9 a las 48 horas de incubación (Garrote, 1999), de 4,0 (Kemp, 1984), 4,4 - 4,6 (Koroleva, 1988), 4,3- 4,5 (Alm, 1980), 4,31 - 4,38 (Botazzi Botazzi, Zacconi, Sarra, Dallavalle \& Parisi, 1994) y 4,2 - 4,6 (Odet, 1995). También se reportó la presencia de ácidos como el láctico y acético en la leche fermentada con gránulos de kefir CIDCA AGK1, AGK2, AGK3 y AGK4, todos los cuales presentaron concentraciones de ácidos muy similares pasadas las 48 horas de fermentación (Garrote, 1999).

En el estudio presente, se analizó la fermentación del gránulo de kefir en leche a diferentes temperaturas para evaluar su posterior efecto antifúngico y su posible aplicación en la preservación de un alimento como es la arepa de maíz. 


\title{
CAPÍTULO 6:
}

INHIBICIÓN DEL CRECIMIENTO FÚNGICO CON KEFIR

\author{
6.1 - INHIBICIÓN DEL
}

CRECIMIENTO FÚNGICO CON

LECHE FERMENTADA CON

GRÁNULOS DE KEFIR

6.2 - EFECTO ANTIFÚNGICO DEL PERMEADO DE SUERO

FERMENTADO CON GRÁNULOS

DE KEFIR (PSFG) Y CON

MICROORGANISMOS AISLADOS

DE GRÁNULOS DE KEFIR (PSFM) 


\subsection{INHIBICIÓN DEL CRECIMIENTO FÚNGICO CON LECHE FERMENTADA}

CON GRÁNULOS DE KEFIR

En la búsqueda de la inhibición fúngica se han evaluado los metabolitos ácidos de diferentes microorganismos, determinando sus Concentraciones Inhibitorias Minimas (CIM) contra hongos filamentosos. De esta manera se han ensayado los ácidos láctico, acético y propiónico liberados por bacterias durante la fermentación. Se determinó que los ácidos con mayor actividad contra los hongos Aspergillus fumigatus J9, A. nidulans J283, son el propiónico y el acético y el de menor capacidad antifúngica es el láctico. Para $A$. fumigatus y $A$. nidulans respectivamente, a pH 3 el ácido propiónico tiene que estar en concentración de 8 y 10 mM; láctico en 250 y 200 mM y el acético en 20 y 4 mM. A pH 5 se requiere una concentración de $50 \mathrm{mM}$ de propiónico para ambos, 80 y $120 \mathrm{mM}$ de acético y mas de 500 mM de láctico; a pH 7 es necesaria una concentración mayor de $500 \mathrm{mM}$ para cualquiera de los tres ácidos (Lind, Jonsson \& Schnürer, 2005). También se determinó el efecto combinado y el modelo predictivo de crecimiento de $A$. parasiticus combinando tratamientos combinados de temperatura y ácido propiónico comercial empleado en panificación (Molina \& Gianuzzi, 1999). Davidson (2001) demostró que el ácido láctico en concentraciones entre 0,2 y $2,5 \%$ puede inhibir bacterias y hongos pero no presenta un valor más exacto para los hongos toxigénicos.

Teniendo en cuenta que uno de los principales factores microbiológicos que reducen la vida útil de la arepa son los hongos y levaduras y dado que se busca reemplazar los preservantes químicos por los de origen biológico, se decidió probar el efecto del kefir ya que el mismo contiene ácidos orgánicos producidos naturalmente por los microorganismos que lo componen. Este estudio implicó conocer las cinéticas de fermentación de los gránulos de kefir en leche y determinar su efecto inhibitorio sobre A. flavus AFUNL5. Una vez determinados los productos fermentados que tuvieron mayor actividad antifúngica, se adicionaron a la fórmula de la arepa para estudiar si conferían resistencia a la contaminación natural y a la contaminación artificial con A. flavus AFUNL5. 


\subsection{INHIBICIÓN DEL CRECIMIENTO FÚNGICO CON LECHE FERMENTADA}

CON GRÁNULOS DE KEFIR

\subsubsection{Objetivos.}

\subsubsection{Objetivo General.}

6.1.2.1.1 Evaluar la capacidad inhibitoria sobre $A$. flavus de los sobrenadantes libres de células (SLC) de leche fermentada con gránulos de kefir.

\subsection{Objetivos específicos.}

6.1.2.1.1 Determinar las mejores condiciones de fermentación de la leche con el gránulo de kefir, en cuanto a temperatura, $\mathrm{pH}$ final y dilución del sobrenadante, para la inhibición fúngica.

6.1.2.1.2 Establecer las cinéticas de fermentación de la leche con el gránulo de kefir a las diferentes temperaturas evaluadas.

6.1.2.1.3 Comparar el efecto antifúngico de los ácidos orgánicos débiles puros (acético y láctico) y de un ácido fuerte $(\mathrm{HCl})$ agregados a leche, con el efecto producido por los sobrenadantes libres de células obtenidos con la leche fermentada.

6.1.2.1.4 Analizar el efecto que produce la adición de leche fermentada con gránulos de kefir sobre la vida útil, resistencia a la contaminación y propiedades sensoriales de la arepa de maíz.

\subsubsection{Materiales y métodos.}

\subsubsection{Gránulos de Kefir.}

Se emplearon los gránulos CIDCA AGK1 y AGK2, caracterizados en el CIDCA, UNLP (Garrote, 1999), que se conservaron y activaron tal como se describió en materiales y métodos generales. 


\subsubsection{Hongos filamentosos.}

El hongo estudiado en este capítulo fue Aspergillus flavus AFUNL5, cedido por la Universidad Nacional del Litoral (UNL, Argentina). El hongo se conservó y activó tal como se describió en materiales y métodos generales.

\subsubsection{Medios de cultivo de los hongos filamentosos.}

El hongo se conservó en agar agua $(0,2 \%)$ a $4 \stackrel{\circ}{ } \mathrm{C}$, se cultivó en Agar PDA-papa dextrosa $\left(\right.$ Merck $^{\circledR}$, Darmstadt, Alemania) y se prepararon las soluciones de conidios de acuerdo a lo descripto en materiales y métodos generales.

\subsubsection{Medios de cultivo de los gránulos de kefir.}

Los gránulos de kefir se conservaron y reactivaron en leche tal como se describió en materiales y métodos generales.

\subsubsection{Obtención de los Sobrenadantes Libres de Células (SLC).}

Los SLC se obtuvieron fermentando leche UHT descremada, con los gránulos CIDCA AGK1 y AGK2, según lo descripto en materiales y métodos generales.

\subsubsection{Obtención de las soluciones de conidios.}

Las soluciones de conidios empleadas en este capítulo se prepararon según lo descripto en materiales y métodos generales.

\subsubsection{Medios de cultivo para los ensayos de inhibición fúngica.}

Los ensayos de difusión en agar se hicieron en medio de cultivo malta (Anexo 1).

\subsubsection{Ensayos de Inhibición del crecimiento fúngico.}

La inhibición del crecimiento fúngico se determinó mediante el método de difusión en agar. 


\subsection{Método de difusión en agar.}

Los SLC obtenidos de leche fermentada con gránulos de kefir, se mezclaron con el medio malta fundido a $45^{\circ} \mathrm{C}$, en concentraciones $50 \%, 10 \%, 1 \%$ y $0,1 \%$ y se dejaron gelificar. El pH final del medio malta con los SLC se determinó según materiales y métodos generales. Los hongos filamentosos se cultivaron, se diluyeron e inocularon según materiales y métodos generales. El control se hizo con con medio de cultivo malta sin adición de SLC. A partir de las mediciones realizadas, se obtuvieron las curvas de crecimiento de Diámetro vs. tiempo, la tasa de crecimiento $K_{D}(\mathrm{~mm} / \mathrm{h})$, el tiempo de duración de la fase de latencia Lag (h)y los índices de inhibición de la tasa de crecimiento IIK $_{\mathrm{D}}(\%)$ y de incremento de la fase de latencia, IILag (\%) (Molina \& Giannuzzi, 1999). Todos los experimentos fueron realizados por triplicado.

6.1.3.8.1.1 Determinación de la tasa de crecimiento $K_{D}(\mathrm{~mm} / \mathrm{h})$ y del tiempo de duración de la fase Lag (h).

La tasa de crecimiento fúngico $\mathrm{K}_{\mathrm{D}}(\mathrm{mm} / \mathrm{h})$ y la fase de latencia (lag) (h) se calcularon con la regresión lineal de la curva de crecimiento y con la ecuación 4.1 descripta en materiales y métodos generales.

$\operatorname{Lag}(\mathrm{h})=\left(\Phi-\mathrm{Y}_{0}\right) / \mathrm{K}_{\mathrm{D}}$.

Ecuación 4.1.

Donde:

$\Phi=$ Diámetro de inóculo inicial

$Y_{0}=$ Punto de corte de la recta de la regresión lineal en el eje $Y$

$K_{D}=$ pendiente de la recta de la regresión lineal del crecimiento fúngico (Molina \& Giannuzzi, 1999).

6.1.3.8.1.2 Determinación del Índice de Inhibición de $\mathrm{K}_{\mathrm{D}}\left(\mathrm{II} \mathrm{K}_{\mathrm{D}} \%\right)$ y del Índice de Incremento de la fase Lag (IILag \%).

Se calcularon IIK $(\%)$ e IILag (\%) según las ecuaciones 4.2 y 4.3 descriptas en materiales y métodos generales. 
IIK $=\left\{\left(K_{\text {Dcontrol }}-K_{D \text { Tratamiento }}\right) / K_{\text {Dcontrol }}\right\} \times 100$

Ecuación 4.2

Donde:

$\mathrm{K}_{\text {Dcontrol }}=$ Tasa de crecimiento del control

$\mathrm{K}_{\mathrm{DTratamiento}}=$ Tasa de crecimiento de cada tratamiento

IILag $=\left\{\left(\operatorname{Lag}_{\text {Tratamiento }}-\operatorname{Lag}_{\text {control }}\right) / \operatorname{Lag}_{\text {control }}\right\} \times 100$

Ecuación 4.3

Donde:

Lag $_{\text {control }}=$ Tiempo de la fase Lag del control

$\operatorname{Lag}_{\text {Tratamiento }}=$ Tiempo de la fase Lag de cada tratamiento

6.1.3.9 Fabricación de la arepa y determinación de la estabilidad del alimento adicionado de leche fermentada con gránulo CIDCA AGK1.

\subsection{Fabricación de la arepa.}

Las arepas se fabricaron tal como se describió en materiales y métodos generales. Las arepas se enfriaron a temperatura ambiente por 90 minutos, se empacaron en bolsas de polietileno selladas y se almacenaron a $14^{\circ} \mathrm{C}$. El $\mathrm{pH}$ final de las arepas se midió en un pHmetro Hannah pH 211 Microprocessor. Los tratamientos fueron:

- Se adicionó leche fermentada con gránulo de kefir CIDCA AGK1 $(\mathrm{pH} 3,3)$ a la masa de las arepas en una proporción del 10\%.

-Arepas control hechas sólo con la masa normal.

\subsection{Estabilidad de la Arepa adicionada de leche fermentada con gránulo CIDCA AGK1.}

Se hicieron las siguientes determinaciones para las arepas. 
6.1.3.9.2.1 Determinación de pH y de la concentración de ácidos orgánicos en la Arepa Antioqueña.

El pH y los ácidos presentes en las arepas se determinaron según lo descripto en materiales y métodos generales. La concentración de ácidos no disociados láctico y acético en la leche fermentada con gránulos de kefir, con microorganismos del kefir y en la arepa antioqueña, se calculó tal como se describió en la metodología general.

\subsection{Supervivencia de las BAL y LEV provenientes de leche} fermentada con kefir y estudio de la resistencia de la arepa adicionada de kefir a la contaminación natural.

Se hicieron los recuentos en los días 1, 5 y 10 del almacenamiento. Los recuentos de BAL, levaduras y hongos filamentosos se hicieron tal como se describió en materiales y métodos generales. Los recuentos fúngicos se hicieron con el fin de determinar si en el tiempo de almacenamiento, el alimento no superaba el máximo permitido de $10^{3} \mathrm{UFC} / \mathrm{g}$ de hongos permitido por la Norma Técnica Colombiana NTC 5372 (ICONTEC, 2007). La vida útil se definió como el tiempo necesario en días para que los hongos alcanzaran el máximo recuento permitido.

6.1.3.9.2.3 Estudio de la resistencia de la arepa adicionada de leche fermentada con kefir a la contaminación artificial.

Las arepas se contaminaron con A. flavus AFUNL5 tal como se describió en materiales y métodos generales. El control se hizo adicionando agua destilada estéril en la misma proporción. Una vez contaminadas, se dejaron secar y se almacenaron en bolsas de polietileno selladas a $14^{\circ} \mathrm{C}$. Las bolsas de arepas se observaron diariamente y se compararon los días necesarios para que se diera la aparición visible del hongo (Gerez, Torino, Rollán \& Font de Valdez, 2009). 


\subsection{INHIBICIÓN DEL CRECIMIENTO FÚNGICO CON LECHE FERMENTADA}

CON GRÁNULOS DE KEFIR

\subsubsection{Prueba de perfil sensorial de sabor de las arepas con kefir.}

Se realizó un estudio sensorial con ocho jueces entrenados del Laboratorio de Análisis Sensorial de Alimentos de la Universidad de Antioquia, MedellínColombia, en arepas de maíz y elaborada con leche fermentada con gránulos de kefir adicionada a la masa al 10\%. Se analizaron los sabores y sensaciones percibidas, mediante una prueba descriptiva de Perfil de sabor bajo la Norma Técnica Colombiana NTC 3929 (ICONTEC, 1996). Durante el análisis de las muestras los jueces calificaron los gustos y sensaciones percibidas en una escala de 0 a 5 , donde 1 es débil y 5 intenso. Antes de iniciar los ensayos se controlaron las condiciones ambientales de temperatura y humedad relativa, se acondicionaron las muestras realizando tratamiento térmico de asado y se sirvieron las arepas en platos codificados con números aleatorios de tres dígitos. (ICONTEC, 1996)

\subsubsection{Análisis Estadístico.}

Todos los parámetros de crecimiento se analizaron con el programa SIGMAPLOT $9.0^{\circledR}$ y el análisis sensorial con Excell $\left(\right.$ Microsoft ${ }^{\circledR}$ ). Los resultados de tres ensayos independientes se presentan como valores de media \pm desviación estándar. Se analizaron las diferencias significativas mediante prueba de análisis de varianza (ANOVA), a un nivel de significancia del $5 \%(p<0,05)$ usando el programa STATGRAPHICS Plus $5.1^{\circledR}$ software. Todos los experimentos se hicieron por triplicado. 


\subsubsection{Resultados y Discusión.}

\subsubsection{Cinética de acidificación a $30^{\circ} \mathrm{C}$ y a $37^{\circ} \mathrm{C}$, de la leche inoculada con gránulo CIDCA AGK1.}

Las cinéticas de acidificación se realizaron con el fin de establecer los tiempos requeridos para alcanzar diferentes valores de $\mathrm{pH}$ y así lograr la obtención estandarizada de los SLC a los efectos de emplearlos en los estudios de inhibición fúngica. Se realizaron las cinéticas a 20,30 y $37^{\circ} \mathrm{C}$, y a modo de ejemplo se presentan las cinéticas de las dos últimas temperaturas.

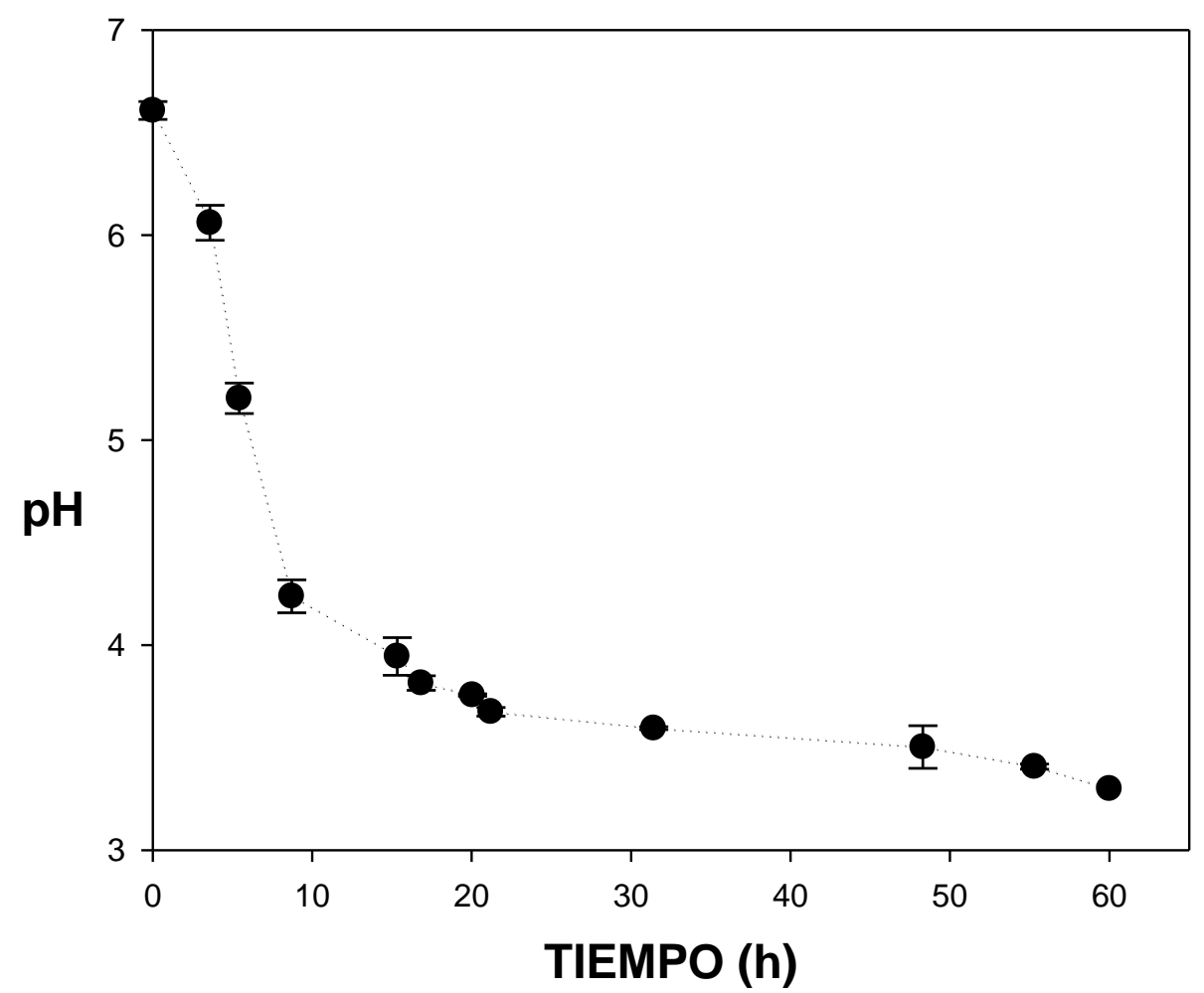

Figura 6.1.1. Cinética de acidificación de leche con gránulo CIDCA AGK1 al $10 \%$ y a $30{ }^{\circ} \mathrm{C}$.

Los gránulos fueron inoculados al $10 \%$ en leche Sancor descremada y se incubaron a $30^{\circ} \mathrm{C}$. Las mediciones de $\mathrm{pH}$ se hicieron cada hora en un pHmetro Altronix TPX - III. La leche fermentada con gránulo CIDCA AGK1 alcanzó el pH 4,5 alrededor de la hora 8, y tardó 30 horas para alcanzar $\mathrm{pH}$ de 3,5 y 60 horas para alcanzar $\mathrm{pH}$ de 3,3 respectivamente. Los recuentos de BAL y levaduras a las 60 horas de fermentación, a pH 3,3 fueron $4,50 \times 10^{8}$ y $2,25 \times 10^{7} \mathrm{UFC} / \mathrm{ml}$ 


\subsection{INHIBICIÓN DEL CRECIMIENTO FÚNGICO CON LECHE FERMENTADA}

CON GRÁNULOS DE KEFIR

respectivamente. Los mismos estudios de acidificación se hicieron con el gránulo CIDCA AGK2 obteniéndose resultados similares.

En la figura 6.1.2 se observa la cinética de acidificación de la leche con gránulo CIDCA AGK1 a $37^{\circ} \mathrm{C}$.

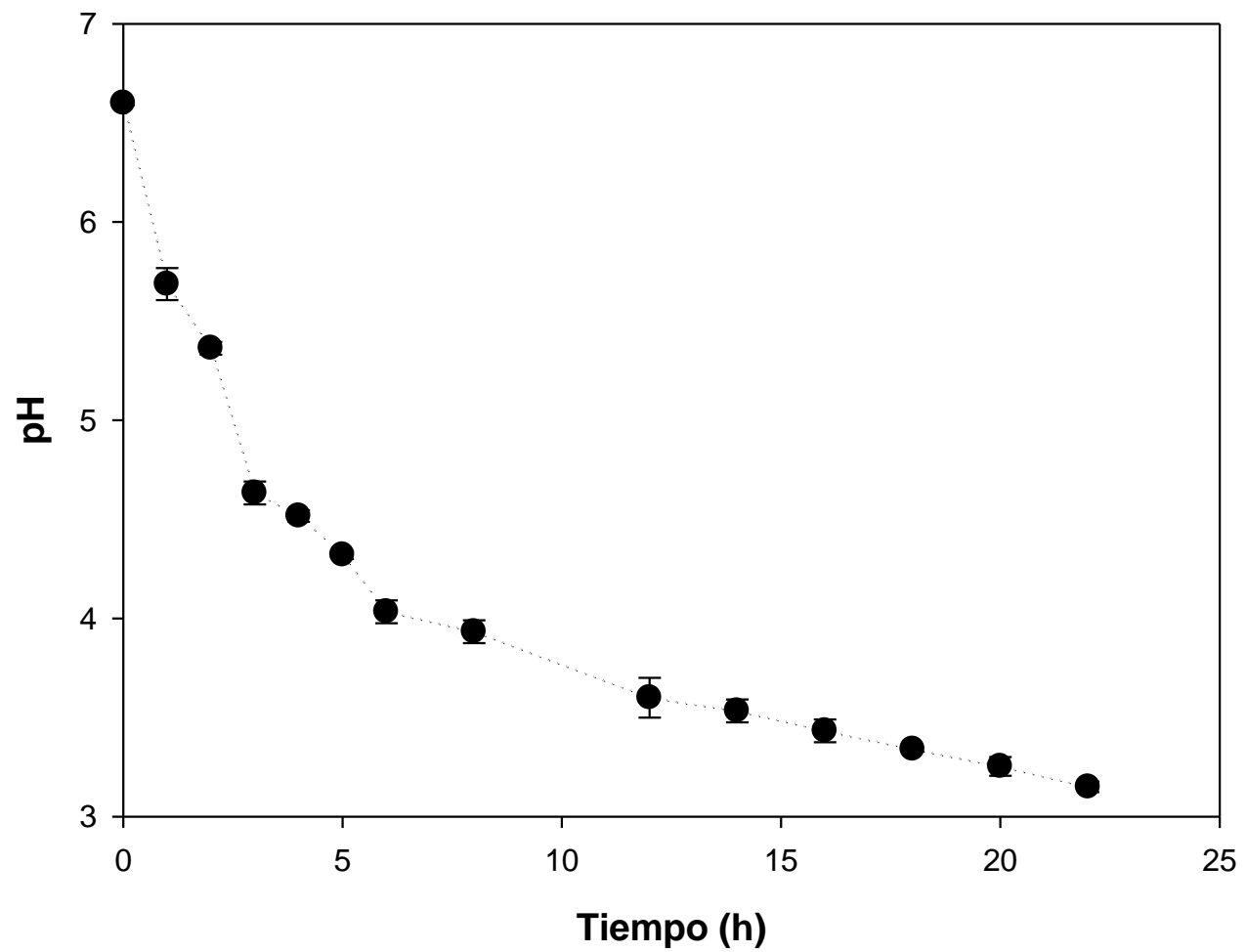

Figura 6.1.2 Cinética de acidificación de leche con gránulo CIDCA AGK1 al 10\% y a $37^{\circ} \mathrm{C}$.

El pH inicial de la leche fue 6,56 y al adicionar los gránulos éste descendió inmediatamente a $6,32 \pm 0,02$. Durante las primeras 8 horas de fermentación, el gránulo descendió a $\mathrm{pH} 3,98 \pm 0,07$; a la hora 16 alcanzó un $\mathrm{pH}$ alrededor de

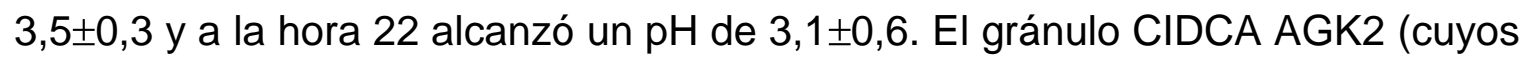
datos no se presentan) presentó una cinética de acidificación más lenta que AGK1 a esta temperatura, alcanzando $\mathrm{pH}$ de $4,75 \pm 0,1$ a la hora 8 y tardando aproximadamente 36 horas para alcanzar pH de 3,1. 


\subsubsection{Estudios de Inhibición de A. flavus AFUNL5 con SLC obtenidos de leches fermentadas con gránulos de kefir CIDCA AGK1 y AGK2.}

A continuación se presentan curvas de crecimiento y regresiones lineales del hongo A. flavus AFUNL5 cuando fue desafiado con SLC obtenidos a diferentes temperaturas como fueron $20^{\circ} \mathrm{C}, 30^{\circ} \mathrm{C}$ y $37^{\circ} \mathrm{C}$. El cultivo del hongo con los SLC siempre se realizó a $30^{\circ} \mathrm{C}$. En la figura 6.1 .3 se presenta la curva de crecimiento control del hongo filamentoso $A$. flavus AFUNL5 en medio MEA (extracto de malta, extracto de levadura y agar) (a) su regresión lineal (b).
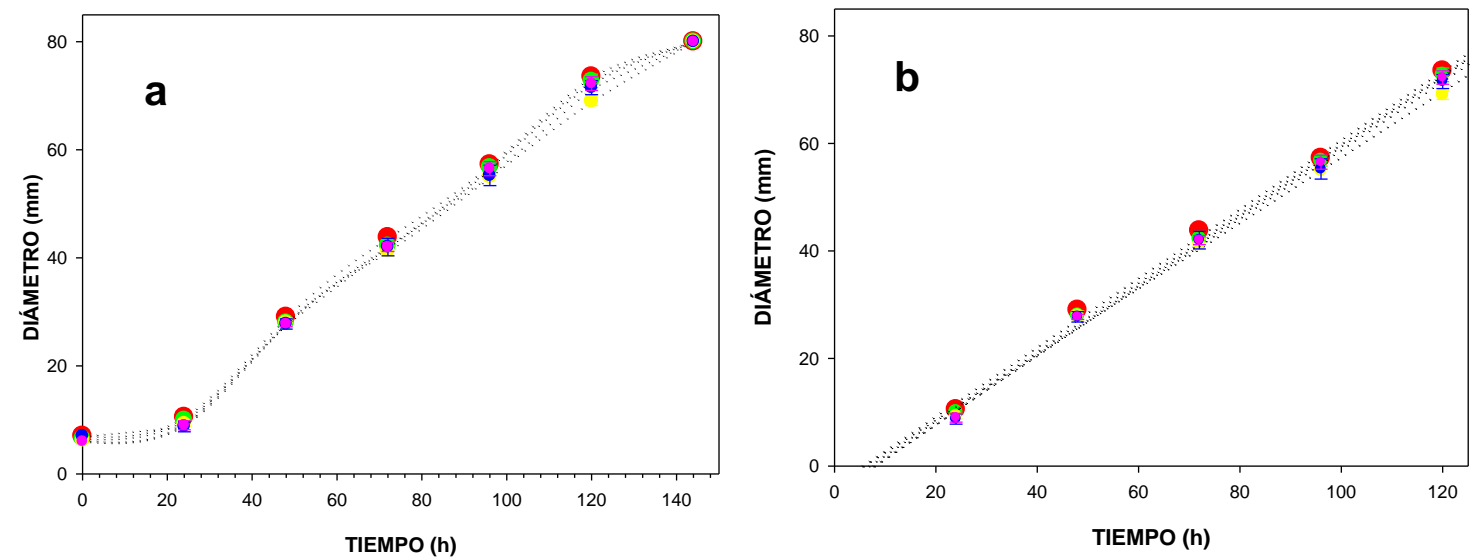

Figura 6.1.3 Curva de crecimiento A. flavus AFUNL5 a $30{ }^{\circ} \mathrm{C}$ (a) y Regresión lineal (b). Se hicieron cinco experimentos independientes;los resultados se indican con diferentes colores.

๑०; ;๑;॰.

En la figura 6.1.3 se observa que el control alcanzó el diámetro máximo de la caja de petri en 144 horas. La curva de crecimiento se hizo lineal aproximadamente entre las 24 y 120 horas, rango empleado para calcular la regresión lineal del crecimiento y los parámetros cinéticos del control. Éstos

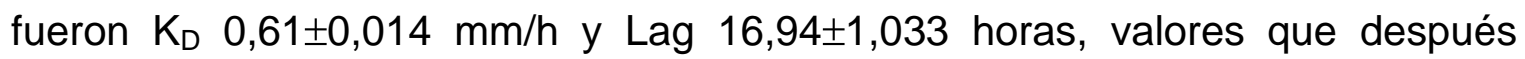
fueron empleados en la determinación de los índices de inhibición de la tasa de crecimiento (IIK $\mathrm{K}_{\mathrm{D}} \%$ ) y de incremento de la fase Lag (IILag\%) con los diferentes tratamientos. A continuación se discutirán los resultados obtenidos en la inhibición fúngica obtenida con SLC de leches fermentadas con ambos gránulos a diferentes temperaturas y a diferentes valores de $\mathrm{pH}$ final. 


\subsection{Efecto antifúngico sobre A. flavus AFUNL5, de los SLC de leches fermentadas a $20^{\circ} \mathrm{C}$ con gránulos de kefir CIDCA AGK1 y CIDCA AGK2.}

La leche se fermentó con gránulos CIDCA AGK1 y AGK2 a $20{ }^{\circ} \mathrm{C}$ hasta diferentes $\mathrm{pH}$ y los SLC se obtuvieron como se describió en materiales y métodos generales. En las figuras 6.1.4 y 6.1.5, se indican algunas curvas de crecimiento y regresiones lineales y en la Tabla 6.1 .5 se resumen los parámetros Tasa de crecimiento $\mathrm{K}_{\mathrm{D}}(\mathrm{mm} / \mathrm{h})$ y Fase de latencia Lag (h) de $A$. flavus AFUNL5 cultivado en medio MEA adicionado con SLC de kefir fermentado a $20^{\circ} \mathrm{C}$.

\subsection{Efecto antifúngico de SLC de leche fermentada con gránulo CIDCA AGK2 a $20^{\circ} \mathrm{C}$ sobre A. flavus AFUNL5.}

Los SLC se obtuvieron a valores de $\mathrm{pH} 3,5,3,3$ y 3,1 y se adicionaron al medio en concentración final de $50 \%, 10 \%, 1 \%$ y $0,1 \%$. Las diluciones $1 \%$ y $0,1 \%$ no presentaron diferencias significativas con el control en los parámetros cinéticos como se observa en la figura 6.1.4. Es por ello que en los siguientes apartados se presentan los resultados obtenidos con las concentraciones mayores.

A partir de los datos presentados en la curva a pH 3,5, correspondientes a la dilución del 50\% se pudo establecer que con el SLC del gránulo CIDCA AGK2, A. flavus AFUNL5 presentó $K_{D}$ de $0,48 \mathrm{~mm} / \mathrm{h}$ y una fase de latencia de 17,7 horas, las cuales tuvieron un IIK $K_{D}$ de 20,97 \% y un IILag de 34,4 \%. El mínimo $\mathrm{pH}$ obtenido con la leche fermentada con gránulos de kefir CIDCA AGK2 estuvo en valores entre 3,3 y 3,1 . A estos valores, en la concentración del $50 \% \mathrm{~K}_{\mathrm{D}}$ fue 0,40 $\mathrm{mm} / \mathrm{h}$ y la fase Lag ya se observa desde lo gráfico, superior a la del control, con un valor de 52,3 horas. Sus valores de IIK $K_{D}$ y de IILag fueron respectivamente de 34,66 y $297,06 \%$. 

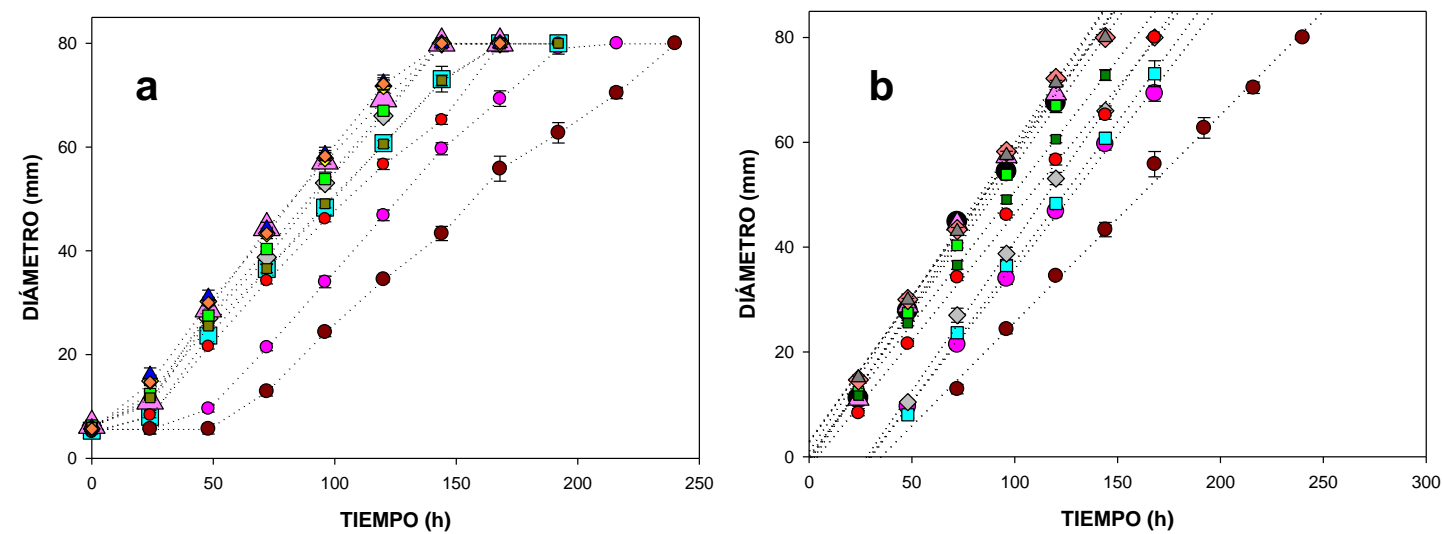

Figura 6.1.4 Curva de crecimiento (a) y Regresión lineal de la curva de crecimiento (b) de $A$. flavus AFUNL5 tratado con SLC de gránulo de kefir CIDCA AGK2 fermentado a $20{ }^{\circ} \mathrm{C}$, a pH 3,5 3,3 y 3,05, con el SLC en concentración del 50\%, 10\%, 1\% 0,1\%. SLC pH 3,5 concentración

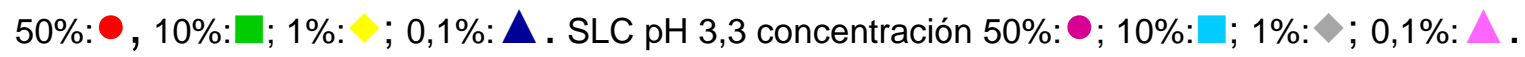
SLC pH 3,0 concentración 50\%: ; 10\%: : $1 \%: \diamond$.

\subsection{Efecto antifúngico de SLC de leche fermentada con gránulo CIDCA AGK1 a $20^{\circ} \mathrm{C}$ sobre A. flavus AFUNL5.}

Del gránulo CIDCA AGK1, a modo de ejemplo se presenta sólo la curva de crecimiento del hongo desafiado con el SLC a pH 3,1 y a concentración del 50\%.
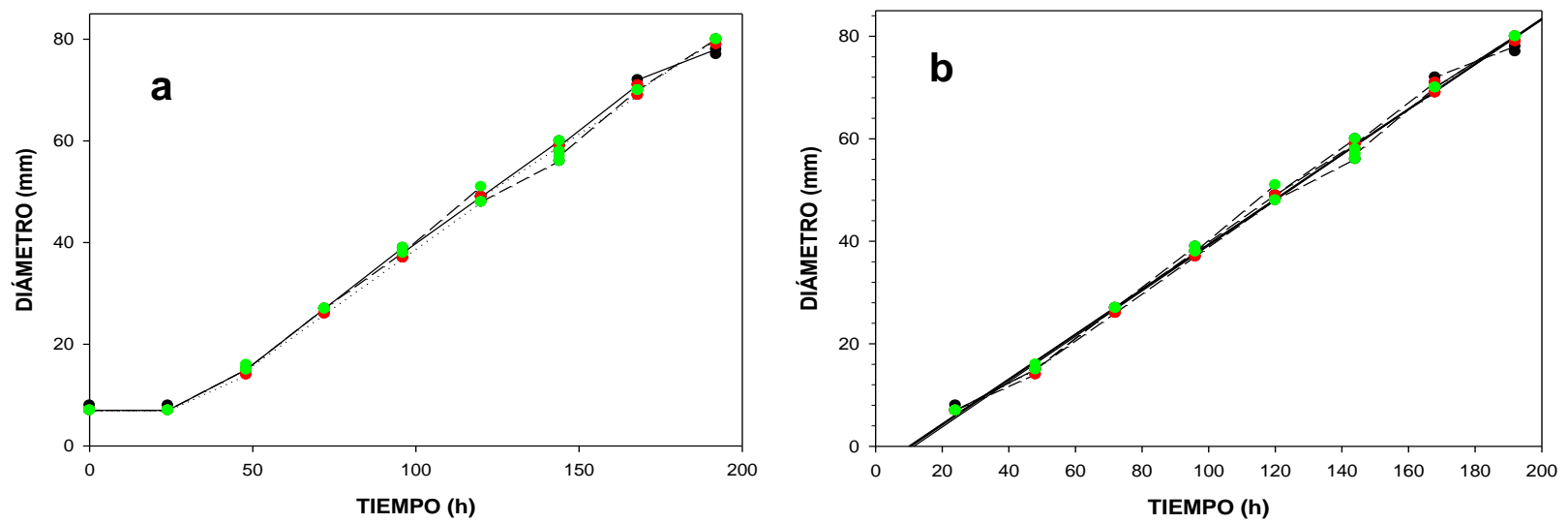

Figura 6.1.5 Curva de crecimiento (a) y Regresión lineal de la curva de crecimiento (b) de $A$. flavus AFUNL5 cultivado con SLC de gránulo de kefir CIDCA AGK1 fermentado a $20{ }^{\circ} \mathrm{C}$, a $\mathrm{pH}$ 3,1 , con el SLC en concentración del 50\%. Se realizaron tres experimentos independientes y los resultados se indican con diferentes colores. 


\subsection{INHIBICIÓN DEL CRECIMIENTO FÚNGICO CON LECHE FERMENTADA \\ CON GRÁNULOS DE KEFIR}

El SLC obtenido del gránulo CIDCA AGK1 a pH 3,1 y a concentración del 50\% redujo la velocidad de crecimiento con un valor de $0,44 \mathrm{~mm} / \mathrm{h}$ y 20,99 horas de fase Lag, lo cual corresponde a 27,27 \% y 102,46 \% para los índices IIK e IILag. Resulta llamativo que en las mismas condiciones de fermentación, el SLC proveniente de AGK1, produjo una inhibición inferior a la de AGK2, lo cual pudo deberse aparentemente a la mayor concentración de ácidos que produjo el gránulo CIDCA AGK2. En la siguiente tabla se resumen los parámetros cinéticos del crecimiento fúngico obtenidos mediante la adición de los SLC, al medio de cultivo. Se incluyen las concentraciones de ácidos determinadas en los SLC y en los medios de cultivo, mediante HPLC.

Tabla 6.1.1 Velocidad de crecimiento y fase Lag de A. flavus AFUNL5 en presencia de SLC de leche fermentada con gránulos de kefir CIDCA AGK1 y AGK2 incubados a $20^{\circ} \mathrm{C}$.

\begin{tabular}{|c|c|c|c|c|c|c|c|c|}
\hline $\begin{array}{c}\text { SLC } \\
\text { Adicionado }\end{array}$ & pH & $\begin{array}{l}\text { Acido } \\
\text { láctico } 2 \\
(\%)\end{array}$ & $\begin{array}{c}\text { Ácido } \\
\text { Acético } 2 \\
(\%)\end{array}$ & $\begin{array}{c}\text { Concentración } \\
\text { del } \\
\text { SLC } \\
(\%)\end{array}$ & $\begin{array}{l}\text { Acido } \\
\text { láctico }^{3} \\
(\%)\end{array}$ & $\begin{array}{c}\text { Ácido } \\
\text { Acético }^{3} \\
(\%)\end{array}$ & $\begin{array}{c}\text { Media } K_{D}^{4} \\
(\mathrm{~mm} / \mathrm{h})\end{array}$ & $\begin{array}{c}\text { Media } \\
\operatorname{Lag}^{4}(\mathrm{~h})\end{array}$ \\
\hline \multirow{4}{*}{ AGK1 } & \multirow{2}{*}{3,5} & \multirow{2}{*}{1,743} & \multirow{2}{*}{0,095} & 50 & 0,932 & 0,133 & $0,49 \pm 0,011$ & $20,99 \pm 1,11$ \\
\hline & & & & 10 & 0,236 & 0,057 & $0,54 \pm 0,002$ & $15,77 \pm 2,01$ \\
\hline & \multirow{2}{*}{3,1} & \multirow{2}{*}{1,870} & \multirow{2}{*}{0,111} & 50 & 0,927 & 0,120 & $0,44 \pm 0,001$ & $26,66 \pm 0,91$ \\
\hline & & & & 10 & 0,279 & 0,087 & $0,56 \pm 0,002$ & $16,2 \pm 1,54$ \\
\hline \multirow{4}{*}{ AGK2 } & \multirow{2}{*}{3,5} & \multirow{2}{*}{1,332} & \multirow{2}{*}{0,070} & 50 & 1,322 & 0,068 & $0,48 \pm 0,02$ & $17,7 \pm 3,31$ \\
\hline & & & & 10 & 0,179 & 0,060 & $0,56 \pm 0,001$ & $12,77 \pm 2,12$ \\
\hline & \multirow{2}{*}{3,1} & \multirow{2}{*}{1,977} & \multirow{2}{*}{0,123} & 50 & 1,047 & 0,113 & $0,40 \pm 0,023$ & $52,3 \pm 1,23$ \\
\hline & & & & 10 & 0,230 & 0,051 & $0,50 \pm 0,012$ & $13,18 \pm 2,25$ \\
\hline CONTROL $^{1}$ & 6,5 & $\mathrm{NC}^{5}$ & $\mathrm{NC}$ & $\mathrm{NC}$ & NC & NC & $0,63 \pm 0,014$ & $16,94 \pm 1,03$ \\
\hline
\end{tabular}

${ }^{1}$ Control de medio sin SLC.

${ }^{2}$ Concentraciones en el SLC original determinadas mediante HPLC

${ }^{3}$ Concentraciones en el medio de cultivo adicionado y determinadas mediante HPLC.

${ }^{4}$ Los valores $\mathrm{K}_{\mathrm{D}}$ y Lag fueron obtenidos a partir de las curvas 6.1 .4 y 6.1.5 y mediante la ecuación 4.2

${ }^{5}$ NC: No cuantificado

En la Tabla 6.1.1 se observa que en presencia de los SLC de kefir a $20{ }^{\circ} \mathrm{C}$, la fase Lag (h) aumentó y el $K_{D}(\mathrm{~mm} / \mathrm{h})$ se redujo a medida que descendía el pH y aumentaba la concentración de sobrenadante en el medio de cultivo. Además, el descenso de $\mathrm{pH}$ fue correspondiente con un aumento en la concentración de los ácidos orgánicos que estuvieron entre 1,33 y casi $2 \%$ para el láctico y entre 0,07 y $0,123 \%$ para el acético en sus SLC originales. También se determinaron mediante HPLC las concentraciones de los ácidos orgánicos cuando se diluyeron los SLC en concentraciones de $50 \%$ y $10 \%$ en el medio de cultivo. Se pudo confirmar que la concentración de ácido se reducía y que los desafíos se hicieron en presencia de concentraciones que estuvieron entre 0,170 y $1,322 \%$ 
de láctico y 0,051 y 0,133\% de acético. En vista de lo analizado en el capítulo 5, se podría confirmar que la inhibición se debe al menos en parte a la presencia de ambos ácidos. De esta manera, el SLC obtenido a pH 3,1 del gránulo de kefir CIDCA AGK2, adicionado al 50\%, aumentó la fase Lag de forma más significativa que con el gránulo CIDCA AGK1 y a su vez tuvo la mayor concentración de ácidos orgánicos.

\subsection{Efecto antifúngico sobre $A$. flavus AFUNL5, de los SLC de leches fermentadas a $30{ }^{\circ} \mathrm{C}$ con gránulos de kefir CIDCA AGK1 y CIDCA AGK2.}

Los SLC se obtuvieron fermentando leche a $30^{\circ} \mathrm{C}$ hasta valores de $\mathrm{pH}$ de 4,5 , 3,5 y 3,3 y se agregaron al medio al $50 \%$ y al $10 \%$. En las siguientes figuras, se presentan las curvas de crecimiento y regresiones lineales de $A$. flavus AFUNL5 crecido en el medio MEA adicionado de SLC a pH 4,5; 3,5 y 3,3.

\subsection{Efecto antifúngico sobre $A$. flavus AFUNL5 con SLC de leche fermentada con gránulo CIDCA AGK1 a $30^{\circ} \mathrm{C}$.}
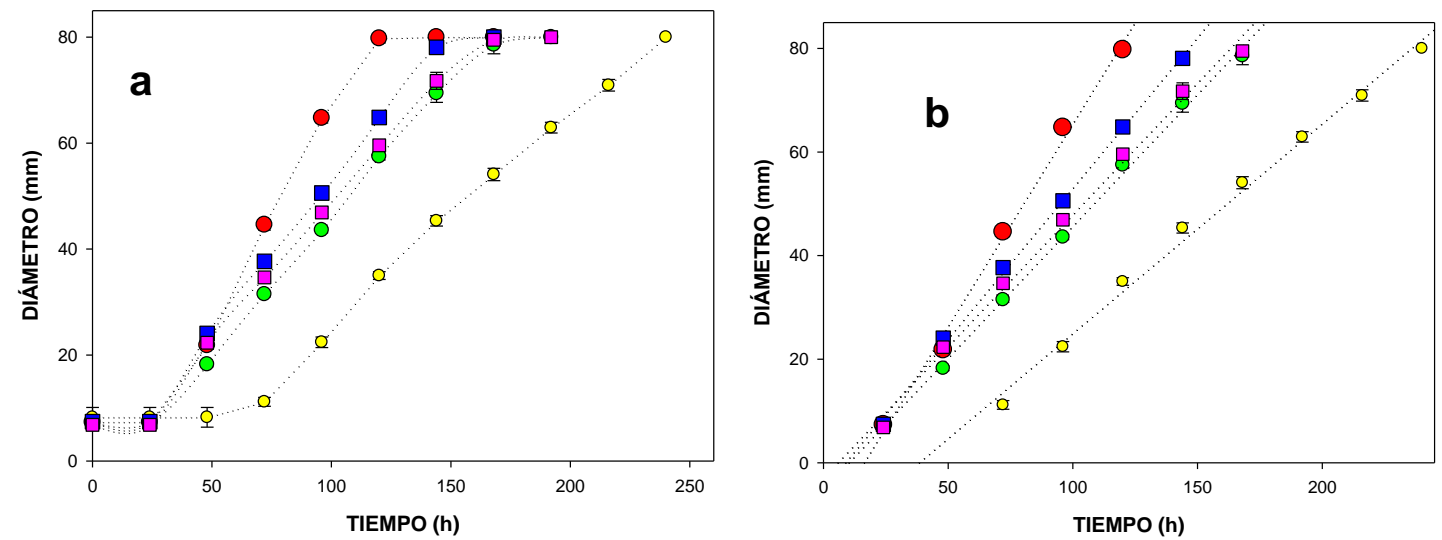

Figura 6.1.6 Curva de crecimiento (a) y Regresión lineal (b) de A. flavus AFUNL5 cultivado con SLC de gránulo de kefir CIDCA AGK1 fermentado a $30^{\circ} \mathrm{C}$, hasta $\mathrm{pH} 4,5 ; 3,5$ y 3,3; concentración del SLC del 50\% y 10\%. SLC pH 4,5 concentración 50\%: •; SLC pH 3,5 concentración $50 \%$ y 10\%: $\square$; SLC pH 3,3 concentración 50\%: y 10\%:

En la figura 6.1.6 (a) se observa la curva de crecimiento de A. flavus AFUNL5 en presencia de SLC de AGK1 a pH 4,5; 3,5 y 3,3 en concentraciones de SLC del $50 \%$ y $10 \%$. En primer lugar se determinó que la adición de leche a un pH poco 
inhibitorio como 4,5 hace prevalecer el efecto estimulante debido a los nutrientes presentes en la leche fermentada. Por tal motivo, se favoreció el crecimiento del hongo, a tal punto que su $K_{D}(0,78 \pm 0,004 \mathrm{~mm} / \mathrm{h})$ fue superior al $K_{D}$ correspondiente al control.

Se observa diferencia en las curvas correspondientes a ambas diluciones a $\mathrm{pH}$ 3,5. En $50 \%$, el hongo alcanzó el máximo diámetro de la caja en 200 horas, tardando 56 horas más que el control (144 h), mientras que no hubo diferencia entre la concentración $10 \%$ y el control. En la figura 6.1.6 (b) se visualiza también que la pendiente de crecimiento a pH 3,5 de la concentración $50 \%$ fue $0,52 \mathrm{~mm} / \mathrm{h}$, inferior a la de concentración $10 \%(0,58 \mathrm{~mm} / \mathrm{h})$, y ambas inferiores a la del control $(0,61 \mathrm{~mm} / \mathrm{h})$. Por otro lado, la fase Lag fue superior $(25,61 \mathrm{~h})$ al $50 \%$ con respecto al $10 \%(21,48 \mathrm{~h})$ y ambas muy superiores a la fase Lag del control de 13,04 horas. De los resultados anteriores se puede afirmar que este sobrenadante tuvo efecto antifúngico superior al mismo SLC obtenido a $20^{\circ} \mathrm{C}$. Se analizó si el SLC obtenido a $30{ }^{\circ} \mathrm{C}$, y a pH 3,3 tendría mayor efecto antifúngico.

El hongo desafiado con SLC obtenidos con gránulo CIDCA AGK1 a pH 3,3 en concentración 50\%, tardó 240 horas en alcanzar el diámetro máximo de la placa, unas 100 horas más que el control; mientras que a concentración 10\% tardó 198 horas, superando en 58 horas al control. En la figura 6.1.6 (b), se determinó la regresión lineal de ambas curvas de crecimiento, siendo de 0,45 y $0,55 \mathrm{~mm} / \mathrm{h}$ y las fases Lag fueron de 63,7 y 17,03 horas para las concentraciones 50 y $10 \%$ respectivamente. Se determinó que al descender el pH de 3,5 a 3,3 y al 50\%, la fase Lag aumentó (de 25,61 a 63,7 horas) y la tasa de crecimiento disminuyó (de 0,52 a $0,45 \mathrm{~mm} / \mathrm{h}$ ). 


\section{- Efecto antifúngico sobre A. flavus AFUNL5 con SLC de leche fermentada con gránulo CIDCA AGK2 a $30^{\circ} \mathrm{C}$.}
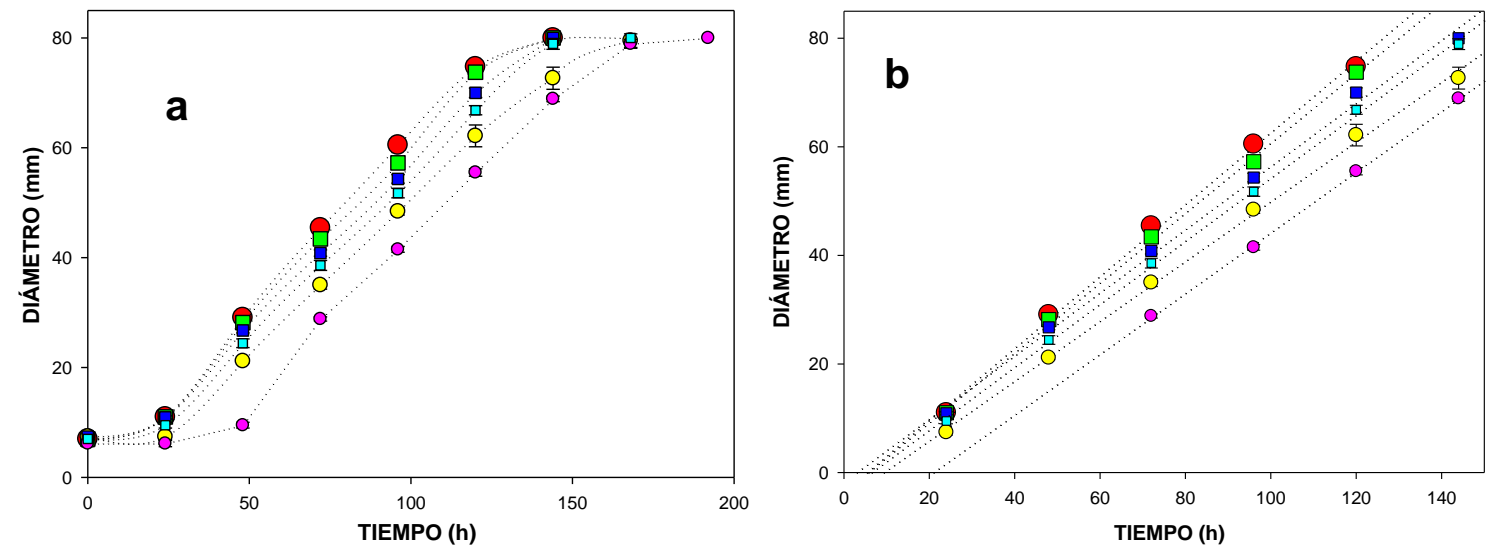

Figura 6.1.7 Curva de crecimiento (a) y Regresión lineal (b) de A. flavus AFUNL5 cultivado con SLC de gránulo de kefir CIDCA AGK2 fermentado a $30 \stackrel{\circ}{\circ}$, hasta $\mathrm{pH} 4,5 ; 3,5$ y 3,3; en concentración del 50\% y 10\%. SLC pH 4,5, 50\%: •; y 10\%: : SLC pH 3,5, 50\%: y 10\%: SLC pH 3,3, 50\%: - y $10 \%$ : :.

El hongo desafiado con el SLC de leche fermentada a pH 4,5 con gránulo CIDCA AGK2, tuvo una $K_{D}$ que no se diferenció del control y su fase Lag fue inferior a la del control. Dados los resultados obtenidos con los SLC a pH 4,5 provenientes de ambos gránulos, se decidió no continuar evaluando la inhibición fúngica a este $\mathrm{pH}$ con los SLC provenientes de la fermentación con gránulos de kefir. Los SLC de la leche fermentada con el gránulo CIDCA AGK2 a pH 3,5 en concentración 50\% aumentaron el tiempo total para alcanzar el diámetro total de la caja de petri (168 horas) con respecto a la concentración del 10\% (144 h), tal como se observa en la figura 6.1.7 (a). A partir de la regresión lineal, Figura 6.1.7 (b), se estableció la tasa de crecimiento a pH 3,5 de la dilución $50 \%$ y $10 \%$ en 0,57 y $0,60 \mathrm{~mm} / \mathrm{h}$ respectivamente y la fase de latencia 23,87 y 17,41 horas. Con estos resultados se determinó que a este pH el SLC de AGK2 tuvo, al igual que AGK1, efecto inhibidor sobre el crecimiento del hongo, siendo mayor el efecto logrado por AGK1. Se continuó evaluando el efecto antifúngico con el SLC de AGK2 a un pH mas acido, de 3,3. En la figura 6.1.7 (a) también se presenta el crecimiento del hongo en presencia de SLC obtenidos con gránulo CIDCA AGK2 a $\mathrm{pH}$ de 3,3 en concentraciones $50 \%$ y $10 \%$. 


\subsection{INHIBICIÓN DEL CRECIMIENTO FÚNGICO CON LECHE FERMENTADA CON GRÁNULOS DE KEFIR}

A pH 3,3, concentración 50\%, el hongo tardó más tiempo que el control en alcanzar el diámetro con un tiempo total de 168 horas; mientras que en la concentración $10 \%$ fue el mismo tiempo de 144 horas del control, Figura 6.1.7 (a). No obstante, con ambas diluciones, el hongo tardó menos que cuando estuvo en presencia del SLC del gránulo CIDCA AGK1 al mismo pH. Las tasas de crecimiento, Figura 6.1 .7 (b), fueron 0,56 y $0,58 \mathrm{~mm} / \mathrm{h}$ y las fases Lag 31,98 y 18,52 horas en las concentraciones $50 \%$ y $10 \%$. En la concentración $50 \%$, el índice de inhibición sobre la tasa de crecimiento fue $7,95 \%$ y el índice de incremento sobre la fase de latencia fue 145,27\%. Ambos efectos fueron inferiores significativamente con respecto a los obtenidos con el gránulo CIDCA AGK1, los cuales fueron IIK de $25,43 \%$ e IILag de $388,47 \%$.

En la tabla 6.1.2 se resumen los parámetros cinéticos de tasa de crecimiento y fase de latencia del hongo cultivado en el medio sólido adicionado de los SLC obtenidos a $30{ }^{\circ} \mathrm{C}$ y la concentración de ácidos orgánicos en dichos SLC.

Tabla 6.1.2 Velocidad de crecimiento y fase Lag de $A$. flavus AFUNL5 en presencia de SLC de gránulos de kefir CIDCA AGK1 y AGK2 incubados a $30^{\circ} \mathrm{C}$.

\begin{tabular}{|c|c|c|c|c|c|c|c|c|}
\hline $\begin{array}{c}\text { SLC } \\
\text { Adicionado }\end{array}$ & $\mathrm{pH}$ & $\begin{array}{c}\text { Acido } \\
\text { láctico }^{2} \\
(\%)\end{array}$ & $\begin{array}{c}\text { Ácido } \\
\text { Acético } \\
(\%)\end{array}$ & $\begin{array}{c}\text { Concentración } \\
\text { del } \\
\text { SLC } \\
(\%) \\
\end{array}$ & $\begin{array}{c}\text { Acido }^{3} \\
\text { láctico }^{3} \\
(\%)\end{array}$ & $\begin{array}{c}\text { Ácido } \\
\text { Acético }^{3} \\
(\%)\end{array}$ & $\begin{array}{c}\text { Media } K_{D}{ }^{4} \\
(\mathrm{~mm} / \mathrm{h})\end{array}$ & $\begin{array}{c}\text { Media Lag } \\
\quad{ }^{4}(\mathrm{~h})\end{array}$ \\
\hline \multirow{6}{*}{ AGK1 } & \multirow{2}{*}{4,5} & \multirow{2}{*}{0,407} & \multirow{2}{*}{0,030} & 50 & 0,2035 & 0,0150 & $0,78 \pm 0,004$ & $25,57 \pm 0,62$ \\
\hline & & & & 10 & 0,0407 & 0,0030 & $>0,61$ & $16,23 \pm 0,52$ \\
\hline & \multirow{2}{*}{3,5} & \multirow{2}{*}{1,947} & \multirow{2}{*}{0,044} & 50 & 0,9735 & 0,0220 & $0,52 \pm 0,013$ & $24,47 \pm 1,16$ \\
\hline & & & & 10 & 0,1947 & 0,0044 & $0,58 \pm 0,008$ & $21,48 \pm 0,28$ \\
\hline & \multirow{2}{*}{3,3} & \multirow{2}{*}{3,171} & \multirow{2}{*}{0,124} & 50 & 1,5855 & 0,0620 & $0,40 \pm 0,009$ & $59,008 \pm 2,54$ \\
\hline & & & & 10 & 0,3171 & 0,0124 & $0,53 \pm 0,021$ & $20,67 \pm 1,37$ \\
\hline \multirow{6}{*}{ AGK2 } & \multirow{2}{*}{4,5} & \multirow{2}{*}{0,347} & \multirow{2}{*}{0,014} & 50 & 0,1735 & 0,007 & $0,67 \pm 0,004$ & $15,89 \pm 0,24$ \\
\hline & & & & 10 & 0,0347 & 0,0014 & $0,64 \pm 0,0016$ & $16,55 \pm 0,23$ \\
\hline & \multirow{2}{*}{3,5} & \multirow{2}{*}{0,614} & \multirow{2}{*}{0,033} & 50 & 0,307 & 0,0165 & $0,55 \pm 0,014$ & $22,76 \pm 0,43$ \\
\hline & & & & 10 & 0,0614 & 0,0033 & $0,58 \pm 0,002$ & $15,72 \pm 0,14$ \\
\hline & \multirow{2}{*}{3,3} & \multirow{2}{*}{1,986} & \multirow{2}{*}{0,104} & 50 & 0,993 & 0,052 & $0,56 \pm 0,003$ & $31,98 \pm 0,62$ \\
\hline & & & & 10 & 0,1986 & 0,0104 & $0,58 \pm 0,002$ & $18,52 \pm 0,46$ \\
\hline CONTROL' & 6,5 & $\mathrm{NC}^{5}$ & $\mathrm{NC}$ & $\mathrm{NC}$ & $\mathrm{NC}$ & $\mathrm{NC}$ & $0,63 \pm 0,014$ & $16,94 \pm 1,033$ \\
\hline
\end{tabular}

Control de medio sin SLC.

${ }^{2}$ Concentraciones en el SLC original determinadas mediante HPLC

${ }^{3}$ Calculados a partir de la concentración original.

${ }^{4}$ Los valores $\mathrm{K}_{\mathrm{D}}$ y Lag fueron obtenidos a partir de las curvas 6.1 .6 y 6.1 .7 y mediante la ecuación 4.2

${ }^{5}$ NC: No cuantificado. 
En la Tabla 6.1.2 se observa que en presencia de los SLC de leche fermentada con gránulos de kefir a $30^{\circ} \mathrm{C}$, la fase Lag (h) aumentaba y $\mathrm{K}_{\mathrm{D}}(\mathrm{mm} / \mathrm{h})$ disminuía a medida que descendía el pH y aumentaba la concentración de sobrenadante en el medio de cultivo. Todo a excepción del pH 4,5, cuya $K_{D}$ fue superior a la del control, lo cual se debió posiblemente a que los compuestos de la leche pudieron estimular el crecimiento fúngico superando el efecto inhibitorio de los ácidos presentes en el kefir, que no pudieron inhibir debido a su baja concentración y al alto $\mathrm{pH}$ del SLC.

A esta temperatura de fermentación de la leche, se determinó que los SLC de la leche fermentada con gránulo CIDCA AGK1 eran más inhibitorios que los obtenidos con gránulo CIDCA AGK2, lo cual pudo deberse a una mayor concentración de ácidos en la concentración del 50\%, que correspondía a $1,5855 \%$ de ácido láctico y $0,0620 \%$ de ácido acético. Una vez evaluados los SLC producidos a 20 y $30^{\circ} \mathrm{C}$, se procedió a evaluar el efecto antifúngico del SLC obtenido a $37^{\circ} \mathrm{C}$.

\subsection{Efecto antifúngico sobre $A$. flavus AFUNL5, de los SLC de leches fermentadas a $37^{\circ} \mathrm{C}$ con gránulos de kefir CIDCA AGK1 y CIDCA AGK2.}

La leche se fermentó con gránulos de kefir a $37^{\circ} \mathrm{C}$, alcanzando valores de $\mathrm{pH}$ de 3,5 y 3,3. Las curvas de crecimiento de $A$. flavus AFUNL5 y las gráficas de regresión lineal se presentan en las figuras 6.1 .8 y 6.1.9.

\subsection{Efecto antifúngico sobre $A$. flavus AFUNL5 con SLC de leche fermentada con gránulo CIDCA AGK1 a $37^{\circ} \mathrm{C}$.}

En la Figura 6.1.8 (a) y (b) se observa la curva de crecimiento y la regresión lineal de $A$. flavus AFUBA5 tratado con SLC de leche fermentada con gránulo CIDCA AGK1, incubado a $37^{\circ} \mathrm{C}$ hasta $\mathrm{pH} 3,3$ en concentración $50 \%$. El hongo tardó 168 horas en alcanzar el borde de la caja, tardando 24 horas más que el control. Su tasa de crecimiento fue $0,54 \pm 0,0001 \mathrm{~mm} / \mathrm{h}$, inferior al control $(0,61$ $\mathrm{mm} / \mathrm{h}$ ) y la fase Lag tuvo una duración de $23,4 \pm 0,3$ horas, unas 10 más que el 


\subsection{INHIBICIÓN DEL CRECIMIENTO FÚNGICO CON LECHE FERMENTADA \\ CON GRÁNULOS DE KEFIR}

control. La concentración $10 \%$ (no graficada) tuvo $\mathrm{K}_{\mathrm{D}}$ igual al control y su fase Lag sólo superó en tres horas la correspondiente al control. Este SLC a pH 3,3 tuvo efecto antifúngico en la concentración $50 \%$.
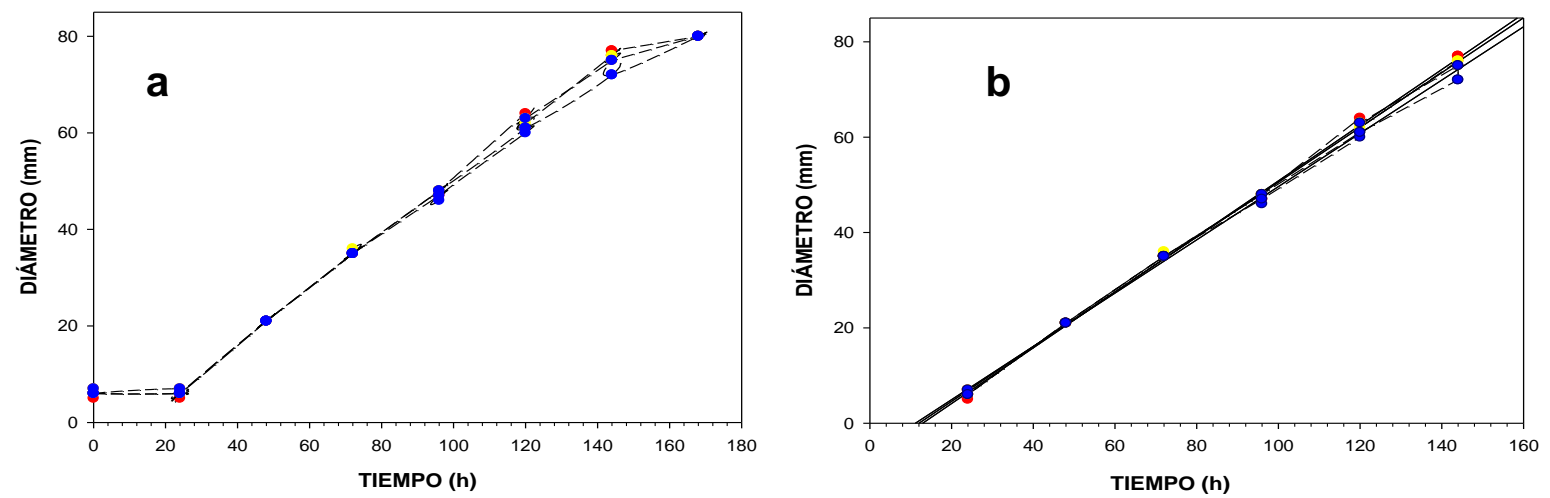

Figura 6.1.8 Curva de crecimiento (a) y Regresión lineal de la curva de crecimiento (b) de $A$. flavus AFUNL5 cultivado con SLC de gránulo de kefir CIDCA AGK1 fermentado a $37^{\circ} \mathrm{C}$, a $\mathrm{pH}$ 3,3 , con el SLC en concentración del $50 \%$. Se realizaron tres experimentos independientes que se indican con diferentes colores:

\subsection{Efecto antifúngico sobre A. flavus AFUNL5 con SLC de leche fermentada con gránulo CIDCA AGK2 a $37^{\circ} \mathrm{C}$.}
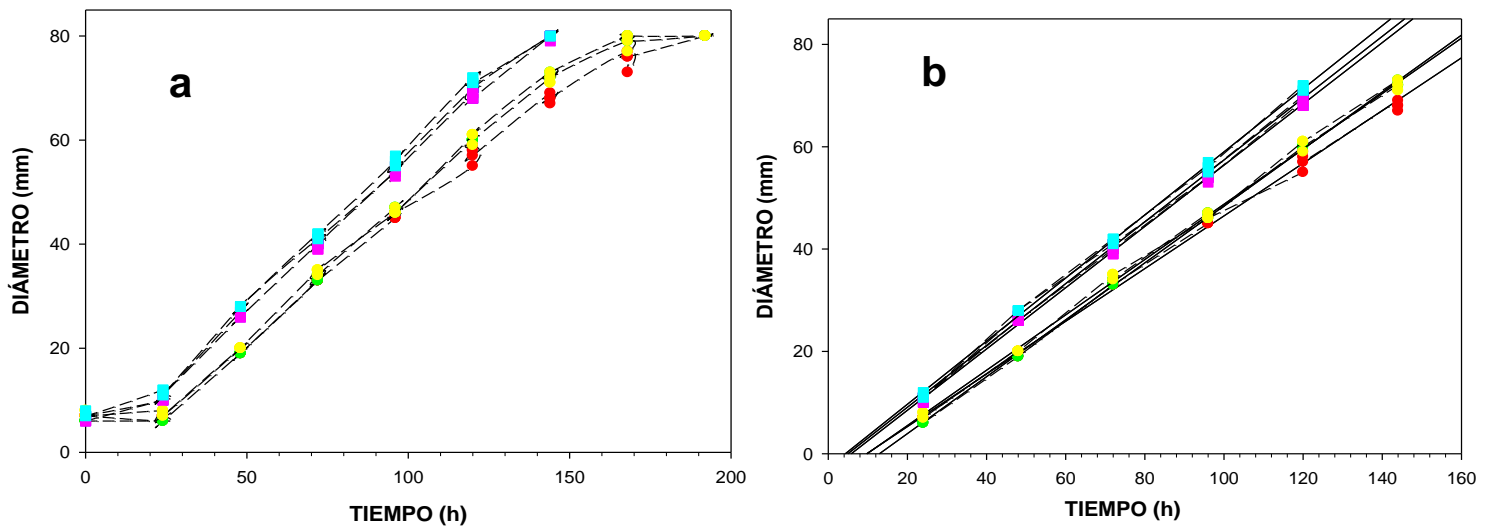

Figura 6.1.9 Curva de crecimiento (a) y Regresión lineal de la curva de crecimiento (b) de $A$. flavus AFUNL5 cultivado con SLC de gránulo de kefir CIDCA AGK2 fermentado a $37^{\circ} \mathrm{C}$, a pH 3,3. Se realizaron tres experimentos independientes con el SLC en concentración $50 \%$ y $10 \%$ en el medio de cultivo. SLC AGK2 pH 3,3, 50\%:๑; ; ; SLC AGK2 pH 3,3, 10\%: $\mathbf{\square} ; \mathbf{\square} ; \square$. 
Tal como se visualiza en la figura 6.1 .9 (a), a concentración $50 \%$, el hongo tardó 192 horas en alcanzar el diámetro de la caja de petri, 48 horas más que el control y 24 más que con el SLC de AGK1 al mismo pH. A la concentración 10\% no hubo diferencia con el control. A partir de la regresión lineal, Figura 6.1 .9 (b), se estableció para la concentración $50 \%$ de SLC una $K_{D}$ de $0,57 \pm 0,0001 \mathrm{~mm} / \mathrm{h}$, inferior al control y una fase Lag de $22,8 \pm 0,81$ horas, a partir de lo cual se pudo concluir que este SLC tenía también efecto antifúngico.

En la tabla 6.1 .3 se resumen los valores de ácidos orgánicos presentes y de los parámetros cinéticos del hongo cultivado en el medio con el SLC obtenido con los gránulos a $37^{\circ} \mathrm{C}$.

Tabla 6.1.3 Velocidad de crecimiento y fase Lag de A. flavus AFUNL5 en presencia de SLC de gránulos de kefir CIDCA AGK1 y CIDCA AGK2 incubados a $37^{\circ} \mathrm{C}$.

\begin{tabular}{|c|c|c|c|c|c|c|c|c|}
\hline $\begin{array}{c}\text { SLC } \\
\text { Adicionado }\end{array}$ & $\mathrm{pH}$ & $\begin{array}{c}\text { Ácido } \\
\text { láctico } 1 \\
(\%)\end{array}$ & $\begin{array}{c}\text { Ácido } \\
\text { Acético }{ }^{1} \\
(\%)\end{array}$ & $\begin{array}{c}\text { Concentración } \\
\text { sobrenadante }\end{array}$ & $\begin{array}{c}\text { Ácido } \\
\text { láctico } \\
(\%)\end{array}$ & $\begin{array}{c}\text { Ácido } \\
\text { Acético } 2 \\
(\%)\end{array}$ & $\begin{array}{c}\text { Media } \mathrm{K}_{\mathrm{D}}^{3} \\
(\mathrm{~mm} / \mathrm{h})\end{array}$ & $\begin{array}{c}\text { Media } \\
\text { Lag }^{3} \\
\text { (h) }\end{array}$ \\
\hline \multirow{4}{*}{ AGK1 } & \multirow{2}{*}{3,5} & \multirow{2}{*}{1,363} & \multirow{2}{*}{0,082} & $50 \%$ & 0,6815 & 0,041 & $0,64 \pm 0,001$ & $24,34 \pm 1,2$ \\
\hline & & & & $10 \%$ & 0,1363 & 0,0082 & $0,62 \pm 0,0002$ & $18,72 \pm 1,1$ \\
\hline & \multirow{2}{*}{3,3} & \multirow{2}{*}{1,186} & \multirow{2}{*}{0,325} & $50 \%$ & 0,593 & 0,1625 & $0,54 \pm 0,0001$ & $23,4 \pm 0,3$ \\
\hline & & & & $10 \%$ & 0,1186 & 0,0325 & $0,61 \pm 0,0001$ & $16,14 \pm 1,3$ \\
\hline \multirow{4}{*}{ AGK2 } & \multirow{2}{*}{3,5} & \multirow{2}{*}{1,223} & \multirow{2}{*}{0,075} & $50 \%$ & 0,6115 & 0,0375 & $0,60 \pm 0,001$ & $22,11 \pm 1,2$ \\
\hline & & & & $10 \%$ & 0,1223 & 0,0075 & $0,56 \pm 0,0003$ & $15,89 \pm 1,01$ \\
\hline & \multirow{2}{*}{3,3} & \multirow{2}{*}{1,359} & \multirow{2}{*}{0,278} & $50 \%$ & 0,6795 & 0,139 & $0,57 \pm 0,0001$ & $22,8 \pm 0,81$ \\
\hline & & & & $10 \%$ & 0,1359 & 0,0278 & $0,61 \pm 0,002$ & $16,23 \pm 1,3$ \\
\hline CONTROL $^{4}$ & 6,5 & $N C^{5}$ & $\mathrm{NC}$ & $\overline{N C}$ & $\overline{N C}$ & $\overline{N C}$ & $0,61 \pm 0,11$ & $13,04 \pm 1,01$ \\
\hline
\end{tabular}

Determinados en el SLC original mediante HPLC.

${ }^{2}$ Calculados a partir de la concentración original.

${ }^{3}$ Valores $K_{D}$ y Lag fueron obtenidos a partir de las curvas 6.1 .8 y 6.1 .9 y mediante la ecuación 4.2

${ }^{4}$ Control de medio sin SLC.

${ }^{5}$ NC: No Cuantificado.

En presencia del SLC obtenido con gránulo CIDCA AGK1 a pH 3,5, concentración $10 \%$, A. flavus AFUNL5 tuvo $\mathrm{K}_{\mathrm{D}}$ de 0,62 $\pm 0,0002 \mathrm{~mm} / \mathrm{h}$, casi igual al control y su Lag de $18,72 \pm 1,1$ horas fue ligeramente superior al control. A concentración del 50\%, la velocidad de crecimiento de $0,64 \pm 0,001 \mathrm{~mm} / \mathrm{h}$, fue superior al control y la fase de adaptación fue de 24,34 $\pm 0,3$ horas, 11 horas más que el control. En presencia del SLC obtenido con gránulo CIDCA AGK2 al mismo $\mathrm{pH}$ de 3,5, concentración 10\%, hubo una inhibición aunque leve del hongo, pues su $K_{D}$ fue $0,56 \pm 0,003 \mathrm{~mm} / \mathrm{h}$ y lag fue $15,89 \pm 1,01$ horas. 
Al emplear el SLC de leche fermentada con gránulo CIDCA AGK1 a pH 3,3, concentración $50 \%, K_{D}$ fue de $0,54 \pm 0,0001 \mathrm{~mm} / \mathrm{h}$ y Lag $23,4 \pm 0,3$ horas, inhibición un poco superior a la del SLC obtenido con AGK2 cuya $K_{D}$ fue $0,57 \pm 0,0001 \mathrm{~mm} / \mathrm{h}$ y Lag $22,8 \pm 0,81$ horas. Estos dos SLC, generaron la mayor inhibición del hongo en esta serie de experimentos. La concentración 10\% de AGK1 a este $\mathrm{pH}$ no se graficó pero se observa que $K_{D}$ fue igual al control y que su fase lag solo superó en tres horas la Lag control. En conclusión, a esta temperatura no se observaron grandes diferencias en la capacidad inhibitoria de ambos gránulos y los efectos sobre la fase Lag fueron inferiores a los observados a 20 y $30^{\circ} \mathrm{C}$.

6.1.5 Determinación del Índice de Inhibición de la tasa de crecimiento IIK (\%) y del Índice de Incremento de la fase de latencia IILag (\%) de los tratamientos con SLC de leche fermentada con gránulos CIDCA AGK1 y AGK2.

A partir de la fase Lag $(\mathrm{h})$ de los diversos tratamientos y su respectiva $\mathrm{K}_{\mathrm{D}}(\mathrm{mm} / \mathrm{h})$ se calcularon los índices de Incremento de la fase Lag (IILag\%) y de Inhibición de $K_{D}\left(I I K_{D} \%\right)$ según se describió en materiales y métodos generales, mediante las siguientes ecuaciones.

$\| K_{D}(\%)=\left\{\left(K_{\text {Dcontrol }}-K_{D \text { Tratamiento }}\right) / K_{\text {Dcontrol }}\right\} \times 100$

Ecuación 4.2

Donde

$\mathrm{K}_{\text {Dcontrol= }}$ Tasa de crecimiento del control

$\mathrm{K}_{\mathrm{DTratamiento}}$ tasa de crecimiento de cada tratamiento

IILag (\%) $=\left[\left(\operatorname{Lag}_{\text {Tratamiento }}-\right.\right.$ Lag $\left.\left._{\text {Control }}\right) / \operatorname{Lag}_{\text {Control }}\right] \times 100$

Ecuación 4.3

Donde:

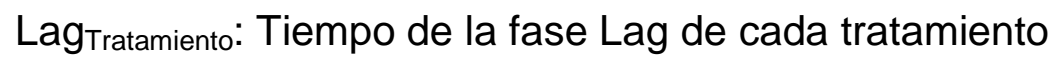

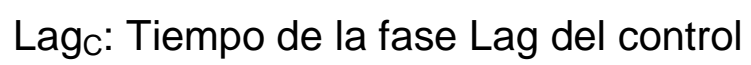




\subsection{INHIBICIÓN DEL CRECIMIENTO FÚNGICO CON LECHE FERMENTADA \\ CON GRÁNULOS DE KEFIR}

Tabla 6.1.4 IILag (\%) e IIK $(\%)$ de $A$. flavus AFUNL5 en presencia de SLC obtenidos con leche fermentada a 20,30 y $37^{\circ} \mathrm{C}$, con gránulos de kefir CIDCA AGK1 y AGK2.

\begin{tabular}{|c|c|c|c|c|c|c|c|c|}
\hline \multirow[b]{2}{*}{$\begin{array}{c}\text { SLC } \\
\text { adicionado }\end{array}$} & \multirow[b]{2}{*}{$\mathrm{pH}$} & \multirow{2}{*}{$\begin{array}{c}\text { Concentración } \\
\text { SLC } \\
\text { (\%) }\end{array}$} & \multicolumn{2}{|c|}{ Fermentación $20^{\circ} \mathrm{C}$} & \multicolumn{2}{|c|}{ Fermentación $30^{\circ} \mathrm{C}$} & \multicolumn{2}{|c|}{ Fermentación $37^{\circ} \mathrm{C}$} \\
\hline & & & $\begin{array}{c}\text { Media IIK } \\
(\%)\end{array}$ & $\begin{array}{c}\text { Media IILag } \\
(\%)\end{array}$ & $\begin{array}{c}\text { Media IIK } \\
(\%)\end{array}$ & $\begin{array}{c}\text { Media IILag } \\
(\%)\end{array}$ & $\begin{array}{c}\text { Media IIK } \\
(\%)\end{array}$ & $\begin{array}{c}\text { Media IILag } \\
(\%)\end{array}$ \\
\hline \multirow{4}{*}{ AGK1 } & \multirow{2}{*}{3,5} & 50 & $22,22 \pm 1,01^{d}$ & $23,91 \pm 2,11^{9}$ & $19,97 \pm 2,06^{9}$ & $44,37 \pm 6,84^{i}$ & $-4,92 \pm 0,011^{i}$ & $86,65 \pm 1,23^{h}$ \\
\hline & & 10 & $14,29 \pm 2,23^{\mathrm{e}}$ & $-6,91 \pm 2,15^{i}$ & $8,57 \pm 1,28^{\mathrm{e}}$ & $26,72 \pm 1,66^{g}$ & $-1,64 \pm 0,991^{\mathrm{e}}$ & $43,56 \pm 2,22^{9}$ \\
\hline & \multirow{2}{*}{$3,0^{1}$} & 50 & $30,16 \pm 1,11^{b}$ & $57,38 \pm 2,12^{d}$ & ${ }^{3} 35,86 \pm 1,48^{c}$ & $248,17 \pm 15,02^{\mathrm{a}}$ & ${ }^{4} 11,47 \pm 0,81^{f}$ & $79,45 \pm 0,85^{\dagger}$ \\
\hline & & 10 & $11,11 \pm 1,71^{\mathrm{e}}$ & $-4,36 \pm 2,34^{i}$ & $17,08 \pm 3,34^{9}$ & $21,94 \pm 8,09^{9}$ & $0^{\mathrm{e}}$ & $23,77 \pm 0,211^{i}$ \\
\hline \multirow{4}{*}{ AGK2 } & \multirow{2}{*}{3,5} & 50 & $23,79 \pm 1,00^{d}$ & $4,48 \pm 1,09^{g}$ & $13,40 \pm 2,27^{1}$ & $34,30 \pm 2,56^{\mathrm{e}}$ & $1,64 \pm 0,91^{\mathrm{e}}$ & $74,85 \pm 0,68^{\mathrm{e}}$ \\
\hline & & 10 & $11,11 \pm 1,91^{\mathrm{e}}$ & $-24,62 \pm 2,56^{h}$ & $8,54 \pm 0,38^{9}$ & $7,25 \pm 0,83^{g}$ & $8,20 \pm 0,411^{g}$ & $21,86 \pm 2,53^{i}$ \\
\hline & \multirow{2}{*}{$3,0^{1}$} & 50 & ${ }^{2} 36,51 \pm 1,11^{\mathrm{a}}$ & $208,74 \pm 7,23^{b}$ & $12,05 \pm 0,44^{\prime}$ & $88,70 \pm 3,68^{c}$ & $\sqrt[4]{6,56 \pm 0,2^{h}}$ & $74,85 \pm 1,1^{i}$ \\
\hline & & 10 & $20,63 \pm 3,31^{d}$ & $-22,19 \pm 3,25^{h}$ & $8,75 \pm 0,34^{e}$ & $9,28 \pm 2,74^{g}$ & $\overline{0^{\mathrm{e}}}$ & $24,46 \pm 1,7^{i}$ \\
\hline
\end{tabular}

${ }^{*}$ Resultados con diferentes letras en la misma columna difieren significativamente.

${ }^{1} \mathrm{pH} 3,3$ a temperaturas 30 y $37^{\circ} \mathrm{C}$.

${ }^{2,3,4}$ Tratamientos con mayor efecto antifúngico a las tres temperaturas evaluadas.

${ }^{4}$ El símbolo negativo indica que la $K_{D}$ del tratamiento fue superior $a K_{D}$ del control.

En la tabla 6.1.4 se resaltaron en verde los tratamientos con mayor poder inhibitorio a cada temperatura de fermentación. Ambos gránulos disminuyeron la tasa de crecimiento fúngica e incrementaron la fase Lag de $A$. flavus AFUNL5 y hubo diferencia entre los efectos causado por ambos gránulos. A medida que descendía el pH, se observó aumento del efecto inhibitorio de los SLC, ya que la inhibición fúngica, al menos en parte, depende de la presencia de ácidos orgánicos en el medio (tales como láctico y acético).

De todos los tratamientos, en el 83,33\% (20 de 24) de los casos hubo incremento de la fase Lag en un rango entre $4,48 \pm 1,09 \%$ y $248,17 \pm 15,02 \%$. No hubo incremento de la fase Lag con SLC obtenido con el gránulo CIDCA AGK2 y AGK1 en todos los SLC obtenidos a $20^{\circ} \mathrm{C}$ de incubación, adicionados al medio en concentración del 10\%. La tasa de crecimiento disminuyó con respecto al control, en el $91,67 \%$ de los casos (22 de 24 ), obteniéndose \%llK $\mathrm{K}_{\mathrm{D}}$ entre 0 y $36,51 \pm 1,11 \%$. No hubo reducción de la tasa de crecimiento en los tratamientos con SLC a pH 3,5 obtenido con gránulo CIDCA AGK1 a $37^{\circ} \mathrm{C}$ de incubación, en ambas concentraciones.

Los tratamientos también presentaron diferencias en la actividad antifúngica de acuerdo a la temperatura de incubación del kefir. Cuando la fermentación tuvo lugar a $20^{\circ} \mathrm{C}$, el SLC obtenido con gránulo CIDCA AGK2 tuvo mayor efecto inhibitorio que el SLC obtenido con gránulo CIDCA AGK1. Hubo diferencia 


\subsection{INHIBICIÓN DEL CRECIMIENTO FÚNGICO CON LECHE FERMENTADA}

CON GRÁNULOS DE KEFIR

significativa entre los índices de los dos tratamientos más efectivos, los cuales correspondieron al SLC obtenido con gránulo CIDCA AGK2 a pH 3,0 y concentración del 50\% y con gránulo CIDCA AGK1 al mismo pH y concentración. Este resultado fue especialmente notorio en el IILag, el cual fue 3,6 veces superior con los SLC del gránulo CIDCA AGK2.

Cuando la fermentación se realizó a $30^{\circ} \mathrm{C}$, los SLC de ambos gránulos tuvieron un efecto inhibidor superior al obtenido con los SLC fermentados a $20^{\circ} \mathrm{C}$. En esta condición $\left(30^{\circ} \mathrm{C}\right)$, el SLC proveniente del gránulo CIDCA AGK1 a pH 3,3 y concentración 50\% generó ambos índices con un valor 3 veces superior a los obtenidos con el SLC proveniente del gránulo CIDCA AGK2 al mismo pH.

La condición de incubación a $37^{\circ} \mathrm{C}$ produjo los SLC menos efectivos, observándose porcentajes inferiores al $100 \%$ en todos los casos, teniendo el mayor efecto inhibidor el SLC proveniente gránulo CIDCA AGK1 a pH 3,3 en concentración del 50\%.

En conclusión, los SLC obtenidos con gránulo CIDCA AGK2 produjeron el mayor efecto antifúngico cuando la fermentación de la leche se hizo a $20{ }^{\circ} \mathrm{C}$; mientras que los SLC obtenidos con gránulo CIDCA AGK1 tuvieron el mayor efecto antifúngico cuando la leche se fermentó a 30 y $37^{\circ} \mathrm{C}$. Todos los tratamientos causaron la mayor inhibición cuando se emplearon en concentración del 50\% y ello correspondió tanto a la disminución de la tasa de crecimiento como al incremento de la fase de latencia. El parámetro de crecimiento fúngico más afectado por los SLC de kefir fue la fase de latencia.

Es así que la mayor inhibición fúngica se obtuvo en la condición gránulo CIDCA AGK1, fermentado a $30^{\circ} \mathrm{C}$ hasta $\mathrm{pH} 3,3$ y adicionado en concentración del 50\% en el medio de cultivo (IIK $35,86 \pm 1,48 \%$ e IILag $248,17 \pm 15,02 \%$ ). Los resultados obtenidos sugieren que este SLC podría ser utilizado como biopreservante para aumentar la vida útil de determinados alimentos. En consecuencia, se evaluó su efecto preservante en arepas, tanto sobre la 


\subsection{INHIBICIÓN DEL CRECIMIENTO FÚNGICO CON LECHE FERMENTADA}

CON GRÁNULOS DE KEFIR

contaminación natural como la contaminación artificial con A. flavus, tal como se describirá al final de este capítulo.

En coincidencia con nuestros estudios, se ha demostrado previamente la capacidad de los SLC de leche fermentada con los gránulos de kefir CIDCA AGK1 y AGK2 de inhibir (mediante ensayos de difusión en agar), el crecimiento de Escherichia coli, E. coli EHEC, Salmonella spp., Shigella sonnei y Sh. flexneri, Bacillus cereus, B. subtilis, Staphylococcus aureus St.faecalis, Pseudomonas aeruginosa, S. typhi y Klebsiella pneumoniae (Garrote, Abraham \& De Antoni, 2000; Ismaiel, Ghaly \& El-Naggar, 2011).

También se demostró que los SLC de leche fermentada con gránulos de kefir adicionados a caldo nutritivo, inhibieron el crecimiento de $E$. coli a $37^{\circ} \mathrm{C}$, aún después de 24 horas de incubación, demostrando un efecto bacteriostático sobre dicho microorganismo cuando es inoculado en concentraciones iniciales de $10^{1}$, $10^{2}$ y $10^{3}$ UFC/ml (Garrote, 1999; Garrote, Abraham \& De Antoni, 2000). Otros autores también han reportado la capacidad antibacteriana del kefir tanto contra bacterias (Staphylococcus sp. y bacilos gram-positivos) como contra hongos (Candida spp., Saccharomyces spp., Rhodotorula spp., Torulopsis spp., Microsporum spp. y Trichopyton spp.) (Cevikbas, Yemni, Ezzedenn, Yardimici, Cevikbas \& Stohs, 1994).

En un estudio reciente, se evaluó la capacidad antifúngica del SLC de kefir adicionado en concentraciones de 0,5 a $10 \%$ en caldo Czapek-Dox, determinando el peso del micelio seco. En ese estudio se estableció que la concentración mínima a la cual no ocurría crecimiento fúngico era $10 \%$ y que al $9 \%$, la producción de micelio seco era un 18,77\% con respecto al control, o sea que obtuvieron una reducción del crecimiento del 81,23\% (Ismaiel, Ghaly \& ElNaggar, 2011). El anterior estudio coincidió con el nuestro en que se demostró la capacidad de la leche fermentada con gránulos de kefir de reducir el crecimiento fúngico. No obstante, ambos difieren en los porcentajes de inhibición fúngica. En el anterior, al emplear un $10 \%$ de kefir en el medio de cultivo, se obtuvo inhibición total del crecimiento, mientras que en esta investigación, a la máxima 


\subsection{INHIBICIÓN DEL CRECIMIENTO FÚNGICO CON LECHE FERMENTADA}

CON GRÁNULOS DE KEFIR

concentración de 50\%, no se inhibió totalmente el desarrollo fúngico. Nuestros resultados con las mayores inhibiciones en la velocidad de crecimiento a concentración $50 \%$, estuvieron entre $11,47 \pm 0,81$ y $36,51 \pm 1,11 \%$ y los mayores aumentos en la fase de latencia estuvieron entre $79,45 \pm 0,85 \%$ y $248,17 \pm 15,02 \%$.

Muchos lactobacilos producen un rango amplio de compuestos antimicrobianos, incluyendo ácidos orgánicos (láctico y acético), dióxido de carbono, peróxido de hidrógeno, etanol, diacetilo y péptidos (bacteriocinas) que pueden reducir el desarrollo de patógenos y bacterias alteradoras durante la producción de alimentos y almacenamiento y que también pueden emplearse en el tratamiento y prevención de desórdenes gastrointestinales e infecciones vaginales (Bonade, Murelli, Vescovo \& Scolari, 2001; Jamuna \& Jeevaratnam, 2004; Messens \& De Vuyst, 2002). Los productos fermentados en nuestro estudio, alcanzaron valores de $\mathrm{pH}$ cercanos al $\mathrm{pK}_{\mathrm{a}}$ de los ácidos débiles predominantes, láctico y acético, con valores de 3,75 y 4,76 respectivamente, que favorecen el estado no disociado, en el cual pueden ingresar a la célula fúngica. Se determinó la presencia de dichos ácidos orgánicos en concentraciones no disociadas para SLC mas inhibitorios. Así, para el SLC obtenido con AGK2 a $20{ }^{\circ} \mathrm{C}$ a pH 3,1 el ácido láctico no disociado fue 202,36 mM y el acético 20,84 mM. El SLC de AGK1 a $30^{\circ} \mathrm{C}, \mathrm{pH} 3,3$ tuvo una concentración de ácido láctico no disociado muy superior, de 356,77 y para acético, igual al anterior, de 20,74 mM. En el caso del SLC de AGK2 a pH 3,3 obtenido a $37^{\circ} \mathrm{C}$, la concentración de láctico no disociado fue de 139,10 mM y de acético de 46,49 mM. A estos pH, el porcentaje de ácido láctico no disociado es superior al 75\% y de acético no disociado es superior al 96\%. Los ácidos en conjunto tienen un efecto sinérgico en la inhibición bacteriana. Lo anterior se atribuye a que el efecto del ácido acético se potencia con el pH ácido generado por el ácido láctico, favoreciendo el equilibrio hacia la forma no disociada de los ácidos (Helander, von Wright \& MattilaSandolhm, 1997). Los resultados obtenidos fueron similares a otros encontrados previamente, donde se determinó la actividad antifúngica de sobrenadantes de Lactobacillus sanfrancisco CB1 frente a Aspergillus, Fusarium, Penicillium y Monilia, y en los cuales se atribuyó dicha actividad a una mezcla de ácidos orgánicos como ácido acético, caproico, fórmico, propiónico, butírico y n-valérico, 
presentes en los sobrenadantes y actuando de modo sinérgico (Corsetti, Gobbetti, Rossi \& Damiani, 1998). Podría pensarse que con los sobrenadantes de kefir ocurre lo mismo, ya que se ha demostrado que los sobrenadantes de kefir incubados a $20^{\circ} \mathrm{C}$ tenían altas concentraciones ácido láctico (entre 2,07 y $2,35 \%$ ), menores de ácido acético (entre 0,11 y $0,18 \%$ ) y bajas concentraciones de ácido cítrico, ácido úrico y ácido orótico (Garrote, 1999). Un resultado importante que se obtuvo de lo experimentado, es que en los sobrenadantes de kefir hay dos procesos antagónicos que se ponen en juego. Uno es el efecto inhibidor de los sobrenadantes por la presencia de ácidos orgánicos y otros metabolitos. $\mathrm{Y}$ el otro, es un efecto estimulante sobre el hongo por los componentes de la leche que quedan en el sobrenadante. En la mayoría de los casos, a mayores concentraciones de sobrenadante de kefir predominó el efecto inhibidor, mientras que a las concentraciones mas diluidas, predominó el efecto estimulante sobre el inhibidor.

\subsubsection{Efecto de soluciones mezcla de ácidos orgánicos preparadas en agua destilada, sobre el crecimiento de $A$. flavus AFUNL5 en medio sólido}

Con el fin de evaluar el efecto antifúngico de la presencia únicamente de los ácidos láctico y acético en la concentración reportada en el kefir sin intervención de otros compuestos, se prepararon soluciones en agua destilada, a los $\mathrm{pH} 4,5$, 3,5 y 3,3 tal como los evaluados con los SLC del kefir. A. flavus AFUNL5 fue cultivado en medio MEA adicionado de las soluciones con mezclas de ácidos orgánicos puros, correspondientes a los determinados en leche fermentada con gránulos de kefir. Al igual que con los SLC provenientes de los gránulos de kefir, se obtuvieron curvas de crecimiento fúngico y regresiones lineales. A partir de los datos obtenidos se calcularon la tasa de crecimiento $K_{D}(\mathrm{~mm} / \mathrm{h})$, fase Lag $(\mathrm{h})$ y los índices IILag (\%) e IIK $(\%)$. En la figra 6.1.10 se observa el crecimiento de A. flavus AFUNL5 control cultivado en medio MEA sin adición de ácidos orgánicos. El hongo alcanzó el borde de la caja en 168 horas y su fase Lag fue de 12 horas, figura 6.1.10 (a); mientras que $K_{D}$ fue $0,56 \mathrm{~mm} / \mathrm{h}$, figura 6.1 .10 (b). 


\subsection{INHIBICIÓN DEL CRECIMIENTO FÚNGICO CON LECHE FERMENTADA \\ CON GRÁNI II OS DF KFFIR}
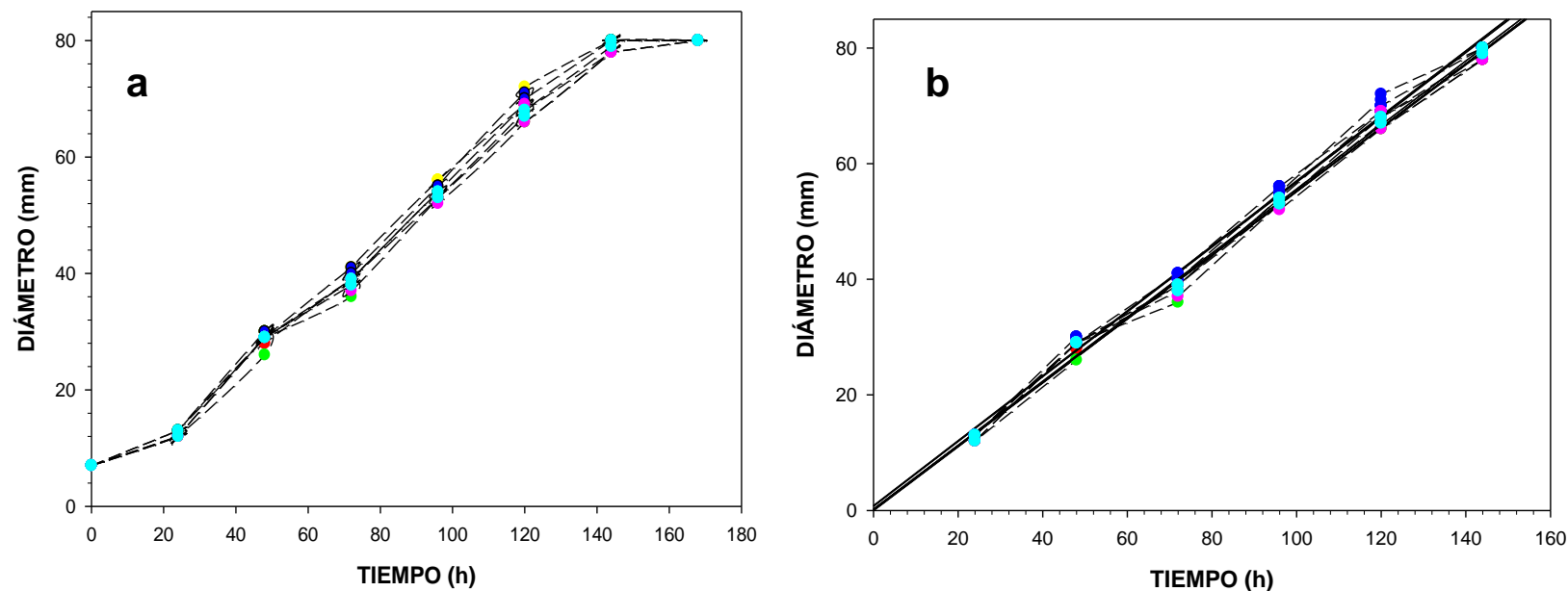

Figura 6.1.10 Curva de de crecimiento de A. flavus AFUNL5 (a) y Regresión lineal (b) en medio MEA sin adición de ácidos orgánicos. Se realizaron cinco experimentos independientes y los resultados se indican con diferentes colores $\bullet$; $\bullet$; $\bullet$; $\bullet$; $\bullet$;

En las Figuras 6.1.11 y 6.1.12 se presentan las curvas de crecimiento y regresiones lineales de $A$. flavus AFUNL 5 cultivado en medio MEA adicionado de soluciones con mezcla de ácidos orgánicos puros preparados en agua destilada (Tabla 6.1.5) correspondientes a los determinados en leche fermentada con gránulos de kefir CIDCA AGK1, a pH 3,5 y 3,3.
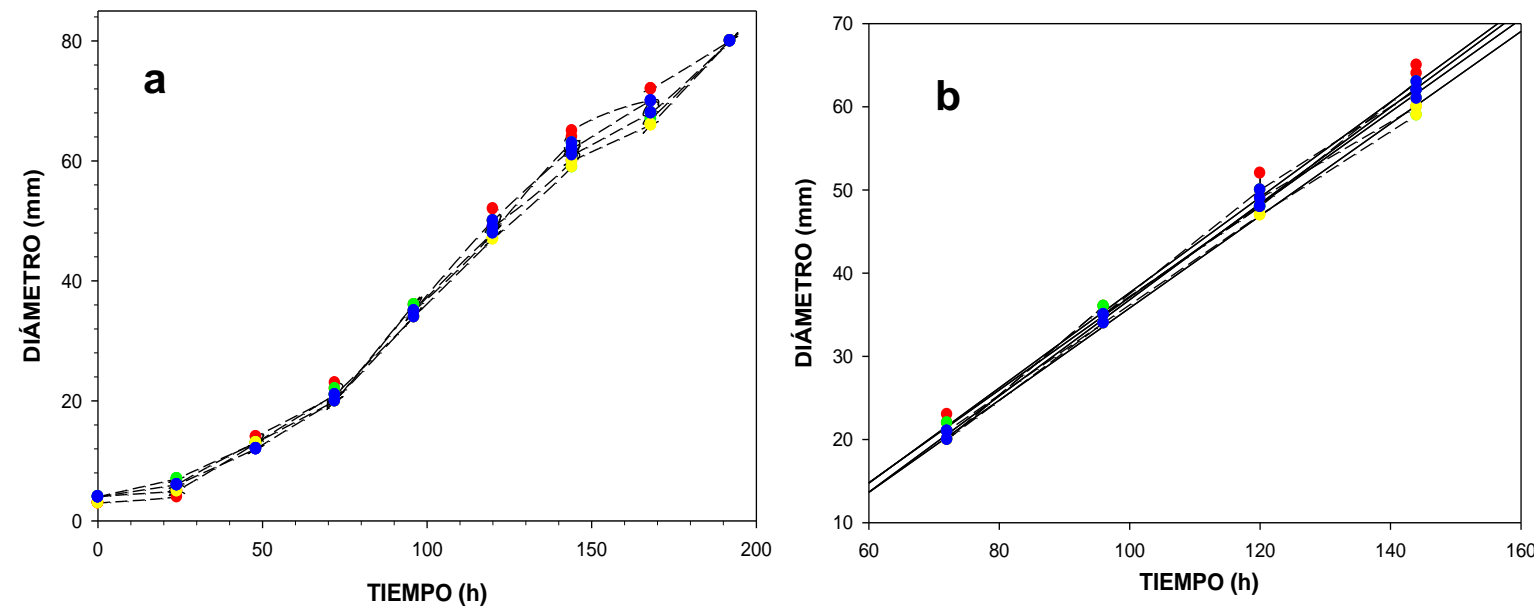

Figura 6.1.11 Curva de crecimiento (a) y Regresión lineal de la curva de crecimiento (b) de $A$. flavus AFUNL 5 cultivado con mezcla de ácidos orgánicos preparada en agua destilada a pH 3,5 (símil SLC obtenido con gránulo CIDCA AGK1). Se realizaron cuatro experimentos independientes y los resultados se indican con diferentes colores: $\bullet ;$ La composición de la mezcla se indica en la tabla 6.1.5 


\subsection{INHIBICIÓN DEL CRECIMIENTO FÚNGICO CON LECHE FERMENTADA \\ CON GRÁNULOS DE KEFIR}

El hongo cultivado en medio adicionado de ácidos orgánicos a pH 3,5, necesitó un tiempo de 192 horas para alcanzar el diámetro máximo, superando en 1 día el tiempo requerido por el control e incrementó su fase Lag, que fue $41,25 \pm 1,01$ horas, Figura 6.1.11 (a). Su tasa de crecimiento fue $0,57 \pm 0,0011 \mathrm{~mm} / \mathrm{h}$, no diferenciándose de la correspondiente al control, Figura 6.1.11 (b), por lo que el efecto antifúngico se redujo a incrementar la fase de adaptación, pero no a reducir la velocidad de crecimiento. Se quiso comparar este efecto con aquel ejercido por la mezcla de ácidos pero a un pH un inferior, de 3,3, como se observa en la siguiente figura.
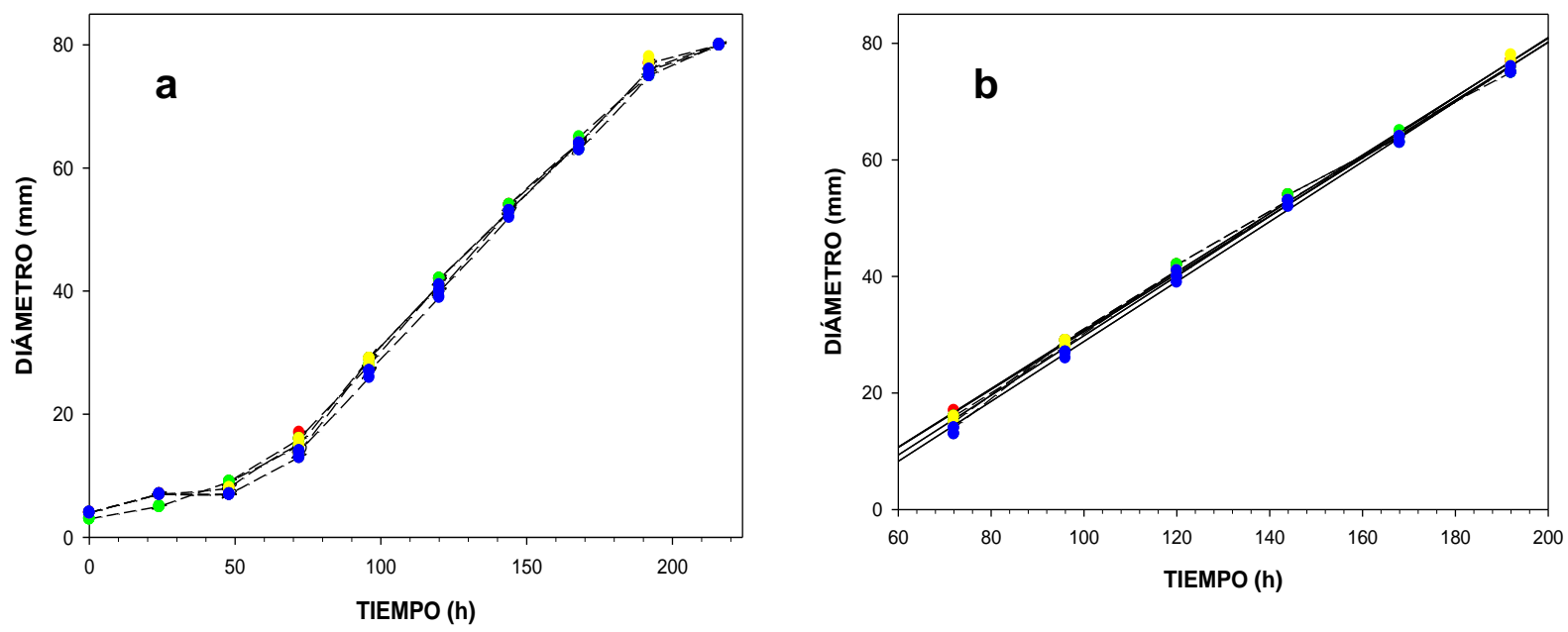

Figura 6.1.12 Curva de crecimiento (a) y Regresión lineal de la curva de crecimiento (b) de $A$. flavus AFUNL5 cultivado con mezcla de ácidos orgánicos preparada en agua destilada, a pH 3,3 (símil SLC obtenido con gránulo CIDCA AGK1). Se realizaron cuatro experimentos independientes y los resultados se indican con diferentes colores: La composición de la mezcla se indica en la tabla 6.1.5

En presencia de la solución símil de ácidos a pH 3,3 la inhibición del hongo fue mayor que a pH 3,5, lo cual se determinó en la curva de crecimiento, figura 6.1.12 (a), que muestra un tiempo de 216 horas para alcanzar el borde de la caja, 72 horas más que el control y 24 más que el símil a pH 3,5. A partir de la regresión lineal pudo establecerse también que la solución a $\mathrm{pH} 3,3$ redujo la tasa de crecimiento por debajo del control, en un valor de $0,51 \pm 0,0091 \mathrm{~mm} / \mathrm{h}$ y produjo una fase de latencia de $48,08 \pm 2,00$ horas. En la tabla 6.1 .5 se presentan las concentraciones de ácido en los medios de cultivo, los parámetros de crecimiento 


\subsection{INHIBICIÓN DEL CRECIMIENTO FÚNGICO CON LECHE FERMENTADA}

CON GRÁNULOS DE KEFIR

y los índices de inhibición obtenidos cuando se cultivó $A$. flavus AFUNL5 con mezclas de ácidos láctico y acético, a los $\mathrm{pH} 4,5,3,5$ y 3,3.

Tabla 6.1.5 Parámetros de crecimiento $\mathrm{K}_{\mathrm{D}}(\mathrm{mm} / \mathrm{h})$ y Lag e índices $I I \mathrm{~K}_{\mathrm{D}}$ y Lag $(\%)$ de A. flavus AFUNL5 en presencia de mezclas de ácidos orgánicos preparadas en agua destilada (láctico y acético) $)^{1,2}$.

\begin{tabular}{|c|c|c|c|c|c|c|c|c|}
\hline $\begin{array}{l}\text { SLC adicionado } \\
\text { al medio }\end{array}$ & $\begin{array}{c}\mathrm{pH} \\
\text { mezcla }\end{array}$ & $\begin{array}{c}\text { Ácido } \\
\text { Láctico1 }^{1} \\
\text { (\%) }\end{array}$ & $\begin{array}{c}\text { Ácido } \\
\text { Acético } \\
(\%)\end{array}$ & $\begin{array}{c}\text { Concentración } \\
\text { de la mezcla } \\
(\%)\end{array}$ & $\begin{array}{c}\text { Media } K_{D} \\
(\mathrm{~mm} / \mathrm{h})\end{array}$ & $\begin{array}{l}\text { Media Lag } \\
\text { (h) }\end{array}$ & $\begin{array}{c}\text { Media } \\
\text { IIK }_{\mathrm{D}} \\
(\%)\end{array}$ & $\begin{array}{c}\text { Media } \\
\text { IILag } \\
(\%)\end{array}$ \\
\hline \multirow{3}{*}{$\begin{array}{c}\text { Ácido láctico y } \\
\text { acético en la misma } \\
\text { concentración } \\
\text { obtenida con } \\
\text { gránulo CIDCA } \\
\text { AGK1 fermentado a } \\
30^{\circ} \mathrm{C}\end{array}$} & 4,5 & 0,407 & 0,03 & 50 & $0,71 \pm 0,0012$ & $17,11 \pm 0,91$ & $-27,81^{\mathrm{a}}$ & $42,54^{a}$ \\
\hline & 3,5 & 1,947 & 0,044 & 50 & $0,57 \pm 0,0011$ & $41,25 \pm 1,01$ & $-1,91^{b}$ & $243,77^{6}$ \\
\hline & 3,3 & 1,076 & 0,065 & 50 & $0,51 \pm 0,0091$ & $48,08 \pm 2,00$ & $8,88^{c}$ & $300,67^{c}$ \\
\hline CONTROL & 6,5 & NC & $\overline{N C}$ & $\mathrm{NC}$ & $0,56 \pm 0,02$ & $12,01 \pm 1,01$ & & \\
\hline
\end{tabular}

${ }^{1}$ Concentraciones de ácidos basadas de las determinadas mediante HPLC en el SLC de leche fermentada con gránulo CIDCA AGK1 a $30^{\circ} \mathrm{C}$.

${ }^{2}$ Resultados con diferentes letras en la misma columna difieren significativamente.

${ }^{3} \mathrm{NC}$ : no corresponde

En los tres tratamientos se observó incremento de la fase Lag y a medida que descendió el $\mathrm{pH}$, el efecto incrementó. Al desafiar el hongo con la mezcla de ácidos, se encontró que a pH 4,5 la fase de latencia sólo fue cinco horas mayor al control y una vez la superó, su tasa de crecimiento superó ampliamente a la tasa de control, por lo que se puede considerar que este tratamiento tuvo, contrario a lo esperado, un efecto promotor del crecimiento (el IIK $\mathrm{K}_{\mathrm{D}}$ tuvo signo negativo, indicando que el hongo creció a una velocidad mayor que el control). Algo similar se observó a pH 3,5, donde $\mathrm{K}_{\mathrm{D}}$ no se redujo con relación al control, pero si aumentó la fase Lag aproximadamente en un $244 \%$. En presencia de la mezcla a $\mathrm{pH} 3,3$, la fase Lag tuvo un incremento superior de $300 \%$ y su $\mathrm{K}_{\mathrm{D}}$ se redujo casi en un 9\%. Al comparar esta inhibición con la obtenida con los SLC del kefir, se observó que el incremento en la fase Lag fue superior al que se obtuvo con el SLC obtenido con el gránulo CIDCA AGK1 (249\%) y AGK2 (209\%), En este experimento con ácidos puros, la inhibición de la tasa de crecimiento fue muy baja, de máximo $8 \%$, mientras que con el SLC de gránulo CIDCA AGK2 se logró una máxima de aproximadamente 37\%.

En términos generales, se puede afirmar que con la adición de las mezclas de ácidos orgánicos preparados en agua destilada, si bien se obtuvieron aumentos muy significativos en la fase Lag (300\%), el hongo pudo crecer de manera favorable una vez se adaptó a las condiciones del medio de cultivo. Además, los 


\subsection{INHIBICIÓN DEL CRECIMIENTO FÚNGICO CON LECHE FERMENTADA \\ CON GRÁNULOS DE KEFIR}

ácidos puros solos en agua destilada, adicionados al medio de cultivo, ejercieron un efecto inhibidor del crecimiento de A. flavus AFUNL5, pero en proporción inferior a la que se obtuvo con los SLC de los gránulos de kefir a 20 y a $30{ }^{\circ} \mathrm{C}$. De allí que dichos SLC deben contener otros compuestos con acción antifúngica que aún no han sido elucidados en el estudio. Deberá evaluarse en el SLC la concentración de los ácidos ya mencionados como fenil láctico y péptidos que liberan las BAL y que ya han sido reportados (Magnusson, 2001; Gerez, Rollán, Torino \& Font de Valdés, 2009). Debe resaltarse por último, que no todos los productos fermentados garantizan la acción antifúngica y que debe evitarse la aplicación de algunos como los SLC obtenidos a pH 4,5 con los cuales $K_{D}$ en lugar de disminuir, aumentó, constituyendo un problema en lugar de una solución para la inhibición fúngica. El resumen de los índices obtenidos con las soluciones de ácidos en agua se presenta en la figura 6.1.13.

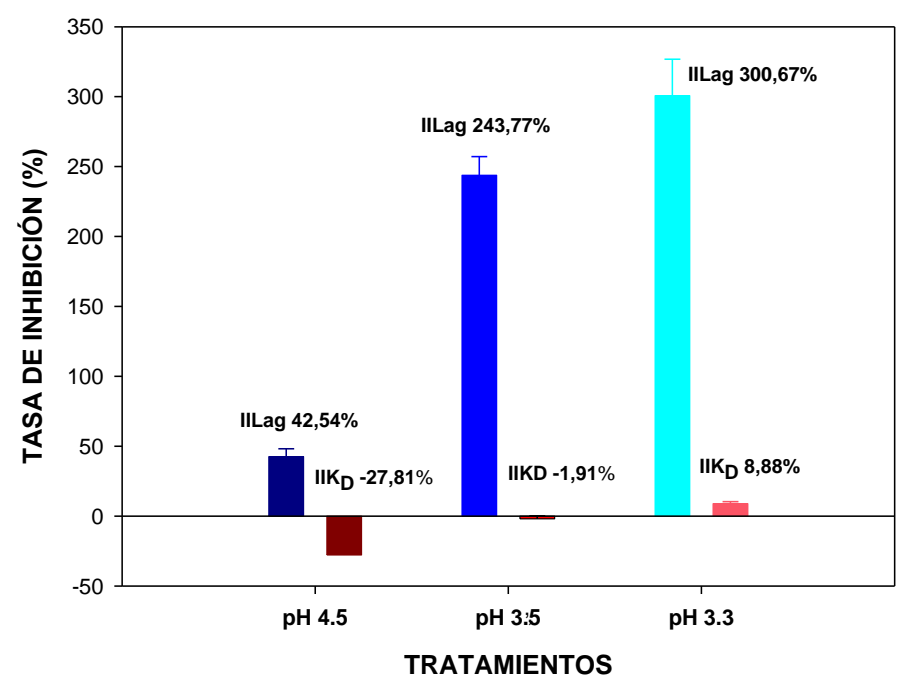

Figura 6.1.13 Comparación de los Índices IIK $_{\mathrm{D}}$ e IILag de A. flavus AFUNL5 cultivado con mezclas de ácidos orgánicos preparados en agua destilada. - IILag mezcla $\mathrm{pH} 4,5$; $\square$ IIK mezcla pH 4,5; - IILag mezcla pH 3,5; III mezcla pH 3,3. 


\subsubsection{Efecto de soluciones de ácidos orgánicos preparadas en leche, sobre el crecimiento de A. flavus AFUNL5 en medio sólido.}

Las mezclas de ácidos se prepararon como se indicó en materiales y métodos generales en leche UHT $\left(\right.$ Sancor $\left.^{\circledR}\right)$, simulando las concentraciones determinadas en los SLC obtenidos con los gránulos CIDCA AGK1 y AGK2 (las cuales se indican en la tabla 6.1.6). Los sobrenadantes a pH 4,5; 3,5 y 3,0 se adicionaron al medio de cultivo MEA en concentraciones 50 y $10 \%$, inoculando posteriormente los hongos filamentosos. Se calcularon los parámetros $\mathrm{K}_{\mathrm{D}}$, Lag, IIK $\mathrm{D}$ e IILag.

\subsubsection{Efecto de mezcla de ácidos orgánicos preparados en leche en las mismas concentraciones del SLC obtenido con gránulo CIDCA AGK1, sobre el crecimiento de A. flavus AFUNL5 en medio sólido.}

Las Figuras 6.1 .14 y 6.1 .15 presentan las curvas de crecimiento (a) y regresiones lineales (b) de $A$. flavus AFUBA5 cultivado con sobrenadantes de leche acidificada simulando las concentraciones de ácidos láctico y acético presentes en el SLC obtenidos con gránulo CIDCA AGK1.
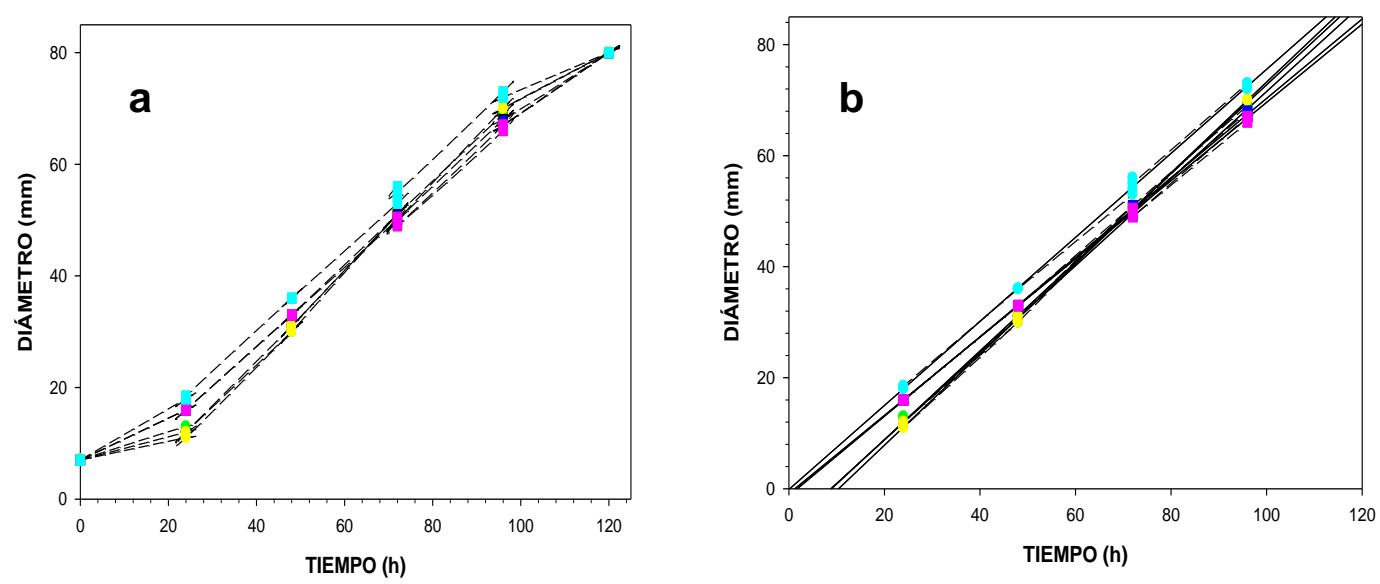

Figura 6.1.14 Curva de crecimiento (a) y Regresión lineal de la curva de crecimiento (b) de $A$. flavus AFUNL 5 cultivado con sobrenadantes de leche acidificada con ácidos orgánicos símil SLC obtenido con gránulo CIDCA AGK1, a pH 3,5 concentraciones $50 \%$ y $10 \%$ en el medio. Se realizaron tres experimentos independientes para cada concentración. Sobrenadante leche ácidos puros pH 3,5, 50\%: ; ; ;Sobrenadante leche ácidos puros pH 3,5, 10\%:ロ; ; ; . La composición de la mezcla se indica en la tabla 6.1.6 


\subsection{INHIBICIÓN DEL CRECIMIENTO FÚNGICO CON LECHE FERMENTADA \\ CON GRÁNULOS DE KEFIR}

Es llamativo observar que en este tratamiento el hongo tardó 120 horas en alcanzar el extremo de la caja, Figura 6.1.14 (a) o sea 48 horas menos que el control y que en relación con ello, la tasa de crecimiento, Figura 6.1.14 (b), fue $0,8 \mathrm{~mm} / \mathrm{h}$, superior a la del control de $0,56 \mathrm{~mm} / \mathrm{h}$. La fase Lag fue 18,11 horas, superior al control de 12 horas. Dado lo anterior, se podría decir que el hongo tardó un tiempo en adaptarse a los nutrientes de la leche, pero una vez superada la fase de latencia, la velocidad de crecimiento fue superior a la del control. Podría afirmarse que de acuerdo a estos resultados, cuando el hongo estuvo en presencia del SLC obtenido con gránulos de kefir, no experimentó inhibición en la velocidad de crecimiento exclusivamente por la acción de los ácidos orgánicos, sino también por la presencia de otros compuestos que será necesario estudiar.

A continuación se presenta el efecto del sobrenadante de leche acidificada con ácidos orgánicos como los del gránulo CIDCA AGK1, a pH 3,3.
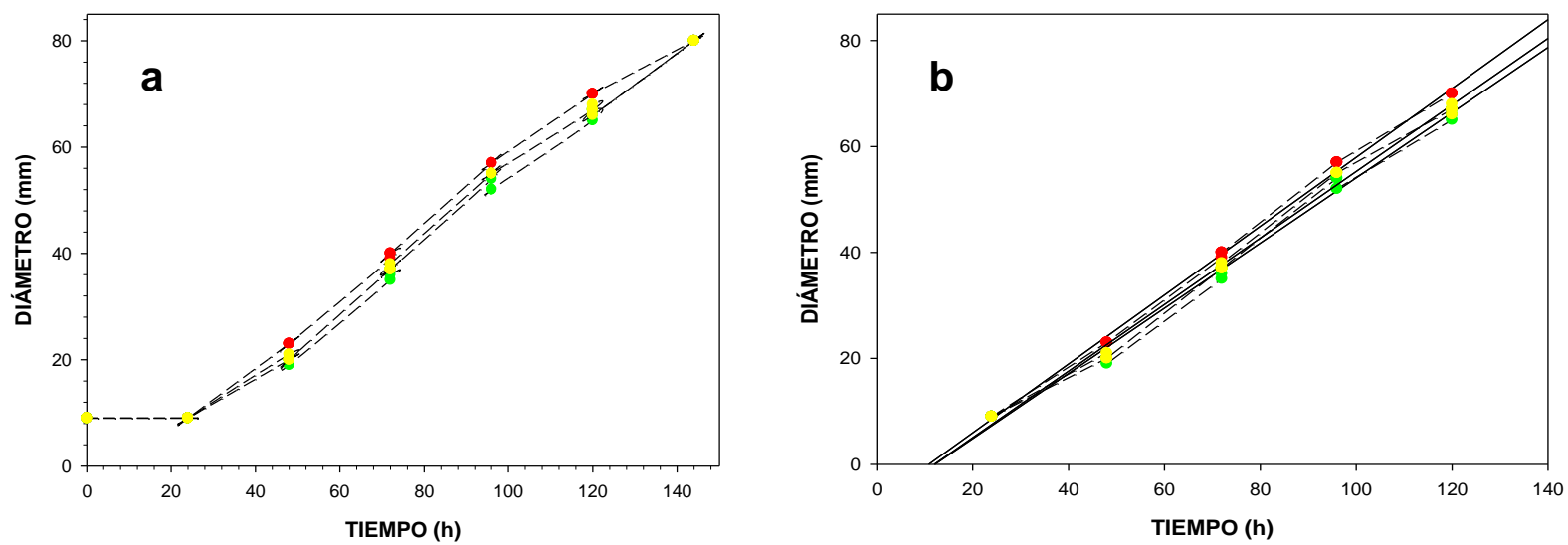

Figura 6.1.15 Curva de crecimiento (a) y Regresión lineal de la curva de crecimiento (b) de $A$. flavus AFUNL5 cultivado con sobrenadantes de leche acidificada con ácidos orgánicos símil SLC obtenido con gránulo CIDCA AGK1, a pH 3,0 y 50\% en el medio. Se realizaron tres experimentos independientes. Sobrenadante leche ácidos puros pH 3,3, concentración 50\%: ๑; $\bullet$; La composición de la mezcla se indica en la tabla 6.1.6 
En este tratamiento, $A$. flavus demoró 144 horas en alcanzar el diámetro total de la caja, Figura 6.1.15 (a), o sea que a este pH más ácido, fueron necesarias 24 horas más que a $\mathrm{pH} 3,5$. No obstante, este tiempo fue inferior al tiempo necesario para el control (168 h). Una vez superada la fase Lag, su $K_{D}$ fue superior al control, siendo igual a 0,63 mm/h, Figura 6.1.15 (b).

\subsubsection{Efecto de la mezcla de ácidos orgánicos preparados en leche en las mismas concentraciones del SLC obtenido con gránulo CIDCA AGK2, sobre el crecimiento de A. flavus AFUNL5 en medio sólido.}
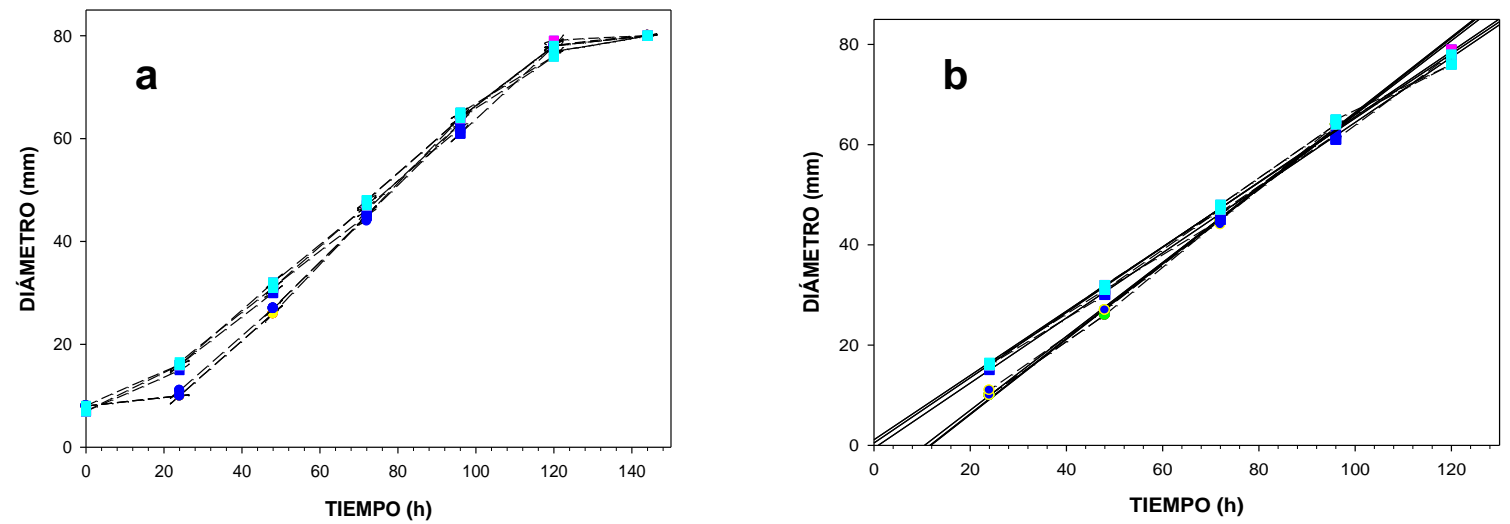

Figura 6.1.16 Curva de crecimiento (a) y Regresión lineal de la curva de crecimiento (b) de $A$. flavus AFUNL5 cultivado con sobrenadantes de leche acidificada con ácidos orgánicos símil SLC obtenido con gránulo CIDCA AGK2, a pH 3,3, dilución 50 y $10 \%$ en el medio. Se realizaron tres experimentos independientes para cada dilución. Sobrenadante leche ácidos puros pH 3,3,50\%:

๑;॰; Sobrenadante leche ácidos puros pH 3,3, 10\%:—; ; . .

La composición de la mezcla se indica en la tabla 6.1.6

Se evaluó el efecto de los sobrenadantes de leche acidificada con ácidos orgánicos láctico y acético en la misma concentración detectada en el SLC de leche fermentada con gránulo CIDCA AGK2, a fin de comparar con dichos SLC y también compararlo con el resultado obtenido con el símil gránulo CIDCA AGK1 al mismo pH. En primer lugar, se observó en la figura 6.1.16 (a), que el hongo tardó el mismo tiempo en alcanzar el máximo diámetro de la caja (144 horas) y que su fase de latencia (22,3 horas), Figura 6.1.16 (b), también fue muy similar al valor cuando fue cultivado en presencia del símil gránulo CIDCA AGK1. Al igual que lo sucedido con el símil $A G K 1$ su $K_{D}$ fue mayor a la del control de 0,75 $\mathrm{mm} / \mathrm{h}$. En presencia del SLC obtenido con AGK2, la fase Lag tuvo un índice de 


\subsection{INHIBICIÓN DEL CRECIMIENTO FÚNGICO CON LECHE FERMENTADA}

CON GRÁNULOS DE KEFIR

inhibición de 83,6\%, similar al obtenido con el SLC de leche fermentada con este gránulo a $\mathrm{pH} 3,5$ a $30^{\circ} \mathrm{C}(83,05 \%)$. Aún cuando hubo aumento en el tiempo de latencia, no se pudo reducir la $\mathrm{K}_{\mathrm{D}}$ como sí ocurrió con los SLC de leche fermentada con el gránulo, confirmando el hecho de que además de los ácidos presentes, el SLC del gránulo debe contener otros compuestos que inciden en la tasa de crecimiento fúngica.

El último experimento de este tipo fue realizado con símil de leche fermentada con gránulo CIDCA AGK2 y acidificado hasta pH 3,0, con el fin de determinar si al pH más ácido se aumentaría el efecto en el crecimiento fúngico.
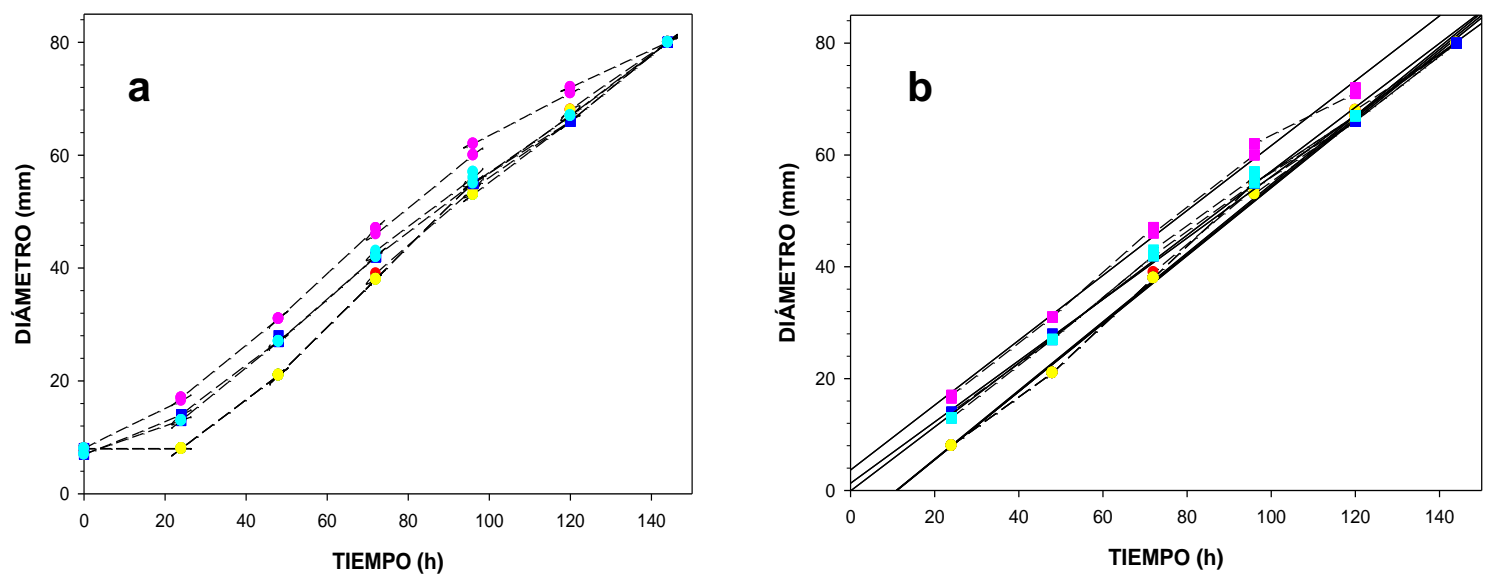

Figura 6.1.17 Curva de crecimiento (a) y Regresión lineal de la curva de crecimiento (b) de $A$. flavus AFUNL5 cultivado con sobrenadante de leche acidificada con ácidos orgánicos símil SLC obtenido con gránulo CIDCA AGK2, a pH 3,0 concentraciones $50 \%$ y $10 \%$ en el medio. Se realizaron tres experimentos independientes para cada concentración. Sobrenadante leche ácidos puros pH 3,0 concentración $50 \%: \odot ;$; Sobrenadante leche ácidos puros pH 3,0, concentración 10\%: $\square ; \square ;$;

La composición de la mezcla se indica en la tabla 6.1.6

A. flavus AFUNL5 en presencia del símil AGK2 a pH 3,0, tardó el mismo tiempo de $144 \mathrm{~h}$ para invadir toda la caja, que a $\mathrm{pH}$ 3,3 y que en presencia del símil AGK1 a pH 3,3. Figura 6.1.17 (a). No obstante, se repitió el hecho de que este tiempo fue inferior al requerido por el control. $\mathrm{K}_{\mathrm{D}}$ fue $0,61 \mathrm{~mm} / \mathrm{h}$, Figura 6.1.17 (b), similar a la obtenida en presencia del símil AGK1 a pH 3,5 y al control. Por último, su fase Lag de 24 horas, fue superior a la obtenida en presencia del símil 
AGK2 a pH 3,3; un poco inferior a la obtenida en presencia del símil AGK1 a pH 3,3 pero superior a la del control en un $100 \%$.

En la tabla 6.1.6 se resumen las concentraciones de ácido en los medios, los parámetros de crecimiento y los índices obtenidos cuando se desafió $A$. flavus AFUNL5 con leches acidificadas con mezclas de ácidos láctico y acético simulando las concentraciones de ácidos presentes en los gránulos de kefir CIDCA AGK1 y AGK2, a pH 4,5, 3,5, 3,3 y 3,0, en concentraciones $50 \%$ y $10 \%$.

Tabla 6.1.6 Parámetros de crecimiento $\mathrm{K}_{\mathrm{D}}(\mathrm{mm} / \mathrm{h})$ y Lag e índices $\quad I I \mathrm{~K}_{\mathrm{D}}$ y Lag $(\%)$ de A. flavus AFUNL5 en presencia de sobrenadantes de leche acidificada con mezclas de ácidos orgánicos (láctico y acético) ${ }^{1}$.

\begin{tabular}{|c|c|c|c|c|c|c|c|c|}
\hline $\begin{array}{c}\text { Sobrenadante } \\
\text { adicionado al } \\
\text { medio }\end{array}$ & $\mathrm{pH}$ & $\begin{array}{c}\text { Ácido } \\
\text { Lactico }^{2} \\
(\%)\end{array}$ & $\begin{array}{c}\text { Ácido } \\
\text { Acético }{ }^{2} \\
(\%)\end{array}$ & $\begin{array}{c}\text { Concentración } \\
\text { sobrenadante } \\
(\%)\end{array}$ & $\begin{array}{c}\text { Media } K_{D} \\
(\mathrm{~mm} / \mathrm{h})\end{array}$ & $\begin{array}{c}\text { Media } \\
\text { Lag (h) }\end{array}$ & $\begin{array}{c}\text { Media } \\
\text { IILag (\%) }\end{array}$ & $\begin{array}{l}\text { Media } \\
\text { IIK }(\%)\end{array}$ \\
\hline \multirow{6}{*}{$\begin{array}{c}\text { SÍMIL KEFIR } \\
\text { AGK1 }\end{array}$} & 4,5 & \multirow{2}{*}{0,407} & \multirow{2}{*}{0,03} & 50 & 0,81 & 10,65 & $-11,22^{c}$ & $-46,23^{d}$ \\
\hline & & & & 10 & 0,72 & 9,66 & $-19,54^{c}$ & $-29,75^{\mathrm{C}}$ \\
\hline & 3,5 & \multirow{2}{*}{1,947} & \multirow{2}{*}{0,044} & 50 & 0,8 & 18,11 & $50,9^{0}$ & $-44,2^{\mathrm{d}}$ \\
\hline & & & & 10 & 0,73 & 10,71 & $-10,78^{\mathrm{c}}$ & $-30,75^{c}$ \\
\hline & 3,0 & \multirow{2}{*}{3,171} & \multirow{2}{*}{0,1241} & 50 & 0,63 & 25,92 & $116,01^{\mathrm{a}}$ & $-13,74^{\mathrm{b}}$ \\
\hline & & & & 10 & $\mathrm{NA}^{3}$ & NA & NA & NA \\
\hline \multirow{6}{*}{$\begin{array}{c}\text { SÍMIL KEFIR } \\
\text { AGK2 }\end{array}$} & 4,5 & \multirow{2}{*}{0,347} & \multirow{2}{*}{0,014} & 50 & NA & NA & NA & NA \\
\hline & & & & 10 & 0,72 & 8,32 & $-30,66^{c}$ & $-29,22^{c}$ \\
\hline & 3,3 & \multirow{2}{*}{0,823} & \multirow{2}{*}{0,048} & 50 & 0,75 & 22,03 & $83,6^{\mathrm{a}}$ & $-34,57^{c}$ \\
\hline & & & & 10 & 0,65 & 10,79 & $-10,05^{\mathrm{c}}$ & $-16,68^{\mathrm{D}}$ \\
\hline & 3,0 & \multirow{2}{*}{1,986} & \multirow{2}{*}{0,104} & 50 & 0,61 & 24,03 & $100,27^{\mathrm{a}}$ & $-10,13^{b}$ \\
\hline & & & & 10 & 0,56 & 10,36 & $-13,69^{c}$ & $-1,31^{a}$ \\
\hline CONTROL & & & & & 0,56 & 12,01 & & \\
\hline
\end{tabular}

${ }^{1}$ Resultados con diferentes letras en la misma columna difieren significativamente.

${ }^{2}$ Concentraciones determinadas mediante HPLC en los SLC de leche fermentada a $30^{\circ} \mathrm{C}$, con gránulos de kefir CIDCA AGK1 y AGK2.

${ }^{3} \mathrm{NA}$ : no analizado.

Puede resumirse a partir de los resultados obtenidos, que en coincidencia con los SLC de las leches fermentadas con los propios gránulos, la fase Lag se incrementó cuando el pH de los SLC símil era 3,5 y 3,0 en concentración 50\% para ambos, siendo superior el incremento del símil gránulo CIDCA AGK1. En el resto de los IILag (\%), los resultados arrojaron signo negativo, indicando que la fase Lag fue más corta que la del control.

Contrario a lo anterior, ninguna $K_{D}$ fue inferior al control; por el contrario, fueron todas superiores, evidenciándose que hubo un efecto estimulante del crecimiento del hongo con la presencia de las mezclas de ácidos símil AGK1 y AGK2. El IIK $(\%)$ tuvo signo negativo en todos los casos, indicando que el 


\subsection{INHIBICIÓN DEL CRECIMIENTO FÚNGICO CON LECHE FERMENTADA \\ CON GRÁNULOS DE KEFIR}

hongo en todos los tratamientos creció a una tasa mayor que el control. Una vez que el hongo se adaptó a las condiciones del medio, creció rápidamente ya que predominó el efecto estimulante de los sobrenadantes de leche sobre el efecto inhibidor. La fase Lag fue el parámetro de crecimiento mas afectado, pero sólo en cuatro tratamientos.

Es importante resaltar que un factor determinante por el cual se observaron resultados distintos los obtenidos en el numeral anterior, fue que la solución con la que se realizaron estos experimentos fue preparada en leche, mientras que en el anterior fue una mezcla de agua con ácidos orgánicos. Debido a esta diferencia, este medio de cultivo resultó favorable para el hongo, con un efecto estimulante aportado por los nutrientes del sobrenadante de leche sobre el hongo. En conclusión, el SLC proveniente de leche fermentada con gránulo de kefir debe contener otros compuestos diferentes a los ácidos puros que aportan a la inhibición fúngica. En la Figura 6.1.18 se observa el resumen de los índices obtenidos con $A$. flavus AFUNL5 con sobrenadantes de leches acidificadas con ácidos láctico y acético puros, simulando las concentraciones presentes en leches fermentadas con el propio gránulo.

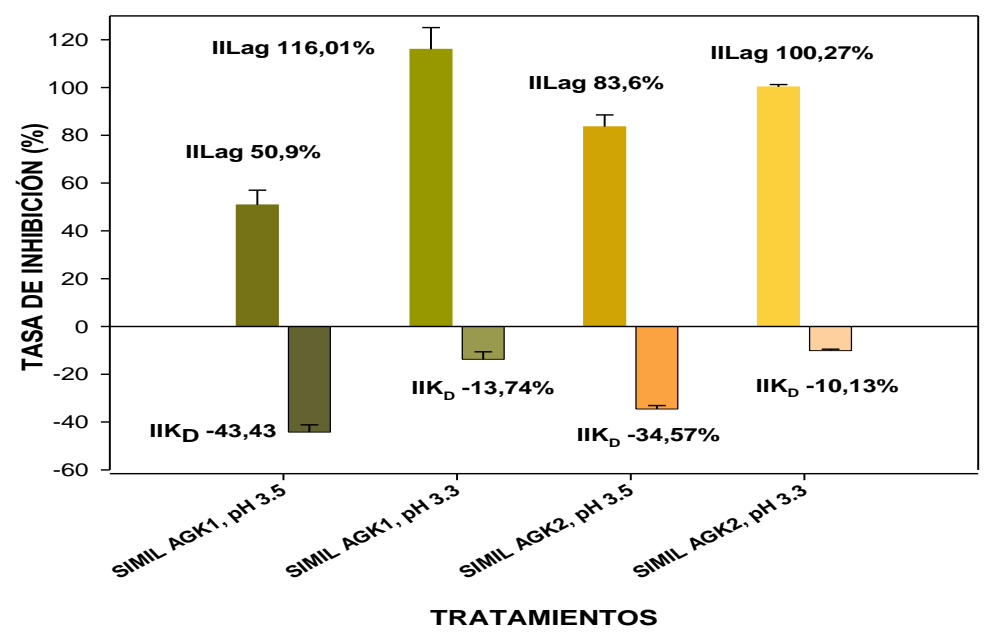

Figura 6.1.18 Comparación de los Índices IIK $_{\mathrm{D}}$ e IILag de A. flavus AFUNL5 cultivado con sobrenadantes de leche acidificada con mezclas de ácidos orgánicos. IILag símil AGK1 pH

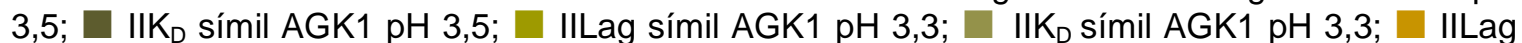

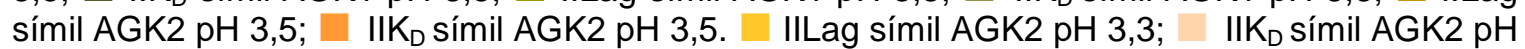
3,3.

La composición de las mezclas se indica en la tabla 6.1.6 


\subsection{INHIBICIÓN DEL CRECIMIENTO FÚNGICO CON LECHE FERMENTADA}

CON GRÁNULOS DE KEFIR

Otros autores encontraron un efecto totalmente inhibitorio al cultivar $E$. coli con leches acidificadas artificialmente, demostrando que la leche suplementada con ambos ácidos a la misma concentración y $\mathrm{pH}$ de la leche fermentada con kefir, inhibía E. coli. Pero cuando la leche fue suplementada individualmente con cada ácido a mismo pH y concentración de la leche fermentada, el efecto inhibitorio solo se observó para el acido láctico (Garrote, Abraham \& De Antoni, 2000).

\subsubsection{Efecto de sobrenadantes de leche acidificada con ácidos fuertes sobre el crecimiento de $A$. flavus AFUNL5.}

En vista de que en este estudio quiso determinarse si el efecto antifúngico del SLC de leche fermentada con gránulos de kefir se debía exclusivamente a la presencia de los ácidos láctico y acético, o al efecto combinado de éstos con el $\mathrm{pH}$ final, se analizó el efecto antifúngico del SLC de leche acidificada exclusivamente con un ácido fuerte.

Para ello se acidificó leche UHT $\left(\right.$ Sancor $^{\circledR}$ ) con HCl $3 \mathrm{M}$ hasta valores de pH de 3,5 y 3,0, similares a los que se obtuvieron durante los experimentos anteriores. Una vez acidificada la leche, se obtuvieron los sobrenadantes y se procedió a la adición de éstos a los medios de cultivo y al estudio de crecimiento de los hongos.

Al igual que en los experimentos anteriores, se realizaron curvas de crecimiento fúngico y regresiones lineales, y con los datos obtenidos se calcularon los parámetros de crecimiento $\mathrm{K}_{\mathrm{D}}(\mathrm{mm} / \mathrm{h})$, Lag (h) y los índices IILag (\%) e IIK $(\%)$.

En la Figura 6.1.19 se pueden observar las curvas de crecimiento y regresiones lineales de $A$. flavus AFUNL5 cultivado en medio adicionado con sobrenadantes de leches acidificadas con el ácido fuerte. 

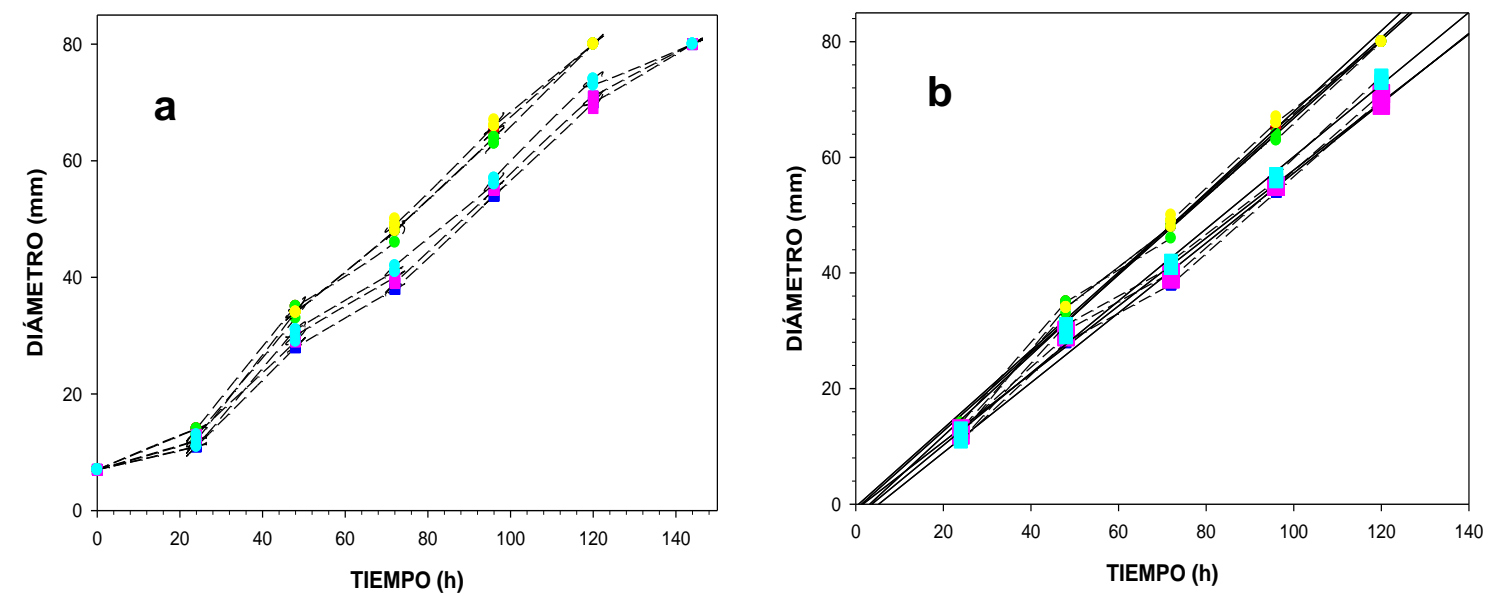

Figura 6.1.19 Curva de crecimiento (a) y Regresión lineal de la curva de crecimiento (b) de $A$. flavus AFUNL5 cultivado con sobrenadantes de leche acidificada con $\mathrm{HCl} 3 \mathrm{M}$, a pH 3,5 concentración $50 \%$ y $10 \%$ en el medio. Se realizaron tres experimentos independientes para cada concentración. Sobrenadante leche $\mathrm{HCl}$ pH 3,5,concentración 50\%: ०; ०; ०; Sobrenadante leche $\mathrm{HCl} \mathrm{pH} \mathrm{3,5,} \mathrm{concentración} \mathrm{10 \% :} \mathbf{\square}$; $\mathbf{\square}$;

El sobrenadante de leche acidificada a pH 3,5 con $\mathrm{HCl}$, tardó un tiempo total de 120 horas para alcanzar el diámetro de la caja en la concentración 50\%, mientras que tardó 24 horas más a la concentración 10\%. Figura 6.1.19 (a). Coincidentes con esto fueron los resultados de la fase de latencia, donde el hongo tardó más en superar dicha fase con la concentración 10\% (15,06 h) que al 50\% (11,93 h). No obstante, el IILag fue bajo, de 25,55\% y además su tasa de crecimiento fue superior a la tasa del control. A fin de corroborar el resultado obtenido con el producto acidificado con $\mathrm{HCl}$ a $\mathrm{pH} 3,5$, se analizaron los parámetros de la cinética fúngica con el sobrenadante acidificado hasta el mínimo pH alcanzado de 3,0, que se observa en la figura 6.1.20. 

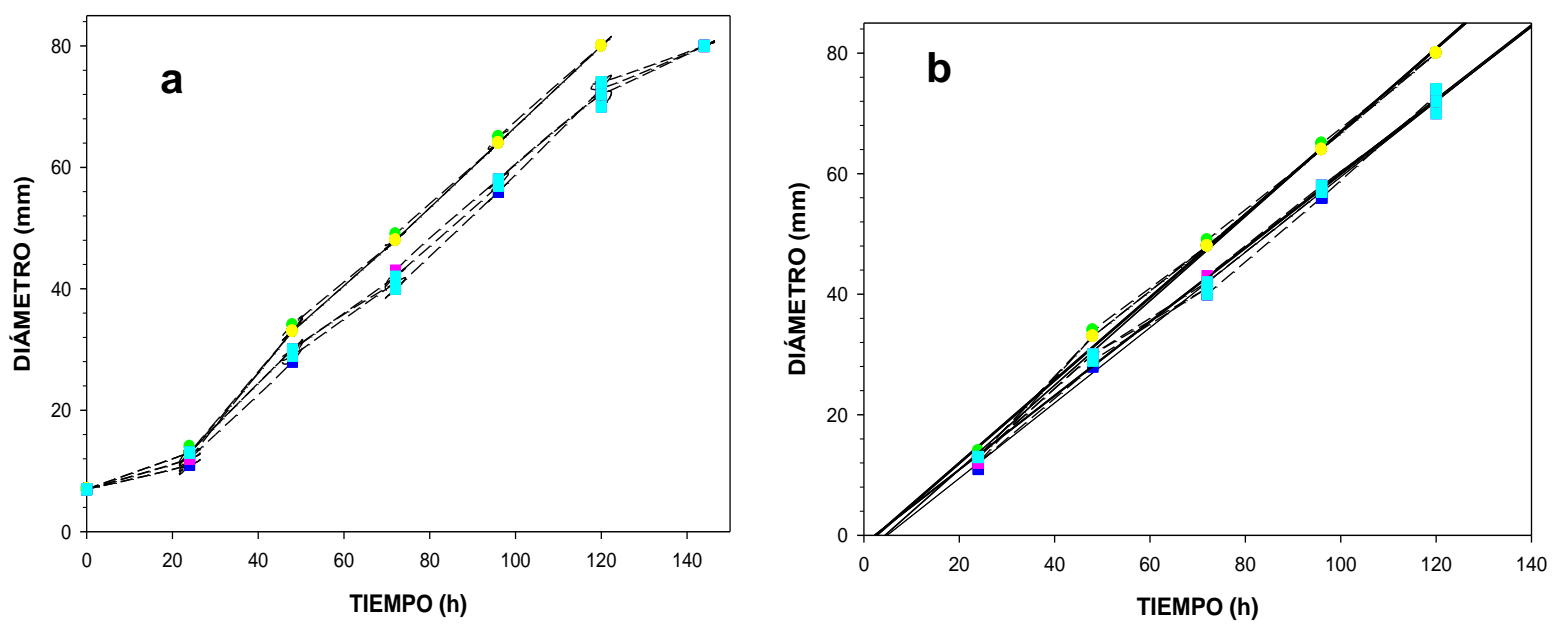

Figura 6.1.20 Curva de crecimiento (a) y Regresión lineal de la curva de crecimiento (b) de $A$. flavus AFUNL5 cultivado con sobrenadante de leche acidificada con $\mathrm{HCl} 3 \mathrm{M}$, a pH 3,0 concentración $50 \%$ y $10 \%$ en el medio. Se realizaron tres experimentos independientes para cada concentración. Sobrenadante leche $\mathrm{HCl}$ pH 3,0, concentración 50\%: ๑; ๑; Sobrenadante leche $\mathrm{HCl}$ pH 3,0, concentración 10\%: $\mathbf{\square}$; $\mathbf{\square}$; $\square$.

A pH 3,0, A. flavus tardó el mismo tiempo que a pH 3,5 para invadir la caja totalmente. $K_{D}$ fue también superior a la velocidad del hongo control y su Lag fue superior en sólo dos horas al control.

Los resultados obtenidos con los sobrenadante acidificados con ácidos fuertes indican que este tratamiento no genera una inhibición fúngica significativa a los $\mathrm{pH}$ evaluados. Los valores de los parámetros de crecimiento y los índices de inhibición de estos tratamientos se incluyen en la tabla 6.1.7 incluyendo los $\mathrm{pH}$, $3,5,3,3$ y 3,0 .

Tabla 6.1.7 Parámetros de crecimiento $\mathrm{K}_{\mathrm{D}}(\mathrm{mm} / \mathrm{h})$ y Lag (h) e índices $\| \mathrm{K}_{\mathrm{D}}$ y Lag (\%) de A. flavus AFUNL5 en presencia de SLC de leche acidificada con ácido fuerte $(\mathrm{HCl} 3 \mathrm{M})$.

\begin{tabular}{|c|c|c|c|c|c|c|}
\hline Tratamiento & $\mathbf{p H}$ & $\begin{array}{c}\text { Concentración } \\
\text { sobrenadante (\%) }\end{array}$ & $\begin{array}{c}\text { Media } \mathbf{K}_{\mathrm{D}} \\
(\mathbf{m m} / \mathbf{h})\end{array}$ & $\begin{array}{c}\text { Media } \\
\text { Lag (h) }\end{array}$ & $\begin{array}{c}\text { Media } \\
\text { IILag (\%) }\end{array}$ & $\begin{array}{c}\text { Media } \\
\text { IIK }_{\mathrm{D}}(\%)\end{array}$ \\
\hline & 3,5 & 50 & 0,69 & 11,93 & $-0,58^{\mathrm{a}}$ & $-23,31^{\mathrm{a}}$ \\
\cline { 2 - 7 } & 10 & 0,6 & 15,06 & $25,55^{\mathrm{a}}$ & $-9,04^{\mathrm{a}}$ \\
\hline \multirow{4}{*}{$\begin{array}{c}\text { Leche acidificada } \\
\text { con HCl 3 M }\end{array}$} & 3,3 & 50 & 0,68 & 11,45 & $-4,59^{\mathrm{a}}$ & $-22,62^{\mathrm{a}}$ \\
\cline { 2 - 7 } & 3,0 & 10 & 0,62 & 14,89 & $24,07^{\mathrm{a}}$ & $-10,86^{\mathrm{a}}$ \\
\cline { 2 - 7 } & 50 & 0,69 & 13,32 & $10,99^{\mathrm{a}}$ & $-24,62^{\mathrm{a}}$ \\
\hline Control & 6,5 & 10 & 0,62 & 14,46 & $20,5^{\mathrm{a}}$ & $-11,23^{\mathrm{a}}$ \\
\hline
\end{tabular}

${ }^{\star}$ Resultados con diferentes letras en la misma columna difieren significativamente. (ANOVA por rangos, falla normalidad. Se transforma los datos, el parámetro IILag tiene distribución normal. Test posterior SNK).

*NA: no analizado 


\subsection{INHIBICIÓN DEL CRECIMIENTO FÚNGICO CON LECHE FERMENTADA}

CON GRÁNULOS DE KEFIR

Como se observa en los datos, la fase de latencia de varios tratamientos fue superior a la del control y curiosamente, era mayor a concentración 10\% que al $50 \%$, es decir que a diferencia de todos los experimentos anteriores, tardó más tiempo en adaptarse cuando el sobrenadante estaba mas diluido. El máximo IILag se obtuvo a pH 3,5 concentración 10\%, pero sin embargo, no hubo diferencia significativa en ninguno de estos índices. Además, todos los IILag fueron muy inferiores a los obtenidos con SLC de leche fermentada con gránulos de kefir. $\mathrm{K}_{\mathrm{D}}$ a todo $\mathrm{pH}$ fue mayor a la $\mathrm{K}_{\mathrm{D}}$ del control, arrojando IIK $\mathrm{K}_{\mathrm{D}}$ negativo en todos los tratamientos. En resumen, la acidificación con ácidos fuertes, al igual que con los SLC acidificados con ácidos puros, sólo generó un incremento en la fase Lag, pero muy bajo, y no disminuyó la velocidad de crecimiento. Por consiguiente, se puede decir que el pH por sí solo no tuvo ningún efecto tanto en la fase Lag como en la tasa de crecimiento fúngica. El cambio de $\mathrm{pH}$ sin ácidos orgánicos en el medio, no disminuyó la tasa de crecimiento fúngica; por el contrario, los compuestos de la leche estimularon el crecimiento con independencia del $\mathrm{pH}$.

Los resultados en este experimento concordaron, al menos en parte, con los estudios de inhibición de E. coli con sobrenadantes de kefir, donde se buscó determinar si el efecto antibacteriano obtenido se debía únicamente al descenso de $\mathrm{pH}$ o a la combinación de ácidos orgánicos y el descenso del pH. Se demostró que el pH por sí solo no tuvo efecto inhibitorio ya que la leche acidificada con $\mathrm{HCl}$ no inhibió el crecimiento de la bacteria (Garrote, Abraham. De Antoni, 2000). Si bien esta fue una investigación con bacterias, los resultados dejaron en claro que el pH por sí solo carecía de efecto inhibidor.

Con los resultados obtenidos en los experimentos anteriores, podría decirse que el efecto inhibidor de los sobrenadantes de kefir se debía parcialmente a los ácidos orgánicos producidos por los microorganismos del kefir, y que el poder inhibidor de los sobrenadantes podría deberse a la presencia de otros metabolitos. En este sentido los resultados coinciden con los obtenidos por Garrote (1999), quien demostró que la actividad antibacteriana de los sobrenadantes de kefir no se perdió con tratamientos enzimáticos ( $\alpha$ - 
quimiotripsina, pepsina, catalasa, proteinasa $\mathrm{K}$, tripsina, lisozima), ni térmicos, pero si se perdía con la neutralización, atribuyendo su actividad en parte a los ácidos orgánicos presentes en los sobrenadantes. Debido a todo lo anterior, será necesario realizar investigaciones posteriores para dilucidar la presencia de otros compuestos intervinientes en la inhibición fúngica.

Una vez estudiado el efecto antifúngico de los SLC de la leche fermentada con gránulos de kefir, se procedió a evaluar esta capacidad aplicándolo en un alimento proveniente del maíz como fue la Arepa Antioqueña, lo cual se desarrollará en el siguiente apartado.

Otros investigadores demostraron que los SLC obtenidos con Lactobacillus plantarum aislados del gránulo de kefir afectaban la cinética de crecimiento de $E$. coli. El pH de la solución afectó la DO máxima y se obtuvo una correlación lineal entre los pH 4,1 y 3,8 con la DO del microorganismo. No obstante, también se determinó que los SLC obtenidos con L. plantarum CIDCA 8323, 8324, 8336 y 83114 producían la mayor inhibición a pH entre 4,1 y 4,3. Lo anterior permitió afirmar que el efecto inhibitorio no sólo se debía al ácido láctico producido por los lactobacilos y que ya se conocían otros metaboilitos producidos por $L$. plantarum con actividad antimicrobiana como bacteriocinas. (Golowczyc, Gugliada, Hollman, Delfederico, Garrote, Abraham, Semorile \& De Antoni, 2008; Suskovic, Kos, Matosk \& Maric, 1997; Toksoy, Beyatly \& Aslim, 1999; Kostinek, Specht, Edward, Schillinger, Hertel, Holzapfel \& Franz, 2005)

\subsubsection{Efecto de la adición de leche fermentada con gránulo CIDCA AGK1 en la estabilidad de la Arepa.}

La arepa se preparó con leche fermentada con gránulos de kefir CIDCA AGK1 a $\mathrm{pH} 3,3$, tal como se describió en materiales y métodos generales. Se hicieron dos tipos de arepas: arepas de maíz y arepa de maíz adicionada con Kefir en la masa. 
6.1.9.1 Determinación de $\mathrm{pH}$ y de la concentración de ácidos orgánicos en la Arepa.

En la tabla 6.1 .8 se presentan el pH y la concentración de ácidos determinados en las arepas de maíz.

Tabla 6.1.8 pH y concentración de ácidos orgánicos en la Arepa antioqueña

\begin{tabular}{|c|c|c|c|}
\hline Tratamiento & pH final & Acido láctico (ppm) (\%) & Acido acético (ppm) (\%) \\
\hline Arepa con agua & $4,8 \pm 0,2$ & $\mathrm{ND}^{1}$ & ND \\
\hline Arepa + kefir & $4,0 \pm 0,1$ & $(284,78 \pm 5,01)(0,0285 \pm 0,0005)$ & ND \\
\hline
\end{tabular}

Se determinó el pH y la concentración de ácidos láctico y acético en la arepa control y la arepa con kefir. El pH de la arepa con agua fue más alto, cerca de 5 y el de la arepa adicionada con kefir de 4. Esto correspondió a que en la arepa antioqueña adicionada se detectó la presencia del ácido láctico en una concentración aproximada de 285 ppm. No se detectó presencia de ácido acético en la arepa con kefir.

- Supervivencia de las BAL y LEV en las arepas adicionadas con kefir y resistencia de las mismas a la contaminación natural.

La concentración de bacterias ácido lácticas, levaduras y hongos filamentosos en arepas, se determinó durante los días 1,5 y 10 de almacenamiento a $14^{\circ} \mathrm{C}$ y los resultados se presentan en la tabla 6.1.9. La vida útil se definió como el tiempo necesario en días para que los hongos alcanzaran el recuento máximo de $10^{3}$ UFC/g según la Norma Técnica Colombiana NTC 5372 (ICONTEC, 2007).

Tabla 6.1.9 Recuentos de Bacterias Ácido Lácticas (BAL), Levaduras (LEV) y Hongos Filamentosos (HF) en la Arepa.

\begin{tabular}{|c|c|c|c|c|c|c|}
\hline \multirow[b]{3}{*}{ DÍA } & \multicolumn{6}{|c|}{ TRATAMIENTO } \\
\hline & \multicolumn{3}{|c|}{ AREPA SÓLO CON AGUA } & \multicolumn{3}{|c|}{ AREPA CON KEFIR } \\
\hline & BAL (UFC/ml) & $\begin{array}{c}\text { LEV } \\
\text { (UFC/ml) }\end{array}$ & $\begin{array}{c}\text { HONGOS } \\
\text { FILAMENTOSOS } \\
\text { (UFC/ml) }\end{array}$ & $\begin{array}{c}\text { BAL } \\
\text { (UFC/ml) }\end{array}$ & $\begin{array}{c}\text { LEV } \\
\text { (UFC/ml) }\end{array}$ & $\begin{array}{c}\text { HONGOS } \\
\text { FILAMENTOSOS } \\
\text { (UFC } / \mathrm{ml})\end{array}$ \\
\hline 1 & $<10^{2}$ & $<10^{2}$ & $2,00 \pm 0,11 \times 10^{2}$ & $<10^{2}$ & $<10^{2}$ & $1,00 \pm 0,31 \times 10^{2}$ \\
\hline 5 & $6,00 \pm 0,14 \times 10^{4}$ & $3,52 \pm 0,14 \times 10^{4}$ & $2,8 \pm 0,71 \times 10^{3}$ & $<10^{2}$ & $<10^{2}$ & $1,12 \pm 0,24 \times 10^{2}$ \\
\hline 10 & $>10^{4}$ & $1,53 \pm 0,59 \times 10^{6}$ & $4,7 \pm 0,32 \times 10^{3}$ & $<10^{2}$ & $<10^{2}$ & $1,78 \pm 0,15 \times 10^{2}$ \\
\hline
\end{tabular}




\subsection{INHIBICIÓN DEL CRECIMIENTO FÚNGICO CON LECHE FERMENTADA}

CON GRÁNULOS DE KEFIR

En las arepas hechas sólo con agua no se detectaron BAL ni LEV en el primer día, pero éstas aparecieron a partir del día 5, provenientes del medio ambiente. Se observa que el recuento de las BAL se mantuvo casi constante y que las levaduras aumentaron en dos órdenes logarítmicos. En éstas, los hongos filamentosos estuvieron en el primer día por debajo del máximo permitido, pero lo alcanzaron al día 5, manteniéndose en el mismo orden hasta el día 10.

En primer lugar, pudo observarse que las BAL y LEV provenientes del kefir no soportaron el asado de la arepa, lo cual se tradujo en el recuento del día uno. Este mismo día, el recuento de los HF fue similar al de la arepa con agua, estando por debajo del nivel máximo permitido. Durante los 10 días de almacenamiento el recuento de BAL y LEV estuvo por debajo de $10^{2} \mathrm{UFC} / \mathrm{ml}$ y los HF se mantuvieron en un recuento de $10^{2} \mathrm{UFC} / \mathrm{ml}$. Esto demostró que la adición del kefir a la arepa, aunque no garantizó la supervivencia de los probióticos en el alimento, si logró prolongar la vida útil manteniendo los recuentos de HF por debajo de los límites de $10^{3}$ establecidos por la legislación Colombiana (ICONTEC, 2007). Lo anterior se pudo deber al efecto protector del ácido láctico y el descenso de $\mathrm{pH}$, aportados por la presencia del kefir en la masa, observados en la tabla 6.1.8.

\subsubsection{Estudio de la resistencia de la arepa adicionada de leche} fermentada con kefir a la contaminación artificial.

Las arepas elaboradas con leche fermentada con kefir y las arepas sin kefir, se contaminaron pulverizando cada 100 gramos con $1 \mathrm{ml}$ de solución de $1 \times 10^{4}$ conidios/ml de $A$. flavus AFUNL5. El control se hizo adicionando en lugar de solución de conidios, agua destilada estéril en la misma proporción. Una vez contaminadas, se dejaron secar y se almacenaron en bolsas de polietileno selladas a $14{ }^{\circ} \mathrm{C}$. Se empacaron 5 arepas por bolsa y ésas se observaron diariamente y se compararon los días necesarios para que se diera la aparición visible del hongo en los (Gerez, Torino, Rollán \& Font de Valdez, 2009), que se presentan en la tabla 6.1.10. 


\subsection{INHIBICIÓN DEL CRECIMIENTO FÚNGICO CON LECHE FERMENTADA}

CON GRÁNULOS DE KEFIR

Tabla 6.1.10 Días transcurridos para la aparición visible del hongo adicinado a las arepas.

\begin{tabular}{|c|c|}
\hline Tratamiento & $\begin{array}{c}\text { Días necesarios para la aparición visible del } \\
\text { hongo filamentoso }\end{array}$ \\
\hline AREPA CON AGUA NO CONTAMINADA & $>11$ \\
\hline AREPA CON KEFIR Y CONTAMINADA & $11 \pm 0,5$ \\
\hline AREPA CON AGUA Y CONTAMINADA & $8 \pm 0,3$ \\
\hline
\end{tabular}

Pudo determinarse en primer lugar que la aparición de los hongos visibles, correspondía a la contaminación dado que las arepas no contaminadas no presentaron aparición visible de los hongos en el tiempo evaluado. El tiempo de resistencia de las arepas con agua fue de aproximadamente 8 días y el de las arepas con kefir de 11 días, ejemplo de lo cual se observa en la figura 6.1.21. Se puede concluir de esta prueba que la presencia del kefir en la masa aumentó de manera significativa $(p<0,05)$ la resistencia de las arepas a la contaminación artificial con conidios de $A$. flavus AFUNL5.

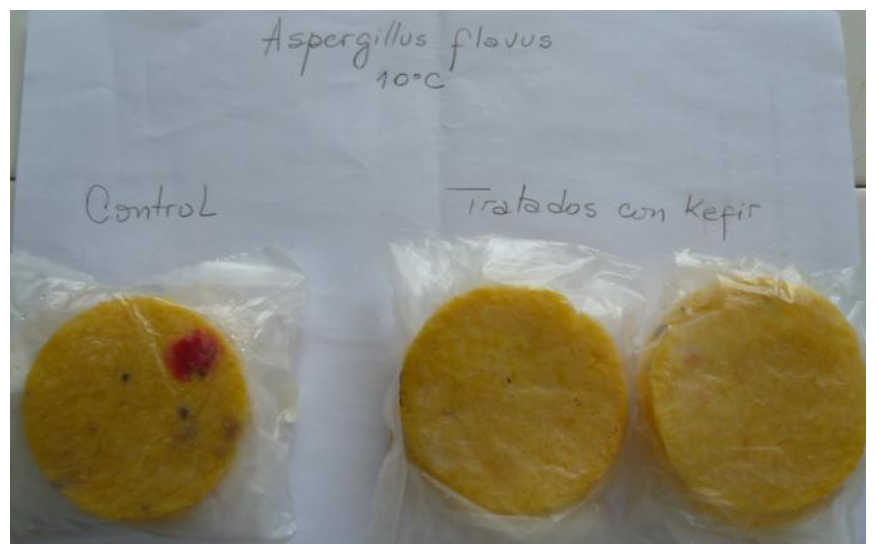

Figura 6.1.21 Arepas contaminadas con conidios de A. flavus AFUNL5. La arepa control fue elaborada sólo con agua y las arepas tratadas con kefir fueron adicionadas con kefir en la masa.

Como se observa en la figura 6.1.22, las arepas pueden tener diferentes tiempos de vida útil dependiendo el empaque y de los preservantes adicionados. En algunas el tiempo de vida útil puede ser de 12 días (a) y en otras con mayor cantidad de preservantes como propionato y sorbato de sodio, puede ser hasta de cerca de 40 días (b, c y d). El empleo del kefir podría seguir siendo evaluado en la vida útil de las arepas antioqueñas realizando comparaciones con los preservantes empleados, encaminando la búsqueda de un preservante más natural y que aporte al producto otros nutrientes derivados de la leche. 

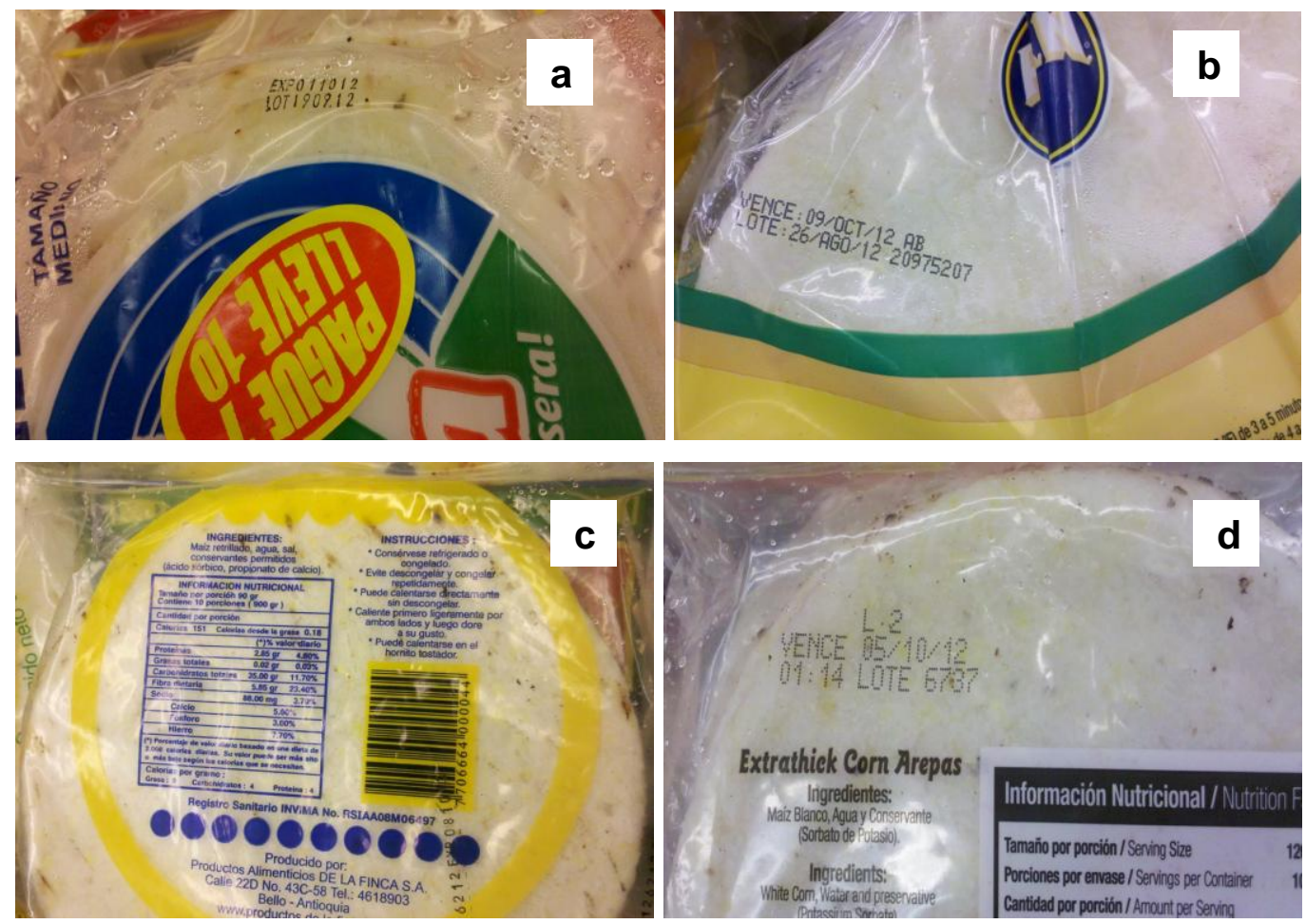

Figura 6.1.22 Arepas comerciales en Colombia. a y b: fechas del lote y del vencimiento. c y d: ingredientes empleados en su manufactura.

\subsubsection{Perfil sensorial de sabor de arepas de maíz con kefir.}

La arepa de maíz es un producto autóctono colombiano, que tal como se describió anteriormente, hace parte de los hábitos cotidianos de la alimentación (Martínez \& Arcila, 2006). En el Laboratorio de Análisis Sensorial de Alimentos de la Universidad de Antioquia- Colombia se dispone de un panel de jueces entrenados en el análisis de diversos productos, entre ellos la arepa antioqueña. Dado que en Argentina no existía un panel entrenado en dicho producto, se decidió hacer el primer estudio de perfil de sabor en dicho laboratorio. Para ello se empleó leche semidescremada (Colanta ${ }^{\circledR}$, Medellín, Colombia) que se fermentó en Medellín con gránulos de kefir CIDCA AGK1 y se fabricaron las arepas tal como se describió en materiales y métodos generales.

El estudio sensorial se efectuó con ocho jueces entrenados, los cuales evaluaron arepas de maíz y arepa de maíz adicionada con Kefir en la superficie y en masa al $10 \%$. En los tres productos se realizó el perfil de sabor según la norma técnica Colombiana NTC 3929 (ICONTEC, 1999). Los gustos y sensaciones percibidas se calificaron en una escala de 0 a 5 , de 1 débil a 5 


\subsection{INHIBICIÓN DEL CRECIMIENTO FÚNGICO CON LECHE FERMENTADA}

CON GRÁNULOS DE KEFIR

intenso. Las arepas se entregaron a los jueces en platos codificados con números aleatorios de tres dígitos. Durante el desarrollo del perfil de sabor, los jueces percibieron los sabores siguientes que se presentan en la tabla 6.1.11.

Tabla 6.1.11 Sabores detectados por los jueces del Panel sensorial, en las Arepas fabricadas con y sin kefir.

\begin{tabular}{|c|c|c|}
\hline Sabor todas las muestras & Sabor muestras con kefir & Sensaciones trigeminales \\
\hline Maíz cocido & Lácteo & Metálica, \\
\hline Salado & Fermento & Astringente \\
\hline Asado & Alcohólico sólo en muestra con 10\% masa & Entumecimiento \\
\hline Alcalino & Mayor intensidad de sabor ácido & Picante \\
\hline Tierra & & \\
\hline Quemado & & \\
\hline Tostado & & \\
\hline Amargo & & \\
\hline Afrecho & & \\
\hline Alcohólico & & \\
\hline Graso & & \\
\hline Químico & & \\
\hline Jabón & & \\
\hline Moho & & \\
\hline Harina & & \\
\hline Mantequila & & \\
\hline & & \\
\hline
\end{tabular}

En la figura 6.1.23 se muestran los perfiles de sabor de las arepas analizadas.

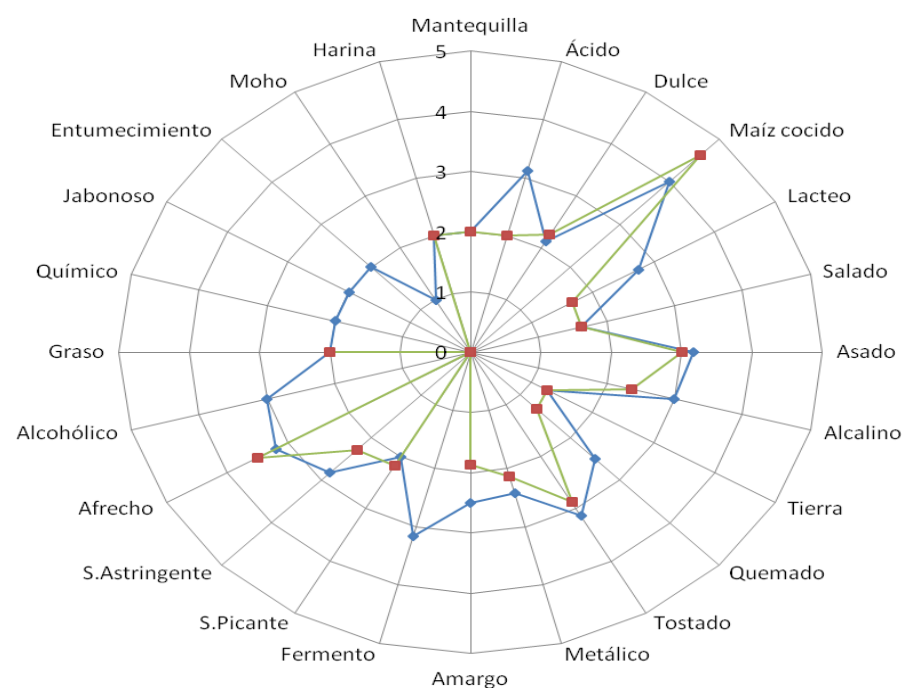

Figura 6.1.23. Perfil de sabor de Arepa control y Arepa con kefir en masa al 10\%. Arepa control:ロ; Arepa con kefir en masa: $\diamond$.

Los tratamientos presentaron los sabores más intensos de maíz cocido, asado, tostado, y afrecho. Los valores de sabor con mayor intensidad percibidos en las 


\subsection{INHIBICIÓN DEL CRECIMIENTO FÚNGICO CON LECHE FERMENTADA}

CON GRÁNULOS DE KEFIR

arepas control fueron maíz cocido $(4,625)$, asado $(3,0)$, tostado $(2,875)$ y Afrecho $(3,5)$. El control fue el único producto donde se percibió el sabor graso $(2,0)$ y en él no se percibió sabor a fermento, alcohólico, químico, jabonoso, entumecimiento ni moho. Sólo en la arepa con kefir en masa se percibieron los sabores alcohólico $(3,0)$, químico (2), jabonoso (2), entumecimiento (2) y moho (1). Además tuvo los sabores con mayor valor de ácido $(3,125)$, alcalino $(3,0)$, quemado $(2,5)$, tostado $(3,14)$, metálico $(2,43)$, amargo $(2,5)$, fermento $(3,17)$ y astringente $(2,83)$.

Si bien hay diferencias, la presencia de sabores típicos y la aparición de unos nuevos indican que la arepa adicionada de kefir es una variante de la tradicional pero no un producto absolutamente diferente. Este producto aporta al tradicional, básicamente los sabores alcohólico, fermento y ácido. Se podría plantear a continuación una prueba de aceptación del consumidor, que indique si sería aceptada entre los consumidores generales y si la adquirirían o no. En conclusión, es posible hacer una arepa con kefir y que sea consumible.

\subsubsection{Conclusiones}

En este capítulo se estudió la capacidad antifúngica de los SLC obtenidos con leche fermentada con gránulos de kefir CIDCA AGK1 y AGK2 a diferentes temperaturas y adicionados en diferentes concentraciones al medio de cultivo.

Se evaluó la inhibición fúngica sobre dos parámetros básicos de la cinética fúngica: la tasa de crecimiento y la fase de latencia. De ambos, el parámetro de crecimiento fúngico más afectado en todos los tratamientos fue la fase Lag.

De todas las variantes fermentadas evaluadas, la mayor inhibición fue producida por los SLC obtenidos con gránulo CIDCA AGK1 a pH 3,3, incubado a $30^{\circ} \mathrm{C}$, $10 \%$ inóculo y al $50 \%$ de concentración del sobrenadante en el medio de cultivo.

Las mezclas de ácidos orgánicos solos en agua destilada, demostraron un importante efecto inhibitorio sobre el crecimiento del hongo. Sin embargo, 


\subsection{INHIBICIÓN DEL CRECIMIENTO FÚNGICO CON LECHE FERMENTADA \\ CON GRÁNULOS DE KEFIR}

cuando los ácidos se colocaron en leche, el efecto de estos sobrenadantes fue significativamente menor. Al evaluar el efecto del $\mathrm{pH}$ sobre el crecimiento fúngico se determinó que no había efecto inhibidor. Por tanto, se concluye que la leche por si sola confiere protección al hongo frente a los ácidos orgánicos que es necesaria la combinación del $\mathrm{pH}$ y la presencia de los ácidos para ejercer un efecto inhibidor.

El efecto inhibidor de los sobrenadantes de kefir se debería parcialmente a los ácidos orgánicos producidos por los microorganismos del kefir y que el poder inhibidor de los sobrenadantes debe involucrar otros metabolitos que deberán ser estudiados.

El kefir elaborado a pH 3,3 fue empleado en el estudio de la vida útil de la arepa antioqueña. A partir de los resultados obtenidos se determinó que los microorganismos probióticos no sobreviven al proceso de horneo. Los ácidos en especial el ácido láctico permanecen en la masa y ejercen un efecto protector contra la contaminación natural y artificial prolongando la vida útil de la Arepa.

A nivel sensorial, la adición del kefir mantiene sabores de la arepa tradicional pero adiciona otros provenientes del producto fermentado. Puede considerarse que el kefir puede emplearse como biopreservante en la arepa antioqueña. 


\subsection{EFECTO ANTIFÚNGICO DEL PERMEADO DE SUERO FERMENTADO CON GRÁNULOS DE KEFIR (PSFG) Y CON MICROORGANISMOS AISLADOS DE GRÁNULOS DE KEFIR (PSFM)}

\subsubsection{Introducción}

La contaminación de alimentos por hongos filamentosos y levaduras es causa de grandes pérdidas económicas en todo el mundo, y además conlleva la producción de esporas alergénicas y la liberación de micotoxinas (Pitt \& Hocking, 1999). Las condiciones de colonización de los sustratos por los hongos micotoxigénicos, así como su posterior contaminación con micotoxinas juegan un papel fundamental en las estrategias de vigilancia y control de la industria alimentaria.

Los cambios en las preferencias de los consumidores han conducido a un aumento en el consumo de carne de aves, así como la reducción de los precios en la carne de pollo lo que lleva a una expansión de su consumo a nivel mundial (Evans \& Wright, 2003). En Argentina, la faena anual de aves se incrementó en un 140\% en el período 1990-2000, lo cual se debió a que durante esta década se redujo el precio en el mercado interno y hubo cambios en los hábitos del consumidor (SAGPyA, 2001) y entre los años 1994 y 2011, Argentina aumentó el consumo aparente de carne pollo en el orden de un $83 \%$. En el mismo período se redujeron las importaciones y se comenzaron a exportar los excedentes de producción (Caramella, 2012).

Durante el año 2010, la estimación de producción mundial de carne aviar, superó los 74 millones de toneladas, lo que representó un incremento de $3,3 \%$ en relación con el año 2009. Por su parte, Argentina ha mantenido un espacio en el mercado internacional ocupando el séptimo lugar como productor y el quinto como exportador. Durante 2010 la producción de carne aviar Argentina fue de 150 mil toneladas. (Ministerio de Agricultura Ganadería y Pesca Argentina, 2010). Hoy en día el grueso de la producción se encuentra en las provincias de Entre Ríos (47\%) y Buenos Aires (44\%). Mientras que existen diversas empresas 
integradas como Rasic, Avex, Avícola Sarmiento, Miralejos, Ecoave y Prosavic, entre otras. (Caramella, 2012).

La contaminación con hongos filamentosos es un problema que afecta la producción de carne aviar, en lo relacionado a los alimentos para animales producidos a escala industrial. Estos alimentos se diferencian entre simples y balanceados; los simples están constituidos por un solo componente mientras que los balanceados se obtienen por la mezcla de varios alimentos simples. Un alimento simple como el maíz es rico en carbohidratos pero pobre en proteínas, minerales y algunas vitaminas. Para compensar la deficiencia en nutrientes, debe mezclarse con otros alimentos como harina de carne, harina de soja, girasol, hueso y conchilla que aportan calcio y fósforo, obteniéndose un alimento balanceado (Bonino \& Azcona, 1992). En la producción aviar actual, se obtiene la energía de los granos y de la grasa, siendo el maíz y el sorgo los granos empleados con mayor frecuencia, aunque en otros lugares son populares también el trigo y el centeno. La fuente de proteína principal proviene de la harina de soja, harina de pescado, harina de carne, hueso, sangre, plumas, y mezclas de las anteriores (Dale, 2002).

Un problema de contaminación en la producción avícola es la presencia de hongos y micotoxinas en los alimentos y camas de criaderos de aves, los que generan pérdidas grandes de producción. A partir de alimentos para animales se aíslan con frecuencia hongos de los géneros Aspergillus spp., Penicillium spp., Fusarium spp., Mucor spp., Rhizopus spp., Cunningamella spp., Cladosporium spp., Phoma spp., Endomyces spp. y Eurotium spp (Dante, 2003). Las micotoxinas más importantes en aves y cerdos son las aflatoxinas, ocratoxina $A$ (OTA), zearalenona (ZEA), fumonisinas, citrinina y los tricotecenos deoxinivalenol (DON o vomitoxina) y toxina T-2 (Daghir, 1998; Tapia, 1986).

La contaminación del grano o durante la manufactura del alimento, ocurre por contaminación con esporas fúngicas, especialmente cuando los granos de cereales se someten a peletizado (Suárez, 1999). Como se describió anteriormente, muchos de los hongos contaminantes de alimentos pueden producir micotoxinas y la presencia de hongos y micotoxinas puede conducir a la 
pérdida del valor nutricional del alimento y a efectos perjudiciales sobre la salud y producción animal como inmunodepresión (Dietert, Golemboski \& Austic, 1994), rechazo al alimento, reducción en la ganancia diaria de peso y de la uniformidad del lote, disminución en la razón de conversión, en la producción de huevos y nacimiento de pollos y mayor tasa de mortalidad (CAST, 2003) y efectos teratogénicos (Basílico, 2008).

Las aves y en especial los pollos tienen una gran sensibilidad a la Aflatoxina B1, manifestando un descenso en el crecimiento y en la producción, en el peso y calidad de huevo, comprometiendo su incubabilidad. La afección del sistema inmune también se hace evidente con el oportunismo de microorganismos de su flora natural, desencadenando patologías que no supondrían ninguna relación con la presencia de las micotoxinas (Gimeno \& col., 2003). Se ha informado que concentraciones mayores a $50 \mathrm{ppb}$ de AFB1 en pollos, se inhibe el crecimiento de estos y hay manifestación macroscópica de daño hepático. En aves, concentraciones de $100 \mathrm{ppb}$ en el alimento, reducen la tasa de crecimiento, la calidad del huevo y su incubabilidad.

A partir de todo lo anterior es evidente la necesidad de un estricto control de la calidad micológica de los alimentos. Los estudios que se han realizado sobre contaminación fúngica de alimentos balanceados para animales han aislado con mayor frecuencia los géneros Aspergillus sp., Penicillium sp. y Fusarium sp. (Abarca, Bragulat,Castellá \& Cabañes, 1994; Moreno, Ramos, Rodríguez \& Suárez, 1986; Dalcero, Magnoli, Luna, Ancasi, Reynoso, Chiacchiera, Miazzo \& Palacios, 1998; Bueno, 2003). Todo lo anterior indica que el estudio del la calidad en el alimento balanceado destinado a pollos es un área de gran importancia en la inocuidad de los alimentos, que está siendo explorada en la actualidad y que incluye tanto la identificación de los hongos alteradores como posibles alternativas de inhibición fúngica. 
La identificación taxonómica de hongos filamentosos se hace mediante técnicas fenotípicas y genotípicas. La identificación a nivel molecular se basa en que los ribosomas eucariotas poseen dos subunidades, la subunidad grande $60 \mathrm{~S}$ y la subunidad pequeña 40S. En los hongos filamentosos, la región del ADN que codifica para el $A R N_{R}$ está conformada por la secuencia de los genes que codifican el ARNr 18S, 5,8S, 28S y 5S. Las secuencias espaciadoras no codificantes entre las secuencias del $18 \mathrm{~S}$ y $5,8 \mathrm{~S}$ y entre las secuencias $5,8 \mathrm{~S}$ y 5S se conocen como ITS1 e ITS2 (Internal Transcribed Secuence), como se observa en la Figura 6.2.1. Esas son las secuencias variables y se emplean con frecuencia para la identificación molecular de los hongos filamentosos a nivel de especie. Para ello, el ADN obtenido de los hongos se amplifica con primers que se fijan en la secuencia conservadas, conocidos como ITS1 e ITS4 (o ITS5), y se secuencian los amplicones obtenidos. Las secuencias obtenidas se comparan con las secuencias de los mismos genes que están depositadas en bases de datos, y con base en la homología se establece la especie del hongo. (Vero, 2011)

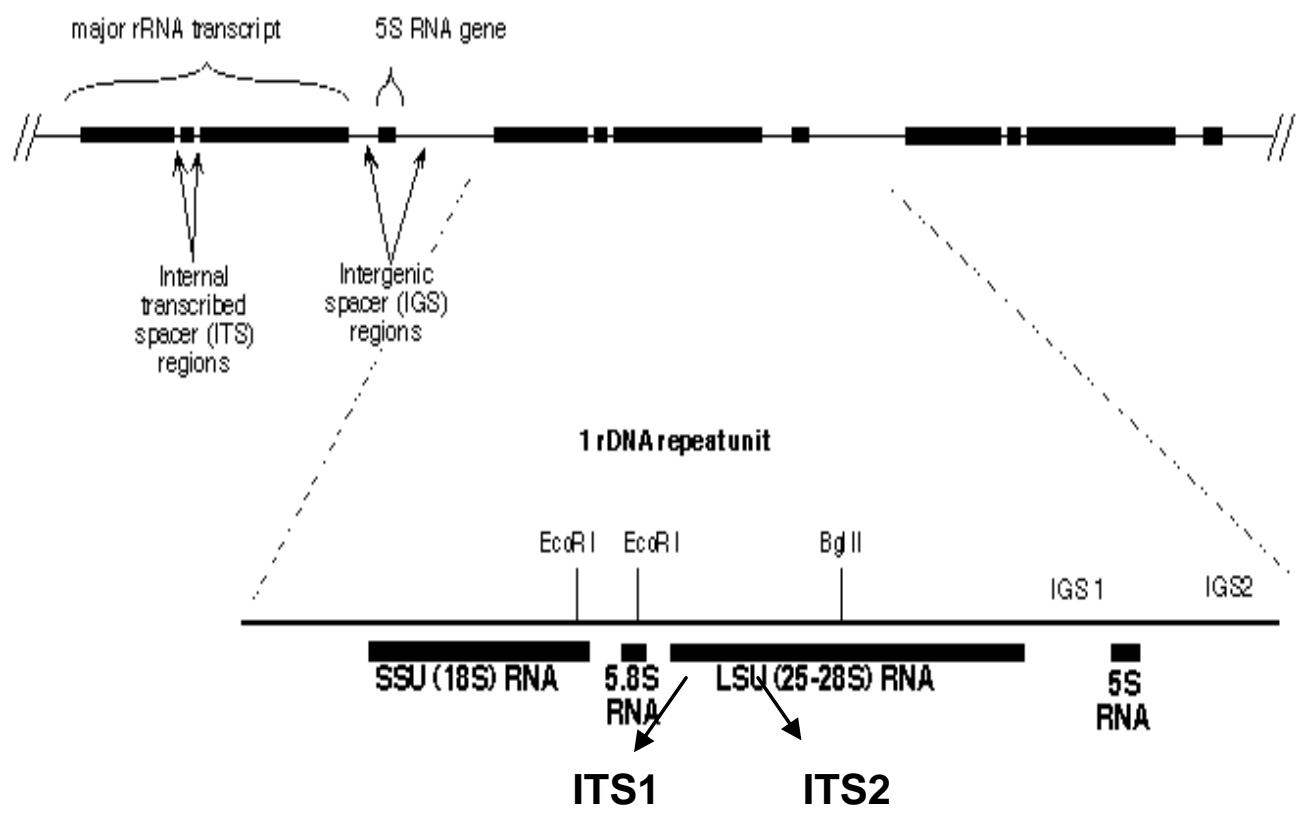

Figura 6.2.1 Gen que codifica para el ARN ribosomal RNA18SrDNA - 5,8SrADN - 28S y \%S RNA.

Según se vio en los capítulos 5 y 6.1, los ácidos orgánicos (AO) (láctico y acético) y los sobrenadantes libres de células (SLC) de leche fermentada con 
gránulos de kefir (GK) que contienen $A O$, participan del efecto antifúngico que prolonga la fase de adaptación (Lag), disminuye la tasa de crecimiento fúngica $\left(K_{D}\right)$ y reduce la germinación de conidios (León, Serna, Quintero, Gamba, De Antoni \& Giannuzzi, 2012; Molina \& Giannuzzi, 1999). Cabría preguntarse si la inhibición fúngica producida por el kefir y sus microorgansimos resulta de aplicación en una matriz alimenticia mas compleja como es la de alimento para pollos.

No obstante los resultados obtenidos con leche fermentada con kefir generaron una reducción en el crecimiento fúngico en el capítulo 6.1; se consideró de interés evaluar el aprovechamiento de un sustrato más económico, aplicable en la industria de alimento para animales y que a su vez no aportase los compuestos nutritivos residuales de la leche que estimulan parcialmente el crecimiento fúngico. Se eligió el permeado de suero, proveniente del lactosuero, subproducto de la industria láctea. Se estima que unas 450 mil toneladas de suero líquido se generan anualmente (Speranza, 2011) y para disminuir el impacto ambiental de este subproducto y dar un valor agregado, el suero se filtra para extraer las proteínas, obteniéndose un subproducto adicional que es el permeado de suero (PS). Este tiene potencial para ser fermentado por el kefir, ya que su componente principal, luego del agua, es la lactosa, que puede utilizarse como sustrato para la fermentación.

En esta etapa de la investigación se propuso el aprovechamiento del PS evaluando la capacidad fermentativa de los microorganismos del kefir (MK) y del gránulo de kefir sobre dicho sustrato. Se evaluó la actividad antifúngica de los sobrenadantes libres de células (SLC) de los productos fermentados tanto a partir del permeado de suero fermentado con gránulo de kefir (PSFG) como con Lactobacillus plantarum y Kluyveromyces marxianus (aislados del gránulo de kefir) contra los hongos filamentosos de la colección de la Cátedra de Microbiología y los aislados del alimento de pollo. Adicionalmente se determinó si el efecto antifúngico se debía al descenso de $\mathrm{pH}$ o a la combinación de la producción de ácidos orgánicos y el pH final. Para ello se realizó el estudio del 
porcentaje de reducción de la germinación de conidios (\%RG) (Gerez, Torino, Rollán \& Font de Valdez, 2009). También se estudió la aplicación de los productos fermentados en la vida útil de alimentos para pollos. Para ello, los productos fermentados se adicionaron a alimento para pollos de 0 a 28 días marca Nutrisur ${ }^{\circledR}$. La incidencia del $\mathrm{pH}$ y los ácidos orgánicos se evaluó por acidificación del PS con ácidos láctico y acético en las concentraciones presentes en los productos fermentados y con ácido clorhídrico. La supervivencia de los microorganismos probióticos en el pienso se estudió mediante recuentos de microorganismos viables y la resistencia del alimento a la contaminación artificial se evaluó contaminando el pienso con conidios, determinando la cantidad de días transcurridos hasta hacerse visible el crecimiento del hongo.

\subsubsection{Objetivos}

\subsubsection{Objetivo General}

- Evaluar la capacidad antifúngica del permeado de suero fermentado con microorganismos del kefir y su aplicación en alimentos para pollos.

\subsubsection{Objetivos Específicos}

- Aislar e identificar a nivel fenotípico y molecular, hongos filamentosos presentes en el alimento para pollos.

- Establecer la cinética de fermentación del PS con microorganismos aislados del kefir y con gránulo de kefir CIDCA AGK1.

- Determinar la composición de microorganismos y de proteínas, lactosa, sólidos totales y ácidos orgánicos del PS sin fermentar (PS), fermentado con gránulos de kefir (PSFG) y fermentado con microorganismos del kefir (PSFM).

- Estudiar el efecto antifúngico de los sobrenadantes del PS fermentado con microorganismos del kefir (PSFM) y con el gránulo de kefir (PSFG), contra A. parasiticus A.flavus, A. fumigatus, $A$. terreus, $P$. sumatrense, $P$. 
6.2 Efecto Antifúngico del permeado de suero fermentado con gránulos de kefir y con microorganismos aislados del kefir

crustosum, F. graminearum, Trichoderma longibrachiata y Rhizopus microsporus var. rhizopodiformis.

- Evaluar la supervivencia de los microorganismos del kefir en el alimento adicionado del PSFG.

- Determinar la capacidad del alimento para pollos adicionado con PSFG, de resistir la contaminación fúngica natural y artificial.

\subsubsection{Materiales y Métodos}

\subsubsection{Alimento para pollos.}

El alimento para pollos empleado fue alimento balanceado marca Nutrisur ${ }^{\circledR}$, en presentación de paquetes de $25 \mathrm{Kg}$. Su composición según indica el fabricante, consta de harina de girasol, harina de soja, poroto de soja desactivado, trigo, sorgo, afrechillo de trigo, gluten, cebada, harina de carne, harina de pescado, metionina, sal, coccidiostato, antioxidante (BHT), vitaminas A, D3, E, B2, B6, K3, $\mathrm{B} 1, \mathrm{~B} 12$, ácido nicotínico, ácido fólico, pantotenato de $\mathrm{Ca}$, biotina, colina, $\mathrm{Mn}, \mathrm{Zn}$, $\mathrm{Fe}, \mathrm{Cu}, \mathrm{I}$ y Se $\left(\right.$ Nutrisur $\left.^{\mathrm{Q}}\right)$.

\subsubsection{Hongos filamentosos.}

De los hongos filamentosos presentados en la metodología general, se usaron en los siguientes experimentos A.flavus AFUNL5, A. parasiticus NRRL 2999, Trichoderma longibrachiatum CMUNLP5, Aspergillus fumigatus CMUNLP2, Rhizopus macrosporus var. rhizopodiformis, Penicillium sumatrense CMUNLP3, Penicillium crustosum CMUNLP4 y Aspergillus terreus CMUNLP1.

\subsubsection{Aislamiento y Clasificación de hongos filamentosos del alimento para pollos.}


El alimento se homogenizó en agua de peptona al 0,1\% en stomaker (Laboratory Blender -stomacher $400^{\circledR}$, England) y se realizaron diluciones seriadas de éste, de las cuales se sembraron $0,1 \mathrm{ml}$ en superficie de cajas de Petri conteniendo agar Diclorán Rosa de Bengala Cloramfenicol (DRBC, Biokar ${ }^{\circledR}$ ) utilizando perlas de vidrio estériles. Las placas se incubaron por cinco días a $30^{\circ} \mathrm{C}$ en oscuridad. Después de la incubación se realizó la observación macroscópica de las colonias mediante lupa Nikon C-PS (Nikon ${ }^{\circledR}$, Japan) y observación microscópica de las estructuras reproductivas con microscopio LEITZ Laborlux 12 (LEITZ ${ }^{\circledR}$, Germany). Las colonias diferentes se siguieron aislando por tres repiques sucesivos sembrando en triángulo (por punción con ansa de punta en tres puntos equidistantes) en medio DRBC para luego incubar a $30 \stackrel{\circ}{\circ}$. Una vez terminado este aislamiento se procedió a la clasificación morfológica de cada colonia típica siguiendo la metodología propuesta por Pitt y Hocking (1999). Para ello se hicieron por triplicado, cultivos de cada aislado sembrando en tres puntos equidistantes en los medios Czapeck, G25N (Glicerol 25\%) y Malta, y se incubó durante 7 días a 5,25 y $37^{\circ} \mathrm{C}$. Se analizaron los diámetros máximos alcanzados por cada colonia, color y textura de la colonia, color de los pigmentos liberados al medio de cultivo y se observaron al microscopio las estructuras reproductivas. El material fúngico fue examinado haciendo preparaciones en portaobjetos. En las colonias sospechosas de corresponder al género Aspergillus, se tomaron porciones de agar y se cubrieron con un portaobjetos, se sometieron al calor del mechero hasta aparecer las primeras burbujas, y se hizo una presión suave sobre el vidrio. En las colonias sospechosas de pertenecer al género Rhizopus, se extrajo la muestra colocando una cinta pegante transparente en la superficie del cultivo y pegándola a continuación sobre la superficie de un portaobjetos. En las colonias sospechosas de pertenecer al género Penicillium se raspó parte de la colonia con un cubreobjetos, sobre el cual se vertieron gotas de etanol al $70 \%$, con el fin de arrastrar parte de los conidios; éste se colocó sobre un portaobjetos y se observó al microscopio con aumento de 40X. Todas las muestras fueron observadas en microscopio a 40X para analizar la estructura de la hifa reproductiva y en 100X para analizar la forma de los conidios (Basílico, 2008). La identificación efectuada de los hongos aislados se confirmó mediante técnicas 
moleculares, por secuenciación de las regiones espaciadoras intergénicas ITS1 e ITS2, tal como se describe a continuación.

\subsubsection{Obtención de ADN e identificación molecular de los hongos aislados.}

\subsection{Obtención del micelio y Ruptura celular.}

Cada hongo se incubó por cinco días sin agitación en caldo YES (2\% Extracto de levadura, $15 \%$ sacarosa) a $25^{\circ} \mathrm{C}$, el cual, debido a su alta concentración de sacarosa retarda la esporulación. Se buscó obtener mayor proporción de micelio y la menor cantidad posible de conidios, ya que éstos aportan impurezas a la preparación, las cuales pueden interferir en reacciones posteriores de amplificación. Para romper la pared celular, se extrajo con pinzas estériles el micelio del caldo de cultivo y se secó en papel secante estéril. Una porción aproximadamente de $150 \mathrm{mg}$ se depositó en un tubo eppendorf, se congeló con nitrógeno líquido y se pulverizó hasta polvo fino por presión mecánica con varilla de vidrio. A partir del micelio pulverizado se adicionaron $500 \mu \mathrm{l}$ de buffer de lisis (Tris-HCl, EDTA, $\mathrm{NaCl}$ y SDS), incubando una hora a $65^{\circ} \mathrm{C}$ a fin de favorecer la ruptura de la membrana celular y nuclear (Vero, 2011; Garmendia, 2011).

\subsection{Purificación del ADN.}

Una vez realizada la lisis celular, se procedió a la purificación del ADN. Se agregó 1 volumen de solución de fenol: cloroformo: alcohol isoamílico (25:24:1) a $\mathrm{pH}$ 8, favoreciendo la liberación de protones del ADN. Se centrifugó 10 min a $10000 \mathrm{rpm}$ y a $4^{\circ} \mathrm{C}$, quedando el ADN en la fase acuosa. Para purificar el ADN, se trasvasaron $300 \mu \mathrm{l}$ del $A D N$ en solución a un tubo eppendorff estéril, adicionando $150 \mu \mathrm{l}$ de $\mathrm{NaCl} 1 \mathrm{M}$ y $150 \mu \mathrm{l}$ de $\mathrm{NaCH}_{3} \mathrm{COO} 3 \mathrm{M}$. Se agitó en vortex y se precipitó con un volumen de isopropanol frío (aproximadamente $600 \mu \mathrm{l}$ ), se invirtió el tubo suavemente tres veces y se incubó a $-20^{\circ} \mathrm{C}$ por dos horas. EI ADN 
precipitado se centrifugó por 10 minutos a $10000 \mathrm{rpm}$ a $4^{\circ} \mathrm{C}$, se descartó el sobrenadante y se agregaron a continuación $100 \mu \mathrm{l}$ de Etanol 70\%. Se repitió la centrifugación a $10000 \mathrm{rpm}, 4^{\circ} \mathrm{C}$, descartando el sobrenadante y dejando secar el precipitado (30 min a 1 hora) a temperatura ambiente. Después se resuspendió el pellet en $50 \mu$ de agua MilliQ, se agregó $1 \mu$ de ARNasa (10 $\mathrm{mg} / \mathrm{ml}$ ), se agitó en vortex para asegurar una buena interacción con todo el ADN y se incubó por 1 hora a $37^{\circ} \mathrm{C}$. A continuación se agregaron $150 \mu \mathrm{l}$ de $\mathrm{NaCl}$ y $150 \mu \mathrm{l}$ de $\mathrm{CH}_{3} \mathrm{COONa} 3 \mathrm{M}$, se agitó en vortex y se agregaron $300 \mu \mathrm{l}$ de solución de fenol: cloroformo: alcohol isoamílico (25:24:1), agitando en vortex. Se centrifugó por 10 minutos a $10000 \mathrm{rpm}, 4^{\circ} \mathrm{C}$ y se separó el sobrenadante a otro eppendorf estéril de $1,5 \mathrm{ml}$. Se adicionó 1 volumen de isopropanol frio (aproximadamente $200 \mu \mathrm{l}$ ), se invirtió el tubo suavemente por tres veces y se almacenó a $-20^{\circ} \mathrm{C}$ por toda la noche. Se agregaron $100 \mu \mathrm{l}$ de etanol $70 \%$, centrifugando 10 minutos a $10000 \mathrm{rpm}, 4^{\circ} \mathrm{C}$ y descartando el sobrenadante. El pellet se secó 1 hora a temperatura ambiente y se resuspendió en $50 \mu \mathrm{l}$ de agua MiliQ para ser amplificado mediante Reacción en Cadena de la Polimerasa (Vero, 2011).

\subsection{Amplificación del ADN por PCR.}

La amplificación de la región ITS1-5,8SrADN - ITS2 del ADN se realizó de la siguiente manera. Los primers utilizados fueron ITS1 (5' TCCGTAGGTGAACCTGCGG - 3') e ITS4 (5' - TCCTCCCGCTTATTGATATGC - 3') (BYO.SYNTHESIS Company ${ }^{\circledR}$, Lewisville, Texas, USA). La reacción de amplificación se realizó en un volumen final de $25 \mu$ l conteniendo 2,5 $\mu$ l buffer 10X (Fermentas International Inc., Canadá), 16,9 $\mu$ le agua miliQ estéril, $1 \mu$ de cada primer $25 \mu \mathrm{M}, 2,5 \mu \mathrm{l}$ de dNTP $2 \mu \mathrm{M}, 0,1 \mu \mathrm{l}$ de Taq polimerasa (Fermentas International Inc., Canadá) $5 \mathrm{U} / \mu \mathrm{l}$ y $1 \mu \mathrm{l}$ de ADN. La amplificación comenzó con un paso de desnaturalización de cinco minutos a $95^{\circ} \mathrm{C}$, seguido de 35 ciclos de $94^{\circ} \mathrm{C} 1$ minuto para desnaturalizar el $\mathrm{ADN}, 55^{\circ} \mathrm{C} 2$ minutos para la hibridación de los primers y $72^{\circ} \mathrm{C}$ (2 min) para la polimerización de los DNTP's. Al final de los 35 ciclos se sostuvo la temperatura a $72^{\circ} \mathrm{C}$ para la extensión, que favorece la adición final de los DNTP's que hayan faltado por polimerizar (Magnani, Fernández, Cavenaghi, Homechim, Sataque, Vilas-Boas, Sartori, Furlaneto \& 
Pellegrinelli, 2005). La amplificación se hizo en un termociclador Multigene II Mini (LabNet International, Inc., USA)

\subsection{Electroforesis en Gel de Agarosa.}

Se verificó la presencia de ADN extraído y la amplificación correcta de las regiones ITS1 5,8S ITS2, mediante electroforesis en gel de agarosa. Se corrieron $3 \mu \mathrm{l}$ de la muestra en un gel de agarosa (Promega Corporation ${ }^{\circledR}$, Madison, USA) al 0,8\%. Para ello se diluyeron $0,16 \mathrm{~g}$ de agarosa en $20 \mathrm{ml}$ de solución de Buffer TBE 0,5X fundiendo el agar hasta clarificar en placa de calentamiento con agitación. Se empleó Bromuro de Etidio como indicador a una concentración final de $0,5 \mu \mathrm{g} / \mathrm{ml}$ (Sigma Aldrich ${ }^{\circledR}$, USA.) (Sambrook \& Russell, 2000). El gel se preparó en una base de 8 carriles, se dejó solidificar, se introdujo en una cuba de corrida i-mupid minigel migration through (Cosmobio Co. Ltd., Tokyo, Japan) y se cargaron las muestras mezcladas con buffer de corrida (life technologies ${ }^{\circledR}$, USA). Las corridas se hicieron por 35 minutos y tanto las bandas de ADN como los amplicones de la PCR se revelaron bajo una lámpara UV. Los amplicones obtenidos fueron secuenciados en Macrogen ${ }^{\mathrm{TM}}$ (Korea). Las secuencias se compararon con las secuencias depositadas en NCBI mediante el programa BLAST determinando el \% de homología del hongo aislado con las cepas tipo (Morgulis, Coulouris, Raytselis, Madden, Agarwala y Schäffer, 2008).

\subsubsection{Gránulos de Kefir}

Para los estudios de inhibición fúngica producida por Permeado de Suero fermentado con gránulos de kefir CIDCA AGK1 (PSFG), los gránulos reactivados se sometieron a diez pasajes de fermentación en Permeado de suero (PS) para adaptarlo a este sustrato. Se empleó permeado de suero deshidratado (PS) (ILOLAY ${ }^{\circledR}$, Santa Fé, Argentina). El PS se reconstituyó en agua mineralizada 
(Sujumarcu $^{\circledR}$, Buenos Aires,Argentina) al $5 \%$, se esterilizó en autoclave a $121^{\circ} \mathrm{C}$ por 15 minutos.

\subsubsection{Microorganismos aislados de gránulos de Kefir (MK).}

En este capítulo se emplearon L. plantarum y $K$. marxianus aisladas del gránulo de kefir y conservadas a $-20^{\circ} \mathrm{C}$ en la colección del CIDCA (Garrote, 1999). Se conservaron en leche y caldo MRS a $-20^{\circ} \mathrm{C}$ y se reactivaron mediante dos pasajes consecutivos de 24 horas a $30^{\circ} \mathrm{C}$ en caldo MRS (DIFCO ${ }^{\circledR}$, Francia), antes de ser cultivadas en PS.

6.2.3.7 Curvas de acidificación del permeado de suero fermentado con gránulos de kefir (PSFG) y con microorganismos aislados del kefir (PSFM).

Las curvas de acidificación se hicieron tal como se describió en la metodología general.

\subsubsection{Obtención del permeado de suero fermentado con gránulo CIDCA} AGK1 (PSFG) y con microorganismos aislados del kefir (PSFM).

La fermentación con con gránulo CIDCA AGK1 y MK se hizo tal como se describió en la metodología general.

6.2.3.9 Obtención del SLC a partir del permeado de suero fermentado con gránulo CIDCA AGK1 (PSFG) y PS fermentado con microorganismos del kefir (PSFM).

Los SLC del PSFG y del PSFM se obtuvieron tal como se describió en la metodología general. 
6.2.3.10 Determinación de la composición del permeado de suero sin fermentar (PS), del permeado de suero fermentado con gránulos de kefir (PSFG) y del permeado de suero fermentado con microorganismos del kefir (PSFM).

\subsection{Determinación de Lactosa.}

Se determinaron los azúcares reductores expresados como porcentaje de lactosa, según la técnica de Nelson-Somogyi (Collmer, Ried, y Mount, 1988). La reacción se hizo en tubos de ensayo con tapones de vidrio; en cada tubo se adicionaron $2 \mathrm{ml}$ de reactivo de cobre y $2 \mathrm{ml}$ de solución de PSFG o de PSFM, se introdujeron en un baño de agua hirviendo durante $10 \mathrm{~min}$ y se enfriaron 5 minutos en agua corriente. Se agregó $1 \mathrm{ml}$ de reactivo de arsenomolibdato, se mezcló, se llevó a un volumen definido de $10 \mathrm{ml}$ y se midió la absorbancia a 520 $\mathrm{nm}$. Para la determinación de la concentración de la muestra, se preparó una curva patrón de lactosa a las siguientes concentraciones: 0, 50, 150, 300 y 400 $\mu \mathrm{g} / \mathrm{ml}$ (Southgate, 1976).

\subsection{Determinación de sólidos solubles totales.}

Se midieron como grados Brix ( ${ }^{\circ}$ Brix) en refractómetro termostatizable ABBE Thermo Scientific $^{\circledR}$ (USA). Se tomó $1 \mathrm{ml}$ de la muestra de PSFG o PSFM, se graduó la escala de lectura y se realizó la lectura en la escala correspondiente a ${ }^{\circ}$ Brix del refractómetro a una temperatura de $20^{\circ} \mathrm{C}$. Los resultados se expresaron en ${ }^{\circ}$ Brix a $20^{\circ} \mathrm{C}$ (ICONTEC, 1994).

\subsection{Determinación de Nitrógeno total.}

Se determinó por el método de micro Kjeldahl en un equipo micro Kjeldahl VELP Scientifica (Italia). Para la digestión se empleó como catalizador $4 \mathrm{~g}$ de mezcla de $\mathrm{CuSO}_{4}\left(\right.$ J.T.BAKER $^{\circledR}$, USA), $\mathrm{K}_{2} \mathrm{SO}_{4}$ (J.T.BAKER ${ }^{\circledR}$, USA), y $10 \mathrm{ml}$ de $\mathrm{H}_{2} \mathrm{SO}_{4}$ 
concentrado (96\%) (Merck $^{\circledR}$, Germany) y se adicionaron $5 \mathrm{ml}$ de muestra, calentando a $420^{\circ} \mathrm{C}$ por 45 minutos. El Nitrógeno amoniacal se destiló en medio alcalino sobre $50 \mathrm{ml}$ de $\mathrm{H}_{3} \mathrm{BO}_{3}$ (Merck ${ }^{\circledR}$, Darmstadt, Germany) al $4 \%$ y el borato de amonio obtenido se tituló con $\mathrm{HCl} 0,1 \mathrm{~N}$ (Merck ${ }^{\circledR}$, Darmstadt, Germany). Como blanco de reactivos se empleó papel de filtro. La concentración de Nitrógeno se calculó mediante la siguiente fórmula.

$\% \mathrm{~N}=\left[14 \mathrm{mg} / \mathrm{meq}\left(\mathrm{Vol}_{\mathrm{HClm}}-\mathrm{Vol}_{\mathrm{HClb}}\right)^{*} \mathrm{~N}^{*} 100\right] / \mathrm{w}$

\section{Ecuación 6.2.1}

Donde:

$\% \mathrm{~N}=$ Porcentaje de Nitrógeno total

$\mathrm{N}=$ Normalidad del titulante $(\mathrm{HCl} 0,1 \mathrm{~N})$

$14 \mathrm{mg}=$ peso en $\mathrm{mg}$ de un miliequivalente de Nitrógeno

$\mathrm{Vol}_{\mathrm{HClm}}=$ Volumen en $\mathrm{ml}$ de $\mathrm{HCl} \mathrm{0,1} \mathrm{N}$ empleado en la titulación de la muestra

Vol ${ }_{\mathrm{HClb}}=$ Volumen en $\mathrm{ml}$ de $\mathrm{HCl} 0,1 \mathrm{~N}$ empleado en la titulación del blanco de reactivos

$\mathrm{W}=$ Peso de la muestra en miligramos.

(AOAC, 1997; ICONTEC, 1994).

\subsection{Cenizas totales.}

Las muestras se pesaron a la décima de $\mathrm{mg}$ en una cápsula de porcelana previamente calcinada a $500-550^{\circ} \mathrm{C}$, enfriada en desecador y pesada al tomar temperatura ambiente. Como eran muestras líquidas, se evaporaron hasta sequedad y se continuó con la calcinación en mufla a $500-550^{\circ} \mathrm{C}$ hasta cenizas de color gris claro y peso constante. Éstas se enfriaron en desecador y se pesaron al alcanzar la temperatura ambiente.

\subsubsection{Análisis por HPLC de los ácidos láctico y acético en los SLC.}

Las concentraciones de ácido láctico y ácido acético en los sobrenadantes obtenidos mediante la fermentación del PS se analizaron por HPLC tal como se describió en la metodología general (Garrote, 1999). Para estas determinaciones se hicieron curvas patrón de ácido acético (Merck ${ }^{\circledR}$, Darmstadt, Alemania) de 25, 
50, 100, 200, 700 y 1500 ppm y de ácido láctico (Carlo Erba ${ }^{\circledR}$, Milán, Italia) de $500,1000,4000,8000,10.000$ y 14.000 ppm.

6.2.3.12 Preparación del permeado de suero (PS) acidificado artificialmente con ácidos orgánicos puros y con $\mathrm{HCl}$.

Para la acidificación artificial con ácidos orgánicos y con $\mathrm{HCl}$ se procedió tal como se describió en la metodología general.

\subsubsection{Preparación del inóculo de hongos filamentosos.}

Los hongos filamentosos se cultivaron y prepararon para los ensayos tal como se describió en la metodología general.

\subsubsection{Determinación del porcentaje de reducción de la germinación de} conidios (\%RG).

Se estudió la capacidad para reducir la germinación de los conidios, de los sobrenadantes libres de células (SLC) del permeado de suero fermentado con gránulos CIDCA AGK1 (PSFG), del PS acidificado artificialmente, y del PS fermentado con microorganismos del kefir (PSFM), según la técnica de reducción de la germinación de los conidios descripta en la metodología general.

\subsubsection{Adición al alimento para pollos del PS fermentado con gránulos de kefir CIDCA AGK1 (PSFG), y del PS acidificado artificialmente con ácidos puros y con $\mathrm{HCl}$.}

El permeado de suero fermentado con gránulos de kefir CIDCA AGK1 (PSFG) se separó de los gránulos mediante un colador y se adicionó en proporción 1:1 o 2:1 al alimento mezclándose hasta quedar bien homogenizado. Se distribuyó el alimento en bandejas de acero inoxidable en una película de aproximadamente $0,5 \mathrm{~cm}$ de espesor y se sometió a secado en estufa de convección forzada 
Estigia $^{\circledR}$ (Argentina) a $50^{\circ} \mathrm{C}$. También se hicieron los siguientes tratamientos: adición al alimento de la solución de PS acidificado artificialmente con ácidos orgánicos, de solución de PS acidificado con $\mathrm{HCl} 3 \mathrm{M}$ hasta $\mathrm{pH}$ 3,7 y control de alimento adicionando el mismo alimento con agua destilada estéril. Se tomaron los pesos de las bandejas solas, las bandejas con alimento seco y las bandejas con el alimento húmedo al inicio y cada media hora durante todo el proceso de secado, hasta alcanzar de nuevo el peso de la bandeja más el alimento seco y el peso de los sólidos que aportaba el permeado. Una vez alcanzado el peso final se dejó enfriar el alimento, se determinó su actividad acuosa en un equipo AQUALAB y se dispuso en bolsas de polietileno selladas para su análisis posterior y su almacenamiento a $20^{\circ} \mathrm{C}$.

\subsubsection{Determinación de la estabilidad del alimento para pollos adicionado con permeado de suero fermentado con gránulos de kefir CIDCA AGK1 (PSFG).}

Con el fin de conocer la estabilidad del alimento adicionado con PSFG se hicieron las siguientes determinaciones durante los días 0,15 y 30 después de la adición del PSFG.

\subsection{Supervivencia de las BAL y LEV provenientes del PSFG adicionado al alimento.}

Se realizaron recuentos del PSFG antes de ser adicionado al alimento y del alimento al salir del secado los días 0,15 y 30 del almacenamiento, según se describió en la metodología general.

\subsection{Determinación de la actividad acuosa $\left(a_{w}\right)$.}

Se determinó la $a_{w}$ del alimento antes de ser adicionado, y al salir del secado, en un equipo para medición de la actividad acuosa AQUA LAB Version 1.5 (Decagon Devices, Inc., USA).

\subsection{Determinación de pH y de la concentración de ácidos orgánicos.}


Se tomaron muestras de $5 \mathrm{gr}$ del alimento y se homogenizaron en $45 \mathrm{ml}$ de agua destilada estéril, se ultracentrifugaron y filtraron en esterilidad con filtros de 0,22 $\mu \mathrm{m}$ (. Se midió el pH en un pHmetro ALTRONIX TPX-III (ALTRONIX, Taiwan). Los ácidos presentes en los sobrenadantes estériles se determinaron mediante cromatografía de alta definición según la técnica descripta en la metodología general.

\subsection{Determinación de la presencia de aflatoxinas en el alimento.}

$25 \mathrm{gr}$ de muestra se diluyeron en $250 \mathrm{ml}$ de una solución de metanol: agua destilada 70\%:30\%. La mezcla se agitó con perlas en un vortex por 5 minutos y a 120 rpm por 30 minutos, se filtró en papel whatman y en filtro estéril de 0,22 $\mu \mathrm{m}$. La concentración de aflatoxinas de realizó tal como se describió en la metodología general.

\subsection{Estudio de la Resistencia del alimento adicionado a la contaminación natural.}

Se hizo de acuerdo a lo descripto en la metodología general.

6.2.3.16.6 Estudio de la resistencia del alimento adicionado a la contaminación artificial.

Se hizo de acuerdo a lo descripto en la metodología general. 


\subsubsection{Resultados y Discusión}

\subsubsection{Hongos filamentosos aislados del alimento para pollos.}

\section{A) Clasificación a nivel morfológico.}

De los recuentos iniciales se aislaron colonias de hongos morfológicamente diferentes en medio CYA, los cuales presentaron características que se enuncian en la tabla 6.2.1 y recibieron la siguiente nomenclatura inicial.

Tabla 6.2.1 Nomenclatura inicial y características de los hongos aislados del alimento para pollos.

\begin{tabular}{|c|c|}
\hline NOMENCLATURA & CARACTERISTICAS \\
\hline $\begin{array}{l}\text { Algodonoso gris tipo } \\
\text { Rhizopus (1) }\end{array}$ & $\begin{array}{c}\text { Colonia algodonosa con puntos negros y apariencia gris, tipo mucorales. } \\
\text { Observación microscópica de hifas blancas, con rizoides y cabeza conidial } \\
\text { similar a Rhizopus }\end{array}$ \\
\hline Verde (2) & $\begin{array}{l}\text { Colonia de agregados verdes y amarillos, irregulares. Observación microscópica } \\
\text { de hifas de las que salen conidios elipsoidales }\end{array}$ \\
\hline Azul tipo Aspergillus (3) & $\begin{array}{l}\text { Colonia aterciopelada, color azul oscuro. Observación microscópica de hifas } \\
\text { septadas, cabeza aspergilar. }\end{array}$ \\
\hline $\begin{array}{l}\text { Marrón tipo Aspergillus } \\
(4)\end{array}$ & $\begin{array}{c}\text { Colonia granulosa, color marrón. Observación microscópica de hifas septadas, } \\
\text { cabeza aspergilar. }\end{array}$ \\
\hline Gris tipo penicillium (5) & $\begin{array}{l}\text { Colonia plana, pequeña, muy pulverulenta, color gris. Observación microscópica } \\
\text { de hifas septadas y penicilos. }\end{array}$ \\
\hline Azul tipo penicillium (6) & $\begin{array}{c}\text { Colonia plana, muy pulverulenta, color azul, gris oscuro. Observación } \\
\text { microscópica de hifas septadas y penicilos. }\end{array}$ \\
\hline
\end{tabular}

Los hongos anteriores fueron cultivados en los medios malta, G25N y CYA a 5, 25 y $37^{\circ} \mathrm{C}$, durante siete días y se analizó si hubo o no crecimiento. Se midió el tamaño máximo de la colonia a las $24,48,72$ hrs y a los 7 días. Dado que muy pocos Aspergillus germinan a $5^{\circ} \mathrm{C}$ en 7 días, se recomienda que si se sabe que el aislado es un Aspergillus, se omita el estudio de las placas a $5^{\circ} \mathrm{C}$. No obstante se analizó el crecimiento de ambos hongos a $5^{\circ} \mathrm{C}$. Se analizó la textura del micelio, el color de las estructuras reproductivas, así como algunas observaciones microscópicas de las hifas reproductivas (Pit \& Hocking, 1999). A partir de los cultivos se obtuvieron los siguientes resultados que se muestran a continuación en la Tabla 6.2.2. 
6.2 Efecto Antifúngico del permeado de suero fermentado con gránulos de kefir y con microorganismos aislados del kefir

Tabla 6.2.2 Diámetro de crecimiento $(\mathrm{mm})$ de los hongos a las $24,48,72$ horas y 7 días, (a) $5^{\circ} \mathrm{C}$; (b) $25^{\circ} \mathrm{C}$ y (c) $37^{\circ} \mathrm{C}$.

\begin{tabular}{|c|c|c|c|c|}
\hline \multicolumn{5}{|c|}{ a. Crecimiento a $5^{\circ} \mathrm{C}(\mathrm{mm})$} \\
\hline Tiempo: & 24 hs. & 48 hs. & 72 hs. & 7 días \\
\hline \multicolumn{5}{|c|}{ Algodonoso gris tipo Rhizopus (1) } \\
\hline Malta & 0 & 0 & 0 & 0 \\
\hline CYA & 0 & 0 & 0 & 0 \\
\hline G25N & 0 & 0 & 0 & 0 \\
\hline \multicolumn{5}{|c|}{ Verde (2) } \\
\hline Malta & & 0 & 0 & 0 \\
\hline CYA & & 0 & 0 & 0 \\
\hline G25N & & 0 & 0 & 0 \\
\hline \multicolumn{5}{|c|}{ Azul tipo Aspergillus (3) } \\
\hline Malta & & 0 & 0 & 0 \\
\hline CYA & & 0 & 0 & 0 \\
\hline G25N & & 0 & 0 & 0 \\
\hline \multicolumn{5}{|c|}{ Marrón tipo Aspergillus (4) } \\
\hline Malta & & 0 & 0 & 0 \\
\hline CYA & & 0 & 0 & 0 \\
\hline G25N & & 0 & 0 & 0 \\
\hline \multicolumn{5}{|c|}{ Gris tipo Penicillium 5.} \\
\hline DRBC & & 0 & 0 & 0 \\
\hline Malta & & 0 & 0 & 0 \\
\hline CYA & & 0 & 0 & 0 \\
\hline \multicolumn{5}{|c|}{ Azul tipo Penicillium 6.} \\
\hline Malta & & 0 & 0 & 3 \\
\hline CYA & & 0 & 0 & 2,5 \\
\hline G25N & & 0 & 0 & 0 \\
\hline
\end{tabular}

\begin{tabular}{|c|c|c|c|c|}
\hline \multicolumn{5}{|c|}{ b. Crecimiento a $25^{\circ} \mathrm{C}(\mathrm{mm})$} \\
\hline Tiempo: & 24 hs. & 48 hs. & 72 hs. & 7 días \\
\hline \multicolumn{5}{|c|}{ Algodonoso gris tipo Rhizopus (1) } \\
\hline Malta & & 48 & 75 & 90 \\
\hline CYA & & 49 & 90 & 90 \\
\hline G25N & & 0 & 0 & 0 \\
\hline \multicolumn{5}{|c|}{ Verde (2) } \\
\hline Malta & 90 & 90 & 90 & 90 \\
\hline CYA & ND & 11,5 & 35,5 & 90 \\
\hline G25N & 0 & 0 & 0 & 0 \\
\hline \multicolumn{5}{|c|}{ Azul tipo Aspergillus (3) } \\
\hline Malta & ND & 9,5 & 21,5 & 60 \\
\hline CYA & ND & 6,5 & 17,5 & 55 \\
\hline G25N & 0 & 0 & 0 & 3 \\
\hline \multicolumn{5}{|c|}{ Marrón tipo Aspergillus (4) } \\
\hline Malta & ND & 12 & 19 & 27 \\
\hline CYA & ND & 13 & 22,5 & 48,5 \\
\hline G25N & 0 & 0 & 5,5 & 22 \\
\hline \multicolumn{5}{|c|}{ Gris tipo Penicillium (5) } \\
\hline Malta & ND & 8 & 12 & 24 \\
\hline CYA & ND & 9 & 14 & 31 \\
\hline G25N & 0 & 0 & 3,5 & 12 \\
\hline \multicolumn{5}{|c|}{ Azul tipo Penicillium (6) } \\
\hline Malta & ND & 11,5 & 16 & 34 \\
\hline CYA & ND & 6,5 & 10 & $19^{\star \star}$ \\
\hline G25N & 0 & 0 & 4 & 13 \\
\hline
\end{tabular}




\begin{tabular}{|c|c|c|c|c|}
\hline \multicolumn{5}{|c|}{ C. Crecimiento a 37으 (mm) } \\
\hline Tiempo: & $\mathbf{2 4}$ hs. & $\mathbf{4 8}$ hs. & $\mathbf{7 2}$ hs. & 7 días \\
\hline \multicolumn{5}{|c|}{ Algodonoso gris tipo Rhizopus (1) } \\
\hline Malta & 90 & 90 & 90 & 90 \\
\hline CYA & 90 & 90 & 90 & 90 \\
\hline \multicolumn{5}{|c|}{ Verde (2) } \\
\hline Malta & 90 & 90 & 90 & 90 \\
\hline CYA & ND & 25 & 47 & 90 \\
\hline
\end{tabular}

\begin{tabular}{|c|c|c|c|c|}
\hline G25N & 0 & 0 & 0 & 0 \\
\hline c. Crecimiento a 37으 (mm) (continuación) \\
\hline \multicolumn{5}{|c|}{ Azul tipo Aspergillus (3) } \\
\hline Malta & ND & 37 & 47 & 87 \\
\hline CYA & ND & 27,5 & 35 & 90 \\
\hline G25N & ND & 2,5 & 7 & 16 \\
\hline \multicolumn{3}{|c|}{ Marrón tipo Aspergillus (4) } \\
\hline Malta & ND & 22 & 29,5 & 46,5 \\
\hline CYA & ND & 22,5 & 35,6 & 70 \\
\hline G25N & ND & 13 & 18 & 55 \\
\hline
\end{tabular}

En las figuras 6.2.2, 6.2.3 y 6.2.4 se puede observar el crecimiento de algunos de los hongos analizados en diferentes medios de cultivo y las características que presentaron.

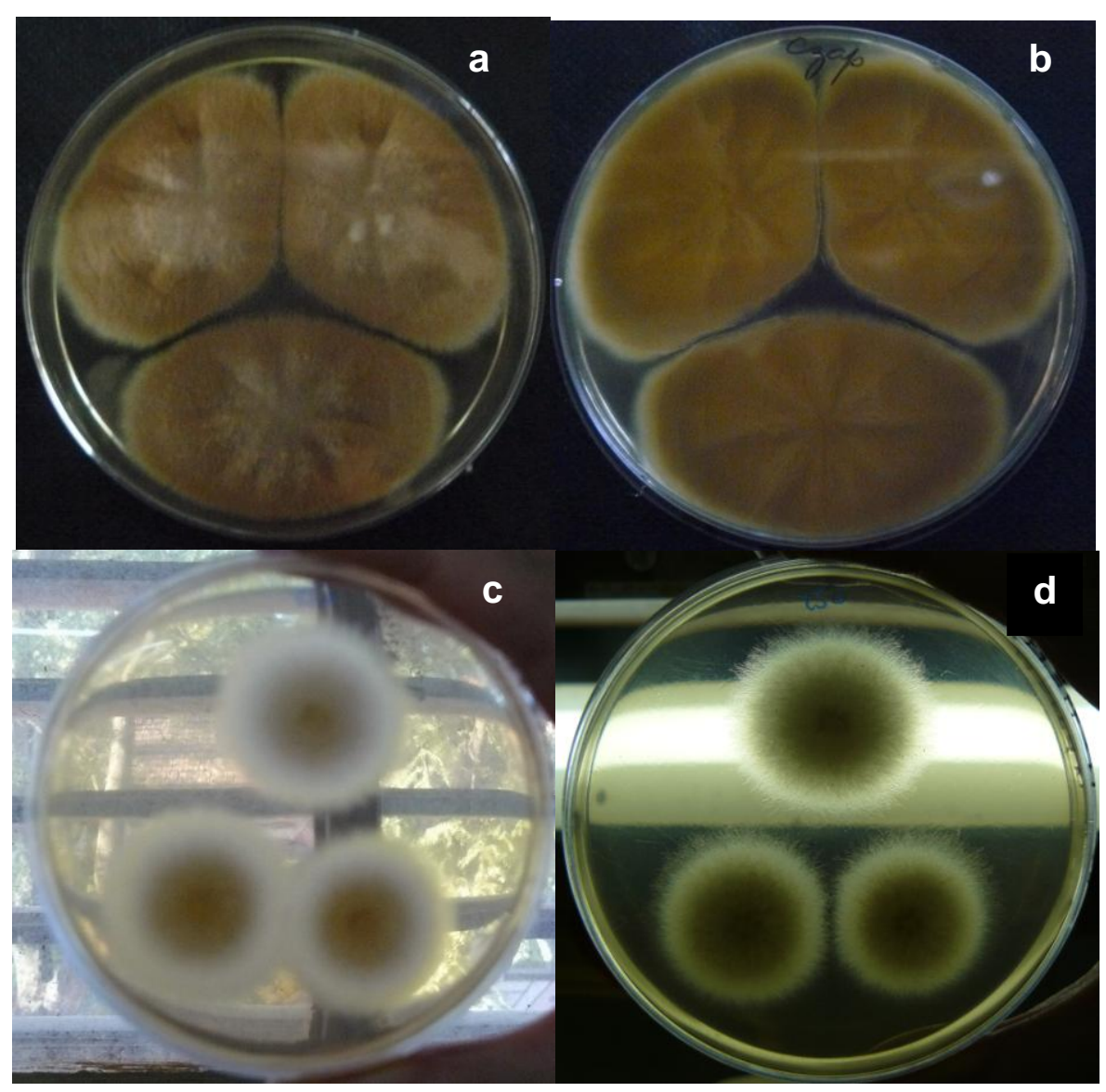


6.2 Efecto Antifúngico del permeado de suero fermentado con gránulos de kefir y con microorganismos aislados del kefir
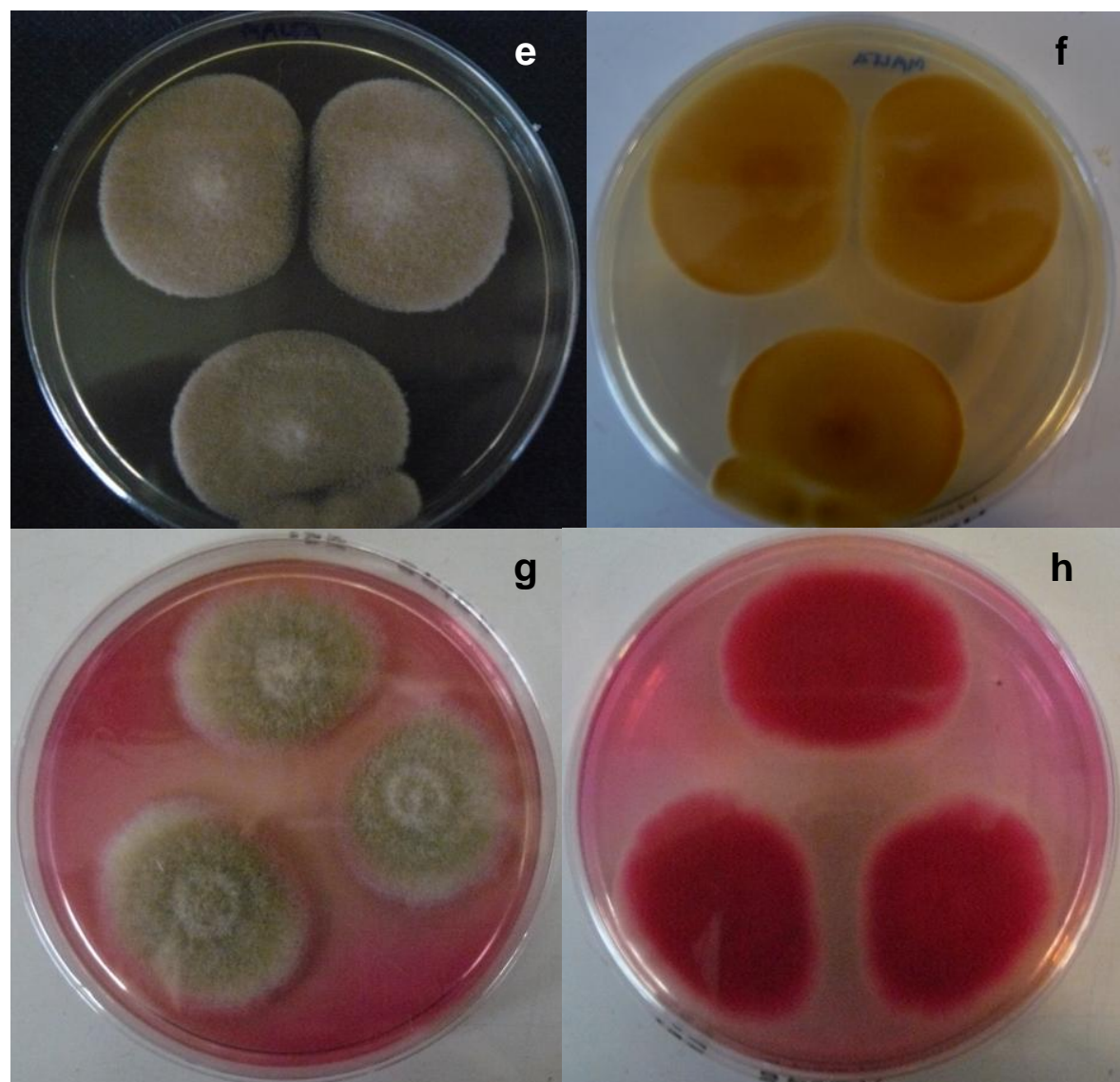

Figura 6.2.2 Crecimiento en 7 días de incubación del hongo marrón tipo Aspergillus (4) en diferentes medios de cultivo. Czapeck: (a) Anverso y (b) Reverso. G25N: (c) Anverso y (d) Reverso. Malta: (e) Anverso y (f) Reverso. DRBC: (g) Anverso y (h) Reverso.

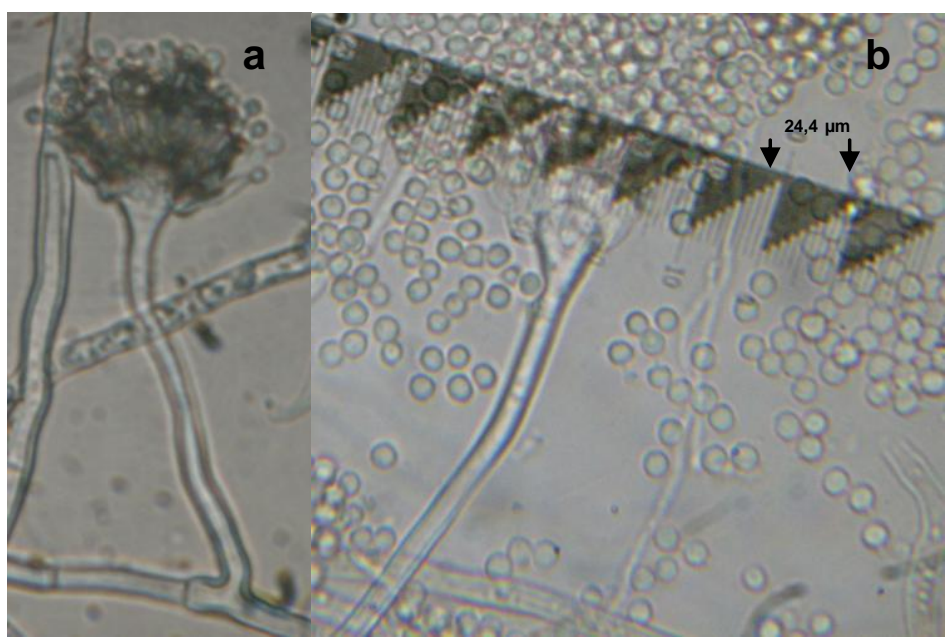

Figura 6.2.3 ${ }^{1}$ (a) Célula reproductiva y (b) Estipe, Vesícula y conidios del hongo Marrón tipo Aspergillus (4).

${ }^{1}$ Aumento $100 \mathrm{X}$ y escala de $2,44 \mu \mathrm{m}$ 
En la figura 6.2.2 se observa el crecimiento del hongo marrón tipo Aspergillus (4) en cuatro medios diferentes: CYA, Malta, G25N y DRBC. En todos se observa que el hongo presenta un micelio marrón de textura aterciopelada, tanto en el anverso como el reverso, excepto en DRBC, donde tiende a ser un poco mas flocosa. El color más claro se obtuvo en G25N. La observación microscópica de la célula reproductiva, Figura 6.2.3 (a), permite ver la hifa septada y la hifa pié. En la Figura 6.2.3 (b) se observa el estipe no septado, vesícula de 21,6 $\mu \mathrm{m}$, conidios de superficie lisa y esféricos de aproximadamente $7,3 \mu \mathrm{m}$, medidos con escala de 2,44 $\mu \mathrm{m}$ en objetivo $100 \mathrm{X}$.

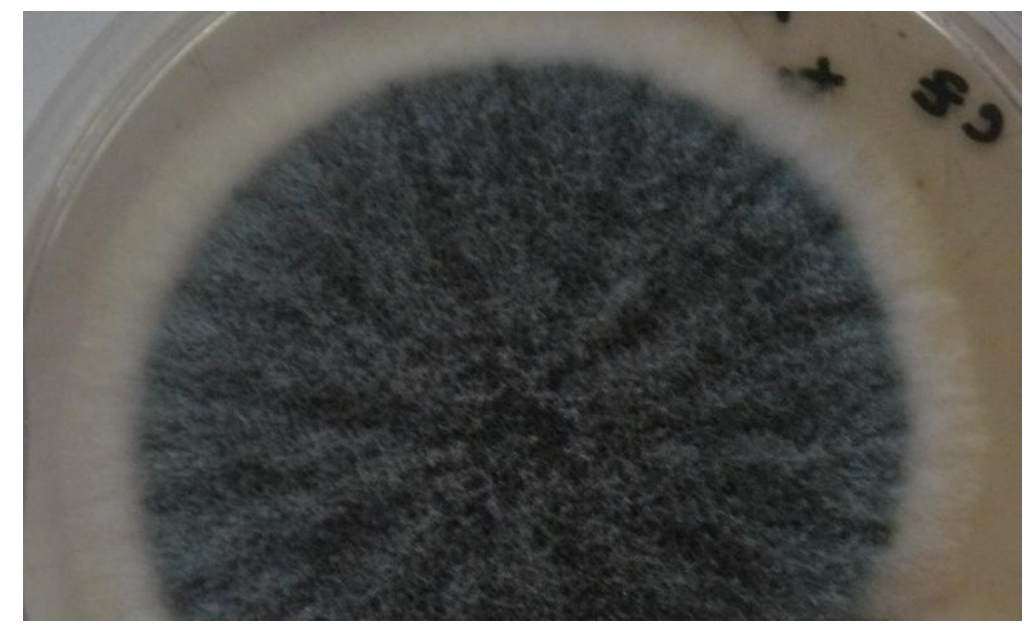

Figura 6.2.4 Hongo Azul tipo Aspergillus (3) en medio CYA.

En la figura 6.2.4 puede observarse cómo se desarrolla la colonia del hongo azul tipo Aspergillus (3), en CYA. En este hongo, el color de la colonia en medio CYA, Malta y DRBC fue de color azul oscuro. El anverso fue de color verde pálido en Malta y marrón en CYA. En la figura 6.2.5 se muestran las cabezas aspergilares, observadas en el microscopio. 


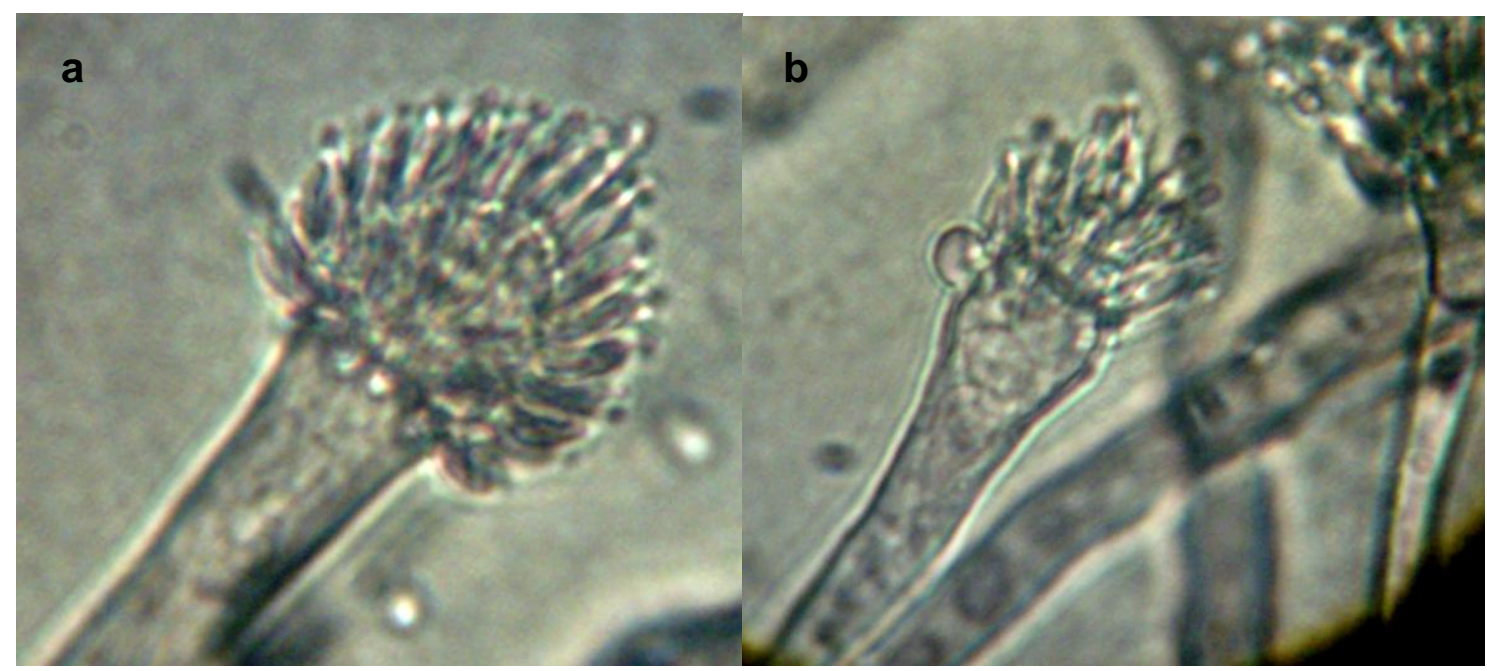

Figura 6.2.5 ${ }^{1}$ Cabeza aspergilar de hongo azul tipo Aspergillus (3). En (a) se observa la vesícula y las fiálides y en (b) puede apreciarse parte del estipe, la vesícula, las fiálides y algunos conidios.

${ }^{1}$ Aumento $100 \mathrm{X}$
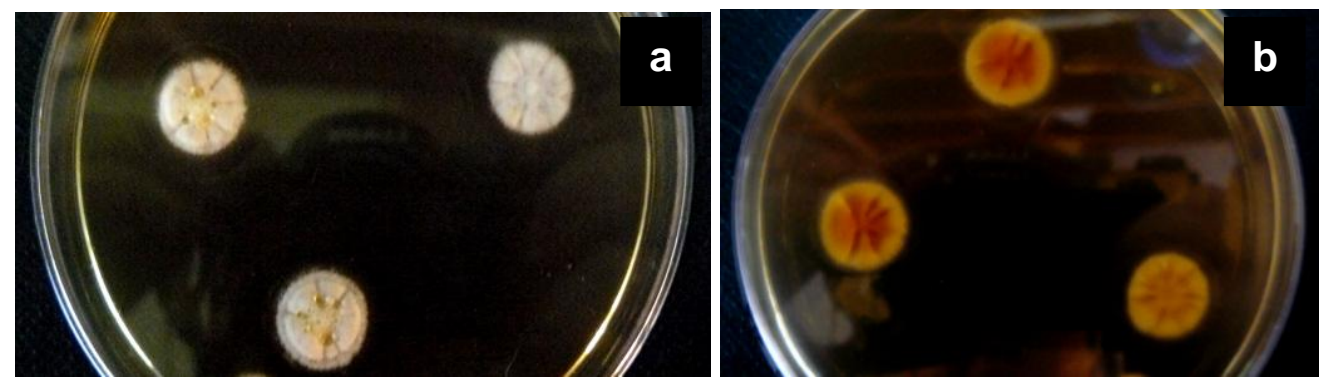

Figura 6.2.6 Crecimiento en 7 días de incubación del hongo gris tipo Penicillium (5), en medio de cultivo G25N: (a) anverso y (b) reverso.

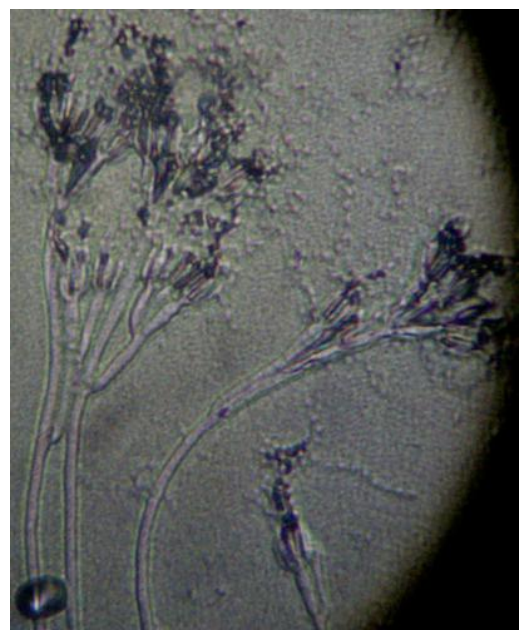

Figura 6.2.7 Hifa fértil y conidios del hongo gris tipo Penicillium (5), cultivado en medio Malta. ${ }^{1}$ Aumento $100 \mathrm{X}$. 
El hongo gris tipo penicillium (5) y el azul tipo Penicillium (6), se diferenciaron en que el primero no creció a $5^{\circ} \mathrm{C}$ y el segundo sí. Además, ambos presentaron diferentes diámetros de crecimiento en los medios evaluados a $25^{\circ} \mathrm{C}$. El hongo gris tipo Penicillium (5) presentó exhudado en G25N, Figura 6.2.6 (a) y microscópicamente se observan tres verticilos, Figura 6.2.7. Su micelio fue blanco a crema en G25N por el anverso y amarillo pálido por el reverso, Figura 6.2.6 (a) y (b). Su micelio fue gris en medio CYA y Malta.

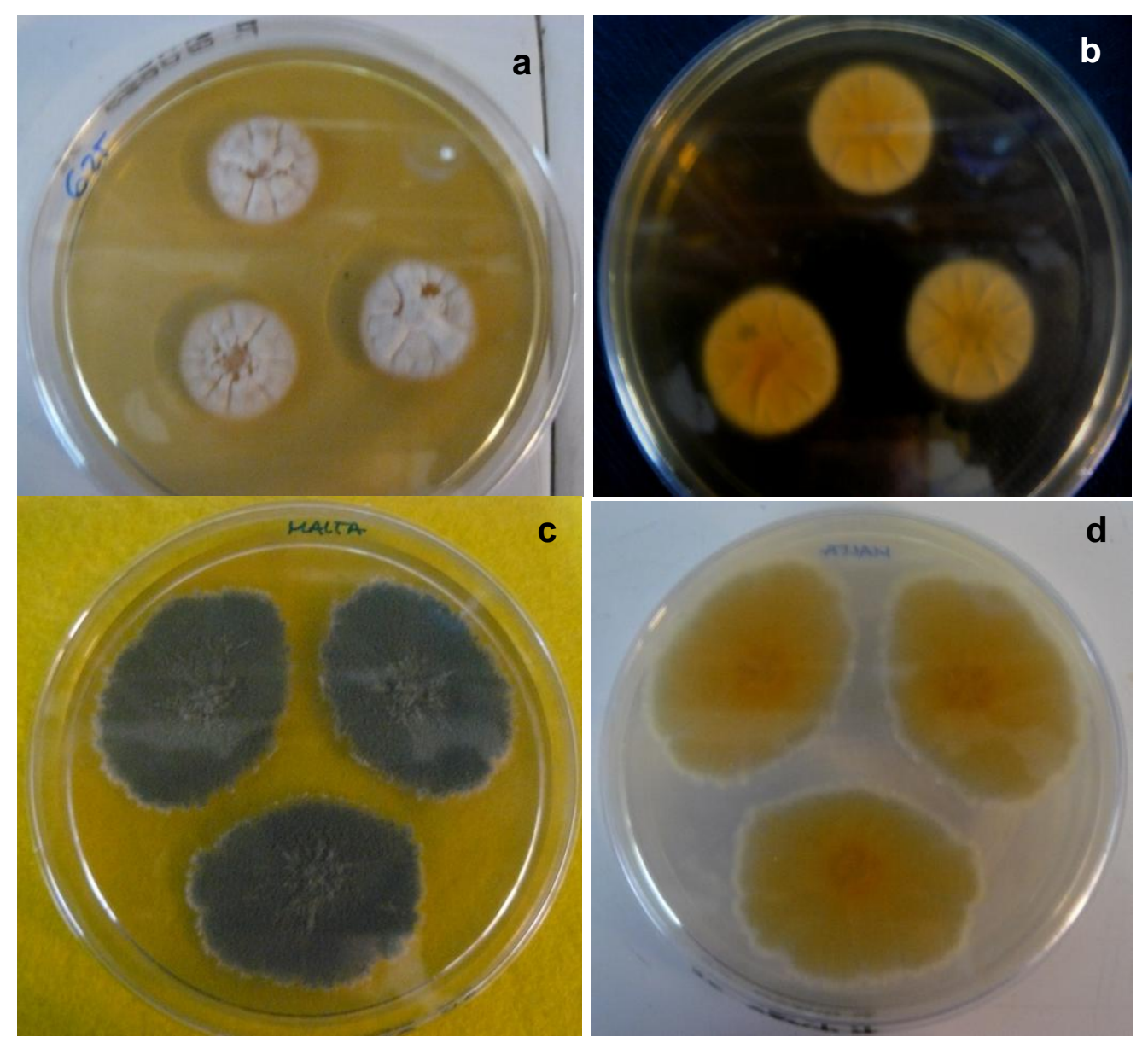

Figura 6.2.8. Crecimiento en 7 días de incubación del hongo azul tipo Penicillium (6) en diferentes medios de cultivo. G25N: (a) Anverso y (b) Reverso. Malta: (c) Anverso y (d) Reverso. 


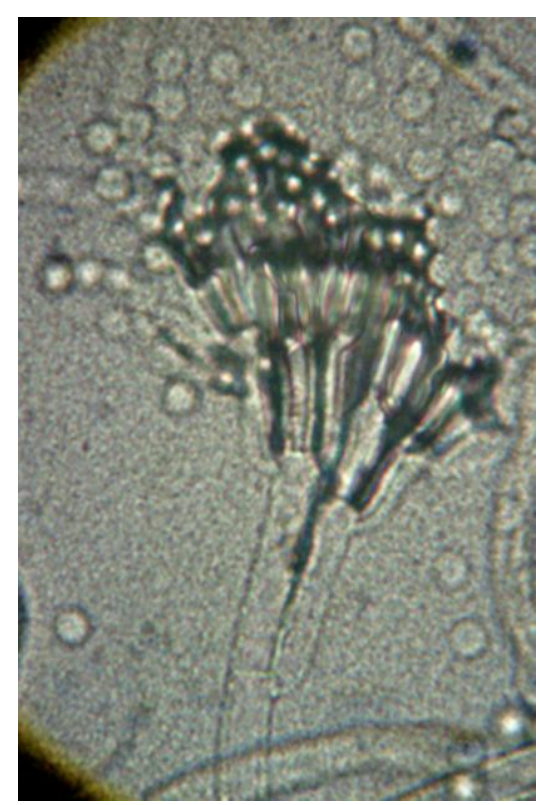

Figura 6.2.9 Hifa fértil y conidios del hongo azul tipo Penicillium (6), cultivado en medio Malta. Aumento 100X.

Como puede verse en la tabla 6.2.2, el hongo azul tipo Penicillium (6), creció 2,7 y $3 \mathrm{~mm}$ en medio CYA y malta a $5^{\circ} \mathrm{C}$, a diferencia del hongo gris tipo Penicillium (5) que no creció en ningún medio a $5^{\circ} \mathrm{C}$. Por otro lado, Penicillium (6) creció 34 $\mathrm{mm}$ en G25N, $19 \mathrm{~mm}$ en CYA y $13 \mathrm{~mm}$ en G25N, a $25^{\circ} \mathrm{C}$. Como se observa en la figura 6.2.8 (a) y (b), creció con un micelio blanco con exudado y amarillo claro, por el anverso y reverso respectivamente en medio G25N. En medio Malta, se observa azul oscuro y de textura pulverulenta por el anverso y amarillo por el reverso. Figura 6.2.8 (c) y (d). En la figura 6.2 .9 se observa la hifa fértil de este hongo, la cual muestra un septo, tres verticilos, las fiálides y los conidios que de ella salen. 


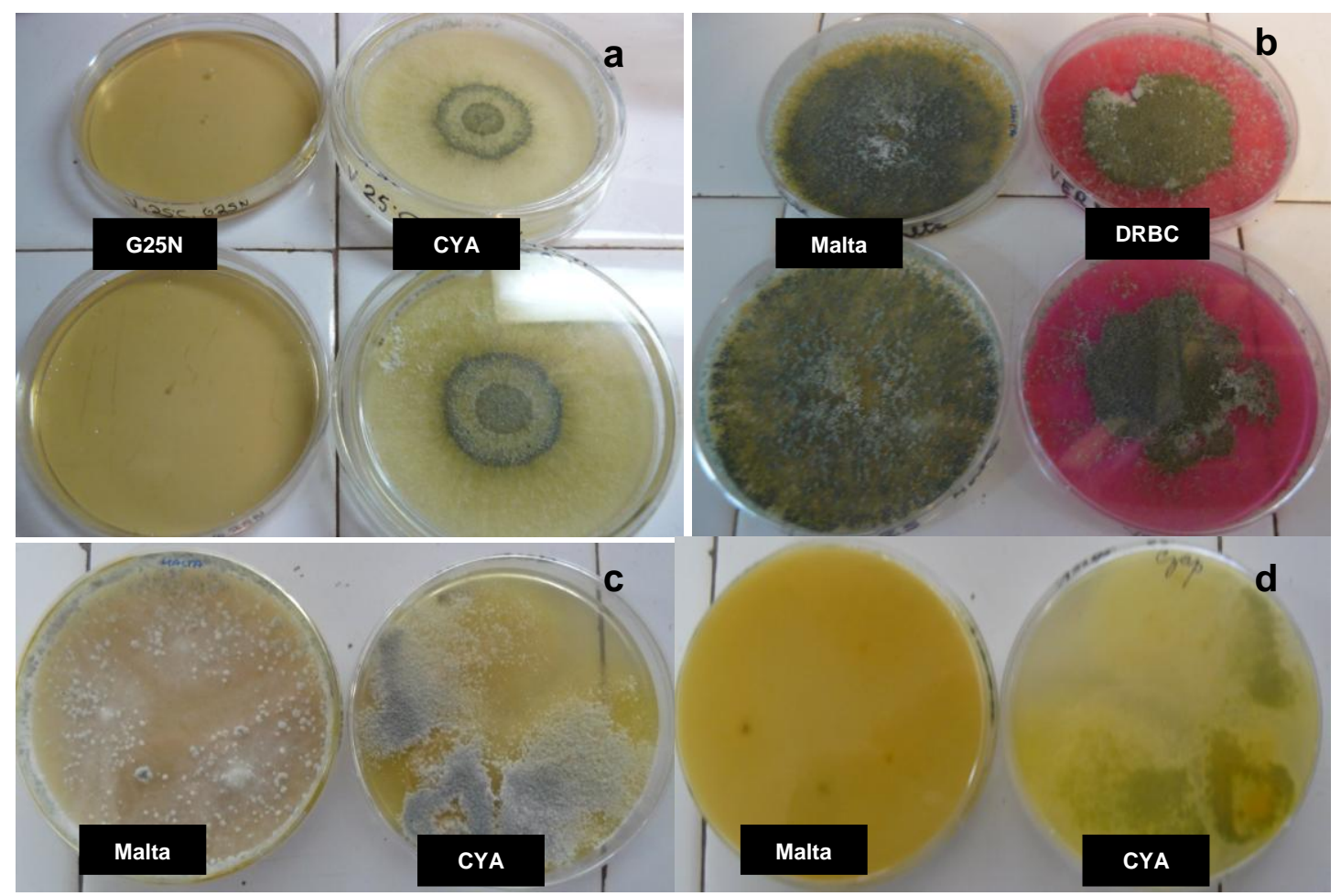

Figura 6.2.10 Colonias de Hongo verde (2) a $25^{\circ} \mathrm{C}$ en medios G25N, CYA, Malta y DRBC.

En esta figura se sembró una colonia en el centro de la caja y se observó su crecimiento. Se observa en las figuras 6.2.10 (a) y (b) el crecimiento de la colonia del hongo verde en los cuatro medios. No hubo crecimiento en G25N, mientras que si lo hubo en CYA, Malta y DRBC.

En estas se puede observar que el hongo invade toda la caja y las colonias son irregulares, con penachos o aglomeraciones por sectores. Esto se repite en la figura 6.2.10 (c), donde se observa el anverso de la caja sembrada en tres puntos tanto de Malta como de CYA. El hongo crece también en tonos verdes, algunos blancos y aglomerados por sectores. En la figura 6.2.10 (d) se observa el anverso de los medios malta y CYA, resaltándose más la coloración por el anverso en el medio CYA, de tono verde. 

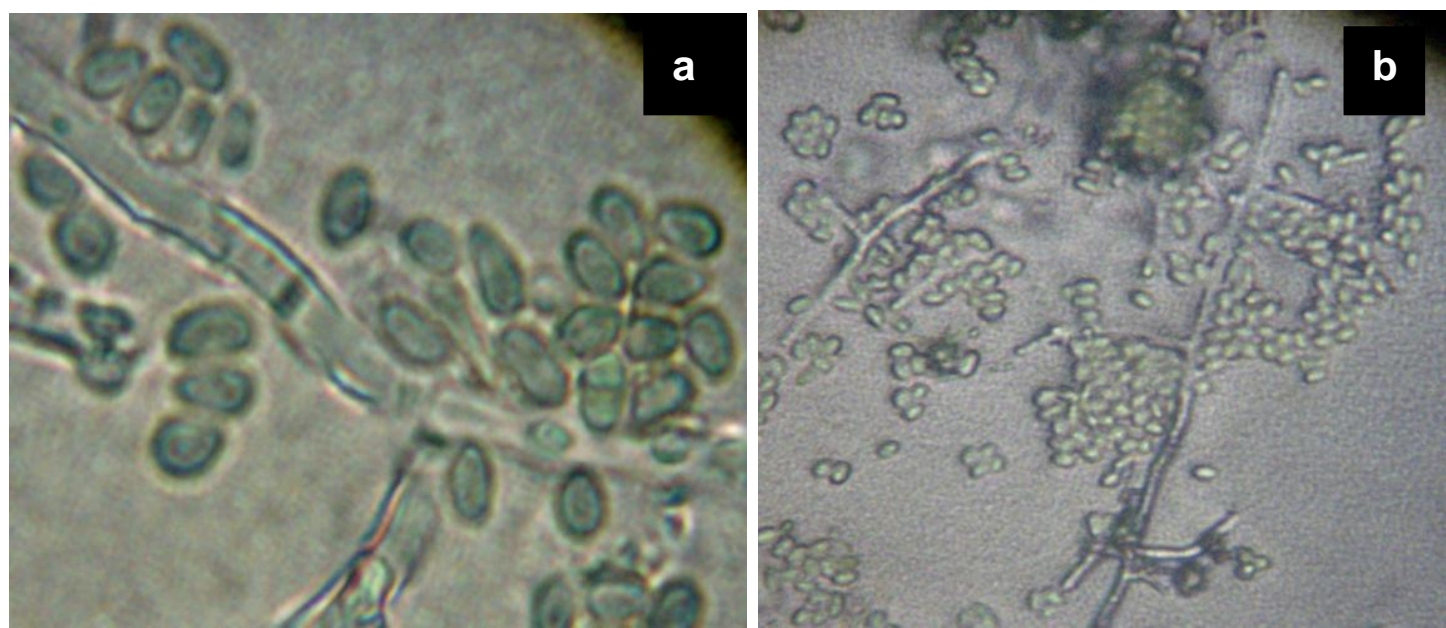

Figura 6.2.11 ${ }^{1}$ Hifas y conidios de Hongo verde (2).

${ }^{1}$ Aumento de 100X.

En la figura 6.2.11 (a) se aprecian los conidios elipsoidales del hongo y la hifa septada; mientras que en (b) puede observarse que el hongo verde (2) presenta ramificaciones en ángulo recto con respecto a la hifa, de las cuales salen los conidios, tal como se ha descripto para Trichoderma sp. (Pitt \& Hocking, 1999).
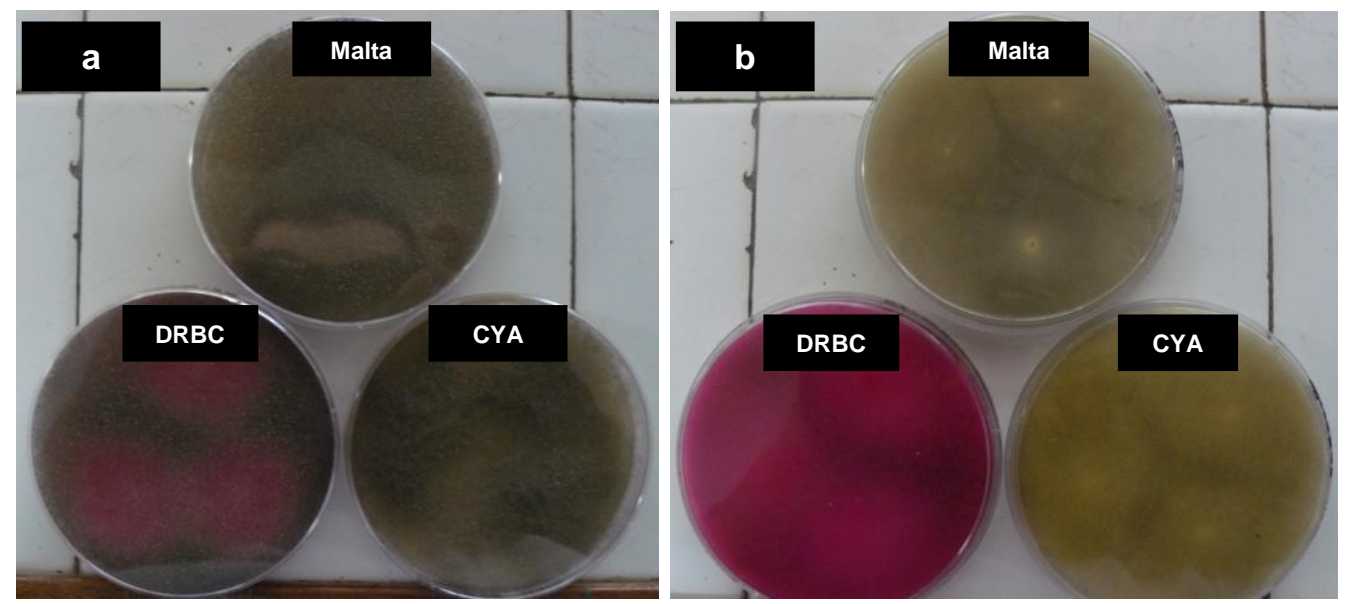

Figura 6.2.12 Crecimiento en 7 días de incubación del hongo algodonoso gris tipo Rhizopus (1) en diferentes medios de cultivo. (a) Anverso: DRBC, Malta y CYA y (b) Reverso: DRBC, Malta y CYA. 


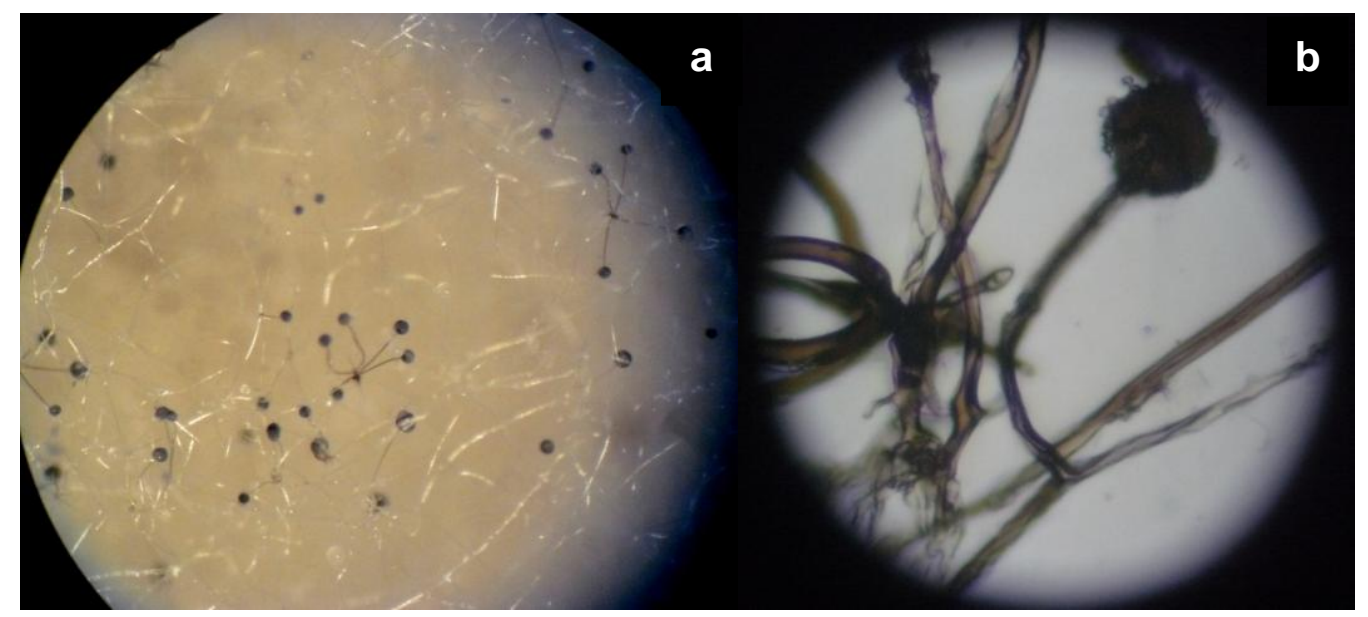

Figura $6.2 .13^{1}$ Hifa fértil de del hongo algodonoso gris tipo Rhizopus (1) en medio de cultivo Malta.

${ }^{1}$ (a) Aumento 4X de Lupa y (b) Aumento 100X microscopio.

El hongo algodonoso gris tipo Rhizopus (1) creció a $25^{\circ} \mathrm{C}$ y a $37^{\circ} \mathrm{C}$ en medios malta, CYA y en el medio DRBC, llegando a invadir toda la caja. No creció en G25N a $25^{\circ} \mathrm{C}$ ni en ningún medio a $5^{\circ} \mathrm{C}$. Las colonias como se observan en la Figura 6.2.12 (a), por el anverso, eran algodonosas y de apariencia gris clara. Por el reverso, Figura 6.2.12 (b), por el reverso, mostraban una apariencia blanca o crema en medio malta y amarilla clara a verdosa en CYA. En DRBC, se observó bajo el agar con apariencia blanca.

En la observación con la lupa, se observaron las hifas blancas a crema de las que salen ramificándose los esporangióforos en grupos de a tres o cuatro y en la parte superior la columela, como se observa en la Figura 6.2.13 (a). En la observación microscópica, pudo observarse la hifa no septada, los rizoides en la base del esporangióforo y un esporangióforo que se proyecta con su columela. Figura 6.2.13 (b).

\subsubsection{A.1 Aplicación de la Clave taxonómica según Pitt \& Hocking, 1999.}

La clave taxonómica empleada para identificar morfológicamente los hongos, se hizo según Pitt \& Hocking, 1999. El análisis siguiendo las claves taxonómicas se presenta en el anexo 6.1 


\subsubsection{A.2 Caracterización de cada hongo según las claves taxonómicas (anexo 2).}

El hongo azul tipo Aspergillus (3) coincidió con Aspergillus fumigatus. El hongo marrón tipo Aspergillus coincidió con Aspergillus terreus (coincide excepto en el tamaño del conidio; el hongo marrón presentó vesícula de 21,6 $\mu \mathrm{m}$, estipe no septado y conidios esféricos de 7,2 $\mu \mathrm{m}$ ). En la tabla 6.2 .3 se presentan los diámetros promedio que deben alcanzar en los medios básicos los dos hongos identificados morfológicamente como Aspergillus (Pitt \& Hocking, 1999). Para A. terreus los diámetros coincidieron con el medio CYA, G25N y CYA a $37^{\circ} \mathrm{C}$, pero estuvieron por debajo en MEA. Para $A$. fumigatus, los diámetros coincidieron en los medios CYA, MEA Y G25N, pero no en CYA a $37^{\circ} \mathrm{C}$.

Tabla 6.2.3 Diámetro de las colonias para Aspergillus ${ }^{1,2}$.

\begin{tabular}{|c|c|c|c|c|}
\hline Hongo & CYA & MEA & G25N & $\mathbf{3 7}^{\circ} \mathbf{C}$ \\
\hline A. terreus & $\begin{array}{c}40-50 \mathrm{~mm} \\
(48,5 \mathrm{~mm})\end{array}$ & $40-60 \mathrm{~mm}(27 \mathrm{~mm})$ & $\begin{array}{c}18-22 \mathrm{~mm} \\
(22 \mathrm{~mm})\end{array}$ & $50-70 \mathrm{~mm}(\mathrm{CYA}: 70 \mathrm{~mm})$ \\
\hline A. fumigatus & $40-60 \mathrm{~mm}(55 \mathrm{~mm})$ & $\begin{array}{c}40-60 \mathrm{~mm} \\
(60 \mathrm{~mm})\end{array}$ & $0-10 \mathrm{~mm}(3 \mathrm{~mm})$ & $\begin{array}{c}55-65 \mathrm{~mm}(\mathrm{CYA}: \\
90 \mathrm{~mm})\end{array}$ \\
\hline
\end{tabular}

${ }^{1}$ Según Pitt \& Hocking (1999).

${ }^{2}$ Entre paréntesis los diámetros obtenidos con el hongo problema

Para Penicillium sp., dado que la clasificación morfológica se hizo dudosa de ubicar desde los subgéneros, se conservó la nominación hongo azul tipo Penicillium (5) y hongos gris tipo Penicillium (6) y se pasó directamente a hacer la identificación a nivel molecular, como se verá en el apartado siguiente.

El hongo verde (2) se clasificó en el género Trichoderma. En éste, la reproducción se logra mediante conidios individuales producidos a partir de fiálides, los cuales se disponen en verticilos irregulares, con fiálides subterminales que salen en ángulo recto del estipe. Las colonias son bajas y se diseminan rápidamente, invadiendo toda la caja como se observó en la tabla 
6.2.2, en malta y CYA; el crecimiento micelial es de textura dispersa y se desarrolla irregularmente, en montículos o parches aislados, y los conidios son verdes en las especies en general, tal como se observó en la figura 6.2.10. (Bisset, 1991; Samuels, 1996). Ya se ha planteado que la especiación en Trichoderma es excepcionalmente difícil y la morfología de la colonia es de poco uso en la identificación de Trichoderma ya que ocurren grandes variaciones dentro de una especie y en consecuencia, las colonias con una apariencia muy similar, pueden ser muy diferentes microscópicamente (Pitt \& Hocking, 1999). T. harzianum Rifai es la especie que más se ha asilado de alimentos (Domsch, Gams \& Anderson, 1980; Bisset, 1991) y es probable que la mayoría de los Trichoderma alteradores de alimentos pertenezcan a Trichoderma harzianum (Pitt \& Hocking, 1999). Con el fin de alcanzar una identificación de este hongo a nivel de especie, se realizó la identificación de éste a nivel molecular como se verá más adelante.

De acuerdo a la clave taxonómica, el hongo algodonoso gris tipo Rhizopus (1) pertenece al género Rhizopus. Este género se diferencia de otros géneros Mucorales por la formación de rizoides o sea apéndices con forma de raíces pequeñas, abundantes en la base de los esporangióforos. Figura 6.2.13 (b). También se caracterizan por las columelas que a menudo colapsan en forma de sombrilla al pasar el tiempo y por esporangiosporas con paredes estriadas (Pitt \& Hocking, 1999). La clasificación a nivel de especie se hizo con técnicas moleculares.

\section{B) Clasificación a nivel Molecular.}

En hongos filamentosos, el ADN que codifica para el ARN ribosomal está organizado en unidades que se repiten cientos de veces a lo largo del genoma, las cuales están separadas por una región denominada IGS (Inter Genic Spacer). Cada una de estas unidades está conformada por tres genes, uno que codifica para la subunidad 18S, uno que codifica para la subunidad 5,8S y otro que codifica para la subunidad 26S. Estos genes están intercalados por secuencias denominadas ITS1 e ITS2 (Internal Transcribed Spacer). 
La zona empleada con mayor frecuencia para la identificación a nivel de especie en hongos es la denominada ITS1-5,8SrADN-ITS2. Esto se debe a la variación que aportan las zonas ITS1 e ITS2, las cuales varían en tamaño y secuencia dependiendo del género y la especie, variabilidad que puede estudiarse mediante secuenciación o RFLP (Restriction Fragment Length Polymorphism) empleando enzimas adecuadas. La amplificación de la zona ITS1-5.8SrADNITS2 se hace a partir de primers universales diseñados a partir de las zonas que codifican para el ARN ribosomal y por tanto altamente conservadas. Los primers son denominados ITS1 (TCCGTAGGTGAACCTGCGG) e ITS4 (TCCTCCCGCTTATTGATATGC), aunque también se emplean los primers ITS5 e ITS4. En la figura 6.2.14 se observan los amplicones obtenidos de algunos de los hongos analizados.
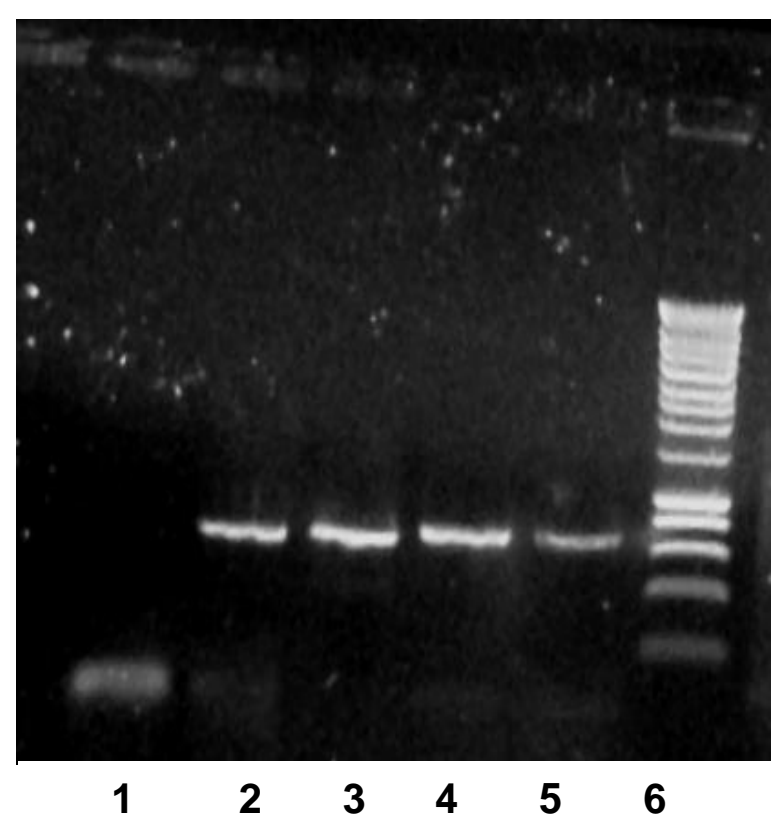

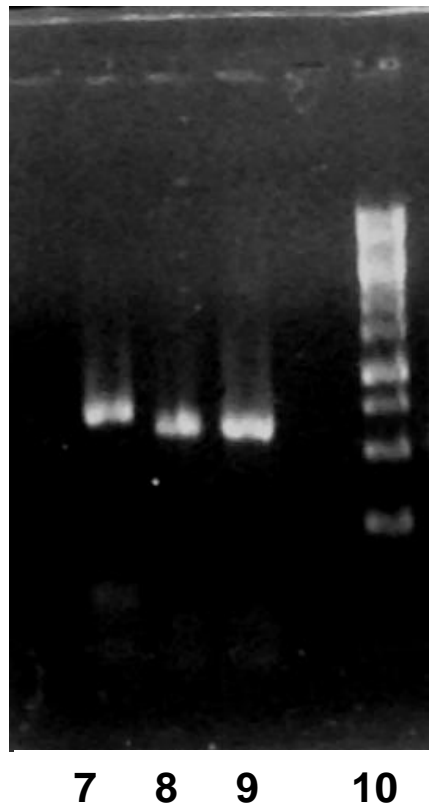

$\begin{array}{llll}7 & 8 & 9 & 10\end{array}$ GeneRuler Ikb DNA Ladider

Figura 6.2.14 Productos de la PCR de la región ITS1 - 5,8S ${ }_{R}$ DNA - ITS2, de algunos hongos aislados. Los carriles corresponden a: 1: Blanco de reactivos. 2: Azul tipo Penicillium. 3: Azul tipo Aspergillius (A. fumigatus). 4: verde (Trichoderma sp.) 5: Verde (Trichoderma sp.). 7: Algodonoso gris tipo Rhizopus (Rhizopus sp.) 8: Marrón tipo Aspergillus (A. terreus), 9: Marrón tipo Aspergillus (A. terreus), 6 y 10: Marcador de Peso Molecular de $1 \mathrm{~Kb}\left(\right.$ Generuler $\left.^{(}\right)$. 
Los amplicones obtenidos fueron de los siguientes tamaños: entre 750 y $1000 \mathrm{~kb}$ los de Azul tipo Penicillium, Azul tipo Aspergillius. (A. fumigatus) y verde (Trichoderma sp.) y entre 500 y $750 \mathrm{~kb}$ los de Algodonoso gris tipo Rhizopus (Rhizopus sp.) y Marrón tipo Aspergillus (A. terreus). Se obtuvieron las secuencias de las regiones espaciadoras intergénicas ITS1 e ITS2, y los gráficos de calidad de dicha secuencia.

El límite de corte para el gráfico de calidad se consideró del 20\%. Anexo 3 . Se empleó el software BLAST (Basic Local Alignment Search Tool), disponible en NCBI (National Center for Biotechnology Information, USA); en éste se eligió el nucleotide blast y la base de datos fue la de nucleotide collection (nr/nt), eligiendo optimizar para secuencias altamente similares. BLAST encuentra regiones similares entre secuencias, al comparar secuencias de nucleótidos 0 proteínas con bases de datos de secuencias $\left(\right.$ GenBank $^{\circledR}$, EMBL -European Bioinformatics Institute, DDBJ - DNA Database of Japan y PDB - Protein Data Bank) y calcula similaridades con significancia estadística. Se estableció el porcentaje de homología con las secuencias de las cepas tipo, y se clasificaron los hongos aislados del alimento para pollos tal como se observa en la tabla 6.2.4. 


\subsection{Efecto Antifúngico del permeado de suero fermentado con gránulos de kefir y}

con microorganismos aislados del kefir

Tabla 6.2.4 Clasificación molecular de los hongos aislados del alimento de pollo.

\begin{tabular}{|c|c|c|c|c|}
\hline $\begin{array}{l}\text { HONGO IDENTIFICADO } \\
\text { MORFOLÓGICAMENTE }\end{array}$ & $\begin{array}{l}\text { ALINEAMIENTO } \\
\text { SIGNIFICATIVO }\end{array}$ & $\begin{array}{c}\text { No. } \\
\text { ACCESO }\end{array}$ & REFERENCIA & $\begin{array}{c}\% \\
\text { HOMOLOGIA }\end{array}$ \\
\hline \multirow{2}{*}{ (Verde) Trichoderma sp. } & $\begin{array}{c}\text { Cepa tipo } \\
\text { Trichoderma } \\
\text { Iongibrachiatum IMI } \\
291014\end{array}$ & EU401560 & $\begin{array}{c}\text { Druzhinina, Komon- } \\
\text { Zelazowska, Kredics, } \\
\text { Hatvani, Antal, } \\
\text { Belayneh \& Kubicek, } \\
2008 .\end{array}$ & 100 \\
\hline & $\begin{array}{c}\text { Cepa tipo } \\
\text { Trichoderma } \\
\text { Iongibrachiatum } \\
\text { DAOM } 167674\end{array}$ & EU280099 & $\begin{array}{l}\text { Hoyos-Carvajal, } \\
\text { Orduz, \& Bissett, } \\
2009 .\end{array}$ & 100 \\
\hline \multirow{2}{*}{$\begin{array}{l}\text { (Azul tipo Aspergillus) } \\
\text { Aspergillus fumigatus }\end{array}$} & $\begin{array}{c}\text { Aspergillus } \\
\text { fumigatus DAOM } \\
215394\end{array}$ & JN942916 & $\begin{array}{c}\text { Schoch, Seifert, } \\
\text { Huhndorf, Robert, } \\
\text { Spouge, Levesque \& } \\
\text { Chen, 2012. }\end{array}$ & 98 \\
\hline & $\begin{array}{c}\text { Aspergillus } \\
\text { fumigatus JF5, JF7. }\end{array}$ & HQ882185 & $\begin{array}{c}\text { Singer, Reddy, } \\
\text { Gladden, Guo, Hazen, } \\
\text { Simmons \& } \\
\text { Vandergheynst, } 2011 .\end{array}$ & 98 \\
\hline $\begin{array}{l}\text { (Gris tipo Penicillium) } \\
\text { Penicillium sp. (5) }\end{array}$ & $\begin{array}{c}\text { Cepa tipo } P . \\
\text { sumatrense NRRL } \\
799, P . \\
\text { meleagrinum var. } \\
\text { viridiflavum }\end{array}$ & AFO33424.1 & Peterson, 2000. & 98 \\
\hline $\begin{array}{l}\text { (Azul tipo Penicillium) } \\
\text { (Penicillium sp.(6) }\end{array}$ & $\begin{array}{c}\text { Cepa tipo } \\
\text { Penicillium } \\
\text { crustosum FRR } \\
1669\end{array}$ & AY373907 & $\begin{array}{c}\text { Haugland, Varma, } \\
\text { Wymer \& Vesper, } \\
2004 .\end{array}$ & 99 \\
\hline $\begin{array}{c}\text { (Marrón tipo Aspergillus) } \\
\text { A. terreus }\end{array}$ & $\begin{array}{c}\text { Cepa tipo } \\
\text { Aspergillus terreus } \\
\text { NRRL } 1923\end{array}$ & EF669580 & Peterson, 2008. & 99 \\
\hline $\begin{array}{c}\text { (Algodonoso gris tipo } \\
\text { Rhizopus) } \\
\text { Rhizopus sp. }\end{array}$ & $\begin{array}{c}\text { Cepa tipo Rhizopus } \\
\text { microsporus var. } \\
\text { rhizopodiformis CBS } \\
536,80\end{array}$ & HM999971 & $\begin{array}{l}\text { Vitale, de Hoog, } \\
\text { Schwarz, Dannaoui, } \\
\text { Deng, Machouart, } \\
\text { Voigt, van de Sande, } \\
\text { Dolatabadi, Meis \& } \\
\text { Walther, 2012. }\end{array}$ & 100 \\
\hline
\end{tabular}

Uno de los dos Penicillium sp. aislados, presentó 99\% de homología en la secuencia de la región ITS1 - 5,8S RDNA - ITS2, con la cepa tipo $P$. sumatrense 
NRRL 799 y con P. meleagrinum var. viridiflavum, pertenecientes a la sección Citrina. Esta sección fue delimitada usando una combinación de las secuencias génicas de los ITS (genes de la región espaciadora intergénica y del 5,8S rDNA) y las secuencias parciales RPBS (genes que codifican para las 10 subunidades de la RNA polimerasa II) y usando una aproximación polifásica (patrones fenotípicos y extrolitros). Para la delimitación de las especies se emplearon secuencias de parte de los genes de la $\beta$-tubulina y de la calmodulina en combinación con características fisiológicas, macro y micromorfológicas (Houbraken, Frisvad \& Samson, 2011). Las especies de la sección Citrina se encuentran con frecuencia en suelo, alimentos, espacios interiores y otros sustratos (Raper \& Thom, 1949; Pitt, 1980; Ramírez, 1982), crecen óptimamente entre 23 y $26^{\circ} \mathrm{C}$, a baja actividad acuosa (como en el alimento de pollo, cuya $\mathrm{a}_{\mathrm{w}}$ es de 0,6$)$ y en sustratos con $\mathrm{NaCl}$. Constituyen un riesgo para la salud pública ya que pueden producir citrinina, citreoviridina, antraquinonas, alcaloides - indol, paxilina y/o isocromantoxinas (Frisvad \& Filtenborg, 1990; Frisvad \& Samson, 2004). Es importante resaltar que ya algunos investigadores establecieron que $P$. sumatrense es un sinónimo de $P$. meleagrinum var. viridiflavum. Lo anterior se observa en una comparación de la disposición taxonómica de miembros de la sección Citrina en diferentes estudios sobre Penicillium, de la cual se presenta una fracción en la Tabla 6.2.5 (Houbraken, Frisvad \& Samson, 2011).

Tabla 6.2.5 Comparación de la clasificación del hongo $P$. sumatrense según diferentes autores (Houbraken, Frisvad \& Samson, 2011)

\begin{tabular}{|c|c|c|c|c|}
\hline $\begin{array}{c}\text { Nombre original } \\
\text { especie }\end{array}$ & Pitt (1980) & $\begin{array}{c}\text { Ramírez } \\
\text { (1982) }\end{array}$ & $\begin{array}{c}\text { Pitt, Samson \& } \\
\text { Frisvad (2000) }\end{array}$ & $\begin{array}{c}\text { Houbraken, Frisvad \& } \\
\text { Samson (2011) }\end{array}$ \\
\hline P. baradicum & P. citrinum & P. baradicum & P. citrinum & P. sumatrense \\
\hline P. meleagrinum & P. janthinellum & $\begin{array}{c}\text { P. } \\
\text { janthinellum }\end{array}$ & P. janthinellum & P. sumatrense \\
\hline P. sumatrense & P.corylophilum & $\begin{array}{c}\text { P. } \\
\text { corylophilum }\end{array}$ & P. corylophilum & P. sumatrense \\
\hline
\end{tabular}


En la tabla se observa que para algunos autores $P$. sumatrense y Penicillium meleagrinum var. viridiflavum son sinónimos. $P$. sumatrense ha sido denominado también $P$. baradicum, $P$. citrinum, $P$. janthinellum, $P$. corylophium y $P$. meleagrinum var. viridiflavum. Sin embargo existen discrepancias aún en la similitud, pues otros investigadores demostraron que Penicillium meleagrinum var. viridiflavum es cercano genéticamente a la cepa tipo de $P$. sumatrense y que la congruencia entre los filogramas de cuatro loci diferentes indicaba que esta podría ser una especie diferente (Serra, Peterson, CTCOR \& Venâncio, 2008). También se ha encontrado variación entre las secuencias de cepas de $P$. sumatrense, pero no se halló en los patrones fenotípicos y extrolitros (metabolitos liberados), por lo cual se mantiene como una especie (Houbraken, Frisvad \& Samson, 2011).

Según el estudio anterior, $P$. sumatrense en un sinónimo del $P$. meleagrinum var. viridiflavum, cuyas secuencias fueron las que presentaron los mayores $\%$ de homología con la secuencia analizada. Pudo así determinarse que el hongo Penicillium (1) aislado del alimento de pollo tiene una homología en la secuencia ITS 1 ITS2 del 98\% con la correspondiente a P. sumatrense.

En medio G25N, el hongo presentó un exudado como gotas amarillas pálidas (tal como se observa en la figura 6.2.6 (a) y el reverso fue entre amarillo y marrón, similar a como se ha descripto para el medio DG 18. Los conidióforos son principalmente biverticilados, con una ramificación adicional ocasionalmente; estipes hasta $200 \mu \mathrm{m}$ de largo con paredes lisas o ligeramente rugosas, de 2,0 a 3,0 $\mu \mathrm{m}$ de ancho. Las fiálides son ampuliformes, de 8,0-10 $\times 2-3,5 \mu \mathrm{m}$. Los conidios son subglobosos o ampliamente elipsoidales; levemente rugosos, ocasionalmente lisos de 2,0 a 2,5 um de diámetro.

P. sumatrense produce lo siguientes exolitros, algunos de los cuales puede producir un riesgo a la salud del animal: Curvularina (Vesonder, Ciegler, Fenell \& Tjarks, 1976; Malmstrøm, Christophersen \& Frisvad, 2000), dehydrocurvularina, "POTO", "SAAT", "TERRIT", "TIDL", "VOX" (Houbraken, Frisvad \& Samson, 2011). 
P. crustosum produce penitrem A, una neurotoxina muy poderosa (Pitt, 1979), perteneciente a los tremórgenos cuya toxicidad en animales se ha demostrado, causando polipnea, taquicardia, ataxia, convulsiones, fiebre, dilatación de las pupilas, hiperestesia, vómito (Walter, S, 2002; Eriksen, Jäderlund, MoldesAnaya, Schönheit, Bernhoft, Jaeger, Rundberget, \& Skaar, 2010) Casi todas las especies de este hongo producen esta toxina en grandes cantidades, por lo que su presencia en alimentos es una señal para tener cuidado (Pitt \& Hocking, 1999). A. fumigatus produce fumitremorgenos, verruculogeno y gliotoxina (Cole, $1981^{\text {a }}$, ; Dorner, Cole \& Hill, 1984; Moreau, 1990).

La gliotoxina es importante en la invasión de pulmones de animales y aves por A. fumigatus, mediante mecanismos de inmunosupresión (Spikes, Xu, Nguyen, Chamilos, Kontoyiannis \& Jacobson, 2008). A. terreus produce una amplia gama de metabolitos entre los cuales son muy importantes los territremas, los cuales son toxinas tremorgénicas, que a diferencia de los tremorgenos, carecen de una molécula con Nitrógeno (Frisvad \& Samsom, 1991). Los territremas A, B y C inyectados en ratones y ratas producen toxicidad aguda con temblor, micción permanente, debilidad de las extremidades, salivación y convulsiones (Ling, Liou, Fu, Kuo, Tsai \& Lin, 1986); mientras que la intubación oral de filtrado del cultivo de $A$. terreus en ratas blancas produce daño hepatocelular y nefrotóxico (Sharma, Kumar \& Roy, 1983).

Rhizopus microsporus fue relacionado con la producción de Rhizonina A (Wilson, Rabie, Fincham, Stein \& Schipper, 1984; Jennessen, Nielsen, Houbraken, Lyhne, Schnürer, Frisvad \& Samson, 2005), la cual fue clasificada como la especie más tóxica de Rhizopus en patitos y ratas (Wilson, Rabie, Lübien, Schipper, Van Heerden \& Fincham, 1985). Esta causa daño en los hepatocitos desde degeneración hasta necrosis, proliferación del ducto de bilis periportal y el epitelio tubular renal mostró cambios desde degeneración hasta necrosis (Wilson, Rabie, Fincham, Stein \& Schipper, 1984). No obstante, se ha demostrado que específicamente este hongo no produce la micotoxina sino la bacteria endosimbionte Burkholderia, que fue encontrada por microscopía electrónica en el citosol fúngico (Partida-Martinez, Flores de Looß, 
Ishida, Ishida, Roth, Buder, \& Hertweck, 2007). En alimentos no ha sido muy reportado pero se aisla de productos tropicales con frecuencia. De un $18 \%$ de muestras de maíz en filipinas y del $3 \%$ de todas las mazorcas examinadas y en menor número se ha aislado de maní, arroz, soja y pimienta negra de Filipinas (Pitt \& Hocking, 1999).

Es también interesante resaltar que este hongo se caracteriza por tener un crecimiento fuerte a $37^{\circ} \mathrm{C}$ y por crecer hasta $46^{\circ} \mathrm{C}$ (Schiper \& Stalpers, 1984), lo cual puede favorecer su resistencia al secado en el horno de convección. De lo anterior se comprende que estos productos son base del alimento para pollos y por lo tanto potenciales fuentes de este hongo. Trichoderma longibrachiatum es un hongo dominante en los ambientes húmedos. Aunque anteriormente no se le relacionaba con compuestos tóxicos, recientemente se reportó que produce metabolitos secundarios tóxicos para las mitocondrias de los mamíferos llamados trilonginas. Éstas forman canales permeables de $\mathrm{Na}^{+} / \mathrm{K}^{+}$en las membranasbiológicas, alterando su funcionamiento. Su estudio apenas está comenzando. (Mikkola, Andersson, Kredics, Grigoriev, Sundell \& SalkinojaSalonen, 2012)

Finalmente, debe indicarse los códigos finales con los cuales se identificaron los hongos en la colección de la Cátedra de Microbiología de la FCE de la UNLP: e indicarse los posibles exolitros producidos por los hongos aislados: $A$. terreus CMUNLP1, $A$. fumigatus CMUNLP2, Penicillium sumatrense CMUNLP3, Penicillium crustosum CMUNLP4, Trichoderma longibrachiatum CMUNLP5 y Rhizopus macrosporus var. rhizopodiformis. CMUNLP6.

Una vez realizado el aislamiento y clasificación taxonómica de los hongos del alimento, se procedió a efectuar los experimentos de fermentación y estudios de inhibición fúngica que se observan a continuación. 


\subsubsection{Cinética de acidificación del PS fermentado con gránulos de kefir CIDCA AGK1 (PSFG) y con microorganismos aislados del kefir (PSFM).}

Con el fin de conocer los tiempos que tarda el PS en alcanzar el pH final deseado para la determinación de su actividad antifúngica, se estudió la cinética de acidificación del PS fermentado tanto con el gránulo de kefir CIDCA AGK1 como con los microorganismos del kefir. Se ha demostrado previamente tanto con los productos de leche y suero de quesería fermentados con gránulos de kefir como con algunos lactobacilos, ya que éstos poseen propiedades potencialmente probióticas de resistencia a la acidez y a la bilis y actividad antimicrobiana, inhibiendo in vitro el crecimiento de Escherichia coli, Salmonella entérica serovar Typhimurium, Sal. gallinarum, Sal. entérica serovar. Enteritidis y Shigella sonnei (Garrote, 1999; Garrote, Abraham \& De Antoni, 2000; Golowczyc, Gugliada, Hollmann, Delfederico, Garrote, Abraham, Semorile \& De Antoni, 2008; Londero, Quinta, Abraham, Sereno, De Antoni \& Garrote, 2011).

Los sobrenadantes libres de células (SLC) de estos microorganismos cultivados en leche redujeron el porcentaje de germinación de conidios, aumentaron la fase Lag del crecimiento y generaron halos de inhibición en cultivos por sobrecapa de A. flavus AFUNL5 y A.parasiticus NRRL 2999 como se demostró en el capítulo 6.1. A partir de dichos resultados, se seleccionaron las cepas de L. plantarum que generaron la mayor reducción de la germinación (\%RG) y el mayor halo de inhibición en sobrecapa, para ser cultivadas en PS y evaluar la capacidad antifúngica de sus SLC. Éstas fueron: L. plantarum 83114, L. plantarum 8316, L. plantarum 8329 y L. plantarum 8318. También se evaluó la capacidad inhibitoria de la levadura $K$. marxianus 8154, la cual presenta propiedades probióticas como tolerancia a la acidez $(\mathrm{pH} 2,5)$ y resistencia a las sales biliares $(1 \%)$ (Diosma, 2009) y gran capacidad de consumo de la lactosa, reduciéndola en leche de la concentración inicial de 4,03 $\pm 0,46 \%$ p/p a una concentración final de $0,12 \pm 0,03 \% \mathrm{p} / \mathrm{p}$ durante 48 horas de fermentación (Echeverría, 2007). Todos los cultivos se incubaron a $30^{\circ} \mathrm{C}$, tomándose mediciones periódicas del descenso de $\mathrm{pH}$, que se observan en la figura 6.2.15. 
6.2 Efecto Antifúngico del permeado de suero fermentado con gránulos de kefir y con microorganismos aislados del kefir

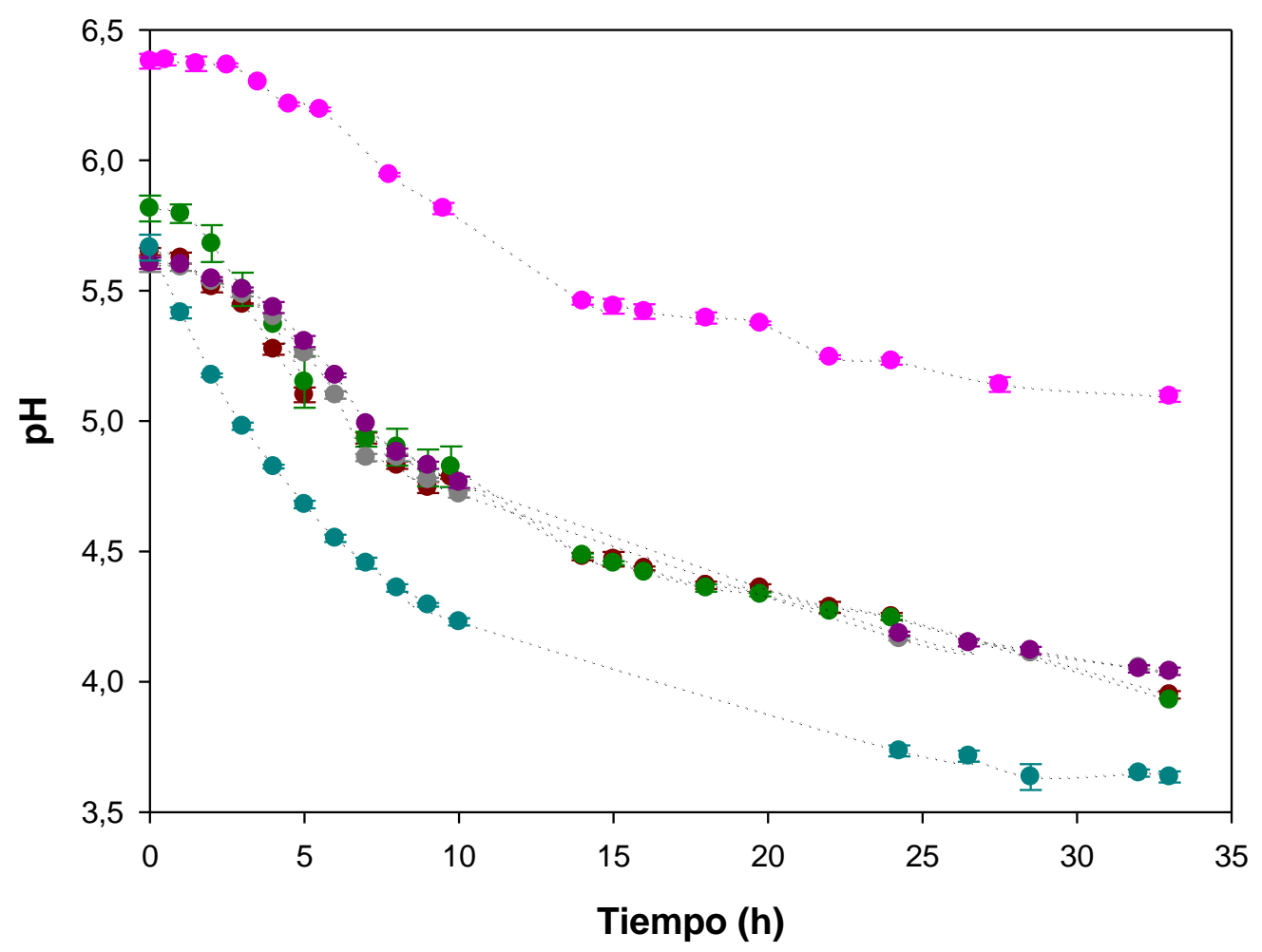

Figura 6.2.15 Cinética de acidificación del PS adicionado de gránulo de kefir CIDCA AGK1 al $10 \%$ o de microorganismos aislados del kefir (concentración inicial $2 \times 10^{7} \mathrm{UFC} / \mathrm{ml}$ ). • Gránulo de kefir CIDCA AGK1; • L. plantarum CIDCA 8316; • L. plantarum CIDCA 8329; • L. plantarum CIDCA 83114; • L. plantarum CIDCA 8318; • K. marxianus CIDCA 8154.

Ya con anterioridad se había estudiado la capacidad fermentativa del kefir y sus microorganismos aislados en otros productos lácteos como leche y suero de quesería. El gránulo de kefir CIDCA AGK1 inoculado al 10\% en leche e incubado a $30^{\circ} \mathrm{C}$ alcanzaba en 30 horas un $\mathrm{pH}$ de 3,5 (capítulo 6.1). Cuando la leche se fermentó por 48 horas con L. plantarum, alcanzó valores de pH entre 3,3 y 4,0 (capítulo 6.1). En otros estudios se analizó la capacidad de fermentación del suero de quesería por gránulos de kefir, alcanzando $\mathrm{pH}$ alrededor de 3,8 en aproximadamente 24 horas (Londero, 2012). En esta investigación se pudo determinar en primer lugar que el PS puede ser fermentado tanto por el gránulo de Kefir como por los microorganismos aislados del kefir, acidificándose desde $\mathrm{pH}$ 6,3 correspondiente al PS, hasta los pH finales medidos a las 33 horas. Se 
determinó que la cinética de acidificación mas rápida la presentó el PS fermentado con el gránulo de kefir CIDCA AGK1, el cual tuvo una pendiente más pronunciada de descenso del $\mathrm{pH}$ en las primeras horas de la fermentación, alcanzando un $\mathrm{pH}$ de 3,7 a la hora 10 y un valor mínimo de $\mathrm{pH}$ de 3,64 $\pm 0,021$ a la hora 33 de incubación. Los pH mínimos alcanzados por los lactobacilos individuales, fueron un poco superiores a los del gránulo, estando entre 3,9 y 4,0. Dichos valores de $\mathrm{pH}$ fueron $3,95 \pm 0,14 ; 4,04 \pm 0,01 ; 4,04 \pm 0,01$ y $3,93 \pm 0.04$ para L. plantarum CIDCA 83114, L. plantarum CIDCA 8329, L. plantarum CIDCA 8318 y L. plantarum CIDCA 8316 respectivamente. K. marxianus CIDCA 8154 fue el microorganismo menos acidificante, el cual alcanzó pH final de 5,06. No obstante las diferencias observadas entre los lactobacilos, la levadura y el gránulo de kefir, se pudo determinar que en todos los casos, el descenso más rápido de $\mathrm{pH}$ tiene lugar durante las primeras diez horas de incubación, tiempo a partir del cual el descenso de pH se hizo más lento para todos los microorganismos.

\subsubsection{Determinación de la composición del PS, el PS fermentado con gránulos de kefir CIDCA AGK1 (PSFG) y con microorganismos del kefir (PSFM).}

En la tabla 6.2.6 se presentan los resultados del análisis de la composición de los SLC del PS fermentado y sin fermentar. EI PS estéril sin fermentar, tuvo un $\mathrm{pH}$ de 6,5, cercano a la neutralidad y un contenido muy bajo de Nitrógeno total de $0,0207 \pm 0,0002 \%$.

El contenido de sólidos solubles totales se determinó como ${ }^{\circ}$ Brix en porcentaje de lactosa (ICONTEC, 1994). Los ${ }^{\circ}$ Brix del PS antes de la fermentación fueron $5,30 \pm 0,2097$ y el contenido de lactosa fue $3,33 \pm 0,35 \%$. El descenso de $\mathrm{pH}$ se logró hasta valores de $\mathrm{pH}$ entre 3,5 y 5,06. El porcentaje de Nitrógeno total fue muy bajo, probablemente porque en este producto ya han sido extraídas casi todas las proteínas. Por eso, el PS estéril tiene tan poco como un $0,02 \%$ de nitrógeno y éste casi no sufrió variación con los diferentes cultivos microbianos. Al igual que el PSFG los lactobacilos individuales disminuyeron la concentración de lactosa, hasta concentraciones entre 2,24 y $2,9 \%$ y el porcentaje de ${ }^{\circ}$ Brix entre 4,04 y $4,6 \%$, lo cual indicó que realizaron una actividad fermentativa sobre 
la lactosa. Esto se expresó en el contenido final de ácidos orgánicos que estuvo en concentraciones entre 0,62 y $0,97 \%$ de ácido láctico y entre 0,09 y $0,26 \%$ de ácido acético.

En cuanto al consumo de lactosa, se evidenció la gran capacidad de transformarla por parte de $K$. marxianus 8154 , alcanzando la concentración final mínima de 1,01\% lo cual correspondió al menor valor de ${ }^{\circ}$ Brix de $2 \%$. En coincidencia con estos resultados, previamente se demostró que $L$. plantarum 83114 sólo disminuyó el porcentaje de lactosa en leche desde 4,03 $\pm 0,46$ hasta $3,91 \pm 0,13 \%$, mientras que $K$. marxianus 8154 logró alcanzar una concentración muy inferior, de 0,12 $\pm 0,03 \%$ (Echeverría, 2007). La levadura transformó la lactosa en metabolitos no ácidos, lo cual se tradujo en que su pH final fue el más alto de todos $(5,06)$ y el porcentaje de ácidos láctico y acético fueron de $0,05 \%$ y de $0,09 \%$ respectivamente. En contraste, el microorganismo más acidificante de todos fue L. plantarum 83114, con un \% de ácido láctico de 0,97\%. La mayor cantidad de ácido acético la tuvo el PSFG en una concentración de 0,262\%.

Tabla 6.2.6 Composición del PS y del PS fermentado durante 33 horas a $30^{\circ} \mathrm{C}$ con gránulo de kefir CIDCA AGK1 y con L. plantarum aislados de gránulo de kefir.

\begin{tabular}{|c|c|c|c|c|c|c|c|}
\hline \multirow[t]{2}{*}{$\begin{array}{l}\text { Producto } \\
\text { fermentado }\end{array}$} & \multirow[t]{2}{*}{ pH } & \multirow{2}{*}{$\begin{array}{c}\text { NITRÓGENO } \\
\text { TOTAL } \\
(\%)\end{array}$} & \multirow{2}{*}{$\begin{array}{c}\text { LACTOSA } \\
\text { (\%) }\end{array}$} & \multirow{2}{*}{$\begin{array}{l}{ }^{\circ} B r i x \\
(\% p / p)\end{array}$} & \multirow{2}{*}{$\begin{array}{c}\text { Cenizas } \\
(\%)\end{array}$} & \multicolumn{2}{|c|}{$\begin{array}{c}\text { Acidos orgánicos HPLC } \\
\text { (\%) (ppm) }\end{array}$} \\
\hline & & & & & & Láctico & Acético \\
\hline PS estéril al 5\% & 6,50 & $0,0207 \pm 0,0002$ & $3,33 \pm 0.35$ & $5,30 \pm 0,2097$ & $0,2824 \pm 0,0055$ & $\begin{array}{c}(0,08) \\
(838,32)\end{array}$ & $\begin{array}{c}(0,04) \\
(424,29)\end{array}$ \\
\hline PSFG & 3,72 & $0,0111 \pm 1,70^{-5}$ & $2,23 \pm 0,14$ & $4,04 \pm 0,1673$ & $0,2959 \pm 0,0144$ & $\begin{array}{c}(0,658) \\
(6582,34)\end{array}$ & $\begin{array}{c}(0,262) \\
(2624,15)\end{array}$ \\
\hline $\begin{array}{c}\mathrm{PS}+L . \text { plantarum } \\
83114\end{array}$ & 3,50 & $0,0265 \pm 0,0031$ & $2,62 \pm 0,13$ & $4,35 \pm 0,3000$ & $0,3286 \pm 0,0042$ & $\begin{array}{c}(0,97) \\
(9794,41)\end{array}$ & $\begin{array}{c}(0,16) \\
(1679,51)\end{array}$ \\
\hline $\begin{array}{c}\text { PS+L. plantarum } \\
8316\end{array}$ & 3,77 & $0,0246 \pm 2,14 \times 10^{-5}$ & $2,9 \pm 0,27$ & $4,07 \pm 0,1155$ & $0,3190 \pm 0,0016$ & $\begin{array}{c}(0,80) \\
(8060,19)\end{array}$ & $\begin{array}{c}(0,12) \\
(1248,73)\end{array}$ \\
\hline $\begin{array}{c}\text { PS }+ \text { L. plantarum } \\
8318\end{array}$ & 3,66 & $0,0274 \pm 3,05 \times 10^{-5}$ & $2,88 \pm 0,21$ & $4,60 \pm 0,1633$ & $0,3163 \pm 0,0109$ & $\begin{array}{c}(0,74) \\
(7457,48)\end{array}$ & $\begin{array}{c}(0,12) \\
(1209,73)\end{array}$ \\
\hline $\begin{array}{c}\text { PS }+ \text { L. plantarum } \\
8329\end{array}$ & 3,70 & $0,0247 \pm 3,23 \times 10^{-5}$ & $2,24 \pm 0,17$ & $4,07 \pm 0,1155$ & $0,3132 \pm 0,0321$ & $\begin{array}{c}(0,62) \\
(6206,18)\end{array}$ & $\begin{array}{c}(0,09) \\
(971,65)\end{array}$ \\
\hline $\begin{array}{c}\mathrm{PS}+K . \text { marxianus } \\
8154\end{array}$ & 5,06 & $0,0167 \pm 3,3 \times 10^{-5}$ & $1,01 \pm 0,23$ & $2,0 \pm 0,0$ & $0,2706 \pm 0,0004$ & $\begin{array}{c}(0,05) \\
(513,57)\end{array}$ & $\begin{array}{c}(0,09) \\
(888,03)\end{array}$ \\
\hline
\end{tabular}


Los recuentos microbiológicos fueron de 2,02 $\times 10^{8} \pm 3,7 \times 10^{7} \mathrm{UFC} / \mathrm{ml}$ de BAL y $2,39 \times 10^{7} \pm 9,19 \times 10^{5} \mathrm{UFC} / \mathrm{ml}$ de levaduras en el PSFG. Los L. plantarum estuvieron en un orden de $10^{8} \mathrm{UFC} / \mathrm{ml}$ y K. marxianus 8154 en un orden de $10^{7}$ $\mathrm{UFC} / \mathrm{ml}$.

\subsubsection{Porcentaje de reducción de la germinación de los hongos filamentosos (\%RG) con permeado de suero fermentado con gránulos de kefir CIDCA AGK1 (PSFG), PS acidificado artificialmente con $\mathrm{HCl}$ y ácidos orgánicos y PS fermentado con microorganismos del kefir (PSFMK).}

En la figura 6.2.16 se observan los resultados obtenidos en el porcentaje de reducción de la germinación (\%RG) de los hongos evaluados cuando se emplearon SLC de PSFG, PS acidificado artificialmente con ácidos orgánicos puros en la misma concentración determinada por HPLC (0,658\% ácido láctico y 0,262 \% ácido acético, datos obtenidos en esta investigación) y PS acidificado con ácido fuerte $\mathrm{HCl} 3 \mathrm{M}$. Todos los SLC fueron llevados a pH 3,7. Los ensayos fueron realizados por octuplicado y tres repeticiones.

En primer lugar, todos los tratamientos pudieron reducir la capacidad de germinación de los hongos. Todos los valores de \%RG obtenidos con PSFG estuvieron dentro del rango alto de inhibición, mayor al 70\%. El \%RG fue superior al 90\% para $A$. flavus AFUNL5, $A$. parasiticus NRRL 2999, $P$. sumatrense CMUNLP3, P. crustosum CMUNLP4, y Rhizopus microsporus var. rhizopodiformis. CMUNLP6. T. longibrachiatum CMUNLP5, F. graminearum FG44, A. terreus y $A$. fumigatus tuvieron un $\% R G$ de $83,87,75$ y $83 \%$ respectivamente.

Los valores de \%RG obtenidos cuando se acidificó el PS con ácidos orgánicos y ácido fuerte, mostraron diferencias significativas entre sí $(p<0.05)$ y también con los correspondientes al PSFG, a excepción de Fusarium graminearum que no presentó diferencia significativa en los tres tratamientos. Los valores de \%RG obtenidos con PS acidificado con ácidos orgánicos, aun cuando fueron inferiores en general a los obtenidos con PSFG, se clasificaron también dentro del rango 
de \%RG alta $(>70 \%)$ para los hongos evaluados. Debe aclararse que aun cuando ambos tratamientos están dentro del rango de \%RG alta, en general el resultado obtenido con la aplicación de los ácidos orgánicos puros estuvo por debajo del proveniente del PSFG. Esto permite pensar que aun cuando los porcentajes de ácidos empleados sean iguales a los determinados por HPLC en el PSFG, éste último debe contener otros compuestos con capacidad antifúngica que generan un mayor efecto inhibitorio de la germinación y que no fueron determinados aún en este producto.

Al analizar finalmente la acción antifúngica que generó la acidificación con un ácido fuerte $(\mathrm{HCl} 3 \mathrm{M})$ hasta $\mathrm{pH} 3,7$, se encontraron los valores menores de $\% R G$, ubicados levemente por arriba del nivel inferior del rango medio de inhibición para A. flavus AFUNL5, A. parasiticus NRRL 2999, A. terreus CMUNLP1, A. fumigatus CMUNLP2, T. longibrachiatum CMUNLP5 y Rhizopus sp. CMUNLP6. A diferencia de los anteriores, los \%RG con PS acidificado con $\mathrm{HCl}$ alcanzaron un valor levemente superior al $70 \%$ para $F$. graminearum FG44, $P$. crustosum CMUNLP4 y $P$. sumatrense CMUNLP3.

No obstante, se pudo observar que la acidificación hasta el mismo valor final de pH pero sólo con ácido fuerte y sin incluir la presencia de los ácidos orgánicos, aun cuando reduce la germinación de los conidios, no alcanza los niveles de inhibición obtenidos cuando existe la mezcla de ácidos y pH o el SLC del PSFG. 


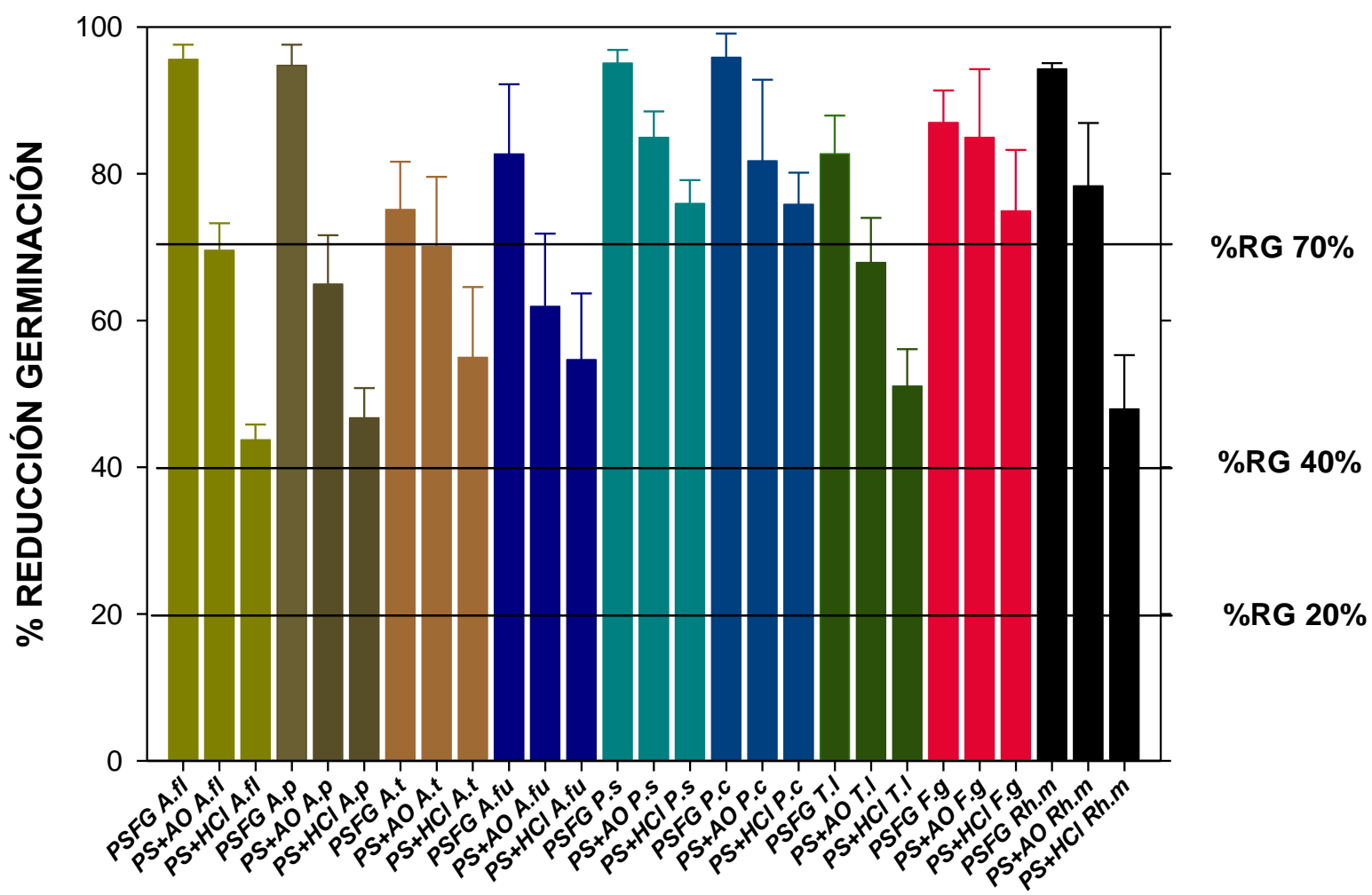

Figura 6.2.16 1,2,3,4. Porcentaje de reducción de la germinación de hongos filamentosos con permeado de suero fermentado con gránulo CIDCA AGK1 (PSFG), permeado de suero PS acidificado con ácidos orgánicos y PS acidificado con $\mathrm{HCl} 3 \mathrm{M}$.

'PSFG: permeado de suero fermentado con gránulo de kefir CIDCA AGK1.

${ }^{2} \mathrm{PS}+\mathrm{AO}$ : PS acidificado con ácidos orgánicos ( $0,658 \%$ ácido láctico y $0,262 \%$ ácido láctico) y acidificado hasta $\mathrm{pH} 3,7$. ${ }^{3} \mathrm{PS}+\mathrm{HCl}$ : PS acidificado con $\mathrm{HCl} 3 \mathrm{M}$ hasta $\mathrm{pH} 3,7$.

${ }^{4}$ A.fl: $A$. flavus AFUNL5. A.p. A. parasiticus NRRL 2999. A.t: A. terreus CMUNLP1. A.fu: A. fumigatus CMUNLP2. P.m: $P$. sumatrense CMUNLP3. P.C: P. crustosum CMUNLP4. T.I.: Trichoderma longibrachiatum CMUNLP5. F.g: Fusarium graminearum FG44. Rh.sp.: Rhizopus sp. CMUNLP6.

Los resultados generales y la variación en la reducción de la germinación indicaron que todos los tratamientos lograron reducir la germinación de los conidios. En la figura se observó una tendencia descendiente en la inhibición de cada hongo pasando del máximo con PSFG, seguido del PS adicionado de ácidos orgánicos y la menor inhibición con PS acidificado con $\mathrm{HCl}$.

Con el fin de determinar la capacidad inhibitoria de los microorganismos aislados del gránulo kefir, se hicieron los estudios de \%RG, seleccionando de entre los hongos evaluados, dos Aspergillus y un Penicillium con base en que los \%RG de todos los hongos evaluados fueron similares con el PSFG. Los resultados se observan en la tabla 6.2.7. 
6.2 Efecto Antifúngico del permeado de suero fermentado con gránulos de kefir y con microorganismos aislados del kefir

Tabla 6.2.7 Porcentajes de reducción de la germinación de hongos filamentosos con PS fermentado con MK.

\begin{tabular}{|c|c|c|c|}
\hline HONGO FILAMENTOSO & PS FERMENTADO CON MK & $\mathbf{p H}$ & $\% \mathbf{R G}$ \\
\hline A. flavus AFUNL5 & L. plantarum CIDCA 83114 & 3,5 & $75,61 \pm 0,99$ \\
\hline A. flavus AFUNL5 & L. plantarum CIDCA 8316 & 3,8 & $66,99 \pm 3,31$ \\
\hline A. flavus AFUNL5 & L. plantarum CIDCA 8318 & 3,8 & $66,71 \pm 3.81$ \\
\hline A. flavus AFUNL5 & L. plantarum CIDCA 8329 & 3,8 & $59,13 \pm 4,67$ \\
\hline A. flavus AFUNL5 & K. marxianus CIDCA 8154 & 5,1 & $52,04 \pm 1,08$ \\
\hline A. parasiticus NRRL 2999 & L. plantarum CIDCA 83114 & 3,5 & $79,58 \pm 1,36$ \\
\hline A. parasiticus NRRL 2999 & L. plantarum CIDCA 8316 & 3,8 & $67,19 \pm 5,04$ \\
\hline A. parasiticus NRRL 2999 & L. plantarum CIDCA 8318 & 3,8 & $67,39 \pm 6,33$ \\
\hline A. parasiticus NRRL 2999 & L. plantarum CIDCA 8329 & 3,8 & $54,47 \pm 7,24$ \\
\hline A. parasiticus NRRL 2999 & K. marxianus CIDCA 8154 & 5,1 & $39,67 \pm 3,24$ \\
\hline P. sumatrense CMUNLP3 & L. plantarum CIDCA 83114 & 3,5 & $80,12 \pm 5,74$ \\
\hline P. sumatrense CMUNLP3 & L. plantarum CIDCA 8316 & 3,8 & $77,13 \pm 5,91$ \\
\hline P. sumatrense CMUNLP3 & L. plantarum CIDCA 8318 & 3,8 & $65,87 \pm 6,67$ \\
\hline P. sumatrense CMUNLP3 & L. plantarum CIDCA 8329 & 3,8 & $66.12 \pm 4.56$ \\
\hline P. sumatrense CMUNLP3 & K. marxianus CIDCA 8154 & 5,1 & $51,29 \pm 3,59$ \\
\hline
\end{tabular}

Los \%RG que se observan en la tabla 6.2.7, demuestran que el PS fermentado con MK también generó reducción de la germinación. Sin embargo, los porcentajes obtenidos no fueron tan altos como los alcanzados con el PSFG. Esto posiblemente se deba a que en el PSFG están presentes los metabolitos producidos por el total de los microorganismos presentes en el gránulo de kefir, mientras que en el PSFM sólo están los metabolitos producidos por cada microorganismo individual. De todos los lactobacilos, L. plantarum 83114 generó las mayores disminuciones de la germinación, todas cerca al rango inferior del \% de reducción alta. Los demás lactobacilos presentaron una tendencia a ubicarse en el rango medio de reducción, entre el 40 y $70 \%$. Por último, K. marxianus 8154, aún cuando generó reducción de la germinación, lo hizo cerca al rango 
inferior de la reducción media, un poco por encima para $A$. flavus AFUNL5 y $P$. sumatrense CMUNLP3 y levemente por debajo para A. parasiticus NRRL 2999.

En la figura 6.2.17 se observa gráficamente la tendencia en el \%RG de los hongos A. flavus AFUNL5, A. parasiticus NRRL 2999 y $P$. sumatrense CMUNLP3, obtenido con los lactobacilos y la levadura. En ella se observa una tendencia donde el mayor \%RG lo generó L. plantarum 83114 y un poco por debajo se ubicaron los demás lactobacilos. Finalmente, se observó una tendencia a que la menor reducción se lograba con el SLC de $K$. marxianus CIDCA 8154.

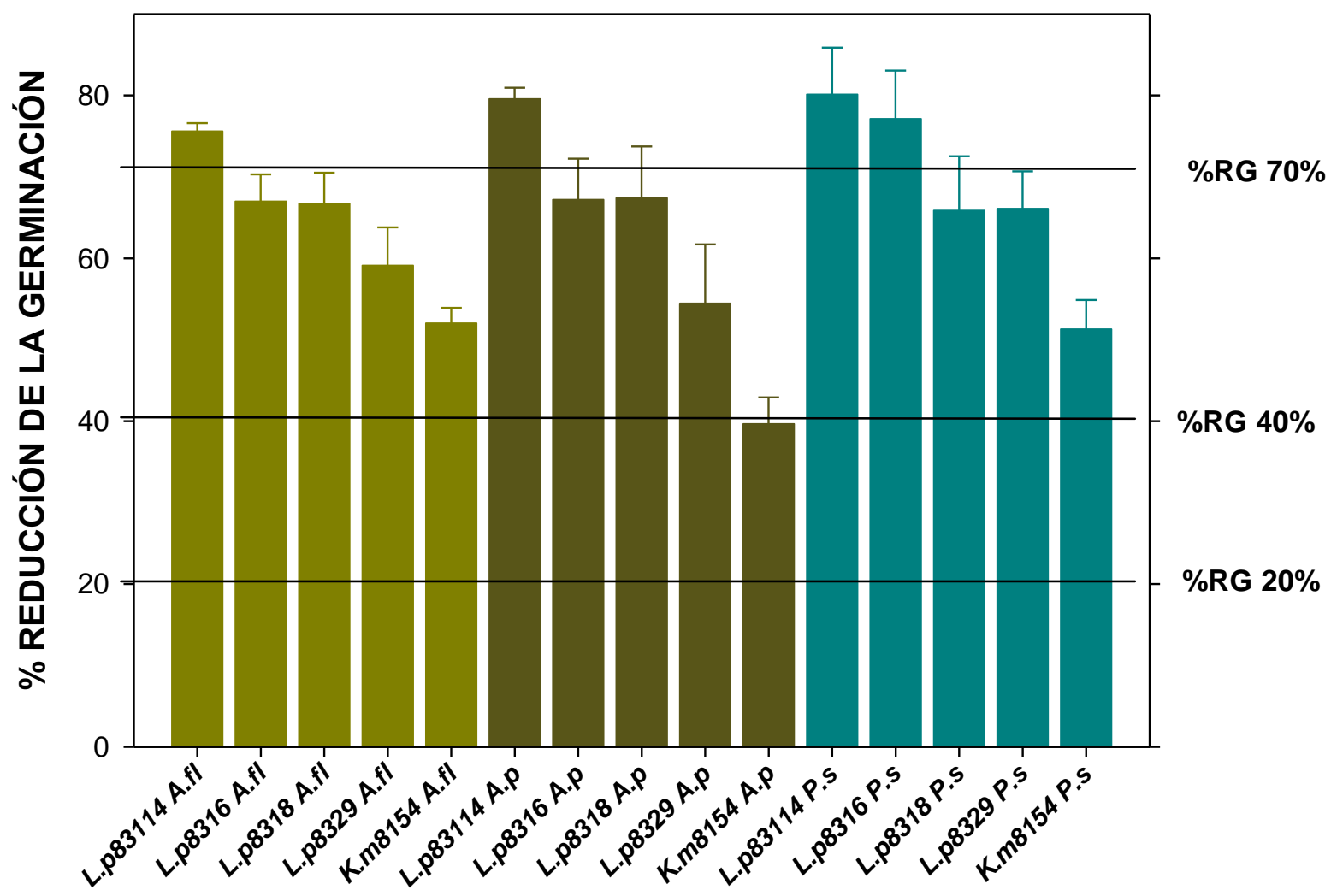

Figura 6.2.17 ${ }^{1}$. Porcentajes de reducción de la germinación de hongos filamentosos con permeado de suero fermentado con L. plantarum y K. marxianus.

'A.fl: A. flavus AFUNL5. A.p. A. parasiticus NRRL 2999. P.s: P. sumatrense CMUNLP3. 
A partir de todos los resultados obtenidos, se pudo concluir que el mayor \%RG se obtenía con el PSFG. En virtud de lo anterior, se seleccionó este producto para adicionar al alimento para pollos y determinar tanto la supervivencia de sus microorganismos como su efecto antifúngico en el alimento.

\subsubsection{Adición del PS fermentado con gránulo de kefir CIDCA AGK1 (PSFG) al alimento para pollos.}

La dosis efectiva recomendada para la mayoría de los probióticos incluidos en alimento balanceado de aves, está en el rango de $10^{8}$ a $10^{9} \mathrm{UFC} / \mathrm{Kg}$ de dieta (Mountzouris, Tsitrsikos, Palamidi, Arvaniti, Mohnl, Schatzmayr \& Fegeros, 2010). También se ha recomendado administrar dosis de $10^{8}$ a $10^{9} \mathrm{UFC} / \mathrm{Kg}$ de alimento (Kim, Ingale, Kim, Kim, Sen, Ryu, Lohakare, Kwon \& Chae, 2012) y de 2 a $6 \times 10^{9} \mathrm{UFC} / \mathrm{Kg}$ (Apata, 2008). Además se ha determinado que el consumo diario aproximado de alimento por pollitos de 1, 4, 6, y 10 días de vida, es de 80, 100, 120 y 150 gramos respectivamente (Londero, 2012). Según lo anterior, el total de probióticos que debería consumir en un día un pollo sería de: $8 \times 10^{7}$ UFC en el día $1 ; 1 \times 10^{8}$ al día $4 ; 1,2 \times 10^{8}$ al día 6 y $1,5 \times 10^{8}$ al día 10.

EI PSFG empleado en los experimentos, presentó un recuento de 2,02 $\times 10^{8}$ $\mathrm{UFC} / \mathrm{ml}$ de BAL y $2,39 \times 10^{7} \mathrm{UFC} / \mathrm{ml}$ de levaduras (LEV) y a partir de esto, se calcularon los recuentos teóricos del total de probiótico que consumirían los pollitos si se usaran dos proporciones de PSFG: $5 \mathrm{ml}$ y $10 \mathrm{ml}$ de PSFG por cada 10 gramos de alimento y si todos estos sobrevivieran al proceso de secado.

Estos cálculos se observan en la tabla 6.2.8 y además fueron determinados por recuento después del secado. Es importante resaltar que aún cuando el permeado de suero es un sustrato pobre en nitrógeno, los recuentos de BAL y LEV del PSFG estuvieron dentro de los parámetros del Código Alimentario Argentino para el Kefir de leche, que exige un recuento mínimo de $10^{7} \mathrm{UFC} / \mathrm{ml}$ de BAL y de $10^{4}$ UFC/ml de levaduras(C.A.A, 2006). 
Tabla 6.2.8. Niveles estimados de bacterias acido lácticas (BAL) y levaduras consumidas por día en el alimento balanceado por pollos de diferentes días de vida'.

\begin{tabular}{|c|c|c|c|c|c|}
\hline $\begin{array}{l}\text { Días } \\
\text { vida } \\
\text { del } \\
\text { pollo }\end{array}$ & $\begin{array}{l}\text { Cantidad }(g) \text { de } \\
\text { alimento } \\
\text { consumido/día }\end{array}$ & $\begin{array}{c}\text { Total de } \\
\text { probiótico que } \\
\text { debe consumir/ } \\
\text { día }^{3} \text { (UFC) }\end{array}$ & $\begin{array}{c}\begin{array}{c}\text { Volumen } \\
(\mathrm{ml})\end{array} \\
\text { PSFG/10 g } \\
\text { alimento }\end{array}$ & $\begin{array}{c}\text { Total de BAL } \\
\text { que consumiría } \\
\text { por día } \\
\text { (UFC/día) }\end{array}$ & $\begin{array}{c}\text { Total de LEV } \\
\text { que consumiría } \\
\text { por día } \\
\text { (UFC/día) }\end{array}$ \\
\hline \multirow{2}{*}{1} & \multirow{2}{*}{80} & \multirow[b]{2}{*}{$8 \times 10^{7}$} & 5 & $8,08 \times 10^{9}$ & $9,6 \times 10^{8}$ \\
\hline & & & 10 & $1,62 \times 10^{10}$ & $1,91 \times 10^{9}$ \\
\hline \multirow{2}{*}{4} & \multirow{2}{*}{100} & \multirow{2}{*}{$1 \times 10^{8}$} & 5 & $1,01 \times 10^{10}$ & $1,20 \times 10^{9}$ \\
\hline & & & 10 & $2,02 \times 10^{10}$ & $2,39 \times 10^{9}$ \\
\hline \multirow{2}{*}{6} & \multirow{2}{*}{120} & \multirow{2}{*}{$1,2 \times 10^{8}$} & 5 & $1,21 \times 10^{10}$ & $1,43 \times 10^{9}$ \\
\hline & & & 10 & $2,42 \times 10^{10}$ & $2,87 \times 10^{9}$ \\
\hline \multirow{2}{*}{10} & \multirow{2}{*}{150} & \multirow{2}{*}{$1,5 \times 10^{8}$} & 5 & $1,52 \times 10^{10}$ & $1,80 \times 10^{9}$ \\
\hline & & & 10 & $3,04 \times 10^{10}$ & $3,6 \times 10^{9}$ \\
\hline
\end{tabular}

${ }^{1}$ Cálculos con base en los recuentos de BAL y LEV del PSFG:

${ }^{2}$ Basado en: Londero, 2012.

${ }^{3}$ Basado en: Mountzouris, Tsitrsikos, Palamidi, Arvaniti, Mohnl, Schatzmayr \& Fegeros, 2010; Kim, Ingale, Kim, Kim,

Sen, Ryu, Lohakare, Kwon \& Chae, 2012 y Apata, 2008.

A partir de los cálculos realizados en la tabla se pudo concluir que con cualquiera de los dos volúmenes habría un consumo teórico entre $10^{8}$ a $10^{10}$ UFC/día de microorganismos probióticos, los cuales están por encima del mínimo recomendado y calculado para el total de alimento consumido por día. A partir de esto se decidió realizar la adición de ambos volúmenes al alimento, determinar el tiempo de secado para las proporciones empleadas y analizar la resistencia de los microorganismos adicionados durante el tiempo de almacenamiento de dicho alimento envuelto en bolsas de polietileno en cámara de temperatura controlada a $20^{\circ} \mathrm{C}$.

\subsubsection{Secado del alimento de Pollo adicionado con permeado de suero fermentado con gránulo de kefir CIDCA AGK1 (PSFG).}

EI PSFG se separó de los gránulos de kefir mediante un colador y se adicionó en proporción 1:1 o 1:2 al alimento para pollos Nutrisur ${ }^{\circledR}$, mezclándose 50 gramos de alimento con 25 y $50 \mathrm{ml}$ de PSFG hasta quedar bien homogenizado. Se 
obtuvo un peso inicial de alimento a secar de 76,6 y 99,9 gramos respectivamente. El secado se hizo según se describió en la metodología y se consideró terminado cuando el alimento alcanzó el peso final estable de 50,72 y la $a_{w}$ final de 0,682 . Los valores del peso del alimento durante el tiempo de secado, se presentan en la figura 6.2.18. En ésta se observa que el alimento adicionado con PSFG en proporción $1: 2 \mathrm{vol} / \mathrm{p}$, secado a $50^{\circ} \mathrm{C}$ en estufa de convección, alcanzó el peso de 50,72 g y la $a_{w}$ inicial del alimento de 0,682 en 60 minutos de secado, mientras que el alimento adicionado con PSFG en proporción 1:1 vol/p, duplicó dicho tiempo. La curva de disminución de peso que se observa en la figura 6.2.18, permite observar que aunque las pendientes de secado de ambos tratamientos son similares en los primeros 60 minutos, el segundo requiere 60 minutos más y tiende a disminuir la velocidad de secado entre los minutos 90 y 120.

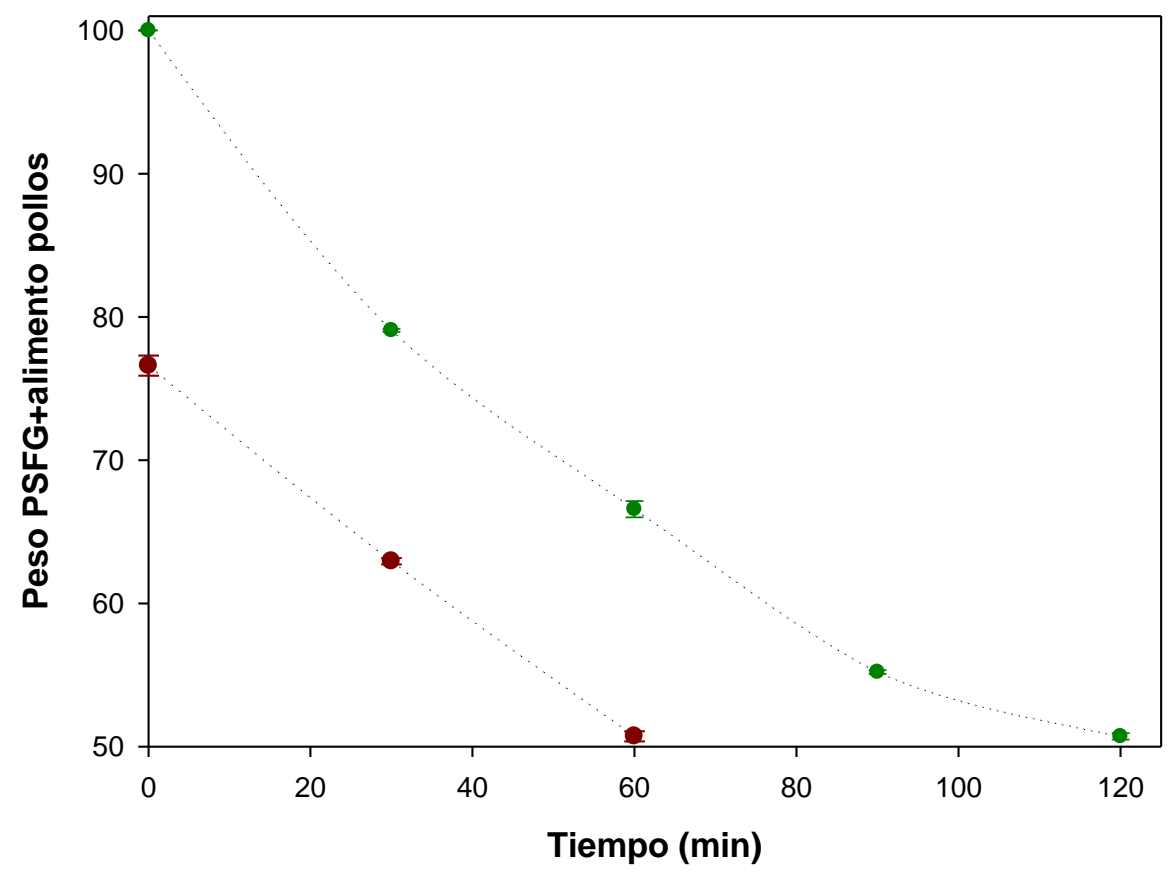

Figura 6.2.18. Proceso de Secado de la mezcla PSFG y alimento de pollo en proporción 1:2 y $1: 1 \mathrm{vol} / \mathrm{p}$. • PSFG y alimento en proporción 1:2. • PSFG y alimento en proporción 1:1. Las barras de error verticales corresponden a valores por duplicado. 
En la relación 1:2, se adicionaron $25 \mathrm{ml}$ de PSFG a $50 \mathrm{~g}$ de alimento mientras que en la relación 1:1 se mezclaron $50 \mathrm{ml}$ de PSFG con $50 \mathrm{~g}$ de alimento. El secado se hizo en estufa de convección forzada a $50^{\circ} \mathrm{C}$ hasta alcanzar peso final de 50,72 g y $a_{w}$ de 0,682. Una vez finalizado el secado, el alimento se dejó enfriar hasta $20^{\circ} \mathrm{C}$, se fraccionó en bolsas de polietileno y se llevó a almacenamiento en cámara de $20^{\circ} \mathrm{C}$, para ser sometido a diferentes análisis.

\subsubsection{Determinación de la estabilidad del alimento para pollos adicionado con permeado de suero fermentado con gránulos de kefir CIDCA AGK1 (PSFG).}

\subsection{Resistencia de los microorganismos del kefir al secado en el alimento adicionado de PSFG.}

Se tomaron muestras del alimento adicionado con PSFG para hacer los recuentos de las BAL y LEV de ambos tratamientos en los tiempos cero (al salir del secado) y en los días 15 y 30 del almacenamiento. Los recuentos se presentan en la tabla 6.2.9. Los recuentos obtenidos con el PSFG inoculado con gránulo AGK1 al 10\% inmediatamente termina el tiempo de fermentación y alcanza el pH de valor 3,7, fueron $2,02 \times 10^{8} \pm 3,7 \times 10^{7} \mathrm{UFC} / \mathrm{ml}$ de BAL y $2,39 \mathrm{x}$ $10^{7} \pm 9,19 \times 10^{5} \mathrm{UFC} / \mathrm{ml}$ de levaduras.

Tabla 6.2.9 Recuentos de BAL y LEV (UFC/g) en el alimento de pollo adicionado con PSFG y secado, durante el almacenamiento.

\begin{tabular}{|c|c|c|c|c|}
\hline \multirow{2}{*}{ TRATAMIENTO } & \multirow{2}{*}{ MICROORGANISMO } & \multicolumn{2}{|c|}{ RECUENTO (UFC/g) durante el almacenamiento } \\
\cline { 3 - 5 } & & Día 0 & Día 15 & Día 30 \\
\hline $\begin{array}{c}\text { PSFG+ALIM. } \\
\text { POLLO 1:2 }\end{array}$ & BAL & $3,68 \times 10^{4} \pm 4,88 \times 10^{3}$ & $1,08 \times 10^{4} \pm 5,73 \times 10^{3}$ & $2,56 \times 10^{3} \pm 5,08 \times 10^{2}$ \\
\cline { 2 - 5 } & LEV & $1,04 \times 10^{5} \pm 8,66 \times 10^{4}$ & $7,44 \times 10^{4} \pm 3,02 \times 10^{3}$ & $1,72 \times 10^{3} \pm 4,25 \times 10^{2}$ \\
\hline $\begin{array}{c}\text { PSFG+ALIM. } \\
\text { POLLO 1:1 }\end{array}$ & BAL & $7,80 \times 10^{6} \pm 5,65 \times 10^{5}$ & $4,50 \times 10^{5} \pm 5,07 \times 10^{4}$ & $2,50 \times 10^{4} \pm 7,07 \times 10^{3}$ \\
\cline { 2 - 5 } & LEV & $4,21 \times 10^{5} \pm 6,36 \times 10^{3}$ & $4,00 \times 10^{5} \pm 9,00 \times 10^{4}$ & $6,15 \times 10^{4} \pm 1,06 \times 10^{4}$ \\
\hline
\end{tabular}

Se adicionaron 25 y $50 \mathrm{ml}$ de PSFG $\left(2,02 \times 10^{8} \pm 3,7 \times 10^{7} \mathrm{UFC} / \mathrm{ml}\right.$ de BAL y $2,39 \times 10^{7} \pm 9,19 \times 10^{5} \mathrm{UFC} / \mathrm{ml}$ de levaduras $)$ a $50 \mathrm{~g}$ de alimento para pollos en las proporciones $1: 2$ y $1: 1$ respectivamente.

${ }^{1}$ Recuentos obtenidos de BAL y LEV en el alimento adicionado con PSFG en relación 1/2. Los recuentos están en UFC/g.

${ }^{2}$ Recuentos obtenidos de BAL y LEV en el alimento adicionado con PSFG en relación 1/1. Los recuentos están en UFC/g. 
Los recuentos obtenidos de BAL y LEV en el alimento para pollos adicionado de PSFG y secado en estufa de convección, en los días 0, 15 y 30 de almacenamiento a $20^{\circ} \mathrm{C}$, demostraron una mayor supervivencia de los microorganismos cuando se adicionó el PSFG al alimento en proporción 1:1, eligiéndose esta proporción para los siguientes ensayos. Se observó que las BAL y las levaduras del alimento adicionado con PSFG (1:1) inmediatamente terminó el secado (día 0), presentaron un descenso de 2 órdenes logarítmicos con respecto al recuento del PSFG líquido.

A los 15 días de almacenamiento, se observó que las BAL descendieron otro logaritmo con relación al día cero y las LEV permanecieron constantes. Al alcanzar el día 30 de almacenamiento, las LEV y BAL disminuyeron en total con respecto a sus recuentos a la salida del secado el día cero, 1 y 2 órdenes logarítmicos respectivamente, siendo $6,2 \times 10^{4} \pm 1,06 \times 10^{4} \mathrm{UFC} / \mathrm{g}$ de levaduras y $2,5 \times 10^{4} \pm 7,07 \times 10^{3} \mathrm{UFC} / \mathrm{g}$ de BAL.

Los resultados obtenidos durante todo el proceso de secado y almacenamiento del alimento adicionado con PSFG, demostraron que las BAL y LEV de los gránulos de kefir CIDCA AGK1 son resistentes tanto a la técnica de secado utilizada como al tiempo de almacenamiento estudiado. En otras palabras, mantienen su viabilidad y están disponibles en el alimento para ser ingeridas por el pollo. A partir de los resultados obtenidos, se recalculó el valor teórico presentado en la tabla 6.2.11 para calcular el total real de probióticos totales que consumirían los pollos.

En la tabla 6.2.10 puede verse el consumo de probiótico por parte del animal de acuerdo a su edad a los 15 y a los 30 días de almacenamiento de alimento adicionado con Permeado de suero fermentado con gránulo CIDCA AGK1 (PSFG). 
Tabla 6.2.10. Consumo esperado de BAL y LEV del alimento de pollo adicionado de PSFG (1:1) a los 15 y 30 días de almacenamiento, según los días de vida del pollo.

\begin{tabular}{|c|c|c|c|c|}
\hline $\begin{array}{c}\text { Días de } \\
\text { vida del } \\
\text { pollo }\end{array}$ & $\begin{array}{l}\text { Cantidad alto. } \\
\text { consumido/día (g) }\end{array}$ & $\begin{array}{c}\text { Día de } \\
\text { almacena/ } \\
\text { alto.+PSFG }\end{array}$ & $\begin{array}{l}\text { Recuento BAL(UFC) } \\
\text { consumidas/día }\end{array}$ & $\begin{array}{l}\text { Recuento Levaduras } \\
\text { (UFC) consumidas/día }\end{array}$ \\
\hline \multirow{3}{*}{1} & \multirow{3}{*}{80} & 0 & $6,24 \times 10^{8}$ & $3,37 \times 10^{\prime}$ \\
\hline & & 15 & $3,60 \times 10^{\prime}$ & $3,20 \times 10^{\prime}$ \\
\hline & & 30 & $2,00 \times 10^{6}$ & $4,92 \times 10^{6}$ \\
\hline \multirow{3}{*}{4} & \multirow{3}{*}{100} & 0 & $7,80 \times 10^{8}$ & $4,21 \times 10^{\prime}$ \\
\hline & & 15 & $4,50 \times 10^{\prime}$ & $4,00 \times 10^{\prime}$ \\
\hline & & 30 & $2,50 \times 10^{6}$ & $6,15 \times 10^{6}$ \\
\hline \multirow{3}{*}{6} & \multirow{3}{*}{120} & 0 & $9,36 \times 10^{8}$ & $5,05 \times 10^{\prime}$ \\
\hline & & 15 & $5,40 \times 10^{\prime}$ & $4,80 \times 10^{\prime}$ \\
\hline & & 30 & $3,00 \times 10^{6}$ & $7,38 \times 10^{6}$ \\
\hline \multirow{3}{*}{10} & \multirow{3}{*}{150} & 0 & $1,17 \times 10^{9}$ & $6,32 \times 10^{\prime}$ \\
\hline & & 15 & $6,75 \times 10^{\prime}$ & $6,00 \times 10^{\prime}$ \\
\hline & & 30 & $3,75 \times 10^{6}$ & $9,22 \times 10^{6}$ \\
\hline
\end{tabular}

Se ha recomendado que el pollo consuma de $10^{8}$ a $10^{9} \mathrm{UFC} / \mathrm{Kg}$ de alimento (Mountzouris, Tsitrsikos, Palamidi, Arvaniti, Mohnl, Schatzmayr \& Fegeros, 2010, Apata, 2008; Kim, Ingale, Kim, Kim, Sen, Ryu, Lohakare, Kwon \& Chae, 2012).

De acuerdo a esto, si se toma en consideración el total de alimento que consumen en un día para el período de vida analizado, el consumo mínimo de probióticos se cumple con el alimento adicionado de PSFG en los tres días de almacenamiento de alimento evaluados. Lo anterior permitiría considerar que la incorporación del PSFG en la elaboración de un producto que aporte a la alimentación y protección del pollo en los primeros días de crianza, podría garantizar el número de probióticos que se recomiendan para su adecuado crecimiento. 


\subsection{Determinación de la actividad acuosa $\left(\mathrm{a}_{\mathrm{w}}\right), \mathrm{pH}$, concentración de ácidos orgánicos, aflatoxinas y resistencia a la contaminación natural por el alimento adicionado con PSFG.}

La adición del PSFG tuvo como finalidad primordial el aporte de microorganismos probióticos, ácidos orgánicos y la inhibición del crecimiento fúngico en el alimento para pollos. Con respecto a la inhibición fúngica, esta depende de factores intrínsecos como la actividad acuosa, el $\mathrm{pH}$ y la concentración de metabolitos como ácidos en el alimento (Pitt \& Hocking, 1997)). También se esperaba que el alimento experimentara cambios en sus condiciones durante el almacenamiento, lo cual podría influenciar la inhibición fúngica. Por ello se determinaron la actividad acuosa, el pH y la concentración de ácidos orgánicos en el alimento y por otro lado, la presencia y concentración de aflatoxinas y el recuento de hongos filamentosos en los días cero, quince y treinta del almacenamiento a $20^{\circ} \mathrm{C}$.

Se compararon los valores del alimento adicionado con PSFG con los del alimento adicionado con agua destilada (control) y sometido al mismo tiempo y condiciones de secado y con el alimento tal cual se obtiene en el comercio sin adición ni secado. Este último se denominó "alimento natural" y se analizó dado que es posible que con la aplicación del calor se destruya una proporción de la micobiota natural del alimento; por ello se comparó el recuento de hongos filamentosos considerando también como control el alimento natural sin adición de agua destilada y sin someterlo al calor del secado.

Los valores de los recuentos fúngicos, $\mathrm{pH}, \mathrm{a}_{\mathrm{w}}$, concentración de ácidos orgánicos y presencia de aflatoxinas se encuentran en la tabla 6.2.11. El pH del alimento adicionado (alrededor de 5,8) fue inferior al de los controles (alrededor de 6,6), debido al aporte de ácidos orgánicos que hizo el PSFG. El pH y la $a_{w}$ de los tres tipos de alimentos se mantuvieron estables durante el almacenamiento.

Los resultados obtenidos con la concentración de ácidos mostraron diferencias entre el alimento adicionado y los alimentos control, adicionados con agua 
destilada y natural. EI PSFG empleado ( $\mathrm{pH} 3,7)$, tenía una concentración de ácido láctico y acético de $0,658 \%$ y $0,262 \%$ p/v respectivamente. Éste fue adicionado en proporción 1:1 al alimento y secado posteriormente, por lo cual se considera que teóricamente esta sería la misma concentración final en el alimento. No obstante, en el alimento adicionado de PSFG, la concentración de ácido el ácido láctico estuvo en concentración de $0,095 \%$ o sea aproximadamente 7 veces menos a la original y la concentración de acético fue alrededor de $0,026 \%$, o sea que se redujo aproximadamente 10 veces con relación a su concentración original en el PSFG.

Debido al calor aplicado, una proporción de los ácidos adicionados posiblemente se haya volatilizado en el alimento y disminuido su concentración. Al comparar el alimento adicionado de PSFG con los controles, se pudo establecer que la concentración de ácido acético es aproximadamente 10 veces superior a los alimentos control. A diferencia del ácido acético, se pudo determinar que el alimento natural tiene una concentración de ácido láctico cercana a la del alimento adicionado de PSFG, alrededor de $0,06 \% \mathrm{p} / \mathrm{v}$, es decir que el alimento ya tiene una acidez previa aportada por el ácido láctico.

La presencia de los ácidos orgánicos y del pH en el alimento adicionado de PSFG, pudo influir en la variación en los recuentos fúngicos. Los recuentos del alimento adicionado de PSFG el día cero fueron muy cercanos a los del alimento con agua destilada, pero se fueron diferenciando durante los días 15 y 30 , donde los recuentos correspondientes al último fueron superiores en un orden logarítmico.

En cuanto al alimento natural, se observó que el recuento fue superior al alimento adicionado con PSFG en un orden logarítmico en los tres días analizados. Como se explicó arriba, se quiso determinar si el secado del alimento pudo influir en el recuento fúngico, lo cual se pudo determinar en la diferencia observada entre los recuentos del alimento adicionado con agua destilada y el alimento natural. El primero estuvo en el mismo orden logarítmico que el adicionado con agua en los días $0\left(10^{2}\right)$, y $15\left(10^{3}\right)$, siendo superado en un orden logarítmico al día 30. El alimento natural y el adicionado con agua 
destilada terminaron con el mayor recuento, de $1,05 \times 10^{4} \pm 3,06 \times 10^{3}$ y $1,16 \times$ $10^{4} \pm 5,24 \times 10^{3} \mathrm{UFC} / \mathrm{g}$ respectivamente. Los resultados obtenidos indican que el secado puede ejercer un efecto protector en los primeros 15 días de almacenamiento para los productos que pasaron por el horno de convección forzada tanto con el probiótico como con agua destilada, pero este efecto se pierde para el día 30, para el alimento que sólo fue adicionado de agua. EI PSFG protegió el alimento al mantener los recuentos en el mismo logaritmo y por debajo del valor de los otros dos productos.

En esta protección puede considerarse que intervienen tanto la mezcla de ácidos con el pH final, como los probióticos presentes en el alimento adicionado con PSFG durante el almacenamiento. Previamente se ha demostrado que mezclas de ácido láctico y acético puros pueden tener efecto antifúngico, en concentraciones de 78,0 mM (7026,24 ppm) y 31,2 mM (1872 ppm) a pH 3,38, respectivamente en concentraciones 4,6 y 1,3 veces inferiores a sus valores de MIC cuando son empleados individualmente contra A. flavus AFUNQ6, AFUNL1, AFUNL2 y AFUNL3 (León, Serna, Quintero, Gamba, De Antoni \& Giannuzzi, 2012).

Los resultados obtenidos coinciden con aquellos reportados al adicionar en la formulación de pan, un iniciador mixto compuesto de cuatro Lactobacilos ( $L$. reutheri CRL 1100, L. brevis CRL 796, L. brevis CRL 772 y L. plantarum CRL 778) y una levadura comercial. El pan hecho con la mezcla de lactobacilos y levadura comercial alcanzó un pH de 5,0 y concentraciones de ácidos de 1729,5 ppm de ácido láctico, 600 ppm de acético y 33,23 ppm de fenil láctico a las 4 horas de fermentación. Por el contrario, el control fabricado con levadura descendió sólo hasta 5,7 y presentó concentraciones inferiores de 225,2ppm de ácido láctico y 12 ppm de ácido acético. Se determinó la capacidad antifúngica del iniciador, contaminando los panes de la misma manera descripta para el alimento de pollo y las arepas. Se comparó la vida útil de los panes hechos con la mezcla de BAL- levadura comercial con la de los panes con levadura sola o con levadura. Al igual que en el alimento de pollo, los panes con lactobacilos 
presentaron la mayor concentración de ácidos y una vida útil de 5 días a diferencia del pan hecho sólo con levadura cuya vida útil fue sólo de 48 horas.prolongado la vida útil del pan (Gerez, Torino, Rollán \& Font de Valdéz, 2009).

Tabla 6.2.11. $\mathrm{a}_{\mathrm{w}}, \mathrm{pH}$ y ácidos orgánicos en el alimento adicionado con PSFG durante el almacenamiento a $20^{\circ} \mathrm{C}$.

\begin{tabular}{|c|c|c|c|c|c|c|c|}
\hline \multirow{2}{*}{ Tratamiento } & Días & $\mathbf{p H}$ & $\mathbf{a}_{\mathbf{w}}$ & $\begin{array}{c}\text { Ác. láctico } \\
(\%)\end{array}$ & $\begin{array}{c}\text { Ác. acético } \\
(\%)\end{array}$ & $\begin{array}{c}\text { AFB1 } \\
\mathbf{( p p b )}\end{array}$ & $\begin{array}{c}\text { Recuento } \\
\text { Hongos (UFC/g) }\end{array}$ \\
\hline \multirow{4}{*}{$\begin{array}{c}\text { Alto.pollos } \\
\text { PSFG }\end{array}$} & 15 & $5,78 \pm 0,205$ & $0,595 \pm 0,006$ & $0,089 \pm 0,001$ & $0,023 \pm 0,002$ & $\mathrm{ND}$ & $1,50 \times 10^{3} \pm 3,78 \times 10^{2}$ \\
\cline { 2 - 8 } & 30 & $5,72 \pm 0,006$ & $0,624 \pm 0,018$ & $0,086 \pm 0,001$ & $0,022 \pm 0,003$ & $\mathrm{ND}$ & $3,50 \times 10^{3} \pm 4,07 \times 10^{2}$ \\
\hline \multirow{2}{*}{$\begin{array}{c}\text { Alto.pollos } \\
\text { Agua } \\
\text { destilada }\end{array}$} & 0 & $6,52 \pm 0,007$ & $0,570 \pm 0,019$ & $0,070 \pm 0,003$ & $0,0035 \pm 0,0002$ & $\mathrm{ND}$ & $3,76 \times 10^{2} \pm 1,41 \times 10^{1}$ \\
\cline { 2 - 8 } & 15 & $6,55 \pm 0,11$ & $0,589 \pm 0,015$ & $0,067 \pm 0,001$ & $0,0031 \pm 0,0002$ & $\mathrm{ND}$ & $2,52 \times 10^{3} \pm 4,12 \times 10^{2}$ \\
\hline \multirow{2}{*}{$\begin{array}{c}\text { Alto.pollos } \\
\text { natural }\end{array}$} & 15 & $6,52 \pm 0,02$ & $0,559 \pm 0,034$ & $0,065 \pm 0,002$ & $0,002 \pm 0,0001$ & $\mathrm{ND}$ & $1,16 \times 10^{4} \pm 5,24 \times 10^{3}$ \\
\cline { 2 - 8 } & 30 & $6,59 \pm 0,014$ & $0,614 \pm 0,021$ & $0,069 \pm 0,002$ & $0,0031 \pm 0,0002$ & $\mathrm{ND}$ & $1,05 \times 10^{4} \pm 3,06 \times 10^{3}$ \\
\hline
\end{tabular}

${ }^{*} \mathrm{ND}$ : no fueron detectadas mediante el análisis por veratox ${ }^{\circledR}$.

En la figura 6.2.19 se pueden observar las curvas de los recuentos microbianos en el alimento para pollos. Se observa que disminuye el recuento de los microorganismos del kefir y aumenta el correspondiente a los hongos filamentosos. En el alimento adicionado con PSFG, entre los días 1 y 30 de almacenamiento disminuyeron en 1 y 2 logaritmos los recuentos de levaduras y BAL respectivamente. De otro lado, durante los 30 días a $20^{\circ} \mathrm{C}$, los hongos filamentosos del mismo alimento incrementaron un logaritmo. Las curvas de recuento fúngico del alimento natural (no adicionado ni secado) y del alimento adicionado de agua destilada y secado, indican un mayor incremento, en 1 logaritmo. De lo anterior se puede afirmar que dado que durante los 30 días subsisten los microorganismos del kefir, éstos ejercen un efecto protector adicional al de los ácidos orgánicos que aporta el PSFG, ralentizando el crecimiento fúngico. 


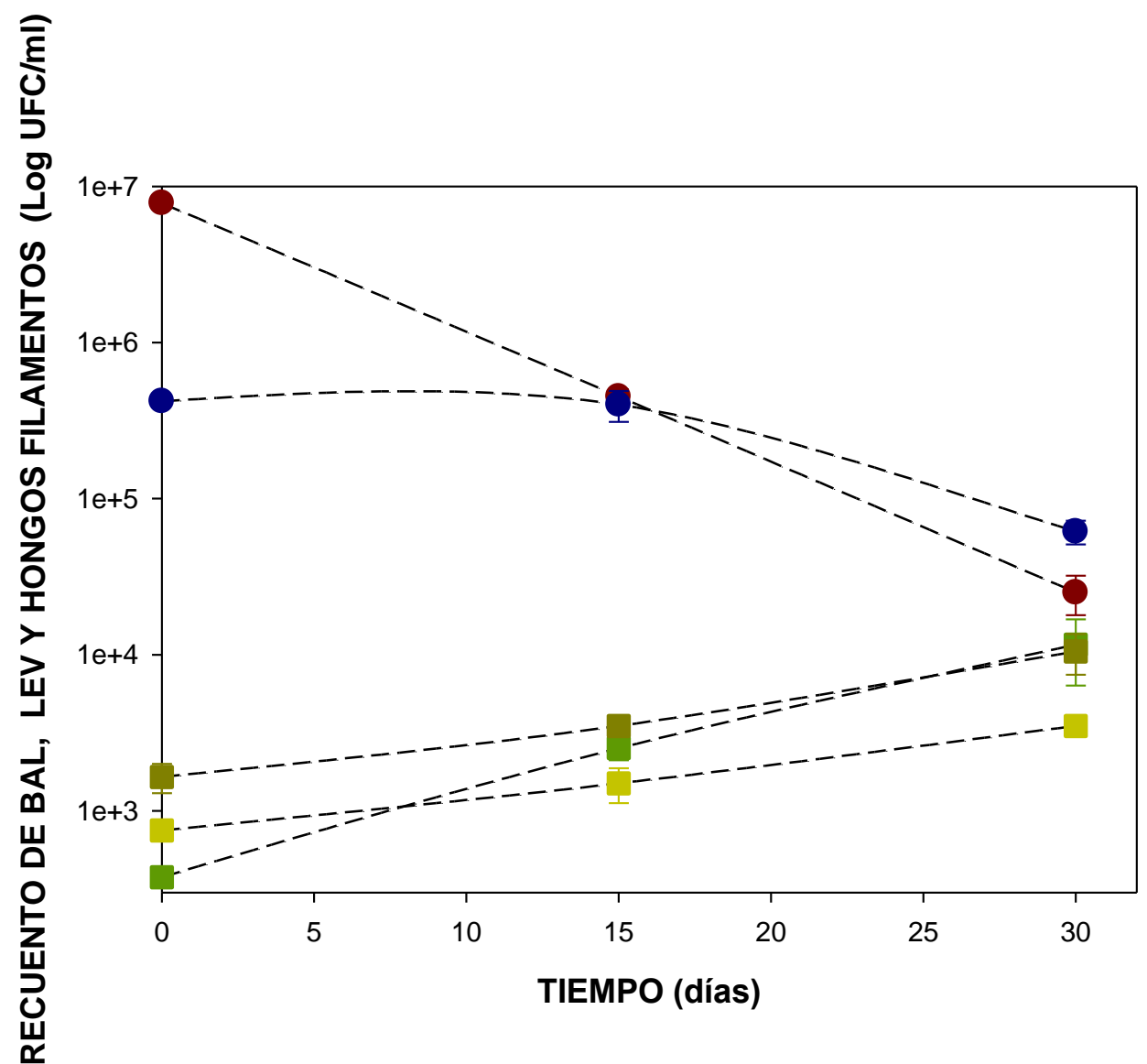

Figura 6.2.19. Evolución de los microorganismos del kefir y de los hongos filamentosos naturales del alimento para pollos adicionado con PSFG (1:1) durante 30 días de almacenamiento a $20^{\circ} \mathrm{C}$. BAL de alimento adicionado con PSFG (Log UFC/g). • LEV de alimento adicionado con PSFG (LogUFC/ml), Hongos filamentosos de alimento adicionado con PSFG(LogUFC/ml), Hongos filamentosos de alimento adicionado con agua destilada(LogUFC/ml), Hongos filamentosos de alimento natural (LogUFC/ml).

\subsection{Estudio de la resistencia del alimento adicionado con Permeado} de Suero Fermentado con Gránulos (PSFG) a la contaminación artificial con hongos filamentosos.

El alimento para pollos fue adicionado con PSFG, PS adicionado de ácidos orgánicos en la misma concentración en que están en el PSFG y con $\mathrm{HCl} 3 \mathrm{M}$ hasta $\mathrm{pH}$ de 3,7 . El alimento se secó y los hongos se pulverizaron según se indicó en la metodología. Una vez realizada la contaminación artificial del alimento con conidios, el alimento se almacenó en bolsas de polietileno a $20^{\circ} \mathrm{C}$, se observó diariamente y se contaron los días necesarios para que se hicieran 
visibles los hongos contaminantes. Se analizaron los mismos hongos evaluados en el \%RG y los resultados se exponen en la tabla 6.2.12.

El menor tiempo necesario para determinar presencia visible de hongos tuvo lugar en los controles, donde el mínimo lo tuvo $A$. terreus CMUNLP1 en 9 días y el máximo $A$. parasiticus NRRL 2999 en 14 días. Los alimentos que fueron adicionados con PSFG presentaron una gran capacidad de resistir a la contaminación por hongos filamentosos.

El tiempo de almacenamiento sin presencia visible de los hongos duplicó o triplicó el requerido por el control, prolongándose más de 30 días para todos los hongos evaluados. Los alimentos que fueron adicionados con PS acidificado con ácidos orgánicos puros tardaron por lo general en mostrar presencia visible del hongo adicionado, una cantidad de días inferior al tiempo requerido por los adicionados con PSFG y superior al tiempo requerido por el control. Así, los alimentos contaminados artificialmente con A. parasiticus NRRL 2999 y $R h$. macrosporus var. rhizopodiformis CMUNLP6 tardaron los mismos días que el control; $A$. flavus AFUBA5 y $A$. terreus CMUNLP1 tardaron 1 día más; $A$. fumigatus CMUNLP2 y $T$. longibrachiatum CMUNLP5, 2 días más; $P$. sumatrense CMUNLP3, 3 días más y F. graminearum FG44, 5 días más. En los alimentos adicionados con PS acidificado con $\mathrm{HCl} 3 \mathrm{M}$ hasta $\mathrm{pH} 3,7$, más de la mitad de los hongos evaluados (A. flavus AFUNL5, A. parasiticus NRRL2999, $F$. graminearum FG44, Rhizopus macrosporus var. rhizopodiformis CMUNLP6, A. fumigatus CMUNLP2 y $T$. longibrachiatum CMUNLP5) se observaron a simple vista al mismo tiempo que tuvo lugar en el control. $P$. sumatrense CMUNLP3 y $A$. terreus CMUNLP1 tardaron aproximadamente 1 y 2 días mas que el control en hacerse visibles.

En un estudio previo, se comparó la capacidad antifúngica del pan elaborado con un iniciador para fabricar panes, compuesto de cuatro cepas de lactobacilos más levadura comercial, con la de un pan sólo fabricado con levadura comercial. Se contaminaron los panes con $A$. niger $\mathrm{CH} 101$ de la misma manera descripta para el alimento de pollo y las arepas y se comparó la vida útil de los panes. Al igual que en el alimento de pollo, los panes con lactobacilos presentaron la mayor 
concentración de ácidos y una vida útil de 5 días a diferencia del pan hecho sólo con levadura cuya vida útil fue sólo de 48 horas, demostrándose el efecto antifúngico de los ácidos en el alimento (Gerez, Torino, Rollán \& Font de Valdéz, 2009).

Tabla 6.2.12. Vida útil del alimento para pollos adicionado con permeado de suero fermentado con gránulos (PSFG), adicionado de ácidos orgánicos $(\mathrm{AO})$ y acidificado con ácidos fuertes $(\mathrm{HCl}$ $3 \mathrm{M})$, contaminado con hongos filamentosos.

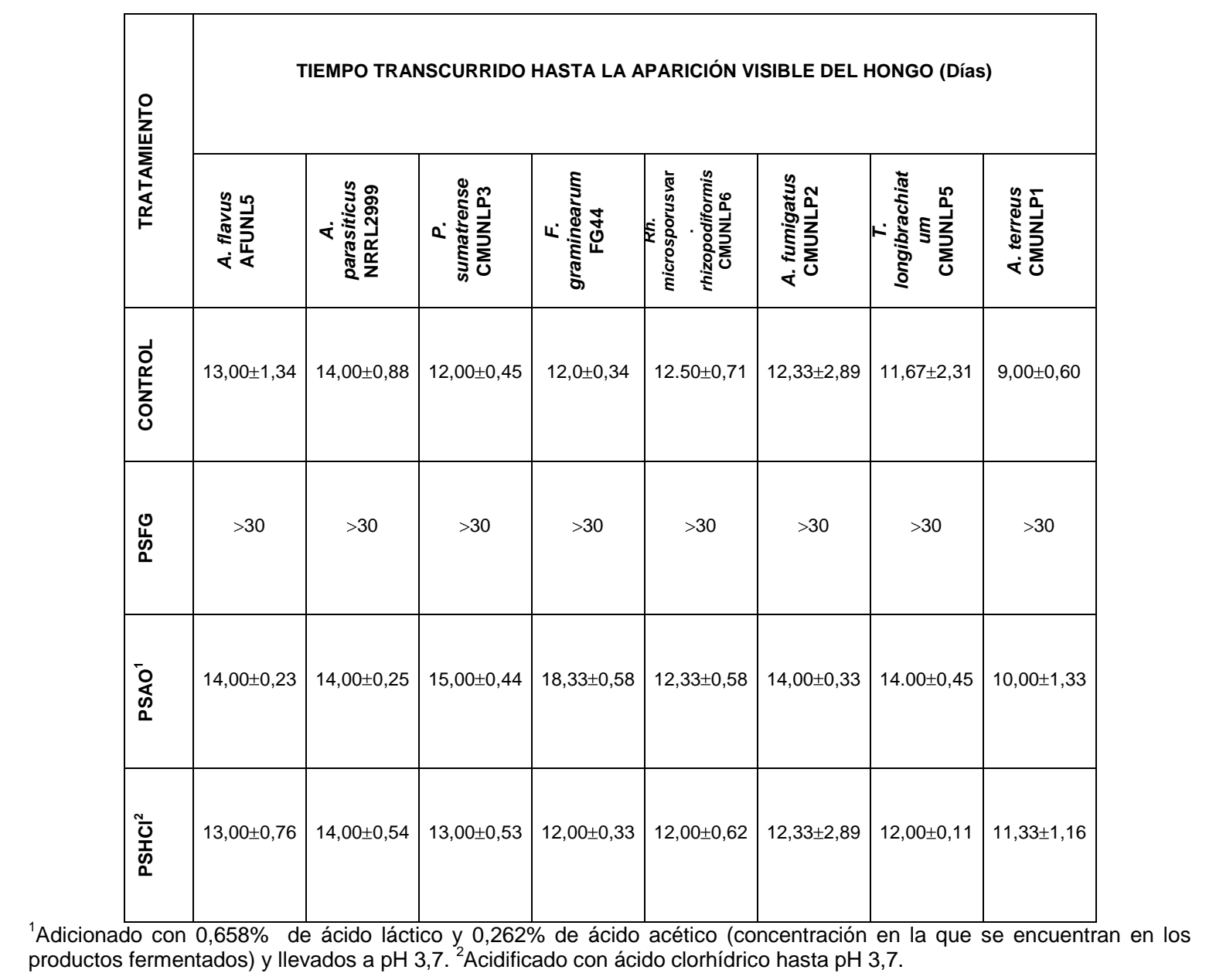

La figura 6.2.20 permite observar gráficamente el estado de crecimiento de uno de los hongos evaluados, A. parasiticus NRRL 2999, a los 30 días de la contaminación del alimento, en el control y en los tratamientos con PSFG. Puede observarse el nivel de deterioro de los primeros contrastado con el estado del 
alimento protegido con el producto fermentado, donde aún no se observa desarrollo micelial.

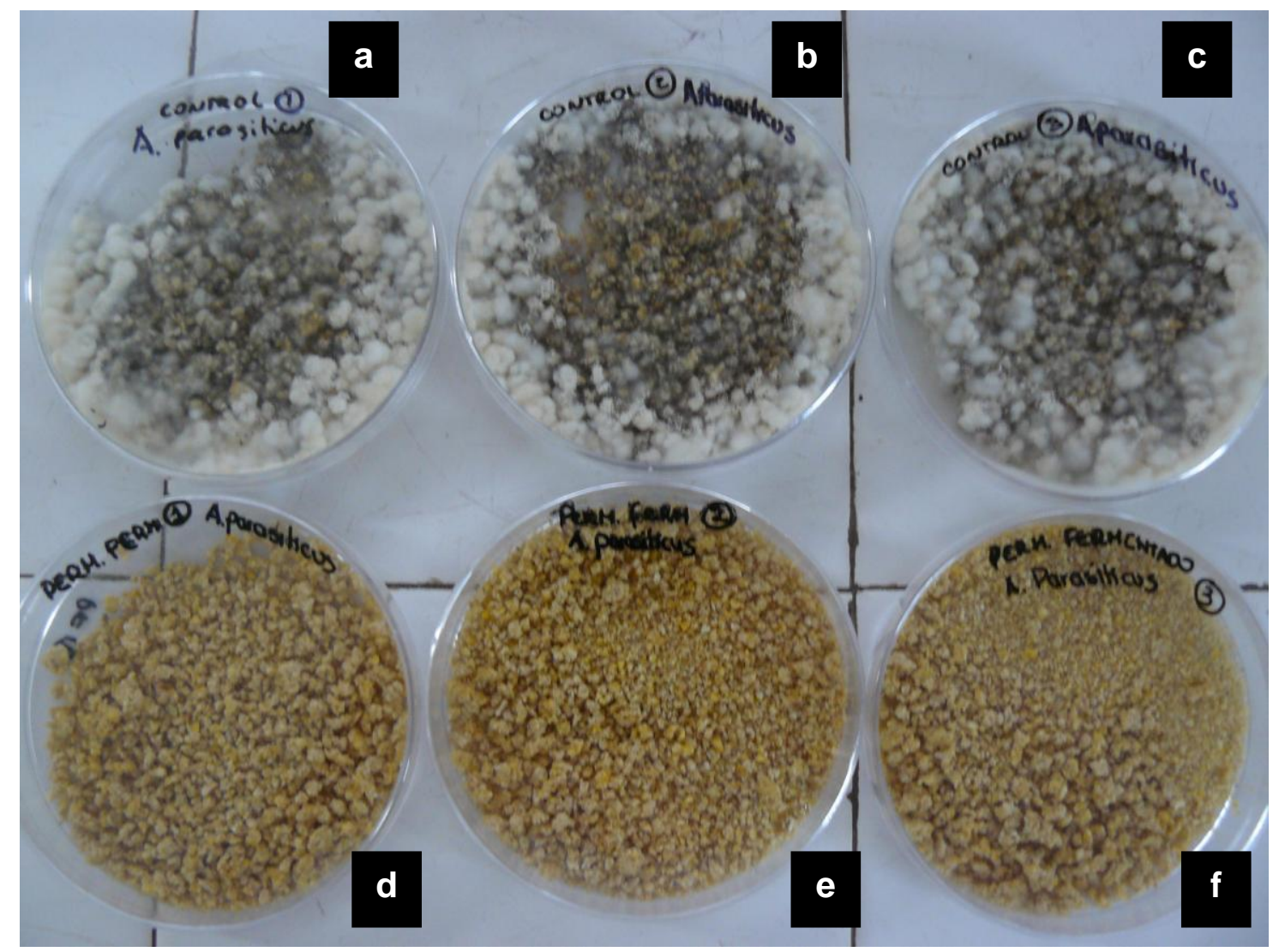

Figura 6.2.20. Estado de desarrollo del alimento para pollos, contaminado con A. parasiticus NRRL 2999 a los 30 días de almacenamiento. a., b. y c.: alimento control. d., e. y f.: alimento adicionado de PSFG.

\subsubsection{Conclusiones}

El PS estéril puede ser fermentado con gránulos de kefir CIDCA AGK1 y por microorganismos del kefir como L. plantarum CIDCA 83114, L. plantarum CIDCA 8325, L. plantarum CIDCA 8318, L. plantarum CIDCA 8316 y K. marxianus CIDCA 8154 acidificándose desde pH de 5,0 en el producto estéril hasta valores de $\mathrm{pH}$ ácidos de 3,6.

La composición del PSFG es diferente a la correspondiente al PS fermentado con los microorganismos del kefir. Tiene lugar una mayor disminución de la concentración de lactosa y de ${ }^{\circ}$ Brix en el producto fermentado con $K$. marxianus 
6.2 Efecto Antifúngico del permeado de suero fermentado con gránulos de kefir y con microorganismos aislados del kefir

CIDCA 8154, seguida del producto fermentado con gránulo de Kefir y por el PS fermentado con los lactobacilos. El porcentaje de nitrógeno total no varió significativamente entre el producto estéril y los productos fermentados, siendo muy bajo en todos los casos.

El pienso adicionado con PSFG contiene microorganismos probióticos cuando se adiciona en proporción $1: 1$ y se seca a $50{ }^{\circ} \mathrm{C}$, aún luego de 30 días de almacenamiento a $20^{\circ} \mathrm{C}$.

EI PSFG y acidificado con AO causó reducción alta de la germinación de los conidios (70\%); mientras que los sustratos acidificados con $\mathrm{HCl}$ fueron moderadamente inhibitorios (PSHCl: 40-70\%). El alto \%RG causado por los productos fermentados se debe a la combinación AO-pH mientras que la acidificación con $\mathrm{HCl}$ causa menor efecto antifúngico.

El pienso contaminado artificialmente con hongos filamentosos fue más resistente a la aparición visible de éstos cuando se adicionó con PSFG que cuando no fue adicionado de éste o cuando se adicionó con PS acidificado con ácidos orgánicos puros o cuando fue adicionado con PS acidificado con $\mathrm{HCl} 3 \mathrm{M}$. 


$$
\begin{gathered}
\text { CAPÍTULO 7: } \\
\text { ESTUDIO DE LA } \\
\text { CAPACIDAD DE } \\
\text { DECONTAMINACIÓN DE } \\
\text { AFLATOXINA AFB1 } \\
\text { POR } \\
\text { MICROORGANISMOS } \\
\text { DEL KEFIR }
\end{gathered}
$$




\section{ESTUDIO DE LA CAPACIDAD DE DECONTAMINACIÓN DE AFLATOXINA AFB1 POR MICROORGANISMOS DEL KEFIR}

\subsection{Introducción}

Las micotoxinas son metabolitos secundarios producidos por varios géneros y especies de hongos filamentosos, que se producen cuando hay deficiencia de nutrientes esenciales o cuando el crecimiento del hongo termina y comienza el metabolismo secundario produciendo antibióticos y micotoxinas (Díaz, 1996). Éstas constituyen un grupo de compuestos de bajo peso molecular (generalmente 300 a $400 \mathrm{Da}$ ) producidas principalmente por cepas de hongos de los géneros Aspergillus (aflatoxinas), Fusarium (Zearalenona, DON, fumonisinas), Penicillium (ocratoxina, patulina, etc.), Claviceps y Alternaria (Steyn \& Stander, 1999). La exposición humana a micotoxinas por consumo de alimentos contaminados es un asunto de salud pública mundial dado que las aflatoxinas son consideradas contaminantes inevitables de los alimentos (FAO, 1993). La contaminación fúngica de los alimentos puede ocurrir en el campo antes 0 después de la cosecha o durante el transporte y almacenamiento del producto (Díaz, 1996).

Antes de la cosecha, el riesgo para el desarrollo de aflatoxinas es más grande durante los períodos de sequía, dado que cuando la humedad está debajo del valor normal y la temperatura es alta, el número de esporas de Aspergillus spp. en el aire aumenta y éstas infectan las cosechas a través los insectos y se favorece la producción de aflatoxinas (Christensen, 1987). Durante la fase de post-cosecha, la proliferación de hongos y producción de aflatoxinas puede exacerbarse en sitios de almacenamiento calientes y húmedos (Díaz, 2006).

Con frecuencia, el maíz es atacado por hongos filamentosos, principalmente Fusarium spp., Aspergillus spp. y Penicilium spp., los cuales liberan micotoxinas. Entre ellas, las producidas por A. flavus (AFB1 y AFB2), son teratogénicas, inmudepresoras y mutagéncas, siendo AFB1 reconocida como cancerígena en humanos (IARC, 1993). La exposición crónica a las aflatoxinas es más común 
que la exposición aguda pero es más difícil de identificar. Los animales y el hombre están expuestos al consumo de cierta cantidad de toxina durante toda su vida o por largos períodos de tiempo (Santos, 1999). La exposición crónica a aflatoxinas induce la producción de células cancerígenas, convirtiéndolo en un problema de salud pública, cuando se asegura que del 20 al $50 \%$ de todos los cánceres están relacionados con factores de la dieta (Montesano, 1997; Groopman, Jiaqui \& Donahue, 1992). La aflatoxina AFB1 y el virus de la hepatitis $\mathrm{B}$, son considerados como los factores de riesgo de cáncer hepatocelular en China y África del Norte, estimándose en 250.000 muertes anuales (Eaton \& Groopman, 1994).

En Colombia no se dispone de mucha información sobre la presencia de aflatoxinas; sin embargo, los estudios disponibles han probado que el problema existe. En algunas investigaciones realizadas en el Departamento de Antioquia, Colombia, se encontró que de 50 muestras de maíz, 26 de los especímenes estaban contaminados con $A$. flavus toxigénico y que en la arepa antioqueña preparada con el maíz, también había presencia de micotoxinas (Shigematsu, Osorio \& Restrepo, 1976; Martínez \& Alvarez, 2006). El Laboratorio de Toxicología de la Universidad Nacional de Colombia ha determinado altos niveles de aflatoxinas en alimentos de consumo humano y animal (fabricados con maíz, sorgo, harina de arroz, torta de algodón, fríjol de soya, entre otros). Para cumplir la legislación sobre concentración mínima de aflatoxinas, las industrias de alimentos animales deben controlar los niveles de aflatoxinas en las materias primas, rechazando aquellas contaminadas. Cuando esto sucede, los comercializadores venden el maíz en las plazas de mercado donde pueden evitar los controles y éste es adquirido por las industrias de alimentos para consumo humano, en especial las fábricas de arepas de maíz. La entidad que controla la incidencia de la toxina en alimentos y animales oficialmente es el ICA (Instituto Colombiano Agropecuario), pero no es responsable de los reportes estadísticos de la incidencia o prevalencia de AFB1 en humanos. La entidad encargada de este seguimiento es el Ministerio de Salud, el cual a la fecha tampoco tiene un registro detallado de casos de aflatoxicosis. 
El uso de métodos físicos y químicos para la detoxificación de alimentos contaminados con micotoxinas es limitado debido a problemas de seguridad, posible pérdida del valor nutricional de los alimentos tratados, eficacia limitada y costos altos (Kabak, Dobson \& Var, 2006), lo cual ha llevado a buscar otras alternativas, como el uso de métodos biológicos para la decontaminación.

Algunos organismos estudiados han sido las bacterias y levaduras que han demostrado capacidad de capturar micotoxinas. Existe una gran variedad de bacterias y hongos con capacidad de degradar o remover distintas micotoxinas de una solución, pero no todas han pasado las pruebas in vivo (Kabak \& Dobson, 2009).

Diferentes bacterias lácticas demostraron ser eficientes en la remoción de aflatoxina $\mathrm{B}_{1}\left(\mathrm{AFB}_{1}\right)$ y Zearalenona (ZEA) de distintos medios líquidos, actuando como secuestrantes biológicos (El-Nezami, Kankaanpää, Salminen \& Ahokas, 1998; El-Nezami, Polychronaki, Salminen \& Mykkanen, 2002).

Las primeras publicaciones sobre captura de micotoxinas demostraron que las bacterias ácido lácticas y otras bacterias intestinales eran capaces de secuestrar contaminantes de la dieta como las aflatoxinas (El-Nezami, Salminen \& Ahokas, 1996; El-Nezami, Kankaanpää, Salminen \& Ahokas, 1998a; Thyagaraja.\& Hosono, 1994). Para $\mathrm{AFB}_{1}$ se conoce que este proceso responde a una adsorción de tipo física (pared celular bacteriana- $\mathrm{AFB}_{1}$ ) en un proceso rápido (menos de 1 minuto), siendo la unión reversible tanto en bacterias vivas como muertas y dependiente de la cantidad de toxina y de la concentración bacteriana (Bueno, Casale, Pizzolitto, Salvano \& Oliver, 2007).

En experimentos realizados en intestino de pollos alimentados con una mezcla probiótica compuesta por Lactobacillus rhamnosus LC-705-Propionibacterium freudenreichii subsp. Shermanii JS (Bioprofit ${ }^{\circledR}$ ) y $\mathrm{AFB}_{1}$, se observó que sólo el $25 \%$ de la toxina fue capturada por las bacterias, pero que sin embargo, también se redujo la absorción a nivel intestinal de la aflatoxina. También se estableció 
que el mucus intestinal disminuía la unión de $\mathrm{AFB}_{1}$ a las bacterias (Gratz, Mykkänen \& El-Nezami, 2005) y que Lactobacillus rhamnosus GG disminuía la absorción de $\mathrm{AFB}_{1}$ al tejido intestinal de pollo, favoreciendo la eliminación efectiva de las aflatoxinas en la heces (El-Nezami, Mykkänen, Kankaanpää, Salminen, \& Ahokas, 2000). Para el caso de ZEA, DON y fumonisinas $B_{1}$ y $B_{2}$ $\left(\mathrm{FB}_{1}, \mathrm{FB}_{2}\right.$ ), se determinó la unión de la toxina in vitro con cepas de Lactobacillus, Pediococcus, Streptococcus, Lactococcus, Leuconostoc y propionibacterias (ElNezami, Polychronaki, Salminen \& Mykkanen, 2002; Niderkon, Boudra \& Morgavi, 2006; Niderkorn, Morgavi, Pujos, Tissandier \& Boudra, 2007). Se encontró que algunos lactobacilos y Leuconostoc transformaban ZEA a $\alpha$ zearalenol, un compuesto menos tóxico (Niderkorn, Morgavi, Pujos, Tissandier \& Boudra, 2007).

En diferentes levaduras se demostró también la capacidad secuestrante dependiente de su pared celular. Un glucomanano esterificado de Sacharomyces cerevisiae se ha empleado en productos comerciales para alimentación aviar, como adsorbente de $A F B_{1}$, Ocratoxina (OTA) y toxina T-2 (Raju \& Devegowda, 2000). No obstante, este producto no presentó capacidad de secuestrar deoxinivalenol (DON) (Dänicke, Goyarts \& Valenta, 2007). Se encontró que otro componente de la pared celular de $S$. cerevisiae, el $\beta$-D glucano, captura zearalenona (ZEA) (Yiannikouris, Francois, Poughon, Dussap, Bertin, Jeminet, \& Jounay, 2004). S. cerevisiae CECT 1891 demostró su capacidad de capturar AFB1 (Bueno, Casale, Pizzolitto, Salvano \& Oliver, 2007; Pizzolitto, Bueno, Armando, Cavaglieri, Dalcero \& Salvano, 2011) y fumonisina B1 (Pizzolitto, Salvano \& Dalcero, 2012). También se estudió la mezcla de una bacteria y una levadura que dieron lugar a un suplemento microbiano patentado (Biomin MTV ${ }^{\circledR}$ ), capaz de detoxificar todo tipo de tricotecenos, ZEA y OTA (Schatzmayr, 2004).

La captura de aflatoxinas está influenciada por el estado fisiológico de la célula bacteriana y por su viabilidad, habiéndose demostrado que las bifidobacterias muertas por calor capturaban aflatoxina AFB1 de forma cepa dependiente (Oatley, Rarick, Ji \& Linz, 2000). Algunas investigaciones han demostrado que la 
remoción de aflatoxinas envuelve el secuestro probable a nivel de la pared celular o de sus componentes (El-Nezami, Kankaanpää, Salminem \& Ahokas, 1998b; Haskard, El-Nezami, Kankaanpää, Salminen \& Ahokas, 2001) y que la eliminación de algunos componentes específicos de la pared celular como carbohidratos y proteínas producían un descenso en la captura de AFB1 como se determinó para Lb. rhamnosus GG (Haskard, Binnion \& Ahokas, 2000).

Puede observarse de lo anterior que la capacidad de secuestrar AFB1 por parte de los microorganismos potencialmente probióticos es un tema de interés y de franco desarrollo y experimentación. La capacidad de secuestro de los microorganismos aislados del kefir y los factores que modifican el secuestro de AFB1 es un tema poco explorado y requiere ser estudiado en profundad para comprender mejor los mecanismos derivados de esa interacción. Si bien se ha estudiado la capacidad de secuestro de aflatoxinas por diferentes tipos de microorganismos y en diferentes condiciones, en esta tesis se planteó como objetivo ver si el conjunto de microorganismos presentes en el kefir presentaba esta propiedad y en el caso de encontrarla, dilucidar cuáles o que grupos de los microorganismos constituyentes eran mas eficientes en la capacidad de secuestro y cómo variaba su capacidad de acuerdo a diferentes condiciones de desafío con la micotoxina.

\subsection{Objetivos.}

\subsubsection{Objetivo general.}

7.2.1.1 Estudiar la capacidad secuestrante in vitro de aflatoxina AFB1 por diferentes microorganismos aislados del gránulo de kefir y los microorganismos totales del gránulo de kefir CIDCA AGK1.

\subsubsection{Objetivos específicos.}

7.2.2.1 Establecer la capacidad de los microorganismos del kefir para secuestrar aflatoxina AFB1 cuando son cultivados en medios de cultivo diferentes. 
7.2.2.2 Determinar si la hidrofobicidad superficial de los microorganismos influye en su capacidad para secuestrar aflatoxina AFB1.

7.2.2.3 Establecer la cinética de secuestro de aflatoxina AFB1 durante un período de incubación de 48 horas y la capacidad de retención de la aflatoxina AFB1 por parte de los microorganismos una vez producido el secuestro.

7.2.24 Analizar la capacidad de secuestro de aflatoxina AFB1 por los microorganismos en diferentes condiciones de $\mathrm{pH}$, concentración de microorganismos y viabilidad.

\subsection{Materiales y Métodos.}

\subsubsection{Microorganismos empleados.}

Se evaluó la capacidad secuestrante de aflatoxina AFB1 de Bacterias Ácido Lácticas (BAL) y Levaduras (LEV) aisladas de gránulos de kefir, por microorganismos totales del gránulo AGK1 y por microorganismos aislados de productos fermentados y de colección. En la Tabla 7.1 se presentan los microorganismos empleados en este capítulo.

Tabla 7.1 Microorganismos evaluados en la capacidad de secuestrar aflatoxina AFB.

\begin{tabular}{|c|c|}
\hline CEPA & ESPECIE \\
\hline CIDCA 83114 & Lactobacillus plantarum \\
\hline CIDCA 8316 & L. plantarum \\
\hline CIDCA 8318 & L. plantarum \\
\hline CIDCA 8327 & L. plantarum \\
\hline CIDCA 8348 & Lactobacillus kefir \\
\hline CIDCA 8325 & L. kefir \\
\hline CIDCA 83111 & L. kefir \\
\hline JCM $5818^{*}$ & Lefir \\
\hline CIDCA 8112 & Saccharomyces lipolytica \\
\hline CIDCA 81103 & S. cerevisiae \\
\hline CIDCA 8116 & S. cerevisiae \\
\hline CINDEF* & S. boularddii \\
\hline CIDCA 8154 $^{*}$ Kluyveromyces marxianus \\
\hline CINDEFI* & K. lactis \\
\hline
\end{tabular}

*Microorganismos de colección. Todos los microorganismos CIDCA fueron aisladas por la Dra. Graciela Garrote a partir de gránulos de kefir (Garrote, 1999). Las levaduras CINDEFI fueron cedidas de la colección del CINDEFI. 


\subsubsection{Medios de cultivo y de diluciones.}

\subsubsection{Cultivo de microorganismos.}

Los lactobacilos y levaduras se conservaron y se reactivaron tal como se describió en Materiales y métodos generales.

\subsubsection{Soluciones y medios de cultivo para recuento de microorganismos.} Los recuentos de las BAL se hicieron en agar MRS (Difco ${ }^{\circledR}$, Beauvais, Francia) y los de levaduras en agar YGC (Biokar Diagnostics ${ }^{\circledR}$, Beauvais, France). Las diluciones y los recuentos se hicieron tal como se describió en materiales y métodos generales

\subsubsection{Preparación de la solución de aflatoxina AFB1.}

\subsubsection{Preparación de la solución madre y la solución de trabajo de} aflatoxina.

Para preparar la solución madre se utilizó aflatoxina AFB1 $\left(\mathrm{SIGMA}^{\circledR}\right)$ en estado sólido. Se disolvieron $10 \mathrm{mg}$ en $5 \mathrm{ml}$ de metanol (J.T.BAKER®, Mallinckrodt, Alemania), alcanzando una concentración final aproximada de (2000 ppm) y se tomaron $500 \mu \mathrm{lllevando}$ hasta $100 \mathrm{ml}$, para alcanzar una concentración final de $1 / 100 \mathrm{ml}(10 \mathrm{ppm})$. Para determinar el coeficiente de absortividad, se preparó una solución de $\mathrm{H}_{2} \mathrm{SO}_{4}$ (Merck ${ }^{\circledR}$, Darmstadt, Alemania) 0,018 $\mathrm{N}$ y tres soluciones de $\mathrm{K}_{2} \mathrm{Cr}_{2} \mathrm{O}_{7}$ (J.T.BAKER ${ }^{\circledR}$, Mallinckrodt, Alemania) en concentraciones 0,25; 0,125 y $0,0625 \mathrm{mM}$. Para ello el $\mathrm{K}_{2} \mathrm{Cr}_{2} \mathrm{O}_{7}$ se secó en estufa a $100 \stackrel{\circ}{\mathrm{C}}$ durante 20 horas y el pesado se realizó en balanza analítica con sensibilidad de 0,001 mg. Se determinó la absorbancia (A) de las tres soluciones de $\mathrm{K}_{2} \mathrm{Cr}_{2} \mathrm{O}_{7}$ a $350 \mathrm{~nm}$, contra un blanco de $\mathrm{H}_{2} \mathrm{SO}_{4} 0,018 \mathrm{~N}$, en un espectrofotómetro con celda de cuarzo. Para cada concentración se calculó la absortividad $\varepsilon=(A \times 1000 / \mathrm{mM})$ y se promediaron los tres valores para obtener la $\varepsilon$ media. Se calculó también el factor de corrección (CF) para el instrumento y las celdas mediante la ecuación siguiente. 
Donde 3160 es el factor de corrección para las soluciones de $\mathrm{K}_{2} \mathrm{Cr}_{2} \mathrm{O}_{7}$. El valor promedio de $\varepsilon$ fue 3040,5 y el CF 1,04, quedando dentro del rango de aceptación mayor a 0,95 y menor a 1,05, según se muestra en la tabla 7.2.

Tabla 7.2 Absorbancia y $\varepsilon$ obtenidos para las tres concentraciones de $\mathrm{K}_{2} \mathrm{Cr}_{2} \mathrm{O}_{7}$

\begin{tabular}{|c|c|c|}
\hline$\left[\mathbf{K}_{\mathbf{2}} \mathbf{C r}_{2} \mathbf{O}_{\mathbf{7}}\right]$ & $\boldsymbol{A}$ & $\boldsymbol{\varepsilon}$ \\
\hline 0,25 & 0,7856 & 3142 \\
\hline 0,125 & 0,3764 & 3011,2 \\
\hline 0,625 & 0,1855 & 2968 \\
\hline \multicolumn{3}{|c|}{ PROMEDIO } \\
$\varepsilon=3040,5, \mathbf{C F}=\mathbf{1 , 0 4}$ \\
\hline
\end{tabular}

\subsubsection{Determinación de la concentración de aflatoxinas.}

Se determinó la absorbancia $(A)$ de la solución de aflatoxina 10 ppm a 360 nm y se calculó la concentración real de la solución mediante la fórmula:

$\varepsilon=(A \times M W \times 1000) / \mu g$ aflatoxina $/ \mathrm{ml}$.

Ecuación 7.2

Donde MW es el peso molecular de la aflatoxina AFB1 (312) (AOAC,1984).

$\left[A F B_{1}\right]=(0,5065 \times 312 \times 1000) / 21800=7,25 \mu \mathrm{g} / \mathrm{ml}: 7,25 \mathrm{ppm}$.

Multiplicado por el FC dio una concentración de 7,54 ppm o 7540 ppb.

La concentración real de aflatoxina AFB1 fue corroborada mediante lectura en HPLC utilizando un patrón de aflatoxina AFB1 (BIOPURE ${ }^{\circledR}$ ).

A partir de la solución madre, se prepararon la solución de trabajo de $5 \mathrm{ppm}, 1$ ppm, 500 ppb 300 ppb, 150 ppb, 75 ppb y 20 ppb en PBS. Para ello se tomó el volumen necesario de aflatoxina en metanol, se adicionó al PBS y se evaporó en cabina el metanol hasta su eliminación total. Las concentraciones finales fueron corroboradas mediante lectura en HPLC, lo cual se presenta en la tabla 7.3 y la figura 7.3. Las soluciones de trabajo se alicuotaron y se almacenaron a $-20^{\circ} \mathrm{C}$ hasta su utilización. 
Tabla 7.3 Concentraciones teóricas de AFB1 y área obtenida en la corrida de HPLC

\begin{tabular}{|c|c|}
\hline CONCENTRACION TEÓRICA (ppb) & AREA CORRIDA \\
\hline 5000,0000 & 457113,0000 \\
\hline 1000,0000 & 75035,0000 \\
\hline 500,0000 & 37647,0000 \\
\hline 100,0000 & 6383,0000 \\
\hline 50,0000 & 2707,0000 \\
\hline 25,0000 & 1880,0000 \\
\hline 10,0000 & 736,0000 \\
\hline 1,0000 & 0,0000 \\
\hline
\end{tabular}

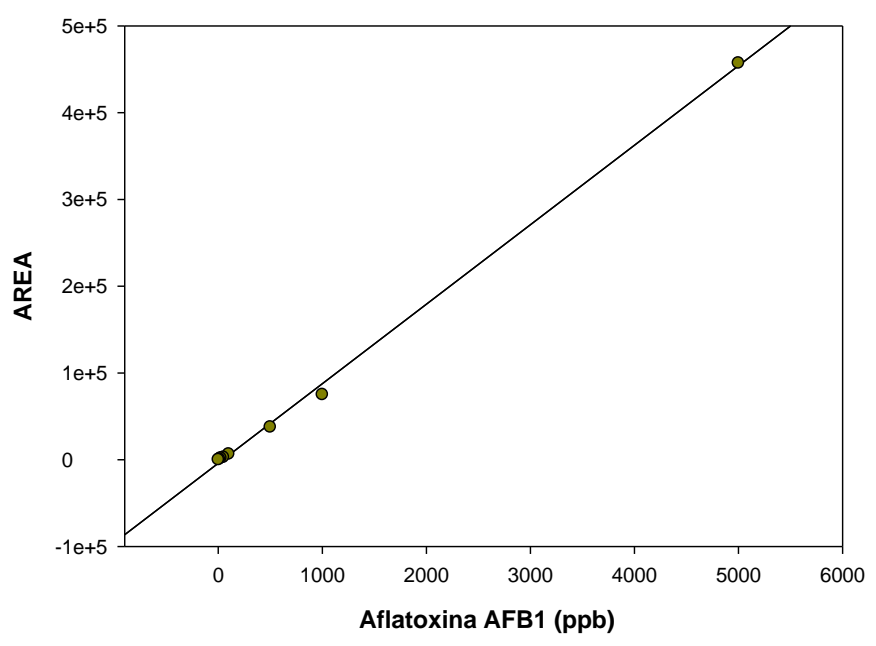

Figura 7.1. Regresión lineal de las áreas y concentraciones de aflatoxina AFB1

\subsubsection{Solución de aflatoxina AFB1 a diferentes pH.}

Se hizo en solución salina ( $\mathrm{NaCl}$ 0,85\%) adicionada de $\mathrm{HCl} 3 \mathrm{M}$ (Merck ${ }^{\circledR}$,

Darmstadt, Alemania) o $\mathrm{NaOH} 1 \mathrm{~N}\left(\right.$ Merck $^{\circledR}$, Darmstadt, Alemania) hasta alcanzar valores de $\mathrm{pH}$ de $2,1,5,1$ y 8,0 . 


\subsubsection{Preparación de los microorganismos para los experimentos de secuestro de aflatoxina AFB1.}

\subsubsection{Microorganismos Aislados del gránulo de kefir.}

Los microorganismos aislados (Tabla 7.1), fueron sometidos a dos pasajes de 24 horas a $30^{\circ} \mathrm{C}$ en caldo MRS a los efectos de ser reactivados. Una vez reactivados, los microorganismos se cultivaron en $30 \mathrm{ml}$ de caldo MRS o de permeado de suero (PS). Los microorganismos se cosecharon a las 24 horas de incubación y se centrifugaron a 3000 rpm por 5 minutos en centrífuga Rolco ${ }^{\circledR}$.

\subsubsection{Conjunto de microorganismos totales del gránulo de kefir.}

Se utilizaron gránulos de kefir CIDCA AGK1 congelados a $-20^{\circ} \mathrm{C}$, los cuales se reactivaron mediante dos pasajes consecutivos en leche. Estos gránulos se adaptaron al PS mediante pasajes sucesivos en PS durante 4 semanas. El permeado de suero fermentado con el gránulo CIDCA AGK1 (PSFG) se separó de los gránulos mediante colador de malla de $1 \mathrm{~mm}^{2}$ y se centrifugó a $3000 \mathrm{rpm}$ por 5 minutos en centrífuga Rolco $^{\circledR}$. Se consideró que el pellet de microorganismos obtenidos a partir del PSFG contenía los microorganismos representativos del gránulo de kefir CIDCA AGK1.

\subsubsection{Captura de aflatoxina AFB1 por microorganismos aislados del kefir y microorganismos totales del gránulo CIDCA AGK1.}

Tanto para los microorganismos aislados como para el conjunto de microorganismos provenientes del gránulo de kefir, se continuó con el siguiente procedimiento. Se hicieron dos lavados con PBS (Solución tampón de fosfato: $\mathrm{Na}_{2} \mathrm{HCO}_{3}, \mathrm{KH}_{2} \mathrm{PO}_{4}$ y $\mathrm{NaCl}$ ) a $\mathrm{pH} 7$ y una vez con agua bidestilada estéril. Los pellets se resuspendieron en $2 \mathrm{ml}$ de solución de aflatoxina ABF1. En paralelo se hizo un control sin aflatoxina resuspendiendo los pellets en PBS y un control de aflatoxina sin microorganismo. 
Para cada experimento, las concentraciones de microorganismos se corroboraron por recuento en MRS e YGC respectivamente en pellets resuspendidos en PBS, obteniéndose concentraciones de aproximadamente $1 \mathrm{x}$ $10^{9} \mathrm{UFC} / \mathrm{ml}$ de bacterias y $1 \times 10^{8} \mathrm{UFC} / \mathrm{ml}$ de levaduras para los microorganismos aislados. En el caso del conjunto de microorganismos del gránulo, las concentraciones fueron de $1 \times 10^{8} \mathrm{UFC} / \mathrm{ml}$ de bacterias y $1 \times 10^{7}$ UFC/ml de levaduras.

Los desafíos se hicieron co-incubando los microorganismos resuspendidos en 2 $\mathrm{ml}$ de solución de $150 \mathrm{ppb}$ de aflatoxina AFB1 a $30^{\circ} \mathrm{C}$ durante diferentes lapsos de tiempo, de acuerdo al experimento (variando entre 30 minutos y 48 horas) en un agitador orbital (Peltonen, El-Nezami, Haskard, Ahokas \& Salminen, 2001). Una vez terminado el desafío, se centrifugó toda la solución por 15 minutos a 13000 rpm en ultracentrífuga Eppendorf 5415D (Eppendorf ${ }^{\circledR}$, Alemania), separando el sobrenadante $(\mathrm{SN})$ del pellet $(\mathrm{P})$, los cuales se almacenaron a $20^{\circ} \mathrm{C}$.

La capacidad de secuestro de aflatoxina por los microorganismos, se determinó midiendo la cantidad de aflatoxina restante en el SN mediante cromatografía líquida de alta resolución (HPLC), determinándose el área del pico de aflatoxina AFB1 en el sobrenadante. Se utilizó como control solución de aflatoxina AFB1 en la concentración usada en el desafío disuelta en PBS. Por último, la capacidad de retención de aflatoxina por parte de los microorganismos, se determinó mediante lavados sucesivos del pellet microbiano con PBS. Los pasos seguidos para realizar los experimentos de captura se observan en la Figura 7.2. 


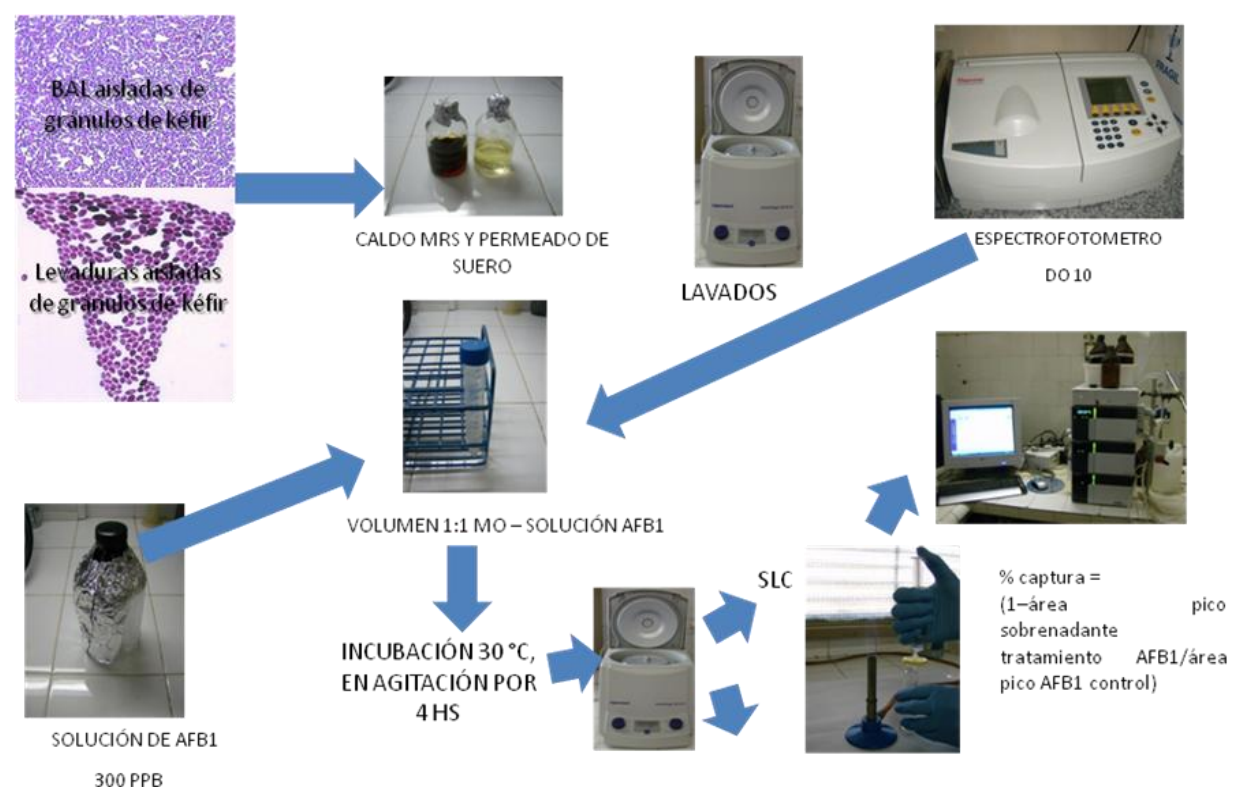

Figura 7.2. Etapas de los experimentos de captura de aflatoxina AFB1.

\subsubsection{Recuento de los microorganismos empleados en los estudios de captura de aflatoxina AFB1.}

Previo al ensayo de captura se hizo el recuento de los microorganismos empleados. Se hizo el homogenizado diluyendo $1 \mathrm{ml}$ de la solución de microorganismos en $9 \mathrm{ml}$ de agua de peptona y se hicieron diluciones seriadas $1 / 10$, hasta la dilución $1 \times 10^{-7}$ para lactobacilos y $1 \times 10^{-6}$ para levaduras. Se sembraron $100 \mu \mathrm{l}$ de las últimas tres diluciones en superficie de agar MRS (Difco ${ }^{\circledR}$, Beauvais, Francia) e YGC (Biokar Diagnostics ${ }^{\circledR}$, Beauvais, Francia) para las BAL y LEV respectivamente, dispersando el inóculo con perlas de vidrio estériles. Las placas se incubaron a $30^{\circ} \mathrm{C}$ por 48 horas las BAL y 5 días las levaduras. En los experimentos donde el desafío microorganismo - aflatoxina se hicieron a diferentes valores de $\mathrm{pH}$, se hizo recuento de los microorganismos antes y después del desafío a fin de determinar si morían por las condiciones del medio y poder relacionarlo con la captura de aflatoxina AFB1. 


\subsubsection{Determinación de la concentración de aflatoxina AFB1 en el sobrenadante (SN) del desafío, mediante HPLC.}

La concentración de aflatoxina presente en el sobrenadante luego del desafío se evaluó inyectando $20 \mu \mathrm{l}$ del SN en un HPLC (JENCK S.A Instrumental, CBM20A, SPD-M20A, LC20AT,DGUD60-20As) con detector de arreglo de diodos y Columna C-18, rango constante de escaneo $190-800 \mathrm{~nm}$ y longitud de onda del análisis de $360 \mathrm{~nm}$. El flujo de corrida fue de $1 \mathrm{ml} / \mathrm{min}$ y la mezcla de solventes de corrida fue agua: acetonitrilo: metanol (60:30:10). AFB1 tuvo un tiempo de retención de 8 minutos y la corrida total 15 minutos. Se estableció el límite de cuantificación del método en $25 \mathrm{ppb}$ y el límite de detección en 10 ppb. Se integró el área del pico de la aflatoxina remanente en el SN de cada tratamiento y en el SN del control de aflatoxina AFB1. El porcentaje de captura de aflatoxina AFB1 (\%CAFB1) en cada tratamiento se calculó mediante la siguiente fórmula.

$\% C A F B 1=\left[1-(\text { Área del pico del tratamiento/Área del pico del control AFB1) }]^{\star} 100\right.$

Ecuación 7.3

(Peltonen, El-Nezami, Haskard, Ahokas \& Salminen, 2001).

\subsubsection{Desafío de 48 horas con aflatoxina AFB1.}

\subsubsection{Coincubación con aflatoxina AFB1.}

Los microorganismos del gránulo CIDCA AGK1, L. plantarum 83114 y $K$. marxianus 8154 se desafiaron con 150 ppb de aflatoxina AFB1 en PBS. Se tomaron alícuotas del desafío a los 30 minutos, 4, 24 y 48 horas. Estas se centrifugaron y tanto los $\mathrm{SN}$ como los pellets se almacenaron a $-20^{\circ} \mathrm{C}$.

\subsubsection{Determinación de la estabilidad del complejo toxina-levadura.}

Para esto se lavó el pellet de microorganismos con aflatoxina adherida, obtenido en cada tiempo de la coincubación (30 minutos, 4, 24 y 48 horas) con el mismo volumen total del desafío ( $2 \mathrm{ml})$. Se agitó por 15 segundos y se incubó 10 
minutos a $30^{\circ} \mathrm{C}$ (Peltonen, El-Nezami, Haskard, Ahokas \& Salminen, 2001). Se centrifugó por 10 min a 13000 rpm y se recolectó el sobrenadante, congelándolo a $-20 \stackrel{\circ}{ } \mathrm{C}$ hasta su posterior lectura por HPLC. Se realizaron tres lavados en total.

7.3.9 Curva dosis - respuesta de secuestro de aflatoxina AFB1 con diferentes concentraciones de L. plantarum 83114, K. marxianus 8154 y de microorganismos totales del gránulo de kefir CIDCA AGK1.

Se analizaron cuatro concentraciones diferentes de microorganismo frente a una misma concentración de aflatoxina AFB1 (150 ppb). L. plantarum 83114, K. marxianus 8154 y el gránulo CIDCA AGK1 se cultivaron en PS 5\% estéril por 24 horas a $30^{\circ} \mathrm{C}$ y cada cultivo se preparó para el desafío como se describió en Materiales y métodos generales. A partir de la concentración máxima obtenida al final de los lavados y la resuspensión en PBS, se realizaron tres diluciones seriadas equivalentes a 1/10,1/100 y 1/1000, que se desafiaron con la concentración de 150 ppb de AFB1, concentración empleada hasta el momento como estándar de todas las pruebas.

\subsubsection{Desafío en presencia de microorganismos viables y no viables.}

Los cultivos de L.plantarum 83114 y de Kluyveromyces marxianus 8154 obtenidos en caldo MRS fueron introducidos en baño de agua a $75{ }^{\circ} \mathrm{C}$ durante 45 minutos, al cabo de los cuales fueron enfriados en baño de agua fría. Para comprobar la muerte de los microorganismos se sembraron estrías en agar MRS (Difco $^{\circledR}$, Francia), para lactobacilos e YGC (Biokar Diagnostics ${ }^{\circledR}$, Beauvais, Francia) para levaduras y se incubaron a $30^{\circ} \mathrm{C}$ con el fin de determinar su viabilidad. El procedimiento de lavado y concentración se realizó de la misma forma como se hace con microorganismos vivos y el desafío se realizó como se describió anteriormente. 


\subsubsection{Desafío a diferentes valores de pH.}

L.plantarum 83114, Kluyveromyces marxianus CIDCA 8154 y el gránulo de kefir CIDCA AGK1 se cultivaron en PS y se procesaron tal como se describió anteriormente. El desafío con aflatoxina AFB1 se realizó a tres valores de $\mathrm{pH}$, siendo 2,$1 ; 5,1$ y 8,0 de acuerdo a lo descripto previamente. Se hizo recuento de los microorganismos desafiados antes y después del desafío para determinar si hubo muerte microbiana durante el desafío debido al $\mathrm{pH}$.

\subsubsection{Determinación de la hidrofobicidad de los microorganismos.}

Se analizó la hidrofobicidad superficial de los lactobacilos y levaduras mediante el método de partición en n-hexadecano. Este método se basa en la tendencia de los microorganismos de mantenerse en la fase acuosa (hidrofilicidad) o migrar a la fase no polar (hidrofobicidad) de acuerdo a las características de su superficie (MATH assay, Microbial Adhesión to Hydrocarbons (Rosenberg, Gutnik \& Rosenberg, 1980). Los microorganismos se cultivaron en caldo MRS y en PS a $30^{\circ} \mathrm{C}$ por 24 horas. Se cosecharon por centrifugación a $3000 \mathrm{rpm}, 5$ minutos en centrífuga Rolco ${ }^{\circledR}$ (Argentina), se lavaron dos veces con PBS y se llevaron a densidad óptica 1 leída en espectrofotómetro Metrolab 330 (Metrolab $^{\circledR}$, Argentina). Se tomaron $2 \mathrm{ml}$ de la suspensión microbiana en PBS y se agregaron a $0,5 \mathrm{ml}$ de $\mathrm{n}$-hexadecano (J.T. Baker ${ }^{\circledR}$, Mallinckrofdt Inc.). Se midió la densidad óptica inicial (DOi) y se agitaron las mezclas en vortex durante 2 minutos. Las muestras permanecieron 2 minutos en reposo hasta la separación de las fases y se midió la densidad óptica de la fase acuosa (DOf) a $600 \mathrm{~nm}$, El porcentaje de hidrofobicidad se calculó mediante la siguiente ecuacción.

Hidrofobicidad $(\%)=\left[\left(D O_{i}-D O_{t}\right) / D O_{i}\right] \times 100 \quad$ Ecuación 7.4

Donde $\mathrm{DO}_{i}$ es la densidad óptica inicial de la suspensión microbiana en la fase acuosa y $\mathrm{DO}_{\mathrm{f}}$ es la densidad óptica de la fase acuosa después de la partición. 


\subsubsection{Análisis estadístico.}

Los resultados que presentados son el promedio de experimentos realizados por triplicado. Para determinar diferencias estadísticamente significativas entre los tratamientos se aplicó un ANOVA de una vía $(P=0,05)$. Cuando se encontró significancia en el ANOVA, la diferencia entre tratamientos se estableció a partir de las pruebas de diferencia de medias de Mínima diferencia significativa. Valores $P<0,05$ se consideraron significativos. 


\subsection{Resultados y Discusión.}

Se quiso determinar si el uso de la comunidad entera de microorganismos del gránulo puede generar una captura de la aflatoxina, lo cual nos permite esperar un uso potencial de la bebida obtenida con el gránulo entero como producto que captura la aflatoxina AFB1. Para ello se desarrolló el experimento que se describe a continuación.

\subsubsection{Determinación de la capacidad de captura de aflatoxina AFB1 por el conjunto de microorganismos del gránulo de Kefir CIDCA AGK1 cultivados en PS.}

EI PS fermentado con gránulos de kefir CIDCA AGK1 a pH 3,8 se preparó tal como se describió anteriormente, obteniéndose el pellet de microorganismos totales, los cuales se desafiaron en PBS con 150 ppb de aflatoxina AFB1. Los resultados obtenidos se presentan en la tabla 7.4.

Tabla 7.4 Porcentaje de captura de los microorganismos totales del kefir cultivados en PS al 5\%.

\begin{tabular}{|c|c|c|c|}
\hline pH final del PS fermentado & $\begin{array}{c}\text { BAL } \\
\text { (UFC/ml) }\end{array}$ & $\begin{array}{c}\text { LEV } \\
\text { (UFC/mI) }\end{array}$ & $\begin{array}{c}\% \\
\text { Captura }\end{array}$ \\
\hline 3,8 & $5,01 \times 10^{8} \pm 7,78 \times 10^{7}$ & $2,69 \times 10^{7} \pm 9,19 \times 10^{6}$ & $66,38 \pm 5,18$ \\
\hline
\end{tabular}

Los microorganismos del kefir entero presentaron un alto porcentaje de captura de $66,38 \%$. Esto indica el poder de captura de la comunidad microbiana, que a pesar de ser mas compleja para estudiar su mecanismo, ofrece un resultado interesante para su aplicación como una bebida de la cual se puede resaltar su gran capacidad de captura y se podría profundizar el estudio en diferentes condiciones como las realizadas con los microorganismos aislados. Ya se ha demostrado que en leche contaminada artificialmente con tres concentraciones de aflatoxina AFM1 (0,1, 0,2 y 0,5 ppb), la fermentación con gránulos de kefir lleva a una disminución en su concentración. En efecto, la proporción de AFM1 que quedó en el kefir fue de 60,60 y $80 \%$ con respecto a las concentraciones originales de 0,1,0,2 y 0,5 ppb, respectivamente, mientras que el \% final en el gránulo fue de 1,6,2,6 y 2,6\%. Estos autores demostraron que entonces la aflatoxina disminuía con la fermentación, quedando parte en el gránulo y la leche 
fermentada y que esta disminución era mayor a medida que había mayor concentración original de aflatoxina (Kendirci \& Altug, 2004). En el estudio que se está presentando se observa la capacidad del kefir de atrapar una aflatoxina diferente a AFM1 con un esquema experimental diferente, donde la aflatoxina no se incorpora directamente a la leche y se espera la fermentación, sino que se desafía directamente con los microorganismos que quedan de la fermentación del producto. Es decir, se simula una condición donde se desafía el microorganismo directamente con la aflatoxina. Por otro lado, pudo obtenerse una captura superior, alrededor del $66 \%$, mientras que en el estudio de los anteriores, las capturas variaron entre 20 y $40 \%$.

\subsubsection{Determinación de la capacidad de captura de aflatoxina AFB1 por microorganismos aislados del gránulo de kefir.}

Teniendo en cuenta que el conjunto de los microorganismos del kefir tiene la capacidad de secuestrar AFB1 se realizaron experimentos con microorganismos aislados para determinar si esta propiedad dependía del tipo de microorganismo y si se podían detectar microorganismos específicos con alta capacidad de captura.

\subsubsection{Captura de aflatoxina AFB1 por lactobacilos.}

Se evaluó la capacidad de capturar aflatoxina AFB1 por parte de varios lactobacilos aislados del gránulo de kefir, cultivados en dos medios de cultivo, MRS (Difco ${ }^{\circledR}$, Beauvais, Francia) y permeado de suero (PS). En la tabla 7.5 se observan los porcentajes de captura y los recuentos obtenidos de cada lactobacilo. Puede observarse que los recuentos de un mismo microorganismo en los dos medios no presentaron variación para L. plantarum 83114 y 8316 mientras que descendieron un logaritmo en PS para L. plantarum 8327 y 8318. Los $L$. kefir en general capturaron menos aflatoxina que los L. plantarum y también presentaron mayor variación entre sí en. El mayor porcentaje de captura de los microorganismos cultivados en ambos medios, lo presentó $L$. plantarum 83114 con un $59,26 \%$ y $52,08 \%$ para MRS y PS respectivamente. 
Tabla 7.5 Porcentajes de captura de aflatoxina AFB1, 150 (ppb) por lactobacilos aislados de gránulos de kefir ${ }^{1}$.

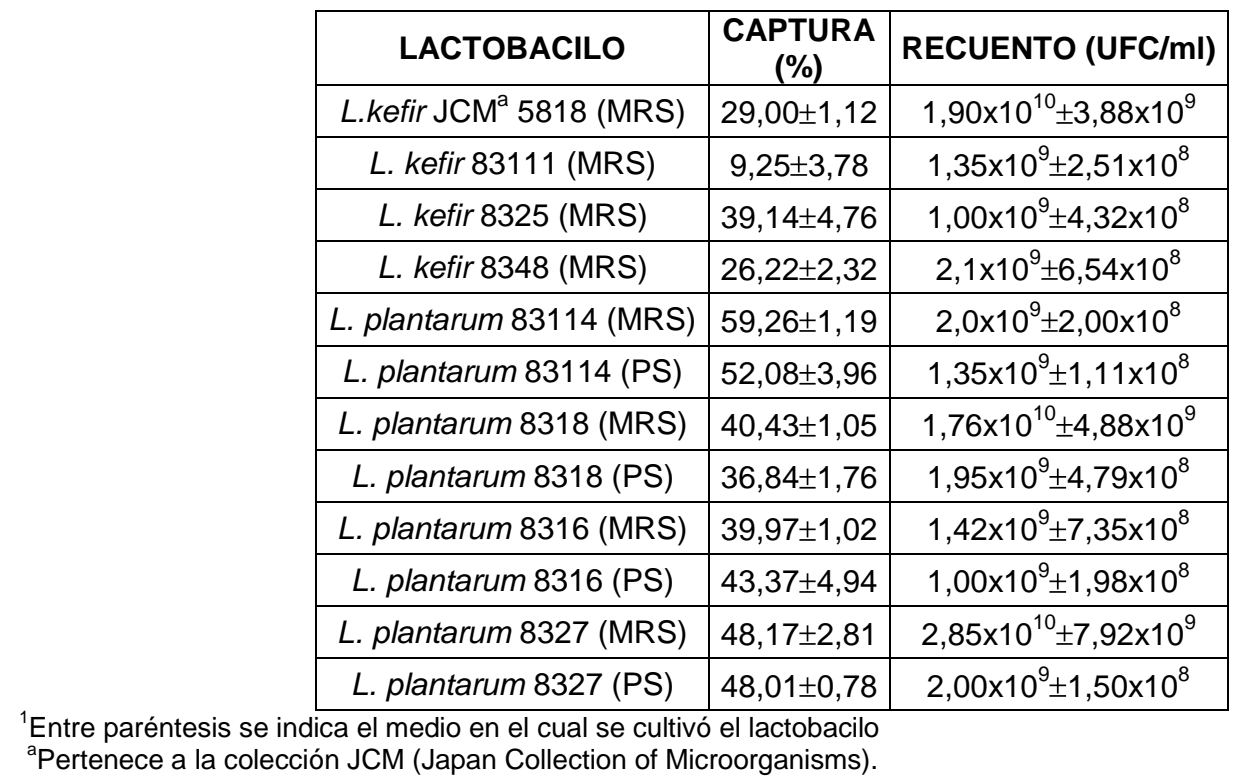

A efectos de favorecer la visualización de la captura de aflatoxina, los valores de la tabla se observan en la figura 7.3. En la misma se observa el porcentaje de captura de los lactobacilos evaluados cuando se cultivan en dos tipos de medio de cultivo: MRS (Difco ${ }^{\circledR}$, Beauvais, Francia) y Permeado de Suero. Debe aclararse que los $L$. kefir sólo se evaluaron cuando se cultivaron en MRS, ya que no crecieron en medio PS en las condiciones ensayadas. Todos los microorganismos cultivados en ambos medios, capturaron aflatoxina AFB1 en diferentes porcentajes y el porcentaje de captura no presentó diferencias significativas para un mismo microorganismo cultivado en los dos medios. 


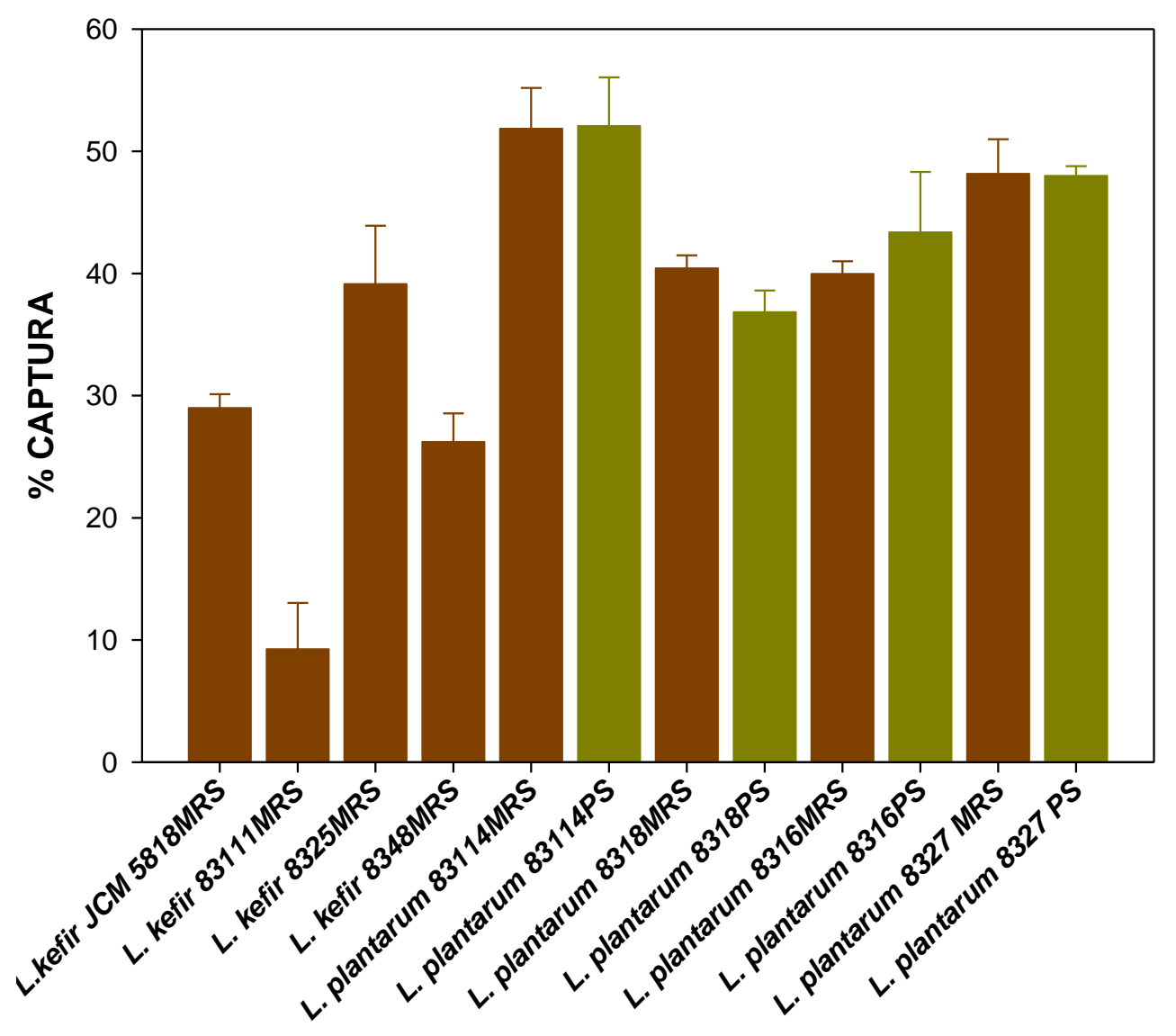

LACTOBACILOS Y MEDIO DE CULTIVO

Figura 7.3 Porcentaje de captura de aflatoxina AFB1 por lactobacilos en función del medio de cultivo. En marrón y en verde se indican los porcentajes de captura obtenidos con los lactobacilos cultivados en caldo MRS y en PS respectivamente.

Como ya se indicó, L. plantarum 83114 tuvo la mayor capacidad de captura, de $59,26 \pm 1,89 \%$. Este microorganismo presenta otras características positivas en la inhibición fúngica. En los ensayos de inhibición fúngica indicados en el capítulo 6.1, L. plantarum 83114 presentó buenos porcentajes de reducción de la germinación, superiores al 90\%, sobre A. flavus AFUBA5 y A. parasiticus NRRL 2999. Por otra parte, generó un halo de inhibición mayor a $5 \mathrm{~mm}$ sobre $A$. flavus AFUNL5 en la técnica de sobrecapa. De otro lado, es capaz de transformar el sustrato en que crece, reduciendo el porcentaje de lactosa de $3,33 \%$ en el permeado estéril hasta 2,62\%; es acidificante, dado que cuando se incubó a $30^{\circ} \mathrm{C}$ por 24 horas, acidificó el PS a un pH de 3,5 con una concentración de 
ácido láctico y acético de $0,97 \%$ y $0,16 \%$ respectivamente, tal como se indicó en el capítulo 6.2.

En vista de lo anterior, esta cepa presenta un conjunto de propiedades probióticas que determinarían su potencial aplicación industrial. A partir de lo anterior, se decidió seleccionar L. plantarum 83114 para efectuar los estudios posteriores de captura de aflatoxina.

\subsubsection{Captura de AFB1 por parte de levaduras}

En la tabla 7.6 y en la figura 7.4 se pueden observar los resultados de la captura de aflatoxina AFB1 con levaduras del kefir y otras aisladas de otros productos fermentados cuando fueron cultivadas en dos medios diferentes, MRS (Difco ${ }^{\circledR}$, Beauvais, Francia) y permeado de suero (PS). En primer lugar, debe destacarse que todas las levaduras provenientes de los gránulos CIDCA, secuestraron aflatoxina cuando se cultivaron en ambos medios. Las levaduras provenientes de otros productos fermentados fueron $K$. lactis que demostró capacidad de secuestrar pero no así $S$. boularddii. El mayor porcentaje de captura obtenido con levaduras crecidas en MRS y PS respectivamente fueron logrados por $S$. cerevisiae $8112(56,44 \pm 6,55 \%)$ y S. cerevisiae $8116(41,54 \pm 2,4 \%)$.

Tabla 7.6 Porcentajes de captura de aflatoxina AFB1 (150 ppm)por levaduras aisladas del kefir y de otros productos lácteos fermentados ${ }^{1}$.

\begin{tabular}{|c|c|c|c|}
\hline \multicolumn{1}{|c|}{ LEVADURA } & CAPTURA (\%) & RECUENTO (UFC/mI) \\
\cline { 2 - 4 } & K. marxianus 8154 (MRS) & $25,0 \pm 2,11$ & $1,14 \times 10^{7} \pm 6,43 \times 10^{6}$ \\
\hline K. marxianus 8154 (PS) & $27,27 \pm 2,11$ & $1,48 \times 10^{8} \pm 5,22 \times 10^{7}$ \\
\cline { 2 - 4 } & S. cerevisiae 8116 (MRS) & $26,12 \pm 1,47$ & $1,10 \times 10^{7} \pm 3,37 \times 10^{6}$ \\
\hline S. cerevisiae 8116 (PS) & $41,54 \pm 2,40$ & $1,00 \times 10^{8} \pm 8,45 \times 10^{7}$ \\
\cline { 2 - 4 } & S. cerevisiae 8112 (MRS) & $56,44 \pm 6,55$ & $1,11 \times 10^{8} \pm 6,98 \times 10^{7}$ \\
\hline S. cerevisiae 8112 (PS) & $47,12 \pm 3,24$ & $9,26 \times 10^{8} \pm 2,54 \times 10^{7}$ \\
\hline S. cerevisiae 81103 (MRS) & $35,67 \pm 3,85$ & $1,21 \times 10^{8} \pm 3,12 \times 10^{7}$ \\
\hline S. cerevisiae 81103 (PS) & $46,14 \pm 0,92$ & $1,94 \times 10^{7} \pm 4,31 \times 10^{6}$ \\
\hline K. lactis CINDEFI (MRS) & $30,72 \pm 5,50$ & $1,00 \times 10^{8} \pm 3,44 \times 10^{7}$ \\
\hline K. lactis CINDEFI (PS) & $38,11 \pm 2,12$ & $1,22 \times 10^{7} \pm 2.64 \times 10^{6}$ \\
\cline { 2 - 4 } & S. boulardii CINDEFI (MRS) & 0 & $1,41 \times 10^{7} \pm 4,64 \times 10^{6}$ \\
\hline
\end{tabular}


En la figura 7.4 se observa el gráfico de barras donde se comparan los porcentajes de captura obtenidos con cada levadura crecida en ambos medios de cultivo. Puede observarse que todas las levaduras aumentaron su capacidad de secuestrar AFB1 cuando se cultivaron en PS, a excepción de S. cerevisiae 8112. La única levadura que no presentó capacidad de secuestrar fue $S$. boularddii, proveniente de un producto fermentado diferente al kefir. Tomando los datos en general, las diferencias obtenidas en la captura no corresponderían al incremento en los recuentos que ocurren en algunos microorganismos en PS. Estos cambios podrían atribuirse a la composición diferente de la pared celular, proveniente del cultivo en dos medios diferentes.

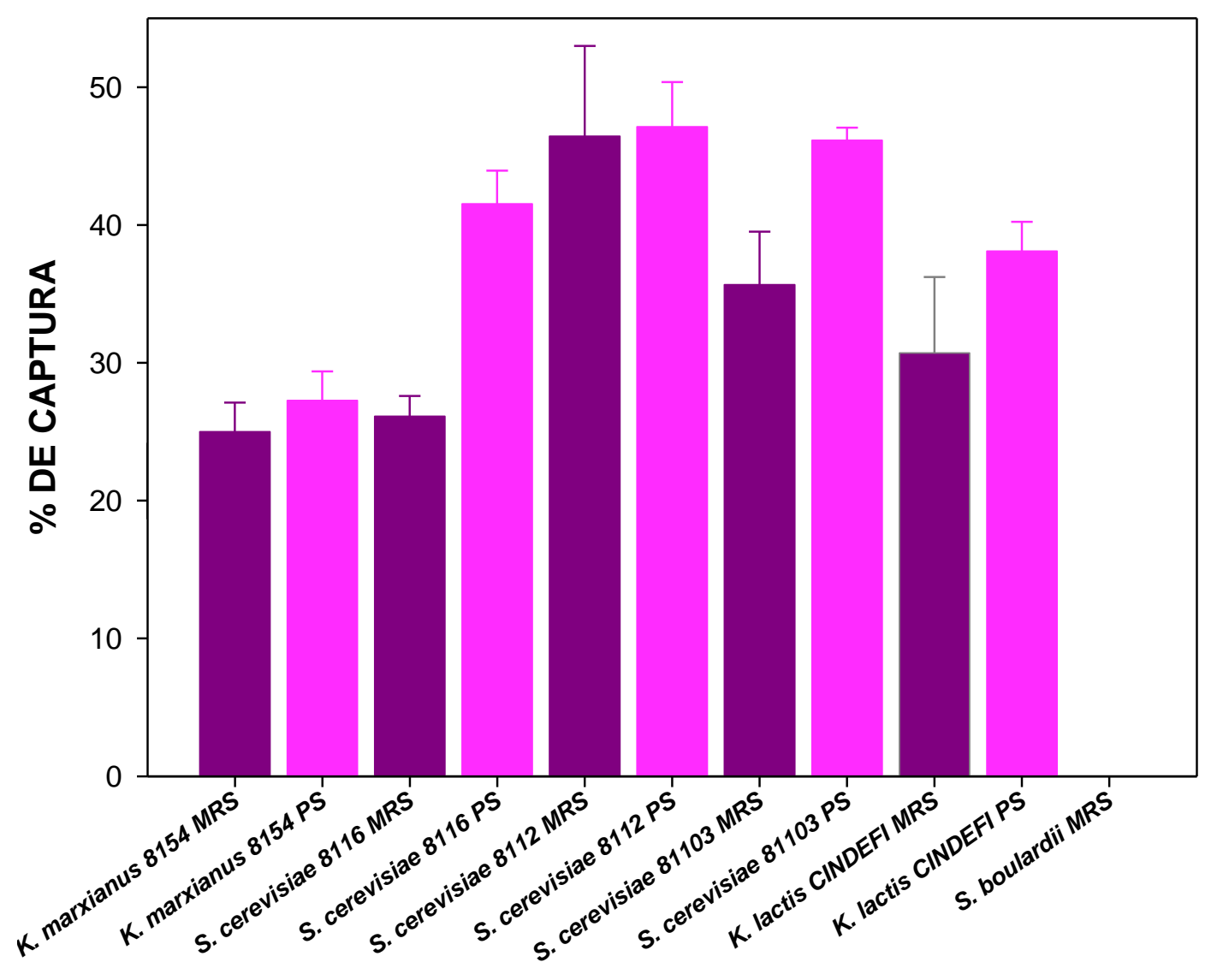

LEVADURAS Y MEDIOS DE CULTIVO

Figura 7.4 Porcentaje de captura de aflatoxina AFB1 por levaduras aisladas de gránulos de kefir y de colección. En violeta y rosa se indican los porcentajes de captura obtenidos con las levaduras cultivadas en caldo MRS y en PS respectivamente. 
En la tabla 7.6 puede observarse que $K$. marxianus 8154 presentó un porcentaje de captura de aflatoxina AFB1 de 25,0 $\pm 2,11 \%$ (con un recuento de $10^{7} \mathrm{UFC} / \mathrm{ml}$ ) cultivada en MRS y de $27,27 \pm 2,11$ (con un recuento de $10^{8} \mathrm{UFC} / \mathrm{ml}$ ) cultivada en permeado de suero al 5\%. Aún cuando no presentó el mayor \% de captura, esta levadura ha demostrado una gran capacidad de reducir la lactosa presente en el Permeado de Suero, durante 24 horas de fermentación a $30 \stackrel{\circ}{\circ}$, pasando de una concentración inicial de 3,33\% de lactosa en el PS sin fermentar a 1,01\% al final de la fermentación a un $\mathrm{pH}$ de 5,06, Capítulo 6.2, lo cual le hace un microorganismo de interés para elaborar una mezcla microbiana con el $L$. plantarum 83114 que fermenten un producto lácteo, tengan actividad antifúngica y capturen aflatoxina AFB1.

A partir de las condiciones anteriores de captura de micotoxina, el consumo de lactosa y capacidad antifúngica, se seleccionaron L. plantarum 83114 y $K$. marxianus 8154 para profundizar los estudios sobre su capacidad de captura de aflatoxina AFB1.

Las primeras publicaciones sobre captura de micotoxinas demostraron que las bacterias ácido lácticas y otras bacterias intestinales eran capaces de secuestrar contaminantes de la dieta como las aflatoxinas (El-Nezami, Salminen \& Ahokas, 1996; El-Nezami, Kankaanpää, Salminen, Ahokas, 1998a; Thyagaraja \& Hosono, 1994). También se demostró que las bifidobacterias muertas por calor capturaban aflatoxina AFB1 de forma cepa dependiente (Oatley, Rarick, Ji \& Linz, 2000). Algunas investigaciones realizadas previamente demostraron que la remoción de aflatoxinas envuelve el secuestro probable a nivel de la pared celular o Lb. rhamnosus de sus componentes (El-Nezami, Kankaanpää, Salminen \& Ahokas, 1998b; Haskard, El-Nezami, Kankaanpää, Salminen \& Ahokas, 2001) y que la eliminación de algunos componentes específicos de la pared celular como carbohidratos y proteínas producen un descenso en la captura de AFB1 como se determinó para GG (Haskard, Binnion \& Ahokas, 2000). 
Dado que la captura de aflatoxina se ha interpretado como dependiente de la composición de la pared celular, (Peltonen, El-Nezami, Haskard, Ahokas \& Salminen, 2001; Haskard, El-Nezami, Kankaanpää, Salminen \& Ahokas; Hernández - Mendoza, García \& Steele, 2009) se decidió evaluar si existe correlación entre la hidrofobicidad superficial determinada por las moléculas presentes en la superficie de los microorganismos y la captura de micotoxinas.

\subsubsection{Estudio de la influencia del porcentaje de hidrofobicidad superficial en la captura de aflatoxina AFB1.}

Dado que las aflatoxinas son moléculas ligeramente apolares, se quiso determinar si la hidrofobicidad superficial $(\% \mathrm{H})$ de los lactobacilos cultivados en dos medios de cultivo diferentes, ejercía un efecto en la capacidad de captura. Para comprobarlo se cultivaron los lactobacilos plantarum en MRS (Difco®), Beauvais, Francia) y en permeado de suero (PS). Se determinó el \% de hidrofobicidad de los microorganismos y se desafiaron con la aflatoxina.

En la tabla 7.7 se relacionó el porcentaje de captura de los lactobacilos con el porcentaje de hidrofobicidad $(\% \mathrm{H})$ en hexadecano, al ser cultivados en ambos medios de cultivo.

Tabla 7.7 Porcentaje de captura de aflatoxina AFB1 y porcentaje de Hidrofobicidad de lactobacilos aislados del kefir.

\begin{tabular}{|c|c|c|}
\hline LACTOBACILO & $\begin{array}{c}\text { CAPTURA } \\
(\%)\end{array}$ & $\begin{array}{c}\text { HIDROFOBICIDAD } \\
(\%)\end{array}$ \\
\hline L. kefir JCM 5818 (MRS) & $29,00 \pm 1,12$ & $83,0 \pm 1,0^{\mathrm{a}}$ \\
\hline L. kefir 83111 (MRS) & $9,25 \pm 3,78$ & $80,5 \pm 2,5^{\mathrm{a}}$ \\
\hline L. kefir 8325 (MRS) & $39,14 \pm 4,76$ & $79,0 \pm 0,0^{\mathrm{a}}$ \\
\hline L. kefir 8348 (MRS) & $26,22 \pm 2,32$ & $83,0 \pm 2,0^{\mathrm{a}}$ \\
\hline L. plantarum 83114 (MRS) & $59,26 \pm 1,19$ & $1,2 \pm 0,8^{\mathrm{a}}$ \\
\hline L. plantarum 83114 (PS) & $52,08 \pm 3,96$ & $0,23 \pm 0,03^{\mathrm{b}}$ \\
\hline L. plantarum 8318 (MRS) & $40,43 \pm 1,05$ & $2,0 \pm 0,1^{\mathrm{a}}$ \\
\hline L. plantarum 8318 (PS) & $36,84 \pm 1,76$ & $0,80 \pm 0,08^{\mathrm{b}}$ \\
\hline L. plantarum 8316 (MRS) & $39,97 \pm 1,02$ & $3,5 \pm 0,2^{\mathrm{a}}$ \\
\hline L. plantarum 8316 (PS) & $43,37 \pm 4,94$ & $2,03 \pm 0,33^{\mathrm{b}}$ \\
\hline L. plantarum 8327 (MRS) & $48,17 \pm 2,81$ & $1,00 \pm 0,1^{\mathrm{a}}$ \\
\hline L. plantarum 8327 (PS) & $48,01 \pm 0,78$ & $0,99 \pm 0,02^{\mathrm{b}}$ \\
\hline
\end{tabular}

a'(Golowczyck, 2007).

Valores determinados en esta investigación 
En la figura 7.5 se relaciona el porcentaje de captura de los lactobacilos con el porcentaje de hidrofobicidad $(\% \mathrm{H})$ en hexadecano, al ser cultivados en ambos medios de cultivo. En ella se observan dos grupos: L. kefir hidrofóbicos y L.plantarum hidrofílicos. Los lactobacilos hidrofóbicos con \% hidrofobicidad entre 79 y $83 \%$, presentaron \% captura variable entre 9 y $40 \%$ y los hidrofílicos con $\%$ hidrofobicidad inferior a $5 \%$ (varió entre 1 y 3,5 y entre 0,23 y $2,03 \%$ cultivados en MRS y PS respectivamente), capturaron entre 40 y $50 \%$ aproximadamente.

Se observó que el \% de captura varió considerablemente entre las diferentes cepas de $L$. kefir mientras que fue muy similar entre todas las cepas de $L$. plantarum. Entre los L. plantarum, se pudo observar que su \% de hidrofobicidad y de captura de aflatoxina AFB1 disminuían levemente cuando se cultivaban en PS, a excepción de L. plantarum 8316 que aumentó su captura de 39,97 a $43,37 \%$ de PS a MRS. No obstante, no hubo diferencias significativas entre los $\%$ de hidrofobicidad y los \% de captura respecto al medio donde se cultivaron.

Finalmente, al comparar la capacidad de secuestrar la aflatoxina, se observó que dos lactobacilos con dos \% de hidrofobicidad significativamente diferentes, como son L. kefir 83125 en MRS (\%H: 79\%) y L. plantarum 8316 en MRS (\%H: 3,5), tuvieron un $\%$ de captura muy similar, de 39,14 y $39,97 \%$. Todo lo anterior permitió observar que los L. plantarum, con un \% de hidrofobicidad inferior al de L. kefir, tienden a capturar mayor \% de aflatoxina, pero que no se cumple en todos los casos. Es decir, no puede afirmarse que la hidrofobicidad superficial sea una medida que determine la capacidad de captura de los microorganismos.

Podría pensarse otros factores que estén asociados a la composición de la pared, como la presencia de ácidos teicoicos (Hernández-Mendoza, García \& Steele, 2009) o la transformación en la estructura de algunas proteínas por tratamientos como calor, que expongan superficies afines a la aflatoxina (Haskard, El-Nezami, Kankaanpää, Salminen \& Ahokas, 2001), o la capacidad de crear uniones al peptidoglicano de la pared celular (Lahtinen, Haskard, Ouwehand, Salminen \& Ahokas, 2004). 


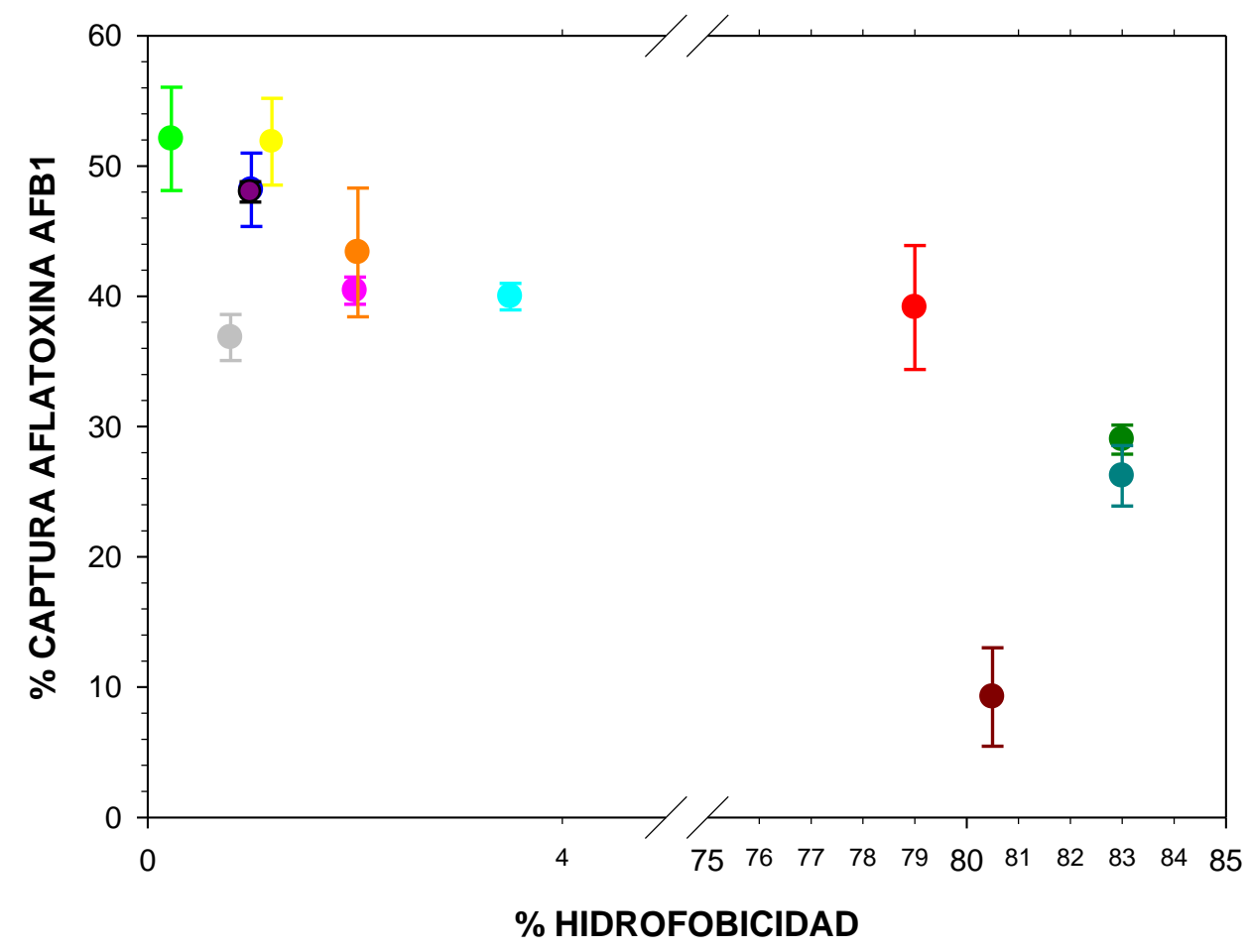

Figura 7.5 Relación entre el \% de captura de Aflatoxina AFB1 y el \% de Hidrofobicidad de los lactobacilos evaluados. - L. kefir JCM 5818 MRS; • L. kefir 83111 MRS; • L. kefir 8325 MRS; - L. kefir 8348 MRS; $\quad$ L. plantarum 83114 MRS; $\quad$ L. plantarum 83114 PS; $\bullet \quad$ L. plantarum 8318 MRS; ㄴ. plantarum 8318 PS; ․ plantarum 8316 MRS; ․ plantarum 8316 PS; • L. plantarum 8327 MRS; • L. plantarum 8327 PS.

En la tabla 7.8 y en la figura 7.6 se observa el \% de hidrofobicidad superficial de las levaduras cultivadas en ambos medios de cultivo y el porcentaje de captura de aflatoxina AFB1. S. cerevisiae 8112 incrementó drásticamente su hidrofobicidad en PS al igual que S. cerevisiae 103, pero mientras que en la primera no hubo cambio en su porcentaje de captura, en la segunda éste aumentó. Al contrario de las anteriores, el \% de hidrofobicidad de S. cerevisiae 8116 disminuyó en PS aumentando su capacidad de secuestrar AFB1. K. marxianus 8154 no presentó diferencia significativa en la hidrofobicidad cuando se cultivó en ambos medios, pero su capacidad de captura fue inferior en PS que en MRS. 


\section{ESTUDIO DE LA CAPACIDAD DE DECONTAMINACIÓN DE AFLATOXINA AFB1 POR MICROORGANISMOS DEL KEFIR.}

Tabla 7.8 Porcentaje de captura de aflatoxina AFB1 y porcentaje de Hidrofobicidad de levaduras aisladas del kefir.

\begin{tabular}{|c|c|c|}
\hline LEVADURA & $\begin{array}{c}\text { CAPTURA } \\
(\%)\end{array}$ & $\begin{array}{c}\text { HIDROFOBICIDAD } \\
(\%)^{\mathrm{a}}\end{array}$ \\
\hline K. marxianus 8154 (MRS) & $25,0 \pm 2,11$ & $94,92 \pm 0,66$ \\
\hline K. marxianus 8154 (PS) & $27,27 \pm 2,11$ & $94,91 \pm 0,59$ \\
\hline S. cerevisiae 8116 (MRS) & $26,12 \pm 1,47$ & $48,89 \pm 8,49$ \\
\hline S. cerevisiae 8116 (PS) & $41,54 \pm 2,40$ & $27,72 \pm 5,22$ \\
\hline S. cerevisiae 8112 (MRS) & $56,44 \pm 6,55$ & $52,81 \pm 8,83$ \\
\hline S. cerevisiae 8112 (PS) & $47,12 \pm 3,24$ & $89,73 \pm 3,73$ \\
\hline S. cerevisiae 81103 (MRS) & $35,67 \pm 3,85$ & $51,41 \pm 3,33$ \\
\hline S. cerevisiae 81103 (PS) & $46,14 \pm 0,92$ & $95,02 \pm 4,35$ \\
\hline K. lactis CINDEFI (MRS) & $30,72 \pm 5,50$ & $1,07 \pm 0,78$ \\
\hline K. lactis CINDEFI (PS) & $38,11 \pm 2,12$ & $31,8 \pm 1,35^{\text {b }}$ \\
\hline S. boulardii CINDEFI (MRS) & 0 & $2,69 \pm 0,39$ \\
\hline
\end{tabular}

${ }^{a}$ Los valores indicados fueron determinados en esta investigación

${ }^{b}$ Valor determinado por Golowczyc, 2007

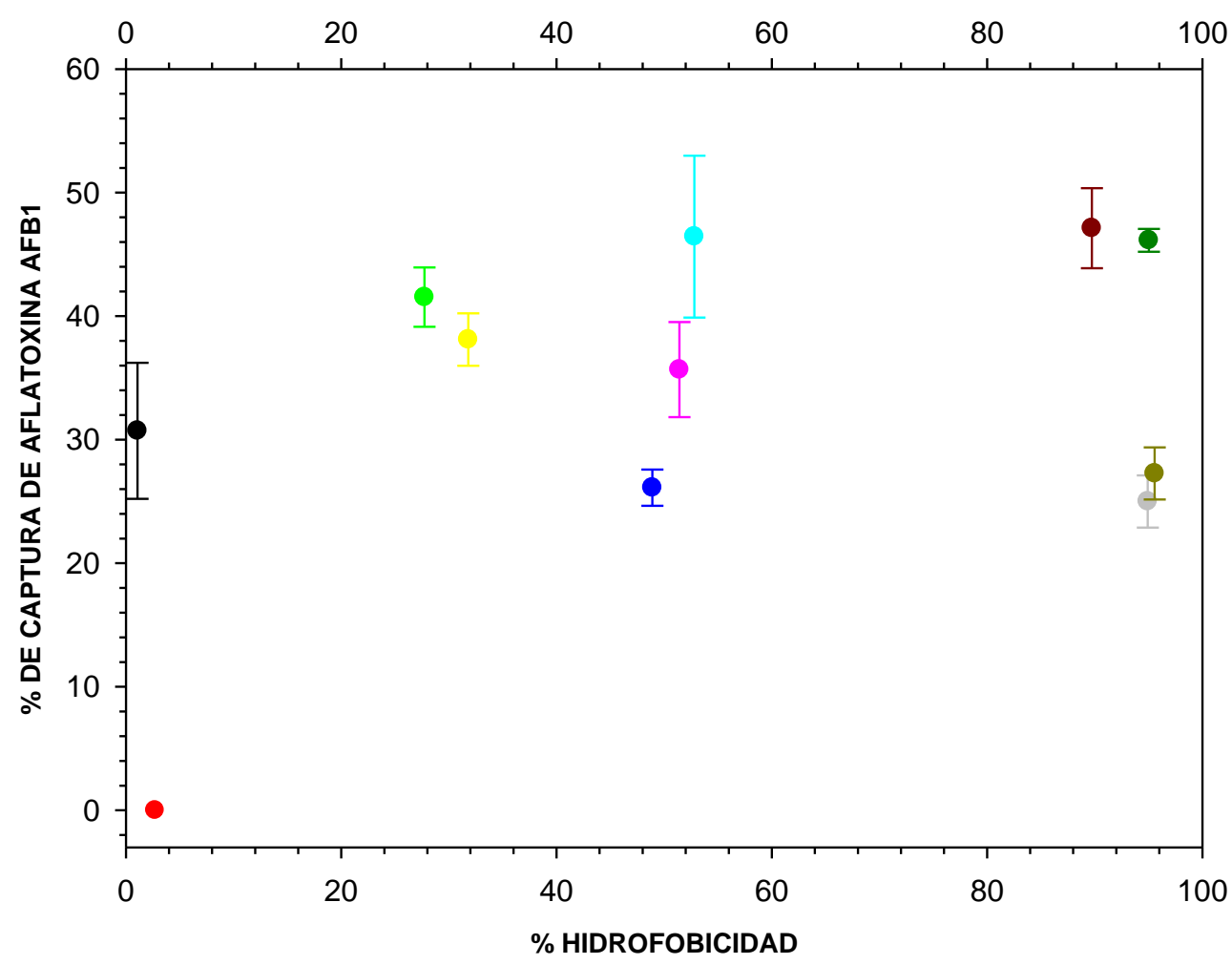

Figura 7.6 Relación entre el \% de captura de Aflatoxina AFB1 y el \% de Hidrofobicidad de las levaduras evaluadas.

K. lactis CINDEFI, MRS;

K. lactis CINDEFI, PS;

S. boularddii CINDEFI, MRS; S. cerevisiae 8116, MRS; S. cerevisiae 8116 , PS, S. cerevisiae 8112 , MRS; - S. cerevisiae 8112, PS; S. cerevisiae 81103, MRS; - S. cerevisiae 81103, PS; K. marxianus 8154, MRS; - K. marxianus 8154, PS. 
Los resultados obtenidos permitieron concluir que la hidrofobicidad de las levaduras aisladas del gránulo de kefir varía de acuerdo al medio de cultivo, excepto en el caso de $K$. marxianus 8154. Dado que los mismos resultados se encontraron con los lactobacilos cultivados en medio MRS y PS, no se pudo establecer una relación entre el porcentaje de captura y el porcentaje de hidrofobicidad. Los resultados nuestros coincidieron con los obtenidos con $L$. rhamnosus GG, L.rhamnosus LC-705

y Propionibacterium freudenreichii subsp. shermanii JS desafiados en PBS con aflatoxina AFB1, donde no se encontró correlación entre la hidrofobicidad y la afinidad por AFB1 (Lee, El-Nezami, Haskard, Gratz, Puong, Salminen \& Mykkänen, 2003).

\subsubsection{Cinética de captura durante 48 horas de aflatoxina AFB1 por microorganismos totales del gránulo de kefir CIDCA AGK1, Lactobacillus plantarum 83114 y Kluyveromyces marxianus 8154 cultivados en Permeado de suero (PS).}

El tiempo de contacto de la aflatoxina con el microorganismo puede tener muchas variaciones. Puede tener lugar desde la preparación, donde una materia prima contaminada se mezcla con el producto fermentado y quedar un tiempo en contacto durante el almacenamiento, o tener lugar al consumir alimentos contaminados con aflatoxinas junto al producto fermentado. En todo caso, la capacidad de retener la aflatoxina tendrá que superar el tiempo de tránsito a través del tracto gastro intestinal (GI). Para esto se han establecido tiempos permanencia del alimento desde que es ingerido hasta que éste sale del cuerpo en las heces. El tránsito por el estómago puede durar 2 a 6 horas, en el intestino delgado 3 a 5 horas y 20 a 140 horas con una media de 60 (2,5 días) en el intestino grueso (Wilson, 2005). A partir de lo anterior, se eligió un período de 48 horas para determinar si la capacidad de captura de los microorganismos era variable. 


\subsubsection{Captura de Aflatoxina AFB1 en función del tiempo de co-incubación} con microorganismos totales del gránulo de kefir CIDCA AGK1 cultivado en permeado de suero PS 5\%.

La figura 7.7 presenta el porcentaje de captura de los microorganismos totales del kefir a diferentes tiempos de desafío con AFB1 en PBS. La máxima captura ocurrió al minuto treinta de coincubación y el mínimo a las 4 horas y en un punto medio estuvieron las capturas a las horas 24 y 48 . No obstante, no hubo diferencia estadísticamente significativa entre los resultados obtenidos a los diferentes tiempos del experimento. Se evaluó si el pH del medio de desafío podría descender y que dichos cambios hubieran intervenido en la captura. Para ello se midió el pH en a cada uno de los intervalos, encontrándose que sus valores fueron similares, de $7,07 \pm 0,014,7,045 \pm 0,007,6,82 \pm 0,014$ y $6,88 \pm 0,022$ a las horas $0,5,4,24$ y 48 respectivamente.

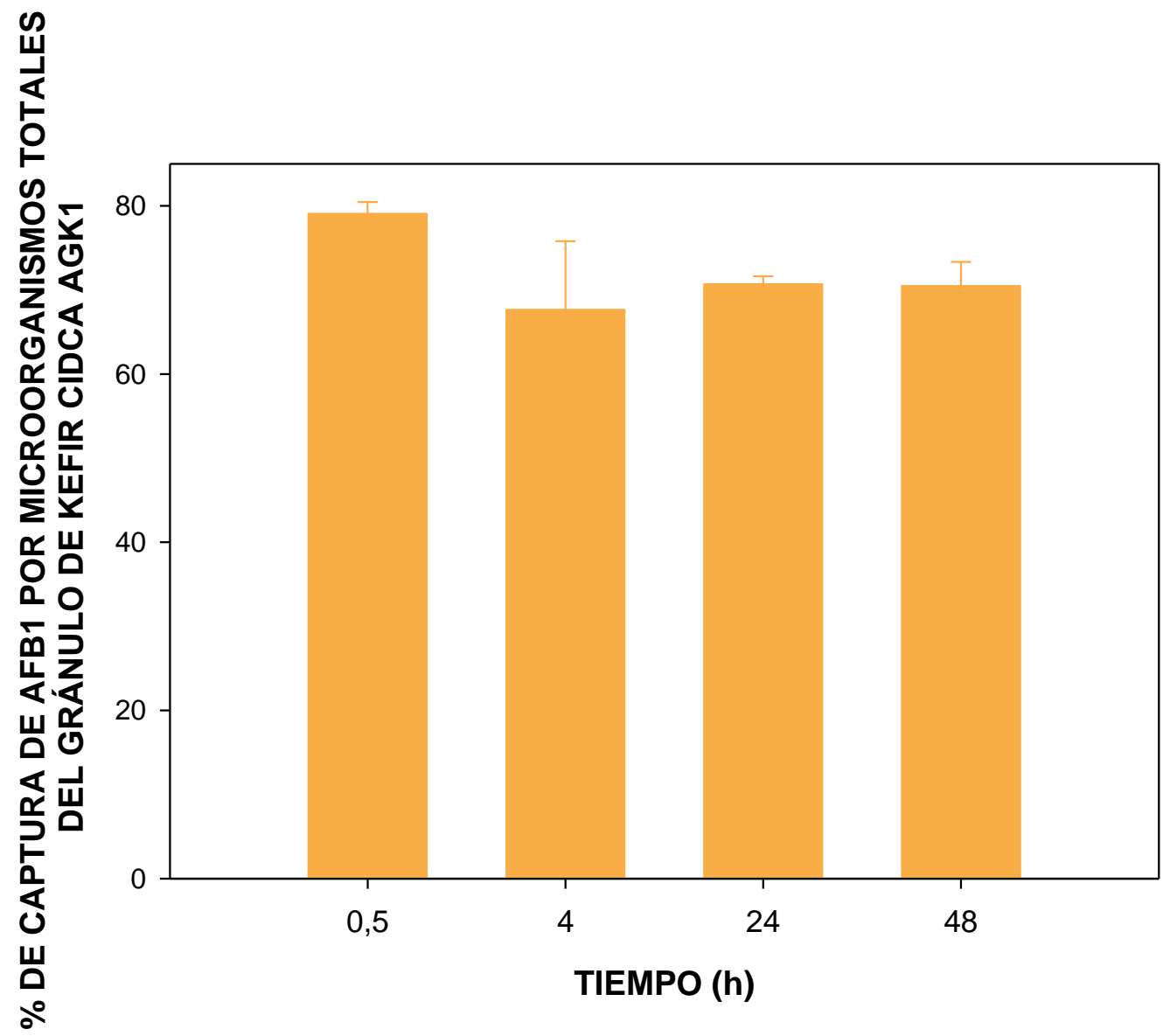

Figura 7.7 Porcentaje de captura de aflatoxina AFB1 del total de microorganismos del kefir durante 48 horas. 


\subsubsection{Captura de Aflatoxina AFB1 en función del tiempo de co-incubación con L. plantarum 83114 cultivado en Permeado de suero PS $5 \%$.}

Se evaluó la capacidad de captura que exhibió L. plantarum 83114 cuando se cultivó en Permeado de Suero al 5\% (PS) y se desafió durante 48 horas con aflatoxina AFB1. En la figura 4 se observan los porcentajes de captura de aflatoxina AFB1 que tuvieron lugar durante los tiempos 0,$5 ; 1 ; 4 ; 24$ y 48 horas de desafío en PBS. En el caso de L. plantarum 83114, la mayor cantidad de toxina capturada al tiempo 0 (30 minutos), (55,45 $\pm 8,17 \%$ ), fue significativamente superior a la obtenida a las 24 horas $(41,58 \pm 5,26 \%)$, pero no con respecto a la captura obtenida a la hora $4(51,863,33 \%)$ y $48(50,18 \pm 4,75 \%)$. Estos dos últimos tiempos, por su parte, no tuvieron diferencia significativa entre sí.

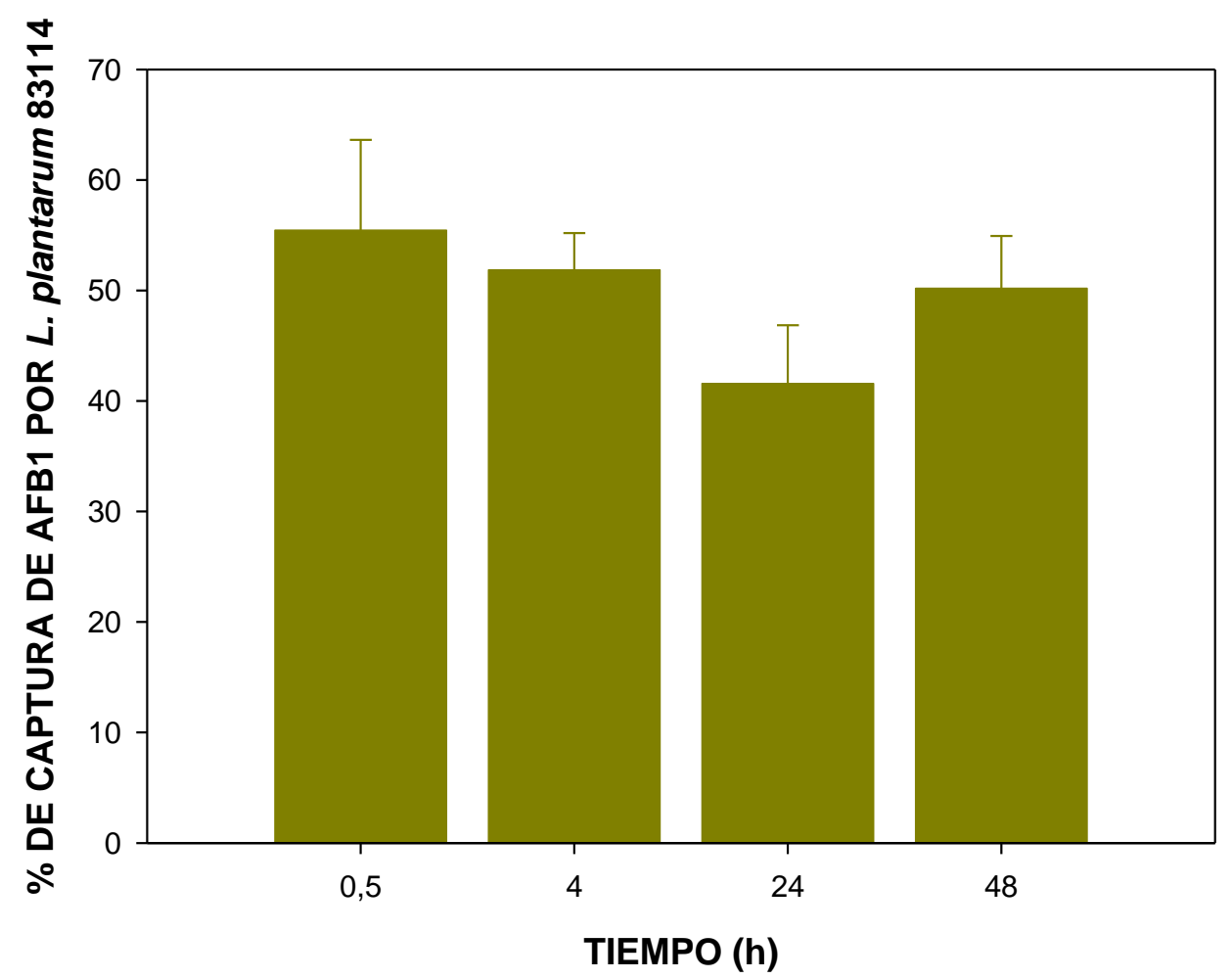

Figura $7.8 \%$ de captura de aflatoxina AFB1 en función del tiempo de co-incubación con $L$. plantarum 83114 cultivado previamente en PS. $(P<0,05)$

En la figura 7.8 se evidencia que la captura de aflatoxina varió durante el tiempo de incubación, y que el mayor porcentaje $(55,45 \pm 8,17 \%)$ se alcanzó al tiempo 
cero, descendó al tiempo $4(51,86 \pm 3,33 \%)$ y $24(41,58 \pm 5,26 \%)$ y volvió a ascender a la hora $48(50,18 \pm 4,75 \%)$. A partir de estos resultados se seleccionó el tiempo de 30 minutos para los siguientes desafíos con este microorganismo.

\subsubsection{Captura de Aflatoxina AFB1 en función del tiempo de co-incubación con K. marxianus 8154 cultivada en Permeado de Suero al 5\%.}

Se realizaron experimentos de captura de aflatoxina AFB1 por la levadura $K$. marxianus 8154 cultivada previamente en caldo en Permeado de Suero al 5\% (PS), a fin de determinar si existen variaciones en la capacidad de captura durante el tiempo de co-incubación. En la figura 7.9 se observan los gráficos de barras del porcentaje de captura de aflatoxina AFB1 por la levadura $K$. marxianus 8154 previamente cultivada en PS y desafiada con la aflatoxina durante 48 horas de incubación a $30^{\circ} \mathrm{C}$, con agitación, en PBS.

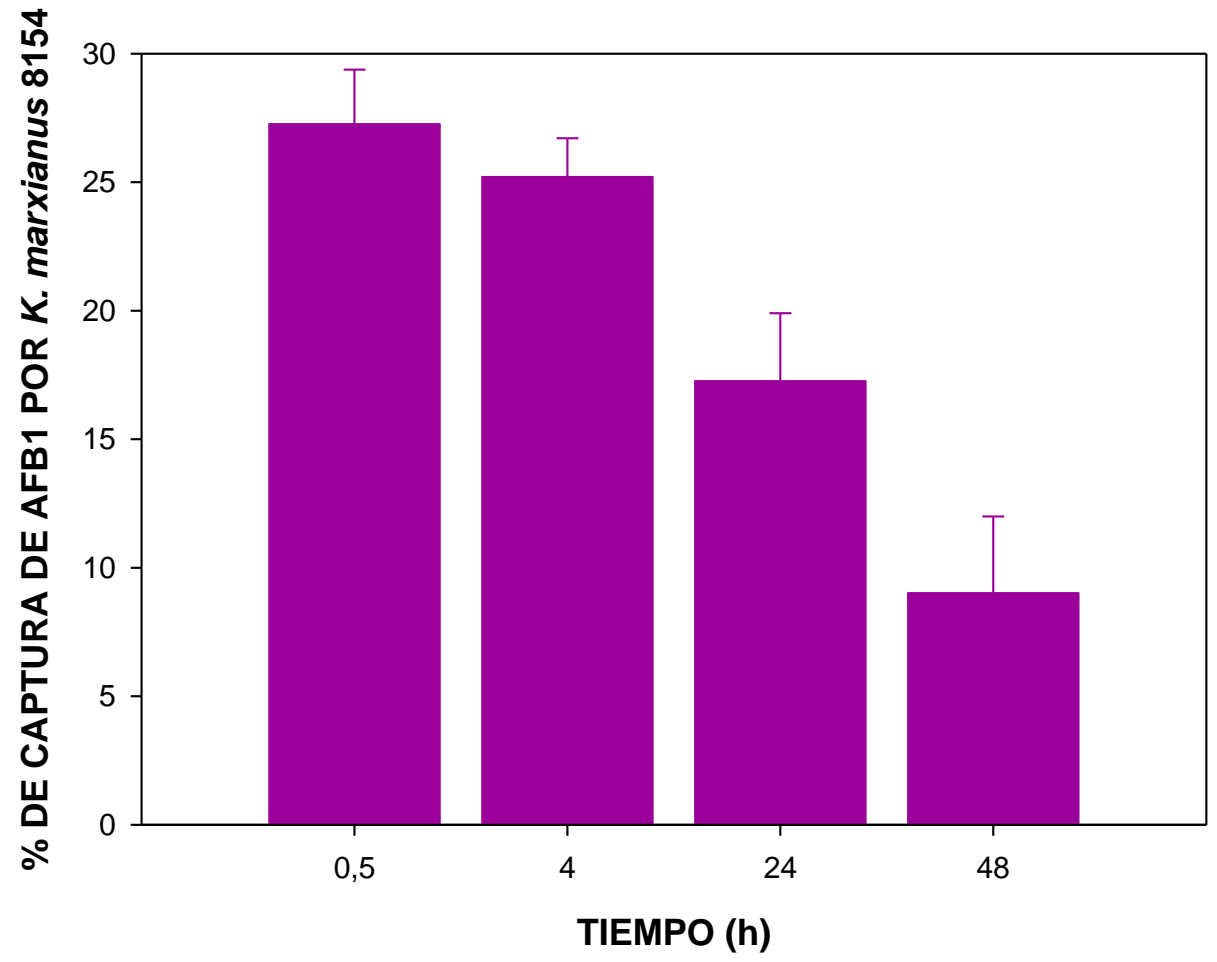

Figura 7.9 Porcentaje de captura de aflatoxina AFB1 en función del tiempo de coincubación con Kluyveromyces marxianus 8154 cultivada previamente en caldo MRS.

En el presente estudio, el secuestro de aflatoxinas presentó variaciones significativas durante el período de incubación. El máximo porcentaje de captura de aflatoxina AFB1 por K. marxianus 8154, obtenido a la media hora de 
incubación $(27,27 \pm 2,11 \%)$, no presentó diferencia significativa con el obtenido a la hora $4(25,21 \pm 1,4 \%)$ pero si con los determinados a la hora $24(17,27 \pm 2,63 \%)$ y $48(9,02 \pm 2,97 \%)$ del ensayo.

La máxima captura obtenida con K. marxianus 8154 se obtuvo a la media hora de incubación $(27,27 \pm 2,11 \%)$, descendió a la hora $4(25,21 \pm 1,49 \%)$ a la hora 24 $(17,27 \pm 2,63 \%)$ y el mínimo porcentaje de captura se obtuvo a la hora 48 $(9,02 \pm 2,97 \%)$. El recuento obtenido de la levadura fue de $1,14 \times 10^{7} \pm 6,43 \times 10^{6}$ UFC/ml. Dado que su tamaño puede oscilar entre 1-10 $\mu \mathrm{m}$ ancho por 2-3 $\mu \mathrm{m}$ de longitud, el recuento total de estas levaduras por cada mililitro de producto fermentado podría cubrir máximo entre 2,28 y $3,42 \mathrm{~cm}^{2}$. Ello indica que la levadura presenta una gran superficie para realizar el proceso de adsorción en comparación con el lactobacilo aún cuando el recuento de células sea inferir al de los lactobacilos. La máxima captura obtenida con esta levadura fue a los 30 minutos, tiempo que se eligió para realizar los siguientes experimentos de desafío.

Pudo observarse que K. marxianus 8154 y L. plantarum 83114 secuestraron el mayor porcentaje de aflatoxina AFB1 a los 30 minutos de coincubación, ocurriendo variaciones en los tiempos siguientes. La captura eficiente de micotoxinas en un corto período de tiempo ha sido informada para otras BAL. Dentro de la hora cero de desafío, $L b$. rhamnosus GG y Lb. rhamnosus Lc 705 secuestraron aproximadamente el $80 \%$ de AFB1 (El-Nezami, Kankaanpää, Salminen \& Ahokas, 1998a) y Lb. amylovorus CSCC 5160, Lb. amylovorus CSCC 5197 y Lb. rhamnosus Lc $1 / 3$, capturaron por encima del $50 \%$ de dicha micotoxina (Peltonen, El-Nezami, Haskard, Ahokas \& Salminen, 2001).

Como pudo observarse, el secuestro de AFB1 varió durante los períodos de incubación, lo cual no coincidió con lo reportado para los microorganismos que capturan eficientemente, estudiados por El-Nezami, Kankaanpää, Salminen \& Ahokas (1998a). Sin embargo, otros autores han encontrado variaciones significativas en los tiempos de incubación en ensayos realizados durante 72 
horas. Lb. amylovorus CSCC 5160 incrementó significativamente el secuestro de AFB1 durante el tiempo de desafío, de 52,6\% (0 h) a 73,2\% (72 h). Por el contrario, se encontró que otra cepa de Lb.amylovorus CSCC 5197 disminuyó significativamente $(P<0,05)$ la captura de AFB1 entre la hora cero y la 24 , y aumentó el secuestro a partir de esta hora. Lb. rhamnosus Lc 1/3 también redujo su capacidad de secuestro entre las horas 0 y 24 y entre este tiempo y el final del desafío se mantuvo constante (Peltonen, El-Nezami, Haskard, Ahokas \& Salminen, 2001).

Mientras que con L. plantarum 83114 y K. marxianus 8154 el máximo porcentaje de captura obtenido se logró a la media hora de incubación (58,6 y 27,27\% respectivamente) otros lactobacilos han presentado un máximo en otros tiempos como son: Lb.amylovorus CSCC 5160 y CSCC 5197, y Lb.rhamnosus Lc 1/3: horas $72(73,2 \%)$, 48(72,4\%), y cero $(76,9 \%)$, respectivamente (Peltonen, ElNezami, Haskard, Ahokas \& Salminen, 2001).

Ambos microorganismos fueron capaces de capturar AFB1, pero en cantidades diferentes. Las diferencias obtenidas en el secuestro de AFB1 podría deberse a diferencias en la pared celular y de compuestos presentes en su cubierta.

Los resultados encontrados indican que parte de la aflatoxina AFB1 se une fuertemente a las cepas estudiadas y que AFB1 podría ser liberada de nuevo a la solución a partir del complejo microorganismo/AFB1. Puede afirmarse que el secuestro es un fenómeno que ocurre casi inmediatamente entran en contacto el microorganismo y la aflatoxina y que éste puede variar durante el tiempo de incubación ocurriendo liberación y recaptura de AFB1. Por ello, surge la pregunta si el complejo formado Aflatoxina - célula bacteriana es suficientemente estable durante el tiempo cono para asegurar su posible aplicación en alimentos, lo cual es sujeto de estudio en el punto siguiente 


\subsubsection{Determinación de la estabilidad del complejo toxina-microorganismo.}

\subsubsection{Estabilidad del complejo K. marxianus 8154 - aflatoxina AFB1.}

Los pellets obtenidos de los desafíos realizados con ambos microorganismos, $L$. plantarum 83114 y $K$. marxianus 8154 , se lavaron con PBS tres veces consecutivas y la cantidad de aflatoxina AFB1 que fue liberada al sobrenadante después del lavado, se determinó mediante HPLC, tal como se describió previamente y la cantidad de aflatoxina liberada al SLC después de cada lavado se determinó.

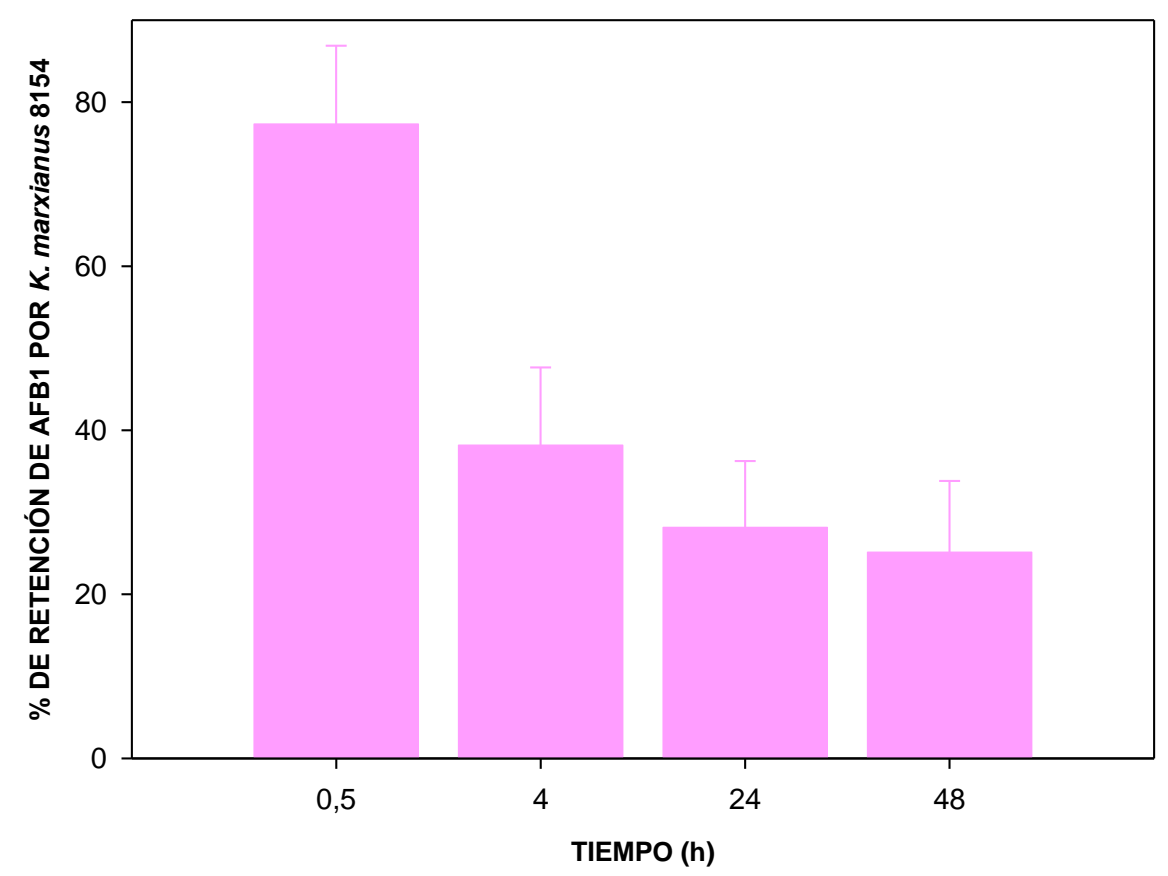

Figura 7.10 Porcentaje de retención de aflatoxina AFB1 por K. marxianus CIDCA 8154 después del primer lavado del pellet obtenido durante los distintos tiempos de coincubación.

Los datos del segundo y tercer lavado no se indicaron en la figura ya que no fueron detectados mediante HPLC en ninguno de los casos.

Tal como se observa en la figura 7.10 , sólo fue detectable la cantidad de aflatoxina en el SN del primer lavado siendo indetectable la liberación en el segundo y tercer lavado. Se determinó que la máxima retención de aflatoxina de $77,31 \pm 9,53 \%$, la exhibió el pellet correspondiente a los 30 minutos de coincubación. La capacidad de retención disminuyó en el pellet obtenido a la hora 
cuatro $38,19 \pm 9,47 \%$, y la retención disminuyó otro poco en los pellets correspondientes a 24 y 48 horas, pero siendo de un valor similar en ambos de $28,15 \pm 8,10 \%$ y $25,12 \pm 8,70 \%$ respectivamente. En otras palabras, el pellet de levadura obtenido a los 30 minutos de coincubación sólo perdió un 22\% aproximado de la aflatoxina, a diferencia de los demás tiempos que perdieron entre el 61 y $75 \%$, lo cual puede deberse a que la unión generada en el tiempo se haya debilitado o a que hubo uniones inespecíficas que se rompieron fácilmente. En conclusión, los pellets de $K$. marxianus CIDCA 8154 sólo liberaron una cantidad detectable de aflatoxina en el primer lavado y la máxima retención la presentaron los pellets obtenidos a los 30 minutos de co-incubación.

\subsubsection{Estabilidad del complejo L. plantarum 83114 - aflatoxina AFB1.}

La cantidad de aflatoxina AFB1 liberada al sobrenadante después del primer lavado del pellet de L. plantarum 83114 , se observa en la figura 7.11 .

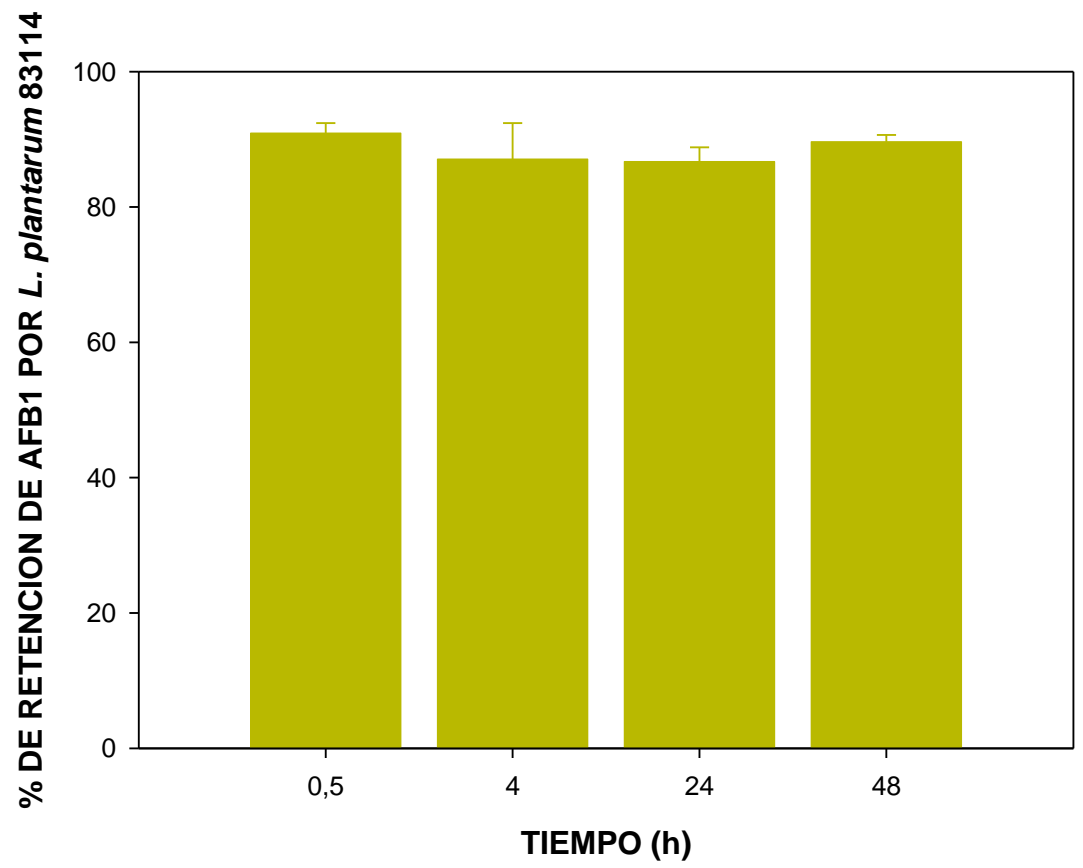

Figura 7.11 Porcentaje de retención de aflatoxina AFB1 por L. plantarum CIDCA 83114 en los lavados de pellets obtenidos durante 48 horas de co-incubación.

En la figura 7.11 se observa el porcentaje de retención de aflatoxina AFB1 determinado para los pellets de L. plantarum 83114 obtenidos a los tiempos 0,5, 
4, 24 y 48 h. Los mayores porcentajes de retención $(90,89 \pm 1,5 \%)$ se obtuvieron a la hora cero y no presentaron diferencia significativa con los obtenidos a las horas $48(89,63 \pm 2,13 \%), 4(87,07 \pm 5,35 \%)$ y $24(86,69 \pm 1,0 \%)$.

L. plantarum 83114 demostró capacidad de retener aflatoxina AFB1 después del primer lavado y no fue detectable la liberación de AFB1 en los lavados subsiguientes, observándose lo mismo para K. marxianus 8154. La levadura presentó su máxima capacidad de retención en el pellet obtenido a los 30 minutos, con valores de $77,31 \pm 9,53 \%$. A 0,5 horas, se observó que la capacidad de retención de $L$. plantarum $90,89 \pm 3,03 \%$ fue superior a la de la levadura. La capacidad de retención de K.marxianus 8154 descendió significativamente $(P<0,05)$ con respecto a los siguientes períodos de coincubación desde $38,19 \pm 9,47 \%$ a la hora 4 hasta $28,15 \pm 8,10 \%$ y $25,12 \pm 8,70$ a las horas 24 y 48 respectivamente. Por el contrario, L. plantarum 83114 mantuvo una capacidad de retención de aflatoxina superior al $86 \%$ durante todo el tiempo de coincubación de $87,07 \%, 86,69 \%$ y $89,63 \%$ a las horas 4,24 y 48 respectivamente y sólo presentó diferencia significativa entre la retención de las horas 0 y 24 .

En un estudio previo sobre las propiedades cepa dependientes en la reversibilidad del complejo bacteria - aflatoxina AFB1, se evaluaron diferentes cepas de L. casei. A partir de diferentes lavados con PBS, se estableció que \% AFB1 liberado, estaba entre indetectable y $9,2 \%$, lo cual sugería que al menos una porción de la aflatoxina se captura irreversiblemente (Hernández-Mendoza, García \& Steele, 2009), lo cual coincidió con los resultados obtenidos con $K$. marxianus 8154 y con $L$. plantarum 83114. En la investigación con cepas de $L$. casei se sugiere que la variación entre cepas se debe ya sea a que hay sitios de unión completamente diferentes entre cepas diferentes o más probablemente que hay diferencias menores entre sitios de unión similares de cepas diferentes, lo cual varía de forma cepa - dependiente (Hernández-Mendoza, García \& Steele, 2009). Por lo tanto, la variación en la capacidad de retener AFB1 puede ser diferente entre una bacteria y una levadura hasta el punto donde no varíe en 
una, mientras que en la otra disminuya en pellets obtenidos a diferentes tiempos de coincubación.

También se encontró coincidencia en cuanto a que puede ocurrir desde muy poca a ninguna liberación de aflatoxina tal como $L$. casei 7R1, y en esta investigación, L. plantarum 83114 liberó sólo un 9,11\% del total que retuvo. Por último debe resaltarse que la capacidad de capturar establemente AFB1 en un medio acuoso es muy relevante en el uso de microorganismos para captura de aflatoxinas en alimentos fermentados, donde el objetivo es capturarlas antes del consumo. Otra estrategia posible consiste en evitar la absorción de la aflatoxina en el organismo capturándola con microorganismos en el tracto Gl, y lograr mantener el complejo bacteria - aflatoxina durante el tracto $\mathrm{Gl}$, hasta ser eliminado con las heces.

Dado que el tracto Gl posee unas propiedades específicas, se decidió estudiar el efecto del pH en la capacidad de captura de aflatoxina, así como la capacidad de capturar de los microorganismos vivos, muertos y a diferentes concentraciones de ellos. Estos estudios son importantes ya que los probióticos que se adhieren a la pared intestinal pierden capacidad de adhesión en presencia de compuestos como el mucus, disminuyendo así el peligro de acumular la aflatoxina AFB1 en el hospedero. De este modo se podría garantizar que los probióticos que se están usando son medios potentes y seguros para reducir la absorción y aumentar la excreción de AFB1 en el organismo (Gratz, Mykkänen, Ouwehand, Juvonen, Salminen \& El-Nezami, 2004).

\subsubsection{Determinación de la capacidad de captura de aflatoxina AFB1 por microorganismos totales del gránulo de kefir CIDCA AGK1, L. plantarum 83114 y K. marxianus 8154 en solución salina a diferentes pH.}

A lo largo del tracto gastrointestinal la presencia de fluidos como el alimento ingerido, el jugo gástrico, el jugo pancreático, las sales biliares y otros, determinan cambios significativos en el pH. Es así como el pH del estómago, dada la presencia de ácido clorhídrico, puede variar entre 1 y 5 en un período de 
24 horas donde el valor mínimo corresponde a los estadios entre comidas y el máximo a la hora de la ingesta de alimentos. En el intestino delgado el $\mathrm{pH}$ del quimo aumenta dada la presencia del jugo intestinal ( $\mathrm{pH} 7,6)$, el jugo pancreático ( $\mathrm{pH} 7,1-8,2)$ y la bilis ( $\mathrm{pH} 7,6-8,6)$. En el duodeno, el pH varía entre 5,7 y 6,4; en el yeyuno entre 5,9 y 6,8 y en el Íleon entre 7,3 y 7,7. En el tramo inicial del intestino grueso, el ciego, el pH desciende alrededor de 5,7, debido a la fermentación bacteriana de los carbohidratos que no fueron absorbidos en el intestino delgado, liberando ácidos grasos de cadena corta como propionato, butirato y acetato.

El pH se mantiene levemente ácido tanto en el colon ascendente $(5,6)$ como transverso $(5,7)$ y asciende a 6,6 en el colon descendiente y sigmoideo. Por último, el pH del recto varía entre 6,6 a 6,8. (Wilson, 2005). Dado que el encuentro entre los microorganismos y la aflatoxina AFB1 puede tener lugar tanto antes como durante la ingesta del alimento, se evaluó la capacidad de captura que presentan los microorganismos del kefir cuando el desafío se realizó directamente a valores de $\mathrm{pH}$ del tracto Gl. Los microorganismos fueron crecidos en PS al 5\% y la aflatoxina fue preparada en solución salina (150 ppb) que se llevó a pH 2,1; 5,1; 7,1 y 8,1; el desafío se hizo como se describió anteriormente, por un período de 30 minutos. Al final del desafío, se hicieron los recuentos de los microorganismos presentes a fin de determinar si el cambio brusco de $\mathrm{pH}$ alteró su viabilidad. En la figura 7.12 se presentan los porcentajes de captura de aflatoxina AFB1 por los microorganismos totales del gránulo de kefir CIDCA AGK1, por L. plantarum 83114 y K. marxianus 8154. 


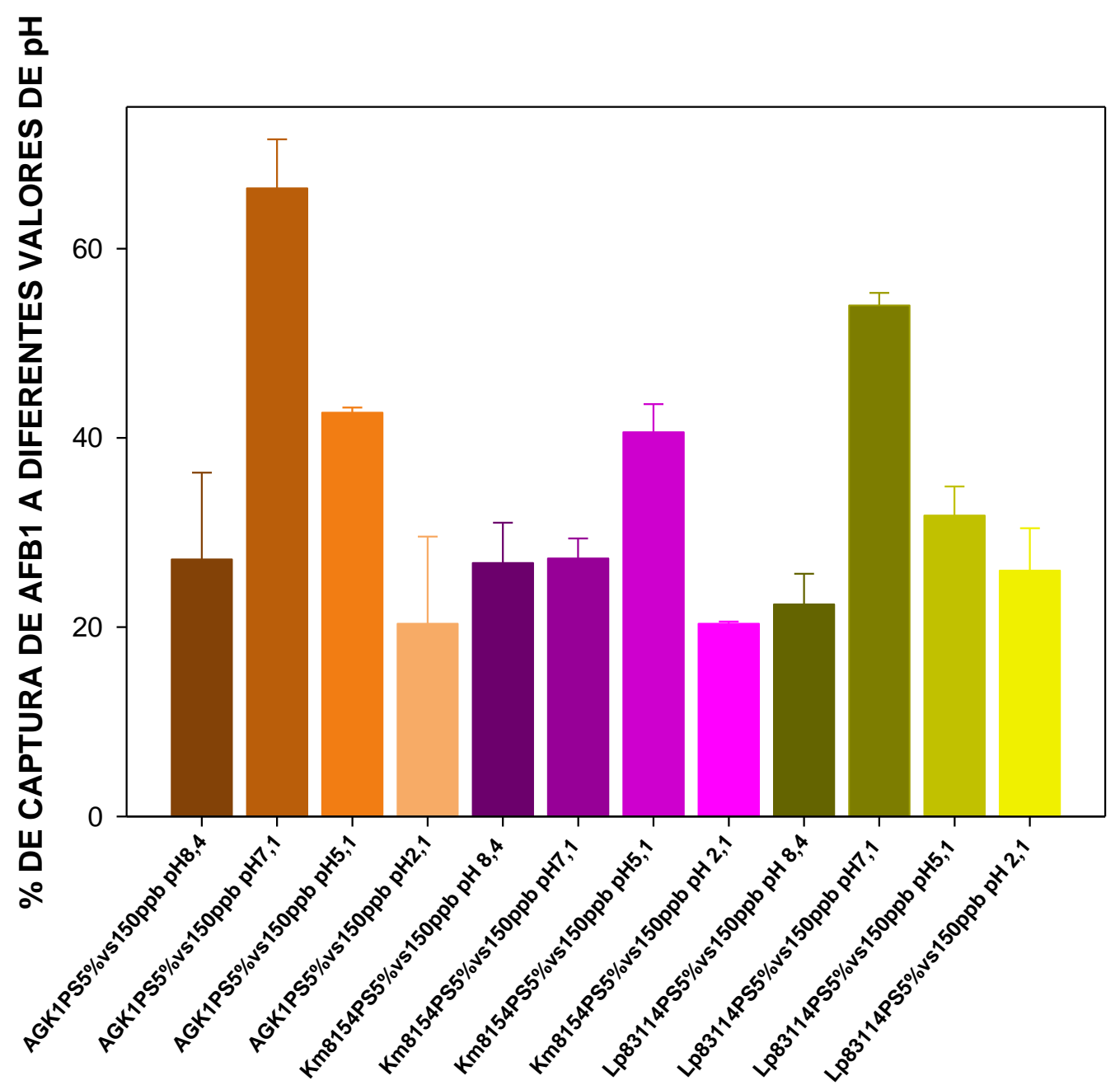

Figura 7.12 Porcentaje de captura de AFB1 por microorganismos totales del gránulo CIDCA AGK1, L. plantarum 83114 y K. marxianus 8154, a diferentes valores de $\mathrm{pH}$.

Tanto los microorganismos totales del kefir como los microorganismos individuales no perdieron la capacidad de capturar aflatoxina; sin embargo, ésta varió con los cambios de $\mathrm{pH}$ del medio y entre los microorganismos. $K$. marxianus 8154 tuvo su máxima capacidad de captura a pH de 5,1 y la mínima a $\mathrm{pH} 2,1$, mientras que a $\mathrm{pH} 7,1$ y 8,4 no presentó diferencias significativas. $L$. plantarum 83114 presentó un comportamiento diferente frente a los diferentes pH. La máxima captura tuvo lugar a pH 7,1 seguido de $\mathrm{pH} 5,1$ y 2,1 mientras que la mínima captura fue a pH 8,4. Lo anterior permite suponer que en la levadura y 
en la bacteria puedieron ocurrir cambios de conformación en la pared al cambiar el pH, que permitieron la disposición de diferentes sitios de unión a aflatoxinas.

Al parecer, en el caso de la levadura, el pH de 5,1 favoreció la mayor disposición de sitios de unión a AFB1 que cuando estuvo a pH cerca de la neutralidad, y que éstos se redujeron al estar sometida a un $\mathrm{pH}$ muy ácido. En el lactobacilo se pudo observar que a pH 8,4 parecía ocurrir la menor exposición de sitios a la micotoxina y que estos alcanzaron su mayor disposición a pH 7,1, mientras que iban descendiendo a medida que bajaban a $\mathrm{pH}$ de 5,1 y 2,1 pero sin una diferencia significativa entre ambos. El hecho de que el recuento a pH 7,1 y 5,1 era equivalente pero descendía la captura, indican que la captura no está relacionada con la viabilidad. La disminución en la captura a pH 5,1 puede deberse a un cambio en la conformación de la pared debida al descenso de pH.

Los microorganismos provenientes del gránulo de kefir tuvieron la máxima capacidad de captura a pH 7,1 (66,38 $\pm 5,1782)$, seguida de la obtenida a pHs 5,1 $(42,68 \pm 0,5433)$ y $2,1(42,19 \pm 9,0342)$, mientras que a $\mathrm{pH} 8$ presentaron una mínima captura $(27,17 \pm 9,1688)$. No obstante, se estableció que sólo hubo diferencia estadísticamente significativa $(P<0,05)$ entre los porcentajes de captura obtenidos a los mayores $\mathrm{pH}$ de 7,1 y 8,4. De allí que el pH óptimo para la captura de aflatoxina AFB1 por los microorganismos totales del kefir es 7,1. En cuanto al recuento de microorganismos del gránulo a los diferentes pHs, éstos disminuyeron en un orden sólo a pH 2,1. Este descenso no afectó significativamente la capacidad de captura pues fue igual a la obtenida a $\mathrm{pH} 8$, cuyo recuento fue superior; además, aunque su \% de captura fue un poco inferior a la máxima obtenida a pH 7,1, no tuvieron diferencia significativa entre sí.

Se pudo observar una tendencia similar en la variación del porcentaje de captura del kefir y de $L$. plantarum 83114, lo que se corresponde con el hecho de que las bacterias lácticas en el kefir prevalecen o están en una concentración diez veces 


\section{ESTUDIO DE LA CAPACIDAD DE DECONTAMINACIÓN DE AFLATOXINA AFB1 POR MICROORGANISMOS DEL KEFIR.}

superior a la de las levaduras, determinando el comportamiento del kefir frente a la captura.

En la tabla 7.9 se presentan los recuentos de todos los microorganismos evaluados a los diferentes valores de $\mathrm{pH}$. se determinó que a pesar de los $\mathrm{pH}$ ácidos como en el estómago, los microorganismos no perdieron totalmente su viabilidad. L. plantarum 83114 tuvo un recuento del orden de $10^{9} \mathrm{UFC} / \mathrm{ml}$ a pH $8,1,7,1$ y 5,1 ; mientras que a $\mathrm{pH} 2,1$ el recuento se redujo en 3 órdenes, pero no perdió la capacidad de captura. Es decir, a este pH su recuento se redujo, pero su capacidad de captura fue similar a la obtenida a $\mathrm{pH} 8,1$, lo cual podría explicarse en que a dicho pH ácido, la conformación de la pared del microorganismo podría ofrecer una cantidad de sitios de unión a la aflatoxina que le permitirían lograr un \% de captura similar al que alcanzó cuando estuvo en un recuento tres órdenes superiores pero a otro valor de $\mathrm{pH}$ donde tal vez no se favorecía tanto la presencia de sitios de unión a AFB1. Por su parte, $K$. marxianus 8154 tuvo un recuento máximo a pH 7,1 en un orden de $10^{8} \mathrm{UFC} / \mathrm{ml}$, mientras que a los otros pH estuvo un orden por debajo. Su máxima capacidad de captura se dio a pH 5,1 lo cual podría explicarse también por la disposición de sitios de captura a dicho $\mathrm{pH}$.

A pH 8,4 y 7,1 la levadura capturó un \% muy similar de aflatoxina aún cuando existía diferencia en su recuento, la cual no hizo efecto al parecer sobre el secuestro. Por último, aún cuando la levadura tuvo el mismo orden de recuento a $\mathrm{pH}$ 2,1 que a pH 8,4, su capacidad de captura fue inferior, evidenciándose que a este $\mathrm{pH}$ disminuyeron fuertemente los posibles sitios de unión a la aflatoxina.

Tabla 7.9 Recuentos de los microorganismos después del desafío con aflatoxina AFB1 a diferentes valores de $\mathrm{pH}^{1}$.

\begin{tabular}{|c|c|c|c|c|}
\hline \multirow{2}{*}{ Microorganismo } & \multicolumn{4}{|c|}{ Recuento (UFC/mI) } \\
\cline { 2 - 5 } & $\mathbf{p H ~ 2 , 1}$ & $\mathbf{p H ~ 5 , 1}$ & $\mathbf{p H ~ 7 , 1}$ & $\mathbf{p H ~ 8 , 4}$ \\
\hline Microorganismos del & $\mathrm{BAL}$ & $\mathrm{BAL}$ & $\mathrm{BAL}$ & $\mathrm{BAL}$ \\
gránulo de kefir & $1,12 \times 10^{7} \pm 2,26 \times 10^{6}$ & $1,04 \times 10^{8} \pm 9,90 \times 10^{6}$ & $5,01 \times 10^{8} \pm 7,78 \times 10^{7}$ & $1,22 \times 10^{8} \pm 3,54 \times 10^{6}$ \\
CIDCA AGK1 & $\mathrm{LEV}$ & $\mathrm{LEV}$ & $\mathrm{LEV}$ & $\mathrm{LEV}$ \\
& $3,86 \times 10^{6} \pm 3,11 \times 10^{5}$ & $1,56 \times 10^{7} \pm 4,43 \times 10^{6}$ & $2,69 \times 10^{7} \pm 9,19 \times 10^{6}$ & $1,99 \times 10^{7} \pm 5,54 \times 10^{6}$ \\
\hline L. plantarum 83114 & $2,25 \times 10^{6} \pm 7,07 \times 10^{4}$ & $5,11 \times 10^{9} \pm 3,32 \times 10^{8}$ & $1,28 \times 10^{9} \pm 9,38 \times 10^{7}$ & $5,21 \times 19^{9} \pm 7,21 \times 10^{8}$ \\
\hline K. marxianus 8154 & $6,83 \times 10^{7} \pm 6,13 \times 10^{6}$ & $5,43 \times 10^{7} \pm 2,12 \times 10^{6}$ & $2,28 \times 10^{8} \pm 5,33 \times 10^{7}$ & $7,63 \times 10^{7} \pm 9,35 \times 10^{6}$ \\
\hline
\end{tabular}

'La concentración inicial de los microorganismos fue de $10^{8} \mathrm{UFC} / \mathrm{ml}$ y $10^{\prime} \mathrm{UFC} / \mathrm{ml}$ de BAL y LEV para el kefir; $19^{9} \mathrm{UFC} / \mathrm{ml}$ de $L$. plantarum 83114 y $10^{8} \mathrm{UFC} / \mathrm{ml}$ de K. marxianus 8154 . 
Previamente, otros autores han estudiado el efecto del $\mathrm{pH}$ en la capacidad de secuestrar aflatoxina AFB1 y otros compuestos tóxicos y no hay un consenso final sobre este efecto. Algunos investigadores han planteado la importancia de determinar la capacidad de captura de las bacterias al $\mathrm{pH}$ del intestino delgado (6-8), dado que este es el punto clave de la digestión donde se inhibe la absorción de la aflatoxina (Haskard, Binnion \& Ahokas, 2000). Estos autores demostraron que la capacidad de secuestrar aflatoxina AFB1 por parte de $L$. rhamnosus GG ya fuera viable o muerto por acidez o por calor, era independiente del $\mathrm{pH}$ de la solución en un rango de 2,5 a 8,5, indicando entonces que la formación de puentes de hidrógeno no era determinante para el secuestro y que éste podría ocurrir en cualquier punto del tracto Gl (Haskard, Binnion \& Ahokas, 2000).

En contraste con lo anterior y de acuerdo a lo que se pudo determinar en esta investigación, algunos autores han planteado que la captura de compuestos cancerígenos como aminas heterocíclicas formadas durante la cocción de alimentos ricos en proteínas variaba entre diferentes BAL y diferentes valores de $\mathrm{pH}$. Streptococcus thermophilus 1131 capturó $85 \%$ o más de Trp-P-1 a pH entre 4 y 9 mientras que $L$. delbrueckii subsp. bulgaricus 2038 capturó el máximo a pH 4 y menos del $50 \%$ cuando éste se redujo a 7. (Terahara, Meguro \& Kaneko, 1998).

La captura de aflatoxinas y compuestos cancerígenos (aminas heterocíclicas) dependía de las condiciones de $\mathrm{pH}$ durante la incubación y dicho efecto fue mayor sobre Bifidobacterium longum que sobre L. acidophilus (Bolognani, Rumney \& Rowland, 1997). Así mismo se evaluó la capacidad de secuestro de Trp-P-2 por Streptococcus cremoris Z-25, directamente en jugo gástrico y se concluyó que ésta variaba con el cambio de $\mathrm{pH}$ y fué mayor a pH entre 4 y 8 que a pH ácido de 1,2, 1,48 y 2,1 (Zhang \& Ohta, 1991). La captura de aflatoxina AFB1 a lo largo del tracto GI depende del recuento que haya en los diferentes compartimentos del tracto y del estado fisiológico de los microorganismos 
(Hernández-Mendoza, García \& Steele, 2009). Dado que el pH del estómago es muy ácido, el recuento de microorganismos en él es muy bajo, usualmente inferior a $10^{3}$ UFC por gramo de contenido estomacal. Éste aumenta a $10^{4}$ en el duodeno hasta alcanzar $10^{7}$ UFC por gramo de contenido intestinal al final del íleo (Booijink, Zoetendal \& Kleerebezem, 2007). Otros estudios in vivo previos demostraron que al consumir leche fermentada con L. casei, el recuento del probiótico en el íleo fue 10 a 100 veces superior a la microbiota residente (Oozeer, Leplingard, Mater, Mogenet, Michelin, Seksek, Marteau, Dore, Bresson, $\&$ Corthier, 2006). Aunque los resultados que se obtuvieron en este estudio, fueron hechos in vitro, se demostró que el recuento de L. plantarum 83114 descendió hasta $10^{6} \mathrm{a} \mathrm{pH}$ estomacal y en el pH cercano al del íleon alcanzó un recuento de $10^{7}$. K. marxianus 8154 tuvo un recuento de $10^{7}$ en ambos pH. Estos recuentos son superiores a los que han sido indicados en el estómago y son similares a los del íleon de acuerdo a lo indicado por Boojink, Zoetendal \& Kleerebezem, 2007. Los resultados obtenidos tanto con kefir entero como con los microorganismos aislados, hacen interesante el estudio de estos microorganismos en la captura de aflatoxina AFB1, ya que demostraron que son capaces de sobrevivir y capturar aflatoxina cuando el desafío tiene lugar a pHs similares a los del tracto digestivo. No obstante, deberán realizarse estudios in vitro donde se analice la captura de aflatoxina combinando la variación de $\mathrm{pH}$ con la presencia de jugos gástricos, pancreáticos, intestinales y biliares.

\subsubsection{Captura de aflatoxina AFB1 en presencia de microorganismos viables y no viables.}

Considerando que los microorganismos seleccionados cumplían con la capacidad de capturar aflatoxina AFB1, se buscó determinar si es condición necesaria para la captura la presencia de microorganismos vivos, o si aquellos no viables (pasteurizados) conservaban la capacidad de captura presentada por los viables. Para evaluarlo, los cultivos de L.plantarum 83114 y de Kluyveromyces marxianus 8154 se cosecharon en fase estacionaria, con un recuento de $6,3 \times 10^{9} \pm 1,34 \times 10^{8}$ para L.plantarum 83114 y de $1,48 \times 10^{8} \pm 5,22 \times 10^{7}$ para K. marxianus 8154 y se sometieron a pasteurización. Se comprobó que los 
microorganismos no eran viables al observar que no hubo crecimiento de las estrías de los microorganismos inoculados en medio sólido. Posteriormente se sometieron al desafío con aflatoxina AFB1, como se indicó previamente.

La figura 7.13 muestra que la capacidad de captura de L. plantarum 83114 fue de $55,00 \pm 3,33 \%$ para las células viables y de $40,0 \pm 3,57 \%$ para las no viables. En el caso de $K$. marxianus 8154 , las levaduras viables capturaron $27,27 \pm 2,11 \%$ y las no viables un $18,15 \pm 2,22 \%$. A partir de los resultados obtenidos pudo establecerse que la capacidad de captura de aflatoxina por parte de $L$. plantarum 83114 y por $K$. marxianus 8154 , no se perdió aunque disminuyó alrededor de un $10 \%$ para ambos, lo cual podría atribuirse a cambios en la conformación de la pared y alteración de los sitios de captura debidos a la aplicación de calor.

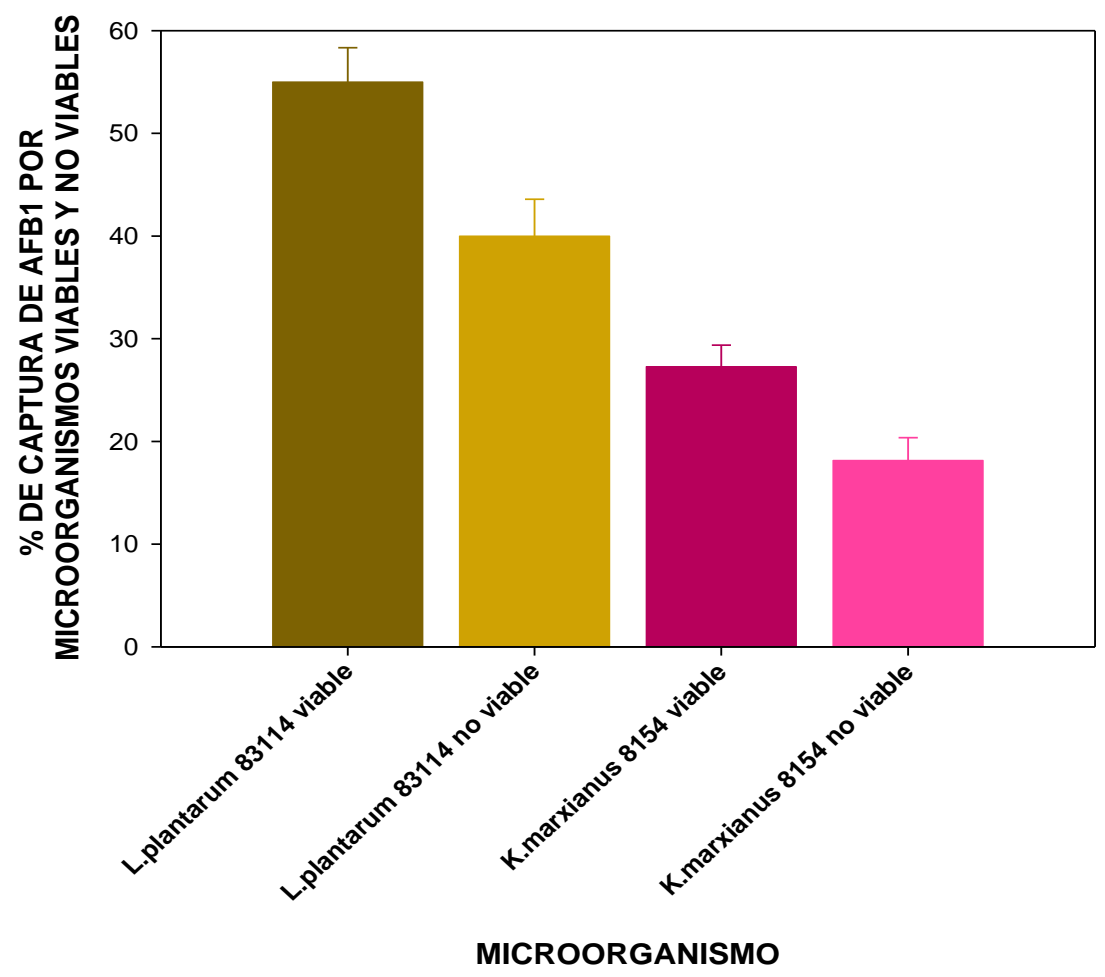

Figura 7.13 Porcentaje de captura de aflatoxina AFB1 por L. plantarum 83114 y K. marxianus 8154 viables y no viables por pasteurización. 
A través de diferentes investigaciones previas, se demostró que las BAL tratadas con calor capturaban efectivamente aminoácidos pirolizados (Orrhage, Sillerstroom, Gustafsson, Nord \& Rafter, 1994; Rajendran \& Ohta, 1998; Zhang \& Ohta, 1990, 1991, 1993; Thyagaraja \& Ozono, 1994) y aflatoxinas (El-Nezami, Kankaanpää, Salminen \& Ahokas, 1998b; Thyagaraja \& Ozono, 1994) y que las bifidobacterias muertas por calor capturaban aflatoxina AFB1 de forma cepa dependiente (Oatley, Rarick, Ji \& Linz, 2000). La remoción de aflatoxinas envuelve el secuestro probable a nivel de la pared celular o de sus componentes (El-Nezami, Kankaanpää, Salminen \& Ahokas, 1998b; Haskard, El-Nezami, Kankaanpää, Salminen \& Ahokas, 2001) y el descenso en esta capacidad tal como ocurrió en la presente investigación, puede deberse a la eliminación de algunos componentes específicos de la pared celular tal como se ha demostrado con carbohidratos y proteínas de pared que al ser retirados, produjeron un descenso en la captura de AFB1 de un lactobacilo como $L b$. rhamnosus GG (Haskard, Binnion \& Ahokas, 2000) y de L. casei (Hernández-Mendoza, García $\&$ Steele, 2009).

Adicionalmente, cabe resaltar que la captura de aflatoxina AFB1 aun cuando disminuyó, no se perdió debida a la muerte por pasteurización de los microorganismos, lo cual es un elemento positivo para tener en cuenta, ya que así haya muerte microbiana, se conserva parte de la capacidad de secuestro de la micotoxina. El hecho de que la capacidad de secuestro de los microorganismos muertos por calor no se pierda totalmente o se reduzca comparado con las células viables, indica que éstas no metabolizan las aflatoxinas. El tratamiento por calor puede cambiar el sitio de captura original del microorganismo viable y/o exponer nuevos sitios de unión al desnaturalizar las proteínas (Haskard, Binnion \& Ahokas, 2000). Es por ello que en estudios posteriores se debería estudiar la capacidad de captura de los microorganismos muertos por otros medios como radiación UV, o aplicación de calor más fuerte como esterilización. También se deberá extraer la pared celular y estudiar la capacidad de captura de ésta y de algunos de sus componentes. 


\subsubsection{Capacidad de captura de aflatoxina AFB1 con diferentes concentraciones de L. plantarum 83114 y K. marxianus 8154.}

Aún cuando en el estudio a diferentes $\mathrm{pH}$ se observó que a un pH determinado podía disminuir el recuento microbiano pero conservar parte de su capacidad de captura de aflatoxina, se investigó el efecto de la variación de la concentración de los microorganismos en la captura de aflatoxina AFB1 en PBS y a pH 7,1. En la figura 7.14 se observa el descenso en la captura de aflatoxina AFB1 cuando disminuye la concentración de L. plantarum 83114 y de K. marxianus 8154 en el medio del desafío, hasta casi no observarse captura a la dilución 1/1000.
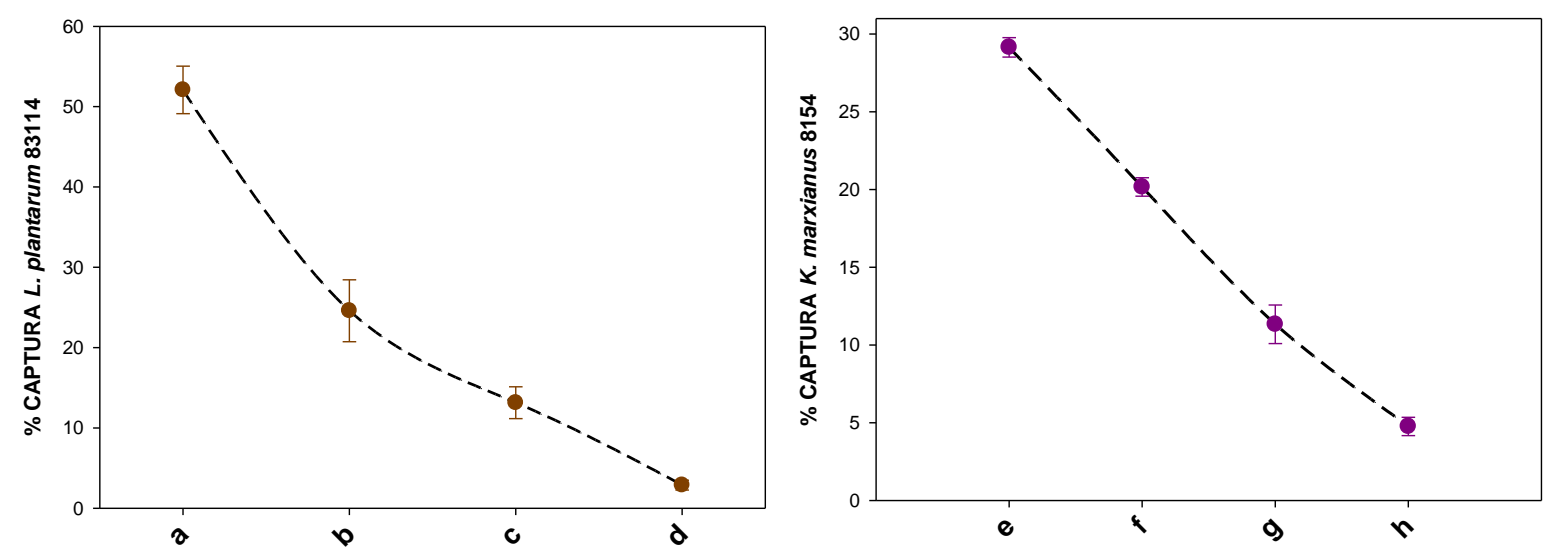

Figura 7.14 Porcentaje de retención de aflatoxina AFB1 (150 ppb) por L. plantarum CIDCA 83114 y K. marxianus CIDCA 8154 en diferentes concentraciones de microorganismo. L. plantarum 83114: a:concentración directa; b: concentración 1/10; c: concentración 1/100; d: concentración 1/1000. K. marxianus 8154: e: concentración directa; f: concentración 1/10; g: concentración 1:100; h: concentración 1/1000.

Los desafíos fueron realizados a $30^{\circ} \mathrm{C}$ por 30 minutos. La concentración inicial de $L$. plantarum fue de $1,82 \pm 0,276 \times 10^{9}$ y la de $K$. marxianus 8154 de $1,81 \pm 0,355 \times 10^{8}$.

Para el lactobacilo, el porcentaje de captura fue $52,08 \pm 7,45 \%$ en la concentración $1,82 \pm 0,276 \times 10^{9} \mathrm{UFC} / \mathrm{ml}$; disminuyó a la mitad $(24,59 \pm 9,86 \%)$, a la cuarta parte $(13,14 \pm 8,98 \%)$, y 20 veces $(2,88 \pm 0,61 \%)$ a medida que su concentración se redujo en 10, 100 y 1000 veces respectivamente. De igual manera, $K$. marxianus 8154 capturó $29,15 \pm 0.623 \%$ en la concentración original de $1,81 \pm 0,355 \times 10^{8}$ y se redujo en $1,45(20,17 \pm 0.59 \%), 2,6(20,17 \pm 0.59 \%)$ y 7,25 $(4,76 \pm 0.59 \%)$ veces a medida que su concentración disminuyó 10, 100 y 1000 
veces respectivamente. A partir de lo anterior se concluyó que el número de microorganismos presente en el desafío, es determinante en el \% de captura, pues al pH evaluado, se estableció que la captura disminuye proporcionalmente al descenso de concentración microbiana. Al comparar las capturas de los dos tipos de microorganismo cuando están en la misma concentración expresada como UFC/ml, se observó que la levadura capturaba entre 5 y diez veces más, lo cual podría explicarse por la mayor área superficial de la levadura.

\subsection{CONCLUSIONES}

Los microorganismos totales del kefir, los lactobacilos y levaduras aislados del gránulo de kefir demostraron capacidad de capturar aflatoxina AFB1 en PBS y fue cepa dependiente. El único microorganismo que no capturó aflatoxina AFB1 fue $S$. boularddii proveniente de la colección CINDEFI.

La capacidad de secuestrar aflatoxina AFB1 cambió de acuerdo al medio de cultivo del microorganismo y no tuvo relación con el porcentaje de hidrofobicidad superficial.

Los microorganismos totales del kefir no tuvieron una captura significativamente diferente de aflatoxina AFB1 durante 48 horas de coincubación mientras que los aislados si presentaron variaciones. En todos, la máxima captura se obtuvo a los 30 min de coincubación.

L. plantarum 83114 y K. marxianus 8154 liberaron un porcentaje detectable de la aflatoxina capturada, cuando fueron lavados una vez con PBS, siendo mucho mayor la capacidad de retención del lactobacilo.

L. plantarum 83114 y K. marxianus 8254 redujeron pero no perdieron totalmente su capacidad de secuestrar aflatoxina AFB1 cuando fueron muertas por calor.

La variación en el $\mathrm{pH}$ del medio del desafío también generó cambios en la capacidad de captura, y los $\mathrm{pH}$ de máxima captura fueron variables, para los microorganismos del kefir entero, el lactobacilo y la levadura. 


$$
\begin{aligned}
& \text { CAPÍTULO 8: } \\
& \text { CONCLUSIONES } \\
& \text { GENERALES Y } \\
& \text { PERSPECTIVAS }
\end{aligned}
$$




\section{CONCLUSIONES GENERALES Y PERSPECTIVAS}

\section{CONCLUSIONES GENERALES Y PERSPECTIVAS}

Los años 60 dieron inicio a los estudios con aflatoxinas, su identificación y el estudio de los hongos que las producían. A partir de esto, comenzaron a realizarse múltiples estudios sobre cómo eliminarlas de los alimentos. Desde los 90's, el aumento de las investigaciones con microorganismos probióticos permitió encontrar que en especial, las Bacterias Ácido Lácticas podían tener efectos antifúngicos y por otro lado, disminuir la concentración de micotoxinas en distintos sustratos, gracias a su capacidad de adsorción a nivel de pared.

Aún cuando este trabajo de tesis partió de los antecedentes mencionados y podría considerarse redundante, éste buscó ampliarlos con la aplicación de un producto natural y milenario tal como es el kefir. Los estudios sobre las propiedades probióticas del kefir se han profundizado en las dos últimas décadas en especial acerca de su capacidad antimicrobiana y contra patógenos intestinales, pero no tanto en lo relativo a su capacidad antifúngica.

La pregunta inicial fue si esta comunidad microbiana podría tener también un efecto antifúngico?, si esto se debería a la presencia de ácidos orgánicos producidos por las BAL?; si éste podría ampliar la vida útil de un alimento en cuanto a la inhibición del crecimiento fúngico y si además éste tendría la capacidad de capturar la aflatoxina AFB1, producida por A. flavus?. Estas fueron las preguntas básicas por las cuales se decidió iniciar esta investigación.

En primer lugar se investigó sobre la capacidad de los ácidos orgánicos láctico y acético solos y en mezclas para inhibir el crecimiento de A. flavus. En este estudio se pudo determinar que ambos ácidos individualmente pueden llegar a inhibir totalmente el crecimiento del hongo. Y que las mezclas de ambos también pueden detener su crecimiento, siendo necesarias concentraciones menores de cada ácido a las que se usaron cuando estaban individualmente en el medio de cultivo.

Una vez demostrado lo anterior, se quiso estudiar el efecto de los sobrenadantes libres de células (SLC) obtenidos de leche fermentada con gránulos de kefir CIDCA AGK1 y CIDCA AGK2 sobre el crecimiento de A. flavus. En esta etapa se encontró que el principal efecto antifúngico se logra alargando la fase 
de latencia del hongo, mas no es tan significativo sobre la tasa de crecimiento. A medida que desciende el pH de la leche fermentada, el efecto antifúngico se incrementa y una mayor concentración del SLC en el medio de cultivo causa efecto antifúngico. También se determinó que los SLC obtenidos de la leche fermentada con gránulo CIDCA AGK1 a $30^{\circ} \mathrm{C}$ y que alcanzó un pH de 3,3 fueron más efectivos que los obtenidos con éste y con AGK2 a 20 y $37{ }^{\circ} \mathrm{C}$. Pudo relacionarse que la acción antifúngica aumentaba con la concentración de ácidos orgánicos no disociados.

Esta tesis buscaba además la aplicación los resultados obtenidos en la prolongación de la vida útil de un producto derivado de un cereal. Éste fue la arepa, producto de maíz, muy consumido en Colombia y Venezuela. Se estudió el efecto causado por los ácidos puros y por el kefir cuando eran adicionados en la masa de la arepa previa a su cocción. En ambos casos pudo establecerse que la adición prolongaba la vida útil de la arepa y su resistencia a la contaminación artificial con hongos. También se determinó que la adición de una concentración efectiva de ácido láctico hacía poco aceptable la arepa a diferencia de la concentración empleada de acético y la mezcla de ambos, que no la diferenciaban significativamente del control. Posteriormente y en vista del poder inhibitorio del kefir, se adicionó este a la arepa prolongando la vida útil del producto. La prueba sensorial de las arepas con kefir se hizo en Colombia, dado que allí existen páneles entrenados para evaluar alimentos típicos del país. La adición de kefir a la masa de la arepa, generó los mismos sabores que la arepa tradicional pero incluyó otros relacionados con lo lácteo y las fermentaciones. Será muy interesante poder continuar todos los estudios sensoriales en especial en lo referente a las pruebas de aceptación del consumidor.

Una vez realizado el estudio con los ácidos puros y la leche fermentada con gránulos de kefir, surgió la pregunta sobre cómo sería el efecto antifúngico si se aprovechara un efluente de la industria quesera, sustrato más simple y económico que la leche para la fermentación, como es el permeado de suero y si éste producto fermentado se podría aplica en un alimento para animales. Para este estudio se decidió además ampliar los hongos a estudiar aislando e identificando a nivel molecular hongos filamentosos naturalmente presentes en 
alimento para pollos. En primer lugar, se estableció que el gránulo de kefir y algunos microorganismos aislados del kefir tenían la capacidad de fermentar el permeado de suero (PS) reconstituido en agua. En segundo lugar, se demostró que los SLC obtenidos de estos productos fermentados tenían la capacidad de reducir la germinación de los conidios de los hongos estudiados. Sin embargo, la mayor inhibición fúngica se obtuvo con el SLC proveniente del permeado de suero fermentado con gránulo de kefir (PSFG). A partir de ello se decidió evaluar la capacidad de aumentar la vida útil del alimento para pollos cuando el PSFG se adicionaba al alimento y se secaba hasta alcanzar su $\mathrm{a}_{\mathrm{w}}$ original. Al igual que con la arepa, se determinó la resistencia a la contaminación natural y artificial y se estableció que ambas eran superiores a la del alimento no adicionado. También se encontró que en el alimento adicionado del PSFG sobrevivían las levaduras y $B A L$ del kefir durante un mes de almacenamiento a $20^{\circ} \mathrm{C}$, aun cuando descendía su recuento.

Tanto en el permeado de suero como en la leche fermentados con gránulo de kefir se estudió si el efecto antifúngico se debía a la sola acción de los ácidos láctico y acético puros en la misma concentración que la determinada en los SLC; ó al pH, a la combinación de ambos o si podrían intervenir otros compuestos. En ambos casos se encontró que la sola disminución del pH con ácidos fuertes, no causaba casi inhibición fúngica. De otro lado, aún cuando se usaron ácidos orgánicos láctico y acético puros en las mismas concentraciones que en los productos fermentados, su capacidad de inhibición era inferior a la que se obtuvo cuando se usaban los SLC provenientes de las fermentaciones. Esto permitió concluir que aun cuando los ácidos orgánicos son causantes de la inhibición fúngica; en ésta deben participar otros compuestos cuyo estudio deberá continuarse.

Una vez estudiada la inhibición fúngica con el kefir, los microorganismos del kefir y con ácidos orgánicos puros, se pasó a la última pregunta formulada al inicio de la investigación. Se estudió la capacidad de los microorganismos del kefir de capturar aflatoxina AFB1 cuando se incubaban en medio líquido microorganismos y aflatoxina. Se comprobó la capacidad secuestrante de los microorganismos totales obtenidos del PSFG y de los microorganismos 
individuales aislados previamente de gránulos de kefir (colección CIDCA) cultivados también en PS. En primer lugar, se demostró que los microorganismos totales del gránulo (en concentración máxima de $10^{8}$ UFC/mI) capturan mayor porcentaje de aflatoxina AFB1 que los microorganismos individuales a la misma concentración. La capacidad de secuestro de aflatoxina AFB1 aumentó con la concentración de microorganismos; varió en el tiempo de incubación, siendo máxima en los primeros 30 minutos; fué variable de acuerdo al microorganismo (levadura o bacteria) y de acuerdo al pH del desafío; no dependía de la viabilidad del microorganismo ni de su hidrofobicidad superficial y la unión microorganismo-aflatoxina era reversible.

De esta investigación surgen preguntas que aún no han sido contestadas. Como esta línea de trabajo se continuará con nuevos becarios y tesis doctorales, a continuación se listan las perspectivas a desarrollar en un futuro cercano

Con respecto a la captura de aflatoxinas se propone determinar:

La relevancia de paredes celulares de levaduras y bacterias ácido lácticas del kefir,

Qué moléculas superficiales de dichos microorganismos están involucradas en la captura,

La acción de enzimas y moléculas presentes en el tracto gastrointestinal que pudieran inhibir o potenciar la captura (enzimas digestivas, bilis, mucus, $\mathrm{HCl}$ )

Papel del kefir y de los microorganismos aislados del kefir en la disminución de la absorción de aflatoxina en sistemas de células modelo del tracto gastrointestinal in vitro (líneas celulares) e in vivo (modelos animales ratas y aves). Por otro lado, se ha planteado la identificación de otros compuestos que pueden interactuar con el ácido láctico y acético del kefir en la inhibición fúngica. Además, es de interés poder profundizar los estudios sensoriales sobre la arepa con kefir, que se perfila como un producto con un valor agregado para la población. Sería de gran interés continuar el desarrollo de alimento para animales suplementados con PSFG y con microorganismos aislados del kefir. 


$$
\begin{gathered}
\text { CAPÍTULO 9: } \\
\text { REFERENCIAS } \\
\text { BIBLIOGRÁFICAS }
\end{gathered}
$$




\section{REFERENCIAS BIBLIOGRÁFICAS}

- Abarca M.L., Bragulat M.R., Castellá G. \& Cabañes F.J. (1994). Mycoflora and aflatoxins - producing strains in animal mixed feeds. Journal of Food Protection, 57, 256 - 258.

- $\quad$ Abraham A. \& De Antoni G.L. (1999). Characterization of kefir grains in cow's milk and in soya milk. Journal of Dairy Reserch, 66, 327-333.

- $\quad$ Acuña A., Diaz G.J. \& Espitia M.E. (2005). Aflatoxinas en maíz: Reporte de un caso en la Costa Atlántica colombiana. Revista de la Facultad de Medicina Veterinaria y de Zootecnia, Universidad Nacional, 52(2), 156-162.

- Adams M.R. \& Hall C.J. (1988). Growth inhibition of food-borne pathogens by lactic and acetic acids and their mixtures. International Journal of Food Science and Technology, 23, 287- 292.

- $\quad$ Allcroft R., Carnaghan R.B.A., Sargeant K. \& O'Kelly J. (1961). A toxic factor in Brazilian groundnut meal. Veterinary Records, 73, 428-429.

- $\quad$ Alm L. (1980). Effect of fermentation on lactose, glucose and galactose content in milk and suitability of fermented milk products for lactose intolerant individuals. Journal of Dairy Science, 65, 346 - 352.

- Álvarez M.T., Carvajal M., Ruisánchez N. \& Rojo F. (2000) AductosADN-Aflatoxina como biomarcadores de exposición en grupos de riesgo de cáncer de hígado. Revista Cubana de Oncología, 16, 35-9.

- $\quad$ Álvarez M. \& Restrepo L. (2003). La variedad de alimentos disponibles en el hogar: metodología para identificar vulnerabilidad a la inseguridad alimentaria y nutricional en hogares campesinos. Revista Salud Pública y Nutrución, 1- 13.

- $\quad$ Álvarez M., Benjumea M.V., Roldan P., Martínez M., Maya M. \& Montoya E.C. (2004). Perfil Alimentario y Nutricional de los hogares de Antioquia. Medellín: Divergráficas. 2004

- Amoa-Awua, Phyllis Anlobe W., Kpodo J., Halm K., Hayford M., Ewurafua A. \& Mogens J. (2007). The effect of applying GMP and HACCP to traditional food processing at a semi-commercial kenkey production plant in Ghana. Food Control, 18, 1449-1457. 
- AOAC. (1997). Official methods of analysis of AOAC international. $16^{\text {th }}$ Edition. $3^{\text {rd }}$ revision. AOAC Method 954, 01; Micro Kjeldahl method. Association of Official Analytical Chemists, Washington DC, USA.

- $\quad$ Apata D.F. (2008). Growth performance, nutrient digestibility and immune response of broiler chicks fed diets supplemented with a culture of lactobacillus bulgaricus. Journal of the Science of Food and Agriculture, 88(7), 1253-1258.

- $\quad$ Armando M.R., Dogi C.A., Pizzolitto R.P., Escobar F., Peirano M.S., Salvano M.A., Sabini L.I., Combina M., Dalcero A.M. \& Cavaglieri L.R. (2011). Saccharomyces cerevisiae strains from animal environmen with aflatoxin B1 detoxification ability and anti pathogenic bacteria influence in vitro. World Mycotoxin Journal, 4, 59-68.

- $\quad$ Ascioglu S., Rex J.H., de Pauw B., Bennett J.E., Bille J., Crokaert F., Denning D.W., Donnelly J.P., Edwards J.E., Erjavec Z., Fiere D., Lortholary O., Maertens J., Meis J.F., Patterson T., Ritter J., Selleslag D., Stevens D.A. \& Walsh T.J. (2002). Defining opportunistic invasive fungal infections in immunocompromised patients with cancer: An international consensus. Clinical Infectious Disease, 34, 7-14.

- AOAC. (1984) Association of Official Analytical Chemistry, Official Methods of Analysis (14th ed.) Washington D. C.

- Azziz-Baumgartner E., Lindblade K., Gieseker K., Schurz-Rogers H., Kieszak S., Njapau H., Schleicher R., McCoy L., Misore A., DeCock K., Rubin C. \& Slutsker L. (2005). Aflatoxin Investigative Group. Case control study of an acute aflatoxicosis outbreak, Kenya, 2004. Environmental Health Perspectives, 113, 1779-1783.

- Basílico J.C. (2008). Los hongos: problemática como contaminantes del ambiente y de los alimentos. Curso de Posgrado. Universidad Nacional del Litoral. Abril 2008.

- Begley M., Gahan C.G.M. \& Hill C. (2005). The interaction between bacteria and bile. FEMS Microbiological Review, 29, 625 - 651.

- Bennett J.W. \& Klich M. (2003). Mycotoxins. Clinical Microbiology Reviews, 16, 497-516. 
- Berenbaum M.C. (1977). Synergy, additivism and antagonism in immunosuppression. A critical review. Clinical \& Experimental Inmunology, 28, 1-18.

- Bisset J. (1991). A revision of the genus Trichoderma. I. Section Longibrachiatum. sect. nov. Canadian Journal of Botany, 62, 924 - 931.

- $\quad$ Blom H. \& Mortvedt C. (1991). Anti-microbial substances produced by food associated micro-organisms. Biochemical Society Transactions, 19, $694-$ 698.

- Blount W.P. (1961). Turkey "X" disease. Journal British Turkey Federation. 1, 5162.

- Bogaert J.C. \& Naidu A.S. (2000). Lactic acid. In A. S. Naidu (Ed.), Natural food antimicrobial systems, 613-635. Boca Raton, Florida: CRC Press.

- Bolognani F., Rumney C.J. \& Rowland I.R. (1997). Influence of carcinogen binding by lactic acid-producing bacteria on tissue distribution and in vivo mutagenicity of dietary carcinogens. Food Chemical and Toxicology, 35, $535-545$.

- Bonade A., Murelli F., Vescovo M. \& Scolari, G. (2001). Partial characterization of a bacteriocin produced by Lactobacillus helveticus. Letters in Applied Microbiology, 33, 153 - 158.

- Bonino M. \& Azcona J. (1992). Avicultura de campo, $2^{\text {a }}$ parte. Revista CHACRA, 740.

- Booijink C.C., Zoetendal E.G. \& Kleerebezem, M. (2007). Microbial communities in the human small intestine: coupling diversity to metagenomics. Future Microbiology, 2, 285 - 295.

- $\quad$ Botazzi V., Zacconi C., Sarra P.G., Dallavalle P. \& Parisi, M.G. (1994) Kefir. Microbiologia, chimica e tecnologia. L'industria del latte, 1, 41-62.

- $\quad$ Bressac B., Kew M., Wands J. \& Ozturk M. (1991). Selective G to T mutations of p53 gene in hepatocellular carcinoma from Southern Africa. Nature, 350, 429-431.

- $\quad$ Brialy C., Rivalland P., Coiffard L. \& De Roeck Holtzhauer Y. (1995). Microbiological study of lyophilized dairy kefir. Folia Microbiologica, 40, 198200. 
- $\quad$ Bron P.A., Molenaar D., de Vos W.M. \& Kleerebezem M. (2006). DNA micro-array based identification of bile-responsive genes in Lactobacillus plantarum. Journal of Applied Microbiology, 100, 728 - 738.

- $\quad$ Brul S. \& Coote P. (1999). Preservative agents in foods: mode of action and microbial resistance mechanisms. International Journal of Food Microbiology, 50, 1-17.

- Bueno D., Salvano M.A., Silva J.O., González S.N. \& Oliver G. (2001). Mycotoxins: Diagnosis and prevention in poultry. Boletín Micológico, 16, 23-36.

- Bueno D. (2003). Detoxificación de Micotoxinas Presentes en Alimentos de Aves de Corral. Tesis Doctoral. Universidad de Tucumán, Facultad de Bioquímica, Química y Farmacia - Centro de Referencia de Lactobacilos (CERELA). $217 \mathrm{p}$.

- Bueno D.J., Casale C.H., Pizzolitto R.P., Salvano M.A. \& Oliver G. (2007). Physical adsorption of aflatoxin B1 by lactic acid bacteria and Saccharomyces cerevisiae: a theoretical model. Journal of Food Protection, 70 , $2148-2154$.

- Busby W.F. \& Wogan G.N. (1984). Aflatoxins. In: Chemical Carcinogens, $2^{\text {nd }}$ Edition (Searle C. E., ed), 9461135. Washington, D.C.: American Chemical Society.

- C. A. A. Código Alimentario Argentino. (2006). Capítulo VIII. Alimentos Lácteos. ADMINISTRACIÓN NACIONAL DE ALIMENTOS. MINISTERIO DE SALUD. PRESIDENCIA DE LA NACIÓN. Argentina.

- C.A.A. (2006). Código Alimentario Argentino. Capitulo XIII. Bebidas Fermentadas.Art.1082-(Res2142,5.9.83). ADMINISTRACIÓN NACIONAL DE ALIMENTOS. MINISTERIO DE SALUD. PRESIDENCIA DE LA NACIÓN. Argentina,http://www.anmat.gov.ar/CODIGOA/CAPITULO XIII BebFermentada s(actualiz 09-06).pdf.

- $\quad$ CAA (Código Alimentario Argentino). Artículo 554 - (Res 22, 30.01.95).

- $\quad$ CAA (Código Alimentario Argentino). Artículo 576 - (Res 295, 14.04.99).

- Carnaghan R.B., Hartley R.D. \& O'Kelly J. (1963). Toxicity and Fluorescence Propertiesof the Aflatoxins. Nature, 200, 1101. 
- $\quad$ Cassio F., Leao C. \& Van Uden N. (1987). Transport of lactate and other short-chain monocarboxylates in the yeast Saccharomyces cerevisiae. Applied and Environmental Microbiology, 53, 509-513.

- $\quad$ CAST. (2003). Mycotoxins: Risks in Plant, Animal, and Human Systems. Task Force Report No, 139.Council for Agricultural Science and Technology. Ames, lowa. USA.

- $\quad$ CDC (Center for Disease Control and Prevention) (2004). Outbreak of aflatoxin poisoning-eastern and central province, Kenya, January-July, 2004. MMWR Morbility Mortal Weekly Report, 53, 790-792.

- $\quad$ Cevikbas A., Yemni E., Ezzedenn F.W., Yardimici T., Cevikbas U. \& Stohs S.J. (1994). Antitumoural antibacterial and antifungal activities of kefir and kefir grain. Phytotherapy Research, 8 (2), 78 - 82

- $\quad$ Choi S.T. \& Chang D.S. (2003). Identification of effective microorganisms from kefir fermented milk. Food Scice Biotechnol, 12, 476-479

- $\quad$ Christensen C.M. (1987). Food and Beverage Mycology 2 ed, New York: Van Nostrand Reinhold, 23-134.

- $\quad$ Ciegler A., Lillehoj E.B., Peterson R.E. \& Hall H.H. (1966). Microbial detoxification of aflatoxin. Journal of Applied Microbiology, 14, 934-939.

- $\quad$ Clung W. \& Cummins M. (1999). Conceptos de Genética. Prentice Hall, Iberia, Madrid. 5aㅡ ed. ISBN. 84-8322042-3, 365-368.

- $\quad$ Coker R.D. (1995). Controlling mycotoxins in oilseeds and oilseed cakes. Chemistry \& Industry, 7, 260-264.

- Collmer A., Ried J. \& Mount M. (1988). Assay Methods for Pectinc Enzymes. Methods in enzymology, 161, 333 - 334.

- ICONTEC. (2005) Instituto Colombiano de Normas Técnicas. Norma Técnica Colombiana. NTC 5372, Septiembre 14 de 2005. Arepas de Maíz Refrigerado. Requisitos del producto. Bogotá: ICONTEC; 2005.

- $\quad$ Conner D. E., Scott V. N. \& Bernard D. T. (1990). Growth inhibition and survival of Listeria monocytogenes as affected by acidic conditions. Journal of Food Protection, 53, 652- 655.

- $\quad$ Corsetti A., Gobbetti M., Rossi J. \& Damiani P. (1998). Antimould activity of sourdough lactic acid bacteria: identification of a mixture of organic acids 
produced by Lactobacillus sanfrancisco CB1. Applied Microbiology and Biotechnology, 50, 253-256.

- Cortinas C. (1998). Cáncer: ambiente y herencia. Méjico, FCE. http://bibliotecadigital.ilce.edu.mx/sites/ciencia/volumen2/ciencia3/096/html/sec _2.html

- $\quad$ Cotty P.J. (1988). Aflatoxin and sclerotial production by Aspergillus flavus: influence of $\mathrm{pH}$. Phytopathology, 78, 1250-1253.

- Cotty P.J., Bayman P., Egel D.S. \& Elias K.S. (1994). Agriculture, aflatoxins and Aspergillus. In: Powell KA (Ed) The genus Aspergillus. Plenum, New York, 1-27.

- Council for Agricultural Science and Technology, CAST. (2003). Mycotoxins: risk in plant, animal, and human systems. Ames, lowa, USA, Task Force Report No.139.

- $\quad$ Coursaget P., Depril N., Chabaud M., Nandi R., Mayelo V., LeCann P. \& Yvonnet B. (1993). High prevalence of mutations at codon 249 of the p53 gene in hyptocellular carcinomas from Senegal. British Journal of Cancer, 67, 13951397.

- Cramer J.A. \& Prestegard J.H. (1977). NMR studies of pH/induced transport of carboxylic acids across phospholipids vesicle membranes. Biochemical and Biophysical Research Communications, 75, 295-301.

- $\quad$ Cuppers H.G., Oomes S. \& Brulm S. (1997). A model for the combined effects of temperature and salt concentration on growth rate of food spoilage molds. Applied and Environmental Microbiology, 63, 3764-3769.

- Dada L.O. \& Muller H.G. (1983). The fate of aflatoxin B1 in the production of Ogi, Nigerian fermented sorghum porridge. Journal of Cereal Science, 1, 63-70.

- Daghir N. (1998). Mycotoxins in Poultry Feeds. In: Daghir, N. (Ed.). Poultry Production in Hot Climates. The University Press, Cambridge., 157-184.

- Dalcero, A. (1989). Mycoflora and naturally ocurring mycotoxins in poultry feeds in Argentina. Mycopathologia, 141, 37-43. 
- Dalcero A.M., Magnoli C., Chiacchiera S., Palacios G. \& Reynoso M. (1997). Mycoflora and incidence of aflatoxin B1, zearalenone and deoxynivalenol in poultry feeds in Argentina. Mycopathologia, 137, 179-184.

- Dalcero A., Magnoli C., Luna M., Ancasi G., Reynoso M., Chiacchiera S., Miazzo R. \& Palacios G. (1998). Mycoflora and naturally ocurring mycotoxins in poultry feeds in Argentina. Mycopathologia, 141 (1), 37 - 43.

- Dale N. (2002). A brief overview of poultry nutrition. GA International Poultry Course. Athens, Georgia, USA. January 19-23.

- Dale N. (2002). Mejorando la competitividad de la producción avícola por medio de los programas de nutrición y alimentación. Mundo Avícola y Porcino, 14, 22-23.

- Dänicke S., Goyarts T. \& Valenta H. (2007). On the specific and unspecific effects of a polymeric glucomannan mycotoxin adsorbent on piglets when fed with uncontaminated or with Fusarium toxins contaminated diets. Archives of Animal Nutrition, 61, 266 - 275.

- $\quad$ Davidson P.M. \& Parish M.E. (1989). Methods for testing the efficacy of food antimicrobials. Food Technology, 43, 148-155.

- Davidson P. (2001). Chemical preservatives and natural antimicrobial compounds. In M. P. Doyle, L. R. Beuchat, \& T. J. Montville (Eds.), Food microbiology: Fundamentals and frontiers, Chap. 29, 593-627. Washington, DC: ASM Press.

- $\quad$ De Man J.C., Rogosa M. \& Sharpe M. (1960). A medium for cultivation of lactobacilli. Journal Applied Bach, 23, 130-135.

- $\quad$ De Muynck C., Leroy A.I.J., De Maeseneire S., Arnaut F., Soetaert W. \& Vandamme E.J. (2004). Potential of selected lactic acid bacteria to produce food compatible antifungal metabolites. Microbiological Reserch, 159, 339-346.

- De Urraza P. (1997). Obtención de Bacterias Lácticas para cultivos starters. Aislamiento, caracterización y conservación. Tesis Doctoral, Centro de Investigación en Criotecnología de Alimentos (CIDCA), Facultad de Ciencias Exactas, Universidad Nacional de La Plata.

- Debevere J.M. (1989). The effect of sodium lactate on the shelf-life of vacuumpacked coarse liver pâté. Fleischwirtsch, 69, 223-224. 
- $\quad$ Diamond H. \& Cooke B.M. (2003). Preliminary studies on biological control of the Fusarium ear blight complex of wheat. Crop Protection, 22, 99107.

- Diaz G. \& Céspedes J. (1997). Natural occurrence of zearalenone in feeds and feedstuffs used in poultry and pig nutrition in Colombia. Mycotoxin Research, 13, 81-87.

- Díaz G., Perilla N. \& Rojas Y. (2001). Ocurrence of aflatoxins in selected Colombian foods. Mycotoxin Research, 17, 15-20.

- Díaz G.J. (2006). Micotoxinas y micotoxicosis de importancia en salud humana en Colombia. VII Congreso Latinoamericano de Microbiología e Higiene de Alimentos COLMIC, Bogotá, Colombia.

- $\quad$ Dickson J.S. \& Maynard E.A. (1992). Microbiological decontamination of food animal carcasses by washing and sanitizing systems: a review. Journal of Food Protection, 55, 133-140.

- $\quad$ Diniz R.O., Garla L.K., Schneedorf J.M. \& Carvalho J.C.T. (2003). Study of anti-inflammatory activity of Tibetan mushroom, a symbiotic culture of bacteria and fungi encapsulated into a polysaccharide matrix. Pharmacological Reserch, 47(1), 49-52.

- Diosma G. (2010). Estudio y selección de levaduras con propiedades probióticas. Tesis de Maestría. Maestría en Ciencia y Tecnología de Alimentos. Facultad de Ciencias Exactas. Universidad Nacional de La Plata. 86 p.

- $\quad$ Domsch K.H., Gams W. \& Anderson T.H. (1980). Compendium of soil fungi. Londres, Academic Press.

- Doyle M., Applebaum R., Brackett R. \& Marth E. (1982). Physical, chemical and biological degradation of mycotoxins in foods and agricultural commodities. Journal of Food Protection, 45, 964-971.

- $\quad$ Druzhinina I., Komon-Zelazowska M., Kredics L., Hatvani L., Antal Z., Belayneh T. \& Kubicek C. (2008). Alternative reproductive strategies of Hypocrea orientalis and genetically close but clonal Trichoderma longibrachiatum, both capable of causing invasive mycoses of humans. Microbiology, 154, 3447 - 3459. 
- $\quad$ Duarte S. \& Villamil L. (2007). Micotoxinas en la Salud Humana. Revista de Salud Pública, Instituto de Salud Pública, Facultad de Medicina-Universidad Nacional de Colombia, 8 (1).

- Dvorackova I. (1990) ${ }^{a}$ Mycotoxins and humans diseases. In: Aflatoxins and Human Health, CRC Press Inc., Boca Raton, Florida. p.: 21 - 35.

- Dvorackova I. (1990) Aflatoxin and Reye's Syndrome. In: Aflatoxins and Human Health. CRC Press Inc., Boca Raton, Florida. p.: 1 - 13.

- $\quad$ Eaton D. \& Groopman J. (1994). Acute hepatoxicity of aflatoxins In: The toxicology of Aflatoxins, Academic Press Inc, Baltimore, MD. p.: $3-20$.

- Echeverría I. (2007). Utilización de cultivos mixtos de Bacterias Lácticas y Levaduras para la formulación de nuevos probióticos. Trabajo de Tesis Licenciatura en Ciencia y Tecnología de Alimentos. Facultad de Ciencias Agrarias. Universidad Nacional de Mar de Plata. Facultad de Ciencias Exactas, Universidad Nacional de La Plata. 54 p.

- $\quad$ Echeverría I., Garrote G.L. \& De Antoni G.L. (2007). Formulación de una leche fermentada probiótica y con bajo contenido de lactosa. Tecnología Láctea Latinoamericana, 48, 44 - 47.

- Eguiazú G.M. (1984). Comportamiento de almacenaje del girasol III. Grasas y Aceites, 35, 325-329.

- $\quad$ Eklund T. (1980). Inhibition of growth and uptake processes in bacteria by some chemical food preservatives. Journal of Bacteriology, 48, 423-432.

- $\quad$ El-Nezami H., Salminen S. \& Ahokas J. (1996). Biological control of food carcinogen using Lactobacillus GG. Nutrition Today, 31, 41 - 42.

- $\quad$ El-Nezami H., Kankaanpaa P., Salminen S. \& Ahokas J. (1998a). Ability of dairy strains of lactic acid bacteria to bind a common food carcinogen, aflatoxin B1. Food Chemistry Toxicology, 36, 321-326.

- El-Nezami H., Kankaanpaa H., Salminen S. \& Ahokas J. (1998b). Physicochemical alterations enhance the ability of dairy strains of lactic acid bacteria to remove aflatoxin from contaminated media. Journal of Food Protection, 61, 466-468.

- $\quad$ El-Nezami H., Mykkanen H., Kankaanpaa P., Salminen S. \& Ahokas J. (2000a). Ability of Lactobacillus and Propionibacterium strains to remove 
aflatoxin B1 from the chicken duodenum. Journal of Food Protection, 63, 549552.

- $\quad$ El-Nezami H., Mykkanen H., Kankaanpaa P., Suomalainen T., Salminen S. \& Ahokas, J. (2000b). Ability of a mixture of Lactobacillus and Propionibacterium to influence the faecal aflatoxin content in healthy Egyptian volunteers: a pilot clinical study. Bioscience and Microflora (Galvano), 19, 4145.

- $\quad$ El-Nezami H., Polychronaki N., Salminen S. \& Mykkanen H. (2002). Binding rather than metabolism may explain the interaction of two food-grade Lactobacillus strains with zearalenone and its derivative alfa-zearalenol. Applied and Environmental Microbiology, 68, 3545-3549.

- $\quad$ Engel G., Krusch U. \& Teuber M. (1986). Microbiological composition of kefir. Milchwissenschaft, 41, 418-421.

- $\quad$ Evans T. \& Wright C. (2003). Empresas Líderes: Tendencias Mundiales en la Avicultura. Industria Avícola, 50 (1), 16 - 40.

- FAO (1993). El maíz en la nutrición humana. Colección FAO: Alimentación y nutrición, №25. ISBN 92 - 5-303013-5.

- FAO (2013). Oficina Regional de la FAO para América Latina y el Caribe www.rlc.fao.org/es/conozca-fao/que-hace-fao/.../busqueda/?clave

- $\quad$ Farber J.M., Sanders G.W., Dunfield S. \& Prescott R. (1989). The effect of various acidulants on the growth of Listeria monocytogenes. Letters in Applied Microbiology, 9, 181-183.

- $\quad$ Freese E., Sheu C.W. \& Galliers E. (1973). Function of lipophilic acids as antimicrobial food additives. Nature, 241, 321-325.

- Freitas L. (2011). Ese es mi pollo. Revista 2010. 46. doi: http://www.revista2010.com.ar/produccion-nacional/ese-es-mi-pollo.php

- $\quad$ Frisvad J.C. \& Filtenborg O. (1990). Revision of Penicillium subgenus Furcatum based on secondary metabolites and conventional characters. En: Modern Concepts in Penicillium and Aspergillus Classification. Samson, R.A. \& Pitt, J.I., (Eds.) Plenum Press, New York, 159 - 172. 
- $\quad$ Frisvad J.C. (1981). Physiological criteria and mycotoxin production as aids in identification of common asymmetric Penicillia. Applied and Environmental Microbiology, 45, 68-579.

- $\quad$ Frisvad J.C. \& Samson R.A. (2004). Polyphasic taxonomy of Penicillium subgenus Penicillium. A guide to identification of the food and airborne terverticillate Penicillia and their mycotoxins. Studies in Mycology, 49, 1-173.

- Fuchs E., Binder E.M., Heidler D. \& Krska R. (2002). Structural characterization of metabolites after the microbial degradation of type $A$ trichothecenes by the bacterial strain BBSH 797. Food Additives and Contaminant, 19, 379-386.

- $\quad$ Fung F. \& Clark R.F. (2004). Health effects of mycotoxins: a toxicological overview. Journal of Toxicology-Clinical Toxicology, 42, 217-234.

- Gallardo M.G. \& Rodríguez J. (1999). La Carga de la enfermedad en Santa Fe de Bogotá: Indicadores de años de vida ajustados por discapacidad (Avisa) y mortalidad, 1985-1996. Bogotá: Secretaría Distrital de Salud de Santa Fe de Bogotá.

- Galvano F. \& Galofaro Galvano G. (1996). Occurrence and stability of aflatoxin M1 in milk and milk products: a worldwide review. Journal of Food Protection, 10, 1079-1090.

- Gamba R., León Peláez A. \& De Antoni G.L. (2011). Determinación de CFM con ácidos Acético y Láctico y sus mezclas frente a Fusarium graminearum Fg36, Fg44 y Fg48. XII Congreso Argentino de Micología. CAMIXII 2011. XXII jornadas argentinas de micología. Universidad Nacional de posadas. Facultad de Ciencias Exactas, Químicas y Naturales. Posadas, Misiones, Argentina. 15, 16 y 17 de junio de 2011.

- Garrido C.E., Hernández Pezzani C. \& Pacin A. (2012) Mycotoxins occurrence in Argentina's maize (Zea mays L.), from 1999 to 2010. Food Control, 25, 660-665.

- Garrote G. (1999). Bacterias Lácticas y Levaduras para la industria alimentaria: Kefir. Tesis Doctoral. Universidad Nacional de La Plata, Facultad de Ciencias Exactas, Departamento de Química, Departamento de Ciencias Biológicas. $168 \mathrm{p}$. 
- $\quad$ Garrote G., Abraham A. \& De Antoni G. (2000). Inhibitory power of kefir: the role of organic acids. Journal of Food Protection, 63 (3), 364 - 369.

- Garrote G., Abraham A. \& De Antoni G. (2001). Chemical and microbiological characterization of kefir grains. Journal of Dairy Research, 68, 639-652.

- Gerez C., Torino M., Rollán G. \& Font de Valdez G. (2009). Prevention of bread mould spoilage by using lactic acid bacteria with antifungal properties. Food Control, 20, 144-148.

- $\quad$ Giannuzzi L., Contreras E., \& Zaritzky N. (1999). Modeling the aerobic growth and decline of Staphylococcus aureus as affected by $\mathrm{pH}$ and potassium sorbate concentration. Journal of Food Protection, 62, 356-362.

- Gimeno, A. \& Martins M.L. (2003). Micotoxinas y Micotoxicosis en animales y humanos. Special nutrients, INC. Talleres gráficos D.E.L S.R.L. Buenos Aires.

- Golowczyc M., Gugliada M., Hollman A., Delfederico L., Garrote G., Abraham A., Semorile L. \& De Antoni G. (2008). Characterization of Homofermentative lactobacilli isolated from kefir grains: potential use as probiotic. Journal of Dairy Research, 75, 211 - 217.

- $\quad$ Gould G.W. (1995). New methods of food preservation. In G. W. Gould (Ed.). London: Blackie Academic \& Professional. Horner, K., Anagnostopoulos, G. (1973). Combined effects of water activity, pH and temperature on the growth and spoilage potential of fungi. Journal of Applied Bacteriology, 36, 427436.

- Gourama H. \& Bullerman L.B. (1995). Antimycotic and antiaflatoxigenic effect of lactic acid bacteria: A review. Journal of Food Protection, 57, 1275-1280.

- Gourama H. \& Bullerman L. (1995). Inhibition of growth and aflatoxin production of Aspergillus flavus by Lactobacillus species. Journal of Food Protection, 58, (11), 1249-1256.

- $\quad$ Gratz S., Mykkänen H., Ouwehand A., Juvonen R., Salminen S. \& ElNezami H. (2004). Intestinal mucus alters the ability of probiotic bacteria to bind aflatoxin B1 in vitro. Applied and Environmental Microbiology, 70, (10), 63066308. 
- $\quad$ Gratz S., Mykkänen H. \& El-Nezami H. (2005). Aflatoxin $B_{1}$ binding by a mixture of Lactobacillus and Propionibacterium: in vitro versus ex vivo. Journal of Food Protection, 68, 2470 - 2474.

- Groopman J., Jiaqui Z. \& Donahue P. (1992). Molecular dosimetry of urinary aflatoxin-DNA addutcs in people living in Guangxi Autonomous Region. People's Republic of China. Cancer research, 52, 45- 52.

- Groopman J., Wang J. \& Scholl P. (1996). Molecular biomarkers for aflatoxins: from adducts to gene mutations to human liver cancer. Canadian Journal of Physiology and Pharmacology, 74, 203-209.

- Gunn J.S. (2000). Mechanism of bacterial resistance and response to bile. Microbes and Infection, 2, 907 - 913.

- $\quad$ Hall A.J. \& Wild C.P. (1994). Epidemiology of aflatoxinrelated disease. In: The Toxicology of Aflatoxins: Human Health, Veterinary and Agricultural Significance (Eaton D. L., Groopman J., eds), 233258.New York: Academic Press

- Haskard C.A., Binnion C. \& Ahokas J. (2000). Factors affecting the sequestration of aflatoxin by Lactobacillus rhamnosus strain GG. ChemicoBiological Interactions, 128, 39 - 49.

- $\quad$ Haskard C.A., El-Nezami H.S., Kankaanpää P.E., Salminen S. \& Ahokas J.T. (2001). Surface binding of aflatoxin B1 by lactic acid bacteria. Applied and Environmental Microbiology, 67, 3086 -3091.

- $\quad$ Haugland R., Varma M., Wymer L. \& Vesper J. (2004). Quantitative PCR analysis of selected Aspergillus, Penicillium and Paecilomyces species. Journal Systematic Applied Microbiology, 27 (2), 198 - 210.

- $\quad H e l a n d e r ~ I . M .$, von Wright A. \& Mattila-Sandholm T.M. (1997). Potential of lactic acid bacteria and novel antimicrobials against Gram-negative bacteria. Trends in Food Science and Technology, 8, 146 - 150.

- Hernández-Mendoza A., García H.L. \& Steele J.L. (2009). Screening of Lactobacillus casei strains for their ability to bind aflatoxin $B_{1}$. Food and Chemical Toxicology, 47 (6), 1064 - 1068.

- Hofman A.F. (1998). Bile secretion and enterohepatic circulation of bile acids. In: Feldman, M., Scharschmidt, B. \& Sleisenger, M. (Eds.), Sleisengers 
and Fordtran's Gastrointestinal and Liver Diseases, 6 ed. W.B. Saunders, Co., Philadelphia, PA, 937 - 948.

- Horner K., \& Anagnostopoulos G. (1973). Combined effects of water activity, $\mathrm{pH}$ and temperature on the growth and spoilage potential of fungi. Journal of Applied Bacteriology, 36, 427-436.

- Houbraken J., Frisvad C. \& Samson R.A. (2011) Taxonomy of Penicillium section Citrina. Studies in Mycology (70), 53 -138.

- Hoyos-Carvajal L., Orduz S. \& Bissett J. (2009). Genetic and metabolic biodiversity of Trichoderma from Colombia and adjacent neotropic regions. Fungal Genetics and Biology, 46 (9), 615 - 631.

- Hugo A. (2007). Capacidad Probiótica de la cepa CIDCA 133 (L. delbrueckii subsp. lactis). Un recorrido desde modelos in vitro a in vivo. Tesis Doctoral, Centro de Investigación en Criotecnología de Alimentos - CIDCA, Facultad de Ciencias Exactas, Universidad Nacional de La Plata.

- Hunter D. \& Segel I.H. (1973). Effect of weak acids on amino acid transport by Penicillum chrysogenum. Evidence for a proton or charge gradient as the driving force. Journal of Bacteriology, 113, 184-1192.

- International Agency for Research on Cancer IARC (1993). Aflatoxins: naturally occurring aflatoxins (Group 1), aflatoxins M1 (Group 2B). The International Agency for Research on Cancer. (56): 245, 489, 397-445, 467

- ICONTEC - Instituto Colombiano de Normas Técnicas y Certificación. (1994) Manual de Métodos Analíticos para el Control de Calidad en la Industria Alimentaria, GTC1. 1.17.5. Azúcares, Determinación en Solución por Refractometría. Bogotá: ICONTEC, 1994.

- ICONTEC - Instituto Colombiano de Normas Técnicas y Certificación. (1994) Manual de Métodos Analíticos para el Control de Calidad en la Industria Alimentaria, GTC1. 11.3. Nitrógeno, Determinación - 11.3.1. $\mathrm{N}$ total por el Método Kjeldahl. Bogotá: ICONTEC, 1994.

- ICONTEC- Instituto Colombiano de Normas Técnicas y Certificación. Análisis sensorial: metodología. Métodos del perfil del sabor, NTC 3929. Bogotá: ICONTEC, 1996. 
- Ismaiel A., Ghaly M.F. \& El-Naggar A.K. (2011). Milk Kefir: Ultrastructure, Antimicrobial Activity and Efficacy on Aflatoxin B1 Production by Aspergillus flavus. Current Microbiology, 62, 1602 - 1609.

- Ita P. \& Hutkins R.W. (1991). Intracellular pH and survival of Listeria monocytogenes Scott A. in tryptic soy broth containing acetic, lactic, citric and hydrochloric acids. Journal of Food Protection, 54, 15-19.

- Jamuna M. \& Jeevaratnam K. (2004). Isolation and characterization of lactobacilli from some traditional fermented foods and evaluation of the bacteriocins. Journal of General and Applied Microbiology, 50, 79 - 90.

- Jand S.K., Singh P.P. \& Singh A. (1995). Observations on occurrence of poultry diseases associated with mycotoxins in feed. The Indian Journal of Animal Science, 65, 1063-1067.

- Jay J.M. (2000). Modern food microbiology (6th ed.). Gaithersburg, MD: Aspen Publishers.

- Kabak B., Dobson A.D.W. \& Var I. (2006). Strategies to prevent mycotoxin contamination of food and animal feed: a review. Crit. Rev. Food Science and Nutrition, 46, 593-619.

- Kabak B. \& Dobson A.D.W. (2009). Biological strategies to counteract the effects of mycotoxins. Journal of Food Protection, 2006-2016.

- Kakisu E. (2010). Desarrollo y Optimización del proceso para la elaboración de leches fermentadas con microorganismos aislados de gránulos de kefir con características tecnológicas y probióticas definidas. Tesis Doctoral. Facultad de Ciencias Exactas, Universidad Nacional de La Plata. 180 p.

- $\quad$ Kankaanpää P., Tuomola E., El-Nezami H., Ahokas J. \& Salminen S. (2000). Binding of aflatoxin B1 alters the adhesion properties of Lactobacillus rhamnosus strain GG in a Caco-2 model. Journal of Food Protection, 63(3), 412-414.

- Karaman M., Basmacioglu H., Ortatatli M. \& Oguz H. (2005). Evaluation of the detoxifying effect of yeast glucomannan on aflatoxicosis in broilers as assessed by gross examination and histopathology. British Poultry Science, 46(3), 394-400.

- Kaufmann K. (1997). Kefir rediscovered. Alive Book, Burnahy. 
- $\quad$ Kemp N. (1984). Kefir, the champagne of cultured dairy products. Culture Dairy Products Journal, 19, 29 - 30.

- $\quad$ Kendirci P. \& Altug T. (2004). Carry over of aflatoxin M1 to kefir and kefir grains. Milchwissenschaft, 59, (7-8), $399-401$.

- Khan M.R. \& Doohan F.M. (2009). Bacterium-mediated control of Fusarium head blight disease of wheat and barley and associated mycotoxin contamination of grain. Biological Control, 48, 42-47.

- Kheadr E.E. (2006). Impact of acid and oxgall on antibiotic susceptibility of probiotic Lactobacilli. African Journal of Agriculture Reserch, 1, 172 - 181.

- $\quad \quad \quad$ Kim J.S., Ingale S.L., Kim Y.W., Kim K.H., Sen S., Ryu M.H., Lohakare J.D., Kwon I.K. \& Chae B.J. (2012). Effect of supplementation of multi-microbe probiotic product on growth performance, apparent digestibility, cecal microbiota and small intestinal morphology of broilers. Journal of Animal Physiology and Animal Nutrition, 96, 618 - 626.

- $\quad$ Klich M.A. \& Pitt J.I. (1988). Differentiation of Aspergillus flavus from A. parasiticus and other closely-related species. Transactions of the British Mycological Society, 91, 99-108.

- $\quad$ Klich M.A. \& Pitt J.I. (1992). A laboratory guide to common Aspergillus species and their teleomorphs. CSIRO Division of Food Processing, North Ryde, Australia.

- Koroleva N.S. (1988). Technology of kefir and kumis. International Dairy Federation Bulletin, 227, 96 - 100.

- Kosikowski F. (1982). Cheese and fermented milks foods. 2 ed. Ed. New York, Kosikowski and Associates, Pub.

- Kozakiewicz Z. (1989). Aspergillus species on stored products. CAB International Mycological Institute, Kew, Surrey

- $\quad$ Lacey J. (1989). Pre- and post-harvest ecology of fungi causing spoilage of foods and other stored products. Journal of Applied Bacteriology, Sumposium Supplement: $11 \mathrm{~S}$ - 25S

- $\quad$ Lahtinen S.J., Haskard C.A., Ouwehand A.C., Salminen S.J. \& Ahokas J.T. (2004). Binding of aflatoxin $B_{1}$ to cell wall components of Lactobacillus rhamnosus strain GG. Food Additives and Contaminants, 21, (2), 158 - 164. 
- $\quad$ Lavermicocca P., Valerio F., Evidente A., Lazzaroni S., Corsetti A., \& Gobbetti M. (2000). Purification and characterization of novel antifungal compounds from the sourdough lactobacillus plantarum strain 21B. Applied and Environmental Microbiology, 66(9), 4084- 4090.

- Lavermicocca P., Valerio F. \& Visconti A. (2003). Antifungal activity of phenyllactic acid against moulds isolated from bakery products. Applied and Environmental Microbiology, 69, 634-640.

- $\quad$ Lee Y.K., El-Nezami H., Haskard C.A., Gratz S., Puong K.Y., Salminen S. \& Mykkanen H. (2003). Kinetics of adsorption and desorption of aflatoxin B1 by viable and nonviable bacteria. Journal of Food Protection, 66, 426-430.

- Legan J.D. (1993). Moulds spoilage of bread: the problem and some solutions. International Biodeterioration and Biodegradation, 32, 33-53.

- $\quad$ León Peláez A., Serna C., Quintero E., Gamba R., De Antoni G.L. \& Giannuzzi L. (2011). Inhibitory activity of lactic and acetic acid on Aspergillus flavus growth for food preservation. Food Control, 24, 177 - 183.

- León Peláez A., Londero A., Abraham A.G., Garrote G. L., Giannuzzi L. \& De Antoni G. L. (2011). Efecto antifúngico de sobrenadantes de suero y permeado de suero fermentados con gránulos de kefir. XII Congreso Argentino de Micología. CAMIXII 2011. XXII jornadas argentinas de micología. Universidad Nacional de posadas. Facultad de Ciencias Exactas, Químicas y Naturales. Posadas, Misiones, Argentina. 15, 16 y 17 de junio de 2011.

- $\quad$ Leverrier P., Dimova D., Pichereau V., Auffray Y., Boyaval P. \& Jan G. (2003). Susceptibility and adaptive response to bile salts in Propionibacterium freudenreichii: physiological and proteomic analysis. Applied Environmental Microbiology, 69, 3809 - 3818.

- $\quad$ Libudzisz Z. \& Piatkiewicz A. (1990). Kefir production in Poland. Dairy Industries International, 55, 31-33.

- $\quad$ Lind H., Jonsson H. \& Schnürer J. (2005). Antifungal effect of dairy propionibacterial contribution of organic acids. International Journal of Food Microbiology, 2, 157-165.

- $\quad$ Line J., Brackett R. \& Wilkinson R. (1994). Evidence for degradation of aflatoxin B1 by Flavobacterium aurantiacum. Journal of Food Protection, 57(9), 788-791. 
- Llewellyn G., Gee C. \& Sherertz P. (1988). Toxic responses of developing fifth instar milkweed bugs,Oncopeltus fasciatus (Hemiptera), to Aflatoxin B1. Bulletin of environmental contamination and toxicology, 40, 332338

- Loncin M. (1975). Basic principles of moisture equilibria. In S. S. Goldblith, L. Rey, \& W. Rothmayr (Eds.), Freeze drying and advanced food technology (pp. 599-617). New York: Academic Press.

- Londero A. (2012). Alimentos funcionales: Obtención de un producto probiótico para aves a partir de suero de quesería fermentado con microorganismos de kefir. Tesis Doctoral. Universidad Nacional de La Plata. Facultad de Ciencias Exactas. Departamento de Ciencias Biológicas. 290 p.

- $\quad$ Londero A., León Peláez A., Giannuzzi L., De Antoni G.L., Abraham A. G. \& Garrote G.L. (2011). Resistencia a la contaminación fúngica de pienso para pollos adicionado de suero y permeado de suero fermentados con gránulos de kefir. XII Congreso Argentino de Micología. CAMIXII 2011. XXII jornadas argentinas de micología. Universidad Nacional de posadas. Facultad de Ciencias Exactas, Químicas y Naturales. Posadas, Misiones, Argentina. 15, 16 y 17 de junio de 2011.

- Londero A., Quinta R., Abraham A., Sereno R., De Antoni G. \& Garrote G. (2011). Inhibitory activity of cheese whey fermented with kefir grains. Journal Food Protection, 74, (1), 94-100.

- $\quad$ López-Malo A., Palou E., Parish M.E. \& Davidson P.M. (2005). Methods for activity assay and evaluation of results. In P. M. Davidson, J. N. Sofos, \& L. Branen (Eds.), Antimicrobials in foods (3rd ed.). (pp. 659-680) New York: Marcel Dekker.

- $\quad$ López-Malo A., Barreto-Valdivieso J., Palou E. \& San Martín F. (2007). Aspergillus flavus growth response to cinnamon extract and sodium benzoate mixtures. Food Control, 18, 1358-1362.

- Lopitz-Otsoa F., Rementeria A., Elguezabal N. \& Garaizar J. (2006). Kefir: a symbiotic yeasts-bacteria community with alleged healthy capabilities. Revista Iberoamericana de Micología, 23(2), 67-74

- Magalhães K.T., De M. Pereira G., Dias D. \& Schwan R. (2010). Microbial communities and chemical changes during fermentation of sugary 
Brazilian kefir. World Journal of Microbiology and Biotechnology, 26, 12411250.

- $\quad$ Magan N. \& Lacey J. (1988). Ecological determinants of mould growth in stored grain. International Journal of Food Microbiology, 7, 245-256.

- Magnusson J. \& Schnûrer J. (2001) Lactobacillus coryniformis subsp. coryniformis Strain Si3 Produces a Broad-Spectrum Proteinaceous Antifungal compound. Applied and environmental microbiology, 67 (1), 1-5.

- Magnusson J., Ström K., Roos S., Sjögren J. \& Schnürer J. (2003). Broad and complex antifungal activity among environmental isolates of lactic acid bacteria. FEMS Microbiology Letters, 219, 129-135.

- Magnusson J. (2003). Tesis Doctoral: Antifungal Lactic acid Bacteria. Swedish University of Agricultural Sciences.

- Malmstrom J., Christophersen C. \& Frisvad J.C. (2000). Secondary metabolites characteristic of Penicillium citrinum, Penicillium steckii and related species. Phytochemistry, 54, $301-309$.

- Manetta A.C., Di Giuseppe L., Giammarco M., Fusaro I., Simonella A., Gramenzi A. \& Formigoni A. (2005). High-performance liquid chromatography with post-column derivatisation and fluorescence detection for sensitive determination of aflatoxin M1 in milk and cheese. Journal of chromatogram, 1083 (1-2), 219 - 222.

- Marshall V.M., Cole W.M. \& Brooker B.E. (1984). Observations on the structure of kefir grain and the distribution of the microflora. Journal of Applied Bacteriology, 57, 491-497.

- Martinez A, Olga L., Arcila G. \& Maria P. (2006). Factores relacionados con la presencia de Aflatoxinas en la fabricación de la arepa delgada de Maíz blanco en dos industrias de Medellín y su área Metropolitana. 2005. Universidad de Antioquia.

- Martínez O., Arcila M. \& Laverde L. (2006). Factores Asociados con la Presencia de Aflatoxinas en Maíz y su producto Arepa delgada de Maíz Blanco. Tesis de Maestría. Universidad de Antioquia, Facultad de Salud Pública, Maestría en Salud Pública.

- Mendivelso, R. (2006). Leche en Bogotá: calidad en deuda. En: Unimedios (Feb 2005). 
- $\quad$ Messens W. \& De Vuyst L. (2002). Inhibitory substances produced by Lactobacilli isolated from sourdoughs-a review. International Journal of Food Microbiology, 72, $31-43$.

- Messens W. \& De Vuyst L. (2002). Inhibitory substances produced by Lactobacilli isolated from sourdoughs-a review. International Journal of Food Microbiology, 72, $31-43$.

- Ministerio de Agricultura Ganadería y Pesca Argentina. (2010). Boletín Avícola. http://es.scribd.com/doc/34709089/Boletin-Oficial-14-07-10-PrimeraSeccion. Consultado mayo 15 de 2012.

- Molina M. \& Giannuzzi L. (1999). Combined effect of temperature and propionic acid concentration on the growth of Aspergillus parasiticus. Food Research International, 32, 677-682.

- Montesano R. (1997). Hepatocellular carcinoma: From gene to public health. Journal of National Cancer Institute, 89, 1844 - 52.

- Moreno Romo M., Ramos Cartagena M., Rodríguez Ferri E. \& Suárez Fernández G. (1986). Minimal moisture content for growth and aflatoxin production by Aspergillus parasiticus in mixed feeds. Mycopathologia, 95, 145 148.

- Morgulis A., Coulouris G., Raytselis Y., Madden T.L., Agarwala R. \& Schäffer A. (2008). "Database Indexing for Production MegaBLAST Searches", Bioinformatics, 24, 1757-1764.

- Moss, M.O. (1991). The environmental factors controlling mycotoxin formation. En: Smith, JE; Henderson, RS. (eds.) Mycotoxins and animal foods. CRC Press. Boca Raton. págs. 37-56.

- Mountzouris K.C., Tsitrsikos P., Palamidi I., Arvaniti A., Mohnl M., Schatzmayr G. \& Fegeros K. (2010). Effects of probiotic inclusion levels in broiler nutrition on growth performance, nutrient digestibility, plasma immunoglobulins, and cecal microflora composition. Poultry Science, 89(1), 58 67.

- $\quad$ Nesbitt B.F, O Elly J., Rgeant K. \& Shkdan A. (1962). Toxic metabolites of Aspergillus flavus. Nature, 1062-1063. 
- $\quad$ Nidekrnorn V., Boudra H. \& Morgavi D.P. (2006). Binding of Fusarium mycotoxins by fermentative bacteria in vitro. Journal of Applied Microbiology, 101, 849 -856.

- $\quad$ Niderkorn V., Morgavi D.P., Pujos E., Tissandier A. \& Boudra H. (2007). Screening of fermentative bacteria for their ability to bind and biotransform deoxynivalenol, zearalenone and fumonisins in an in vitro simulated corn silage model. Food Additives and Contaminant, 24, 406-415.

- $\quad$ Nout M.J.R. (1994). Fermented foods and food safety. Food Research International, 27, 291-298

- $\quad$ Oatley J., Rarick M., Ji G. \& Linz J. (2000). Binding of aflatoxin B1 to bifidobacteria in vitro. Journal of Food Protection, 63(8), 1133-1136.

- $\quad$ Odet G. (1995). Fermented milks. International Dairy Federation Bulletin, $300,98-100$.

- Ofek I. \& Doyle R. (1994). Bacterial adhesion to cells and tissues. Chapman \& Hall, New York. ISBN 0-412-03011-X

- OMEGA.(2005).www.omega.ilce.edu.mx:3000/sites/ciencia/volumen2/cie ncia3/096/htm/sec_8.htm. Agosto 15 de 2005

- Onilude A., Fagade O., Bello M. \& Fadahunsi I. (2005). Inhibition of aflatoxin - producing aspergilli by lactic acid bacteria isolates from indigenously fermented cereal gruels. African Journal of Biotechnology, 12, 1404-1408.

- $\quad$ Oozeer R., Leplingard A., Mater D.D.G., Mogenet A., Michelin R., Seksek I., Marteau P., Dore J., Bresson J.L. \& Corthier G. (2006). Survival of Lactobacillus casei in the human digestive tract after consumption of fermented milk. Applied Environmental Microbiology, 72, 5615 - 5617.

- $\quad$ Orrhage K., Sillerstroom E., Gustafsson J-A., Nord C.E. \& Rafter J. (1994). Binding of mutagenic heterocyclic amines by intestinal and lactic acid bacteria. Mutation Research, 311, 239 - 248.

- $\quad$ Peltonen K., El-Nezami H., Salminen S. \& Ahokas J. (2000). Binding of aflatoxin $\mathrm{B}_{1}$ by probiotic bacteria. Journal of the Sciences of Food and Agriculture, 80, 1942-1945. 
- $\quad$ Peltonen K., El-Nezami H., Haskard C., Ahokas J. \& Salminen S. (2001). Aflatoxin B1 Binding by Dairy Strains of Lactic Acid Bacteria and Bifidobacteria. Journal of Dairy Science. 84, 2152-2156.

- Pitt Jl. \& Leistner, L. 1991. Toxigenic Penicillium species. En: Mycotoxins and Animal Foods. Smith JE, Henderson RS (Ed.). CRC Press, Boca Ratón, Florida. p. 81-99

- $\quad$ Periaca M., Radi B., Lucic A. \& Pavlovic M. (1999). Efectos tóxicos de las micotoxinas en el ser humano. Bulletin of the World Health organization, 77 , 754-766.

- Perilla N. \& Diaz G. (1998). Incidence and levels of fumonisins contamination in Colombian corn and corn products. Mycotoxin Research, 14, 74-82.

- Peterson S.W. (2000). Phylogenetic analysis of Penicillium species based on ITS and LSU-rDNA nucleotide sequences. En: Samson, R.A. \& Pitt, J.I. (Eds.). Integration of Modern Taxonomic Methods for Penicillium and Aspergillus Clasification. Harwood Academic Publishers, the Netherlands. p.:163-178

- Peterson S. (2008). Phylogenetic analysis of Aspergillus species using DNA sequences from four loci. Mycologia, 100 (2), 205 - 226.

- Pfeiler E.A., Azcarate-Peril M.A. \& Klaenhammer T.R. (2007). Characterization of a novel bile-inducible operon encoding a two-component regulatory system in Lactobacillus acidophilus. Journal of Bacteriology, 189, 4624 - 4634.

- Phillips T. (1999). Dietary clay in the chemoprevention of aflatoxininduced disease. Toxicology Science, 52, 118-126.

- Pitt J.I. (1980). The genus Penicillium and its teleomorphic states Eupenicillium and Talaromyces. Academic Press, London.

- $\quad$ Pitt J.I. \& Hocking A. (1999). Fungi and Food Spoilage. 2a Ed. Aspen Publishers, Inc., UK.593 p.

- $\quad$ Pitt J. (2000). Toxigenic fungi: Which are important?. Medical Mycology, 38, 17-22. 
- $\quad$ Pitt J.I., Samson R.A. \& Frisvad J.C. (2000). List of accepted species and their synonyms in the family Trichocomaceae. In: Samson, R.A., Pitt. J.I. (Eds.) Integration of modern methods for Penicillium and Aspergillus classification. Harwood Academic Publishers: Amsterdam, p.: 9-49.

- Pizzolitto R. (2011). Prevención de micotoxicosis en la industria avícola por microorganismos bioeliminadores de toxinas fúngicas. PhD. Thesis. Departamento de Biología Molecular, Universidad Nacional de Río Cuarto, Argentina

- $\quad$ Prudente A. \& King J. (2002). Efficacy and safety evaluation of ozonation to degrade aflatoxin in corn. Food Chemistry and Toxicology, 67, 2866-2872.

- Rajendran R. \& Ohta Y. (1998). Binding of heterocyclic amines by lactic acid bacteria from miso, a fermented Japanese food. Canadian Journal of Microbiology, 44, 109 - 115.

- Raju M. \& Devegowda G. (2000). Influence of esterified-glucomannan on performance and organ morphology, serum biochemistry and haematology in broilers exposed to individual and combined mycotoxicisis. British Poultry Science, 41(5), 640-650.

- Ramírez C. (1982). Manual and atlas of the Penicillia. Amsterdam, Elsevier Biomedical Press.

- $\quad$ Raper K.B. \& Thom C. (1949). Manual of the Penicillia, Williams \& Wilkins.

- $\quad$ Resnik S., Costarrica L. \& Pacin A. (1995). Micotoxins in Latin America and the Caribbean. Food Control, 6 (1), 19-28.

- $\quad$ Restaino L., Komatsu K. K. \& Syracuse J. (1981). Effects of acids on potassium sorbate inhibition of food-related microorganisms in culture media. Journal of Food Science, 47, 134-143.

- $\quad$ Restaino L., Lenvich L.M. \& Bills S. (1982). Effect of acids and sorbate combinations on the growth of four osmophilic yeasts. Journal of Food Protection, 45, 1138-1142.

- $\quad$ Rosenberg M., Gutnik D. \& Rosenberg E. (1980). Adherence of bacteria to hydrocarbons: A Simple method for measuring cell-surgace hidrophobicity. FEMS Microbiology Letters, 9, 29 - 33. 
- $\quad$ Rubin H.E. (1978). Toxicological model for a two-acid system. Applied and Environmental Microbiology, 36, 623-624.

- $\quad$ SAGPyA. (2001) Boletín Avícola. Anuario 2001. Año 7 (30). Argentina. p.: 34 .

- Salmond C.V., Kroll R.G. \& Booth I.R. (1984). The effect of food preservatives on $\mathrm{pH}$ homeostasis in Escherichia coli. Journal of General Microbiology, 130, 2845-2850.

- Samarajeewa U., Sen A., Choen M. \& Wei I. (1990). Detoxification of aflatoxins in foods and feeds by physical and chemical methods. Journal of Food Protection, 53 (6), 489-501.

- $\quad$ Samuels G.J. (1996). Trichoderma: a review of biology and systematics of the genus. Mycological Research, 100, $923-935$.

- $\quad$ Schnurer J. \& Magnusson J. (2005). Antifungal lactic acid bacteria as biopreservatives. Trends in Food Science \& Technology, 16, 70-78.

- $\quad$ Schoch C., Seifert K., Huhndorf S., Robert V., Spouge J., Levesque C. \& Chen W. (2012). Nuclear ribosomal internal transcribed spacer (ITS) region as a universal DNA barcode marker for Fungi. Proceedings of the National Academy of Science, 109 (16), 6241 - 6246.

- $\quad$ Seiler D. (1988). Microbiological problems associated with cereal based foods. Food and Science Technology Today, 2, 37-41.

- $\quad$ Serot T., Dousset X., Zucca J. \& Torcatis N. (1990). Mise en e'vidence et purification partielle de substances antibacteriennes produites par Leuconostoc mesenteroides et Lactobacillus plantarum isoles de grains de kéfyr. Microbiologie, Aliments, Nutrition, 8, 71-76.

- Serra R., Peterson S.W., CTCOR \& Armando V. (2008). Multilocus sequence identification of Penicillium species in cork bark during plank preparation for the manufacture of stoppers. Research in Microbiology, 159, $178-186$.

- $\quad$ Shank R., Bourgeois C., Keschamaras N. \& Chandavimol P. (1971). Aflatoxins in autopsy specimen from Thai children with an acute disease of an unknown aetiology. Food Cosmet Toxicoogy, 9(4), 501-507. 
- Shatzmayr D. (2004). Estrategias combinadas para el control de micotoxinas. Avicultura Profesional, 22, 28-30.

- $\quad$ Shetty P., Hald B. \& Jespersen L. (2007). Surface binding of aflatoxin B1 by Saccharomycescerevisiae strains with potential decontaminating abilities in indigenous fermented foods. International Journal of Food Microbiology, 113(1), 41-46.

- Sheu C.W., Salomon D., Simmons J.L., Sreevalsan T. \& Freese E. (1975). Inhibitory effect of lipophilic acids and related compounds on bacteria and mammalian cells. Antimicrobial Agents and Chemotherapy, 7, 349-363.

- $\quad$ Simon E.W. \& Blackman G.E. (1949). The significance of hydrogen ion concentration in the study of toxicity. Symposium of the Society of Experimental Biology № 3, pp253-263. Cambridge, University Press.

- $\quad$ Singer S., Reddy A., Gladden J., Guo H., Hazen T., Simmons B. \& Vandergheynst J. (2011). Enrichment, isolation and characterization of fungi tolerant to 1 - ethyl - 3 -methylimidazolium acetate. Journal of Applied Microbiology, 110 (4), 1023 - 1031.

- $\quad$ Sjögren J., Magnusson J., Broberg A., Schnürer J. \& Kenne L. (2003). Antifungal 3-hydroxy fatty acids from lactobacillus plantarum MiLAB 14. Applied and Environmental Microbiology, 69(12), 7554-7557.

- $\quad$ Smith J.E. \& Ross K. (1991). The toxigenic Aspergilli. pp. 101-108 en: Mycotoxins and Animal Foods. Smith JE, Henderson RS, editores. CRC Press, Boca Ratón, Florida.

- $\quad$ Speranza J. (2011). Ecosuero con valor agregado. Noticiero Tecnológico de la Región Centro. INTI. Ministerio de Industria. Presidencia de la Nación. № 16. Octubre de 2011. http://www.inti.gob.ar/noticiero_centro_2011/ntc16.html. Consultado mayo 14 de 2012

- Stoloff L. (1977). Aflatoxins - an overview. In: Mycotoxins in Human and Animal Health. Eds. Rodricks, J.V., Hesseltine, C.W. \& Mehlman, M.A.. Pathotos Publishers, Park Forest South, Illinois. p.: 7-28.

- $\quad$ Stratford M., Plumridge A., Nebe-von-Caron G. \& Archer, D. (2009). Inhibition of spoilage mould conidia by acetic acid and sorbic acid involves 
different modes of action, requiring modification of the classical weak-acid theory. International Journal of Food Microbiology, 136, 37-43.

- Suárez O. (1999). Manejo de los granos en las fábricas de alimentos balanceados y uso de adsorbentes de micotoxinas. IV Seminario Internacional en Ciencias Avícolas. Santa Cruz de la Sierra, Bolivia. p.: 69 - 73.

- Tapia O. (1986). Micotoxicosis en cerdos. Memorias IV Jornadas de Actualización Porcina. Río Cuarto, Argentina, 39-58.

- Ten Brink B. \& Konings W.N. (1980). Generation of an electrochemical proton gradient by lactate efflux in membrane vesicles of Escherichia coli. European Journal of Biochemistry, 11, 59-66.

- $\quad$ Ten Brink B., Otto R., Hansen U. P. \& Konings W.N. (1985). Energy recycling by lactate efflux in growing and nongrowing cells of Streptococcus cremoris. Journal of Bacteriology, 162, 383-390.

- Thyagaraja N. \& Hosono A. (1994). Binding properties of lactic acid bacteria from 'Idly' towards food-borne mutagens. Food and Chemical Toxicology, 32, $805-809$.

- Tomaševic-Canovic M., Dakovic A., Rottinghaus G., Matijasevic S. \& Đuricic M. (2003). Surfactant modified zeolites-new efficient adsorbents for mycotoxins. Micropourus and Mesopourus materials, 61, 173-180.

- Urrego J. \& Díaz G. (2006). Aflatoxinas: Mecanismos de Toxicidad en la Etiología del Cáncer Hepático Celular. Revista de la Facultad de Medicina Universidad Nacional de Colombia, 54 (2).

- Vaamonde G. (1995). Micotoxinas. En: Toxicología de Alimentos. Silvestre (coordinador). Editorial Hemisferio.

- Vaamonde, G. (1996). Micotoxinas Capitulo VIII, en Toxicología de los alimentos. Silvestre A. Ed. Hemisferio Sur.

- Vaamode G., Patriarca A., Fernández V., Comercio R. \& Degrossi C. (2003). Variability of aflatoxin and cyclopiazonic acid production by Aspergillus section flavi from different substrates in Argentina. International Journal of Food Microbiology, 88, 79-84. 
- Varga J., Péteri Z., Tábori K., Téren J. \& Vágvölgyi C. (2005). Degradation of ochratoxin $A$ and other mycotoxins by Rhizopus isolates. International Journal of Food Microbiology, 99, 321-328.

- Vasco G. \& Giraldo J. (1995). Evaluación Genotóxica de Aflatoxinas aisladas de maíz almacenado para consumo humano y animal. [Trabajo de Grado]. Medellín: Universidad de Antioquia. Facultad de Ciencias Exactas y Naturales. Departamento de Biología.

- Vero S. (2011). Identificación de hongos a nivel de especie. En: Herramientas moleculares para la identificación y caracterización de hongos y levaduras. Curso de postgrado. Facultad de Química. Universidad de la República. Uruguay.

- $\quad$ Vesonder R.F., Ciegler A., Fennell D. \& Tjarks L.W. (1976). Curvularin from Penicillium baradicum Baghdadi NRRL 3754, and biological effects. Journal of Environmental Science and Health B. 11 (4), 289-7

- Vitale R., de Hoog G., Schwarz P., Dannaoui E., Deng S., Machouart M., Voigt K., van de Sande W., Dolatabadi S., Meis F. \& Walther G. (2012). Antifungal susceptibility and phylogeny of opportunistic members of the order mucorales. Journal of Clinical Microbiology, 50 (1), 66-75.

- Westby A., Reilly A. \& Bainbridge Z. (1997). Review of the effect of fermentation on naturally occurring toxins. Food Control, 8(5/6), 329-339

- Whitehead K., Versalovic J., Roos S. \& Britton R.A. (2008). Genomic and genetic characterization of the bile stress response of probiotic Lactobacillus reuteri ATCC 55730. Applied Environmental of Microbiology, 74, 1812 - 1819.

- $\quad$ Williams J.H., Phillips T.D., Jolly P.E., Stiles J.K., Jolly C.M. \& Aggarwal D. (2004). Human aflatoxicosis in developing countries: a review of toxicology, exposure, potential health consequences, and interventions. American Journal of Clinical Nutrition, 80(5), 1106-1122.

- Wilson M. (2005). Microbial inhabitants of humans, their ecology and role in health and disease. Chap.7: The gastrointestinal tract and its indigenous microbiota. Cambridge University Press. p.: $252-317$.

- Wu Q., El-Nezami H., Juvonen R., Mykkänen H. \& Turner P.C. (2007). Lactobacillus rhamnosus strain $\mathrm{GG}$ reduces aflatoxin $\mathrm{B} 1$ transport, metabolism 
and toxicity in caco-2 cells. Applied and Environmental Microbiology, 73(12), 3958-3964.

- www.agroindustrias.org/1-02-03_postcosecha_contaminacion.shtml. Agosto 15 de 2005.

- $\quad$ Yang S.T. \& Silva E.M. (1995). Novel Products and New Technologies for use of a Familiar Carbohydrate, Milk Lactose. Journal Dairy Science, 78, $2541-2562$.

- Yiannikouris A., Francois J., Poughon L., Dussap C.G., Bertin G., Jeminet G. \& Jounay J.P. (2004). Adsorption of zearalenone by $\beta$-D-glucans in the Saccharomyces cerevisiae cell wall. Journal of Food Protection, 67, $1195-$ 1200.

- $\quad$ Yu H., Zhou T., Gong J., Young C., Su X., Li X.Z., Zhu H., Tsao R. \& Yang R. (2010). Isolation of deoxynivalenol-transforming bacteria from the chicken intestines using the approach of PCR-DGGE guided microbial selection. BMC Microbiology, 24, 182.

- Yu J., Cleveland T., Nierman W. \& Bennett J. (2005). Genómica de Aspergillus flavus: una puerta a la salud humana y animal, seguridad alimentaria y resistencia de las cosechas a las enfermedades. Revista Latinoamericana de Micología, 22(4), 194-202.

- Zhang X.B. \& Ohta Y. (1990). Antimutagenicity and binding of lactic acid bacteria from a Chinese cheese to mutagenic pyrolyzates. Journal Dairy Science, 73, $2702-2710$.

- $\quad$ Zhang X.B. \& Ohta Y. (1991). In vitro binding of mutagenic pyrolyzates to lactic acid bacterial cells in human gastric juice. Journal Dairy Science, 74, (3), $752-757$.

- Zhang X.B. \& Ohta Y. (1993). Antimutagenicity of cell fractions of microorganisms on potent mutagenic pyrolyzates. Mutation Research, 298, 247 $-253$.

- $\quad$ Zheng Zhang Z., Schwartz S., Wagner L. \& Miller W. (2000). A greedy algorithm for aligning DNA sequences. Journal Computational Biology, 7(1-2), 203-14. 
- Zourari A. \& Anifantakis E.M. (1988). Le kefir caracteres physicochemiques, microbiologiques et nutritionnels. Technologie de production. Une revie, Lait, 68, 373-392. 
ANEXOS 
ANEXO 1 MEDIOS DE CULTIVO Y SOLUCIONES

\begin{tabular}{|l|l|}
\hline \multicolumn{2}{|l|}{ SNA (Spezieller Nahrstoffarmer agar- } \\
Medio para favorecer la esporulación \\
\hline $\mathrm{KNO}_{3}$ & $1 \mathrm{~g}$ \\
\hline $\mathrm{K}_{2} \mathrm{HPO}_{4}$ & $1 \mathrm{~g}$ \\
\hline MgSO & $\mathbf{4} \cdot \mathrm{H}_{2} \mathbf{O}$ \\
\hline $\mathrm{KCl}$ & $0,5 \mathrm{~g}$ \\
\hline Glucosa & $0,5 \mathrm{~g}$ \\
\hline Sacarosa & $0,2 \mathrm{~g}$ \\
\hline Agar & $0,2 \mathrm{~g}$ \\
\hline $\mathrm{H}_{2} \mathrm{O}$ & $15 \mathrm{~g}$ \\
\hline
\end{tabular}

\begin{tabular}{|c|c|}
\hline \multicolumn{2}{|c|}{ Agar agua } \\
\hline Agar agar & $0,2 \%$ \\
\hline Agua & $99,8 \%$ \\
\hline \multicolumn{2}{|c|}{$\begin{array}{l}\text { Se agrega } 1 \mathrm{ml} \text {. o } 2 \mathrm{ml} \text {. a cada CRIOVIAL ( previamente esterilizados por vapor } \\
\text { fluente durante } 30 \mathrm{~min} \text {. semi abierto o } 3 / 4 \text { de vuelta si es tapa rosca). Una vez } \\
\text { los crioviales tienen agregado el medio de cultivo y las placas con los hongos } \\
\text { bien esporulados, se toma una buena cantidad de conidias con un ansa ojal, } \\
\text { depositándola en el criovial. Luego se conservan en heladera (no Frezzer). }\end{array}$} \\
\hline
\end{tabular}




\begin{tabular}{|c|c|}
\hline \multicolumn{2}{|l|}{ Medio Malta modificado } \\
\hline Extracto de Malta (Merck ${ }^{\Theta}$, Darmstadt, Alemania) & $1 \%$ \\
\hline Extracto de levadura(Biokar ${ }^{(\Theta)}$ ) & $2 \%$ \\
\hline Agar agar (Merck ${ }^{\circledR}$, Darmstadt, Alemania) & $2 \%$ \\
\hline Autoclavar a $121^{\circ} \mathrm{C}$ & \\
\hline
\end{tabular}

\begin{tabular}{|c|c|}
\hline \multicolumn{2}{|c|}{ Solución de Dilución de Esporas } \\
\hline Lauril sulfato de sodio (Merck $^{\circledR}$, Darmstadt, Alemania) & $0,01 \%$ \\
\hline solución de glucosa(Carlo Erba ${ }^{\circledR}$, Milán, Italia) & $1 \%$ \\
\hline
\end{tabular}

\begin{tabular}{|c|c|}
\hline \multicolumn{2}{|c|}{ Agar papa - dextrosa } \\
\hline Infusión de papa (200 gr de papa), & $4.0 \%$ \\
\hline D (+) glucosa & $2 \%$, \\
\hline Agar & $1,5 \%$ \\
\hline
\end{tabular}

\begin{tabular}{|l|l|}
\hline \multicolumn{2}{|c|}{ Agar Malta } \\
\hline Extracto de malta & $0,1 \mathrm{~g} / \mathrm{L}$ \\
\hline Extracto de levadura & $0,2 \mathrm{~g} / \mathrm{L}$ \\
\hline Agar & $0,2 \mathrm{~g} / \mathrm{L}$ \\
\hline Agua destilada & $1,0 \mathrm{~L}$ \\
\hline & \\
\hline
\end{tabular}




\begin{tabular}{|l|l|}
\hline \multicolumn{2}{|c|}{ Malta blando } \\
\hline extracto de malta & $2 \%$ \\
\hline agar & $0,7 \%$ \\
\hline
\end{tabular}

\begin{tabular}{|l|l|}
\hline \multicolumn{2}{|c|}{ Medio YES } \\
\hline Extracto de Levadura & $2 \%$ \\
\hline Sacarosa & $15 \%$ \\
\hline \multicolumn{2}{|c|}{$\mathrm{pH}$ final: $7,0-7,5}$. \\
\hline
\end{tabular}




\section{ANEXO 2 APLICACIÓN DE LA CLAVE TAXONÓMICA SEGÚN PITT \& HOCKING, 1999.}

La clave taxonómica que se siguió para identificar morfológicamente los hongos, se observa a continuación, donde se analizaban las siguientes preguntas y de acuerdo a la respuesta si o no se pasaba al capítulo indicado o se continuaba con la clave siguiente:

- Clave taxonómica general para hongos alteradores de alimentos (Pit \& Hocking, 1999):

1- El hongo no creció en ningún medio estándar durante 7 días:

\section{pasar a Capítulo 9: "Hongos Xerofílicos".}

El hongo si creció en un medio o más durante 7 días:

pasar a 2.

2- Colonias de levaduras:

pasar a Capítulo 10: "Levaduras".

El hongo tiene crecimiento filamentoso con $10 \mathrm{~mm}$ de diámetro en uno más de los medios:

pasar a 3.

3- Crecimiento en CYA y/o Malta más rápido que en G25N:

pasar a 4.

Crecimiento en G25N más rápido que en CYA y/o Malta:

pasar a Capítulo 9: "Hongos Xerofílicos”.

4- Hifas septadas frecuentes y llamativas:

pasar a 5.

Hifas no septadas:

pasar a capítulo 6: "Zygomicetos" (Coincide con el hongo algodonoso gris tipo

Rhizopus (1)).

5- No hay esporos maduros presentes a los 7 días:

pasar a 6.

Esporos maduros presentes a los 7 días:

pasar a 9.

(PASAMOS A 9)

9- Esporos o conidios menores de 10 $\mu \mathrm{m}$ largo, que aparecen como cadenas sobre células fértiles (fiálides), sobre estipes bien definidos:

pasar a 10.

Esporos o conidias de varios tamaños que aparecen aislados y si aparecen en cadenas éstas no están agregadas:

pasar a "hongos misceláneos". (Coincide con el hongo Verde (2)) 
10- Fiálides, o métula y fiálides nacen en formación esférica del ápice del estipe: pasar a 11.

Fiálides nacen en penicilos, por ej. Sobre estipes no engrosados con o sin intervención de métulas y ramificaciones:

pasar al capítulo 7: Penicillium y géneros relacionados. (Coincide con los hongos azul y gris tipo Penicillium (5) y (6), respectivamente).

11- Conidios azules o verdes, fiálides producidas sucesivamente sobre vesículas menores de 10 $\mu \mathrm{m}$ de diámetro. Estipes usualmente septados:

pasar al capítulo 7: Penicillium y géneros relacionados.

Conidios de diferentes colores, fiálides y/o métulas producidas simultaneamente sobre las vesículas. Vesículas mayores de $10 \mu \mathrm{m}$ de diámetro. Estipes no septados: pasar al capítulo 8: Aspergillus. 
Identificación de los hongos del género Aspergillus.

\section{- Capítulo 8: Aspergillus:}

Este género pertenece a los Hyphomycetes. Forma estipes grandes de paredes gruesas y ápices hinchados llamados vesículas. Estas usualmente son esféricas pero pueden ser elongadas. Las vesículas sostienen fiálides 0 métulas y fiálides, las cuales usualmente aparecen simultáneamente. Este carácter lo diferencia de Penicillium donde siempre es sucesiva, es decir fiálides en distinto grado de desarrollo (indica Penicillium).

\section{- Otras características del género Aspergillus:}

a) Los estipes se forman a partir de una célula pie (no todos lo tienen).

b) Los estipes generalmente no son septados, de modo que vesícula, estipe y célula pie forman una gran célula única. (Tanto el hongo azul tipo Aspergillus (3) como el marrón tipo Aspergillus (4) no tienen estipe septado).

Las estipes de Penicillium son generalmente septados y raramente con célula pie.

\section{- Clasificación de los Aspergillus en sub-géneros y secciones}

- Presencia de un teleomorfo (estadío sexual y asexual juntos) y sus características.

- Presencia o ausencia de métula.

- Disposición de las métulas o las fiálides en la vesícula.

- Colores de las colonias. En especies que no tienen teleomorfo el color de la colonia está dominado por el color del conidio.

- Clave taxonómica de los dos hongos tipo Aspergillus sp. en los medios de cultivo:

1- Colonias en $\mathrm{CYA}$ a $25^{\circ} \mathrm{C}-37^{\circ} \mathrm{C}$ mayores a $35 \mathrm{~mm}$ :

Coincide con el hongo azul tipo Aspergillus (3) y con el marrón tipo

Aspergillus (4).

2- Colonias negras o grises:

pasar a 3.

Colonias blancas o coloreadas:

pasar a 5.

3- Colonias negras mayores a $50 \mathrm{~mm}$ de diámetro a $25^{\circ} \mathrm{C}$.

Colonias grises entre 25-50 mm de diâmetro: Aspergillus ustus

5- Colonias blancas:

Neosartorya

Colonias coloreadas:

pasar a 6.

6- Colonias azules, conidios pequeños:

Aspergillus fumigatus

(coincide con $h$. azul

tipo Aspergillus (3)).

Colonias amarillas, verde amarillas o marrón: pasar a 7 .

7- Conidios verde oscuro, desarrolla cleistotecio rodeado por células tipo clamidoconidia (cél. Hülle):

Emericella 
Conidios amarillos, amarillo verdoso,marrón sin cleistotecios:pasar a 8.

8- Conidios amarillos o amarillo verdoso:

pasar a 9 .

Conidios marrones o verde oliva:

pasar a 10.

10- Colonias café oliva en CYA, Malta a 25ํㅡ, conidios 5-8 $\mu \mathrm{m}$ de diámetro, pared rugosa, cabeza radiada:

Aspergillus tamarii.

11- Colonias marrones en todos los medios, conidios $<3 \mu \mathrm{m}$ de diámetro, pared lisa, cabeza desarrollada en columnas largas: Aspergillus terreus (coincide con el

hongo marrón tipo Aspergillus, excepto el

tamaño del conidio; el hongo marrón

presentó vesícula de $21,6 \mu \mathrm{m}$, estipe no

septado y conidios esféricos de 7,2 $\mu \mathrm{m}$ ). 


\section{- Clasificación Morfológica de los dos hongos Penicillium sp.}

- Clave taxonómica para subgéneros de Penicillium (Pitt \& Hocking, 1999).

1- Penicilos monoverticilados o con sólo una menor proporción con métulas:

Sub. spergilloides.

Penicilos biverticilados comúnmente o más complejos: pasar a 2.

2- Penicilos biverticilados predominantemente 0 irregularmente monoverticilados y biverticilados; colonias en G25N exceden raramente $18 \mathrm{~mm}$ de diámetro: pasar a 3.

Penicilos predominantemente terverticilados; colonias en $\mathrm{G} 25 \mathrm{~N}$ no menores a $18 \mathrm{~mm}$ de diámetro usualmente:

\section{Subgen. Penicillium \\ (Ambos hongos mostraron \\ tres verticilos pero \\ sus diámetros fueron \\ inferiores a $18 \mathrm{~mm}$ )}

3- Penicilos biverticilados o terverticilados con menos frecuencia; razón longitud métula: fiálide cerca a 1; colonias en G25N menores a $10 \mathrm{~mm}$ de diámetro:

\section{Subgen. Biberticillium \\ (Ambos hongos tienen 3 verticilos y diámetros mayores a 12 y $13 \mathrm{~mm}$ ).}

Penicilos biverticilados o nonoverticilados y biverticilados irregularmente; razón longitud métula: fiálide mucho mayor a 1; colonias en G25N mayores a $9 \mathrm{~mm}$ de diámetro:

Subgen. Furcatum.

\section{(Ambos hongos tienen mas de 2 verticilos $y$ diámetros mayores a 12 y 13 \\ mm). (Pitt \& Hocking, 1999).}

Dado que se la clasificación morfológica se hizo dudosa de ubicar desde los subgéneros, se conservó la nominación hongo azul tipo Penicillium (5) y hongos gris tipo Penicillium (6) y se pasó directamente a hacer la identificación a nivel molecular. 
- Clasificación morfológica del hongo verde (2).

Para ello se siguió la clave taxonómica de hongos misceláneos según Pitt \& Hocking, 1999.

- Clave taxonómica para hongos misceláneos (Pitt \& Hocking, 1999).

1- Colonias en CYA y Malta menores a $60 \mathrm{~mm}$ diámetro en 7 días:

pasar a 2.

Colonias Colonias en CYA y Malta menores a $60 \mathrm{~mm}$ diámetro en 7 días:

pasar a 12.

(Coincide con el hongo verde (2))

(PASAMOS A 12)

12- Las esporas nacen dentro de un cuerpo fructífero cerrado o debajo de la superficie del agar:

pasar a 13.

Las esporas nacen de hifas aéreas o superficiales:

pasar a 17.

(Coincide con el hongo verde (2))

(PASAMOS A 17)

17- Colonias y conidios transparentes o de colores brillantes:

pasar a 18.

(Coincide con el hongo verde (2))

Colonias y conidios de color oscuro:

pasar a 22.

18- Colonias con áreas grises o verdes:

pasar a 19.

(Coincide con el hongo verde (2))

Colonias con blancas, naranja, rosa o purpura:

pasar a 20.

19- Colonias verdes:

Trichoderma.

De acuerdo a las claves seguidas, el hongo verde (2) pertenece al género Trichoderma. 
- Clasificación morfológica del hongo algodonoso gris tipo Rhizopus (1).

Se empleó la clave taxonómica para Mucorales (Pitt \& Hocking, 1999)

- Clave taxonómica para Mucorales.

1- Células reproductivas nacen en espículas alrededor de vesículas:

pasar a 2.

Algunas o todas las células reproductivas son esporangiosporas, nacen dentro de esporangios:

pasar a 3.

(Coincide con el hongo algodonoso gris tipo Rhizopus).

3- Esporangios y agrupaciones en cluster de esporangiolos:

Thamnidium.

Sólo esporangios o columelas derivadas de esporangios: pasar a 4.

4- Columela retiene forma esférica después de la descarga de esporangiosporas. Pared de las esporangiosporas lisas:

pasar a 5.

Columela colapsa para formar forma de sombrilla o de embudo, pared de los esporangiosporos lisa o estriada:

pasar a 6.

(coincide con el hongo algodonoso gris tipo Rhizopus).

6- Columela colapsa con forma de embudo, pared de los esporangiosporas lisa:

Absidia.

Columela colapsa con forma de sombrilla, pared de las esporangiosporas estriada:

Rhizopus.

(coincide con el hongo algodonoso gris tipo Rhizopus).

De acuerdo a las claves taxonómicas, el hongo algodonoso gris tipo Rhizopus (1) pertenece al género Rhizopus. 


\section{ANEXO 3 SECUENCIAS ITS1-5,8SrDNA-ITS2 Y GRÁFICOS DE CALIDAD DE HONGOS AISLADOS DE ALIMENTO PARA POLLOS}

\section{Aspergillus terreus.}

\subsection{Secuencia ITS1-5,8SrDNA-ITS2 de A. terreus:}

GGGGAACCGTACTGCGGGTACTCGTGGCCACCTCCACCCGTGACTATTGTACCTTGTTGCTTCGGCGGGCCCGCCAGCCCTGCTGGCCGCCGGGGGGCGT CTCGCCCCCGGGCCCGTGCCCGCCGGAGACCCCAACATGAACCCTGTTCTGAAAGCTTGCAGTCTGAGTGTGATTCTTTGCAATCAGTTAAAACTTTCAA CAATGGATCTCTTGGTTCCGGCATCGATGAAGAACGCAGCGAAATGCGATAACTAATGTGAATTGCAGAATTCAGTGAATCATCGAGTCTTTGAACGCAC ATTGCGCCCCCTGGTATTCCGGGGGGCATGCCTGTCCGAGCGTCATTGCTGCCCTCAAGCCCGGCTTGTGTGTTGGGTCCTCGTCCCCCGGCTCCGGGGG ACGGGCCCGAAAGGCAGCGGCGGCACCGCGTCCGGTCCTCGAGCGTATGGGGCTTTGTCTTCCGCTCTGCAGGCCCGGCCGGCGCCCGCCGGCGCAATTT TTTGCAACCTTTTATTTTTCCAGGTTGACCTCGGATCAGGTAGGGATACCCGCTGAACTTAAGCATATCAATAAGGCAGGAAGGAATACCGAGTGCGGGG TCTCGTGGCCCAACCTCCCCCGTGGACTATTGGTACCTTGGTTGCTTCGGCGGGGCCGCCGCCTGCTGGGCGCCGGGGGGGCGTCTCCCCCGGGCCCTGC CCCCGAAGACCCACATGGAACCTGGTTCTGGAAAAGCTTGCAGGTCCGGAGATGTGGATTTCTTTTGCCAATCAGTTTTAAAAACTTTTCAACAAATGGG AATCTCTTTGGGGTTTCCCGCCCTCGCATTAAAAAAAAACGCAGCCGCCAAATGCCGGATGAACTAAAAAGGTGGAAATTTGGCAGAAAAATTCAGTTGG AAAATCATCCAAGGGTCTTTTTGGAACGACAACATTGGCGCCCCCCGCGGGTATTTCCCGGGGGGGGGCATTGCCCGGTTCCCAAACCGATCATTTTGCT TGCCCTCAACCCCCGCCCGGGTGTGGTGGTTTTGGGGGGGCCCCCCTCCCTTCCCCGGCCCTCCCGGGGGGGGGAAAGAAGGGCCCCCCCAAAAAAGGG GGGACCAAGCGCGGGGCCCCCGCGCCTTTCCTGGGTTTCCTTCTCTAACGGATATAAAATTTTGGGGGGGTGTTTTTTTTTTTGTTTTTTCTCCCCCCCTC CTTTTTTTTTTGGGGCCCCCGGGGGGGCGGGGGGGGGCCCGCCCACACCGCCCGCCCGGGGCCCAAAAACTATTTTTTTGTTTTTTGTGTTCCACCCACAC CACCCCCCTATTTATTTATTATATTTTTTTTCTTTTCCTCCCTCGGCGGGTGGGGGTATTCTCCAACCTCACCCCCTTTTTTAAACAAACAAAAGAGGGGT GGTGGGGGGGGGGGGGGGAAAGAAAAAATACCCAACCGCCCGCTCCCCCTCCAAATTTAAAAAATTACTTCTTTTTTTATAAAAAAGCCCCACAAAAAGA TTAAAAGTCAATCTATTTGTATTATATTTGGTGGGGGGTGCCCCCACACCACAGAAAGAGAAGCGAGATAAAAGAGAAAGAAAAAAGAGAAGATAAAATT TTAAAAAAAAAAAAAAAAAAAAAAAAAAAAAAAAAAAAAAAAACCCCCCCCAAAAAAAAAAAAAAAAAAAAAAAAAACCCAAAAAAAAAAAAAAAAAAAA AACCCCCAAAAAAAAACTTTTTAAAAAAAAAAAAAAAAGGCCCCCCAAAAACACGGGCACAAACCGAGTTAAGGGCCCGGGTGGGCCATAACCCGTCCCC ACGCAGGTTGAACATAAGACACCAAAACGGAGTGTTGGTCTTTCTCGTATACCCCCGGGTTTTAAAACCCCTGTGTTAAAATTTTTTTCGGAAAATATAA ACCCCGGCGGAGAAATTTTTTTGGGGGGCTTTAGGAACCCCCCTTGGGAAATACCCCCCGAGGAAAACCCCTTTTTTGGGGGAAC

1.2. Gráfico de calidad de la secuencia de A. terreus: 


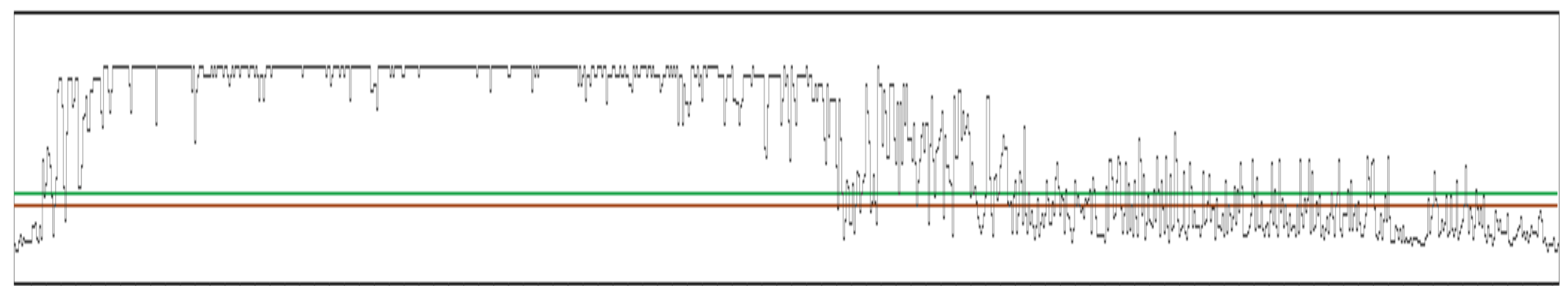

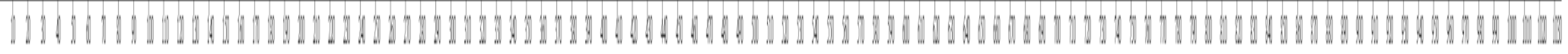

\section{A. fumigatus:}

\subsection{Secuencia ITS1- 5,8SrDNA-ITS2 de A. fumigatus:}

GGGCATCCGAGCGAAGATCTGGGTCACCTCCCACCCGTGTCTATCGTACCTTGTTGCTTCGGCGGGCCCGCCGTTTCGACGGCCGCCGGGGAGGCCTTGC GCCCCCGGGCCCGCGCCCGCCGAAGACCCCAACATGAACGCTGTTCTGAAAGTATGCAGTCTGAGTTGATTATCGTAATCAGTTAAAACTTTCAACAACG GATCTCTTGGTTCCGGCATCGATGAAGAACGCAGCGAAATGCGATAAGTAATGTGAATTGCAGAATTCAGTGAATCATCGAGTCTTTGAACGCACATTGC GCCCCCTGGTATTCCGGGGGGCATGCCTGTCCGAGCGTCATTGCTGCCCTCAAGCACGGCTTGTGTGTTGGGCCCCCGTCCCCCTCTCCCGGGGGACGGG CCCGAAAGGCAGCGGCGGCACCGCGTCCGGTCCTCGAGCGTATGGGGCTTTGTCACCTGCTCTGTAGGCCCGGCCGGCGCCAGCCGACACCCAACTTTAT TTTTCTAAGGTTGACCTCGGATCAGGTAGGGATACCCGCTGAACTTAAGCATATCAGTAAGCGGAGGAACATTACCGAGTGAGGGCCCTCTGGGTCCAAC CTCGCACCCATGTCTATGGTACCTGGTTGCTTCGGCGGGCCCGCCTTTTCACGGCGCCGGAAAGGCCTTGCGCCCGGGCCGCCCCAATACCCAACATGAA AGCTGTTCTGAAAGGTAGGGCAGGTCGGAGTTGAGATTATCGTAGTCAGTTAAAACTTTCAACAACCGGAGCTCTGGGTTCGGCGTCGATGAGTAACGCA CGCACTGCGATAGTATGTGAATTGCAGAATCAGTGATCACGAGTCTTGAACGCACATTGCGCCCCCGGATATTCAGGAGGCATGCCTTGCCAACTCTTAC TGTCTCCCTCACCAGCTGTGTGTTTAGGGCCCGCTCCCTCAACGGGACGGCCTATAGAGTCATGCACGACCTGCTCAAGTCAGAAGTGAGGTGTTCATCG CTCTTGAGCACTCGCACCACAATATTTTGTATGGATGCACTGCGGACTACCCTGACTTCATGATACGAAAGAATAGTGT 


\subsection{Gráfico de calidad de la secuencia de A. fumigatus:}

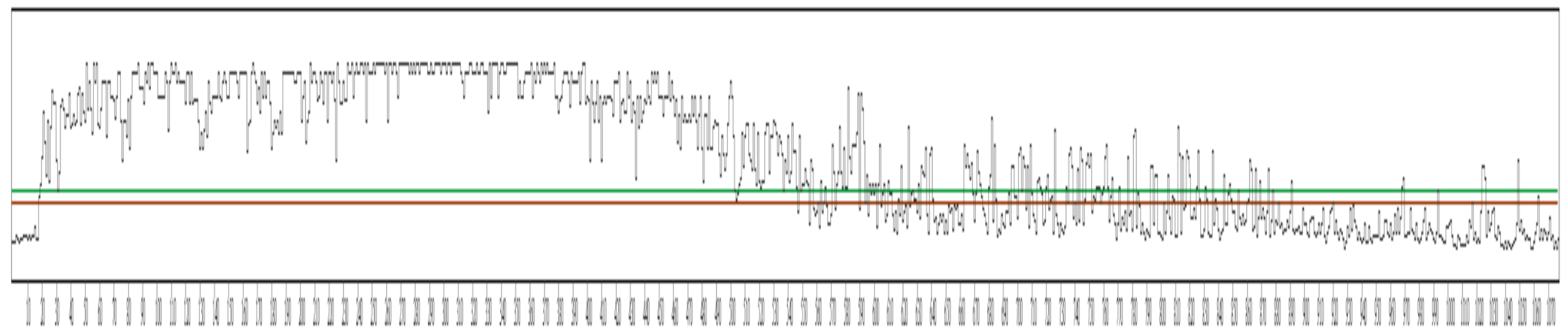

\section{Trichoderma longibrachiatum:}

\subsection{Secuencia ITS1- 5,8SrDNA-ITS2 de Trichoderma longibrachiatum:}

GTTTCCGCGAGCATGTCACTCCCAACCCCAATGTGAACGTTACCAATCTGTTGCCTCGGCGGGATTCTCTTGCCCCGGGCGCGTCGCAGCCCCGGATCCC ATGGCGCCCGCCGGAGGACCAACTCCAAACTCTTTTTTTCTCTCCGTCGCGGCTCCCGTCGCGGCTCTGTTTTATTTTTGCTCTGAGCCTTTCTCGGCGA CCCTAGCGGGCGTCTCGAAAATGAATCAAAACTTTCAACAACGGATCTCTTGGTTCTGGCATCGATGAAGAACGCAGCGAAATGCGATAAGTAATGTGAA TTGCAGAATTCAGTGAATCATCGAATCTTTGAACGCACATTGCGCCCGCCAGTATTCTGGCGGGCATGCCTGTCCGAGCGTCATTTCAACCCTCGAACCC CTCCGGGGGGTCGGCGTTGGGGATCGGCCCCTCACCGGGCCGCCCCCGAAATACAGTGGCGGTCTCGCCGCAGCCTCTCCTGCGCAGTAGTTTGCACACT CGCACCGGGAGCGCGGCGCGGCCACAGCCGTAAAACACCGCAAACTTCTGAAATGTTGACCTCTTATCAAGTAGGAATACCCGCTGAACTTAAGCATATC GATAAGCAGGAGGAATACCGAGTTTACAACTCCCAAACCCAATGTGAACGTTACCAATCTTTGCCTCGGCGGGATTCTCTTGCCCGGGCGCGTCGCAGCG AAACAGGGCGCGCGAGGGACACTCAACTCTTTTTTTCTCTCTCCGGCTCGGTCGCGCCTCTATTTTATGTTTTGCTCTGAGGCGTGTCTAGACACCATCG AGTGCGTCTGGTAGATGAAATCAGACTTTCAACAACGGAGCTTGGTTCTGCATCGATGAATAGCACGAATGCGATAGTATGTGATGCAAATCATGAATCA CGTACTTGAAGCAATGAGCGCGTTATCTGCGGATGTCGTTCAAGTCTTTTACGTACTCGGGTCGCTTGGGGATGCCTCACGGCCCGAAATACAATGGCGG TTGCCACTCTCTCGGCGGAATTGGGACATACGCACGGAGCAGCGTCAATTCACACTGATGAGTCCGAGTACCCGTAGATCATCTAGTT 


\subsection{Gráfico de calidad de la secuencia de Trichoderma longibrachiatum:}

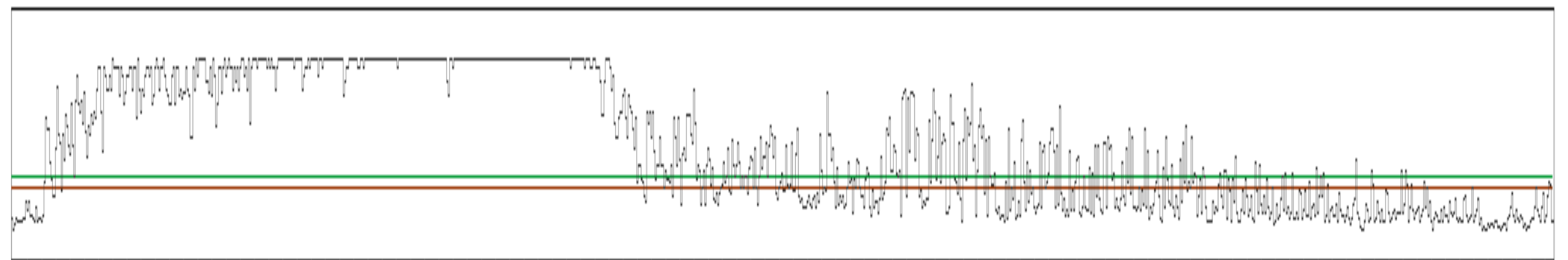

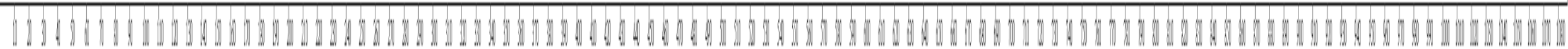

\section{Penicillium sumatraense}

\subsection{Secuencia ITS1- 5,8SrDNA-ITS2 de Penicillium sumatraense:}

GTGCATCTGACTGAGCACTCGGGGTCCACCTCCCACCCGTGTTTAACGAACCTTTGTTGCTTCGGCGGGCCCGCCTCACGGCCGCCGGGGGGCTTCTGCC CCCGGGCCCGCGCCCGCCGAAGACCCCTGTGAACGCTGTCTGAAGTATGCAGTCTGAGAAACTAGCTAAATTAGTTAAAACTTTCAACAACGGATCTCTT GGTTCCGGCATCGATGAAGAACGCAGCGAAATGCGATAACTAATGTGAATTGCAGAATTCAGTGAATCATCGAGTCTTTGAACGCACATTGCGCCCTCTG GTATTCCGGAGGGCATGCCTGTCCGAGCGTCATTGCTGCCCTCAAGCACGGCTTGTGTGTTGGGCCCCCGTCCCCCCCTCGTCGGGGGGACGGGCCCGAA AGGCAGCGGCGGCACCGCGTCCGGTCCTCGAGCGTATGGGGCTTCGTCACCCGCTCTTGTAGGCCCGGCCGGCGCCAGCCGACCCCAACCCTAAATTTTT TTCAGGTTGACCTCGGATCAGGTAGGGATACCCGCTGAACTTAAGCATATCAATAAGCCGAGAGGAATTACTGAGTGAGGGCCCTCGGGGTCCAACCTCC CACCCGTGTTTAACGAACTTTGTTGCTTCGGCGGGCCCGCCTCAGGCGCCGGGGGGCTTTCTGCCCCGGCCCGCCCAAAGACCCGGTGAACGCTTTCTGA AGTAAGCCAGTCGGAGAAACTAGCCTAATTAGTTAAAACTTTCTACCACCGGAGCTCTTGGTTTCCGCATCGATGAAAAACGCACCGAAAGTGCGTATCC ACTAAGGTGAAATTGACAATAATTCGATGAAATCATCTTGTCCTATAAAAGCCCATCCGCCTCCTCTGGATGATTCAGGAGGCCAAGCCTCCTCCGAGCC 
4.2. Gráfico de calidad de la secuencia de Penicillium sumatraense

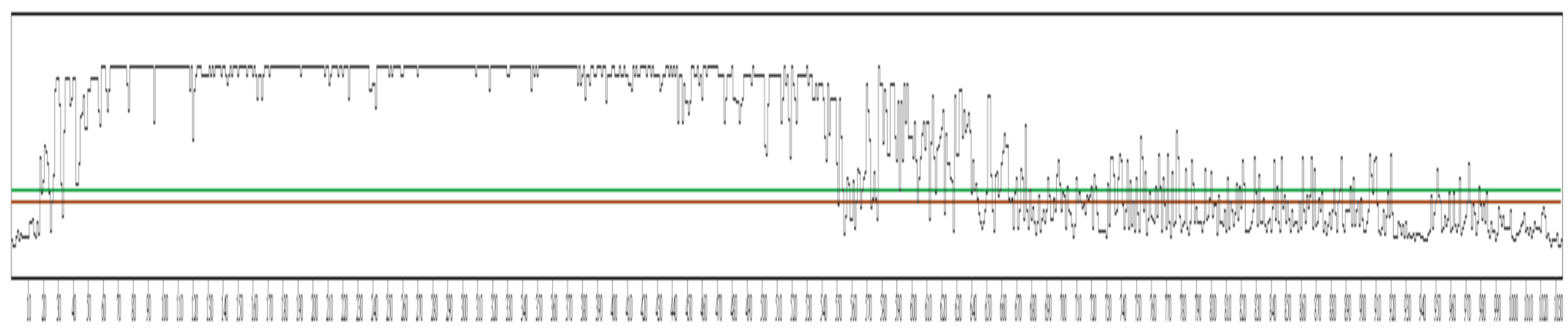

GRAFICO DE CALIDAD: POR ENCIMA DEL 20\% DEL NUCLEOTIDO 40 AL 550

\section{Penicillium crustosum:}

\subsection{Secuencia ITS1- 5,8SrDNA-ITS2 de Penicillium crustosum:}

GTACCGAGTAGTGACTCAGAATCCTGGGTCCACCTCCCACCCGTGTTTAT TTTTACCTTGTTGCTTCCGGCGGGCCCGCCTTAACTTGGCCGCCGGGGGG CTTACGCCCCCGGGCCCGCGCCCGCCGAAGACACCCTCGAACTCTGTCTG AAGATTGAAGTCTGAGTGAAAATATAAATTATTTAAAACTTTCAACAACG

GATCTCTTGGTTCCGGCATCGATGAAGAACGCAGCGAAATGCGATACGTA ATGTGAATTGCAAATTCAGTGAATCATCGAGTCTTTGAACGCACATTGCG CCCCCTGGTATTCCGGGGGGCATGCCTGTCCGAGCGTCATTGCTGCCCTC 
AAGCCCGGCTTGTGTGTTGGGCCCCGTCCCCCGATCTCCGGGGGACGGAC CCAAAAGGTGGCTGCCGCCGGCGGGGGCCGGGGGGGGTTAGGGCCCTTTG CGGCCGTCTCTGGAGGCCCGCCCGGCCATGGCAGTTAAAAAAAATTTTGT GGGAGGGTGGATCCACAAGGAGGGCCATCCCCCCGTGATGATCCTTCAGT ACGATCGGACAGAGACAGTACGGAGTGAGGGCCCTCTGGGTCCAACCTCC CACCCGTGTTTATTTTACCTTGTTGCTTCGGCGGGCCCGCCTTAACTGGC CGCCGGGGGGCTTTACGCCCCCCGGCCCGCGCGCCAAAACATACACACTC AGATCTGAAGATAAGAGAGATCAGTCTGTGGAGAAAATATAATATATTTT TTTTAAATTTTTCACCAACGAGATCTCTTGGGTTTCCGGCATCGATGAAG AACGCAGCGCAATGCGATACGTAATGGTGGAAATGTGCAAATTCTCGTGT GAACTACTCGGTCCTCTTTTAAACACACTTTGCGCCCGCGGGTTTCTTGG GGGGGGGGGGGGTCTTAAAAAAATTTTTTTTCCCACCCCCGCCGTTTTTTT TTTTTGACCTTCCATTTTTTTGGGAGGGGGGCGCGCGAGAGAGGGAGACC CCCCGGCCCTTTCACATAGAGGGGGGGGGACGTCCTTCTCTATCCCGGCC GCGCTGGCGTTACCCAAAATTTATATCTTTGTTGTCTTCGGACCAGGTAG GGTACCGGCTGGACTAGCTCCCTTATTATTTGGGAGAAAAGAAAAGAAA

5.2. Gráfico de calidad de la secuencia de Penicillium crustosum:

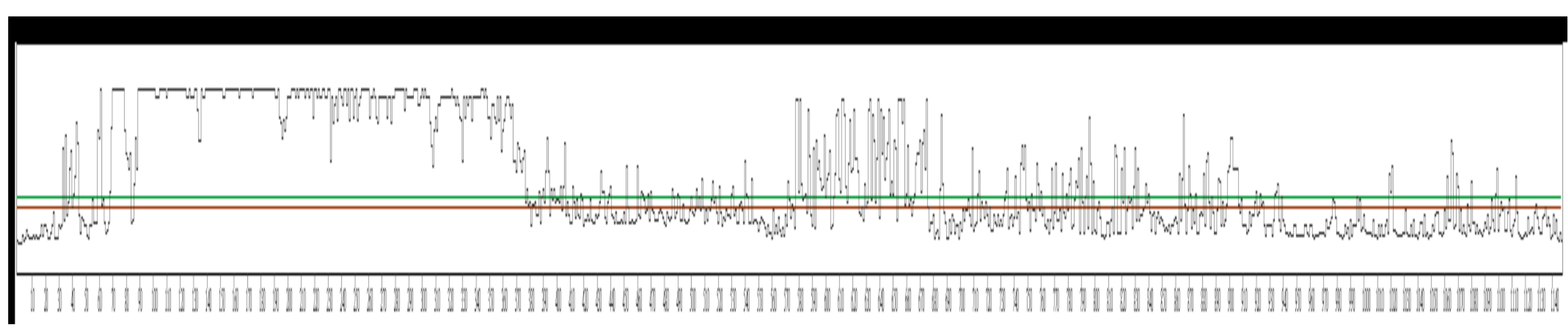


GRAFICO DE CALIDAD: POR ENCIMA DEL 20\% DEL NUCLEOTIDO 90 AL 375.

6. Rhizopus microsporus var. rhizopodiformis:

6.1. Secuencia ITS1- 5,8SrDNA-ITS2 de Rhizopus microsporus var. rhizopodiformis: GAGGAATCCGCTGGGAGCGGCACTTTACTGGGATTTACTTCTCAGTATTG

TTTGCTTCTATACTGTGAACCTCTGGCGATGAAGGTCGTAACTGACCTTC

GAGGAATCCGCTGGGAGCGGCACTTTACTGGGATTTACTTCTCAGTATTG TTTGCTTCTATACTGTGAACCTCTGGCGATGAAGGTCGTAACTGACCTTC GGGAGAGACTCAGGACATATAGGCTATAATGGGTAGGCCTGTTCTGGGGT TTGATCGATGCCAATCAGGATTACCTTTCTTCCTTTGGGAAGGAAGGTGC CTGGTACCCTTTACCATATACCATGAATTCAGAATTGAAAGTATAATATA ATAACAACTTTTAACAATGGATCTCTTGGTTCTCGCATCGATGAAGAACG TAGCAAAGTGCGATAACTAGTGTGAATTGCATATTCGTGAATCATCGAGT CTTTGAACGCAGCTTGCACTCTATGGATCTTCTATAGAGTACGCTTGCTT CAGTATCATAACCAACCCACACATAAAATTTATTTTATGTGGTGATGGAC AAGCTCGGTTAAATTTAATTATTATACCGATTGTCTAAAATACAGCCTCT TTGTAATTTTCATTAAATTACGAACTACCTAGCCATCGTGCTTTTTTGGT CCAACCAAAAAACAACTTATCTACGGGGTCTTCTACCCAGCAGAAATTTT AATGATCGTTAACTATGATCCGAAGTAGAGTGGGACTACCCGCTGAGCGA CTCCCAGGATAACCGGAAGGAAAAAAATCATTAACTAAGGTATTGGCAC

\subsection{Gráfico de calidad de la secuencia de Rhizopus microsporus var. rhizopodiformis}

GRÁFICO DE CALIDAD: NUCLEÓTIDO 42 AL 332 


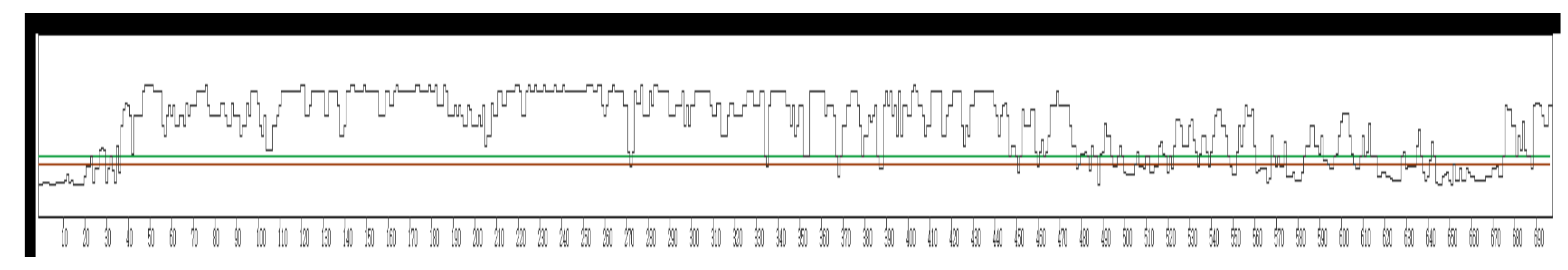

